

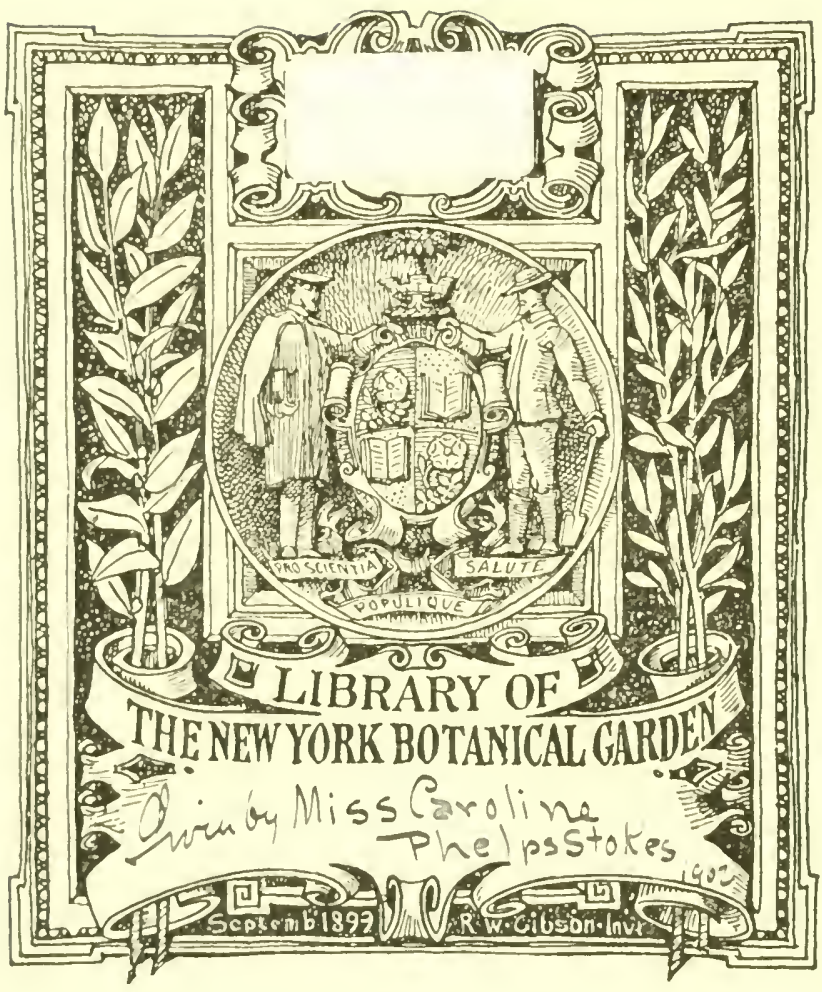







Ueber die

\title{
Fortpflanzungs-Physiologie der
}

niederen Organismen, der Protobionten.

\section{Von}

Dr. Georg Klebs,

Professor in Basel.

\section{Specieller Theil.}

Die Bedingungen der Fortpflanzung bei einigen Algen und Pilzen

\author{
TOI \\ Dr. Georg Klebs, \\ Professor in Basel.
}

Mit 3 Tafeln und I $_{5}$ Textfiguren.

Jena,

Verlag von Gustav Fischer.

I 896 . 


\title{
Die \\ Bedingungen der Fortpflanzung bei
}

\section{einigen Algen und Pilzen.}

\author{
Von
}

Dr. Georg Klebs, Professor in Basel.

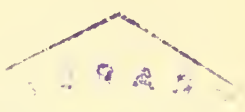

tक

$\because 3$

Mit 3 Tafeln und I5 Textfiguren.

Jena,

Verlag von Gustav Fischer. IS96. 
Alle Rechte vorbehalten. 


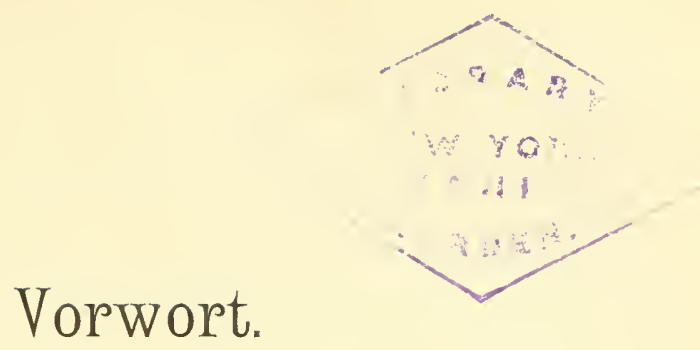

Unter allen Lebenserscheinungen bedeutet die Fortpflanzung in der Entwickelung jedes organischen Wesens die letzte und höchste Stufe; sie hat deshalb seit den Anfängen naturwissenschaftlicher Forschung auch stets das lebendigste Interesse erweckt. Die Fortpflanzung giebt erst dem Organismus die Macht, in dem ewigen Naturspiel des Werdens und Vergehens sich dauernd zu erhalten. Sie erregt und erfordert die vollste Bethätigung aller seiner Kräfte, sie bildet den Höhepunkt in dem Dasein des einzelnen Individuums, wird aber oft zum Anfang seines Unterganges. In der Art der Fortpflanzung prägen sich die charakteristischen Besonderheiten jedes Organismus am schärfsten aus, so daß sie gerade die wesentlichsten und sichersten Merkmale für die systematische Anordnung all der zahllosen Tier- und Pflanzenformen unserer Erde liefert.

Gegenüber dem ungeheueren Material von Thatsachen, welches durch die Forschungen von Jahrhunderten sich in Bezug auf die Morphologie der Fortpflanzungsorgane aufgesammelt hat, und das die heutigen Lehrund Handbücher füllt, sind die Kenntnisse über die der Fortpflanzung zu Grunde liegenden Vorgänge, über die sie bewegenden Stoffe und Kräfte verschwindend gering. Trotz der Arbeiten zahlreicher Gelehrten, die bald hier, bald dort einzelne Seiten des weit sich ausdehnenden Problems in Angriff genommen haben, muß man auch 
heute noch sagen, daß eine nach Ziel und Methode klar bewußt vorgehende Physiologie der Fortpflanzung nicht existiert. Noch immer erscheint die Fortpflanzung als geheimnisvollste, tief in Wesen des Organismus begründete Lebensäußerung und spottet der unendlichen Mühe, mit der die Wissenschaft der Biologie durch Beobachtungen, Versuche und zahllose Hypothesen das Geheimnis zu durchdringen versucht hat. Aber immer von neuem wird der Naturforscher angelockt, sich in das rätselvolle Gebiet zu wagen; immer wieder muß der Versuch gemacht werden, sich einen Weg zu bahnen, wenn auch die Ergebnisse im Verhältnis zur aufgewandten Mühe sehr klein erscheinen mögen. Das vorliegende Werk stellt einen solchen Versuch vor, es will die niederen Organismen als Angriffspunkt benutzen, um von hier aus einen kleinen Schritt in die dunkle Welt der Fortpflanzung zu machen.

Ursprünglich ging ich aus von der Untersuchung der Frage nach den Ursachen des Generationswechsels bei den Süßwasseralgen. Nachdem ich erkannt hatte, daß bei diesen Algen der häufig angenommene, gesetzmäßige Wechsel ungeschlechtlicher und geschlechtlicher Generationen nicht existiert, erhob sich die viel wichtigere Frage nach den Bedingungen der Fortpflanzung überhaupt. Ich kam hierbei auf ein bisher wenig betretenes Geljiet, das jedenfalls noch nie nach verschiedenen Richtungen methodisch durchforscht wurde. Das Ziel, das ich zunächst mir setzte, lag in der Lösung der Aufgabe, die Bedingungen der Fortpflanzung für einige verbreitete Algen so genau kennen zu lemen, daß sie zu ihrer Fortpflanzung, sei sie ungeschlechtlich oder geschlechtlich, genötigt werden können und zwar jederzeit mit derselben Sicherheit, mit der irgend eine andere physiologische Reaktion hervorzurufen ist. Erst nach Erreichung dieses 
praktischen Zieles ist ein fester, sicherer Punkt gewonnen, der ein weiteres Vordringen erlaubt; erst dann ist der Physiologie die Möglichkeit gegeben, die Fortpflanzung in ihren Kreis zu ziehen und statt der bloßen Beschreibung ihrer Formen das innere Wesen zu ergründen.

Das mir vorschwebende, praktische Ziel habe ich, wie die folgende Arbeit nachweisen wird, bei einigen Arten einigermaßen erreicht; bei anderen habe ich mich ihm nur genähert. Aber auch für die Pflanzen, bei welchen die Fortpflanzung nur zu gewissen Zeiten, unter nicht genau bekannten Umständen erfolgt, ist es eine Frage von allgemeiner Bedeutung, den Einfluß bestimmter, äußerer Bedingungen auf den Verlauf des Prozesses zu beobachten. In dieser Beziehung besitzen wir für höhere Pflanzen einige vortreffliche Arbeiten von $\mathrm{Sachs,} \mathrm{Vöch-}$ ting u. a., aber allerdings in sehr geringer Anzahl, wenn wir an die unerschöpfliche Fülle von Problemen denken, die sich hier darbieten. Für die Algen selbst finden sich nur ganz gelegentliche Bemerkungen darüber in der Litteratur. Für die Aufgabe, die Fortpflanzung experimentell zu veranlassen, ist die Grundbedingung, daß man mit den Lebensverhältnissen des zu untersuchenden Organismus auf das genaueste vertraut ist. Der beste Maßstab dafür ist, bis zu welchem Grade man die Kultur des Organismus beherrscht. Im allgemeinen gilt die Kultur von Algen für sehr schwierig, und in der That ist es im Vergleich mit Pilzen und Bakterien sehr viel schwerer, schnell wachsende und immer lebenskräftige Algenkulturen zu erhalten. Die große Empfindlichkeit vieler Arten für kleine, nicht gleich bemerkbare Veränderungen der Lebensbedingungen führt sie in den Räumen des Laboratoriums bald in einen krankhaften Zustand über. Auf der anderen Seite hat man sich noch viel zu wenig mit der Ausarbeitung der Kulturmethoden 
abgegeben. Für meine Untersuchungen lag nun die dringende Notwendigkeit vor, lebenskräftige Kulturen zu haben. Nur diejenigen Algen, die ich in meinem Laboratorium wirklich züchten lionnte, erlaubten es mir, für die Physiologie der Fortpflanzung feststehende Thatsachen und nicht bloß flüchtige Meinungen zu gewinnen. Das Prinzip, dem ich bei den Kulturversuchen folgte, lag in dem Bestreben, für die Alge diejenigen Lebensbedingungen $\mathrm{zu}$ schaffen, welchen sie draußen in der freien Natur unterworfen ist. Wie bei den höheren Pflanzen giebt es auch unter den Algen solche Arten, bei denen die Kulturbedingungen leichter zu erkennen und $\mathrm{zu}$ verwirklichen sind, als bei anderen. Eine große, Anzahl der in Basels Umgebung vorkommenden Süßwasseralgen habe ich zu kultivieren versucht, bis ich einige herausfand, deren Kultur mit den mir zu Gebote stehenden, beschränkten Mitteln meines kleinen Institutes gelang. Bei den einzelnen Arten werde ich näher auf die Methoden eingehen.

In allen Fällen aber bleibt es für eine solche Untersuchung der Algen sehr wesentlich, daß man für die einzelnen Arten in der freien Natur bestimmte Standorte kennt, um ihr Verhalten unter natürlichen Bedingungen stets im Auge zu haben und mit clen Resultaten der Versuche vergleichen zu können.

Nachdem die Untersuchung der Algen einige bemerkenswerte Resultate zu Tage gefördert hatte, lag es nahe, auch die Pilze in gleicher Richtung zu erforschen. Das Studium der myliologischen Litteratur überzeugte mich bald, daß auch bei diesen Organismen die Frage nach den physiologischen Bedingungen der Fortpflanzung nie eingehend untersucht worlen ist, obwohl die Kulturmethoden hoch ausgebildet und jedermann zugänglich sind. Ich veranlaßte zunächst einige meiner Schüler, 
sich mit dieser Frage bei bestimmten Pilzformen zu beschäftigen; die Arbeiten von Bachmann (1895) und Schostakowitsch (I895) zeigen, daß man in dieser Richtung erfolgreich vorgehen kann. Um zu allgemeineren Resultaten zu gelangen, habe ich selbst einige Pilze untersucht. Ich wählte zwei der gemeinsten Formen, die schon oft und genau erforscht worden sind, an denen ich aber nachweisen will, wie die neue Fragestellung zu erneuten Untersuchungen nötigt.

Das vorliegende Werk enthält die Ergebnisse meiner Forschungen, die 1887 ihren Anfang genommen haben, und die trotz vieler Unterbrechungen doch während der folgenden 9 Jahre fortgesetzt worden sind. Einige Resultate sind an verschiedenen Stellen von mir veröffentlicht worden; über die allgemeinen Probleme, um die es sich bei diesen Arbeiten handelt, habe ich mich in der Rede auf der Naturforscher-Versammlung in Lübeck I895 ausgesprochen.

Das Werk zerfällt in 2 Teile, in einen speciellen und einen allgemeinen. Der erste specielle Teil umfaßt die ausführliche Darlegung meiner Beobachtungen und Versuche, die ich an einer Anzahl Süßwasseralgen und einigen Pilzen angestellt habe. Da im Laufe der Jahre das Material an Beobachtungen allmählich sehr beträchtlich angewachsen war, habe ich mich bemüht, nur die wesentlichen Erscheinungen gedrängt darzustellen. Trotzdem konnte ich nicht vermeiden, mich in viele Einzelheiten einzulassen, die vielleicht nur den Specialisten interessieren werden. Auch mußte ich manche Wiederholungen machen, da ich das Verhalten jeder einzelnen Pflanzenspecies für sich behandeln mußte. Denn während in der Physiologie der vegetativen Funktionen der Speciescharakter des Untersuchungsobjektes zurücktritt und die allen Pflanzen zukommenden Eigenschaften in erster 
Linie stehen, drüiclst sich in der Art der Fortpflanzung so sehr der specifische Charakter aus, daß von vornherein ein Eingehen auf die specielle FortpflanzungsPhysiologie notwendig erscheint.

Der zweite Teil, der etwas später erscheinen wird, soll nun auf Grund der Resultate des speciellen Teils und der sonst in der Litteratur zerstreuten Angaben die allgemeine Fortpflanzungs-Physiologie der niederen Organismen, der Protobionten, enthalten; ich rechne zu diesen alle Abteilungen der 'Thallophyten und Protozoen. Es ist der erste Versuch einer solchen Darstellung, die allerdings mehr durch die Fülle des Ungelösten und noch zu Erforschenden auffällt, als durch die Menge des bereits sicher Erworbenen. Das Hauptgewicht lege ich auf den Nachweis, daß die Probleme der Fortpflanzung überhaupt in den verschiedensten Richtungen der experimentellen Forschung unterworfen werden können. Das Werk soll anregen und auffordern, auf diesem Wege, der so aussichtsreich für die Zukunft erscheint, vorzugehen, damit statt der rein theoretischen Erörterungen, die auch heute noch einen so breiten Raum in der Fortpflanzungslehre einnehmen, ein fester Grund und Boden sicherer Kenntnisse gelegt wird.

Zum Schluß möchte ich noch meinem Verleger, Herrn Dr. Fischer, für das große Entgegenkommen, das er mir bei dem Druck des umfangreichen, wissenschaftlichen Werkes entgegengebracht hat, meinen wärmsten Dank aussprechen, und ebenso danke ich meiner Frau für die wesentliche Hilfe, die sie mir bei der Korrektur geleistet hat.

Basel, in August 1896. 


\section{Inhaltsübersicht des speciellen Teiles.}

\section{Erster Abschnitt: Algen.}

Vaucheria.

I. Die ungeschlechtliche Fortpflanzung durch Zoosporen bei Vaucheria repens und clavata . . . . . . . . . . . II

ı. Der Einfluß der Ernährung . . . . . . . 12

2. " " . Feuchtigkeit . . . . . 14

3. " " des Lichtes . . . , . . . . I8

Einfluß der Dunkelheit I9 - Einfluß des schwachen Lichtes 21 - Einfluß der Strahlen des Somnenspektrums 22 - Einfluß der Lichtintensität 24 - Einrichtung der Versuche 25 - Angabe der Versuche 28 - Einfluß der Kohlensäure-Assimilation $35-$ Stoffwechselprodukte bei Vaucheria 37.

4. Der Einfluß der Temperatur . . . . . . . 39

Niedere Temperatur 40 - Hohe Temperatur 45 Nittlere Temperatur und Temperaturschwankungen 47 - Einfluß der Temperatur auf V. clavata 50.

5. Der Einfluß der chemischen Beschaffenheit des Mediums

a) Anorganische Verbindungen . . . . . . 54 Einwirkung der Nährsalzlösung 55 - Uebergang aus Nährsalzlösung in Wasser 60 .

b) Organische Verbindungen

Rohrzucker 6I - Kampfer 63.

c) Der osmotische IVert der Verbindungen . 64

d) Der Einfluß der sauren oder alkalischen Reaktion . . . . . . . . . . . . 
6. Der Einfluf des Sauerstoffs

Widerlegung der W' a lz' schen Hypothese 72 - Einfluß des niederen Luftdruckes 77 - Virkung der Luftverdünnung So.

7. Der Einfluß des strömenden TTassers.

Eigenschaften des strömenden Wassers S2 - Ausscheidungen durch die Alge 83 - Einfluß der mechanischen Reibung 83 - Einflus der Tempcratur $84-$ Einfluß des Sauerstoffs und der Nährsalze 86.

II. Die ungeschlechtliche Vermehrung bei anderen Vaucheria-Arten.

Vaucheria ornithocephala so - Aplanosporen bei V. geminata $90-$ Bedingungen ihrer Bildung 91 - Aplanosporen bei $V$. racemosa, uncinata 93.

III. Die geschlechtliche Fortpflanzung von Vaucheria

1. Der Einfluß des Iichtes.

a) Die Wirkung des Lichtes als Termittler der Ernährung

b) Der Einfluß der Lichtintensität

c) Die Bedeutung farbigen Lichtes

2. Der Einfluß der Feuchtigkeit .

I I I

3 .

.. Temperatur

I I 2

4. " " " " chemischen Beschaffenheit des

Mediums

5. Der Einfluß des Sauerstoffs

6. ," strömenden Wassers

7. Ueber das V'erhältnis des männlichen und weiblichen Geschlechtes.

\section{Hydrodictyon utriculatum Roth}

I. Die Bedingungen der Zoosporenbidung

I. Der Einfluß des Lichtes.

2. " . . . fließenden Wrassers und des Sauerstoffs

3. Der Einfluß der anorganischen Verbindungen I 4 I Wirkung der Nährsalze 1.15 - Uebcrgang aus Nährlüsung in Wasser 146 - Einfluß des Lichtes I47 Zusammenhang mit der Assimilation I 4 S - Wirkungen einzelner Salze 150 - Wirkung ron Magnesiumoxyd und Säuren $I_{52} 2$. 


\section{$-\quad$ XIII}

4. Der Einfluß organischer Stoffe, besonders der Kohlehydrate

Wirkung von Rohrzucker I53 - Wirkung der Maltose I54.

5. Der Einfluß der Temperatur und der Feuchtigkeit

II. Die Bedingungen der Gametenbildung und ihr Verhältnis zur Zoosporenbildung.

a) Netze mit schwacher Neigung zur Zoosporenbildung

Wirkung des Zuckers I6I - Wirkung der Dunkelheit und der Maltose I63 - Einfluß der Temperatur I64Einfluß der Nährsalze I64.

b) Netze mitlebhafter Neigungzur Zoosporenbildung Verhalten der Nährsalznetze 166 - Verhalten der Aquariumnetze 167 - Parthenogenesis 168.

Protosiphon Klebs und Botrydium Wallroth nebst Bemerkungen über die Bedeutung und die Methode der Reinkultur für niedere Algen . . . . .

Einleitende Bemerkungen über die Frage nach der Selbständigkeit niederer Algen I7I - Polymorphismus bei B orzi und Chodat I73-Bedeutung der Reinkultur 175 - Aufzustellende Forderungen für die Untersuchung niederer Algen 177 - Praktische Methode der Reinkultur I82.

I. Der Bau der Zellen von Protosiphon . . . . I87

2. Die Teilung von Protosiphon . . . . . . . I 89

3. Die Sporenbildung von Protosiphon . . . I9 I

4. Die Bildung der Schwärmer (Gameten) . . . 194

a) Die Bildungsweise der Schwärmer . . . . 195

b) Die Bedingungen der Schwärmerbildung . 199

Verhalten der Zellen der Lehmkultur I99 - Verhalten der Nährsalzkulturen $2 \mathrm{OI}$ - Wirkung des Lichtes 202 Einfluß der Temperatur 203 - Wirkung verdünnter Luft 206.

c) Das Verhalten der Schwärmer

Kopulation 207 - Verhinderung der Kopulation durch hohe Temperatur 209 - ebenso durch Nährsalze 2II - Wirkung organischer Stoffe 212 - Unterschiede von Parthenosporen und Zygoten $2 \mathrm{I} 4$ - Wirkung der hohen Temperatur und der Salze 217.

5. Allgemeiner Entwickelungsgang von Protosiphon; Stellung im System . . . . . . 219

6. Botrydium granulatum . . . . . . . . 223 


\section{$-\mathrm{XIV}-$}

Die Konjugaten

Seite

I. Spirogyra

I. Spirogyra inflata I'aucher

2. , varians Hassall

233

236

3. Andere Arten; Allgemeines

4. Parthenogenesis bei Spirogyra

a) Parthenosporen bei kopulierenden SpirogyraArten.

Wirkung von Zuckerlösung auf Sp. Weberi und inflata 246 - Methoden, Parthenogenesis zu erhalten 247 Keimung der Parthenosporen 250 - Verschiedene Stadien der Kopulation 251.

b) Geschlechtslose Spirogyren mit zygotenähnlichen Sporen.

II. Desmidiace en

\section{Oedogonium}

262

Oedogonium diplandrum Juranyi . . 262

I. Die Zoosporenbildung . . . . . . 264

I. Temperatur; strömendes Masser . . . . . 26j

Temperaturgrenzen 265 - Einfluis des Temperatur. wechsels 266 - Uebergang aus tließendem in stehendes

Wasser 268 - Bedeutung des Sauerstoffgehaltes $270-$ Luftdruckversuche $271-$ Zoosporenbildung in der freien Natur 272.

2. Die chemische Beschaffenheit des Mediums

273

3. Das Licht

II. Die geschlechtliche Fortpflanzung . . 276

I. Ruhig stehendes Wasser . . . . . . 278

2. Das I icht . . . . . . . . . . . . . 279

3. Die Nährlösung . . . . . . . . . . . . 280

Oedogonium capillare Kützing . . . 282

I. Die Zoosporenbildung . . . . . . . . 283

Einfluß des Lichtes 285 - Einfluß von Zuckerlösungen 286 - Berleutung der Konzentration 287 - Wirkung von Salzlösungen 289 - Wirliung verdünnter Nährsalzlösungen bei Gegenwart des Lichtes $290-$ Zoosporenbildung im Aquarium 29I - Versuche bei niederem Luftdruck 293 - Zusammenfassung 294. 


\section{$-\mathrm{XV}-$}

II. Die geschlecht1iche Fortpflanzung
Nur Antheridienbildung 295 - Wirkung des Lichtes 297 - Wirkung der Nährsalze 298 - Zoosporenbildung in Antheridienfäden 299 - Das Ergrünen eines Spermatozoons 299.

\section{Ulothrix zonata Kützing . . . . . 300}

I. Die Zoosporenbildung . . . . . . . 303 Bildung und Bau der Zoosporen 304 - Keimung 306.

I. Die Temperatur . . . . . . . . . . . . 307

2. Das Licht . . . . . . . . . . . . . 308

3. Die chemische Beschaffenheit des Mediums . 310

4. Das strömende Wasser . . . . . . . . . 31I

II. Die Bildung der Mikrozoosporen und Gameten........... . . 313

Auftreten der Gameten 3I4 - Bedingungen der Gametenbildung 315 - Auftreten und Bau der Mikrozoosporen 316 - Kopulation der Gameten 317 - Verhalten der Mikrozoosporen zur Temperatur 318 Keimung 319 - Parthenogenesis 32I - Keimung der Zygoten 322 - Unterschied der verschiedenen Schwärmerformen 323 .

\section{Hormidium}

Hormidium nitens Menegheni . . . 328

I. Der Spaltungsprozeß . . . . . . . . 329

Art der Spaltung 330 - Ursache der Spaltung 331 Spaltung in Nährlösung 332 - Ueber die zum Wachstum notwendigen Elemente in Form von Salzen $334-$ Spaltung durch Trockenheit 337 .

II. Die Zoosporenbildung

III. Die Bildung von Dauerzellen

Hormidium flaccidum (K g.) Braun . - Be-
Bau der Fäden 341 - Bau der Zoosporen $342-$. dingungen der Zoosporenbildung $343-$ Konstanz der Charaktere 345 .

\section{Conferva}

Cultur von Conferva minor Klebs 347 - Bau der Fäden 348 - Zoosporen 349 - Keimung 350 - Methode die Zoosporenbildung hervorzurufen 350 .

I. Der Einfluß der organischen Substanzen Gruppe I Substanzen wie Inulin, Glycoside, stark die Zoosporenbildung erregend 353-Gruppe II schwach wirkende Substanzen 358 - Gruppe III hemmend wirkende Substanzen 363 - Gruppe IV schädlich wirkende Substanzen 365 . 
2. Der Einfluß des Lichtes

Wirkung auf den reizbaren Zustand 366 - Verschwinden ler Reizbarkeit 367 - Wirkung des Lichtes bei Gegenwart der Substanzen von Gruppe I 368 - Bedentung des Lichtwechsels 370.

3. Der Einfluß der Temperatur

Temperaturgrenzen 371 - Wirkung höherer Temperatur 373.

4. Das Verhalten von Conferva gegenüber ungünstigen Bedingungen . . . . . . . 374

\section{Bumilleria}

Bumilleria sicula Borzi

I. Die Spaltung

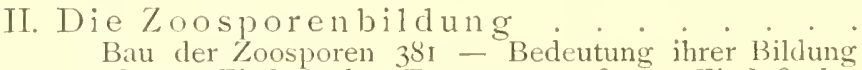
381 - Einflus der Temperatur 382 - Einfluß des Lichtes 355 .

III. Die Bildung ron Dauerzellen.

380

Bumilleria exilis Klebs

Bau der Fäden 390 - Bau der Zoosporen 391 Bedingungen ihrer Bildung 391 .

Kurze Charakteristik der Ulothricheen-Gattungen

Stigeoclonium .

Unsicherheit cler Artbestimmung 398 - Bau ron Sticreoclonium tenue $\mathrm{Kg}$.

I. Die Gestaltung des Thallus

Eintluß äußerer Bedingungen auf die Verzweigung 401

- auf die Haarbildung 403 - Polymorphismus 405.

II. Die Zoosporenbildung

Bau der Zoosporen 406 - Einfluß der Temperatur 407

- Einfluß des Lichtes und der Zuckerlösung 408.

III. Die Mikrozoosporen

Bau der Mikrozoosporen 4IO - Keimung 4II.

\section{Draparnaldia}

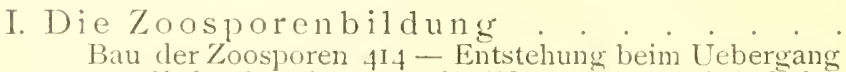
aus fließendem in stehendes Wasser 415 - Einflufs des Lichtes 4I6 - Einfluß der Nïhrsalzlösung 417 .

II. Die Mikrozoosporen und Ruhesporen. Bau der Mikrozoosporen 419-Ruhesporenbildung mit und ohne Kopulation 420 - Keimung der Ruhesporen t21 - Bedingungen der Bildung ron Mikrozoosporen 422. 


\section{- XVII -}

\section{Chlamydomonas}

Seite

I. Teilung von Chlamydomonas media Klebs

II. Die geschlecht1iche Fortpflanzung. . Bau der Gameten 429-Kopulation 430 - Bedingungen der Gametenbildung 430 - Einfluß des Lichtes 431 Einfluß der Nährsalzlösungen 432 - Frage nach den Ursachen der Gametenbildung 435 - Parthenogenesis 437 - Schicksal der Zygoten 438.

\section{Hydrurus}

Bau der Alge 439 - Zoosporen 440 - Bedingungen des IVachstums 44I - Bedingungen der Zoosporenbildung 443 - Bedeutung des Sauerstoffs 444 .

\section{Zweiter Abschnitt: Pilze.}

\section{Eurotium repens de Bary .}

I. Die Bedingungen der Konidienbildung Temperaturgrenzen $448-$ Nahrungsgrenzen $450-$ Frage nach der Bedeutung der Luft für die Konidienajbildung 452 - Versuche mit niedrigem Luftdruck 457 Sauerstoff keine specifische Bedingung 455 - Geringer Einfluß von Kohlensäure, Stickstoff 456 - Bedeutung wasserreicher Substrate 457 - Vegetative Umbildungsformen der Konidienträger 458 - Einfluß der Konzentration 459 - Konzentrierte, organische Substanzen 460 - Verdünnte Zuckerlösungen 462 - Konzentrierte Salzlösungen 464 - Einfluß züher Substanzen $467-$ Einfluß von Agar-Agar, Gelatine 468 - Einfluß des Kontaktes fester Körper 469 - Einflufs der Temperatur auf die Wasseraufnahme 470 - Zusammenfassung der bisherigen Resultate $47 \mathrm{I}$ - Einfluß feuchter und trockener Luft 473 - Vergleich mit Elfving's Beobachtungen an Phycomyces 474 - Einfluß des Lichtes 475 - Vergleich der Konidienbildung mit der Zoosporenbildung von Vaucheria 476.

II. Die Bedingungen der Perithecienbildung und ihr Verhältnis zur Konidienbildung

Bildung der Perithecien 477 - Methode Perithecienbildung zu veranlassen 478 - Bedeutung der Nahrung 479 - Einfluß wasserreicher Substrate 480 - Einfluß verdünnter Zuckerlösungen $48 \mathrm{I}$ - Einfluß hoher Konzentrationen 482 - Einfluß trockener Substrate $484-$ Erzeugung der Perithecien bei niederer Temperatur Gdurch Nahrungsüberfluß 485 - durch Verringerung des Luftraumes 486 - Bedeutung des Luftmangels 487 - Einfluß des Lichtes 488 - Vergleich der Perithecienbildung mit der geschlechtlichen Fortpflanzung der Algen 489 . 


\section{- XVIII}

\section{Mucor racemosus Fresenius}

Seite

492

I. Die siporangienträgrer

Bau der Sporangientrïger 193 - Temperaturgrenzen 195 - Nahrungsgrenzen 496 - 13cileutung der Luft 496 - Versuche mit nicd rem Luftelrnck 497 - Sporangienformen bei diesen Vursuchen 10.9 Einfluß der Nahrungsifuantität und -qualitit auf die Ausbildung der Sporangientriiger 500 - Einfluß der Konzentration 502 - Einfuß höherer Temperatur 503 - Einfluß von Feuchtigkeit und Licht $50 \%$

11. Das schlauchförmige Mycelium Mycelium in zwei rerschiedenen Formen auftretend 505 - Zucker-Mycelium 506 - Abhängrgkeit des Durchmessers von den Salzen, der Konzentration 507 - Peptonmycelium 507.

III. Die Formen des septierten Myceliums. Litteratur 509 - Besprechung der B refeld'schen Anschaumuen $510-$ Wirkung eines gärenden Traubensaftes 5 II.

a) Die Septierung

Wirkung stark konzentrierter Zuckicrlïsungen $513-$ Wirkung konzentrierter Salzlösungen $51+1$ - Erklärung der Wirkung der Konzentration $515-$ Einfluß des Sauerstoffmangels 516 .

b) I)as Anschwellen der Zellen

Wirkung von 3-proz. Citronensäure 517 - Wirkung verdünnterer Citronensäure 5 I9.

Erklärung der Wirkung des gärenden Traubensaftes 520 - Bedeutung des Zuckers 521 - Bedeutung des Luftmangels 521 - Bedeutung der Gürungsprodukte 523 - Zusammenfassung 524 .

1V. Die Gem menbilang

Bedingungen der (Gemmenbildung 526 - Enfluts orgal nischer Substanzen 527 - Eintlus der Konzentration 528 - Einflu\} der Temperatur 529 - Besondere Wirkung reiner Peptonlösungen 530 - Erklärung der Wirkung 531.

Sch 1 u 3 bemerkungen

Litteratur-Verzeichnis . . . . . . . 536

Erklärung der Tafeln 
Specieller Teil.

Die Bedingungen der Fortpflanzung bei einigen Algen und Pilzen. 



\section{ERSTER ABSCHNITT.}

\section{Algen.}

\section{Vaucheria.}

(Holzschnitte Fig. I-3.)

Vaucheria gehört zu der Familie der Siphoneen und zeichnet sich daher durch lang-schlauchförmige Zellen aus. Die einzelligen verzweigten Fäden bilden, zu vielen vereinigt, lebhaft grün gefärbte Ueberzüge auf feuchtem Boden oder frei schwimmende lockere Watten oder festsitzende dicke, weiche Polster. Nur einige Arten haben die Fähigkeit, sich durch besondere Keimzellen ungeschlechtlich zu vermehren, die entweder frei bewegliche Zoosporen oder unbewegliche Zellen sog. Aplanosporen (Wille ${ }^{1}$ ) 87 S. 507) vorstellen. Schon bei schwacher Vergrößerung sind die dunkelgrünen Sporangien an den Enden der Fäden sichtbar; sie sind von Vaucher beschrieben worden I803 in seinem ausgezeichneten Werke über Süßwasseralgen. Das Austreten des Sporangien-

I) Für das Citieren der Verfasser folge ich dem System von Fiel d (vergl. Biologisches Centralblatt 1893 S. 753). Die Verfasser werden am Schluß3 alphabetisch aufgeführt; vor jeder citierten Abhandlung steht als Nummer die abgekürzte Zahl des Jahres der Veröffentlichung, die durch Weglassung der beiden ersten Zahlen IS erhalten wird. Diese abgekürzte Zahl wird neben dem Autor im Text angegeben, so daß man gleich das Jahr erfährt, in dem die citierte Angabe bekannt geworden ist. 
inhaltes in Form einer beweglichen grünen Kugel wurde zum erstenmale I807 von Trentepohl (o7 S. I8o ff.) gesehen.

Diese Beobachtung wurde teils bestätigt, teils wieder bezweifelt, bis Unger I843 eine ausführliche Darlesung der Zoosporenbildung bei Vaucheria clavata lieferte. Seine Arbeit ,über die Tierwerdung der Ptlanze" ist höchst lebendig und anziehend geschrieben, sie drückt die ganze staunende Bewunderung aus, mit der der Naturforscher
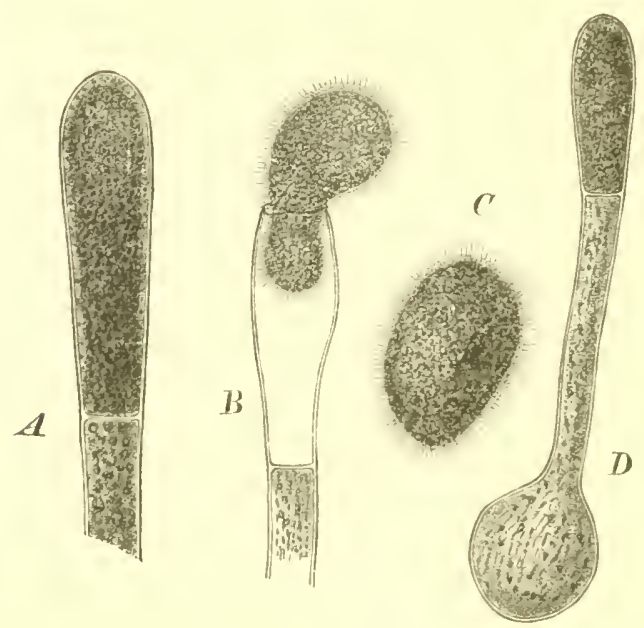

Fig. I 1). Vaucheria repens. A Fadenende mit Zoosporangien. $B$ Zoospore, eben austretend. C Zoospore. D Zoosporenkeimling in neuer Zoosporenbildung. Vergr. 120.

dem seltsamen Phänomen nachging, wenn er auch, von naturphilosophischen Gedanken releitet, falschen Anschauungen sich zuneigte. Trotzdem ragt diese Arbeit selbst über zahlreiche nachfolgende Untersuchungen da-

I) Bei der Herstellung der Zeichnungen für die Holzschnitte hat Herr Göt z mir bereitwilligst geholfen, wofür ich ihm an dieser Stelle meinen besten Dank ausspreche. 
durch hervor, daß sie die ersten physiologischen Versuche mit den Zoosporen enthält. Die richtige Auffassung des Prozesses, seine ausgezeichnet klare Darstellung finden wir in der Abhandlung von Thuret I843. Zahlreiche Gelehrte haben sich seitdem mit der Zoosporenbildung beschäftigt. Schmitz (79), Strasburger (80), Berthold (86) haben den Bildungsprozeß bis in die feinsten Details verfolgt. Das Wesentliche besteht darin, daß am Ende eines Fadens durch Zellteilung eine cylindrische bis keulenförmige Zelle abgesondert wird. Ihr gesamter Inhalt wandelt sich in eine einzige, viele kleine Zellkerne besitzende Zoospore um, die durch ein Loch an der Spitze der.Zellhaut heraustritt (Fig. I $A-C$ ). Die Zoospore, mit bloßem Auge als winziger grüner Punkt bemerkbar, bewegt sich mit Hilfe feiner Cilien, die an der ganzen Oberfläche verteilt sind. Nach kurzer Zeit, oft schon nach einigen Minuten, kommt die Spore zur Ruhe, verliert ihre Cilien und umgiebt sich mit einer Zellhaut. Die grüne, kuglige Zelle treibt dann gleich einen oder zwei Fortsätze, die sich zu grünen Schlauchfäden entwickeln. Unter Umständen kann der junge Keimling sofort wieder Zoosporen bilden (Fig. I D). Zu den Zoosporen bildenden Arten gehören z. B. Vaucheria repens, sessilis, clavata, ornithocephala, polysperma.

Die unbeweglichen, durch Aufplatzen der Sporangienmembran frei werdenden Aplanosporen, die schon vorher eine neue Zellhaut sich gebildet haben, sind von W a l z (66) und Wittrock (67) beobachtet worden. Sie finden sich bei Vaucheria racemosa, geminata, nach $\mathrm{Walz}$ auch bei hamata.

Die Geschlechtsorgane, Antheridien und Oogonien sind von Vaucher zuerst gesehen, aber unrichtig gedeutet worden. Erst die Arbeit von Pringsheim 1855 brachte völlige Klarheit über den Geschlechtsprozeß; er 
beobachtete die männlichen Spermatozoen, die Befruchtung der weillichen Eizelle, ihre Umwandlung in eine rulıende Spore sowie deren Keimung. Ueber die physiologischen Bedingungen der Fortpflanzung von Vaucheria hat nur Walz (o8) einige Angaben gemacht, welche sich aher nicht als richtig erwiesen haben. Eine kurze Darstellung meiner Beobachtungen habe ich 1892 geliefert. Seitdem habe ich immer von nenem daran gearbeitet, möglichst sichere Resultate zu erhalten. Ich habe gerade die Gattung Vaucheria gewählt, um an ihr den Versuch zu machen, wie weit es im Augenblick möglich ist, die Bedingungen ihrer Fortptlanzung nach der Art und dem Grade ihrer Wirkung zu erkennen. Unter den Species dieser Gattung ist es die allbekannte Vaucheria sessilis der Autoren, mit welcher ich mich am eingehendsten beschäftigt habe, während ich die anderen Arten mehr anhangsweise erwähnen werde.

Vaucheria sessilis ${ }^{1}$ ) unterscheidet sich von den anderen Arten der Gattung leicht durch die Zoosporenbildung und die Geschlechtsorgane; sie ist aber selbst eine Sammelspecies, welche aus einer Anzahl Formen besteht, die ron der bisherigen Systematik nicht genügend berücksichtigt worden sind. Ich unterscheide drei Hauptformen resp. Arten:

$$
\begin{aligned}
& \text { repens, } \\
& \text { sessilis, } \\
& \text { clavata. }
\end{aligned}
$$

Die erste und dritte Form stellen die Endpunkte der Varietätenreihe des Typus sessilis vor; sie lassen sich leicht voneinander trennen auch ohne Kenntnis der Geschlechtsorgane, auf die ich erst bei der Behandlung der sexuellen Fortpflanzung eingehen will.

1) Eine eingehende systematische Bearlocitung der SüßwasserVaucherien wird in nächster Zeit mein Schüler, Hcrr Götz, liefern. 
Vaucheria repens Hassall bildet auf feuchtem Boden zartfädige grüne Ueberzüge. Die Fäden haben eine durchschnittliche Dicke von $36 \mu$. Die Sporangien sind fast cylindrisch, kaum merklich angeschwollen. Die Keimlinge der Zoosporen erzeugen niemals Rhizoiden.

V a u cheria cl a va ta Decandolle bildet dicke, weiche, kurzgeschorene Polster, die in Bächen und Flüssen, an Wasserfällen festsitzen. Die Fäden haben eine Dicke von ca. $75 \mu$. Die Sporangien sind dick, keulenförmig. Die Keimlinge erzeugen bei Berührung mit festen Körpern sehr stark verzweigte Rhizoiden (vergl. B orge 94 S. 43).

Diese beiden Formen, welche ich im weiteren stets als Arten anführen werde, haben für die Untersuchung der Zoosporenbildung das meiste Material geliefert; ich berücksichtige sie zunächst allein, um die Darstellung klar und übersichtlich zu machen. Die Mittelformen, welche die beiden Endpunkte verbinden, fasse ich als Vaucheria sessilis (K lebs 92 als fluitans bezeichnet) zusammen. Möglicherweise umschließt diese Art wieder mehrere Formen, von denen die einen mehr der repens, andere mehr der clavata sich nähern. Die von mir untersuchte Form bildet große, lockere, frei schwimmende Fadenmassen in Tümpeln und Teichen. Die Dicke der Fäden beträgt ca. $50 \mu$, die Sporangien sind keulig angeschwollen, die Keimlinge bilden bei Berührung mit festen Körpern Rhizoiden, die aber nie so reichlich verzweigt sind wie bei clavata. Schon aus diesen Bemerkungen geht hervor, daß die beobachtete Form der sessilis in den vegetativen Organen sich mehr der clavata nähert, während sie, wie wir sehen werden, im Bau der Geschlechtsorgane mehr der repens sich zuneigt.

Die Vaucheria-Arten, vor allem repens und clavata, waren für die Aufgabe meiner Untersuchung deshalb ganz besonders geeignet, weil ihre Kultur leicht gelang und 
Material draußen in der freien Natur, abgesehen von der Zeit des Hochsommers, stets zu finden war.

Vaucheria repens kommt seit mehreren Jahren in dem kleinen Farnhats des Basler Gartens auf Coaksstücken vor, auf denen die Töpfe stehen. Durch zeitweise Anfeuchtung läßt sich die Algre stets forterhalten, sie bildet grüne dichte Ueberzüge, die, von den Coaksstücken befreit, das Hauptmaterial für meine Untersuchungen abgaben. In sehr verschiedener Weise, je nach den gerade vorliegenden Fragen, wurde die Vaucheria im Laboratorium weiter kultiviert, entweder in feuchter Luft in großen Glasschalen oder in Wasser oder in Nährlösungen. Besonders die letzteren sind von sehr großer Bedeutung, da sie ein sehr lebenskräftiges reines Material liefern. In allen Fällen wurde die bekannte Knop'sche Nährlösung benutzt, welche ich der Kürze halber immer als KN-Lösung bezeichnen werde. Sie hat den großen Vorzug z. B. vor der von $\mathrm{S}$ a clis angegebenen, daß man sich lionzentriertere Lösungen von einigermaßen bekanntem Salzgehalt verschaffen kann. Die KN-Lösung enthält 4 Teile salpetersauren Kalk, I Teil schwefelsaure Magnesia, I Teil salpetersaures Kali, I Teil phosphorsaures Kali. Für die Bereitung muß man zunächst die beiden Kalisalze und Magnesia auflösen und nach der geeigneten V'erdünnung das für sich aufgelöste Kalknitrat zufügen. Unter solchen Umständen scheidet sich nur ein sehr geringer Teil der unlöslichen Calciumphosphate ab. Eine besondere Zuthat von Eisen ist nicht nötig, da die geringen Spuren, die mit dem Ausgangsmaterial, dem Wasser in die Kultur kommen, vollständig ausreichen. Wenn es sich nur darum handelt, sich kräftigr wachsendes Material von Vaucheria zu verschaffen, so benutzt man am besten Lösungen von $0,2-0,5-p r o z$. Salzcrehalt. Bei längerer Kultur in solchen Lösungen stellen sich schließlich Proto- 


\section{$-9-$}

coccoideen-, Hormidium-Arten ein, die die Kultur verunreinigen. Im Winter kann man diese Gäste für sehr lange vollständig fern halten, wenn man die VaucheriaKulturen in einem kühlen Raum mit einer Temperatur unter $10^{\circ} \mathrm{C}$ wachsen läßt, während man sie im Sommer in gedämpftes Licht stellt.

Vaucheria clavata kommt ausschließlich in lebhaft fließendem Wasser vor; sie findet sich z. B. im Birsig, einem kleinen Juraflusse, der durch Basel strömt und der im Sommer oft von gewaltigen Massen der Alge erfüllt ist. Ferner habe ich diese Art in der Kander, an den Wehren der Wiese bei Hagen und Brambach gesammelt. Von ihrem Standort genommen, muß das Algenpolster von den anhängenden Schmutzteilen, den zahlreichen in ihm sich aufhaltenden Tieren durch lebhaftes Auswaschen gereinigt werden, weil sonst sehr leicht Fäulnis eintritt. Einmal gereinigt, in großen Glasschalen in einem kühlen Zimmer kultiviert, wächst die Alge monatelang prächtig weiter. Die Kultur in Nährlösungen hat, wie wir später sehen werden, für diese Art eine geringe Bedeutung.

Dagegen habe ich sie vielfach in einem Aquarium kultiviert, das beständig von frischem kühlen Wasser durchströmt war und überhaupt für alle meine Untersuchungen von größtem Vorteil sich erwiesen hat. Das Aquarium, aus Glaswänden in Metallrahmen zusammengesetzt, hat gefüllt einen Kubikinhalt von 38 Liter Wasser. In der Mitte des Bodens stehen 2 Röhren aufrecht, von denen die eine mit der Wasserleitung in Verbindung ist, die andere den Ablauf besorgt. In der Zuleitungsröhre steckt, drehbar befestigt, ein gebogenes Rohr, so daß der heraustretende Wasserstralıl nach verschiedenen Stellen des Aquariums hingelenkt werden kann und zugleich eine gleichmäßigere Verteilung des frischen Wassers 
herbeigeführt wird. Die Mündung des Rohres liegt Io cm unter der Wasseroberfläche, welche durch die Höhe des Ablaufrohres gereben ist. Dieses selbst ist mit emem hesonderen Deckel versehen, der zwar den Ablauf des Wassers etwas unterhalb der Oberfiäche gestattet, aber die auf ihr schwimmenden Algen am Mitgehen verhindert. Trotzdem kömnen Fadenalgen leicht in das Ablaufrohr hineingezogen werden. Deshalb habe ich immer dafür gesorgt, daß die Algen irgendwie im Aquarium befestigt wurden, sei es durch Steine auf dem Boden oder dadurch, daß ich einige Fäden an der Glaswand über der Wasserfläche antrocknen ließs.

Das Wasser der Basler Leitung stammt aus dem Jura und ist daher so kalkhaltig, daß kalkfliehende Algen nicht darin kultiviert werden können. Der Druck der Leitung beträgt im Durchschnitt 6 Atmosphären. Für die Zwecke des Aquariums wurde der Druck durch Einschiebung eines Metallringes mit enger Oeffnung stark vermindert; dafür blieh, er sehr konstant.

Das Aquarium war nicht blof wegen seines stets frischen Wassers für kulturen vorteilhaft, sondern vor allem auch durch seine gleichmäßige kühle Temperatur. Das Minimum beträgt im Januar bei anhaltender Frostzeit $3-4^{0}$, das Maximum im Juli bei heißen Tagen $17^{\circ}$. Aeußerst langsam geht die Veränderung der Temperatur vor sich, so daß während 24 Stunden die größte Schwankungr meist nicht einen hallen Grad beträıt; viele Tage lang bleibt die Temperatur auf (ler grleichen Höhe. Direkte Somnenbeleuchtung muß (labei aber ausgeschlossen sein. Wergen seiner gleichmäßiøen Temperatur wurde das Aquarium zu vielen Versuchen benutzt für Kulturen in hegrenzter Flüssigkeitsmenge. Hohe Bechergläser ließ ich im Aquarium schwimmen, oder es wurden Stopfgläser 
an Fäden bis zur Mündung hineingehängt oder unter Umständen ganz untergetaucht.

Nach der Besprechung der Kulturmethoden kann ich mich zum eigentlichen Thema wenden, das ich in folgenden Abschnitten behandeln werde:

I. Die ungeschlechtliche Fortpflanzung durch Zoosporen bei Vaucheria repens und clavata.

II. Die ungeschlechtliche Fortpflanzung bei anderen Vaucheria-Arten.

III. Die geschlechtliche Fortpflanzung der VaucheriaArten.

\section{Die ungeschlechtliche Fortpflanzung durch Zoo- sporen bei Vaucheria repens und clavata.}

Schon in meiner kleinen Arbeit I892 habe ich die Mittel angegeben mit Hilfe welcher es gelingt, jederzeit Zoosporen von Vaucheria repens zu erhalten. Die drei wichtigsten Methoden sind folgende:

I) Die mehrere Tage feucht und hell kultivierte Alge wird mit Wasser begossen.

2) Die in 0,2-0,5 proz. KN-Lösung hell kultivierte Alge wird in reines Wasser übergeführt.

3) Kulturen in Wasser oder in Lösungen von $0, \mathbf{I}-0,2$ Proz. KN-Lösung werden verdunkelt.

Will man ganz besonders lebhafte Zoosporenbildung hervorrufen, so kombiniert man Methode I oder 2 mit Methode 3. Für Vaucheria clavata hat Methode 2 keine große Bedeutung. Für diese Art kommt eine andere Methode hinzu, die darin besteht, die Alge aus lebhaft strömendem Wasser in ruhig stehendes überzuführen. Die große Sicherheit, mit der durch die genannten Methoden die Zoosporenbildung hervorzurufen ist, ge- 
stattet den Einfluß verschiedenartigeräußerer Bedingungen zu erforschen. Ich werle diese nach einander in der Reihenfolge belıandeln: I) Ernährung, 2) Feuchtigkeit, 3) Licht, 4) Temperatur, 5) chemische Beschaffenheit des Mediums, 6) Sauerstoff, 7) strömendes Wasser. Dagegen werde ich den Einfluß der Elektrizitäit nicht besprechen, da meine vorläufigen Versuche keine kliren Resultate ergeben haben; ich überlasse die Untersuchung der interessanten Frage zukünftiger Forschung.

\section{Der Einfluß der Ermilirung.}

Die Ernährung ist die Grundbedingung für jeden anderen Lebensprozeß; je üppiger vorher die Kohlenstoffassimilation bei Gegenwart von Nährsalzen erfolgt ist, je lebhafter infolgedessen auch das Wachstum vor sich gegangen ist, um so intensiver tritt bei Anwendung der früher grenannten Methoden die Zoosporenbildung ein. Es ist von Interesse zu untersuchen, ob eine direkte Beziehung zwischen Ernährung und Zoosporenbildung besteht, in welchem Grade eine Abhängigrkeit dieser von jener vorhanden ist. Die Versuche zeigen klar, daß die Zoosporenbildung auch dann erfolgt, wenn der Ernährungsprozeß vermindert oder überhaupt einige Zeit hindurch verhindert ist. Einige wenige Versuche will ich zum Beweise hier anführen:

a) Eine Wasserliultur von Vaucheria repens wurde $\operatorname{am} 26 . / X I . \quad$ I $89221 / 2$ Meter vom Fenster auf einen bestimmten Platz gestellt, und dort sich sellst ruhig ülserlassen. In dem schwachen Licht wurde eine fortgehende Zoosporenbildung vom 28./X1. I892 bis I./I. I 893 beobachtet.

b) Die Zoosporenbildung kann tagrelang im Dunkelschrank fortgehen, also bei vollständig grehinderter Er- 
nährung, wie zahllose Versuche gezeigt haben. Am klarsten geht aber diese Thatsache aus folgendem Versuche hervor. Ein Rasen von V. repens wurde am I./XII. I893 in feuchter Luft ins Dunkle gebracht, worauf die Fäden infolge ihres Wachstums sich in die Luft erhoben. Am 7./XII. wurde Wasser zugeführt, und am 9.-I2./XII. bildeten sich zahlreiche Zoosporen. Ein anderer Rasen war vom 6.|XII. ab feucht und dunkel kultiviert; ein Teil von ihm wurde nach I4 Tagen mit Wasser begossen und lieferte zahlreiche Zoosporen. Ein anderer Teil blieb bis zum I./I. I894 feucht und dunkel und wurde erst dann, also nach 26 Tagen ohne Ernährung, in Wasser gebracht. Die Fäden wuchsen weiter, erzeugten aber keine Zoosporen mehr.

Aus allem folgt, daß die Zoosporenbildung nach längerer Aushungerung im Dunkeln noch eintreten kann, dass jedoch schließlich ein solcher Mangel an Nahrungsstoffen sich bemerkbar macht, der zwar noch Wachstum, aber nicht Zoosporenbildung zuläßt. Bei dem Aufenthalt im Dunkeln kommt hierfür der Mangel an organischen Substanzen, seien es nun Kohlehydrate oder Fette, in Betracht. Die Unfähigkeit, Zoosporen zu erzeugen, kann aber auch dann eintreten, wenn die Bildung organischer Substanzen im Licht möglich ist, dagegen anorganische Nährsalze fehlen. VaucheriaFäden, in destilliertem Wasser monatelang hell kultiviert, geraten endlich in einen Zustand, wo sie aus Mangel an Nährsalzen wohl noch langsam wachsen können, aber auf keine andere Weise mehr zur Zoosporenbildung zu bringen sind, als bis man ihnen Nährsalze zur Verfügung stellt, und sie dadurch wieder lebenskräftig macht.

Die Zoosporenbildung von V. clavata verhält sich zur Ernährung in entsprechender Weise wie die von repens. 
Nach 'mehrwöchentlichem Aufenthalt im Dunkeln können noch einzelne Zoosporen erzeugt werden. Der Mangel an Nährsalzen, der ihre Bildung schließlich auch bei dieser Art hindert, liommt erst bei monatelanger Kultur der Alge in Betracht, wenn man einen dichten Rasen, an dem noch feine Erdteilchen in Menge sitzen, zum Versuch nimmt.

\section{Der EinfluB der Feuchtigkeit.}

Für die Methode, durch Uebergießen mit Wasser eine Kultur von Vaucheria repens zur Zoosporenbildung zu veranlassen, muß man die Alge vorher einige Tage in feuchter Luft wachsen lassen. Von den dem Substrat, z. B. dem Erdboden, anliegenden Fäden erheben sich zahlreiche Zweige, die dann, von Wasser umgeben, an ihren Enden Zoosporangien erzeugen. In der feuchten Luft selbst entstehen diese niemals; flüssiges Wasser ist eine notwendige Bedingung für die Zoosporenbildung überhaupt; der Uebergang aus feuchter Luft in Wasser wirkt als ein den Prozeß veranlassender Reiz. Auch wenn der Vaucheria-Rasen auf dem Wasser schwimmt, und die. Kultur ins Dunkle gestellt wird, bilden sich an den in die Luft ragenden Fäden keine Zoosporangien. Diese Thatsache, daß die Zoosporen sich nur innerhalb der Flüssigkeit und nicht in mit Wasserdampf gesättigter Luft ausbilden, ist sehr bemerkenswert; die Zoosporen verhalten sich gerade entgegengesetzt wie die Konidien vieler Pilze, die nur in der Luft, aber nicht imnerhalb der Flüssigkeit entstehen kömnen.

Die Reizwirkung des Ueberganges aus Luft in Wasser dauert einige Tage fort. Bei Anwendung von destilliertem Wasser bei heller Beleuchtung, einer mittleren Zimmertemperatur von ca. $15^{\circ} \mathrm{C}$ ist nach 2 Tagen die Zoosporenbildung am lebhaftesten; allmählich nimmt sie 
$\mathrm{ab}$, um ohne besondere Veränderung der Lebensbedìngungen nie mehr aufzutreten.

Der Uebergang aus Luft in Wasser muß ein plötzlicher sein; geschieht er ganz allmählich, so wirkt er nicht zoosporenerregend. Um dieses zu beweisen, muß man den Versuch in folgender Weise anstellen: Man nimmt ein Glasgefäß, am besten ein solches mit rechteckigem Querschnitt und parallelen Wänden, spannt darüber einen im Wasser gut ausgekochten groblöcherigen Stoff und füllt so viel Wasser zu, daß zwischen diesem und dem Stoff ein Luftraum von $\mathbf{I}-2 \mathrm{~cm}$ Höhe bleibt. Auf den Stoff bringt man einen Vaucheriarasen und stülpt über das Ganze eine Glocke, um die Luft feucht $\mathrm{zu}$ erhalten. Die Vaucheriafäden wachsen teils in die Luft, teils durch den Stoff nach unten und gelangen so allmählich immer tiefer in das Wasser. Diese Fäden bilden keine Zoosporen. Andere Fäden wachsen an den Glaswänden herab, und dann kann es sich ereignen, daß sie, bevor sie das Wasser erreichen, Zoosporangien bilden, weil das kapillar sich heraufziehende oder auch das sich zu kleinen Tröpfchen kondensierende Wasser hier und dort das Ende eines Fadens mit einem Male umgiebt und die Zoosporenbildung hervorruft.

Aus dieser Thatsache der Unwirksamkeit des Reizes bei allmählichem Uebergang erklären sich auch andere Erscheinungen, die oft zur Beobachtung kommen. Nimmt man einen in relativ trockener Luft dem feuchten Boden dicht anliegenden Ueberzug von $V$. repens und legt ihn in Wasser, so kann die Zoosporenbildung ganz unterbleiben oder nur sehr vereinzelt sich zeigen. In solchem Falle dauert es einige Zeit, bis die Fäden sich erheben und in das Wasser hinaufwachsen, während dessen sie sich an das flüssige Medium langsam gewöhnen.

Der Aufenthalt in feuchter Luft, der so günstig die 
Zoosporenbildung beim Uebergießen mit Wasser vorbereitet, darf aber nicht zu lange Zeit hindurch dauern. Nach wochenlanger Kultur wirkt der Uebergang in Wasser kaum mehr zoosporenerregend. Das rührt daher, daß die Vaucheria-Fäden, die fortwährend wachsen und sich verlängern, sich mehr und mehr vom Substrat entfernen; sie hängen mit ihm nur durch ihre älteren, meist entleerten Teile zusammen. Die Folge davon ist, daß die obersten Teile der Fäden infolge des Mangels an Nährsalzen schlecht ernährt sind und deshalb keine Zoosporenbildung mehr vollbringen können.

Aus den vorhin gemachten Bemerkungen geht hervor, daß flüssiges Wasser eine notwendige Bedingung für die Zoosporenbildung ist, mag diese auch durch verschiedene Methoden veranlaßt sein. Die Frage stellt sich ein, wie sich die Alge in halbflüssigen Medien verhält. Zur Entscheidung dieser Frage wandte ich zuerst Kieselsäure in wässeriger Lösung an, die Grübler mir nach dem Rezept von $\mathrm{K}$ ühne herstellte. Durch einen Tropfen einer Knop'schen Nährlösung konnte man die Flüssigkeit zur Gerinnung bringen, infolge dessen eine hell durchscheinende feste Gallerte entstand. Vor der Gerinnung führte man in die Flüssigkeit einige VaucheriaFäden aus einer reinen 0,2 KN-Kultur ein. Diese wuchsen in der Gallerte sehr lebhaft weiter, bildeten lebhaft Geschlechtsorgane, und konnten durch Verdunkelung zur Zoosporenbildung innerhalb der Gallerte veranlaßst werden.

Die Kieselsäuregallerte enthielt 3,I 4 Proz. feste Substanz. Da konzentriertere Lüsungen schwer zu erhalten sind, nahm ich zu weiteren Versuchen Agar-Agar, nachdem Gelatine sich als unbrauchbar erwiesen latte. Denn die Vaucheria-Fäden sterben innerhalb der Gelatine $a b$, wahrscheinlich wegen des Sauerstoffmangels. In einer nicht filtrierten Agar-Lösung von 2 Proz. gelang es noch, 
kurz vor dem Festwerden bei ca. $28^{\circ} \mathrm{C}$. Vaucheria-Fäden hineinzuschaffen. Die Alge erholte sich, wuchs in dem Agar und bildete im Halbdunkel Zoosporangien, aus denen aber die Zoosporen meistens nicht heraustraten. Um stärker konzentrierte Lösungen zu gewinnen, mußte ich in anderer Weise verfahren. Ich stellte mir einige Kulturen in I-proz. Agar her und goß, nachdem die Fäden von Vaucheria diesen durchwachsen hatten, heiße4-proz. Lösung darauf, etwa $21 / 2 \mathrm{~cm}$ hoch. Aus I Proz. wuchsen langsam die Fäden in die dicke Gallerte von 4 Proz. Nach I 4-tägigem Wachstum wurde die Kultur verdunkelt; eine Menge Zoosporangien traten in der I-proz. wie auch in der 4-proz. Gallerte auf. Eine andere Agar-Kultur von I Proz. wurde mit einer I $\mathrm{cm}$ hohen Schicht von 5-proz. Agar, eine dritte mit 8-proz. Agar bedeckt. Nach mehrwöchentlichem, sehr langsamem Wachstum wurde durch Verdunkelung sowohl in der Gallerte von 5 wie von 8 Proz. Zoosporangienbildung beobachtet. Die 8-proz. Gallerte war aber bereits sehr wenig durchsichtig, so daß die Fäden nur in der Nähe der Glaswände deutlich beobachtet werden konnten. Unzweifelhaft sah man aber innerhalb der Gallerte die Zoosporangien entstanden. Von weiteren Versuchen nahm ich Abstand; die Grenze der Dichtigkeit einer Gallerte für die Zoosporenbildung habe ich nicht bestimmt. Jedenfalls vermögen die VaucheriaFäden, wenn sie zur Zoosporenbildung gereizt werden, das dafür notwendige flüssige Wasser dicken festen Gallerten zu entziehen.

Das Leben und Wachstum in solchen Gallerten wirkt für sich allein nicht zoosporenerregend.

Vaucheria clavata kommt im allgemeinen nicht auf feuchtem Boden vor, sie vermag aber sehr wohl darauf zu gedeihen. In der freien Natur an Wasserfällen, Wehren, in Bächen bei niedrigem Wasserstand können die Rasen 
zeitweilig vom Wasser kaum bespült sein, was das Wachstum nicht hindert. Aus feuchter Luft in Wasser übergeführt, bildet die Alge massenhaft Zoosporangien. Ein Unterschied gegenüber $\mathrm{V}$. repens, der mich sellsst früher irre geführt hat, zeigt sich darin, daß auch in feuchter Luft die Zoosporenbildung anscheinend stattfinden kann. Bringt man einen Rasen von $V^{\top}$. clavata auf einen Porzellanteller und stülpt eine Glocke darüber, so wachsen die Fäden aufwärts, aber nur solche, die dem Teller anliegen und direkt mit Wasser in Berïhrung kommen, wandeln sich an ihren Enden in Zoosporangien um. Wenn man nun unter der Glocke den Rasen noch mit einen kleinen Gefäße bedeckt, so daß der kleine Luftraum, der die Alge umgiebt, jedenfalls mit Feuchtigkeit gesättigt ist, so erfolgt an vielen Fäden Zoosporangienbildung, sobald man die Kultur verdunkelt. Unter diesen Umständen können die Zoosporen meistens nicht austreten. Indessen zeigt es sich, daß bei so starker Luftfeuchtigkeit in dem dicken Rasen überhaupt Wassertröpfchen, sei es durch Kondensation, sei es durch Ausscheidung, den Fadenenden anhaften und die Zoosporenbildung ermöglichen, so daß doch $\mathrm{V}$. clavata sich nicht anders verhält als $V$. repens, und meine frühere Angabe bezüglich der ersteren ( 92 S. 74 ) (lanach berichtigt werden muß. Zahlreiche ähnliche Versuche lehrten entschieden, daß V. clavata in feuchter Luft keine Zoosporen $z u$ bilden vermag.

\section{Der EinfluB des Lichtes.}

Aus den vorher angegebenen Thatsachen über die weitgehende Unabhängigkeit der Zoosporenbildung von der Ernährung ergiebt sich ohne weiteres, daß das Licht nicht zu den allgemeinen Bedingungen des Prozesses ge- 
hört: Bereits Walz (68 S. 499) hatte festgestellt, daß bei Vaucheria die Zoosporen im Licht und im Dunkeln gebildet werden können. Anfänglich habe ich daher bei meinen Untersuchungen den Einfluß des Lichtes nicht sehr eingehend behandelt, bis ich erkannte, daß Verdunkelung überhaupt das beste und sicherste Mittel ist, Zoosporenbildung hervorzurufen.

Alle Wasserkulturen von Vaucheria repens wie clavata lassen sich durch einfache Verdunkelung bei Ausschluß einer anderen äußeren Veränderung zur Zoosporenbildung bringen. Wenn man die aus feuchter Luft in Wasser übergeführten Algen eine Zeit lang hell kultiviert, so findet nur Wachstum, keine ungeschlechtliche Vermehrung statt ; Mangel des Lichtes ruft oft schon nach 24 Stunden die letztere Erscheinung hervor. Selbst mehrwöchentliche Kulturen in destillirtem Wasser, überhaupt kümmerlich gewachsene Algen können im Dunkeln noch eine Anzahl Zoosporen liefern. Schließlich existiert auch hierfür eine Grenze. Wenn eine Vaucheria-Kultur keine Zoosporen nach Lichtabchluß liefert, so kann man sicher sagen, daß sie zu schlecht ernährt ist. Die Kultur mit Nährsalzen bei heller Beleuchtung macht aber jede solche sterile Vaucheria wieder fähig, Zoosporen zu erzeugen. Einzelne Versuche anzugeben ist unnötig; jeder kann sich leicht von der Richtigkeit der Angaben überzeugen.

Stellt man eine Kultur, die im Dunkeln Zoosporen bildet, wieder an ein helles Fenster, so hört die Bildung auf, in Sommer mit dem Tage, an dem der Wechsel geschieht, während bei dem trüben Tageslicht im Winter die Zoosporen sich bisweilen noch I-2 Tage zeigen können. Mit Benutzung des hellen Lichtes und des Dunkelschrankes kann man an ein und derselben Wasserkultur Zoosporenbildung abwechselnd hervorrufen und unterdrücken (siehe die Tabellen I-III Klebs, 92 S. 53-54). Die Grenze 
ist durch die allmähliche Erschöpfung der Algen gegeben; diese müissen nach öfterer Wiederholung des Versuches erst wieder kräftig ennährt werden. Nur der Uehergang aus Licht in Dunkelheit spielt die Rolle eines auslïsenden Reizes, nicht der Uebergang aus Dunkelheit in Licht. Das Licht wirkt vielmehr hemmend auf die durch andere Reize veranlaßte Zoosporenbildung ein.

Man würde aber sehr irre gehen, wenn man das Hauptgrewicht auf den plötzlichen Uebergang von Licht in Dunkelheit legen würde. Denn die Versuche zeigen, daß der Mangel an Licht fortdauernd als Reiz wirkt und so lange Zoosporenbildung veranlaßt, bis der Mangel an verarbeitbaren Nährstoffen Halt gebietet. Tagelang dauert im Dunkeln die Zoosporenbildung fort; bei vorher kräftig ernährten, üppig gewachsenen Rasen kann man während I4 Tagen täglich bei konstanter Dunkelheit Zoosporen beobachten. Diejenigen von $\mathrm{V}$. repens keimen leicht dabei und bilden an ihren kurzen Schläuchen sofort wieder Zoosporen (s. Fig. Holzschnitt I $D$ S.4), die dasselbe Spiel wiederholen, bis immer kleinere und schwächere Individuen entstehen, die schließlich nur noch dürftig zu wachsen, sich aber nicht mehr zu vermehren vermögen. Die Zoosporen von $\mathrm{V}$. clavata verhalten sich etwas anders. Zwar ist die Angabe Unger's (43 S. 65), daß sie überhaupt nicht im Dunkeln keimen, nicht ganz richtig; sie können sehr wohl kurze Keimschläuche bilden, an denen auch Zoosporangien entstehen. Aber das Wachstum ist im allgemeinen zu kümmerlich, die Zoosporen und jungen Keimlinge gehen leicht zu Grunde. Die alten Fäden einer sehr sauberen Kultur von clavata bilden dagegen reichlich noch längere Zeit (IO-I4 Tage, ja bis zu 3 Wochen) im Dunkeln Zoosporen, die oft nicht zum Austreten kommen. In jedem Falle hat $\mathrm{V}$. clavata die Neigung, im Dunkeln viel leichter zu faulen als repens; ihr Wachstum ist dabei sehr beschränkt und verlangsamt. 
Für das Leben der Vaucherien in der freien Natur hat der Einfluß der Dunkelheit keine große Bedeutung, da die Nacht selbst im Winter keine Wirkung ausübt. Nur bei einer konstanten Temperatur von $22^{\circ}$ gelang es mir im Thermostaten einzelne Zoosporangien nach 16 Stunden zu beobachten. Der Versuch begann um 4 Uhr nachmittags; um 8 Uhr morgens des nächsten Tages waren bereits fertige Zoosporen gebildet. Viel bedeutungsvoller für die in der freien Natur lebenden Algen ist die Thatsache, daß eine Schwächung der Lichtintensität dieselbe Wirkung hervorruft, wie konstante Dunkelheit. Der Versuch gelingt mit derselben Sicherheit, wenn man eine hell am Fenster stehende Vaucheria-Kultur einige Meter entfernt in das Zimmer bringt. Zugleich zeigt sich die gleiche Erscheinung, daß schwaches Licht fortdauernd als Reiz wirkt. Da nun in solchem Licht der Ernährungsprozeß, wenn auch verlangsamt, fortgeht, so kommt es nicht zu einer solchen raschen Aushungerung wie im Dunkeln. Die Zoosporenbildung kann bei einer Temperatur von $10-15^{\circ}$ in schwachem Licht wochenlang weitergehen, wie der S. I2 angeführte Versuch deutlich beweist. Schließlich hört aber die Bildung auf, während das Wachstum noch fortgehen kann.

Die Versuche mit schwachem Licht lassen sich für V. clavata ebenso erfolgreich anstellen wie für repens. $\mathrm{V}$. clavata ist sogar empfindlicher; sie reagiert bereits bei einer Verminderung der Lichtintensität, bei der repens indifferent bleibt. Daher kommt es auch, daß in den trüben Wintermonaten V. clavata, einmal zur Zoosporenbildung veranlaßt, am Fenster wochenlang damit fortfährt, während eine gleichzeitig angelegte und daneben stehende Kultur von repens nach einigen Tagen aufhörte, Zoosporen zu bilden. Der Unterschied in der Lichtempfindlichkeit zwischen clavata und repens zeigt 
sich auch in dem Verhalten der Keimlinge. Diejenigen von $V$. clavata bilden bei Schwächung der Lichtintensität sehr leicht sofort wieder \%oosporangien, während die von repens es meist nur nach völliger Verdunkelung thun.

Die wichtige Thatsache, daß V'erminderung der Lichtintensität Zoosporenbildung hervorruft, erfordert nach zwei Seiten eine eingehendere Behandlung. Zunächst drängt sich die Frage auf, welche Strahlen des Sonnenspektrums hauptsächlich geschwächt werden müssen, und ferner fragt es sich, um wie viel das Licht in seiner Intensität gemindert werden muß, um als Reiz zu wirken.

Da ein Sonnenspektrum von grenügender Intensität mir nicht zur Verfügung stand, so benutzte ich Farbstofflösungen von bekanntem Absorptionsspektrum, um die Bedeutung der verschiedenen Teile des Spelstrums zu erkennen. Ich nahm die bekannten doppelwandigen Glocken und füllte sie mit verschiedenfarbigen Lösungen. $\mathrm{Zu}$ den Versuchen wurden frische Wasserkulturen von $\mathrm{V}$. repens benutzt, die einige Tage hell beleuchtet worden waren und keine Zoosporenbildung mehr zeirrten; daneben wandte ich auch Kulturen in o,2-proz. KN-Lösung an. Die Kulturen standen auf einem Teller mit Sand, und sie wurden dann mit der betreffenden Farbstoffglocke überdeckt. Ich machte srewöhnlich gleichzeitig mit folgenden farbigen Lösungren die Versuche:

a) konzentrierte Pikrinsäure, hellgelb, absorbiert blauviolett;

b) konzentrierte Lösung von saurem chromsauren Kali, rotgelb, absorliert grün bis violett;

c) Kupferoxydammoniak, dunkel blau, alısorbiert grelbrot;

d) Fuchsinlösung von 0,2 Proz., undurchsichtig, rot, absorbiert grün bis violett; 
e) Fuchsinlösung von 0,02 Proz., dunkelrot, schwach durchscheinend, ebenso;

f) Fuchsinlösung von 0,002 Proz., hellrot, durchsichtig, ebenso;

g) Methylenblau von O, I Proz., undurchsichtig, blau, absorbiert rot bis grün;

h) Methylenblau von o,oI Proz., dunkelblau, durchscheinend, ebenso;

i) Methylenblau von 0,001 Proz., hellblau, absorbiert rot bis orange, zum Teil grün.

Ohne die Versuche im einzelnen aufzuführen, will ich als Resultat nur folgendes mitteilen. Die Lösungen c, d, e, g, h wirken am Fenster eines Zimmers zu allen Jahreszeiten bei Ausschluß des direkten Sonnenlichtes zoosporenerregend. Lösung a ist dagegen stets unwirksam; bei den Lösungen b, f, i hängt die Wirkung sehr von der Helligkeit der Tage ab. Die Glocke mit saurem chromsauren Kali ruft im Winter regelmäßig eine Zoosporenbildung hervor, die aber nicht sehr lange andauert; die verdünnten Lösungen von Fuchsin und Methylenblau f und i können ebenfalls zur Winterszeit in gleicher Weise wirken, während sie im Sommer ebenso wie s. chromsaures Kali unwirksam sind. Im allgemeinen kann man sagen, daß die Empfindung des menschlichen Auges für Helligkeit einen ganz richtigen Maßstab für die Empfindlichkeit der Algen abgiebt. Die dem Auge hell erscheinenden Lösungen, namentlich die gelben, hellroten, sind wenig oder nicht wirksam, die dunkel erscheinenden blauen wirken wie schwaches Licht resp. Dunkelheit. Großen Nachdruck kann ich auf diese Versuche nicht legen; sie erwecken aber immerhin den Gedanken, daß die Wirkung schwachen Lichtes auf die Zoosporenbildung in irgend einer Beziehung zu der Verminderung der Kohlensäure-Assimilation stehe. Bekanntlich sind es die gelbroten Strahlen des Spektrums, 
welche für die Assimilation hauptsächlich bedeutsam sind, während die blauvioletten Strahlen an Bedeutung weit zurüclistehen. Daher würde sich bei obiger Annahme erklären, daß das seiner selbroten Strahlen beraubte Licht der blauen Glocken sich wie ganz schwaches Licht oder Dunkelheit verhält. Dann hänıt es alıer sehr von der Konzentration der roten resp. blauen Lösung $\mathrm{ab}$, weil mit steigender Konzentration überhaupt eine Schwächung der Lichtintensität verbunden ist. Bei Methylenblau liegt die Grenze ungefähr bei o,oor Proz.

Die Versuche leiden daran, daß die Intensität des Lichtes, das durch verschiedenartige Farbstofflösungen gegangen ist, sehr schwer anzugeben ist und vor allem daß die fortwährenden und sehr beträchtlichen Schwankungren des Tageslichtes überhaupt in bequemer und sicherer Weise sich nicht messen lassen. Daher war für die mich besonders interessierende Frage nach der Reizschwelle der Lichtintensität durchaus notwendig, eine künstliche Lichtquelle von konstanter und bekannter Intensität zu benutzen.

Da elektrisches Licht mir nicht zur Verfügung stand, so mußte ich zu Gaslampen meine Zuflucht nehmen. Nach einigen Vorversuchen überzeugte ich mich, daß das Auer'sche Gasglühlicht mit Vorteil benutzt werden kann. Das Licht strahlt bei den Lampen von einem griuhenden Aschenskelett in Form eines Strumpfes aus; es zeichnet sich durch große Helligkeit hei mäßigem Gasverbrauch aus, es ist auch deshalb besonders günstigr, weil die Wärmeausstrahlung relativ gering ist. Die Lampe hat den Nachteil, daß sie nach einigen hundert Lichtstunden etwas an Intensität abnimmt. Für die vorliegende Fraşe, für die nur relative Werte in Betracht kommen, ist dieser Fehler ohne Bedeutung. Einmal handelt es sich überhaupt um Versuche, die in kurzer 
Zeit ausgeführt werden können; aber auch bei längerer Versuchsdauer verschwindet der Nachteil, weil das Licht für alle Kulturen in gleichem Grade und dabei sehr langsam abnimmt.

Der Versuch selbst wurde in folgender Weise ausgeführt. Da ein besonderes Dunkelzimmer in meinem Institute nicht einzurichten war, benutzte ich ein Privatzimmer, in welchem ich nach möglichst vollständigem Lichtabschluß noch einen besonderen Dunkelraum schaffte. Ein mattschwarzer Tisch von $\mathrm{I} m$ Breite und $2 \mathrm{~m}$ Länge wurde mit mattschwarzen Pappbogen umgeben, die I Meter über der Tischfläche standen.

Der Tisch befand sich $1 / 2 \mathrm{~m}$ von einer bis zur Decke mit schwarzem Tuch verhüllten Wand, bis $z u$ der die Papprahmen reichten. In dem Zwischenraum von Tisch und Wand stand auf einem niedrigen Schemel die Auer'sche Lampe, verbunden mit einem Elster'schen Gasdruckregulator und einem Elster'schen Gasvolumeter. Die Lampe wurde bei Beginn des Versuches so eingestellt, daß der unterste Rand des leuchtenden Strumpfkegels genau in die Tischebene fiel. Die Lampe wurde während des Versuches in keiner Weise von ihrem Platz gerückt, so daß immer die gleiche Seite des Strumpfes dem Tisch zugekehrt war. Auf diesem waren mit Kreide Kreisbogen geschlagen, als deren Mittelpunkt die Mitte des unteren leuchtenden Randes des Strumpfes angenommen wurde. Die Größe der Radien betrug 25, 30, $35,40,50,75,100,150 \mathrm{~cm}$. In der Entfernung von $25 \mathrm{~cm}$ und $\mathrm{I}, 50 \mathrm{~m}$ war je ein Thermometer aufgehängt. $\mathrm{Zu}$ den Versuchen wurden kleine cylindrische Gläschen benutzt von $50 \mathrm{ccm}$ Inhalt, die mit ihrer Mitte auf dem Kreidestrich standen. Die Höhe der Flüssigkeitsschicht betrug 4-6 cm; doch wurden auch Kulturen mit Flüssigkeit bis zu Io $\mathrm{cm}$ Höhe angewandt. Stets 
standen die Gläser so verteilt, daß eine gegenseitige Beschattung ausgeschlossen war. Bei den Versuchen ließ ich die Lampe ununterbrochen brennen, hauptsächlich wegen der gleichzeitigen Beobachtung der greschlechtlichen Fortpflanzung. Für diese Untersuchungen benutzte ich viclfach Zuckerlösungen, die sich l,ei konstanter Beleuchtung besser hielten, als wenn ich während der Nacht verdunkelte. Für die Zoosporenbildung zeigte sich bei vergleichenden Versuchen, daß die Beleuchtung auch während der Nacht weder besonders förderlich noch schädlich war. Die Vaucherien wachsen sowohl im Licht wie im Dunkeln, sie wachsen bei vollständiçer Dunkelheit wie bei konstanter Beleuchtung. Bei der letzteren ist das Wachstum am lebhaftesten; denn ich bekam dabei prachtvolle Kulturen, weil eben fortwährend Assimilation stattfand. Das fortdauernde Brennen der Lampen hatte aber noch einen besonderen Vorteil. Die Temperatur des Versuchsraumes war sehr gleichmäßsig. Die Versuche wurden im Winter in einem ungreheizten aber kalten Winden nicht ausgesetzten Zimmer ausgeführt. Die Temperatur in $25 \mathrm{~cm}$ Entfernung von der Lampe schwankte während vier Wochen im Winter zwischen I6 und $20^{\circ}$; meistens hielt sie sich um I $8^{\circ}$ herum. Im April dagegen stieg die Temperatur bis auf $23^{\circ}$ in $25 \mathrm{~cm}$ Entfernung. In der Entfernung von $1,50 \mathrm{~m}$ war die Temperatur $1,5-2^{\circ}$ niedriger. Bei läncrerem Brennen der Lampe machten sich dagegen einige Uebelstände lyemerkbar; nach 8- Io Tagren beschlug sich der Cylinder (ler Lampe mit einem feinen weißen Staube; ich habe dann den Cylinder vorsichtig alıgenommen und gereinigt. An jedem Morgen und Abend wurde die Temperatur gremessen, der Gasverbrauch notiert. Die Lampe verbrauchte durchschnittlich pro Stunde ca. So Liter Gas. Die Lampe hatte bei Anfang des Versuches eine Licht- 
stärke von ca. 80 Hefner Lichteinheiten, nach vier Wochen ersetzte ich sie durch eine neue Lampe.

Für die Versuche nahm ich von V. repens Kulturen in Wasser und in 0,2-proz. KN-Lösung; von V. clavata nur erstere. Für specielle Angaben werde ich hauptsächlich die Resultate von $V$. clavata anführen, da diese Art, wie ich schon angedeutet habe, sich durch besondere Empfindlichkeit auszeichnet. Im allgemeinen aber verhalten sich beide Arten wesentlich gleich.

Zuerst war die Frage zu untersuchen, wie das Licht $25 \mathrm{~cm}$ entfernt von der Lampe wirkt. In noch größerer Nähe wurde die Temperatur zu hoch. Kühlvorrichtungen hätten die Intensität des Lichtes wieder geschwächt. Es zeigte sich bald, daß eine größere Lichtintensität als die in $25 \mathrm{~cm}$ Entfernung wirkende nicht notwendig war. Vaucheria repens verhielt sich dabei genau so wie im Tageslicht. Wasser oder Nährsalzkulturen, die diesem ausgesetzt waren, wurden durch die Versetzung auf $25 \mathrm{~cm}$ Distanz nicht zur Zoosporenbildung veranlaßt. Wenn ich durch Uebergießen eines feucht kultivierten Rasens mit Wasser oder durch Ueberfülırung aus Nährsalzlösung in Wasser Anlaß zur Zoosporenbildung gab, so verlief diese wie am Fenster des Laboratoriums. Trotz der konstanten Beleuchtung bildeten sich wie gewöhnlich die Zoosporangien am frühen Morgen aus; sie entleerten sich im Laufe des Vormittags, die Zoosporen keimten und wuchsen normal. Die Zoosporenbildung hörte in solchen Kulturen eher noch früher auf als im Tageslicht und erschien bei unveränderter Stellung niemals wieder. Der gleiche Versuch in $50 \mathrm{~cm}$ Entfernung von der Lichtquelle ausgeführt zeigte dagegen mehrere Tage Zoosporenbildung, die bei $75-150 \mathrm{~cm}$ bis zu I4 Tagen andauern konnte. Für V. clavata will ich näher auf einen solchen Versuch eingehen. 
Ein großer Rasen, der aus dem lebhaft strömenden Birsig geholt und seit 6 Tagen im Zimmer kultiviert war, wurde in 5 Gläsern in destilliertem Wasser am I7./III. I894 verteilt und diese in $25,50,75,100,150 \mathrm{~cm}$ Entfernung von der Auer'schen Lampe gestellt.

Kultur I bei $25 \mathrm{~cm}$ Vom I8.-23./III. mäßige Zoo(Temp. I6,5-20 ${ }^{\circ} \mathrm{C}$ ) sporenbildung; einzelne Keimlinge mit Zoosporangien; am 27./III. Geschlechtsorgane.

Kultur II bei $50 \mathrm{~cm}$ Vom I8.-20./III. lebhafteste Zoosporenbildung; am 2I./III. ältere Fäden kaum mehr vorhanden; Keimlinge zoosporenbildend bis zum 27.IIII.; keine Geschlechtsorgane.

Kultur III bei $75 \mathrm{~cm}$ Verhalten wie bei $50 \mathrm{~cm}$; Keimlinge schlechter gewachsen, nur bis zum 23./III. zoosporenbildend; Kultur absterbend.

Kultur IV bei I $\mathrm{m}$ und Kultur $\mathrm{V}$ bei $1,50 \mathrm{~m}$ Verhalten wie bei $75 \mathrm{~cm}$; Keimlinge (Temp. $14,5^{-1} 8^{\circ} \mathrm{C}$ ) ganz kurz, gleich wieder Zoosporangien bildend.

V. clavata, die an eine größere Lichtintensität in der freien Natur grewöhnt ist als repens, fährt nach Versetzung in $25 \mathrm{~cm}$ Entfernung von der Auerlampe fort, Zoosporen zu bilden, wenn sie vorher dazu veranlaßt war. Nach einiger Zeit hört sie damit auf und erzeugt Geschlechtsorgane. Bereits in $50 \mathrm{~cm}$ Entfernung von der Lichtquelle findet die denkl)ar stärkste Zoosporenbildung statt, die zu allmählicher Erschöppung führt. Weil der Ernährungsprozeßs in $50 \mathrm{~cm}$ Entfernung noch fortgeht, so dauert die Zoosporenbildung aus Keimlingen länger, als bei der Entfernung von $75 \mathrm{~cm}-150 \mathrm{~cm}$, wo sehr luald Nahrungsmangel 
sich bemerkbar macht, und die Kulturen dann infolge zu lebhafter Zoosporenbildung zu Grunde gehen.

Kulturen von $\mathrm{V}$. clavata, welche einige Zeit im Zimmer am Fenster gestanden und aufgehört hatten, Zoosporen zu bilden, wurden durch die Versetzung auf $25 \mathrm{~cm}$ Entfernung von der Auer'schen Lampe gar nicht oder nur in den ersten Tagen zur Zoosporenbildung veranlaßt. Solche ältere Kulturen kann man aber sofort dazu bringen, wenn man sie $25 \mathrm{~cm}$ weiter vom Licht entfernt. Von den zahlreichen Versuchen will ich eine Reihe anführen, die mit ein und derselben Wasserkultur von $V$. clavata angestellt wurde.

Der betreffende Rasen war seit I9./I. 94 in 0,05-proz. KN-Lösung hell kultiviert; am I6./III. wurde er in Wasser übergeführt, in welchem nach einigen Tagen die Zoosporenbildung aufhörte. Jetzt wurde die Kultur abwechselnd verschiedener Lichtintensität, d. h. in verschiedener Entfernung von der Auer'schen Lampe, ausgesetzt und zwar:

Nr. I 2I./III. I894 auf 23./III. zahlreiche Zoosporen. $50 \mathrm{~cm}$ Entfernung

2 23./III. Laboratorium am Fenster

3 27. III. Auer'sche

Lampe $25 \mathrm{~cm}$

" 4 2./IV. auf $50 \mathrm{~cm} \quad 4 .-6 . / \mathrm{IV}$. zahlreiche Zoosporen.

5 6./IV. " 25 "

6 8.IIV. ", $50 "$

7 Io./IV. " 25 "

8 I2.JIV. " 50 "

9 I4./IV. " 75,

IO I6./IV. " 25 "

II I9./IV. " 75 "

I2 2 I./IV. " 25,
24.-25./III. vereinzelte Zoosporen; 26./III. keine. bis 2./IV. keine Zoosporen. 8./IV. keine Zoosporen. Io./IV. zahlreiche Zoosporen. I 2./IV. keine Zoosporen. I4./IV. vereinzelte Zoosporen. I6./IV. zahlreiche Zoosporen. bis I9./IV. keine Zoosporen. 2I./IV. zahlreiche Zoosporen. 23./IV. keine Zoosporen. 
Nr. I3 24. IV. auf $50 \mathrm{~cm} 25 \cdot-26 . / \mathrm{IV}$. mäßige Anzahl von Zoosporen.

"I4 26./ V. " 75 , 28.-29./IV. zahlreiche Zoosporen.

" 15 29./IV. " 25 " bis I./V. keine Zoosporen.

"I) I. V. " 50 " 3.-7./V. tïglich eine Anzahl Zoosporen.

" 17 I3. V. $\quad$, 75 " I5./V. zahlreiche Zoosporen.

Bei gut ernährten Rasen von $V$. clavata läfst sich also durch den Wechsel der Lichtintensität die Zoosporenbildung hervorrufen und unterdrücken. Es genügt zunäichst eine Verminderung um $1 /$ a der vorher herrschenden Intensität, um den denkbar stärksten Grad des Vorganges zu erzielen. Nach mehrmaliger Wiederholung tritt, wie V'ersuch Nr. 8 zeigt, eine Abnahme der Zoosporenbildung bei $50 \mathrm{~cm}$ ein ; eine weitere Schwächung der Lichtintensität um 1/4 ruft aber wieder in lebhaftester Weise den Prozeß hervor. Für V. clavata besitzt das Licht in $50 \mathrm{~cm}$ Entfernung von der Auer'schen Lampe mit ca. So Lichteinheiten, diejenige Intensität, welche auf alle normalen, gut crnährten Kulturen zoosporenerregend wirkt. Läßt man diese bei solcher Intensität, so geht im allgemeinen so lange Zoosporenbildung vor sich, bis eine Erschöpfung an Nährmaterial den weiteren Verlauf hindert. Bei manchen älteren Kulturen kann die Zoosporenbildung von vornherein in schwïcherem Grade erfolgen, dafür um so lïnger andauern, ohne daß im allgemeinen das Endresultat, die völlige lirschëjpfung der Kultur, verhindert wird. Doch kommt es bisweilen vor, clał eine Kultur auf $50 \mathrm{~cm}$ Distanz mit der Zoosporenbildung aufhört und eine Zeit lang langsam weiter wächst. Besonders ereignet dies sich bei Vaucheria-Kulturen, die unter ungünstigen Bedingungen erwachsen sincl. Solche reagieren dann auch nicht bei stärkerer Schwächung oder Entziehungr des Lichtes. 1)ie Grenze 
der Lichtintensität, die Zoosporenbildung veranlaßt, mußte aber noch genauer bestimmt werden. Folgende Versuche geben für V. clavata Aufschluß.

Eine Wasserkultur, welche seit Ende Februar am Fenster des Laboratoriums gestanden hatte und in der zahlreiche Keimlinge mit Geschlechtsorganen sich befanden, wurden in vier Gläser I-IV verteilt und in diesen nach einander in verschiedener Entfernung von der Auerschen Lampe gestellt.

I. 2./IV. I 894 auf $25 \mathrm{~cm}$ 4./IV. vereinzelte Zoosporen; 6./IV. keine.

6./IV. $\quad$ " 40 " 8. - Io./IV. zahlreiche Zoosporen. I2./IV. vereinzelte Zoosporen. I4./IV. keine Zoosporen.

I4./IV. $\quad$ 50 " I6.--r9./IV. eine Anzahl Zoosporen; vom 20./IV. Kultur schwächlich.

II. 2./IV. $\quad$ " $35, \quad 4 . /$ IV. vereinzelte Zoosporen; 6./IV. keine.

6./IV. $\quad 45$ " $4 .-$ Io./IV. eine Anzahl Zoosporen; I2./IV. keine.

I4./IV. $\quad$ " 50 " bis I9./IV. keine Zoosporen.

I9./IV. " „IO0 " 20.-22./IV. eine Anzahl Zoosporen; 23./IV. keine.

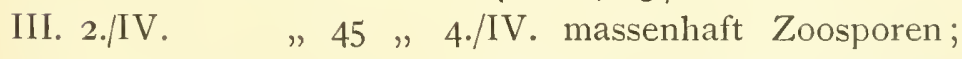
ebenso in den nächsten Tagen. Keimlinge zoosporangienbildend. Io./IV. noch eine Anzahl; r 4./IV. keine.

I4./IV. " 60 " I6.-I9./IV. eine Anzahl Zoosporen; Kultur allmählich kränklich geworden. 
IV. 2./IV. I 894 auf $75 \mathrm{~cm}$ 4.-I4./IV. wie bei Nr. III auf $45 \mathrm{~cm}$ lebhafte Zoosporenbildung; Kultur schließlich schwächlich.

19./IV. " "I50 "22./IV. eine Anzahl Zoosporen.

Eine andere ältere Wasserkultur wurde auf drei Gläser verteilt. Nr. V, VI, VII.

V. 8./IV. I 894 auf $25 \mathrm{~cm} \quad$ Io./IV. keine Zoosporen. IO./IV. " 50 ,

I2.-14./IV.sehr zahlreiche Zoosporen.

VI. 8./IV.

I2./IV.

" 35 " I0.--I2./IV. keine Zoosporen.

" 50 "14./IV. zahlreiche Zoosporen.

VII. 8./IV. , $45 "$

IO.-I3./IV. zahlreiche Zoosporen; I4./IV. keine.

I4/.IV. " 75 " I6.-22./IV. zahlreiche Zoosporen.

Diese Versuche, wie andere nicht angeführte, zeigen, daß ältere Kulturen von V. clavata in $25 \mathrm{~cm}$ Entfernung von der Auer'sche Lampe mit einer Lichtintensität, die gleich 8o Lichteinheiten ist, keine Zoosporen bilden oder nur vereinzelt in den ersten Tagen. Andererseits ruft die Lichtintensität in $50 \mathrm{~cm}$ Entfernung von der gleichen Lichtquelle bei allen normalen Kulturen lebhafte Zoosporenbildung hervor. Zwischen 25 und $50 \mathrm{~cm}$ Entfernung, genauer zwischen 35 und $45 \mathrm{~cm}$, liegt der Grenzwert für diejenige Lichtintensität, welche Zoosporenbildung bei Kulturen veranlaßt, die einige Zeit dem Licht von $25 \mathrm{~cm}$ Entfernung ausgesetzt waren. Absolut genau läßt sich dieser Grenzwert nicht bestimmen, weil die Kulturen sich nicht alle gleich verhalten. Es machen sich individuelle Verschiedenheiten, wie so oft bei Versuchen mit Organismen, bemerkbar, Verschiedenheiten, die 
wahrscheinlich mit der vorhergehenden Ernährung im $\mathrm{Zu}$ sammenhang stehen, ohne daß man im Stande wäre, die Ursachen genauer zu erkennen. In der Nähe des Grenzwertes für die Lichtintensität z. B. in $40 \mathrm{~cm}$ bis $45 \mathrm{~cm}$ Entfernung von der Lampe kann die Kultur nach einigen Tagen sich daran gewöhnen und mit der Zoosporenbildung aufhören. Eine erneute kleine Verminderung der Lichtintensität durch Versetzung z. B. von 40 auf $50 \mathrm{~cm}$ Distanz (s. Versuch I) ruft eine abermalige Periode der Zoosporenbildung hervor. Gerade beim Versuch I sieht man, wie an ein und derselben Kultur drei solcher Perioden zur Beobachtung kamen, wenn man die Bildung von Zoosporen bei $25 \mathrm{~cm}$ Entfernung mitrechnet. Zweimalige Perioden lassen sich häufiger erhalten; weil aber bei der stärkeren Schwächung des Lichtes eine fortdauernde Reizwirkung in Betracht kommt, so tritt bald eine Erschöpfung der Kultur durch zu lebhafte Zoosporenbildung weiteren Versuchen hindernd in den Weg.

V. clavata wächst in der freien Natur an ganz sonnigen Stellen in Bächen zur Zeit des Mai bis Mitte Juli. Sehr wahrscheinlich wirkt die Lichtverminderung, die für die Alge bei der Kultur im Zimmer eintritt, ebenfalls mit bei der lebhaften Zoosporenbildung in den ersten Zeiten. Das Licht von $25 \mathrm{~cm}$ Entfernung ist für V. clavata nur dann indifferent, wenn sie vorher einige Zeit mäßigem Zimmerlicht ausgesetzt war. Daher erklärt es sich auch, daß unter Umständen in $25 \mathrm{~cm}$ Entfernung Zoosporenbildung erfolgen kann. Für V. repens dagegen, die im Schatten oder zwar frei und offen, jedoch nur zur Herbstzeit sich entwickelt, ist das Licht in $25 \mathrm{~cm}$ Distanz von der Auerlampe intensiv genug, um Zoosporenbildung eher zu hemmen als zu veranlassen. Eine Schwächung der Intensität um $1 / 4$ genügt in den meisten Fällen, um als starker 
Reiz zu wirken. Bei relativ frischen Vasserkulturen wirkt bereits eine geringere Schwächung der Lichtintensitït, z. B. die Stellung auf $40-45 \mathrm{~cm}$ Intfernung von der Lampe. Sehr viel leichter als bei V.clavata erfolgt dann eine Anpassung der Kultur an die schwache Lichtintensität, so dars erst eine stärkere Schwächung bei $75 \mathrm{~cm}$, noch deutlicher bei $100 \mathrm{~cm}$ Entfernung emeute Zoosporenbildung hervorruft. Schließlich bei längerer Kultur auf 50 oder $75 \mathrm{~cm}$ Entfernung verliert die betreffencle Kultur die Fähigkeit, Zoosporen zu bilden, sie thut es auch dann nicht, wenn man den stärksten Reiz, völlige Verdunkelung, anwendet. Wir haben hier wahrscheinlich die gleiche Erscheinung, wie bei langer Kultur in feuchter Luft (S. I6). Die langen dünnen Fäden einer solchen Kultur haben zu wenig Nahrungsstoffe zur Verfügung. Man muß die Alge erst wieder in helles Licht bringen, am besten auch das Wasser wechseln, um sie in lebenskräftigen Zustand zu versetzen. Die bloße Gegenwart von Nährsalzen genügt dafür nicht. Denn die Algen in o,2-proz. KN-Lösung verlieren bei konstanter schwacher Lichtintensität noch viel eher die Fähigkeit, nach Verdunkelung Zoosporen zu erzeugen, weil, wie wir später sehen werden, längere Kultur in Nährsalzlïsung die Zoosporenbildung hemmt. Erst nach Ueberführung in Wasser und nachdem die Alge helle Beleuchtung erfahren hat, wird sie von neuem fähig, auf Lichtwechsel mit Zoosporenbildung zu reagieren.

Indem man nun diese Wirkungen andauernder schwacher Lichtintensität und der Nährsalzlösungen lienutzt, gelingt es, für V. repens Kulturen zu erhalten, welche jahrelang (bis jetzt $4 \frac{1}{2}$ Jahre hindurch) und dabei (1)ne Ruheperiode beständig wachsen und nicht mehr Zonsporen erzeugen (s. weiter unten).

Die Frage, ob es möglich sein werde, eine Rasse von V. repens zu erziehen, die überhaupt das Vermögen 
der Zoosporenbildung verloren hat, muß ich vorläufig unentschieden lassen.

Die große Bedeutung des Lichtmangels für die ungeschlechtliche Vermehrung von $\mathrm{V}$. repens und clavata giebt weitere Rätsel auf. Weshalb wirkt die Dunkelheit oder schwaches Licht in solch mächtiger Weise? Zahlreiche Versuche habe ich angestellt, um diesem Problem näher zu treten. Ein sicheres Resultat habe ich nicht erlangt. Ist es doch selbst für die Frage nach der Bedeutung des Lichtmangels für das Vergeilen höherer Pflanzen trotz angestrengter Arbeit vieler Gelehrten nicht gelungen, eine physiologische Erklärung zu geben. Ich strebte danach, wenigstens noch ein Mittel zu finden, das die gleiche Wirkung wie die Dunkelheit hat, d. h. eine ältere Wasserkultur nach Aufhören der Zoosporenbildung wieder dazu zu bringen, ohne daß Lichtschwankungen dabei eine Rolle spielen. Ueber die Resultate dieser Versuche, bei denen andere iußere Einflüsse herangezogen wurden, werden die späteren Kapitel berichten. Doch gelang es nicht, aus diesen Versuchen für die vorliegrende Frage Gewinn zu ziehen. Nur auf eine Versuchsreihe will ich hier eingehen, da sie unmittelbar damit zusammenhängt.

Die Versuche mit verschiedenfarbigen Lösungen machten es wahrscheinlich, daß die Schwächung der gelbroten Strahlen des Spektrums hauptsächlich die Zoosporenbildung veranlaßt. Da es die gleichen Strahlen sind, welche die Hauptrolle bei der Assimilation der Kohlensäure spielen, so lag die Vermutung nahe, daß zwischen diesem Prozeß und der Zoosporenbildung irgend ein Zusammenhang existiert. Deshalb versuchte ich, ältere Wasserkulturen von Vaucheria im Licht, aber bei Ausschluß der Assimilation, zu ziehen. Auf einer matten Glasplatte wurde luftlicht mit einem Ciemisch 
von Wachs und Vaselin eine kleine Glocke von $250 \mathrm{ccm}$ Inhalt befestigt, nachdem vorher ein Glasschälchen mit starker Kalilauge und darüber ein noch kleineres Gläschen mit wenig Wasser und einigen gesunden Vaucheria-Fäden hineingestellt worden waren. Mehrere solche Apparate wurden eingerichtet, die einen beleuchtet, die andern verdunkelt. Die Versuche wurden im Winter wie im Sommer sowohl mit V. repens als auch mit clavata wiederholt gemacht mit dem gleichen Resultat. In dem beleuchteten Apparat zeigten sich keine Zoosporen, in dem verdunkelten eine Anzahl. Wurde der erstere nach wenigen Tagen der Beleuchtung verdunkelt, so erfolgte in ihm ebenfalls Zoosporenbildung.

Bei einem solchen Versuch wird im Licht die Kohlensäurezersetzung nicht vollständig aufgehoben. Die Fäden atmen fortdauernd, die Kohlensäure diffundiert aus dem Wasser sehr langsam, so daß bei Gegenwart von Licht eine Assimilation noch möglich ist, sogar in jenen Versuchen, wo ich ausgekochtes destilliertes Wasser anwandte. Aber sie ist so gering, daß Vaucheria-Fäden schon nach 8 Tagen verhungert aussehen, es scheint fast, dass sie dabei stärker leiden, als bei konstanter 1)unkelheit. In jedem Falle ist die Assimilation viel geringer als bei Kultur in schwachem Licht, wo die Fäden lange fortwachsen und Zoosporen bilden. Daraus scheint zu folgen, daß Verminderung der Assimilation von Kohlensäure nicht als Anlaß für die Zoosporenbildung wirkt, daß durch die Lichtentziehung noch andere Prozesse in Mitleidenschaft gezogen werden, welche dann erst die Vermehrung herbeiführen. Für die Unabhängigkeit der Zoosporenbildung von der Assimilation sprechen auch die früher erwähnten Versuche über den Einfluß der Ernährung. Denn wenn selbst nach längerem Aufenthalt in konstanter Dunkelheit Zoosporen entstehen künnen, 
auch wenn Lichtmangel allein den Anlaß dazu giebt, so kann die Zersetzung der Kohlensäure nicht dabei direkt beteiligt sein. Solche andere Prozesse, die vom Licht beeinflußt werden, könnten z. B. chemische Umwandlungen des Zellsaftes sein, mit denen physikalische Veränderungen besonders solche seines osmotischen Druckes verbunden sind. Ich habe früher für Hydrodictyon (Klebs 9I S. 8Io) nachgewiesen, daß das Licht bei Gegenwart von Nährsalzen auf die durch die Assimilation entstehenden Produkte sehr augenfällig einwirkt. Es kommt nicht zu einer Aufspeicherung der Stärke, die sich nur an den Amylonkernen halten kann; dafür wächst der Plasmakörper mächtig heran. Auch der osmotische Druck des Zellsaftes kann unter solchen Umständen beeinflußt werden (Klebs 90 S. 365).

Das sind Zeichen für besondere Einwirkungen des Lichtes, die uns im einzelnen noch völlig unbekannt sind. Immerhin erregen sie den Gedanken, daß durch den Lichtmangel bei Schwächung oder Abwesenheit der Assimilation Veränderungen der chemischen und physikalischen Eigenschaften des Zellsaftes hervorgerufen werden, die ihrerseits den Anlaß zur Zoosporenbildung abgeben. Leider sind gerade für Vaucheria die Kenntnisse über die chemische Zusammensetzung äußerst gering. Wir kennen nicht einmal die Produkte der Assimilation. Stärke kommt nicht vor; im Zellsaft habe ich vergeblich Zucker nachweisen wollen, und die Bedeutung der Fetttröpfchen die im Plasma sich finden, ist leider auch nicht klar. Borodin (78 S. 5I4) hat die Behauptung aufgestellt, daß dieses Fett als Assimilationsprodukt betrachtet werden müsse, während Schimper (85 S. I87) es als eine nicht weiter verarbeitbare Substanz, als Produkt einer Degeneration, auffaßt. Nach meinen Beobachtungen liommt die Ansicht Borodin's näher der Wahrheit als die Schim per's. 
Lelhaft im Licht oder langsam im Schatten oder in der Dunkelheit wachsende Kulturen führen nur relativ wenig fett unt immer in kleinen Tröpfchen, die im l'lasma in der Nähe (ler Chlorophyllkörper liegen. Sowie solche Vaucherien in 2-proz. Rohrzucker bei heller Beleuchtung weiter gezogen werden, so erfolgt eine massenhafte Ansammlung les Fettes, das in großen Kugeln im Plasma wie im Zellsaft auftritt und schließlich den grö̈ßten Raum in (ler Zelle einnimnt (vergl. auch Loew und Bokorny ${ }^{1}$ ) 87 S. 288). Jeterzeit kann man diese Fettaufspeicherung durch Kultur in Nährlösungen zum Verschwinden bringen, rascher bei Beleuchtung als im Dunkeln. Zweifellos werden die grofien Fettliugeln aufgelöst, ebenso wie diejenigen der Oosporen bei der Keimung. Vollständig fettfreie Fäden kann man allerdings nicht erzielen, auch nicht nach wochenlanger Vertunkelung, wie Schimper richtig angiebt. Dem die Alge ist eben im Stande, das Fett nicht blok aus den direkt assimilierten sondern aus allen verwertharen organischen Stoffen zu bilden, im Dunkeln aus den ahsterbenden älteren Zellteilen. Nir scheint daher die richtigste Ansicht zu sein, daß bei V'aucheria das Fett nicht Protlulst der Assimilation noch der Deseneration ist, sondern daß es durch Umwandlung der organischen Stoffe wahrscheinlich von Kohlehydraten entsteht und als Reservestoff dient. Das bei cler Kohlensäurezersetzung zuerst entstehende Produlit ist für Vaucheria unbekannt; en liefert alser nach meiner Annahne ten Stoff für die Fettbildung.

1) Diese Forscher haben in 20-jroz. Zuckerlisung bei Vaucheria

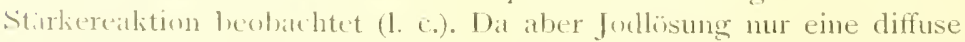
seluwarzhlate liathume der \%ellen hervorricf, so ist es doch fraglich, (o) wirklich Stärhekïner entstanden waren. Ich habe solche nie weschen. 


\section{Der Einfluß der Temperatur.}

Die Temperatur gehört zu den allgemeinsten Lebensbedingungen der Organismen; sie beherrscht in der mannigfachsten Weise ihre Lebensfunktionen. Aus den zahlreichen Beobachtungen über den Einfluß der Wärme auf Wachstum, Assimilation, Reizerscheinungen etc. hat sich die von Sachs klar formulierte Regel ergeben, daß von einem Minimum der Temperatur ab mit ihrer Steigerung eine Zunahme der Intensität der Funktion verbunden ist, bis zu einem Optimum, daß bei weiterer Temperaturerhöhung eine Verminderung der Intensität eintritt, bis bei dem Maximum der Temperatur kurz vor oder mit dem Tode ein Stillstand der Funktion erfolgt. Für jeden Lebensprozeß eines Organismus müssen daher diese drei Kardinalpunkte der Temperatur, wie Sachs sie nennt, bestimmt werden. Allerdings braucht sich nicht jeder Prozeß genau der Regel zu fügen; so zeichnet sich z. B. die Atmung dadurch aus, daß ihre Intensität beständig mit steigender Temperatur bis kurz vor dem Tode zunimmt. Das Optimum liegt daher hier nahe der Todestemperatur. Zunächst fragt es sich, welches die untere und obere Temperaturgrenze für die ungeschlechtliche Vermehrung von Vaucheria ist, in welcher Weise sie innerhalb dieser Grenzen von der Temperatur abhängig ist. Noch eine weitere Frage schließt sich an und macht die Untersuchung verwickelter. Ebenso wie Schwankungen der Lichtintensität Zoosporenbildung hervorrufen, so könnten auch Temperaturveränderungen zum Anlaß dafür werden, und in der That hat sich die Vermutung bestätigt gefunden. Wie wir sehen werden, ist es nicht immer leicht, scharf zu unterscheiden, wann Temperatur als Bedingung oder als Anlaß wirkt. Am übersichtlichsten wird die Darstellung sein, wenn ich 
zuerst das Verhalten von Vaucheria in der Nähe der Temperaturgrenzen und dann ihre Beziehung zu dazwischen liegenden Wärmesraden behandle. Ich berücksichtige zunächst $V$. repens allein.

\section{Niedere Temperatur.}

Schon in meiner ersten Mitteilung habe ich für die Zoosporenhildung als Minimum $3^{\circ}$, als Maximum $26^{\circ} \mathrm{C}$ angegeben. Die immer von neuem wiederholten Versuche haben im allgemeinen dieses Resultat bestätigt, indessen auch einige Abweichungen davon kennen gelehrt. Die Versuche mit niederer Temperatur wurden hauptsächlich in einem während des Winters nicht geheizten Zimmer angestellt, das auch von keiner Seite mit anderen geheizten Zimmern zusammenhing. Die Temperatur dieses Zimmers war lange Zeit ziemlich gleichmäßjig, hielt sich oft während mehrerer Tage konstant. Es standen während der Monate Oktober bis April Temperaturen von $\mathrm{O}^{0} \quad 8^{0} \mathrm{C}$ zur Verfügung. Bei anhaltender stärkerer Kälte wurde das Zimmer ein wenig geheizt, so dats die zahlreichen Kulturen niemals für längere Zeit einfroren. Kam es aber darauf an, eine wirklich grleichmäßi re Temperatur zu gebrauchen, so hing ich die Kulturen in Glasflaschen in das Aquarium, dessen Einrichtung ich früher lesprochen habe, dessen Tenuperatur tagelang sich konstant erhielt und während Wochen nur um ein paar Grade, stets dabei in langsamer Zu- oder Abnahme schwankte. Zu dem gleichen Zwecke benutzte ich auch den fließenden Brunnen meines Giartens.

Für niedere Temperatur $z$ wischen $\mathrm{O}-\mathrm{I}^{0}$ wandte ich einen einfachen Eiskasten an, der am Fenster in dem ungebeizten Zimmer stand. In einen großen hölzernen Kübel, der mit lis gefüllt war, wurde ein Zinkbehälter hineingestellt, dessen Boden durchlöchert war. Er war 
bedeckt mit einer durchbohrten Glasplatte, die in der Durchbohrung ein Thermometer trug. Kam es nicht auf Beleuchtung an, so wurde ein schwarzes Tuch über das Ganze gedeckt. In dem Behälter befanden sich die Kulturen und noch ein zweites ganz eingeschlossenes Thermometer, das in eine der Kulturen hineintauchte. Wenn die Versuche viele Wochen hindurch fortgesetzt wurden, so mußte eben Licht zu den Kulturen treten. Durch einen Heber wurde das Schmelzwasser von Zeit zu Zeit abgelassen; je nach Bedürfnis wurde das Eis erneuert. In dem Zinkbehälter schwankte die Temperatur zwischen 0,2 und $0,8^{\circ}$, ab und $z u$ erreichte sie $1,2^{\circ}$. Die Schwankungen zeigten sich hauptsächlich von dem Zustande des Eises abhängig. So lange frisches Eis den Behälter umgab, war die Temperatur anfangs in ihm $0,8-\mathbf{I}, \mathbf{2}^{0}$; wenn dagegen das Schmelzwasser begann in ihn einzudringen und die Kulturgläser zu umspülen, so sank die Temperatur bis auf $0,2^{\circ}$. Ich ließ daher das Schmelzwasser immer nur zum Teil ab, so daß dieses am Grunde des Behälters vorhanden blieb.

Zahlreiche Versuche lehrten, daß Vaucheria-Rasen, aus feuchter Luft oder aus Nährlösung in reines Wasser übergefülırt, bei Temperaturen unter $3^{0}$ keine Zoosporen bildeten. Wurden jüngere oder ältere Kulturen dabei verdunkelt, so änderte das nicht das Resultat. Deshalb glaubte ich mich berechtigt, $3^{0}$ als Temperaturminimum für die Zoosporenbildung zu bezeichnen. Zwischen $3-4^{0}$ beginnt diese, um schon bei $4-5^{0}$ sehr lebhaft zu erfolgen. Die wochenlang fortgesetzten Versuche mit niederen Temperaturen bewiesen aber, daß dieses Minimum nicht unveränderlich ist, entsprechend wie der Gefrierpunkt oder Schmelzpunkt, sondern daß Vaucheria die Fähigkeit be sitzt, allmählich sich niederen Temperaturen anzupassen und auch zwischen o- $3^{\circ}$ Zoosporen zu bilden. Dieses 
Resultat ergaben sowohl diejenigen Kulturen, welche froi in dem kalten Zimmer standen als auch die, welche im Eiskisten sich befanden. V'on den ersteren will ich zwei erwähnen, weil diese auch in anderer Beziehung sehr lehrreich sind.

I. repens wurde aus feuchter Luft am IO. XII. I 892 in Wasser crehracht und hell ans Fenster des kalten Zimmers gestellt. Im Monat Dezember waren die Temperaturen vom 10.-17./XII. 4-6 ${ }^{\circ}$, vom I8.-25./XII. meist $3^{0}$, vom 25.|XII. 1892 bis 29.J. I893 O-2 ${ }^{0}, \quad 30 . / 1 .-4 /$ II. $3-5^{\circ}$, 5.-8./H. 2,5-10, 9./1I. $3^{0}$, bis 13.11. $5^{0}$, lis IO./III. 5-8". Die Alge wuchs sehr langsam, entwickelte sich aber zu einer sehr kräftigen Kultur. An 7. Januar bemerlite ich zu meinem Erstaunen die ersten Zoosporangrien, trotzdem die Temperatur die ganze Woche vorher zwischen $0-2^{0}$ reschwanlit hatte. Die Kultur bedeckte sich am 9./I. mit Eis und hörte mit der Zoosporenbildung auf. Sie wurle dann zu anderen Temperaturversuchen benutzt, und erst am 21.1. wieder an ihren Platz gestellt. Sie fing bei $3-4^{0}$ wieder an, Zoosporen zu lilden, fuhr damit fort auch an 5.-8./11. bei $0-2^{0}$, und ron nun an bei steigender Temperatur ying der Prozeß fast ununterbrochen, bald mehr, bald weniger lebhaft bis zum I0.111. fort.

V. repens kam aus feuchter Luft in 0,2-proz. KNLiosung, 15. XIl. hell ins kalte Zimmer. Am 3I.1. bemerkte ich bei 3,5-4" die ersten Zoosporen. Der Prozeß ging fort vom 5.-8./Il., Temperatur $0-2^{\circ}$ und dann weiter bei steigender Temperatur bis zum Io./III.

Diese Versuche zeigten, daß Zoosporenbildung jedenfalls auch unter $3^{\circ}$ stattfinden kann; sie hatten aber den Nachteil, daß die Temperaturschwankungen ziemlich beträchtlich waren. Andere Kulturen, namentlich in o,2-proz. KN-Lïsung, wiesen keine solche Anpassung auf. 
Viel sicherer ließ sie sich bei den Kulturen im Eiskasten beobachten. Am IO./XII. stellte ich in den Zinkbehälter 4 Wasserkulturen und 2 Zuckerkulturen hinein. Die beiden letzteren erhielten sich bis Ende Januar, zeigten aber niemals Zoosporen, weil ein mehrwöchentlicher Aufenthalt in einer Zuckerlösung die Zoosporenbildung unmöglich macht. Von den 4 Wasserkulturen wurde eine Ende Dezember, bis zu welcher Zeit keine Zoosporen sich gezeigt hatten, zu anderen Zwecken verwendet. Die drei übrigen Kulturen blieben unverändert in dem Zinkbehälter vom IO./XII 1892 bis 6./III. I 893 bei einer Temperatur von $\mathrm{O}-\mathrm{I}{ }^{0}$. In den ersten 8 Tagen wurde der ganze Apparat verdunkelt, vom I8./XII. ab stand er hell. Das Licht konnte keinen entscheidenden Einfluß auf den Prozeß der Zoosporenbildung ausülben, weil seine Intensität von Ende Dezember stetig zunahm und daher eher hemmend wirken konnte. Während der Verdunkelung erfolgte keine Zoosporenbildung, ebensowenig nach Zutritt des Lichtes. Erst Mitte Februar, vom I4.-16./II. $\mathrm{ab}$, bemerkte ich gleichzeitig in allen drei Kulturen das Auftreten einzelner Zoosporangien, die am 20./Il. schon in sehr großer Menge sich zeigten. Ununterbrochen ging der Prozeß fort bis zum 6./III., wo der Eiskasten nicht mehr mit Eis gefüllt wurde. In der Temperatur des Zimmers von 7-80 in der Zeit vom 6.-I2./III. fand ehenfalls noch lebhafte Zoosporenbildung statt.

Vom 2I./II. bis 28./II. verdunkelte ich den Eiskasten vollständig und stellte zugleich fünf neue Kulturen hinein. Vaucheria, teils aus feuchter Luft, teils aus Nährlösungen, wurde in Wasser gebracht. Die neuen Kulturen bildeten in dem verdunkelten Eiskasten keine Zoosporen, während die alten, sehr lange in ihm stehenden, ruhig fortfuhren, ihre Zoosporen zu erzeugen, ebenso wie vorher und nachher bei Beleuchtung. Nur der lange Aufenthalt bei 
einer niederen Temperatur von $\mathrm{O}-\mathrm{I}^{0}$ macht die Vaucheria fähigr, sich ihr soweit anzupassen, daf sie Zoosporen bildet, während sie sonst bis zu $3^{0}$ nur Wachstum aufweist.

Aus den besprochenen Versuchen ergielst sich noch ein anderes wichtiges Resultat. Niedere Temperatur von 3- $8^{\circ}$ kann als fortlauernder Reiz für die Zoosporenbildung wirken vergleichbar dem Einfluß schwachen Lichtes. Bei den Versuchen im Eiskasten hat gewiß die relativ geringe Lichtintensität etwas mitgeholfen, wenn sie auch, wie vorhin angegeben, nicht die Hauptrolle gespielt hat. Dasselbe Resultat haben auch andere Versuche ergeben, in denen die Lichtintensität noch weniger mitgewirlit hat. Ich hing Glasflaschen mit Wasser, die Vaucheria enthielten, in mein Aquarium, das am Südfenster stand, wobei aber die direkte Sonnenbeleuchtung verhindert wurde. Bei der gleichmäßig niederen Temperatur des Aquariums konnte ich wochenlang Zoosporenbildung bei ein und derselben Kultur beolachten, während auf dem Tische daneben stehende Kulturen nach einigen Tagen damit aufhörten. Der geringe EinHuss des Lichtes lag nur darin, daß es in der Zeit der Versuche vom Januar bis März seine hemmende Wirkung nicht so ausüben konnte, wie etwa in den eigentlichen Sommermonaten. Einzelne trübe Tage konnten auch hin und wieder begünstigend gewirkt haben.

linige Versuche will ich genauer angeben.

V. repens seit I7./XII. 189I in I-proz. KN-Lösung, wurde am 14./I. I892 in einem Glas mit Wasser ins Aquariun gehängt. Die Temperatur des Wassers schwankte in dem relativ warmen Januar und Februar in der Zeit vom I4./1. bis I8./II. von ca. $6-7^{\circ}$ mit sehr langsamer Verïnderung. Am I8./I. sah ich die ersten Zoosporen, und der Prozeß ging von num ab fast ununterbrochen bis zum I8./1I. fort, bald mehr, bald weniger lebhaft. 
V. repens aus feuchter Luft, wurde am I9./I. I893 in 0,2-proz. KN-Lösung in einem zugekorktem Gefäß ins Aquarium gehängt. Die Temperatur betrug anfangs $5^{\circ}$, sank allmählich bis auf $4^{\circ}$ (am 26.|I.), schwankte in der Zeit bis 6./II. zwischen 4 und $4,5^{\circ}$, stieg dann wieder auf $5^{\circ}$ (7./II.) und schwankte dann bis 22./II. zwischen 5 und $6^{\circ}$, vom 22.-26./II. um $6,5^{\circ}, 27 . /$ II.-4./III. um $7^{\circ}$, vom 4.-I2./III. zwischen 7 und $8^{\circ}$. In den ersten I4 Tagen erfolgte nur Wachstum, so daß der Reiz, den etwa die Ueberführung aus feuchter Luft in Nährlösung ausgeübt hatte, längst unwirksam sein mußte. Am 2./II. sah ich die ersten Zoosporen, und von jetzt ab ging die Bildung weiter mit wechselnder Intensität bis zum I2./III.

V. repens in einem Glas mit o,6-proz. KN-Lösung, am 19./I. I892 ins Aquarium gehängt, zeigte am 2./II. zuerst Zoosporen und fuhr damit fort bis zum I./III.

V. repens in einem Glas mit Wasser, am I9./I. I893 ins Aquarium gehängt, zeigte ebenfalls erst am 2./II. lebhafte Zoosporenbildung, die bis zum 20./II. dauerte.

\section{Hohe Temperatur.}

$\mathrm{Zu}$ den Versuchen mit Temperaturen über $20^{\circ}$ wurde ein großer filzbedeckter Thermostat von Desaga benutzt. An der vorderen Seite befand sich eine verschiebbare Glaswand, auf der die Glasthür auflag, welche mit abnehmbarer Filzwand bedeckt war. Die Temperatur wurde durch einen Reichert'schen Regulator und ein genaues Thermometer reguliert. Die Temperaturschwankungen betrugen innerhalb 24 Stunden ca. $1 / 4$ Grad. Für die Versuche, bei denen Licht einwirken sollte, wurde die Filzwand von der Thüre entfernt. In diesem Falle konnten die Temperaturschwankungen bis zu einem halben Grade betragen. 
Die zahlucichen Versuche, die ich im Laufe mehrerer Jahre mit $V$. repens angestellt habe, führten zu dem Resultate, dał dic obere Temperaturgrenze ungefähr bei $20^{\circ} \mathrm{C}$ liegt. Nit absoluter Genauigkeit lïßst sich die Grenze nicht hestimmen, weil die einzelnen Kulturen individuelle Verschiedenheiten aufweisen. Bei manchen Kulturen sah ich bei 25 " keine Zoosporen mehr, bei anderen vereinzelte bei $25,5^{\circ}$. Ihre Bildung hört ebenso wie in der Nähe des Temperaturminimums nicht plötzlich auf, sondern nimmt allmählich ab. Das Wachstum von Vaucheria ist viel weniger empfindlich, es erfolgt noch bei 30 ", um erst bei weiterer Steigerung in Verbindung mit zunehmender Lebensschwäche langsamer zu werden. Die Todestemperatur liegt etwa bei $33^{\circ}$; schon nach 24 Stunden sind die Fäden dabei abgestorben oder sehr liränklich. Bei noch höheren Graden erfolgt das Absterben immer schneller.

Ein längerer Aufenthalt in einer Temperatur von 26) $-27^{\circ}$ bei Gegenwart von Licht bewirkt nicht eine Veränderung der Grenze, wie es bei der niederen Temperatur zu beobachten ist. In Versuchen, in denen Vaucheria-Kulturen während vier Wochen einer Tempratur von $26-26,5^{\circ}$ ausgesetzt waren, trat keine $Z(x)$ sporenliklung ein, trotzdem gleichzeitig nur schwaches Licht zu den Algen treten lionnte. Eine Anpassung crscheint für höhere Temperatur auch weniger wahrscheinlich, weil cliese ganz allgemein auf die Zoosporenbildung hemmend wirkt, in Gegensatz zur niederen Temperatur. Wenn Vaucheria aus feuchter Luft oder Nährlïsung in Wasser übergeführt und in Thermostat lxi $22-24^{\circ}$ verdunkelt wird, so erfolgt in den ersten Tagen lebhafte Zonsporenliklung, die aber bald aufhört. 1)as (ileiche geschieht bei Zutritt von schwachem Licht, so dafs die sonst andauernde zoosporenerregende Wirkung 
der Dunkelheit oder des schwachen Lichtes durch die hohe Temperatur aufgehoben wird.

\section{Mittlere Temperatur und Temperatur- schwankungen.}

Eine mittlere Temperatur von $10-20^{\circ} \mathrm{C}$ übt im allgemeinen keinen entscheidenden Einfluß aus, so daß man auf sie für alle Versuche, die im Zimmer angestellt werden, keine Rücksicht zu nehmen hat. Der begünstigende Einfluß einer Temperatur von 4-10 ${ }^{\circ}$, der hemmende einer solchen von $26-20^{\circ}$ sinkt allmählich von beiden Seiten ohne scharfe Grenze, so daß es nicht möglich ist, die indifferente Zone um 12-1 $8^{\circ}$ herum wirklich genau anzugeben. Es ist thatsächlich für die Versuche gleichgiltig, ob die Temperatur im Arbeitszimmer mehr oder weniger zwischen IO und $20^{\circ}$ schwankt. Solche Schwankungen spielen niemals eine besondere zoosporenerregende Rolle. Dagegen kann man durch stärkere Temperaturschwankungen den Prozeß veranlassen, auch wenn alle anderen Reize ausgeschlossen sind. Wenn man frische Kulturen von o,2-proz. KN-Lösung ins kalte Zimmer steilt bei einer Temperatur von $0-3^{0}$, so bilden sie, wie wir wissen, in den ersten Wochen keine Zoosporen. Der Reiz des Ueberganges aus feuchter Luft in Flüssigkeit ist wirkungslos verschwunden. Nimmt man solche Kulturen und stellt sie hell in ein warmes Zimmer von ca. $15^{\circ}$, so tritt lebhafte Zoosporenbildung ein. Zurückversetzt ins kalte Zimmer hört die Kultur damit auf, um wieder in höherer Temperatur Zoosporen zu erzeugen.

Bei meinen Versuchen standen die Kulturen im kalten Zimmer am Nordfenster, im warmen am Südfenster. Die Lichtintensität konnte infolgedessen keine fördernde Wirkung ausüben. Der Uebergang aus niederer in 
mittlere Temperatur spielte allein die Rolle des auslösenden Reizes. Dagegen gelang es niemals, durch den Uebergang aus mittlerer Temperatur in hohe $\left(20-26^{\circ}\right)$ Zoosporen zu erhalten, ebensowenig durch den Uebergang aus hoher Temperatur in mittlere. Besonders richtete ich meine Aufmerksamkeit auf jene Versuche, in denen ich die Kulturen einer konstanten Temperatur von $26-27^{\circ}$ bei Zutritt des Lichtes aussetzte. Nach einigen Tagen wurden dann die Kulturen neben dem Thermostat ins Zimmer grestellt, so daß die Lichtintensität nicht verändert war. Niemals gelang es mir, in solchen Versuchen Zoosporen zu erhalten, die dagegen massenhaft sich bildeten, sobald ich verdunkelte. Aber auch der Satz von der Wirkung des Ueberganges aus niederer in mittlere Temperatur muß noch eingeschränkt werden. Vaucheria-Kulturen, welche durch mehrwöchentlichen Aufenthalt in Wasser oder Nährlösung bei Zimmertemperatur und Beleuchtung wenig Neigung zur ungeschlechtlichen Vermehrung besitzen, werden durch keinen Temperaturwechsel dazu befähigt, während sie durch Verdunkelung immer noch dazu gebracht werden können. Ich habe solche Kulturen mehrere Tage im Eiskasten gehalten und dann in das warme Zimmer gestellt, aber ohne Erfolg. Der Satz von der Wirliung der Temperaturerhöhung gilt hauptsächlich für frische Kulturen, die von vornherein einer niederen Temperatur ausgesetzt wurden. Zwischen diesen beiden Extremen, dem Verhalten der alten und jungen Kulturen, giebt es natürlich mancherlei Zwvischenstufen; selbst zwei gleichaltrige Zimmerkulturen, die aber noch nicht alt sind, können sich verschieden verhalten. Bei der einen gelingt es, noch durch Temperaturwechsel \%oosporen zu erzeugen, bei der anderen nicht. Hierbei spielen die vorhergehende Behandlung, die Reinheit von anderen Organismen, vielleicht verschiedener Lichteinfluß 


\section{- 49}

eine Rolle, ohne daß man in jedem Falle ein richtiges Urteil gewinnen kann über das Maß der einzelnen Einwirkungen.

Da nach den angegebenen Resultaten die Temperaturerhöhung nur dann sicher zoosporenerregend wirkt, wenn die betreffende Kultur von vornherein einer niederen Temperatur unter dem Minimum ausgesetzt war, so wird man sich vielleicht vorstellen müssen, daß die niedere Temperatur an und für sich als Reiz wirkt, daß aber die Reaktion - die Zoosporenbildung - durch zu niedere Temperatur gehemmt wird. Die Temperaturerhöhung beseitigt nur diese Hemmung, kann aber selbst nicht als besonderer Reiz wirken. Auch bei den älteren Kulturen könnte der Aufenthalt in niederer Temperatur als die eigentliche Reizursache betrachtet werden. Dafür spricht, daß in den verschiedenen Kulturen, die im kalten Zimmer bei $0-3^{\circ}$ gestanden hatten, sich schon Zoosporen zeigten, als die Temperatur auf $4-5^{0}$ stieg; es genügte ihnen also nur eine kleine Erhöhung über das Minimum. Immerhin bleibt die Möglichkeit, daß Temperaturerhöhung für sich zoosporenerregend wirkt; und nur so viel ist sicher, daß ihre Reizwirkung unbedeutend ist gegenüber derjenigen des Lichtmangels, des Ueberganges aus Nährlösung oder feuchter Luft in Wasser.

Zum Schluß handelt es sich noch um die Frage, in welcher Beziehung die Intensität der Zoosporenbildung zur Temperatur innerhalb der Grenzen steht. Man muß dabei zweierlei unterscheiden, einmal die Zahl der Sporangien, die bei einem Versuch gebildet werden, ferner die Zeitdauer, welche für die Bildung nötig ist. Die Zahl der erzeugten Sporangien hängt so gut wie nicht mit der Temperatur zusammen. Die denkbar größte Intensität, bei der überhaupt die Mehrzahl aller Fadenenden einer Kultur Zoosporen erzeugt, kann bereits bei Klebs, Fortpflanzungsphysiologie. 
einer dem Minimum nahen Temperatur erfolgen. So geschah es z. B. an drei Kulturen, welche am 27. I. I893 in 0,2-proz. KN-Lösung ins kalte Zimmer (unter $3^{\text {in }}$ ) gestellt und verdunkelt wurden. Am 29. I. stieg die Temperatur auf $3,5-4^{0}$; die ersten Zoosporen zeigten sich am 3I. I. Am 2. Il. bei 4--4,5" erreichte die Zoosporenbildung in allen drei Kulturen den höchsten Grad. Das Gleiche kann auch bei höheren Temperaturen, selbst bei $22-23^{\prime \prime}$, eintreten; die Intensität hängt nur davon ab, daß die auslösenden Reize in richtiger Weise auf gesunde kräftige Kulturen wirken können. Nur ganz in der Nähe der Temperaturgrenzen macht sich eine Verminderung des Prozesses bemerkbar.

Dagegen ist die Zeitdauer für die Bildung der Zoosporangien von der Höhe der Temperatur abhängig; der Prozeß schließt sich in dieser Beziehung anderen Wachstums- und Lebenserscheinungen an. Genaue Zahlen lassen sich wegen zu großer individueller Verschiedenheiten nicht erhalten. Nur so viel darf ich behaupten, daß bei Temperaturen von $3-6^{0}$ die irgendwie erregte Zoosporenbildung drei Tage braucht, bei Temperaturen von $10-15^{\circ} \mathrm{zwei}$ Tage, bei solchen von $20-24^{\circ}$ einen Tag. Das Optimum liegt ungefähr bei $22^{\circ}$. In I6 Stunden kann dabei der ganze Prozeß der Zoosporenbildung vollendet sein.

Vaucheria clavata verhält sich im allgemeinen wie repens. Das Temperaturminimum liegt auch etwa bei $3^{0}$. Die Grenze läßst sich noch weniger scharf bestimmen, weil die Fäden von $V$. clavata bei so niederer Temperatur ohne rechtes Wachstum sich lange in dem Zustand erhalten, in dem sie vorher waren. So bleiben Zoosporangien in verschiedenen Stadien der Entwickelung längere Zeit bei $0-3^{0}$ stehen und können zu Täuschungen Veranlassung geben. Unzweifelhaft salı ich aber, als ich eine 
Kultur mit Zoosporangien in dem Eiskasten einer Temperatur von $0,2^{\circ}$ aussetzte, nach 2 Tagen noch den Austritt und die Bewegung einzelner Zoosporen. Hat man aber eine Kultur, die keine Anlagen zu Zoosporangien besitzt und verdunkelt sie bei einer Temperatur von $0-3^{0}$, so erfolgt keine Zoosporenbildung. Erst zwischen $3-4^{0}$ beginnt der Prozeß und zwar nicht bloß bei den verdunkelten, sondern auch bei den hell stehenden Kulturen. Weil die relativ schwache Lichtintensität in den Wintermonaten die Zoosporenbildung bei $\mathrm{V}$. clavata sehr fördert, so tritt der Einfluß der niederen Temperatur in der gleichen Richtung nicht so stark hervor wie bei repens. Bei dem Aufenthalt in Temperaturen unter $10^{0}$ bewahrt die Alge in jedem Falle ihre Empfindlichkeit für schwaches Licht länger als bei einer Temperatur von $15^{\circ}$. Mehrere Kulturen, welche am I4./XII. I894 in das kalte Zimmer (Temperatur stets unter $1^{0}$ ) gestellt wurden, bildeten. noch lebhaft Zoosporen Ende März I895, ohne daß irgend eine Aenderung sonst vorgenommen wurde. Allerdings war die Zoosporenbildung während des ganzen Februar wegen der anhaltenden niederen Temperatur unter $3^{\circ}$ zum Stillstand gebracht worden. Sowie die Temperatur im März über $3^{\circ}$ und bis Ende des Monats auf $9^{\circ}$ stieg, so erfolgte lebhafte Zoosporenbildung. Während des Monats Februar ging das Wachstum sehr langsam aber ununterbrochen vor sich; von Ende März an war die Kultur erschöpft, so daß sie zwar noch im Stande war, etwas zu wachsen auf Kosten der absterbenden Fäden, ohne daß aber Zoosporenbildung eintreten konnte.

Wenn noch mit niederer Temperatur (unter $6^{\circ}$ ) helles Licht einwirkt, so gestaltet sich das Resultat bei $\mathrm{V}$. clavata etwas anders. Ich brachte am 4./I. I895 V. clavata frisch aus der freien Natur in mehrere Glasflaschen und hängte diese bis zum Halse in das Aquarium, dessen Temperatur 
im Januar zwischen 4,5 und $5,5^{\circ}$, im Februar zwischen 4,5 und $3^{\circ}$ schwankte, im März allmählich wieder bis auf $60^{\circ}$ stieg. In den ersten drei Wochen fand lebhafte Zoosporenbildung statt; gegen Ende Januar hörte sie auf und zeigte sich im Februar nicht wieder. Dafür war das WVachstum der Vaucherien sehr üppig, bis es dann im März infolge Nangels an Nährsalzen geringer wurde. Das Licht war in der Zeit hell, da die Tage meist klar waren, es beförderte das Wachstum und wirkte zum mindesten nicht fördernd auf die Zoosporenbildung ein, die vielleicht auch dadurch gehemmt wurde, dafj die Temperatur der Grenze $3^{\circ}$ sich näherte. Indessen wirkte später eine Temperaturerhöhung auf die betreffenden Kulturen in den Glasflaschen nicht mehr ein. Da die Versuche erst im März angestellt wurden, so könnte sich das negative Resultat übrigens aus dem nicht mehr gesunden Zustande der Algen erklären.

Überhaupt, wenn eine Kultur von V. clavata im Zimmer, sei es im wärmeren oder liälteren, aufgehört hat, Zoosporen zu bilden, so kann sie nicht durch Temperaturschwankungen allein wieder dazu veranlaßt werden; ihre Reizbarkeit dafür ist verschwunden, während diejenige für Lichtschwankungen noch vorhanden sein kann. Bei ganz frischem Material wirkt jedenfalls eine plötzliche Temperaturerhöhung z. B. ron 6 auf I $5^{0}$ sehr fördernd auf den Prozel3 ein; ob sie bei Konstanz aller anderen Bedlingungen genügt um ihn hervorzurufen, kann ich nicht sicher behaupten. Der T'ersuch müßte so angestellt werden, daß das fliefende Wrasser, in dem die frische nicht zoosporen]jildende Alge wächst, plötzlich um mehrere Grade erwärmt wird. Indessen habe ich versäumt, einen solchen Versuch auszuführen. 


\section{Der Einfluß der chemischen Beschaffenheit des Iediums.}

Für die Ernährung und damit für alle anderen Lebenserscheinungen bedarf Vaucheria wie jede grüne Pflanze anorganischer Verbindungen, die sie dem Erdboden entzieht oder dem Wasser entnimmt. In reinem destilliertem Wasser wachsen die Vaucherien anfangs normal; allmählich wird wegen des Mangels an Nährsalzen das Wachstum sehr langsam. Bei Vaucheria hört es darin selbst nach monatelangem Aufenthalt nie vollständig auf, weil die Fäden an dem einen Ende beständig absterben und dadurch kleine Mengen von Nährsalzen dem wachsenden anderen Ende zuführen. So wie man solche kümmerliche Rasen oder Fäden in Nährlösung versetzt, so erfolgt gleich wieder lebhaftes üppiges Wachstum. Auch wenn Vaucheria durch andere Kulturmethoden, z. B. durch langen Aufenthalt in Zuckerlösung, in einen krankhaften Zustand versetzt worden ist, so erwacht sie in Nährlösung zu neuem frischem Leben.

Unstreitig müssen die Nährsalze teils unmittelbar, teils mittelbar den Prozeß der Zoosporenbildung beeinflussen. Physiologisches Interesse knüpft sich auch weiter an die Frage nach der Einwirkung anderer chemischer Stoffe, die mit der Ernährung nicht notwendig zusammenhängen und ferner an die Untersuchung der physikalischen Eigenschaften der Substanzen, vor allem ihrer wasserentziehenden Kraft. Ich werde die Hauptpunkte in folgender Reihenfolge behandeln:
a) Anorganische Verbindungen;
b) Organische Verbindungen;
c) Der osmotische Wert der Verbindungen;
d) Saure und alkalische Reaktion. 
Als Material diente mir stets, wo nichts besonderes angegeben ist, Taucheria repens.

a) Anorganische V erbindungen.

Unter diesen nehmen die eigentlichen Nährsalze das Hauptinteresse in Anspruch. Schon früher wurde hervorgehoben, daß die von mir angewandte Nährlösung folgende Salze enthält: Salpetersauren Kalk (4 Teile), schwefelsaure Magnesia (I Teil), salpetersaures Kali ( I Teil), phosphorsaures Kali (I Teil).

Die Nährsalzlösungen wurden stets sorgfältig sterilisiert. Da aber das Ausgangsmaterial schwer zu reinigen war, so konnte nicht verhindert werden, daß bei monatelanger Kultur fremde Gäste, Protococcoideen- und Hormidium-Arten oder auch Oscillarien, sich unangenehm vermehrten. Diese Eindringlinge ließen sich einigermaßen fernhalten, so lange eine niedere Temperatur unter IO ${ }^{0}$ oder schwache Beleuchtung herrschte, während in der warmen hellen Tahreszeit die fremden Algen nach einigen Wochen die Kulturen sehr verunreinigen konnten. Kam es auf sehr reine Kulturen an, so wurde das Auscangsmaterial besonders gereinigt. $\mathrm{Zu}$ diesem Zwecke nahm ich aus dem Gewächshaus einen Vaucheriarasen auf Koaksstücken und ließ einige Zeit durch einen lebhaften Wasserstrahl möglichst alle anhängenden Koaksteilchen mit den Unreinigkeiten wexschwemmen. Dann nahm ich die gereinigten Fäden und ließ sie einige Tage in meinem Aquarium heranwachsen.

Die zahlreichen Versuche mit den Nährlösungen verschiedener Konzentrationen zeigen, daß in solchen ron O, I-O,4 Proz. die Vaucheria-Fäden ausgezeichnet wachsen, ohne daß dabei die Konzentration eine merlibare Rolle spielt. Nach zwei Richtungen hin muß die Wirkung der 
Nährsalze auf den Prozeß der Zoosporenbildung untersucht werden. Es fragt sich

I) Wie wirkt überhaupt der Aufenthalt in der Nährlösung auf den Prozeß?

2) Wie wirkt der Uebergang aus Nährlösung in Wasser?

Eine Nährlösung von $\mathrm{O}, \mathrm{I}-\mathrm{O}, 4$ Proz. wirkt auf jede Vaucheria-Kultur durch lebhafte Steigerung des Wachstums ein; sie veranlaßt für sich allein keine Zoosporenbildung. Aus einer beliebigen Wasserkultur in Nährlösung übergeführt, wächst die Vaucheria, pflanzt sich aber nicht ungeschlechtlich fort, so lange Licht und Temperatur unverändert bleiben. Ganz anders verhält es sich, wenn Vaucheria aus feuchter Luft in die Nährlösung gebracht wird. Zunächst spielt der Wechsel des Mediums die Rolle des auslösenden Reizes; die Nährsalze halten innerhalb der angegebenen Grenzen die Zoosporenbildung nicht auf. Doch wirken sie eher dahin, daß bei gewöhnlicher Zimmertemperatur und Beleuchtung der Prozeß früher aufhört als in reinem Wasser. Bei Vaucheria-Rasen, die ziemlich trocken aufgewachsen sind, kann in der Nährlösung unter Mitwirkung hellen Lichtes und einer Temperatur von IO- $20^{0}$ die Zoosporenbildung nur spärlich oder gar nicht erfolgen. Bei anhaltender niederer Temperatur unter $10^{\circ}$ und mäßiger Beleuchtung wie in den Wintermonaten, kann dagegen der Prozeß in Nährlösung, ebenso wie im Wasser wochenlang fortgehen; man vergleiche die früher angegebenen Versuche (S. 42 und 45). In den Nährsalzkulturen, in denen nach einigen Tagen die Zoosporenbildung aufgehört hat, kann sie von neuem durch Verdunkelung veranlaßt werden. Aber auch hierbei wird im allgemeinen Intensität und Dauer des Prozesses in Nährlösungen geringer sein als im Wasser, und die Hemmung wird um so stärker, je 
längere Zeit die Alge in der Nährlösung gelebt hat. Als Beispiel führe ich einen Versuch an mit I2 Kulturen in KN-Lösungen, die in verschiedener Weise vorher behandelt worden waren, aber stets hell gestanden hatten und die am 7. Januar I 893 verdunkelt wurden.

\begin{tabular}{|c|c|c|c|c|c|}
\hline No. & $\begin{array}{l}\text { Datum der } \\
\text { Kulturen }\end{array}$ & Nährl & ösung & \multicolumn{2}{|c|}{$\begin{array}{l}\text { Resultat nach Verdunke- } \\
\text { lung vom } 7 \text { - - I0./I. I893. }\end{array}$} \\
\hline I & I6./XI1. I 892 & $0,4 \mathrm{P}$ & Proz. & vereinzelte & Zoosporen. \\
\hline 2 & I6./XII. I 892 & 0,3 & $"$ & keine & " \\
\hline 3 & I6./XII. I 892 & 0,05 & $"$ & vereinzelte & 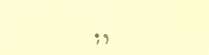 \\
\hline 4 & I7./XII. I 892 & 0,2 & $"$ & vereinzelte & , \\
\hline 5 & 24./XII. I 892 & 0,2 & $"$ & zahlreiche & $"$ \\
\hline 6 & 24. XII. I 892 & 0,1 & $"$ & $"$ & $"$ \\
\hline 7 & 24./XII. I 892 & $0, \mathrm{I}$ & $"$ & " & $"$ \\
\hline 8 & 24./XII. I 892 & $\mathrm{O}, \mathrm{I}$ & $"$ & " & $"$ \\
\hline 9 & 31./XII. I892 & $\mathrm{C}, \mathrm{I}$ & $"$ & " & $"$ \\
\hline IO & 31./XII. I 892 & $\mathrm{O}, \mathrm{I}$ & $"$ & $"$ & $"$ \\
\hline I I & 3I./XII. I 892 & 0,2 & $"$ & , & " \\
\hline I2 & 3I. XII. I 892 & 0,2 & $"$ & , & $n$ \\
\hline
\end{tabular}

Die Algen also, die länger als I4 Tage in der Nährlösung bei Zimmertemperatur hell kultiviert worden waren, reagierten auf Verdunkelung nur schwach oder gar nicht. Zahlreiche andere Versuche lehrten das gleiche; nach wochenlangem Aufenthalt in der Nährlösung sind bei den Kulturen auf keine andere Weise mehr Zoosporen hervorzurufen, als durch Ueberführung in Wasser.

Steigert man die Konzentration der Nährlösung, so wächst auch die hemmende Wirkung der Salze. Für Vaucheria repens bildet eine Nährlösung von 0,7 Proz. die Grenze. Schon in ihr unterbleibt fast stets die Zoosporenbildung, unbedingt bei jeder höheren Konzentration. In einer I-proz. Lösung wachsen die Algenfäden noch 
sehr lebhaft; selbst in 2 Proz. erhält man noch kräftige Rasen, wenn auch erst nach längerer Zeit, da das Wachstum darin verlangsamt wird. Merkwürdig verschieden sind die Resultate der Versuche mit einer Lösung von o,6 Proz., infolge dessen gerade diese Konzentration im Laufe der Jahre immer wieder benutzt wurde, um eine bestimmte Gesetzmäßigkeit im Verhalten der Alge festzustellen. Indessen gelang dieses nicht; es hängt von unbekannten Umständen $a b$, in welchem Grade die Zoosporenbildung in o,6 Proz. eintritt. Wahrscheinlich spielt die raschere oder langsamere Ansammlung der Salze im Zellsaft, die von Licht, Temperatur etc. abhängig ist, die Hauptrolle. Lebhafte und lang andauernde Zoosporenbildung beobachtete ich bei Anwendung niederer Temperatur, so z. B. in einer Kultur vom I8./I. I892, die im kalten Zimmer stand und die periodisch vom I.-6./II., dann vom 27./II.-2./III., weiter noch vom 22.-23./III. Zoosporen bildete (vergl. auch den Versuch in 0,6 Proz. S. 45). Die Mehrzahl solcher Kulturen, die bei gewöhnlicher Zimmertemperatur gleich in schwaches Licht oder ins Dunkle gestellt wurden, bildete wenige oder gar keine Zoosporen.

Um so auffallender erscheint die mehrfach bestätigte Thatsache, daß in Kulturen von 0,6 Proz. in der ersten Zeit kräftiges Wachstum ohne Zoosporenbildung erfolgte, dann aber ohne merkbare Aenderungen der Temperatur und des Lichtes Zoosporen auftraten. So zeigten sich z. B. in einer beleuchteten Kultur vom 28./IV. I89I am 5./V. die ersten Zoosporen, d. h. nach einer Woche, wo längst der Reiz des Mediumwechsels verschwunden war; am 9./V. wurde der Prozeß lebhafter; vom I0.-II6./V. nahm er langsam ab, um dann nicht mehr aufzutreten. Das gleiche beobachtete ich an anderen Kulturen, besonders in den Sommermonaten, wo eher die zunehmende 
Intensität ron Licht und Temperatur die Zoosporenbildung hätte beeinträchtigen sollen. Ich kann nichts anderes annehmen, als daß in ler Konzentration der Nährsalze nahe der Grenze von 0,7 Proz. der Reiz für die Auslösung des Prozesses liegt. Dabei ist nur auffallend, daß dieser Reiz erst nahe der Konzentrationsgrenze stark genug wird, um den Prozeß auszulösen. Hier kommt noch etwas anderes hinzu; die Lösung ron 0,6 Proz. wirlit auch auf das Wachstum ein, und es hängt dann von den anderen äußeren Bedingungen ab, ob) das Wachstum allein oder bei zeitweiliger Hemmung ron diesem die Zoosporenbildung, vor sich geht. Deutlicher ist diese Wirkung der Nährlösung bei V. clavata.

Diese Art verhält sich gegenüber Nährlösungen anders als repens; der physiologische Gegensatz der beiden nahe verwandten Formen tritt in keiner anderen Beziehung schärfer hervor. V'or allem wird das Wachstum von clavata durch Nährlösungen stark gehemmt. Sellsst in Lösungen von 0,05 Proz. macht sich besonders in der ersten Zeit eine Verlangsamung des Wachstums bemerkbar, noch stärker in Lösungen von $0,2,0,5$ und I Proz. Während die Fäden von repens in solchen Lösungen gleichmäßig aufwärts wachsen und sich wenig verzweigen, wird bei clavata lebhafteste Verzweigung veranlaßt, da immer die Fadenenden nach einiger Zeit mit dem Wachstum aufhören, das dann durch Seitenzweige fortgesetzt wird. So bilden sich unregelmäßig und stark verzweigte Fadenmassen, wie sie in der freien Natur nicht vorzuliommen pflegen. Die Zoosporen keimen in Nährlösung von 0,5 Proz. oft tagelang nicht, in I Proz. so gut wie gar nicht, und die Keimschläuche, die später entstehen, gehen leicht zu Grunde.

Die Zoosporenbildung selbst wird aber durch die Nährsalze sehr gefördert, so daf sie bei heller Beleuch- 
tung und Zimmertemperatur von ca. I5" lange fortgeht. So bildete ein frischer Rasen, der am 23./IV. I893 in 0,5-proz. Nährlösung versetzt wurde, bis zum 3I. Mai fortdauernd Zoosporen, trotz des warmen hellen Wetters.

V. clavata erzeugt ihre Zoosporen auch in viel stärker konzentrierten Lösungen als repens. Während für diese eine Lösung von 0,7 Proz. die Grenze bildet, erfolgt bei clavata der Prozeß ungehindert bei I Proz., wobei einzelne Zoosporen noch frei heraustreten können. Sogar in einer Lösung von 1,5 Proz. bemerkte ich noch zahlreiche Zoosporangien, die sich dann meistens nicht öffneten.

Der Aufenthalt in Nährlösungen wirkt zoosporenerregend auf clavata. Keimlinge, aus Wasser in 0,2 Proz. versetzt, wachsen anfangs langsam und beginnen nach einiger ZeitZoosporen zu bilden. Aeltere Fäden von clavata, die nach langer Wasserkultur in heller Beleuchtung keine Zoosporen mehr $\mathrm{zu}$ bilden vermögen, werden wieder dazu veranlaßt, wenn man sie in eine Nährlösung von I Proz. überführt. Dieser Versuch ist wiederholt von mir mit Erfolg gemacht worden. In den ersten 8 Tagen muß sich die Alge langsam an die Salzlösung gewöhnen und verändert sich wenig; allmählich treten dann in immer größerer Anzahl die Zoosporangien auf. Nach einigen Wochen hört, wie bei repens, auch bei clavata jede Zoosporenbildung auf, und die einzige Möglichkeit, sie von neuem zu veranlassen, besteht in der Ersetzung der Salzlösung durch Wasser.

Die zoosporenerregende Wirkung der Nährsalze hängt aber $a b$ von der Beleuchtung; im Dunkeln läßt sich nichts davon bemerken. V. clavata, in eine 0,6- oder I-proz. KN-Lösung versetzt und verdunkelt, kann anfangs infolge des Lichtmangels einige Zoosporen erzeugen, hört aber bald damit auf. Wenn eine solche Kultur 
hell gestellt wird, so wächst sie in der ersten Zeit und fïngt dann Zoosporen zu bilden an. Wir haben hier eine Erscheinung, welche der früheren Darlegung über den Einfluß des Lichtes widerspricht, aber nur anscheinend. Im Dunkeln wächst V. clavata (vergl. S. 20) sehr schlecht und wird durch die Nährsalze noch stärker geschäctigt. So wie Licht zutritt, erholt sich die Alge und kann auf die zoosporenerregenden Reize der Nährlösung reagieren. Eine Hauptrolle spielt hierbei immer die relativ große Hemmung des Wachstums durch die Nährlösung, womit eine wesentliche Förderung der Zoosporenbildung verbunden ist.

Jelle Kultur von $\mathrm{V}$. repens bringt Zoosporen hervor, wenn sie aus Nährlösung in Wasser übergeführt wird, worauf ich schon mehrfach hingewiesen habe. Die Konzentration ist innerhalb der Grenzen von $0,1-2^{\circ}$ von geringer Bedeutung, wenn auch kleinere Unterschiede in der Intensität der Zoosporenbildung je nach der Konzentration vorhanden sein mögen. Schon der Uebergang aus 0,05-proz. Lösung in Wasser kann Zoosporenbildung hervorrufen; ein solcher aus 0,I-0,2 Proz. vermag bereits den stärksten Grad des Prozesses zu bewirlien. Licht und Temperatur beeinflussen Dauer und Intensität in der früher besprochenen Weise. Durch helle Beleuchtung, durch Temperatur über I5 ${ }^{\circ}$ kann die Zoosporenbildung sehr gehemmt oder vollständig unterdrückt werden. Im Dunkeln findet durch vereinigte Wirkung des Mediumwechsels und des Lichtmangels lebhafteste Zoosporenbildungr statt.

Der Aufenthalt in der Nährlösung regt die Alge zur kräftiçsten und vollsten Entwickelung an; die plötzliche Aenderung der chemischen und physikalischen Beschaffenheit des Mediums durclı den Uebergang aus Nährlösung in Wasser löst die Zoosporenbildung aus. Statt der 
zusammengesetzten Nährlösung kann man auch einzelne Salze anwenden, selbst solche, deren Nährwert gering ist, wie z. B. Kochsalz. Nach mehrtägigem Aufenthalt der Alge in solchen Salzlösungen kann der Uebergang in Wasser ebenfalls zum Anlaß für Zoosporenbildung werden. So habe ich mehrfach den Versuch mit 0, I-o,2 Proz. Salpeter gemacht. Indessen ist der Erfolg durchaus nicht sicher, selbst wenn gleichzeitig Dunkelheit einwirkt. Die Vaucheria leidet eben doch in solchen Lösungen einzelner Salze und reagiert deshalb schlecht.

Für Vaucheria clavata hat der Uebergang aus Nährlösung in Wasser lange nicht die große Bedeutung als Mittel zur Zoosporenbildung wie bei repens. Bei längerem Aufenthalt in der Nährlösung gerät die Alge eher in einen pathologischen Zustand, so daß bei Ersatz durch Wasser sehr häufig gar keine Zoosporenbildung eintritt und nicht selten die Alge früh zu Grunde geht. Bei kürzerer Dauer des Aufenthaltes darf man sich nicht täuschen lassen durch den in der Nährlösung selbst vor sich gehenden Prozeß. Am leichtesten erhält man noch die Zoosporen, wenn die Alge nach der Ueberführung aus Nähṛlösung in Wasser gleichzeitig verdunkelt wird.

b) Organische Verbindungen.

Unter diesen sind hauptsächlich einige Kohlehydrate geprüft worden, in denen die Vaucherien eine Zeit lang gut gedeihen, in erster Linie Rohrzucker, dann Maltose und Invertzucker. Wenn man Vaucheria repens aus feuchter Luft oder Nährlösung in Rohrzuckerlösung von 2 oder 4 Proz. bringt, so erfolgt die Zoosporenbildung genau wie im Wasser und steht in der gleichen Abhängigkeit von Licht und Temperatur. Vergleichende Versuche zeigen, daß unter sonst gleichen Verhältnissen, besonders 
gleicher Beleuchtung, in Rohrzucker die Zoosporenbildung etwas kürzer dauert als in Wasser, in Maltose (ron I-2 Proz.) eher etwas länger, ohne daß wegen der grołen Schwankungen bei den einzelnen V'ersuchen bestimmte Zahlen sich angeben lassen. In schwachem Lichte oder im Dunkeln findet in Rohrzucker, Maltose und Invertzucker zunächst eine sehr lebhafte Zoosporenbildung statt, welche aber früher ihr Ende erreicht als in Wasser, weil durch Bakterien und Hefezellen leicht chemische Veränderungen veranlaßt werden.

Der Uebergang aus Wasser in eine der genannten organischen Lösungen wirkt für sich allein nicht zoosporenerregend. Aber auch der Ersatz solcher Lösungen durch Wasser spielt nicht die Rolle eines Reizes, ganz im Gegensatz zu den anorganischen Nährsalzen. Unzweifelhaft hängt es damit zusammen, daß die VaucheriaFäden in den Zuckerlösungen zu stark Reservestoffe aufspeichern und dadurch gelähmt werden. Die allmählich eintretende Unfähigkeit zur Zoosporenbildung ist besonders bemerkbar, wenn man die Zuckerkulturen verdunkelt. Nach 8-io Tagen gelingt es noch, an ihnen Zoosporen zu beobachten, später aber nie mehr. Nur die Kultur in Nährsalzlösungen kann solche Vaucherien wieder reaktionsfähig machen.

Von organischen Verbindungen, die keine Beziehung zur Ernährung haben, will ich nur die Versuche mit Kampfer erwähnen, die ich infolge einer Bemerkung Strasburger's (92 S. 53) anstellte, der die Substanz henutzte, um Algenmaterial für Sendungen eine Zeit lang frisch zu erhalten. Hierbei kam die fäulniswidrige Eigenschaft des Kampfers wohl allein in Betracht. Wegen seiner sonstigen Einwirkungen, besonders auf den tierischen ()rganismus, interessierte mich die Frage nach seinem Einflus auf die Zoosporenbildung. In einem 
Gefäß von $500 \mathrm{ccm}$ Inhalt kultivierte ich Vaucheria repens in Wasser, fügte am I8./XII. I892 Kampferkrystalle hinzu und bedeckte die Kultur sorgfältig. Die Alge veränderte sich in der folgenden Woche nicht, sie wuchs nicht merklich, bildete keine Zoosporen, blieb aber frisch grün. Am 29./XII. wurde das noch stark nach Kampfer riechende Wasser durch reines Wasser ersetzt. Am 6./I. I 893 zeigten sich vereinzelte Zoosporen. Ich fügte am 7./I. wieder Kampfer hinzu und stellte die Kultur dunkel. Die Zoosporenbildung unterblieb bis zum II./I., wo ich das Wasser durch frisches ersetzte. In den nächsten Tagen erfolgte lebhafteste Zoosporenbildung bis zum I4./I., wo ich dann die Kultur hell stellte. Am 20./I. fügte ich von neuem Kampfer hinzu und verdunkelte; keine Zoosporenbildung bis zum 26./I., wo ich wieder frisches Wasser zusetzte, infolgedessen eine höchst lebhafte Zoosporenbildung sich zeigte. Ich wiederholte mit einer anderen Kultur den gleichen Versuch mit demselben Resultat. Kampferwasser verhindert danach die Zoosporenbildung, es wirkt anästhetisierend; die Alge bleibt eine Anzahl Tage dabei vollkommen lebensfrisch und erzeugt nach Entfernung des Kampfers sehr lebhaft. Zoosporen, wenn der Reiz der Dunkelheit mitwirkt. Der Ersatz der Kampferlösung durch Wasser bei Gegenwart von Licht veranlaßte in den wenigen Versuchen, die ich im Winter anstellte, nur vereinzelte Zoosporenbildung, worauf ich deshalb kein großes Gewicht legen kann.

Die Versuche über den Einfluß organischer Verbindungen auf die Zoosporenbildung von Taucheria clavata bieten kein Interesse. Im allgemeinen verhält sie sich wie repens; sie wächst aber meist schlecht, wird bald kränklich, so daß auch die Zoosporenbildung darunter leidet. 
c) Der osmotische Wert der Verbindungen.

Schon bei der Besprechung des Einflusses der Nährlösung gab ich an, daß bej einer Konzentration von 0,7 Proz. die Zoosporenlildung von V'. repens nicht mehr eintritt, während das 1 Tachstum noch bis zu 2 Proz. vor sich gehen kann. Zunächst liegt der Gedanke nahe, daß die Grenze durch die wasseranziehende Eigenschaft der Salze bedingt ist. Ganz allein ist sie nicht dabei wirksam, da die Salze unzweifelhaft in die Zellen, besonders den Zellsaft, eintreten und dadurch innere Veränderungen herbeiführen, die für die Zoosporenbildung maßsgebend sein können. Das geht aus der Thatsache hervor, daß selbst in verdünnteren Lösungen von $0, \mathrm{I}-0,2$ Proz. nach einiger Zeit die Alge zwar wachsen und sich geschlechtlich fortzupflanzen vermag, aber nicht mehr ohne Entfernung der Salze zur Zoosporenbildung gebracht werden kann (siehe S. 56). Jedenfalls gewährte es einiges Interesse, die hemmende Wirkung bestimmter Verbindungen auf die Zoosporenbildung zu untersuchen. Ich wählte als Beispiele Salpeter, Rohrzucker und Kochsalz. Für diese Stoffe folgte ich dem Vorschlage von de Vries (84), die Konzentration der Lösungen nicht nach Gewichtsprozenten, sondern in Molekülen anzugeben, wobei man pro Liter so viel Gramme der Substanz auflöst, als dem Gewichte eines Moleküls entspricht; das gleiche Volumen der Lösung verschiedener Substanzen enthält dann die gleiche Anzahl Moleküle. Diejenigen Kionzentrationen, bei denen die Lösungen verschiedener Stoffe mit derselben Kraft Wasser anziehen, nennt de Vries in seiner vortrefflichen Arbeit isotonische.

Die Hauptfrage für mich war, ob isotonische Lösungen ron Rohrzuclier und Salpeter auch die gleiche hemmende Wirliung auf die Zoosporenbildung ausüben oder nicht. Würde ersteres zutreffen, so würde die 
Hemmung sich ganz aus der wasseranziehenden Eigenschaft der Stoffe erklären.

$\mathrm{Zu}$ den Versuchen benutzte ich die auf Koaksstücken ausgebreiteten zusammenhängenden Rasen von V. repens; sie wurden sorgfältig von den Koaksstücken entfernt, durch Filtrierpapier von anhängender Feuchtigkeit befreit und in die Lösung gebracht. Diese wurde nach den Vorschriften von de Vries bereitet; ich brachte einen 3-4 qcm großen Vaucheria-Rasen in $100 \mathrm{ccm}$ Lösung, so daß der Wassergehalt des Rasens nicht in Betracht kam. Die Kulturen wurden meistens in schwaches Licht oder ins Dunkle gestellt.

\section{Kalisalpeter}

IOI gr auf I Liter $=$ I Mol. $=$ IO, I Proz.

Nr. I.

27./XII. I892 0,OI Mol. hell

$\begin{array}{lll}0,013 & " & , \\ 0,015 & " & , \\ 0,017 & " & " \\ 0,02 & , & ,\end{array}$

Nr. 2.

II./I. I893 O,OI Mol. hell

$$
\text { O,ОI2 , , , }
$$

0,0I4 " " "

6./I. I893 0,009 ", halbdunkel

$\begin{array}{lll}0,0094 & , & , \\ \text { 0,0098 } & , & , \\ \text { O,OI } & , & ,\end{array}$

II./I. I893 O,OI \# dunkel O,OI2 " " 0,0I4 " " ,

I5./I. I893 0,0I5 " , , 0,0I6 " " 0,0I7, , " Klebs, Fortpflanzungsphysiologie.
29./XII.-3./I. I893 eine Anzahl Zoosporen.

keine Zoosporen.

$\begin{array}{ll}" & "\end{array}$

I2.-I8./I. keine Zoosporen; I8./I. dunkel; 20.-22./I. viele Zoosporen.

12.-IS./I. keine Zoosporen; I8./I. dunkel; 20.-22./I. eine Anzahl Zoosporen.

I2.--I8./I. keine Zoosporen; I8./I. dunkel; 20./I. keine.

9.--I3./I. viele Zoosporen. ebenso

I3.--I5./I. viele Zoosporen. ebenso

I4./I. eine kleine Anzahl. keine Zoosporen.

, $\quad$,


17. I. IS93 0,014 Mol. halbdunkel 19.I. eine Anzahl Zoosporen. $0,015, "$, $0,016, ", "$

I9. I. $18930,015 ", "$ $0,017 ", "$ $0,018, ",$.

24. I. I 8930,012 " dunkel

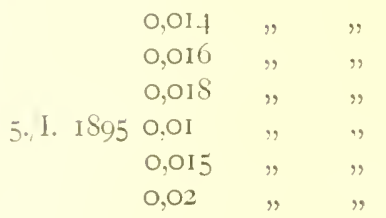
19./I. vereinzelte Zoosporen. 19./I. vereinzelte Zoosporen. lieine Zoosporen. " " 26."-28.I. "eine Anzahl Zoo- sporen.

keine Zoosporen.

" " $"$
8.-I 3.II. eine Anzahl Zoosporen.
S.-9.I. vereinzelte Zoosporen.
9.II. ganz vereinzelte Zoosporen.

Zunächst fallen die großen Schwankungen in den Versuchsresultaten auf. Da die äußeren Bedingungen in allen Versuchen sehr gleichartig waren, so mußte es an der Ungleichheit des Versuchsmaterials liegen, wenn auch dieses unter anscheinend gleichen Verhältnissen aufgewachsen war. Nehme ich noch diejenigen Versuche zu Hilfe, in denen ich mit Lösungen nach Gewichtsprozenten experimentierte, so ergiebt sich, daß in Lösungen von o,or Mol. oder O,I Proz. noch lebhafte Zoosporenbildung stattfindet, daß in solchen von 0,02 Mol. oder 0,2 Proz. diese unterbleibt oder höchst vereinzelt auftritt. Zwischen diesen Grenzen schwanken die Resultate der Versuche je nach den individuellen Verschiedenheiten des Materials; doch schon bei o,or 4 Mol. habe ich niemals lebhafte Zoosporenbildung beobachten können. Als Grenzwert können wir die Konzentration von 0,02 Mol. bezeichnen.

Rohrzuclier

342 gr auf I Liter $=$ I Mol. $=34,2$ Proz.

12. 1. 18,3 0,12 Mol. halbdunkel

I4.-IS. I. viele Zoosporen.

$\begin{array}{ll}0,13 & \\ \text { O,I } & \end{array}$

ebenso

vereinzelte Zoosporen. 


\section{$-67-$}

17./I. I893 0,15 Mol. halbdunkel

$0,16 "$,
$0,17 "$
$0,18 "$,

25./I. I 8930,12,

$0,14 "$

$0,15 "$

$0,16 "$

0,17,

5./I. 18950,12 , dunkel

0,14 " "

O,I6 " "

$0,18, "$, keine Zoosporen.

$", \quad "$
$" \prime$
27.JI. viele Zoosporen.
eine Anzahl Zoosporen.
keine Zoosporen.
ganz vereinzelte Zoosporen.
keine Zoosporen.
9.-II./I. viele Zoosporen.
9.-Io./I. vereinzelte Zoosporen.
9./I. vereinzelte Zoosporen.
keine Zoosporen.

Wir sehen auch beim Rohrzucker die gleichen Schwankungen. Mit dieser Substanz habe ich außerdem eine ganze Anzahl von Versuchen mit Lösungen nach Gewichtsprozenten angestellt, aus denen sich ergiebt, daß in einer solchen von 4 Proz. (O,I2 Mol. $=4, \mathrm{I}$ Proz.) noch lebhafte Zoosporenbildung stattfindet, in einer solchen von 5 Proz (O, I5 Mol. = 5, I Proz.) sehr selten. Als obere Grenze können wir eine Lösung von 0,I6 Mol. $=5,5$ Proz. bezeichnen.

In einer kleinen Tabelle will ich mit der die Zoosporenbildung hemmenden Konzentration von Salpeter und Rohrzucker die wasseranziehende Kraft beider Substanzen vergleichen, wobei ich nach den Angaben von de Vries (84 S. 537) die mit der Salpeterlösung isotonische Rohrzuckerlösung anführe.

\begin{tabular}{l|c|c|c|c}
\hline \hline Substanzen & $\begin{array}{c}\text { Zoosporenbildung hemmende| } \\
\text { Konzentration } \\
\text { in Mol. }\end{array}$ & $\begin{array}{c}\text { isotonische Konzentration } \\
\text { in Mol. }\end{array}$ & in Proz. \\
\hline Salpeter & 0,02 & 0,2 & 0,02 & 0,2 \\
Rohrzucker & O,I6 & 5,5 & 0,03 & 1,03
\end{tabular}

Die Zahlen beweisen, daß die hemmende Wirkung nicht einfach zu erklären ist durch die wasseranziehende Eigenschaft der Verbindungen, daß noch andere Eigen- 
schaften dieser eine Rolle spielen. Rohrzuckerlösung hemmt sehr viel weniger als einer isotonischen Salpeterlösung entspricht. Aehnliche Beobachtungen hat Eschen hagen (So S. 32) über den Einfluß der Salze auf das Wachstum von Pilzen gemacht.

Zur Ergänzung will ich noch meine Versuche mit Kochsalz anführen, obwohl ich nur wenige angestellt habe. So weit diese ein Urteil erlauben, hemmt seine Lösung von o, I Mol., isotonisch mit einer Salpeterlösung von O,I Mol. die Zoosporenbildung, während Salpeter bereits in einer Lösung von 0,02 Nol. hemmend einwirkt. Die einzelnen Salze beeinflussen daher in specifischer Weise die Zoosporenbildung. Es liönnte darin liegen, daß sie in verschiedener Menge in den Zellsaft eintreten und daß sie dort gemäß ihrer besonderen chemischen Eigenschaften den Prozeß beeinflussen. Die relativ sehr viel geringere Hemmung durch Rohrzucker gegenüber Salpeter erklärt sich vielleicht zum Teil daraus, daß der erstere gleich nach seinem Eintritt sofort wieder verbraucht wird, sei es zum WTachstum, sei es zur Aufspeicherung von Fett, während Salpeter sich schnell im Zellsaft ansammeln und eine Konzentration ron ihm herbeiführen kann, durch die der Bildungsprozeß der Zoosporen behindert wird.

d) Der Einfluß der sauren oder alkalischen Reaktion.

Bei Zygnemen beobachtete ich früher (S6 S. 34I), daßs das Masser durch ihre Assimilation alkalisch gemacht wurde, was durch die Rötung des Phenolphtaleins zu Jemerlien war. Ich führte die Erscheinung darauf zurück, dałs die Algen im Licht die sauren kohlensauren Salze durch Wregnahme eines Teiles der Kohlensäure in alkalisch reagierende Karbonate verwandeln, während 
in der Nacht der umgekehrte Prozeß vor sich geht. Hassack ( 88 S. 475), der die Erscheinung bei höheren Pflanzen weiter verfolgte, nimmt dagegen die Ausscheidung eines kohlensauren Alkalis von Seiten der Pflanzen an. In neuerer Zeit hat L oew (93 S. 422) sich mit der Frage beschäftigt und kommt zu der Annahme, daß eine organische Kalkverbindung die Ursache der Rötung sei, oder daß der aus dem doppeltkohlensauren Kalk gebildete oder von den Zellen ausgeschiedene einfach kohlensaure Kalk in einem kolloidalen Zustande durch die secernierte organische Substanz in Lösung gehalten wird und Phenolphtalein rötet. Die zweite Möglichkeit erscheint mir als die wahrscheinlichste. Auch bei Vaucheria konnte ich die für Zygnema gemachte Beobachtung bestätigen. Ich kam dabei auf den Gedanken, ob nicht die alkalische Reaktion des umgebenden Wassers im Licht, die neutrale oder schwach saure im Dunkeln irgend einen Einfluß auf die Zoosporenbildung ausübe und ob nicht daraus die Bedeutung von Licht und Dunkelheit für sie erklärt werden könnt. Ich habe die Idee bald aufgegeben, will aber die Versuche hier mitteilen.

Saure Reaktion.

Ich benutzte, um saure Reaktion hervorzurufen, Citronensäure, die gleiche Säure, die Migula (88) in ihrem Einfluß auf Wachstum und Zellteilung untersucht hat. Aus feuchter Luft wurde Vaucheria repens in eine verdünnte Lösung der Säure gebracht.

$$
\text { Nr. I. }
$$

18. VI. I892 a) in Wasser; dunkel

20./VI. sehr viele Zoosporen.

b) in 0,05 Proz. Citronensäure; 20.jVI. keine Zoosporen. dunkel

20./VI. I892 hell

7./VII. I892 dunkel

Säure nicht mehr nachweisbar.

9./VII. IS92 "

sehr viele Zoosporen. 


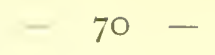

Nr. 2.

2./XII. IS92 a) O,I Proz. Citronensäure; halbdunkel b) 0,05,

Nr. 3 .
4./XII. abgestorben.

4./XII zum Teil lebend; keine Zoosporen.

4. XII. IS92 O,OI Proz. Citronensäure; halbdunkel 8./XII. sehr viele ZooNr. 4. sporen; die Bildung ging fort bis $14 . / \mathrm{XII}$.

7./XII. 1892 a) 0,025 Proz. Citronensäure; halbdunkel 9.-IO./XII. eine Anzahl Zoosporen.

b) $0,025, \quad, \quad$ hell

Nr. 5.

I3./XII. IS92 0,04 Proz. Citronensäure; hell I6./XII. vereinzelte Zoosporen.

Zu dem letzten Versuch bemerke ich noch, daß die Enden der Fäden in der Citronensäure schnell ihre. Wachstumsfähigkeit verloren und zum Teil anschwollen. Dicht unter der Spitze entstand dann ein Zweig, der bald dasselbe Schicksal erfuhr, infolge dessen eine sehr starke und unregelmäßige Verzweigung auftrat. Am 7./1. I893 fügte ich der Kultur frische Lösung von 0,05-proz. Citronensäure zu. Die Alge fing an abzusterben, erholte sich dann nach einigen Tagen, bilclete aber keine Zoosporen.

Aus den Versuchen ergiebt sich, daß in Lösungen von 0,OI-proz. Citronensäure noch lebhafte Zoosporenbildung stattfindet, daß diese bei steigender Konzentration mehr und mehr gehemmt wird; die Grenze bildet eine Lösung von 0,05 Proz., die auch auf das Wachstum schädlich einwirkt.

Alkalische Reaktion.

Ich benutzte kohlensaures Kali und Natriumbicarbonat, um die Kulturflüssigkeit für Vaucheria repens alkalisch zu machen. Den Lösungen fügte ich stets Phenolphtalein zu, damit die alkalische Reaktion direkt sichtbar wurde. 
Nr. I.

I8./VI. I892 a) 0,05 Proz. kohlensaures Kali; dunkel keine Zoosporen.

b) 0,1 , Nr. 2.

2./XII. I892 a) 0,05 Proz. kohlens. Kali; halbdunkel 9./XII. viele Zoosporen. b) $0,1 \quad, \quad " \quad " \quad$ " keine Zoosporen. Nr. 3.

7./XII. I892 a) 0,025 Proz. kohlens. Kali; halbdunkel I I./XII. eine Anzahl Zoo-

b) $0,025, \quad, \quad, \quad$ hell

Nr. 4 .

I3./XII. I892 a) 0,05 Proz. kohlensaures Kali; hell bis 15./XII. keine Zoosporen; 2I./XII. halb. dunkel; alkalische Reaktion verschwunden; viele Zoosporen am 22.-24./XII.

Nr. 5 .

2I./XII. I892 a) 0,05 Proz. Natriumbicarbonat $\left.{ }^{1}\right) ;\{$ 22.-25./XII. viele Zoodunkel $\{$ sporen.

b) 0, I $\quad " \quad$ halbdunkel 22./XII. keine Zoosporen.

c) $0,05 \quad " \quad " \quad$ 22.-24./XII. viele Zoosporen; die letzten am 29./XII.

Nr. 6.

8. I. 1893 a) O,I Proz. Natriumbicarbonat; dunkel IO.-I4./XII. viele Zoosporen.

b) $\mathrm{O}, \mathrm{I} \quad$ " $\quad$ hell bis I4./XII. keine Zoosporen; am I4. XII. dunkel, keine Zoosporen; 20./I. Wassser dunkel; 22.-24./I. viele Zoosporen.

c) $0,2 \quad, \quad$ halbdunkel keine Zoosporen; schlechtes Wachstum.

Diese Versuche zeigen nur so viel, daß Zoosporenbildung noch bei deutlich alkalischer Reaktion (siehe Versuch 3a, 3b, 5a, 5c, 6a) stattfinden kann. Bei be-

I) Diese Lösung färbte Phenolphtalein sehr deutlich rot, höchst wahrscheinlich infolge Beimengung von einfach kohlensaurem Natron. 
leuchteten unl bei den im Hall,dunkeln stehenden Kulturen verschwindet allmählich die allialische Realition, da die Salze von der Alge verarbeitet werden; so war z. B. in Versuch 2 a, bei dem erst nach 7 Tagen die Zoosporenbildung auftrat, die Rötung vorher schwächer geworden. Eine Lösung ron 0,05 Proz. kohlensaurem Kali bildet ungefähr die Grenze. Die Alge vermag aber noch in O,Iproz. Lösung zu leben.

\section{Der Einfluß des Sanerstoffs.}

Neben den Nährsalzen, dem Wasser und der Kohlensäure hat noch ein chemischer Körper die größte Bedeutung für das Leben von Vaucheria, der Sauerstoff. Er ist als Bestandteil organischer Substanzen ein unentbehrliches Glied in der Reihe der Ernährungsprozesse; als freies Element tritt er in die Zelle ein, unterhält die Atmung und ist dadurch eine notwendige Lebensbedingung. So hängt ebenso wie Ernährung, Wachstum auch die Zoosporenbildung rom Sauerstoff ab. Im Vacuum, in einer Atmosphäre von Wasserstoff, findet sie nicht statt.

Dem Sauerstoff wurde indessen auch von $\mathrm{IValz}$ eine specifische Rolle für die Zoosporenbildung zugeschrieben - die einzige Angabe, die, vor meiner Arbeit, von dem Einfluß äußerer Bedingungen auf den Prozeß handelt. Walz (68 S. 497 ff.) beobachtete, daß Oedogonium-Arten, Vaucheria sessilis dadurch zur Zoosporenbildung veranlaßt wurden, daf in den Kulturen das Wasser durch frisches ersetzt oder daß atmosphärische Iuft direkt hineingeleitet wurde. Einen ähnlichen Erfolg hatte das Durchleiten eines galvanischen Stromes, bisweilen auch von Ozon, während bei Zuführung von Sauerstoff keine Veränderung sich zeigte. Im allgemeinen sind die Angaben von $\mathrm{Wal} z$ anerkannt worden; Cornu 
(77 S. 860), später Hartog (87), glaubten einen ähnlichen erregenden Einfluß des Sauerstoffs speciell für die Zoosporenentleerung $\mathrm{zu}$ beobachten. Eine genaue Nachprüfung der Angaben von $\mathrm{Walz}$ ist bis auf meine Arbeit von 1892 nicht geschehen. Da Walz nicht den bedeutsamen Einfluß der Lichtintensität kannte und eine nähere Angabe aller Bedingungen bei seinen Versuchen fehlt, so läßt sich von vornherein die Beweiskraft dieser anzweifeln. Meine Untersuchung zeigt direkt die Unrichtigkeit der Angaben, wie die folgende Erörterung darlegen wird.

Zunächst läßt sich leicht nachweisen, daß eine Zufuhr von atmosphärischer Luft nicht notwendig ist für die Zoosporenbildung älterer Kulturen. Solche von Vaucheria repens und clavata, die mit einer kleinen nicht gewechselten Wassermenge mehrere Wochen bis Monate hindurch ruhig gestanden hatten, erzeugten Zoosporen infolge einfacher Verdunkelung. Im Dunkeln muß dabei der Sauerstoffgehalt durch die Atmung bei mangelnder Assimilation etwas verringert werden. Zahlreiche Versuche, die das Gleiche beweisen, finden sich in den früheren $\mathrm{Ab}$ schnitten angegeben.

Immerhin hätte die Zufuhr frischer Luft in irgend einer Weise der Zoosporenbildung förderlich sein oder sie direkt veranlassen können. Die Versuche haben diese Annahme widerlegt; ich benutzte folgende Methoden:

I) Wechsel des Wassers.

Kulturen von V. repens und clavata, die keine Zoosporenbildung zeigten, wurden bei den gleichen Temperatur- und Lichtverhältnissen mit frischem Wasser versehen; ich nahm bald destilliertes, bald sehr luftreiches Leitungswasser. Eine deutliche Zoosporenbildung wurde dabei nicht bemerkt, so oft ich auch die Versuche wieder- 
holte. Stets machte ich als Probe den weiteren und immer erfolgreichen Versuch, die gleichen Kulturen durch Verdunkelung zur Zoosporenbildung zu bringen.

2) Durclileiten von Luft.

Mit Benützung eines Flaschen-Aspirators wurde während $\mathrm{I}-2$ Tagen langsam Luft durch ältere Kulturen von $V$. repens hindurchgeleitet, ohne daß dadurch Zoosporenbildung erzeugt werden konnte. In anderen Versuchen ließ ich mit Hilfe einer Wasserstrahlpumpe durch mehrere miteinander verbundene Drechssel'sche Flaschen, in denen ältere Vaucheria-Kulturen sich befanden, lebhaft Luft durchsaugen, ebenfalls ohne Erfolg. Die Algen litten eher durch die mechanische Erschütterung. So gingen sie in Kulturen bei einem Versuch, bei dem während 24 Stunden pro Stunde 24 Liter Luft durchgeleitet wurden, zu Grunde.

3) Durchleiten von Sauerstoff.

Wenn Sauerstoff wirklich Zoosporenbildung erregen soll, so hätte man vermuten müssen, daß Durchleiten von reinem Sauerstoff in dieser Weise wirke. Allerdings war bereits der Versuch von Walz selbst von keinem Erfolg begleitet gewesen. Ich habe den Versuch wiederholt. Von einem Gasometer, der mit reinem Sauerstoff gefüllt war, wurde dieser zuerst durch Kalilauge, um Spuren des Chlors zu entfernen, und dann in drei miteinander verbundene Flaschen a, b, c geleitet und konnte durch ein viertes Gefäß d, das nur mit einer Glasplatte lose bedeclit war, in die Luft entweichen. Am 4./II. I893 begann der Versuch, der am 6./II. morgens beendet wurde. Langsam wurde ron 9 Uhr morgens bis 4 Uhr nachmittags Sauerstoff durchgeleitet. Jedenfalls war auch in der übrigen Zeit in den drei ersten Flaschen das Wasser mit Sauerstoff gesättigt. Der Versuch wurde bei Zimmertemperatur $\left(12-16^{\circ}\right)$ und in der Nähe des Fensters angestellt. 
Das Gefäß a enthielt eine Vaucheria-Kultur in destilliertem Wasser, die seit 20. Januar hell gestanden hatte. Am 6./II. zeigten sich vereinzelte Zoosporen; dann wurde die Kultur in schwaches Licht gebracht, und sie entwickelte hier am 7.-8./II. höchst lebhaft Zoosporen.

Das Gefäß b enthielt Vaucheria, die seit 2I. Januar im Wasser hell gestanden hatte. Am 6./II. war keine Zoospore zu sehen; in schwachem Lichte war die Bildung am 7.-8./II. sehr lebhaft.

Das Gefäß c enthielt junge aus Zoosporen erzogene Fäden, bei denen vorher ein Versuch mit Luftdurchleitung ohne Erfolg gemacht worden war. Am 6./II. zeigten sich keine Zoosporen, die dagegen in schwachem Licht massenhaft auftraten.

Das Gefäß d enthielt Vaucheria, die aus Gipswasser in reines Wasser übergeführt worden war. Am 6./II. fanden sich vereinzelte Zoosporen. In schwachem Licht trat lebhafteste Bildung ein.

Das Durchleiten von Sauerstoft hatte jedenfalls die Vaucherien in keiner Weise geschädigt, aber ebensowenig als Reiz für die Zoosporenbildung gewirkt. Denn den vereinzelten Zoosporen in den Gefäßen a und d kann keine Bedeutung beigelegt werden; das Wetter war nicht sehr hell, so daß bei zufällig sehr empfindlichen Fäden die Bildung durch geringe Lichtintensität zu erklären ist. Das Verhalten der Kulturen in schwachem Licht zeigte dann klar, in welchem Grade ein wirklich den Prozeß veranlassender Reiz thätig ist.

4) Durchleiten von Ozon.

Ich stellte in einem Apparat von Krebs das Ozon aus Kaliumpermanganat und Schwefelsäure her, wobei der Apparat im Eiswasser stand. Indessen gab ich die Versuche bald auf, da selbst nur wenigstündiges Einleiten die Vaucherien kränklich machte. 
Aus: diesen Versuchen darf man den Schluß ziehen, dał die Vermehrung des Sauerstoffgehaltes in dem Wasser nicht die Zoosporenbildung veranlassen kann. Schon aus den Versuchen bei Abschluß des Lichtes tritt uns die Thatsache entgegen, daß eine Verringerung des Sauerstoffgehaltes den Prozeß nicht hindert. Das Gleiche folgt aus den Versuchen, bei denen die Alge aus feuchter Luft in Wasser übergeführt wurde, in welchem jedenfalls die Aufnahme des Sauerstoffes etwas erschwert wird. Noch mehr ist es der Fall, wenn die Alge aus feuchter Luft in eine Lösung von Traubenzucker gebracht wird, die Sauerstoff absorbiert und doch die Zoosporenbildung nicht hemmt. Man kann aber noch weiter gehen. Wenn man ein Gefäß mit ausgekochtem, rasch auf Eis abgekühltem Wasser füllt, Vaucheria hineinbringt und es mit eingeschliffenem Glasstopfen rerschließt, so tritt im Dunkeln doch Zoosporenbildung ein. Nit der Alge führt man in die Kultur immer etwas Luft ein, so daß nicht ein absoluter Nangel daran herrscht. Immerhin zeigt der Versuch, daß nur geringe Mengen von Sauerstoff für den Prozeß notwendig sind; er forderte auf, näher zu untersuchen, welches die untere Grenze des Partiärdruckes des Sauerstoffs für die Zoosporenbildung ist.

Die einfachste Methode besteht in der Verringerung des Luftdruckes. Die Versuche Berts' und anderer (vergl. Pfeffer 8I S. 373) haben erwiesen, daß der Luftdruck als solcher ohne wesentlichen Einfluß auf das Leben der Organismen ist, daß der Partiärdruck des Sauerstoffs allein in Betracht kommt. Zu den Versuchen benutzte ich einen Luftpumpenteller, auf dem eine Glocke von $3800 \mathrm{ccm}$ Inhalt (nach Abzug des Rauminhaltes der darin aufgestellten Gegenstände) luftdicht durch eine Mischung von Wachs und Vaselin befestigt werden 
konnte. Das Auspumpen wurde durch eine Arzbergersche Wasserstrahlpumpe besorgt. Unter die Glocke kam ein Thermometer, an einem kleinen Gestell angehängt, und ferner ein abgekürztes Barometer als Manometer. Für den Versuch wurden Fäden von Vaucheria repens aus einer 0,2-proz. KN-Lösung in ein Gläschen mit ein wenig destilliertem Wasser gebracht, das vorher ausgekocht und dann schnell abgekühlt worden war. Die angewandte Algenmenge war immer nur sehr gering, so daß im Verhältnis zu ihr noch immer Sauerstoff, selbst bei ganz niedrigem Druck, zur Verfügung stand. Wegen des langsamen Gasaustausches zwischen Flüssigkeit und Luft gab das Manometer durchaus nicht genau den im Wasser herrschenden Druck an. Da aber der Versuch stets im Dunkeln angestellt wurde, wobei die Algen immer etwas Sauerstoff verbrauchen; da ferner das Wasser vorher ausgekocht war, so wird der thatsächliche Druck immer etwas geringer gewesen sein als das Manometer angab. Diese Fehlerquellen verschwinden gegenüber den sehr viel größeren, die auf den beträchtlichen individuellen Verschiedenheiten der Algen beruhen, infolge deren überhaupt keine genauen Zahlen sich gewinnen lassen. Es kam mir nur darauf an, annähernd die. Grenze des Partiärdruckes festzustellen.

Nach der Beschickung des Apparates pumpte ich ihn $\mathrm{I}^{1} / \mathrm{I}_{2}-2$ Stunden aus und ließ ihn bei dem niedrigsten Druck $2-3 \mathrm{~mm}$ einige Stunden stehen. Dann ließ ich so viel Luft hinzutreten, als mir erwünscht schien. Ueber den Apparat wurde ein schwarzer Cylinder gestellt, der für das Bleirohr der Pumpe einen schmalen Ausschnitt hatte. Die Versuche wurden mit V. repens im Januar und Februar I 893 gemacht; der Apparat stand in der Nähe des Fensters und zeigte im Innern eine ziemlich niedrige 
Temperatur von $10-14^{0}$ C. Für die Tabelle auf S. 79 gebe ich den Luftdruck in Millimetern Quecksilber an, nachdem ich von dem thatsächlich beobachteten Stande des Quecksilbers die der Temperatur entsprechende Tension des Wasserdampfes abgezogen habe. Da im Apparat stets flüssiges Wasser offen stand, so war die Luft jedenfalls mit Wasserdampf gesättigt. Neben der Angabe des Luftdruckes findet sich in der folgenden Rubrik der entsprechende Sauerstoffgehalt angegeben in Prozenten des am Anfang des Versuches vorhandenen Volumens der Luft, deren Zusammensetzung aus 2I Volumteilen Sauerstoff und 79 Teilen Stickstoff angenommen wird. Für jeden Versuch wurden fast stets 2 Gläschen, $a$ und b, mit sterilen Vaucherien verwandt. Einige wenige Versuche, bei denen die Algen durch den gleichzeitigen Wechsel des Mediums und des Luftdruckes kränklich geworden waren, sind in der Tabelle nicht angeführt worden.

Aus den in der Tabelle angeführten Versuchen geht zunächst hervor, daß die Zoosporenbildung bei V. repens bei einem Luftdrucke von $0-20 \mathrm{~mm}$ nicht stattfindet, daß dann bei steigendem Luftdruck allmählich der Prozeß zur Entfaltung kommen kann. Bei $30 \mathrm{~mm}$ kann bereits eine Entleerung der Zoosporen erfolgen.

Die Zoosporenbildung verlangt einen höheren Partiärdruck des Sauerstoffs als das Wachstum, das bei Vaucheria noch bei einem Luftdruck von $3 \mathrm{~mm}$ vor sich gehen kann, vielleicht noch bei stärkerer Verdünnung. Aus den Versuchen Wieler's (83) folgt, daß höhere Pflanzen noch bei sehr starker Verdünnung (mehrfacher Evakuation mit Einleiten von Wasserstoff) zu wachsen vermögen, während Pilze, wie Mucor, Coprinus, bei $3 \mathrm{~mm}$ Barometerstand kaum mehr wachsen.

Meine Versuche zeigen ferner, daß der Wechsel des Luftdruckes, ch. h. der Uebergang aus niederen in 
Vaucheria repens in ausgekochtem destilliertem Wasser.

\begin{tabular}{|c|c|c|c|c|c|}
\hline 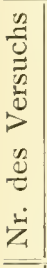 & Datum & 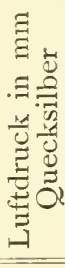 & 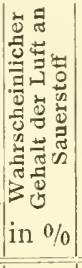 & Resultat & $\begin{array}{c}\text { Weiteres Verhalten der } \\
\text { Kulturen in normaler } \\
\text { Luft }\end{array}$ \\
\hline I & 6./III. I 893 & 3 & 0,08 & $\begin{array}{l}\text { 8./III. keine Zoo- } \\
\text { sporen. }\end{array}$ & $\begin{array}{l}\text { 8./III. hell; 9./III. keine } \\
\text { Zoosporen; 9./III. dun- } \\
\text { kel; IO.-I2./III. viele } \\
\text { Zoosporen. }\end{array}$ \\
\hline 2 & 8./III. I893 & 3 & - & $\begin{array}{l}\text { Io./III. keine Zoo- } \\
\text { sporen. }\end{array}$ & \\
\hline 3 & I I./III. IS93 & 3 & - & $\begin{array}{l}\text { I3./III. keine Zoo- } \\
\text { sporen. }\end{array}$ & $\begin{array}{l}\text { 13./III. Kultur a) hell; } \\
\text { 15./III. keine Zoosporen; } \\
\text { 13./III. Kultur b) dunkel; } \\
\text { I5. III. viele Zoosporen. }\end{array}$ \\
\hline 4 & I3./III. I893 & 3 & - & $\begin{array}{l}\text { I5. III. keine Zoo- } \\
\text { sporen. }\end{array}$ & $\begin{array}{l}\text { I5. III. Kultur a) hell; } \\
\text { I7./III keine Zoosporen; } \\
\text { I5./III. Kultur b) dunkel; } \\
\text { I7./III. viele Zoosporen. }\end{array}$ \\
\hline 5 & IO./I. I894 & 3 & - & $\begin{array}{l}\text { I2./I. keine Zoo- } \\
\text { sporen. }\end{array}$ & $\begin{array}{l}\text { I2./I. dunkel; I 4./I. viele } \\
\text { Zoosporen. }\end{array}$ \\
\hline 6 & I7./III. I893 & IO & 0,28 & $\begin{array}{l}\text { I9./III. in Kultur a) } \\
\text { keine Zoosporen, } \\
\text { in b) eine Zoo- } \\
\text { spore. }\end{array}$ & $\begin{array}{l}\text { I9./III. Kultur a) dunkel; } \\
\text { 2I. III. viele Zoosporen. }\end{array}$ \\
\hline 7 & I9./III. I893 & 20 & 0,55 & $\begin{array}{l}\text { 2I./III. ein paarZoo- } \\
\text { sporangien, ange- } \\
\text { legt aber unfertig. }\end{array}$ & \\
\hline 8 & 2I./III. I893 & 30 & 0,83 & 22./III. wie bei Nr.7. & $\begin{array}{l}\text { 22./III. dunkel; 24./III. } \\
\text { viele Zoosporen. }\end{array}$ \\
\hline 9 & I5./III. I893 & 30 & 0,83 & $\begin{array}{l}\text { I7./III. einige Zoo- } \\
\text { sporangien. }\end{array}$ & $\begin{array}{l}\text { I7./III. Kultur a) hell; } \\
\text { I9./III. keine Zoosporen. } \\
\text { I7./III. Kultur b) dunkel; } \\
\text { I9./III. viele Zoosporen. }\end{array}$ \\
\hline 10 & I2./I. IS93 & 40 & $\mathrm{I}, \mathrm{I}$ & $\begin{array}{l}\text { I4./I. eine Anzahl } \\
\text { Zoosporangien. }\end{array}$ & \\
\hline I I & 27./I. I893 & 50 & $\mathrm{I}, 4$ & 29./I. wie bei Nr. IO. & $\begin{array}{l}\text { 29./I. Kultur a) hell; 3I.II. } \\
\text { keine Zoosporent; 29./I. } \\
\text { Kultur b) dunliel; 3I./I. } \\
\text { viele Zoosporen. }\end{array}$ \\
\hline I 2 & 2./II. I 893 & 50 & $\mathrm{I}, 4$ & $\begin{array}{l}\text { 4./II. wie bei Nr. Io } \\
\text { und II. }\end{array}$ & \\
\hline 13 & 27./I. I894 & 90 & 2,5 & $\begin{array}{l}\text { 29./I. viele Zoo- } \\
\text { sporen. }\end{array}$ & \\
\hline
\end{tabular}


höheren, die Zoosporenbildung nicht begünstigt. Denn die Kulturen, die, wie Versuche Nr. I-5 beweisen. bei niedrigem Druck keine Zoosporen gebildet haben, vermögen es auch nicht nach dem Uebergange in normale Druckverhältnisse, sobald Licht einwirkt. Der Aufenthalt bei niederem Luftdruck hemmt sogar die durch einen anderen Reiz erregte Zoosporenbildung. Denn in allen meinen V'ersuchen, bei denen die Algen aus Nährlösung in Wasser übergeführt wurden, hätte der Prozeß stattfinden sollen, auch im Licht, da es sich namentlich nicht um sehr helles Licht handelte. Doch erst der Reiz der Dunkelheit vermochte in solchen Kulturen nach 48-stündigem Aufenthalt bei niederem Luftdruck die Zoosporenbildung zu veranlassen. Völlig mißlangen meine Versuche, ältere Wasserkulturen von repens zur Fortpflanzung zu bringen, indem ich sie während 24 Stunden in verdünnte Luft stellte.

Eine Reihe entsprechender Versuche über den Einfluß des niederen Luftdruckes stellte ich mit V. clavata an. Wich interessierte bei dieser Art noch mehr die Frage aus Gründen, die im nächsten Abschnitt näher behandelt werden. Leider sind meine zahlreichen Versuche wenig entscheidend. Der Hauptgrund dafür liegt in der großen Empfindlichkeit der Alge, die sehr leicht durch den Aufenthalt in verdünnter Luft oder auch durch das Auspumpen leidet und kränkelt, infolgedessen die Zoosporenbildung in den Versuchen sehr unregelmäßig erfolgt. Auf ausgekochtes destilliertes WVasser habe ich bald verzichten müssen: ich bereitete mir eine Anzahl kleinerer Kulturen in Gläschen vor, so daß die Alge auch leichter auf Fehlen oder Vorhandensein von Zoosporangien untersucht werden konnte. Die Alge wurde dann in den Gläschen eine Zeit lang hell liultiviert und ohne Aenderung des Mediums unter die Glocke der 
Luftpumpe gebracht und nach dem Auspumpen verdunkelt. Eine ausführliche Beschreibung aller Versuche unterlasse ich, weil die Resultate zu wenig prägnant sind. Ich erwähne nur, daß Anlagen von Zoosporangien bei $30 \mathrm{~mm}$ Barometerstand beobachtet wurden, daß ich bei $50 \mathrm{~mm}$ einige, bei $80 \mathrm{~mm}$ viele Zoosporangien und frei heraustretende Zoosporen gesehen habe, während in anderen Versuchen bei 6o, 70, $80 \mathrm{~mm}$ keine Spur davon vorhanden war. Bei einem gleichzeitigen Versuch mit zwei Kulturen konnte die eine Zoosporen zeigen, die andere nicht.

Ebensowenig klare Resultate erhielt ich bei den Versuchen, ältere Wasserkulturen ohne Aenderung der Beleuchtung durch Aufenthalt in verdünnter Luft zur Zoosporenbildung $\mathrm{zu}$ veranlassen. In einigen Kulturen traten, nach 24-stündigem Aufenthalt bei $3 \mathrm{~mm}$ Luftdruck, in normaler Luft Zoosporen auf, bei anderen nicht. Ich kann aus allem, was ích beobachtet habe, nur die Folgerung ziehen, daß die Fäden von V. clavata weit empfindlicher gegen Sauerstoffentziehung sind als die von V. repens, und daß deshalb auch die Zoosporenbildung stärker darunter leidet.

\section{\%. Der Einfluß des strömenden Wassers.}

In lebhaft strömendem Wasser in Rinnsalen, Kanälen, Bächen und Flüssen, in stets sich erneuerndem Wasser von Brunnen findet sich eine charakteristische Algenflora, die aus Diatomeen, Phycochromaceen, Florideen und einer relativ kleinen Anzahl von Chlorophyceen bestelht. Die Mehrzahl dieser Algen ist derartig an das Leben in den Bächen angepaßt, daß sie nirgends anders vorkommen kann. Die Vaucheria-Arten haben noch die Fähigkeit, auch in ruhig stehenden Gewässern oder sogar auf feuchter Erde zu leben. Infolgedessen sind gerade sie geeignet,




uns verstehen zu lehren, worin die Unterschiede des fließenden und stehenden Wassers für das Leben der Algen liegen. Von allen Vaucheria-Arten ist neben ornithocephala $V$. clavata diejenige. welche in der freien Natur fast ausschließlich in fließendem Wasser vorkommt. Untersucht man frische Rasen entweder gleich oder am nächsten Tage, nachdem man sie in ein Gefäß ins Zimmer gestellt hat, so beobachtet man keine oder nur sehr vereinzelte Zoosporenbildung. Nach $2-3$ Tagen wird diese außerordentlich lebhaft. Es unterliegt keinem Zweifel, daß der Uebergang aus fließendem in stehendes Wasser den Prozeß intensiv veranlaßt. Um den Gründen dafür näher zu treten, muß man die wichtigeren Eigenschaften des strömenden Wassers in ihrem Einfluß auf das Leben der Alge untersuchen.

Das strömende Wasser unterscheidet sich von stehendem Wasser kleineren Unfanges für die Alge hauptsächlich in vier Punkten:

I) durch die gleichmäßige und relativ niedere Temperatur;

2) durch die beständig sich erneuernde Zuführung frischer Luft sowie auch von Nährsalzen;

3) durch die mechanische Reibung;

4) durch die schnelle Beseitigung der von toten oder lebenden Organismen ausgeschiedenen Substanzen.

Die beiden letzteren Eigenschaften treten in ihrer Bedeutung für die Alge weit zurück gegenüber den beiden ersteren. Die Reinheit des strömenden Wassers, der Mangel an gelöster organischer Substanz bedingt das Fernbleiben von Bakterien, farblosen Flagellaten sowie von Pilzen und wird für die Entwickelung der Alge förderlich sein. In schlammigen, schmutzigen Kanälen, in Fabrikabwässern kommt sie nicht recht fort. V. clavata ist nicht im Stande gelöste organische Substanz zu ihrem Vorteil zu 
benutzen, wie ihr schlechtes Wachstum in Zuckerlösungen zeigt. Sie neigt ferner sehr leicht dazu, durch Fäulnis zu Grunde zu gehen, was sehr häufig der Fall ist, wenn man einen Rasen aus der freien Natur ins Zimmer bringt. Zwischen den Fäden eines solchen Vaucheria-Rasens herrscht ein reiches tierisches Leben; Krebse, Würmer finden sich in Menge vor, die den Uebergang in stehendes Wasser schlecht vertragen und faulen. Daher ist es so wesentlich, den Vaucheria-Rasen durch starkes Auswaschen im Wasserstrahl von diesen Bewohnern zu reinigen. Ist das geschehen, so wachsen, wie ich schon hervorgehoben habe, die Rasen monatelang ruhig weiter.

Die Frage ist noch ungelöst, ob eine Ausscheidung von Substanzen durch die Alge selbst stattfindet. Loew (93 S. 42I) beobachtete bei Chara eine Ausscheidung organischer Substanz, wenn auch nur in sehr geringen Mengen. Jedenfalls wirken die etwa vorhandenen Ausscheidungen nicht störend auf Vaucheria ein, wie das die monatelangen Kulturen mit relativ kleiner Wassermenge beweisen. Auch die Zoosporenbildung wird dadurch nicht beeinflußt, da solche alten Kulturen sie im Dunkeln lebhaft zeigen. Ich filtrierte von einer alten Kultur das Wasser ab und brachte frische Vaucheria hinein, ohne einen Einfluß davon auf das Wachstum oder die Zoosporenbildung zu beobachten.

Schwieriger ist es, den Einfluß der mechanischen Reibung des strömenden Wassers zu beurteilen. Im allgemeinen wird die Reibung wegen der schleimigen Beschaffenheit der Zellwände nicht sehr groß sein. Immerhin läßt sich eine deutliche mechanische Wirkung des strömenden Wassers auf die Wachstumsweise erkennen. In lebhaft strömendem Wasser an Wehren und Wasserfällen tritt V. clavata stets in Form dicker, kurz und gleichmäßig geschorener Rasen auf. Die reibende 


\section{$-84-$}

scherende Wirkung des Wassers bedingt ein begrenztes und relativ verlangsamtes Längenwachstum der Fäden, aus deren unteren Teilen immer neue Zweige entsprießen, die aber immer wieder nur eine begrenzte Länge erreichen. Sowie ein solcher Rasen in mäßig bewegtes oder gar stehendes Wasser kommt, so erfolgt ein ungehindertes Längenwáchstum der Fäden, die nach allen Seiten ausstrahlen und schließlich eine verworrene Fadenmasse bilden. Diese V'eränderung beobachtete ich stets bei der Kultur der Rasen in meinem Aquarium. Noch deutlicher zeigt sich dieser Einfluß an $V$. sessilis, die in lebhaft strömendem Wasser kurz geschorene Rasen, in Teichen lockere Fadenmassen bildet. Welchen Einfluß die mechanische Reibung auf die Zoosporenbildung ausübt, läßt sich nicht genauer angeben.

Rein theoretisch könnte man sich vorstellen, daß sie den Prozeß begünstige. So oft ich aber die frischen Rasen untersuchte, sah ich weder junge noch leere Zoosporangien. An den Rasen, die ich ins Aquarium brachte, wo eine merkbare mechanische Reibung nicht mehr vorhanden war, herrschte auch das Wachstum vor, so dats ich eher annehmen muß, daß die mechanische Reibung überhaupt keine Rolle für die ungeschlechtliche Fortpflanzung spielt.

Von großer Bedeutung für das Leben in strömendem Wasser ist die Temperatur. Wenn auch große Unterschiede je nach der Herkunft und Beschaffenheit der einzelnen Bäche, Flüsse etc. sich finden mögen, so wird stets in ihnen im Vergleich zu kleineren Teichen eine gleichmäßigere und niederere Temperatur herrschen. Genaue Angaben über die Temperaturen des fließenden Wassers in der Umgebung von Basel kam ich nicht machen. Doch dienen zur Veranschaulichung vielleicht die Zahlen, die ich für das Wasser des laufenden Brunnens in meinem Garten festgestellt habe. Ich gebe die Zahlen, die für 
das Jahr I893 gelten; Schwankungen kommen in den verschiedenen Jahren vor, namentlich wegen des ungleich langen Winters, im Februar und März. So war im Februar I 895 die Temperatur bis auf $1,5^{\circ}$ gesunken, während das Minimum von 1893 und $943^{\circ}$ betrug.

\begin{tabular}{|c|c|}
\hline Januar & $4-2^{0}$ \\
\hline Februar & $3-5^{0}$ \\
\hline März & $5-8^{0}$ \\
\hline April & $8-10^{0}$ \\
\hline Mai & $10-13^{0}$ \\
\hline Juni & $12--16^{0}$ \\
\hline Juli & $\mathrm{I} 4-\mathrm{I} 8^{0}$ \\
\hline August & $16-18^{0}$ \\
\hline September & $14-\mathrm{I} 3^{0}$ \\
\hline Oktober & $\mathrm{I} 3-\mathrm{II}^{0}$ \\
\hline November & II $-7^{0}$ \\
\hline Dezember & $7-4^{0}$ \\
\hline
\end{tabular}

Ueber die Entwickelung der V. clavata in den verschiedenen Jahreszeiten habe ich seit mehreren Jahren im Birsig-Flüßchen in Basel Beobachtungen angestellt. Die Hauptentfaltung fällt in die Monate April, Mai, Juni und kann eine solche Höhe erreichen, daß die Alge das ganze Flüßchen erfüllt, infolgedessen gegen sie eingeschritten werden muß. Von Juli ab, bald früher, bald später, jedenfalls in der heißen Jahreszeit geht das Wachstum der Alge zurück; im Herbst wird sie meist durch V. geminata verdrängt. In anderen Flüssen, z. B. der Kander und der Wiese findet man sie in allen Monaten des Winters, in Jurabächen auch im Hochsommer. Die Grenze für ihre lebhafte Entwickelung liegt in einer andauernden Temperatur über $15^{\circ}$. Das Gleiche gilt auch von den meisten anderen Arten, die sich daher im Hochsommer nicht in kleinen Wasseransammlungen vorfinden. Der 
Einfluß der Temperatur auf die Zoosporenbildung ist früher ausführlich besprochen worden. Daraus ergab sich. daß für den Prozeß etwa eine Temperatur zwischen 5 und $10^{\circ} \mathrm{am}$ günstigsten ist. Durch Versetzung der Alge aus einer niederen Temperatur in höhere kann die Zoosporenbildung befördert werden, weil sich Vaucheria an und für sich bei niederer Temperatur in dem für den Prozeßs günstigsten Zustand befindet. Wenn aus dem kühlen Wasser eines lebhaft strömenden Baches ein Rasen ins Zimmer gebracht wird, so kann die damit verbundene Temperaturerhöhung beitragen, die Zoosporenbildung intensiver $\mathrm{zu}$ machen. Aber ihr Eintreten wird dadurch nicht erklärt, weil es auch dann erfolgt, wenn eine Temperaturerhöhung ausgeschlossen ist. Am einfachsten ließ es sich dadurch beweisen, daßs ich einen Teil des im Aquarium kultivierten Rasens in ein Becherglas mit Wasser brachte, das bis gegen den oberen Rand im Aquariumwasser schwamm und die Temperatur von diesem beibehielt. Auch unter diesen Umständen trat ohne Aenderung der Licht- oder Temperaturverhältnisse lebhafte Zoosporenbildung ein.

Der Grund hierfür muß in einer Veränderung der Beschaffenheit des Wassers liegen. Die anorganischen Nährsalze kommen dabei kaum in Betracht, weil das stehende Wasser solche in den ersten Tagen noch reichlich enthält, namentlich, da an dem Vaucheria-Rasen feine Erdteilchen kleben, die ihn damit versorgen können. Auf kleine Verschiedenheiten in der chemischen Beschaffenheit des Wassers nimmt die Alge wenig Rücksicht, da sie sich ebenso gut in den sehr kalkreichen Juragewässern entwickelt wie auch in der Wiese vorkommt, die wesentlich aus dem Kieselgestein der Feldberggruppe im Schwarzwald herstammt.

Beim Stehen des Wassers entweicht die im Bach- 
wasser reichlich gelöste Kohlensäure; der kohlensaure Kalk scheidet sich aus und macht infolgedessen das Wasser ïberhaupt weniger fähig, Kohlensäure zu lösen. Nach meinen Versuchen scheint aber diese Verminderung des Kohlensäuregehalts keinen besonderen Einfluß auf die Zoosporenbildung auszuüben. Schwächung des Gehaltes an Kohlensäure infolge der Kultur der Alge im abgeschlossenen Raum über Kalilauge bei Lichtzutritt ruft keine Zoosporenbildung hervor (S. 36); andrerseits hindert die Entziehung der Kohlensäure den Prozeß nicht bei dem gleichen Versuch mit Ausschluß des Lichtes. Jetzt bleibt nur noch der Sauerstoffgehalt des Wassers zu berücksichtigen. Die stets sich erneuernde Zufuhr von frischer Luft in strömendem Wasser regt das lebhafteste Wachstum an. In einem kleinen Gefäß mit geringer Menge des gleichen Wassers scheidet sich, wie man leicht sehen kann, Luft aus, die Algen verbrauchen fortwährend Sauerstoff, und die Menge von diesem nimmt trotz der Fortdauer der Assimilation ab. Das Wachstum wird durch die plötzliche Aenderung des Sauerstoffgehaltes verlangsamt, die Zoosporenbildung angeregt.

Ich habe vorhin bemerkt, daß die Versuche, durch weitere Entziehung des Sauerstoffs eine erneute Zoosporenbildung hervorzurufen, nicht recht durchschlagend gelungen sind. Durch längere Kultur wird die Empfindlichkeit der Alge für solche Schwankungen des Sauerstoffgehaltes ebenso verringert werden, wie ihre Empfindlichkeit für Temperaturschwankungen und schließlich sogar die für Lichtschwankungen (S. 30).

Ich komme also zu einem Resultat, das gerade der von Walz ausgesprochenen Meinung entgegengesetzt ist (S. 72). Das strömende Wasser, das ungemein das Wachstum der Alge belebt, vermag dieses hauptsächlich durch die stete Zufuhr frischen Sauerstoffs. Plötzlich 
in stehendes Wasser übergeführt, wird die Alge durch die Verringerung des Sauerstoffgehalts zur Zoosporenbildung veranlaßt, weil das Wachstum verzögert wird. Allmählich gewöhnt sich die Alge an die neue Umgrebung, wächst wieder lebhaft, und es hängt dann von Licht- und Temperaturverhältnissen ab, wie weit das Wachstum die Zoosporenbildung überwiegt oder umgekehrt. Die große Lebhaftigkeit der Zoosporenbildung in den ersten Tagen der Zimmerkultur kann außer durch Erhöhung der Temperatur (siehe vorhin) auch durch die Schwächung der Lichtintensität mit veranlaßt werden, die mit dem Uebergang aus dem freien sonnigen Standort in das Zimmer verbunden ist.

In der freien Natur muß Zoosporenbildung stattfinden, da diese allein die lebhafte Vermehrung der $V$. clavata in den Bächen herbeiführen kann. Einmal können dafür Lichtschwankungen die Rolle des auslösenden Reizes spielen, ferner der Uebergang aus feuchter Luft in Wasser. Denn bei dem wechselnden Wasserstande solcher Bäche kann es sehr leicht vorkommen, daß einzelne auf Steinen sitzende Rasen für einige Zeit üher die Wasseroberfläche ragen und dann nach einem Regenguß völlig untergetaucht, Zoosporen erzeugen.

V. repens kommt relativ selten in lebhaft fließenden Gewässern vor. Bei Ueberführung in stehendes Wasser beobachten wir, wie bei clavata, lebhafte Zoosporenbildung, wahrscheinlich aus ähnlichen Gründen. Ich kultivierte in Frühjahr 1893 V. repens in einem weiten Glasrohr, das an beiden offenen Enden mit grob durchlöchertem Stoff abgeschlossen war, und in der Nähe des Brunnenstrahles hefestigt wurde. Die Alge wuchs prächtig heran, drang durch den Stoff ain einen Ende hindurch und bildete einen dichten rasenähnlichen Filz. Ein Teil der Kultur wurde in ein zugekorlites Gefäß gebracht, das in den 
Brunnen hineingehängt wurde; er bildete dann in den nächsten Tagen massenhaft Zoosporen, während der andere Teil ruhig weiterwuchs.

\section{Die ungeschlechtliche Vermehrung bei anderen Vaucheria - Arten.}

Von Vaucheria-Arten, die, abgesehen von repens und clavata, Zoosporen bilden, untersuchte ich noch V. sessilis, die etwa in der Mitte zwischen den beiden genannten Formen steht, und ferner $V$. ornithocephala. V. sessilis verhält sich sehr ähnlich wie clavata, ohne daß ich die feineren Unterschiede beider ausführlich berücksichtigt habe (vergl. darüber die Arbeit von Götz).

$V$. ornithocephala bildet schön grüne sammetartige weiche Polster in lebhaft strömendem Wasser; ich fand sie im Birsflusse (Jura), wie in der Wiese (Schwarzwald). Die Fäden sind durchschnittlich halb so dick wie die von clavata, deren Rasen sich durch die größere Derbheit der Fäden mit bloßem Auge unterscheiden lassen. Die Keimlinge erzeugen bei Kontakt mit festen Flächen keine Rhizoiden.

In den physiologischen Eigenschaften nähert sich ornithocephala mehr der clavata als der repens. Sie ist im allgemeinen sehr viel empfindlicher gegenüber äußeren Einwirkungen als die beiden genannten Formen. Sie ist in noch höherem Grade als clavata angepaßt an das Leben in strömendem Wasser. Um wirklich gute Kulturen längere Zeit $z u$ erhalten, muß man die Alge niederer Temperatur aussetzen. So bekam ich sehr schöne Kulturen im Eiskasten bei o bis $I^{0}$. Die geringere Widerstandsfähigkeit gegenüber höherer Temperatur zeigt sich 
auch darin, dals Kulturen im Thermostaten bei $20^{\circ}$ sehr rasch zu Grunde gehen. Noch auffallender als bei clavata ist der wachstumhemmende Einfluß verdünnter Nährlïsungen, andererseits ihre Förderung der Zoosporenbildung. Eine Kultur in o,2-proz. KN-Lösung bildete vom I8./I. bis $\mathrm{I}_{5}$. II. bei heller Beleuchtung fortdauernd Zoosporen. Nach mehrwöchentlichem Aufenthalt in der Nährlösung geht V. ornithocephala meist zu Grunde. Der Uebergang aus Nährlösung in Wasser erregt selten die Zoosporenbildung, weil die Alge bald zu Grunde geht oder kränkelt. Ein Unterschied von clavata zeigt sich darin, dafs eine Nährlösung von I Proz. die Zoosporenbildung überhaupt verhindert; in 0,6-proz. Lösung kann sie noch erfolgen. Gegenüber Lichtschwankungen verhält sich ornithocephala wie clavata; in schwachem Licht kann die Zoosporenbildung äußerst lebhaft sein, im Dunkeln dauert sie nur kurze Zeit, weil die Alge zu sehr leidet. Der Uebergang aus strömendem in stehendes Wasser wirkt ebenfalls als lebhafter Reiz für die Zoosporenbildung.

Von den nicht Zoosporen erzeugenden Arten zeichnen sich einige durch ruhende ungeschlechtliche Sporen aus. Walz (66 S. I32-I33) hat ihre Bildung bei V. geminata und hamata, Wittrock (67 S. 34) bei geminata beschrieben. Während es mir bei einer Art, die sonst mit hamata übereinstimmte, nicht gelang, diese Sporen zu sehen, beobachtete ich sie neben geminata bei $V$. racemosa, die gewöhnlich fälschlicherweise mit der geminata zusammengeworfen wird, ferner bei V. uncinata, die der racemosa sehr nahe steht. Wille (87 S. 507) nennt diese ruhenden Sporen Aplanosporen, welche Bezeichnung ich heibehalten will. Sie entstehen in ähnlicher Weise wie die Zoosporen. An den Enden der Fäden oder kurzen Seitenzweige entsteht durch Anschwellung ein ovales 
bis kugeliges Sporangium, das durch eine Querwand vom übrigen Faden abgetrennt wird. Der Zellinhalt umgiebt sich mit einer neuen eigenen Membran; die des Sporangiums platzt an der Spitze auf und läßt die behäutete unbewegliche Spore allmählich heraustreten.

Die physiologischen Bedingungen der AplanosporenBildung unterscheiden sich wesentlich von denjenigen der Zoosporenbildung. Die Aplanosporen treten in größerer Menge in feuchter Luft oder dann auf, wenn seit längerer Zeit die äußeren Bedingungen nicht mehr günstig für das Wachstum gewesen sind. Am meisten habe ich $\mathrm{V}$. geminata in dieser Beziehung untersucht.

Niemals sah ich Aplanosporen bei geminata in fließendem Wasser, obgleich ich im Laufe der Jahre eine Unmasse verschiedener Rasen dieser gemeinen Alge unter den Augen gehabt habe. Nie traten auch die Sporen bei der Kultur im Aquarium auf, selbst nicht nach monatelangem Aufenthalt. In der freien Natur beobachtete ich die Sporen bei solchen Rasen, die auf feuchtem Boden, besonders im Herbst, sich entwickelt hatten. Man kann zu jeder Zeit die Aplanosporenbildung hervorrufen, wenn man V. geminata auf feuchtem Substrat relativ trockener Luft aussetzt. Am besten geschieht der Versuch in der Weise, daß man einen dicken vorher gut ausgewaschenen Rasen auf einen Porzellanteller bringt und eine große Glocke mit offenem Hals darüber deckt. Anfangs geht unter diesen Umständen noch lebhaftes Wachstum vor sich; allmählich macht sich ein Mangel an Nährsalzen bemerkbar, und zugleich wirkt die relativ trockene Luft auf die Alge ein. Neben Geschlechtsorganen zeigen sich immer häufiger die Aplanosporen, die zuerst am Rande des Rasens erscheinen, weil hier die größere Trockenheit herrscht. Man beobachtet dann ganze traubenförmige Büschel solcher Aplano- 
sporen. Die Keimung dieser geht unter den Versuchsbedingungen äußerst langsam ror sich. Am besten bewirkt man ihre Keimung durch Kultur auf feuchtem Lehm oder wenn man die Sporen in ein Glasröhrchen bringt, das an den offenen Enden durch groblöcherigen Stoff verschlossen und in fließendes Wasser gehängt wird. In Nährsalzkulturen bilden sich im allgemeinen keine Aplanosporen, so lange die Fäden darin noch lebhaft wachsen. Sie zeigen sich dagegen an solchen Fäden, die an der Glaswand über die Flüssigkeit sich erhoben haben. Die Zeitdauer, bis die Sporen erscheinen, läßt sich schwer genau angeben, weil sie von dem Ernährungszustande der Kultur wesentlich abhängt. Nur als Beispiel will ich erwähnen, daß ein Rasen von V. geminata, der am I9. III. I892 auf einem Teller unter die Glocke gebracht wurde, einen Monat später in lebhafter Aplanosporenbildung begriffen war.

Bei älteren Kulturen in begrenzter Wassermenge können schließlich die Sporen ebenfalls auftreten. So hatte ich einen Rasen, der rom Uracher Wasserfall (Schwäbischer Jura) stammte, am 29./IX. I892 in feuchte Luft gebracht; im Laufe des Oktober traten noch vor den Geschlechtsorganen die Aplanosporen auf. Am 8. XI. wurde der Rasen in Wasser gehracht, infolgedessen Wachstum eintrat und die Sporenbildung aufhörte. Erst nach einigen Monaten zeigte diese sich wieder, und ying bis Anfang Mai I893 fort, wo dann die Alge bereits in sehr schlechtem Zustande sich befand.

Ferner treten die Sporen in Lösungen von Zucker und Maltose auf. Es kann allerdings vorkommen, namentlich im Sommer, daß die Alge infolge der höheren Temperatur in diesen Lösungen bald in einen patholowischen Zustand gerät, in welchem sie nicht fähig ist, Aplanosporen zu erzeugen. Doch im Winter und Früh- 
jahr werden diese massenhaft gebildet. So zeigten sich bei einer Kultur in 2-proz. Rohrzucker vom I9./II. I89I die Sporen am I8./III, bei einer anderen Kultur in 2-proz. Rohrzucker vom I6./II. I89I erst am I6./IV., ebenso in einer gleichzeitigen Kultur in 2-proz. Maltose. Hier bemerkte ich, wie an den Zweigenden fortwährend neue Sporen erzeugt wurden, so daß die zurückbleibenden Sporangienhäute einen dicken geschichteten Mantel bildeten.

V. racemosa und uncinata schließen sich V. geminata nahe an. Die Aplanosporen finden sich in der freien Natur ebenfalls beim Wachstum auf feuchtem Boden. Wenn ein solcher Rasen ins Wasser gebracht wird, so hört die Bildung der Aplanosporen auf, die Fäden wachsen lebhaft und erzeugen bald Geschlechtsorgane. Sie können dann je nach den Ernährungsumständen später wieder Sporen erzeugen. Im Herbst I89o beobachtete ich im See von Neudorf, Herbst I893 im Teich von Märkt bei Basel eine gewaltige Entwickelung der uncinata in Form großer schwimmender Watten. Bei der Untersuchung des frischen Materiales sah ich keine Aplanosporen, die dann bald massenhaft in den Wasserkulturen auftraten, viel früher und zahlreicher als bei geminata und die sich an der Oberfläche des Wassers ansammelten. In einer Wasserkultur sah ich die Bildung der Sporen vom 20./XII. I892 bis Mitte Mai I893. Sie keimten und erzeugten an den Keimschläuchen sofort neue Aplanosporen. Große Massen von diesen traten auch in 4-proz. Rohrzucker-, 2-proz. Mannit-, 2-proz. Glykose-, 2-proz. Dulcit-Lösungen auf. 


\section{Die geschlechtliche Fortpflanzung von Vaucheria.}

Die Geschlechtsorgane von Vaucheria sind zuerst von $\mathrm{V}$ a u cher I 803 beobachtet worden, wenn auch bereits der ausgezeichnete Forscher M i ch eli i 729 eine Andeutung davon gesehen hatte. V a u cher vermochte noch nicht den Befruchtungsprozeß richtig aufzufassen. Erst Pringsheim (55) erkannte die eigentlichen befruchtenden Elemente, die Spermatozoen, beobachtete die Bildung des Eibehälters und der darin entstehenden Eizelle; er sah das Aufplatzen des Eibehälters und konnte die Ausbildung sowie die Keimung der befruchteten Oosporen verfolgen. Später hat $\mathrm{Walz}^{\mathrm{ral}}$ (66) bei anderen Arten Bau und Bildung der Geschlechtsorgane untersucht, ohne wesentlich neues hinzuzufügen. In die feineren histologischen Details bei dem Befruchtungsprozeß hat erst die Arbeit ron Oltmanns (95) Klarheit gebracht. Bei der Mehrzahl der Arten finden sich die Geschlechtsorgane, die Antheridien und die Oogonien, auf demselben Faden dicht nebeneinander oder auf gemeinsamem Träger. Nur V. dichotoma ist dioecisch (vergl. Solms-Laubach 07). Abgesehen von der letzteren Form, die bei Basel nicht vorkommt, habe ich bei den meisten deutschen Arten die Geschlechtsorgane untersucht; es sind V. sessilis mit ihren Formen, pachyderma, terrestris, hamata, aversa, ornithocephala, polysperma, uncinata, geminata, racemosa, de Baryana. Das Hauptmaterial für meine Untersuchungen haben mir die drei Formen von sessilis geliefert, die ich früher (S. 6) unterschieden habe. Sie lassen sich in Bezug auf ihre Geschlechtsorgane in folgender Weise charakterisieren: 
Vaucheria repens (Fig. $2 A$ ) bildet meistens nur ein Antheridium neben einem Oogonium. Dieses ist schief eiförmig und endigt in einen kurzen Schnabel, der fast horizontal, d. h. dem Faden parallel liegt. Die reife Oospore hat mehrere zerstreut liegende bräunliche Flecke (Degenerationsprodukte des Chlorophylls).

Vaucheria clavata (Fig. $2 B$ ) bildet bald ein, bald zwei Oogonien seitlich vom Antheridium. Das Oogonium ist schlank eiförmig und endigt in einen vertikal stehenden Schnabel. Nicht selten, besonders in Zuckerlösungen, sitzt das Oogonium der Basis des Antheridiumträgers auf. Die reife Oospore hat einen centralen rötlichen Fleck.

Vaucheria sessilis (früher von mir als fluitans bezeichnet, Klebs 92) bildet meistens ein Antheridium zwischen zwei Oogonien.
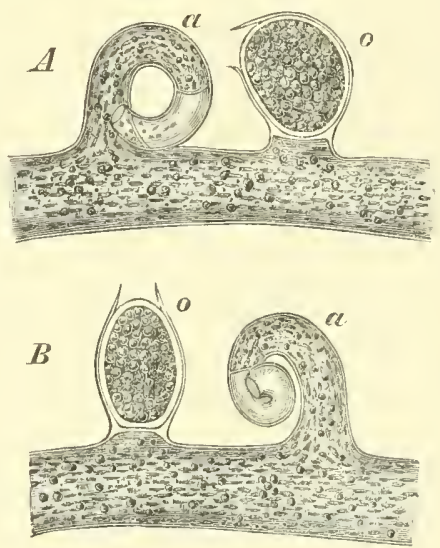

Fig. 2. A Vaucheria repens; $B$ Vaucheria clavata; Geschlechtsorgane, $a$ Antheridium, o Oogonium mit befruchteter Oospore. Vergr. 150.

Das Oogonium, kürzer ei-

förmig als bei repens, geht in einen schief gerichteten Schnabel aus. Die reife Oospore hat einen centralen rötlichen Fleck.

Nach einzelnen Geschlechtsorganen vermag man sehr schwer die Arten auseinander zu halten, namentlich sessilis und clavata. Uebergangsformen in der Gestalt der Geschlechtsorgane zwischen den drei Arten lassen sich leicht beobachten, und doch wird man bei der Bestimmung nicht irre gehen, wenn man reichliches Material zur Verfügung hat. 
Die Vaucheria-Arten lassen sich in der Kultur leicht und sicher zur geschlechtlichen Fortpflanzung bringen, während sie in der freien Natur häufig steril sind. Es giebt unter den Algen wenige andere Beispiele, bei denen man die physiologischen Bedingungen des Sexualprozesses so sicher erkennen und deshalb auch benutzen kann, um diesen jederzeit hervorzurufen. Die oben genannten Arten verhalten sich in dieser Beziehung wesentlich übereinstimmend, weshalb ich sie auch gemeinsam behandeln werde; die Unterschiede werde ich dann an geeigneter Stelle hervorheben. Wenn nichts anderes bemerkt ist, so sind die Versuche mit V. repens angestellt worden. Sie ist deshalb das beste Objekt, weil ihre Fäden in einer Rohrzuckerlösung ron 2-4 Proz. mit größter Sicherheit in 4-5 Tagen bei heller Beleuchtung die Geschlechtsorgane erzeugen. Das ist der Grundversuch, der gestattet den Einfluß der verschiedenen äußeren Bedingungen festzustellen.

\section{Der Einfluß des Liehtes.}

Die Geschlechtsorgane der Vaucheria-Arten treten nur dann auf, wenn das Licht mitwirkt. Diese wichtige Thatsache hob ich bereits in meiner ersten Mitteilung von I892 hervor; ich habe sie im Laufe der folgenden Jahre nur bestätigen können. Aber nicht bloß im Dunkeln, sondern auch in schwächerem Lichte bleiben die I aucheria-Fäden steril, während das Wachstum weitergeht. Es gelingt Jahre hindurch die Alge im Wachstum, aber vollständig in geschlechtlicher Sterilität zu erhalten (siehe auch S. 34). Mir stehen noch heute folgende vier sterile Kulturen von $V$, repens zur Verfügung:

I und II seit I8./I. I 892 in o,6-proz. KN-Lösung, seit 31. XII. I 892 in 0,5-proz.; 
III seit I9./I. I892 in 0,6-proz. KN-Lösung, seit 3I./XII. I892 in 0,5-proz. Lösung;

IV seit 3./II. I892 in 0,6-proz. KN-Lösung, seit 3I./XII. I 892 in 0,5 -proz. Lösung.

Die Kulturen stehen in einer Ecke des Zimmers, im Winter dem Fenster etwas näher gerückt, als im Sommer. Auf den Kulturen bildet sich nach und nach eine weiße Kahmhaut, die von Zeit zu Zeit weggenommen werden muß, wobei dann die alte Nährlösung durch frische ersetzt wird. Die Kulturen sind bis heute, d. h. nach $4^{1 / 2}$ Jahren, frisch; das Wachstum geht ununterbrochen fort, wenn auch natürlich sehr langsam. Da auch die Fäden an ihren alten Teilen absterben, so nimmt die Masse der grünen Alge nur sehr wenig zu. Ihre Fähigkeit, Geschlechtsorgane zu bilden, hat sich noch immer erhalten. Einige Fäden, in Zuckerlösung versetzt und hell beleuchtet, liefern solche nach einiger Zeit.

Die Frage nach der Bedeutung des Lichtes für den Geschlechtsprozeß will ich in folgenden Abschnitten behandeln :

a) Die Wirkung des Lichtes als Vermittler der Ernährung.

b) Der Einfluß der Intensität des Lichtes.

c) Die Bedeutung farbigen Lichtes.

a) Die Wirkung des Lichtes als Vermittler der Ernährung.

Die Bildung der Sexualorgane, besonders der mit Reservestoffen erfüllten Eizelle, beansprucht unstreitig eine sehr viel größere Summe von organischen Nahrungssubstanzen als die Erzeugung von Zoosporangien. Daher muß eine kräftige Ernährung in sehr viel höherem Grade die Vorbedingung für den Geschlechtsprozeß sein. Da das Licht notwendig bei der Bildung der organischen 
Substanz mitwirlst, so muß es in dieser Eigenschaft eine große Bedeutung für den genannten Prozeß haben. Die Unfähigkeit der Algen, bei schwachem oder fehlendem Licht die Geschlechtsorgane zu erzeugen, könnte vielleicht durch Nahrungsmangel erklärt werden. Diese Meinung ließe sich noch durch den Versuch stützen, in welchem die Alge bei Lichtzutritt, aber bei Ausschluß der Kohlensäure-Assimilation, kultiviert wird. Der Versuch wurde in der auf $S .36$ beschriebenen Weise angestellt; neben dem Glas mit Kalilauge befand sich ein anderer Behälter mit sterilen Fäden in destilliertem Wasser. Mehrere in der Art ausgeführten Versuche, wobei die Apparate hell beleuchtet wurden, hatten das gleiche Resultat. Vaucheria blieb 3 Wochen lang steril und ging allmählich zu Grunde; die Alge hatte vollkommen das Aussehen einer langen Dunkelkultur. Unter normalen Luftverhältnissen erholten sich die Fäden und bildeten später Geschlechtsorgane. Nacht man den gleichen Versuch mit kohlensäurefreier Luft, ersetzt das Wasser der Kultur indessen durch eine Rohrzuckerlösung von 2-4 Proz., so erfolgt in $4-5$ Tagen, d. h. so schnell wie sonst die Bildung der Organe. Ich habe in den gleichen Apparat ein Gläschen mit Wasser, ein anderes init Zuckerlösung gebracht; im ersteren blieb Vaucheria steril, im letzteren fruktifizierte sie. Der Zucker kann also die sonst durch Assimilation entstehende organische Substanz ersetzen. Aber niemals kann er in schwachem Licht oder im Dunkeln die Bildung der Sexualorgane veranlassen. Folglich muß das Licht neben seiner Wirkung bei der Ernährung noch eine spezifische Rolle bei der Bildung der Sexualorgane spielen. Hauptsächlich ist es die erste Anlage der männlichen und weiblichen Organe, die unter dem Einflufs des Lichtes stehen. Wenn 3 Tage alte Zuckerkulturen, in denen eben die Organe sich zeigen, ins Dunkle ver- 


\section{$-99$}

setzt werden, so können diese reif werden, und es kann Befruchtung stattfinden. Die Bildung neuer Organe hört aber sofort auf. Welcher Art nun die Wirkungen sind, die das Licht bei dem Sexualprozeß in der Alge ausübt, ist rätselhaft; man wird geneigt sein, bestimmte chemische Wirkungen anzunehmen. Das Problem wird nicht eher gelöst werden, als bis man durch ein anderes Mittel das Licht auch in dieser Richtung ersetzen kann, ebenso wie seine Nährwirkung durch Zucker sich ersetzen läßt.

Bei der günstigen Wirkung des Zuckers auf den Sexualprozeß kommt noch ein anderer Umstand in Betracht; er verzögert das Wachstum direkt, ferner auch indirekt durch seinen Mangel an Nährsalzen, so daß die organischen Substanzen hauptsächlich für den Sexualprozeß3 verbraucht werden können. Noch auffallender wird diese Hemmung in destilliertem Wasser, in welchem deshalb die Geschlechtsorgane sehr früh auftreten, oft nach wenigen Tagen. Die Zeit, in der die Organe in Wasserkulturen sich zeigen, hängt dann von dem Ernährungszustande des Versuchsmaterials ab. Bei Kulturen, die einige Zeit in schwachem Licht gestanden haben, erscheinen die Organe im Licht erst nach 8 bis Io Tagen. Das gleiche ist der Fall, wenn man einen Rasen mit nährsalzhaltigen Erdteilchen ins Wasser bringt. Wie wir wissen, wird das Wachstum von Vaucheria durch verdünnte Nährlösungen sehr gefördert; die Geschlechtsorgane zeigen sich infolgedessen selbst bei guter Beleuchtung später, in $0,2-0,5$-proz. Lösung nach Io bis I2 Tagen, in I-proz. Lösung nach drei Wochen.

Es ereignet sich sehr selten, daß in Rohrzucker bei hellem Licht die Geschlechtsthätigkeit nicht zum Ausbruch kommt. Wenn aber Fäden wochenlang in Rohrzucker kultiviert werden, ohne daß sie infolge schwachen Lichtes oder Luftmangels die Sexualorgane, bilden 
können, so geraten sie in einen pathologischen Zustand, gekennzeichnet durch Anhäufung von Fett, in welchem sie steril bleiben auch nach Zutritt heller Beleuchtung. In ganz wenigen Fällen beobachtete ich selbst bei Wasserkulturen im Licht eine lang andauernde Sterilität unter ähnlichen Umständen.

b) Der Einfluß der Lichtintensität.

Die wesentliche Bedeutung des Lichtes für den Sexualprozeß von Vaucheria erforderte eine eingehendere Untersuchung der Frage, welche Intensität für die verschiedenen Wirkungen des Lichtes maßgebend ist. Aus den angeführten Versuchen folgt, daß die Bildung der Geschlechtsorgane von einer höheren Intensität abhängt, als z. B. die Assimilation, der Heliotropismus, welche Prozesse selbst bei ganz schwachem Licht stattfinden können. Die beste Lösung der Frage mußte der Versuch mit künstlichen Lichtquellen geben. Ich habe die früher beschriebene Einrichtung benutzt (S. 25). Die dort erwähnten Fehlerquellen, vor allem die nicht völlige Konstanz des Lichtes einer Auer'schen Lampe, sind zwar bei längerer Dauer des Versuches für die vorliegende Untersuchung etwas wichtiger, als für diejenige der Zoosporenbildung. Die in jedem Falle sehr allmählich eintretende Verminderung der Lichtstärke hat aber nur Einfluß auf die Genauigkeit der Zahlen, die die angewandten Lichtmengen ausdrücken und die, aus den oft erwähnten Gründen der individuellen Verschiedenheiten überhaupt, nur Annäherungswerte vorstellen. Die Resultate, auf die ich Gewicht lege, werden dadurch nicht verändert.

Für die Versuche selbst war natürlich die Hauptbedingung, daß völlig steriles Material für sie benutzt wurde. Um solches zu erlangen, kultivierte ich in Glas- 
schalen Rasen von $\mathrm{V}$. repens in feuchter Luft bei heller Beleuchtung einige Tage, fügte dann Wasser hinzu und stellte das Gefäß in mäßig schwaches Licht. Die Keimlinge aus den neu gebildeten Zoosporen, ebenso die alten Fäden wuchsen dann zu langen zarten sterilen Fäden heran, die übrigens für jeden Versuch unter dem Mikroskop noch besonders geprüft wurden. Ich nahm dann solche sterilen Fäden und brachte sie in kleine Cylindergläschen, die Zuckerlösung oder Wasser enthielten und die dann in verschiedene Entfernung von der Auer-Lampe gestellt wurden. Die Temperatur, die auf den Sexualprozeß überhaupt nur geringen Einfluß hat, schwankte, wie ich früher angegeben habe, zwischen I6-20\%. Auf die zahlreichen Versuche will ich im einzelnen nicht eingehen; ich werde mich auf die Angaben der allgemeinen Ergebnisse beschränken.

Die Versuche zeigen zunächst, daß die Bildung der Geschlechtsorgane in erster Linie von der Intensität des Lichtes, in zweiter von der Dauer der Beleuchtung abhängt. Schwankungen der Intensität von der hellen Beleuchtung eines Sommertages an bis zu der Lichtstärke in 25 bis $30 \mathrm{~cm}$ Entfernung von einer Auer'schen Lampe von ca. 80 Hefner-Lichteinheiten haben keine Bedeutung für den Prozeß; innerhalb der angegebenen Grenzen, gleich bei welcher Intensität, erfordert er in Zuckerlösung vier Tage. Das Eintreten des Prozesses läßt sich noch etwas genauer feststellen. Bringt man um 9 Uhr vormittags sterile Fäden in 2 Proz. Zucker in $25 \mathrm{~cm}$ Entfernung von der Lampe, so zeigen sich nach 72 Stunden bei ununterbrochener Beleuchtung die ersten Antheridien, im Laufe der nächsten 24 Stunden die Oogonien. Die andauernde Beleuchtung hat ebensowenig für die Sexualorgane wie für die Zoosporenbildung Bedeutung. In derselben Zeit erscheinen die Sexualorgane, wenn man 
von 9 Uhr abends bis 9 Uhr morgens verdunkelt. Es genügen daher $36-48$ Lichtstunden. Aus früher (S. 26) angegebenen Gründen habe ich die Mehrzahl der Versuche ununterbrochen beleuchtet.

Vermindert man die Intensität des Lichtes, indem man die Kulturen weiter von der Lampe entfernt, so ist auch eine größere Zahl von Lichtstunden notwendig, ohne daß sich Genaueres angeben läßt, weil die verschiedenen Kulturen nicht übereinstimmende Resultate lieferten. Tiel hängt dahei von der vorhergehenden Behandlung der Alge ab. Vaucheria-Fäden, die in 0,2-proz. KN-Lösung hell am Fenster gestanden haben und noch steril sind, bilden in $50 \mathrm{~cm}$ Entfernung in 4-5 Tagen die Geschlechtsorgane; in schwachem Licht erzogene brauchen 5-6 Tage. Noch wichtiger ist die vorhergehende kräftige Beleuchtung bei $75 \mathrm{~cm}$ Distanz. Algen in Zuckerlösung, 2 Tage vorher hell beleuchtet, erzeugen hier nach 4 Tagen schon die Organe, weil jedenfalls die ersten Vorbereitungen dafür eingeleitet waren; in schwachem Licht erzogene Fäden brauchen IO-I4 Tage. Bereits bei 50 , noch mehr bei $75 \mathrm{~cm}$ Entfernung von der Auer'schen Lampe ist die Geschlechtsthätigkeit sehr behindert. Man findet nur einzelne normale Organe, man bemerkt zahlreich angelegte Antheridien, die aber nicht fertig ausgebildet sind. In $75 \mathrm{~cm}$ Entfernung sah ich Oogonien vegetativ auswachsen oder in unfertigem Zustande stehen bleiben. In I $m$ Entfernung von der Lampe findet keine Bildung von Organen statt, auch wenn die Kultur vorher 2 Tage hell beleuchtet war; hier ist die Grenze. So habe ich z. B. sterile Vaucheria in 4 -proz. Rohrzucker vom 8.-IO./X. I893 hell, am IO./X. I m, entfernt von der Lampe gestellt. Bis zum 3I. X. war die Kultur noch ganz frisch, aber steril. Eine andere Kultur am 14./I. I894 in 2-proz. Rohrzucker gleich in I in Entfernung gestellt, war am I6./II. noch lebend und steril. 
Wir können also sagen, daß bei Gegenwart von Rohrzucker das Licht einer $25 \mathrm{~cm}$ entfernten Auer'schen Lampe genügt, um lebhafte Geschlechtsthätigkeit bei Vaucheria repens hervorzurufen, daß das Licht in $50-75 \mathrm{~cm}$ Entfernung noch eben ausreicht, einzelne Geschlechtsorgane zu erzeugen, daß ein solches in I $\mathrm{m}$ Entfernung ihre Bildung verhindert.

Wesentlich anders fallen die Versuche aus, wenn man statt Zuckerlösung reines Wasser oder verdünnte Nährsalzlösung für die Kulturen benutzt. In $25 \mathrm{~cm}$ Entfernung von der Lichtquelle wachsen die VaucheriaFäden lebhaft, so daß in 8 Tagen sich aus wenigen eine dichte, schön grüne Masse entwickelt, an der nach Io Tagen auch Geschlechtsorgane sich zeigen. Bereits in $50 \mathrm{~cm}$ Entfernung habe ich weder in Wasser noch in 0,05-proz. KN-Lösung die Organe beobachtet. Nach einigen Wochen sahen die Kulturen nicht mehr sehr frisch aus; in den Schläuchen fanden sich schwärzliche Körnerhaufen, wie sie in Dunkelkulturen auftreten. Noch mehr ist dies natürlich der Fall in $75^{--100 ~} \mathrm{~cm}$ Entfernung von der Lichtquelle. Solche Kulturen, die längere Zeit bei zu schwachem Licht in $75 \mathrm{~cm}$ Entfernung gestanden haben, bilden auch nach Zutritt des Tageslichtes wenige oder keine Geschlechtsorgane. So blieb eine Wasserkultur, die vom 25.-3I./X. $75 \mathrm{~cm}$ von der AuerLampe entfernt gestanden hatte und seit 3I./X. ans Fenster gebracht worden war, steril bis zum I9./XI.

Die Versuche mit künstlichem Licht bestätigen die vorhin erwähnte wichtige Thatsache, daß das Licht nach zwei Richtungen den Geschlechtsprozeß beeinflußt:

Es liefert als Bedingung der Kohlensäure-Assimilation die für den Prozeß notwendigen organischen Nahrungssubstanzen. 
Es wirkt in specifischer Weise direkt bei der Bildung der Sexualorgane mit.

Die unteren Grenzen der Lichtintensität für die beiden Wirkungen fallen nicht zusammen. Diejenige Intensität, welche als Grenze für die indirekte Lichtwirkung maßgebend ist, kann für die direkte Wirkung noch etwa um $1 / 4$ geschwächt werden, sobald durch Zucker dafür gesorgt ist, daß die Erzeugung von Nahrung durch Assimilation nicht notwendig ist.

c) Die Bedeutung farbigen Lichtes.

Die Pflanzenphysiologie lehrt, daß die Lichtstrahlen verschiedener Wellenlänge und dementsprechend verschiedener Brechbarkeit ungleiche Wirkungen auf die Lebenserscheinungen ausüben. Draper, Sachs, Pfeffer u. a. haben nachgewiesen, daß die Strahlen geringerer Brechbarkeit, die unserem Auge rot bis gelb erscheinen, hauptsächlich für die Assimilation wirksam sind, während die Strahlen stärkerer Brechbarkeit, die blauvioletten, besonders die Bewegungserscheinungen beeinflussen. W i es ner ( 78 S. 50) zeigte für den Heliotropismus, daß dieser von allen Strahlengattungen, mit Ausnahme der gelben Strahlen, hervorgerufen wird, daß aber das Maximum der Wirkung einerseits im Ultrarot, andererseits zwischen Violett und Ultraviolett liegt. Ueber die Wirkung des Lichtes verschiedener Wellenlänge auf den Geschlechtsprozeß kennt man für höhere Pflanzen nur eine einzige merkwürdige Beobachtung, die Sachs gemacht hat. Er wies nach (87 S. 384), daß Tropaeolum in einem Licht, das heim Durchgang einer Chininlösung seiner ultravioletten Strahlen beraubt worden war, keine Blüten ausbildete. Sachs nahm daher an, daß gerade diese Strahlen für die Bildung der Blüten am wirksamsten seien. 
Für die Untersuchung der Frage ging ich wieder davon aus, daß V. repens in 4-5 Tagen bei heller Beleuchtung ihre Sexualorgane bildet. Es kam darauf an, verschiedenfarbiges Licht aut seine Wirkung hin zu prüfen. Dabei war stets $\mathrm{zu}$ beachten, daß seine Intensität nicht $\mathrm{zu}$ schwach war. Sie hing von dem Tageslichte ab, wechselte, abgesehen von den täglichen Wetterschwankungen, mit den Jahreszeiten; sie hing ferner von der Konzentration der Farbstofflösung ab. Als Beispiel hierfür will ich einen Versuch mit doppelwandigen Glocken anführen, die mit Methylenblau verschiedener Konzentration gefüllt waren. Unter einer Glocke mit o,ooI Proz., die dem Auge durchsichtig hellblau erschien, bildete V. repens in Wasser im Februar I893 die Organe nach 7 Tagen; unter einer daneben stehenden Glocke mit o,or Proz., die undurchsichtig blau war, blieben die Fäden vom I./II. bis I5./III., wo der Versuch beendet wurde, steril. Das gleiche Experiment wurde am 8./II. I893 mit einer 4-proz. Rohrzuckerlösung gemacht. Bei o,ooI-proz. Methylenblau zeigten sich die Organe nach 4 Tagen; bei o,o I Proz. traten nach I4 Tagen Antheridiumanlagen hervor, die aber nicht zur Ausbildung kamen, so daß am 15./III. die Kultur noch steril war. Dagegen unter einer Glocke von 0,005-proz. Methylenblau zeigten sich Geschlechtsorgane in 2-proz. Rohrzucker Anfang März nach 6 Tagen. Die Glocken standen in allen Fällen dicht am Südfenster, die direkte Sonne wurde durch weiße Rouleaux abgehalten.

Die eigentlichen Versuche über den Einfluß farbigen Lichtes habe ich zuerst in folgender Weise angestellt. Ich nahm Bechergläser von I Liter Inhalt und füllte sie mit der zu prüfenden Farbstofflösung. Direkt in die Flüssigkeit stellte ich ein kleines Gläschen, $5 \mathrm{~cm}$ hoch, $2 \frac{1}{2} \mathrm{~cm}$ breit, in welchem sich sterile Vaucheria- 
Fäden in Zuckerlösung befanden. Das Gläschen war mit eingeschliffenem Glasstopfen versehen, der oben mit Paraffin bedeckt wurde, so daß die Flüssigkeit nicht eindringen konnte. Die Farbstofflösung umgab in einer $3 \mathrm{~cm}$ dicken Schicht das Gläschen ron oben wie von allen Seiten, abgesehen von der Basis. Durch frühere Versuche hatte ich festgestellt, daß die Algen in so abgeschlossenen Gläschen ruhig fruktifizieren. Eine Reihe solcher Versuche stellte ich neben einander an das Südfenster. Von Zeit zu Zeit prüfte ich die Gläschen mit einer scharfen Lupe, die die Geschlechtsorgane leicht erkennen ließ. Glaubte ich solche zu sehen, so wurde die Kultur genau untersucht. Eine kleine Anzahl Versuche blieben infolge von Eindringen des Farbstoffes in die Gläschen erfolglos; sie werden in der Tabelle auf S. IO7 nicht angeführt. Das Absorptionsspektrum der Farbstofflösung untersuchte ich mit einem Brow n in g'schen HandSpektroskop (Firma Zei B) mit Vergleichsprisma.

Dieselbe Versuchs-Anordnung traf ich, um den Ein. fluß der ultravioletten Strahlen auf die Bildung der Geschlechtsorgane zu prüfen. Ich löste schwefelsaures Chinin in W'asser, dem etwas Schwefelsäure zugesetzt wurde. Die Lösung fluorescierte stark blau. Für die einzelnen Versuche nahm ich stets frische Lösungen, um jede Trübung durch Veränderung des Chinins auszuschließen. Folgende Versuche wurden mit V. repens in den oben bezeichneten paraffinierten Gläschen angestellt; die Schicht der Chininlösung betrug $3 \mathrm{~cm}$.

Nr. I.

28.1. 1893 in Wasser

bis 21./II. einzelne Antheridien; Organe beiderlei Art an beigemischter V. terrestris; 3. III. aus der Chininlösung hell; bis 26. IV. V. repens steril.

(Fortsetzung S. I08.) 
Vaucheria repens in 4-proz. Rohrzucker.

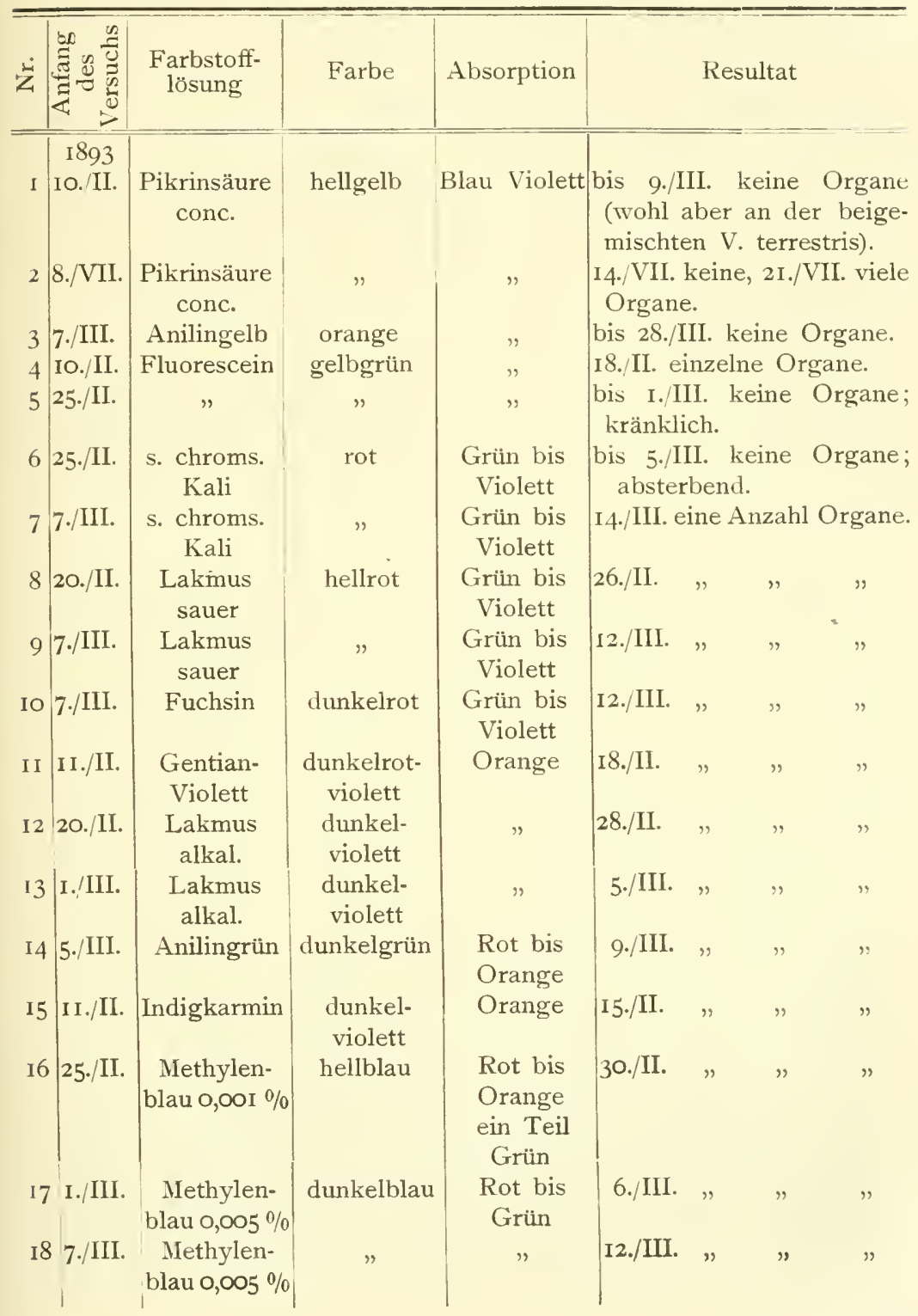


Nr. 2.

15./II. I893 in 4-proz. Rohrzucker

Nr. 3.

25. I1. 1893 in 4-proz. Rohrzucker

Nr. 4.

6. III. I893 in 2-proz. Rohrzucker

Nr. 5.

\$. V'Il. IS93 in I-proz. Rohrzucker

Nr. 6.

15. V11. IS93 in 2-proz. Rohrzucker Nr. 7.

15./VII. I893 in I-proz. Rohrzucker Nr. 8.

2I. VII. 18937 Versuche nebeneinander

a -e in 4-proz. Rohrzucker

$\mathrm{f}-\mathrm{g}$ in W' $\mathrm{Tsser}$
21./I. eine Anzahl Organe.

3./III. , " , , ,

9./IIl. , , , ,

I4./II. keine, 2I./VII. zahlreiche Organe.

21./VII. eine Anzahl Organe.

2I.|VII. ,

27./VII. eine Anzahl Organe in a-d; Versuch e nur wenige Antheridien, dann absterbend; f kränklich; $\mathrm{g}$ abgestorben.

Die Versuche (S. 107) zeigen, daß in Lösungen, die die rotgelben Strahlen absorbieren und unserem Auge dunkelviolett oder -blau erscheinen, die Geschlechtsorgane bei Gegenwart von Zucker normal gebildet werden und nur wenig später als bei normaler Beleuchtung auftreten. Die Chininversuche lehren, daß in der Mehrzahl der Fälle der Mangel an ultravioletten Strahlen für den Geschlechtsprozeß gleichgiltig ist. In den hellgelben bis roten Lösungen, die Blauviolett absorbieren, machen sich dagegen Unregelmäßigkeiten bemerkbar; die Organe erscheinen später oder gar nicht. Auf diese negativen Resultate konnte ich bei weiterer Untersuchung kein großes Gewicht legen. Denn entweder sind die beim Versuch steril gebliebenen Kulturen schließlich zu Grunde gegangen oder sie haben später auch unter normalen Lichtverhältnissen keine Geschlechtsorgane gebildet. Besonders auffallend war es der Fall mit dem Chininversuch Nr. I; es ist einer der auf S. Ioo erwähnten 
höchst seltenen Fälle, daß eine Wasserkultur nicht mehr Sexualorgane $\mathrm{zu}$ bilden vermochte. Bei den negativ ausgefallenen Versuchen waren daher die Algen in einen krankhaften Zustand geraten, und es wäre möglich, daß dort Luftmangel neben anderen unbekannten Umständen eine Rolle gespielt hätte. Die Hemmung infolge des Ausschlusses der blauvioletten Strahlen, wofür die Versuche, Tabelle S. IO7, No. I-5 sprachen, schien mir noch nicht bewiesen.

Bei einer erneuten Untersuchung der Frage benutzte ich wieder die doppelwandigen Glocken, die auf einem mit Sand gefüllten Untersatze standen. Sie haben den großen Vorteil, daß man gleichzeitig unter ihnen mehrere Versuche anstellen kann. Ich machte Oktober I893 mit einer Glocke, die mit Chininlösung gefüllt war, eine ganze Menge Versuche. Ausnahmslos bildeten sich dabei im Wasser wie in Zuckerlösung die Geschlechtsorgane; die ultravioletten Strahlen haben für diese jedenfalls keine Bedeutung. Ich habe deshalb die Chininglocke statt einer Wasserglocke als Kontrollversuch für die Experimente mit anderen farbigen Glocken benutzt. Ich habe eine Glocke mit konzentrierter Pikrinsäure, eine zweite mit konzentriertem saurem chromsaurem Kali, eine dritte mit 0,002-proz. Methylenblau gefüllt (statt des letzteren gebrauchte ich später auch Kupferoxydammoniak). Die vier Glocken, die weißblau-fluorescierende, die gelbe, die rote und die blaue wurden nebeneinander ans Südfenster gestellt. Für die gleichzeitig ausgeführten Versuche benutzte ich sterile Vaucheria repens aus ein und derselben Kultur. Während des Winters I893/94, vom Oktober bis März, habe ich ununterbrochen Kulturen in Wasser und Zuckerlösung unter den vier Glocken gehabt; neben $V$. repens wurden auch $V$. clavata, ornithocephala, terrestris, de Baryana, geminata untersucht. 
Das Resultat dieser Versuche war, daß die Geschlechtsorgane unter der Chinin- wie Pikrinsäure-Glocke sich in derselben Zeit ausbildeten, wie in weißem Licht, dats unter der Methylenblau-Glocke die Bildung sich einige Tage verzögerte; lie Lösung war augenscheinlich für die Winter-Helligkeit ein klein wenig zu konzentriert. Unter der Glocke mit s. chromsaurem Kali besaßen einige Kulturen Geschlechtsorgane; andere bildeten keine und machten dabei einen krankhaften Eindruck.

Ohne aus dem Vorhergehenden einen strengen Beweis entnelımen zu können, wird man doch eher zu der Annahme geneigt sein, dał für die specifische Rolle des Lichtes bei dem Sexualprozel3 die blauvioletten Strahlen wichtiger sind als die rotgelben, welche ihrerseits bei der indirekten Wirkung des Lichtes für die Ansammlung organischer Substanzen wesentlicher erscheinen, wenn auch die beiden Gruppen von Strahlen sich etwas in ihren Wirkungen ersetzen können. Unter normalen Verhältnissen in Wasserkulturen haben wohl beide Hälften des Spektrums ihre besondere Bedeutung, aber in allen Fällen ist es hauptsächlich die Intensität des Lichtes, welcher die Entscheidung über Dasein oler Mangel der Geschlechtsorgane zukommt, während die Art der Strahlengattung an Bedeutung zurücktritt.

Zum Schluß des Abschnittes über den Lichteinfluf will ich noch kurz das Verhalten der anderen VaucheriaArten berühren. Die Hauptresultate grelten auch für sie in gleicher Weise. Nur bei Beleuchtung bilden die Algen Geschlechtsorgane; in schwachem Lichte bleiben sie steril. Ebenso schnell wie repens bildet ornithocephala ihre Organe, sowohl in Wasser wie in Zuckerlösung, langsamer terrestris, de Baryana und die Keimlinge von clavata. Die ganzen Rasen von clavata, ebenso von geminata, racemosa lassen mit ihrer Geschlechtsthätigkeit viel länger, 
oft wochenlang, auf sich warten, was namentlich im Winter bei der relativ schwachen Lichtintensität vorkommt. Solche Rasen wachsen im Wasser sehr lange und kräftig fort, da die absterbenden Fäden und die anhängenden Erdteilchen für das Wachstum reichlich Nahrungsstoffe liefern können. Die Anwendung von Zuckerlösungen hat bei diesen Arten eine viel geringere Bedeutung, weil die Algenfäden eher dabei leiden und bei mäßiger Beleuchtung lange darin kultiviert, überhaupt steril bleiben. Bei guter Beleuchtung wirkt die Zuckerlösung dahin, daß die Organe in großer Menge, aber nicht früher erzeugt werden. Doch habe ich an einzelnen Fäden von clavata und geminata in $25 \mathrm{~cm}$ Entfernung von der AuerLampe in Zuckerlösung die Organe nach 5-6 Tagen auftreten sehen.

\section{Der EinfluB der Feuchtigkeit.}

Die Vaucheria-Arten vermögen ihre Geschlechtsorgane ebenso in feuchter Luft wie in Flüssigkeiten auszubilden. Für V. repens habe ich kaum einen Unterschied in der Zeitdauer bemerken können, während bei clavata, terrestris, geminata, racemosa die Organe sich in feuchter Luft früher und reichlicher entwickeln als im Wasser. In den Wasserkulturen dieser Algen beobachtet man stets die ersten Organe an den Fäden, die längs der Glaswände über die Wasseroberfläche hinaufgewachsen sind. Hier ist auch die Bildung sehr viel üppiger als im Wasser; dicht neben einander sitzen in großer Zahl die Geschlechtsorgane, wobei vielfache Durchwachsungen der Träger bei terrestris, geminata, die sogen. Circinalis-Formen, auftreten. Für die genannten Arten ist große Luftfeuchtigkeit gar nicht notwendig. Selbst in relativ trockener Luft ist die Ge- 
schlechtsthätigkeit sehr lebhaft, wenn nur das Substrat, auf dem der Rasen liegt, feucht gehalten wird. In Gallerten, z. B. von Kieselsäure oder von 1-8-proz. AgarAgar (S. I7), bilden $V$. repens und terrestris normal ihre Früichte aus.

\section{Der Einfluß der 'T'emperatur.}

Die Grenzen der Temperatur, innerhalb welcher die Bildung der Geschlechtsorgane erfolgt, sind die gleichen wie für die Zoosporenbildung. Zuckerkulturen von steriler V. repens, ebenso Wasserkulturen von repens, ornithocephala bilden unter $3^{0}$ im allgemeinen keine Organe. Doch kann $V$. repens sich schließlich der niederen 'Temperatur anpassen. In jenen Kulturen, welche, wie früher beschrieben (S. 43), im Eiskasten mehrere Monate einer Temperatur von $\mathrm{O}-\mathrm{I}^{0}$ ausgesetzt waren, traten schließlich doch Geschlechtsorgane auf. In den Versuchen, bei denen eine Temperatur unter $3^{\circ}$ nicht so lange andauerte, daß eine allmähliche Anpassung der Alge möglich war, entstanden die Organe bei $3-4^{0}$. Die niedere Temperatur verzögert in jedem Falle die Bildung der Organe. Dies bewiesen besonders jene Versuche, in denen ich Gläser mit steriler $V$. repens in das Aquarium hängte. Selbst in 4-proz. Rohrzucker, I-proz. Maltose dauerte es bei einer Temperatur des umgebenden Wassers von $5-6,5^{\circ}$ und mäßiger, aber an und für sich genügender Beleuchtung, 8- Io Tage bis die ersten Organe bemerkbar wurden. Viel auffälliger ist ihr spätes Auftreten in Wasserkulturen, in denen das Wachstum lebhaft vor sich geht. So zeigten Kulturen, die bei einer Temperatur von $5-6^{\circ}$ im Januar und Februar 1892 im Aquarium schwammen, erst nach einem Monat die Geschlechtsorgane, während in der ganzen Zeit leb- 
hafte Zoosporenbildung erfolgte; das gleiche war der Fall bei Kulturen in 0,2-proz. KN-Lösung. Eine höhere Temperatur, etwa von $7-24^{\circ}$, d. h. bis nahe der oberen Grenze, ist dagegen für den Geschlechtsprozeß ziemlich gleichgiltig; in Zuckerkulturen erfordert er immer die gleiche Zeit, 4-5 Tage. In Wasser und Nährsalzkulturen können vielleicht, je nachdem die Temperatur etwas höher oder niedriger ist, die Organe früher oder später erscheinen. Doch läßt sich hierbei der Einfluß der Temperatur gegenüber dem des Lichtes nicht genau abmessen.

Die obere Temperaturgrenze liegt ungefähr bei $26^{\circ}$. Für die Versuche mußte natürlich der Thermostat beleuchtet werden; die Filzdecke der Glasthüre wurde abgenommen, bei trübem Licht die äußere Glasthüre während des Tages aufgemacht. Ich ließ bei Versuchen im Winter auch zeitweilig die direkte Sonne zu dem Apparat treten, wobei dann die innere Glasthür etwas geöffnet wurde, um ein zu starkes Steigen der Temperatur zu verhindern. Aus diesen Gründen waren bei den Versuchen Temperaturschwankungen von ein bis mehreren Graden nicht ausgeschlossen. Die Grenze läßt sich aber aus einem noch viel wichtigeren Grunde nicht genau erkennen; die Sexualorgane werden nicht bei einer bestimmten Temperatur sofort unterdrückt, sondern ganz allmählich rudimentär. Wasser- und Zuckerkulturen zeigen das gleiche Verhalten; die letzteren sind nicht einmal sehr günstig, weil bei der hohen Temperatur leicht chemische V'eränderungen des Zuckers durch Hefe und Bakterien erfolgen, die der Alge schädlich sind.

Einige Versuche will ich anführen, bei denen größere Temperaturschwankungen wegen Ausschlusses des direkten Sonnenlichtes nicht stattgefunden haben: 
Nr. 1 .

V. repens I8./III. 1894 in 2-proz. Rohrzuclier- bei 25-260; bis 30./III. lösung Nr. 2.

V. repens 10./IIl. 1894 in IVasser

bei $25-26^{\circ}$; bis $30 . /$ III.

Nr. 3 .

V. repens $17 . / \mathrm{V}$. I894 in IVasser

bei $25-26^{\circ}$; bis $1 . / \mathrm{V}$. steril.

Nr. 4 .

V. clavata Keimlinge 5./IV. I894 in Wasser bei $25-26^{\circ}$; bis 23./IV. steril mit einzelnen Antheridiumanlagen.

Nr. 5 .

V. clavata 5./IV. I894 in 2-proz. Rohrzucker- bei 25-26 ; bis 23./IV. Nr. 6. lïsung wie bei $\mathrm{Nr}$. 4 . bei $25-26^{\circ} ;$ bis $4 . / V^{r} I I$. steril.

In den Versuchen Nr. 4 und 5 traten deutliche Antheridiumanlagen auf, die aber nicht zur Entwickelung kamen. In anderen Versuchen habe ich die gleiche Erfahrung gemacht; ich sah auch vielfach Oogoniumanlagen, die dann immer den Charakter vegetativer Zweiglein trugen. Noch sehr viel auffallenter zeigen sich solche Organe in verschiedenartigster rudimentärer Ausbildung, wenn man Kulturen zuerst einige Tage ler gewöhnlichen Temperatur und dann der Grenztemperatur aussetzt. Ich werde später darauf zurückkommen.

\section{Jor EinfluB der chemischen Beschaflenheit des Mediums.}

Wie auf die Zoosporenbildung, so wirken auch anf die Ceschlechtsorgane in Wasser crelijte Stoffe ein; organische Stoffe einerseits, anorganische andererseits vermiggen in entgegengesetzter Richtung den Geschlechtsprozeß zu beeinflussen. 
Wir haben schon in den früheren Abschnitten die fördernde Wirkung des Rohrzuckers auf den Geschlechtsprozeß besprochen, die besonders bei $V$. repens sehr deutlich ist, weniger bei anderen Arten. In ähnlicher Weise wie Rohrzucker wirkt Invertzucker (2 Proz.), Maltose (I-2 Proz.), Glykose (I-2 Proz.), Dulcit (I Proz.), Mannit (I Proz.). Diese Substanzen haben aber keinen Vorteil vor dem Rohrzucker voraus, sondern zersetzen sich leichter, was besonders für die drei erst genannten gilt.

Steigert man die Konzentration der Rohrzuckerlösung über 4 Proz., so beginnen allmählich hemmende Wirkungen sich geltend zu machen. Der Geschlechtsprozeß geht indessen bei höherer Konzentration vor sich als die Zoosporenbildung. Noch in 8-proz. Zuckerlösung werden normale Organe, reife Oosporen gebildet. Von da ab kommen immer häufiger unfertige Organe vor oder solche, die zur Zeit der Geschlechtsreife zu Grunde gehen. Während die Antheridien noch normal entleert werden, platzen die Oogonien zu stark, der ganze Inhalt tritt als Kugel heraus und stirbt ab. Bei Io-proz. Lösung liegt ungefähr die Grenze für die Ausbildung reifer Oosporen, während vereinzelte Anlagen in manchen Kulturen noch bei etwas höherer Konzentration auftreten können. Wie V. repens verhält sich V. clavata; dagegen bei V. ornithocephala sah ich bereits in 6-proz. Lösung keine reifen Oosporen, selbst keine rechten Anlagen melır, da meistens Plasmolyse eintrat. Als Merkwürdigkeit will ich erwähnen, daß bei einer Kultur von V. repens in 8-proz. Rohrzuckerlösung, in der zahlreiche Antheridiumanlagen sich entwickelt hatten, diese nach der Ueberführung in Wasser und nach Verdunkelung an ihren Enden in Zoosporangien sich umwandelten.

Die anorganischen Nährsalze fördern das Wachstum und verzögen die Geschlechtsbildung (s. S. 99). Das 
tritt schon bei KN-Lösungen von $\mathrm{O}, \mathrm{I}-\mathrm{O}, 5$ Proz. hervor; bei höherer Konzentration kommen noch specifisch hemmende Wirkungen in Betracht. In I-proz. Lösung bilden bei heller Beleuchtung die Fädlen von $V$. repens erst nach 3 Wochen die Oruane, von denen eine Anzalıl zu Grunde geht oder anormal gestaltet ist; bei mehreren Versuchen mit jungen Keimlingen habe ich selbst nach $2-3$ Monaten nur sterile Fäden gesehen. In I,5-2-proz. Lösung bleiben alle Fäden steril.

Nimmt man statt der Nährlösung einzelne Salze wie Salpeter, Kochsalz, so fällt die das Wachstum fördernde II'irkung fort. Im Gegenteil, solche Salze hemmen eher das Wachstum und fördern dadurch indirekt die Geschlechtsbildung, während sie diese andererseits schon bei geringer Konzentration durch ihre specifischen Eigenschaften störend beeinflussen. So treten in einer o,I-proz. Salpeterlösung die Geschlechtsorgane bereits nach 4 Tagen auf; aber die äußerst zahlreich erscheinenden Organe sind anormal, so daß nur eine kleine Anzahl befruchteter Oosporen zur Ausbildung kommt, während die Mehrzahl kurz vor der Geschlechtsreife zu Grunde geht. Noch mehr gilt das für eine Lösung von 0,2 Proz., während ich in 0,3 Proz. überhaupt keine Anlagen der Oruane bemerkt habe.

In einer 0,2-proz. Chlornatriumlösung traten die Geschlechtsorgane nach 6-7 Tagen auf, und es bildeten sich reife Oosporen in Menge aus. Mit steigender Konzentration machten sich dic störenden Einflüsse der Salzlösung hemerkbar. In 0,3 Proz. sah ich noch einzelne reife Oosporen neben vielen anormalen ()rganen, dagegen nicht melır in 0,4 Proz. Merkwürdigerweise entstanden aber die Anlagen beider Geschlechter noch in 0,5, 0,6, 0,7 Proz.; in der letzteren lösung war ihre Bildung äußerst lebhaft, olwohl kein einziges Antheridium noch Oogonium reif 
wurde. Selbst in I-proz. Chlornatriumlösung sah ich schwach angedeutete Oogonien neben anormal verlängerten und schraubig gekrümmten Antheridiumanlagen. Für diesen Versuch ließ ich die Alge zuerst einige Tage in 0,5 Proz. und brachte sie dann erst in I-proz. Lösung. Vergleicht man die hemmenden Konzentrationen von Rohrzucker, Salpeter, Chlornatrium, so ergiebt sich auch für den Geschlechtsprozeß die gleiche Thatsache, wie für die Zoosporenbildung, daß die wasseranziehenden Eigenschaften die Hemmung nicht erklären, sondern daß specifische chemische Eigenschaften der einzelnen Salze dabei eine Rolle spielen. Eine Zuckerlösung von ı Proz. ist etwa isotonisch einer Salpeterlösung von 2 Proz.; die Geschlechtsthätigkeit wird aber bereits durch eine Salpeterlösung von 0,3 Proz. völlig gehemmt. Diese Lösung ist ihrerseits isotonisch mit einer Chlornatriumlösung von O,I7 Proz.; dagegen bilden sich noch in einer solchen von o,3 Proz. normale Oosporen aus, und Anlagen der Organe lassen sich sogar noch in I Proz. Chlornatrium beobachten.

\section{Der Einfluß des Sanerstofís.}

Aus den Versuchen, bei denen V. repens in Zuckerlösung in einem kleinen abgeschlossenen Luftvolumen lebhaft Geschlechtsorgane gebildet hatte (S. IO6), folgt ohne weiteres, daß der Prozeß relativ wenig Sauerstoff erfordert. $\mathrm{Ob}$ eine Verminderung des Sauerstoffgehaltes für die Geschlechtsbildung förderlich sei, ließ sich daraus nicht nachweisen. In ausgekochter Zuckerlösung in einem verschlossenen Gefäß traten die Organe nicht früher, aber auch nicht später als unter normalen Verhältnissen auf. lmmerhin mußte die Frage beantwortet werden, welches die untere Grenze des Partiärdruckes des Sauerstoffs für den Geschlechtsprozeß sei. Die Versuche wurden in 
dersellen Weise wie auf S. 77 leschrielen wurde, angestellt; nur mufte der Apparat leuchtet werlen. Da infolgedessen Assimilation stattfand, so 1)licben fortwährende kleine Veränderungen in der Zusammensetzung der Luft nicht ansgeschlossen. Das Manometer yab daher nur ungrefähr den luftdruck an. Indessen verschwinden diese Schwankungen gegrenüber dem sehr verschiedenen Verhalten der einzelnen, anscheinend gleich behandelten Kulturen. Einige Versuche will ich ausführlicher angeben; sie sind alle mit $V$. repens angestellt.

Nr. I. 27. XII. I $8($ )2 Luftdruck $3 \mathrm{~mm}$, Temperatur IO-I4". Die Alge befand sich in O,I-proz. KN-Lijsung; sie wurde am I.I., 4./I., Io./I. I 893 untersucht; jedesmal wurde der Apparat lis zum angegebenen Stande des Manometers wieder ausgepumpt. Vom I0.--27./I. blieb der Apparat unberührt. In der ersten Zeit ließ sich ein deutliches Wachstum beobachten; bis zum 27.1. waren die Fäden völlig steril. Frei ans Fenster gestellt, blieben sie steril his zum I8./II, von wo ab die Kultur allmählich zu Grunde gring.

Nr. 2. 24./XIl. I893 Luftdruck 3 mm, Temperatur IO- I $4^{0}$.

a) Fäden in auscekochtem destilliertem IVasser.

b) Keimlinge in auscrekochtem destilliertem Wasser.

c) Keimlinge in 2-proz. KN-Lisung.

Am I 4./ $\mathrm{I}^{\top}$. I $89+$ wurde der Versuch unterbrochen. Alle Kulturen waren völlig steril, dabei noch lebend; dic Fäden waren spärlich verzweigrt. Dic Keimlingre von Kultur l, hatten ilue Membran verlickt und waren augenscheinlich wenig scwachsen.

Nr. 3. IO. V. I893 Luftrluck ; mm bei I4- I $7^{\circ}$. 2 Kulturen in Wasier his 20./V. I803 lelsend und steril. am 20./V. frei ans Fienster gestellt; am 2. VI. in leirlen Kulturen normale Geschlechtsorgane. 
Nr. 4. 18./1X. I 893 Luftdruck $20 \mathrm{~mm}$ bei $13-16^{0}$

a) in 2-proz. Rohrzuckerlösung b) in Wasser.

Beide Kulturen waren bis zum 28./IX. I893 im Apparat steril geblieben und sahen kränklich aus. An diesem Tage frei ans Fenster gestellt, bildeten beide am 7./X. eine Menge Geschlechtsorgane.

Nr. 5. I4./X. I893 Luftdruck $77 \mathrm{~mm}$ bei $13-\mathrm{I}^{0}$
a) in 2-proz. Rohrzucker;
c) in I-proz. Rohrzucker;
b) ",
d) in Wasser.

Die Kultur a war bis zum I8.|X. steril und bildete, frei ans Fenster gestellt, am 2I.|X. zahlreiche normale Organe. Die übrigen Kulturen wurden wieder vom I8.-28./X. einem Luftdruck von $77 \mathrm{~mm}$ ausgesetzt. In b, c und d fanden sich Antheridiumanlagen, aber noch keine Oogonien vor. Vom 28./X. bis zum 2./XI. betrug der luttdruck $76 \mathrm{~mm}$. Das Resultat war nicht verändert; man sah nur Antheridien. Am 2./XI. wurde die Kultur b frei gestellt; sie erzeugte reife Oosporen neben anormalen Geschlechtsorganen.

Nr. 6. 28.|X. I 893 Luftdruck $76 \mathrm{~mm}$ bei $10-14^{0}$ in I-proz. Rohrzuckerlösung; sie war bis 2./XI. steril.

Diese Kultur wurde vom 2.-II./XI. einem Drucke von $90 \mathrm{~mm}$ ausgesetzt; sie blieb steril.

Nr. 7. 2./XI. I 893 Luftdruck $90 \mathrm{~mm}$ bei $10-\mathrm{I} 4^{0}$ in Wasser; sie war bis II./XI. steril.

Am II./XI. wurde die Kultur einem Luftdruck von $95 \mathrm{~mm}$ ausgesetzt; am I9./XI., als der Versuch unterbrochen wurde, fanden sich einzelne Antheridiumanlagen vor.

Nr. 8. I./III. I 894 Luftdruck II 8 min bei I2-I $6^{0}$

a) in I-proz. Rohrzuckerlösung; b) in Wasser.

In Kultur a fanden sich am Io./III. einzelne Antheridium- und Oogoniumanlagen; Kultur b bis zum 30./III. 
im Apparat (luftdruck I $8 \mathrm{~mm}$ ) war steril, abgesehen von zweifelhaften Antheridiumanlagen.

Nr. 9. IO./III. I894 Luftdruck il $8 \mathrm{~mm}$ bei I2-I6" in $\mathrm{N}$ asser.

Die Kultur war bis 20./III. steril; vom 20.-30./III. betrug der Luftdruck eloenfalls is mm. Am 30.1II. beobachtete ich einige normale Antheridien, ein normales Oogonium neben anormalen.

Nr. IO. 20./III. IS94 Luftdruck I24 $\mathrm{mm}$ bei I2-I6" in Wasser.

Am 30./II. wurde die steril gebliebene Kultur 48 stunden frei ans Fenster gestellt; am I.-IO./IV. einem Luftrlruck von $124 \mathrm{~mm}$ ausgesetzt. Am IO./IV. fanden sich befruchtete Oosporen neben anormalen Geschlechtsorganen vor.

Die Versuche zeigen, daß für die Anlagre, noch mehr für die Ausbildung der Geschlechtsorgane ein viel höherer Partiärdruck des Sauerstoffs notwendig ist, als für clie Zoosporenbildung. Normale Geschlechtsormane sah ich erst bei einem Luftlruck von II $8 \mathrm{~mm}$; bei etwa 80 mm begramnen Anlagen sich zu zeigen, in Zuckerlösung etwas frïher und reichlicher als in WVasser. Ueber die Bedeutung des Sauerstoffs für den Geschlechtsprozeß läßs sich ans den Versuchen nichts entnehmen. 1)ieser ist schon selır verwickelt und läuft jedenfalls in einer liette verschiedenartiger Voræänge al, für die der Sallerstoff bald mehr, bald weniger notwoudigr sein kann. Für Wasserkulturen spielt wohl auch die Vermindermug der Assimilation bei niederem laftdruck eine Rolle. Das verschiedene Verhalten der männlichen und weiblichen Oruane gegenüber nicderem luftrlruck werde ich im schluskapitel besperchens. 


\section{Der Einfluß des strömenden Wassers.}

Eine große Anzahl Vaucheria-Arten kommt, wie schon erwähnt wurde, in fließendem Wasser vor. Ein sehr merkwürdiges Verhalten dieser Algen läßt sich dabei beobachten. Die Vaucherien sind immer geschlechtlich steril. In der Litteratur findet sich über diese Erscheinung kaum eine Andeutung, da die Algologen sich nie gerne mit sterilen Pflanzen beschäftigt haben, und doch haben wir es hier mit einer sehr interessanten Thatsache zu thun. Fast alle Vaucheria-Arten in der Umgebung Basels können in den fließenden Gewässern vorkommen; einige aber sind ganz besonders häufig und charakteristisch, vor allem V. clavata und geminata. Die letztere Art findet sich bei Basel äußerst verbreitet, in kleinen Rinnsalen, Bächen, kleineren Flüssen, in Brunnen und Quellen im Jura wie im Schwarzwald. Niemals habe ich bei V. clavata und geminata an solchen Standorten Geschlechtsorgane beobachtet, und dabei habe ich immer die gleichen Standorte im Laufe der letzten Jahre zu den verschiedensten Zeiten untersucht. Da V. clavata nur in fließendem Wasser vorkommt, so habe ich die Organe nur bei Kulturen sehen können; auch unter den zahlreichen Abbildungen der Sammelspecies V. sessilis sind meines Wissens keine Organe der V. clavata zu finden, sondern nur von repens und sessilis. Bei der Annahme der Identität von V. clavata mit orthocarpa würde Reinsch (87) der erste gewesen sein, der ihre Sexualorgane beschrieben hat. V. geminata kommt gar nicht selten auf feuchtem Boden vor und fruktifiziert dann sehr reichlich. Der hemmende Einfluß des strömenden Wassers läßt sich in der freien Natur gerade bei dieser Art gut beobachten. An kleinen 
Wasserfällen im Basler Jura findet man die dichten dunkelgrimen Rasen völlig steril, dort wo sie vom Wasser ülerspült werden. In kleinen Höhlungen am Rande, wo das Wasser nur zeitweilig oder gar nicht hinkommt, fruktifiziert die Alge dagegen reichlich.

Weniger häufig, aber stets steril beobachtete ich in den Bächen und Brumnen V. repens, sessilis, de Baryana, racemosa, aversa. Nur eine einzige Ausnahme ist mir bis jetzt bekannt geworden, es ist V. ornithocephala, die allem Anschein nach am längsten und vollständigsten dem Leben in strömendem Wasser angepaßt ist und darin wie andere Algen des gleichen Standorts, z. B. Ulothrix, Lemanea, Batrachospermum, sich geschlechtlich fortpflanzen kann. Allerdings in der Mehrzahl der Fälle sind die weichen, schön sattgrünen Polster von V. ornithocephala steril, auch im Juni und Juli wie z. B. an dem Wehr der Birs bei Basel. Doch als im Frühjahr I894 die Algre in der Wiese bei Lörrach sich in ganz gewaltiger Menge entwickelte, meist am Boden des Flusses, sah ich an losgerissenen Rasen, die am Rande des Wassers zwischen Wasserptlanzen schwammen, viele Geschlechtsorgane. Es ist sehr wohl möglich, daß die Alge sich gerade an Stellen mit sehr schwacher Strömung befand. Die anderen Arten würden aber auch unter diesen Umständen nicht fruktifiziert haben.

Der hemmende Einfluß des strömenden Wassers ließ sich auch durch das Experiment nachweisen, wenn die Versuche auch nicht sehr lange ausgedehnt werden konnten; immerhin ergänzen sie die Experimente, die im groben durch die Natur selbst angestellt werden. Für die Versuche benutzte ich das kleine Aquarium und den Brunnen in meinem Garten. Im ersteren wurden die Rasen durch einen Stein beschwert und in die Nähe des eintretenden Wasserstrahles aebracht. Für den Brumen brachte ich 
die Vaucheria in eine kleine Glocke mit offenem Tubus; beide Oeffnungen wurden mit grobdurchlöchertem Stoff verschlossen und die Glocke in den Brunnen in die Nähe des Wasserstrahles gehängt. Die länger andauernden Versuche sind besonders mit Rasen von V. geminata gemacht worden; ich will die folgenden erwähnen:

Nr. I. V. geminata im Aquarium vom I9./III. I892 bis 20./VI. I892; die Temperatur stieg langsam während der Zeit von $6^{0}$ auf $14,5^{\circ}$; die Alge blieb bis zu dem Termin, wo der Versuch unterbrochen wurde, steril. Von dem Rasen nahm ich in der Zwischenzeit kleine Proben und kultivierte sie außerhalb des Aquariums:

a) am I9./III. in Wasser; àm 24./III. Geschlechtsorgane;

b) am 4./V. in feuchter Luft; am IO./V. Geschlechtsorgane;

c) am 9./VI. in feucliter Luft; am I8./VI. Geschlechtsorgane.

Nr. 2. V. geminata, seit I3./III. I89I im Brunnen innerhalb einer Glocke bis 8./VI; die Temperatur stieg allmählich von $6^{0}$ auf $14^{\circ}$; die Alge war noch steril als der Versuch unterbrochen wurde.

Auch V. clavata habe ich lange im Aquarium steril erhalten. Am leichtesten und schnellsten bildet, wie früher geschildert wurde, V. repens ihre Geschlechtsorgane. Der sehr stark hemmende Einfluß des fließenden Wassers läßt sich aber auch an ihr zeigen. So habe ich im Frühling I89I wie I 894 schöne üppige, dabei sterile Kulturen im laufenden Brunnen erhalten, z. B. vom 6./III. I894 bis I./V. IS94 (Temperatur 5-II ${ }^{0}$ ). Die Fäden bildeten auf dem Stoff am oberen Ende der Glocke einen dichten Rasen, der den Wasserzufluß zu den in der Glocke lebenden Fäden abhielt. An solchen traten später Geschlechtsorgane auf. 
Wenn man sich nun fragt, welche Eigenschaft des strömenden Wassers seine hemmende Wirkung bedingt, so läßt sich nach memen bisherigen Erfahrungen nur sagren, daß keine der früher (S. 82) angegebenen Eigenschaften für sich allein genügt, die Sterilität zu erklären. Es liommen die mechanische Bewegung, die Temperatur und die chemische Beschaffenheit des Wassers in Betracht. Die Beleuchtung spielt keine Rolle, weil sie in allen Fällen in der freien Natur wie bei den Versuchen ausreichend ist. Ferner weisen die Versuche im Aquarium darauf hin, dafs die mechanische Bewegung bei der Hemmung der Geschlechtsthätigkeit bedeutungslos ist. Denn bei der Einrichtung des Aquariums ist die Bewegung ganz unhedeutend; selbst die Rasen von geminata, die weiter von dem Strahl entfernt wuchsen, blieben gleichfalls steril. Auch in den Brunnentrögen findet man weit ab vom Strahl die Vaucherien steril.

Die gleichmäßige und niedere Temperatur kann ebensowenigr die Sterilität allein erklären. Die Temperatur der fließenden Gewässer ist, abgesehen vielleicht vom Februar, stets über $3^{0}$, d. 1. eine solche, die zur Bildung der Geschlechtsorgane ausreicht. Die Erfahrungen mit $V$. geminata im Brunnen wie im Aquarium lassen erkennen, daß sogar eine Temperatur ïlber Io" die Sterilität nicht aufhelst. Ueberdies habe ich oft den Versuch gemacht die Vaucherien in zugrekorktem Gefäß in den Brunnen ofler das Aquarium zu hängren. Die Geschlechtsthätigkeit wurde verzügrert, aber nicht unterdrüclit.

Die chemische Beschaffenheit des strömenden Wassers, der reiche Giehalt an Salzen, Kohlensïure und Sanerstoff kann auch nicht die L'rsache der Sterilität sein. Denn die Algen bilden auf nährsilzreichen Substrat in fenchter Luft, die ihnen siamerstoff und Kohlensäure reichlich zuführt, lebhaft Geschlechtsorgane. 
Nur das Zusammenwirken von relativ niederer Temperatur, stets sich erneuernder Zufuhr von Sauerstoft, Kohlensäure und Nährsalzen, vielleicht auch unter Mitwirkung der mechanischen Bewegung, erklärt die Sterilität. Besonders die zuerst genannten Faktoren, vor allem Sauerstoff und Nährsalze, veranlassen ein ununterbrochenes lebhaftes Wachstum, während die geschlechtliche Fortpflanzung, die wegen des starken Verbrauches organischer Substanzen notwendig eine Hemmung oder Verringerung des Wachstums verlangt, nicht zur Entfaltung kommen kann. Hier bei Vaucheria haben wir einen der wenigen Fälle, wo wir in dem Antagonismus von Wachstum und sexueller Fortpflanzung erkennen können, welcher Funktion die entscheidende Bedeutung zukommt. Die Vaucherien wachsen in dem strömenden Wasser beständig und bilden deshalb keine Geschlechtsorgane; man kann nicht sagen, die Bildung dieser werde gehemmt, und deshalb wachsen die Vaucherien. Viel eher gilt dieses für jene Sterilität, die durch schwaches Licht oder zu konzentrierte Nährlösungen veranlaßt wird. Hierbei ist die Hemmung der geschlechtlichen Fortpflanzung das entscheidende Moment, und die Folge davon ist, daß die Algen nur Wachstum zeigen.

\section{\%. Ueber das Verhältnis des månnlichen und weibliehen Greschlechtes.}

Bei den von mir untersuchten Vaucheria-Arten werden die männlichen und weiblichen Organe dicht bei einander gebildet. Sie sitzen neben einander bei V. repens, clavata, aversa, ornithocephala, sie sitzen auf gemeinsamen Träger bei terrestris, geminata, de Baryana, racemosa, hamata. Im allgemeinen wird das Antheridium stets zuerst angelegt; bei repens zeigt es sich als ge- 
krümmntes Hörnchen, wenn das Oogonium noch ein kleiner Höcker ist. Die außerordentliche Regelmäßinkkeit in (ler Anordnung der beiden Organe ließ es anfänglich aussichtslos erscheinen, durch äuß̉ere Einflüsie das Verhältnis irgendwie zu ändern. (ielegentliche Beobachtungen fülıten aber doch dazu, len Versuch einer Aenderung zu machen. Als Material diente mir ausschließlich $V$. repens.

$V$. repens bildet für gewölnnlich ein Oogonium neben einem Antheridium, seltener ein Antheridium zwischen zwei Oogonien. Um eine Vorstellung von dem Verhältnis der einweiblichen und zweiweiblichen Gruppen zu geben, will ich einige Zahlen mitteilen.

V. repens, seit 23./XI. I893 in 0,2-proz. KN-Lösung, wurde am 6./I. I894 untersucht. Die Fäden wurden nach einander auf den Objektträger gelegt; bei schwacher Vergrößßerung zählte ich dann die Geschlechtssgruppen. Ich beol achtete Iooo einweibliche, Io zweiweibliche Gruppen und 4, bei denen I Oogonium und daneben 2 Antheridien saßen.

In einer Wasserkultur von repens seit 17./X. I893 beobachtete ich am 6.I. I894 908 einweibliche, 27 zweiweibliche Cruppen.

In Rohrzuckerlösungren finden sich etwas häufiger die zweiweiblichen Gruppen. So beobachtete ich in 2-proz. Zucker (seit I9./IX. I894) an 8. X. auf 63 einweibliche 8 zweiweibliche und 7 Gruppen mit I Oogonium und 2 Antheridien. Noch auffallendere Unregelmäßigkeiten zeigten sich in einimen Kulturen von $2-$ proz. Invertzuclier, so dałs ich die Ueberzeugung gewann, daß äußere Finflüsse das Verhältnis der Geschlechter ändern künnen. Nach mancherlei Versuchen erkannte ich, daß auf zweierlei Weise mit großer Sicherheit solche Aenderungen zu erlangen sind, I) durch höhere 'Temperatur, 2) durch Luftverdünnungr. 
Schon aus den früheren Angaben über die Einwirkungen dieser beiden Faktoren ergab sich, daß in der Nähe ihrer Grenzen für den Geschlechtsprozeß Unregelmäßigkeiten bei der Bildung der Organe sich bemerken lassen. Für die vorliegende Aufgabe muß man die Versuche in folgender Weise einrichten. Man kultiviert die sterile Vaucheria in 2-proz. Rohrzuckerlösung bei heller Beleuchtung; nach 2-3 Tagen bringt man, bevor die ersten Geschlechtsorgane erscheinen, die Kultur in den Thermo-
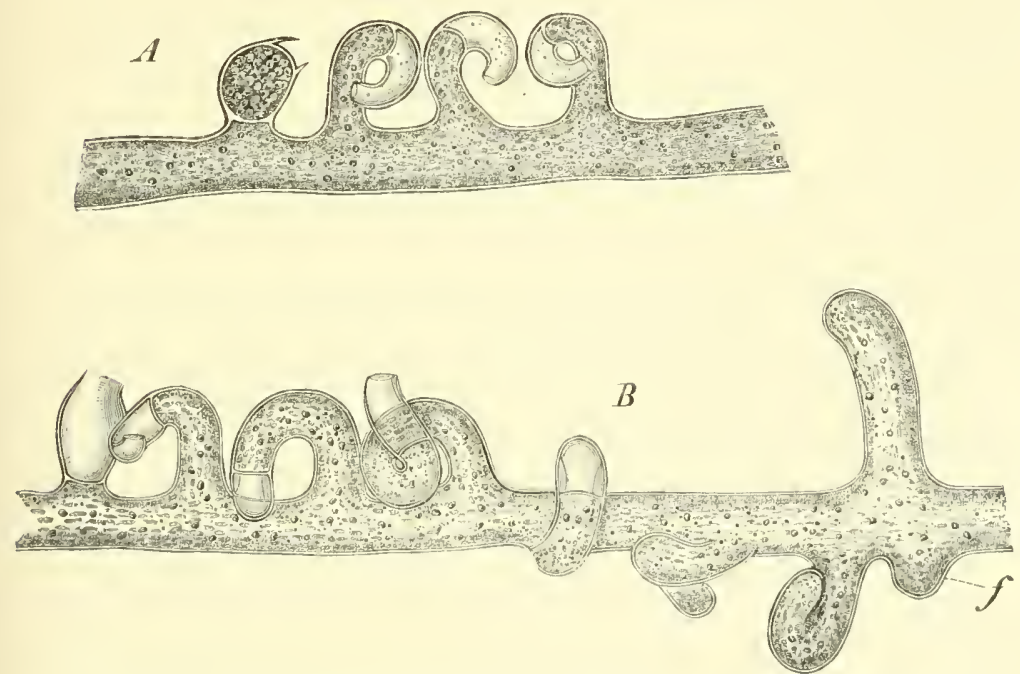

Fig. 3. Vaucheria repens. A Oogonium mit 3 normalen Antheridien. $B$ Oogonium mit 4 entleerten normalen und 3 unreifen Antheridien; das achte $f$ ist ganz unentwickelt. Vergr. I2O.

staten bei $25-26^{\circ}$ oder inter die Luftpumpenglocke bei einem Druck von IOO-I30 mm. In beiden Fällen muß für genügende Beleuchtung gesorgt werden. Nach einigen Tagen bemerkt man bereits Geschlechtsorgane in verschiedenartiger Gestaltung und Anordnung. 
Bei der folgenden Besclureibung der Versuche verstehe ich unter Antheridiumanlage stets das ganze Hörnchen, (l. h. den Träger mit dem Ende, das bei dem reifen Organ als fertile Zelle algetrennt ist. In wie weit bei den anscheinend normalen Antheridien die Spermatozoen völlig normal ausgebildet waren, lasse ich dahinyestellt.

Zwei Versuche werde ich ausführlich behandeln.

Nr. I. V. repens, I8./III. I894 in 2-proz. Zucker, hell am 20./III. bei einem Luftdruck von I24 1mm; die Temperatur schwankte zwischen $12-16^{\circ}$. Am 30./III. fanden sich folgende Formen der Geschlechtsorgane:

a) I5 Fälle: I Oogonium, I Antheridium. Die Oowonien normal gebildet, meist geplatzt. Die Antherilien normal oder nur durch stärkere schraubige Drehung ausgezeichnet.

b) 2 Fälle: 2 Oogonien, I Antheridium.

c) 30 Fälle: I Oogonium, 2 Antheridien. Einige ()ogonien waren befruchtet, die Melırzahl geplatzt. Die Antheridien waren meist normal; nicht selten (I 2 mal unter 30) saf, das eine Antheridium an der Basis des anderen.

d) 6 Fälle: 2 Oogonien, 2 Antheridien. Die normalen Antheridien befanden sich in der Mitte zwischen den ()ogonien.

e) 2 Fälle: 2 Oogonien, zwischen ihnen 3 Antheridien.

f) I Fall: 2 Oogonien, dazwischen 4 Antheridien.

g) 8 Fälle: I Oogonium, 3 Antheridien (Fig. 3 A). l)as ()ogronium normal oder unentwickelt; die Antheridien normal.

h) 2 Fälle: I Oogonium, 4 Antheridien. Die Antheridien stark schraubig gedreht, teils normal, teils nocl unentwickelt, ohne abgetrennte Endzelle. 
i) 30 Fälle: je I Antheridium ohne Oogonium. Die einzeln stehenden Antheridien fanden sich in verschiedenster Ausbildung vor; einige wie kleine, kaum gekrümmte vegetative $Z$ weiglein, andere verlängert und zweimal schraubig gedreht, dazwischen alle möglichen Uebergänge. Eine fertile Endzelle war sehr selten abgetrennt, aber beinahe immer durch das fast farblose und feinkörnige Aussehen des Inhaltes angedeutet.

k) 8 Fälle: 2 Antheridien nebeneinander. Ich sah darunter normale, daneben solche wie bei i.

1) 3 Fälle: 3 Antheridien. In einem Falle waren alle normal.

m) 2 Fälle: 4 Antheridien. In einem Falle alle normal.

n) I Fall: 5 Antheridien. Die Form war normal, die Endzelle noch nicht abgetrennt.

Nr. 2. V. repens seit I8./III. I894 in 2-proz. Zucker hell; am 2I./III. in dem Thermostat hell bei $25-26^{\circ}$. Am 3I./III. untersuchte ich die Kultur. Ich fand kein einziges normales Oogonium, sondern nur vereinzelte Anlagen, die ungefähr die Form davon hatten, aber durch keine Zellwand abgetrennt waren und ihrem Inhalt nach wie vegetative Zweige aussahen. Ich beobachtete folgendes:

a) 50 Fälle: je I Antheridium. Diese verhielten sich wie bei Nr. I i, nur daß sie durchschnittlich stark verlängert waren.

b) 9 Fälle: I Oogoniumhöcker, I Antheridium. In 5 Fällen war das Antheridium normal, in 4 unentwickelt.

c) 8 Fälle: 2 Antheridien. Diese ohne fertile Endzelle.

d) 5 Fälle: 3 Antheridien. Diese stark schraubig gedreht, ohne Endzelle.

e) I Fall: 4 Antheridien. Wie bei d. 
f) 8 Fälle: I Oogoniumhöcker, 2 Antheridien. Das eine Antheridium einer solchen Gruppe war meist normal, das andere unentwickelt, doch in 2 Fällen waren beide Antheridien normal.

g) I Fall: I Oogoniumhöcker, 3 Antheridien. Diese waren verlängert, ohne Endzelle.

Ganz ähnliche Erscheinungen fand ich in allen Kulturen, die in der gleichen Weise behandelt worden waren.

Die Wirkung der verdünnten Luft macht sich auch damn bemerkbar, wenn die Algen, nachdem sie einige Zeit bei sehr niederem Druck, z. B. 3-5 mm, gestanden haben, in gewöhnlicher Luft weiter kultiviert werden.

Alle diese Versuche zeigen klar, daß höhere Temperatur, sowie niederer Luftdruck dahin wirken, daß das weibliche Organ früher vegetativ oder früher unterdrückt wird als das männliche, vor allem aber, daß eine Ueberproduktion der männlichen Organe veranlaßt wird. Statt eines Antheridiums finden wir häufig 2, 3, 4, die dabei röllig normal ausgebildet sein können; bei einem Faden sah ich sogar 7 , dicht neben einander stehende Antheridien (S. I27 Fig. 3B). Auf Grund dieser Thatsachen habe ich bereits in meiner Rede (o+ S. I8) ausgesprochen, dats es gelinge, die zwitterigen Fäden ron Vaucheria in rein männliche umzuwandeln. Hierbei ist nur die Einschränkung zu machen, daß in der Mehrzahl der Fälle, wo einzeln stehende Antheridien erzeugt wurden, diese nicht zur völligen Reife gelangten. Häufiger erfolgte die Reife, wenn das Oogonium als Höcker oder vegetative Zelle noch angedeutet war, oder wenn dieses durch ein Antheridium gleichsam ersetzt war.

Die specifische Bedeutung der höheren Temperatur und des niederen Luftdruckes für die Ueberprodulition der Antheridien geht auch besonders daraus hervor, daß andere äußere Einflüsse den Geschlechtsapparat nicht in 
der gleichen Weise verändern, wenn sie sich der Grenze ihrer Wirkungen auf ihn nähern. Gegenüber dem Licht, dem wichtigsten dieser Einflüsse, ebenso auch gegenüber einer konzentrierten Nährlösung von I Proz., in der die Geschlechtsthätigkeit mancher Kulturen ihre Grenze findet, beobachtet man nicht die reichliche Erzeugung des männlichen Geschlechtes. Die Einwirkung des schwachen Lichtes ließ sich besonders bei den Versuchen mit künstlichen Lichtquellen verfolgen. Die Oogonien werden schon vegetativ, während die Antheridien noch normal sind; bei weiterer Schwächung werden manche Antheridien zu unregelmäßig gekrümmten Zweiglein, die ihre Geschlechtsnatur noch daraus erkennen lassen, daß ihr Längenwachstum früh beendet ist, während andere weiter wachsen und dann nicht mehr von gewöhnlichen Zweigen zu unterscheiden sind. Die Oogoniumanlagen wachsen. in der Mehrzahl der Fälle nicht weiter, selbst nicht wenn wieder helle Beleuchtung Zutritt hat; bei einigen sah ich indessen ein Auswachsen in ähnlicher Weise, wie es Hick (90) bei V. hamata beschrieben hat. Auch bei Keimlingen, die einen Monat hell in I-proz. KN-Lösung sich befanden, sah ich keine oder nur als Höcker hervortretende Oogonien, dagegen einzelne Antheridiumanlagen, die zu unregelmäßig gelsrümmten Zweiglein umgewandelt waren. In allen diesen Fällen erfolgte keine Mehrproduktion weder von normalen noch von anormalen Antheridien.

$\mathrm{Nie}$ ist es mir bisher gelungen, die Antheridien zu unterdrücken und allein die Oogonien zu erhalten, ebensowenig eine Mehrproduktion der letzteren zu veranlassen, abgesehen von der schon kurz erwähnten Thatsache, daß bei V. repens in Zuckerlösung etwas häufiger zwei Oogonien statt eines auftraten. Bei V. ornithocephala beobachtete ich nur so viel, daß bei $25 \mathrm{~cm}$ Entfernung 
von der Auer-Lampe in 2-proz. Rohrzuckerlösung wie gewöhnlich neben einem Antheridium 4-5 Oogonien saßen, während in $50 \mathrm{~cm}$ Entfernung daneben stets nur ein Oogonium ausgrebildet wurde.

Eine parthenogenetische Entwickelung der Eizelle, d. h. die Bildung einer wirklichen Oospore ohne Befruchtung, habe ich bisher nicht beobachten können.

Die Ursachen, welche der Entstehung des männlichen und weiblichen Geschlechtes zu Grunde liegen, sind bei Vaucheria, wie bei allen anderen Organismen in tiefstes Geheimnis gehüllt. Meine Erfahrungen lehren für Vaucheria nur, daß gegenüber den gleichen äußeren Bedingungen die beiden Geschlechter sich verschieden verhalten und daß infolgedessen das weibliche Geschlecht gehemmt oder unterdrückt, das männliche zu außergewöhnlicher Entfaltung gebracht werden kann. 


\section{Hydrodictyon utriculatum Roth.}

(Holzschnitt Fig. 4.)

Das Wassernetz war das erste Beispiel unter den Algen, an welchem ich nachwies, daß die Fortpflanzung von äußeren Bedingungen abhängig ist und daß ein regelmäßiger, notwendiger Wechsel von ungeschlechtlicher und geschlechtlicher Fortpflanzung nicht stattfindet. Aus den vielen Beobachtungen der Jahre I888 und I889 habe ich für meine Arbeit von I890 nur das herausgegriffen, was in engerer Beziehung zu der Frage über den Generationswechsel stand. An dieser Stelle möchte ich das Hauptgewicht auf die Frage nach den physiologischen Bedingungen der Fortpflanzung legen, nachdem ich im Sommer 1895 die Untersuchung von neuem aufgenommen und erweitert habe.

Hydrodictyon erscheint in Form langer, schlauchförmiger, geschlossener Netze, deren cylindrische Zellen zu drei oder vier an den Enden zusammenhängen und fünf- oder sechseckige leere Maschen bilden (Fig. $4 A$ ). Jede der Zellen ist im Stande, sich entweder ungeschlechtlich oder geschlechtlich fortzupflanzen. Die einzelne Zelle, von sehr verschiedener Länge, je nach dem Alter und dem Wachstum der Netze, im Maximum bis zu 8-1o mm lang, besitzt eine derbe Zellhaut, einen dünnen Wand- 

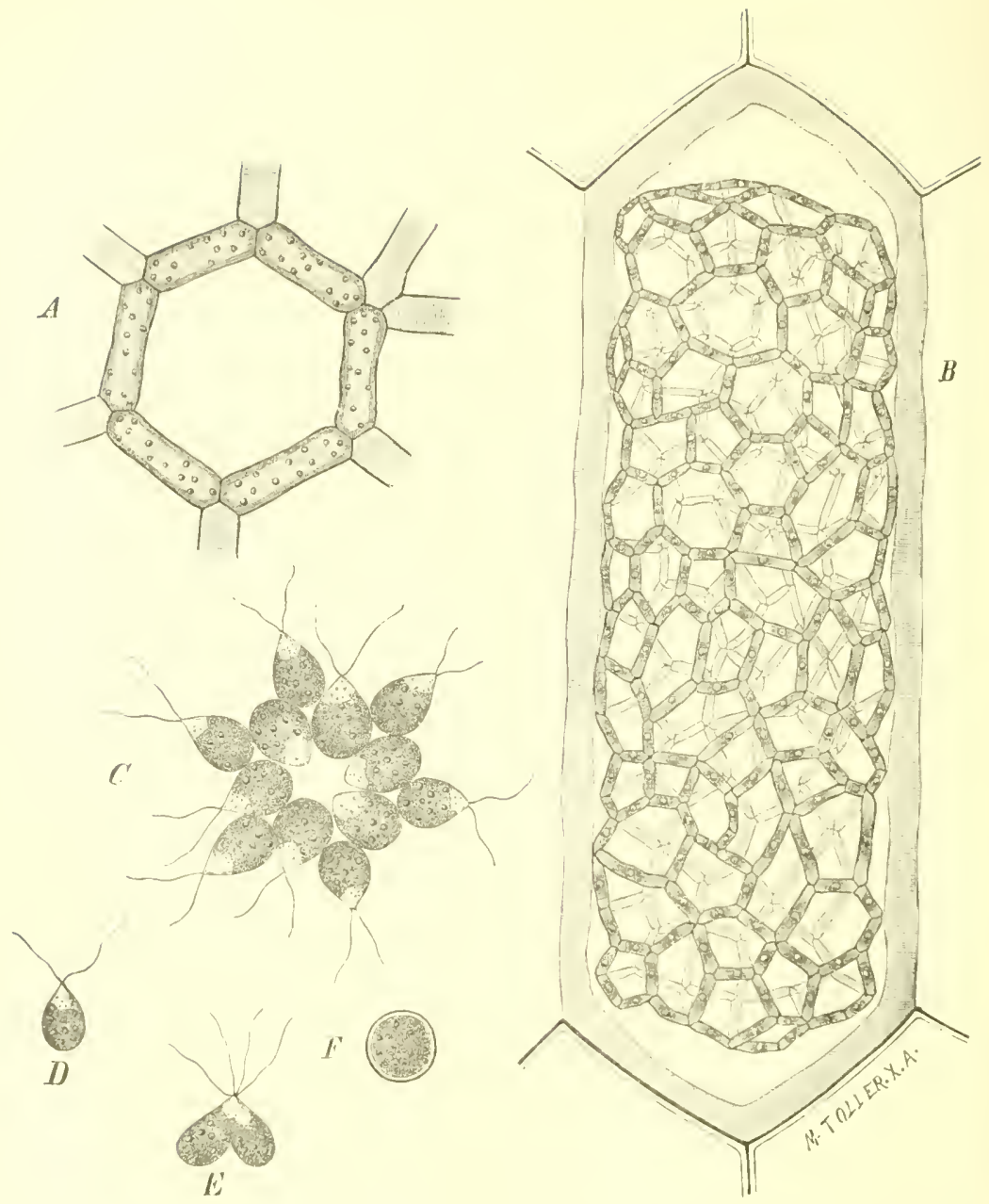

Fig. 4. Hydrodictyon utriculatum. A ein Stück eines Netzes; $B$ eine Zelle mit einem eben gebildeten Netz innerhalb der stark aufgequollenen Zellwand; $C$ eine Anzahl Zoosporen mit einander verbunden (in dieser Gruppierung sich auch bewegend), die drei nach der Mitte gerichteten Zoosporen der Deutlichkeit wegen ohne Cilien gezeichnet; $D$ eine einzelne Gamete; $E$ Kopulation zweier Gameten; $F$ eine Zygote. Vergr. von $A$ und $B$ I20, $C-E$ 1000. 
beleg von Protoplasma und einen großen Zellsaft. 'In dem Wandbeleg findet sich der Chromatophor als dünne, zusammenhängende Chlorophyllschicht, die zahlreiche Amylonkerne enthält; in dem Plasma an der Innenseite des Chromatophors liegen zerstreut eine Menge kleiner Zellkerne. Bei der ungeschlechtlichen Vermehrung zerfällt der Wandbeleg in eine große Anzahl von zweiwimperigen Zoosporen, die innerhalb der stark aufquellenden Mutterzellhaut sich eine Zeit lang auf der Stelle hin und her bewegen. Sie sind durch feine Plasmafäden mit einander verbunden, bewegen sich in bestimmter Anordnung (Fig. $4 C$ ) und legen sich, zur Ruhe kommend, direkt zu einem jungen neuen Netze zusammen (Fig. $4 B$ ). Bei der geschlechtlichen Fortpflanzung entsteht aus einer Zelle eine noch größere Anzahl kleinerer Schwärmer, die Gameten (Fig. $4 D$ ), die aus der Mutterzelle heraustreten, frei umherschwimmen und zu je zweien mit einander verschmelzen (Fig. $4 E$ ). Die Zygoten (Fig. $4 F$ ) erzeugen nach einer Ruhezeit vier große Zoosporen, die zu polyedrischen Zellen heranwachsen, aus denen junge Netze ungeschlechtlich entstehen. (Ueber den Bau der Zellen, die Bildungsgeschichte der Zoosporen und der Gameten vergl. Klebs 9I; über das Schicksal der Zygoten Pringsheim 60.)

Für die Physiologie der Fortpflanzung bietet Hydrodictyon im Vergleich zu Vaucheria ein ganz andersartiges Beispiel dar. Während bei dieser Alge die beiden Fortpflanzungsweisen in sehr losem Zusammenhange stehen, treten sie bei Hydrodictyon in sehr enge Beziehungen zu einander. Denn jede Zelle kann sich entweder ungeschlechtlich oder geschlechtlich fortpflanzen; die Entscheidung darüber liegt in der Außenwelt. Da aber dabei sehr kleine, schwer erkennbare Aenderungen der äußeren Bedingungen oft den Ausschlag geben, läßt sich 
nicht immer der Einfluß der Außenwelt auf die betreffende Fortpflanzungsart klar erkennen. Eine weitere Schwierigkeit liegt in der Eigenschaft der HydrodictyonZelle sich nicht so schnell wie Vaucheria veränderten Lebensbedingungen anzupassen, vielmehr lange Zeit Nachwirkungen der früher herrschenden Bedingungen zu bewahren, so daß das Verhalten der Alge bei Unkenntnis der früheren Lebensverhältnisse oft widerspruchsvoll erscheint. Endlich ist gegenüber Vaucheria für Hydrodictyon hervorzuheben, daß diese Alge sehr viel leichter auf anscheinend unbedeutende, äußere Einwirkungen hin die Fähigkeit verliert, auf die specifischen Reize, die Zoosporen- oder Gametenbildung auslösen, zu reagieren. Die Alge geht aus dem reizbaren Zustand in einen starren oder indifferenten über, ohne daß äußerlich eine Veränderung zu bemerken ist. So wenig bequem aus diesen Gründen sich das Wassernetz für die Untersuchungen erweist, so lehrreich ist es andererseits, weil es manchen neuen Einblick in das Verhältnis der niederen Pflanzen zur Außenwelt eröffnet.

Ueber die Kultur des Wassernetzes habe ich in meiner früheren Arbeit bereits gesprochen. Die Alge habe ich in den früheren Jahren in großen Behältern im Freien lsultiviert; sie ließ sich während des Winters in Nährsalzlösungen frisch erhalten. Als ich im Sommer 1895 die Alge von neuem untersuchen wollte, erhielt ich durch die Freundlichkeit von Oltmanns aus Freiburg neues Material, das ich in meinem Aquarium kultivierte, wo sich die Alge von Ende Mai bis Ende Juli, zu welcher Zeit die Untersuchung abgebrochen wurde, in völlig normalem, lebenskräftigem Zustand erhielt. Als in Herbst I895 neues Material der Alge in das Aquarium gebracht wurde, erhielt es sich den ganzen Winter hindurch, nicht stark wachsend aber auch nicht kränkelnd, so 
daß die Alge im Frühjahr I8g6 zu neuer Vegetation überging.

\section{Die Bedingungen der Zoosporenbildung.}

In meiner früheren Arbeit zeigte ich, daß erst von einer gewissen Größe an die Zellen zur Zoosporenbildung veranlaßt werden können. Bei einer Kultur, die von ganz jungen Netzen ausging, gelang es mir nach 3 Wochen Zellen von $0,8 \mathrm{~mm}$ wieder zur Zoosporenbildung zu veranlassen. Indessen vermögen noch kleinere Zellen sich ungeschlechtlich zu vermehren; ich beobachtete dies z. B. bei Zellen von $0,2 \mathrm{~mm}$, und es ist ja denkbar, daß unter besonderen Bedingungen noch kleinere Zellen dasselbe vermöchten. Die größten Zellen, bei denen Zoosporenbildung gesehen wurde, hatten eine Länge von $10 \mathrm{~mm}$; während der ganzen Zeit, in der die Zellen von $0,2 \mathrm{~mm}$ bis $\mathrm{zu}$ IO $\mathrm{mm}$ sich verlängern können, entscheiden die äußeren Bedingungen, ob wirklich Wachstum oder Zoosporenbildung erfolgt. Für die eigentliche Untersuchung sind die größeren Zellen von I mm an sehr viel günstiger als die kleineren, weil die ersteren sich in stärker reizbarem Zustande befinden.

Bei der früheren Untersuchung habe ich, um Zoosporen zu erhalten, stets die Methode angewandt, die Alge bei heller Beleuchtung in einer Nährsalzlösung von 0,5-I Proz. zu kultivieren und dann in Wasser überzuführen. In neuerer Zeit benutzte ich die Eigenschaft der Alge, beim Uebergange aus dem Aquarium in ruhig stehendes Wasser, sehr lebhaft Zoosporen zu bilden. Der Versuch gelingt mit sehr großer Sicherheit, so daß bei 
geeigneter Temperatur die Mehrzahl der Zellen bereits in 24 Stunden die Netzbildung zeigt, wodurch es möglich wird, den Einfluß der äußeren Bedingungen genauer als bisher zu erforschen.

Ich werde die einzelnen Bedingungen in etwas anderer Reihenfolge als bei Vaucheria besprechen.

\section{Der Einfluß des Lichtes.}

Die Frage nach der Bedeutung des Lichtes für die Zoosporenbildung von Hydrodictyon läßt sich nicht so einfach beantworten; es handelt sich dabei um verwickeltere Verhältnisse, als ich selbst früher angenommen habe.

Zunächst muß der Einfluß des Lichtes auf den reizbaren Zustand der Alge festgestellt werden. Die Alge Hydrodictyon befindet sich in einem solchen Zustande, wenn sie unter sehr günstigen Bedingungen lebt, die lebhaftes Wachstum gestatten, z. B. bei heller Beleuchtung; einer mittleren Temperatur von $15^{\circ}$ und einer genügend großen Wassermenge, wie z. B. in meinem Aquarium. Von Ende Mai bis Ende Juli I895 (Temperatur zwischen I4 - I $6,5^{\circ}$ ) besaßen die darin kultivierten Zellen den denlibar größten Grad der Reizbarkeit. Als ich im Herbst desselben Jahres wieder neues Material aus Freiburg in das Aquarium brachte, bemerkte ich bald eine Verringerung der Reizbarkeit; die Versuche zeigten keine so sicheren Resultate mehr. Der Hauptunterschied gegenüber dem Sommer lag in der sehr viel schwïcheren Beleuchtung; da im November bei der Lage des Institutes und dem Stande der Sonne helles Licht nur wenige Stunden das Aquarium traf.

Die Temperatur darin war etwas niedriger als im 
Sommer, im November zwischen $\mathrm{I} 2$ und I ${ }^{0}$. Die Alge wuchs anfangs noch unter diesen Bedingungen, sie blieb frisch grün, war aber doch unempfindlicher geworden; noch mehr war dies der Fall in den Wintermonaten, wo die Temperatur bis auf $5^{\circ}$ sank. Helles Licht ist ebenso notwendig, wenn die Alge in begrenzter Flüssigkeitsmenge bei Zusatz von Nährsalzen in ihrem reizbaren Zustande bewahrt werden oder ihn erst wieder erhalten soll.

Wenn dagegen eine Alge sich in kleiner, nicht gewechselter, daher nährsalzarmer Wassermenge befindet, so ist es das Licht, welches je nach seiner Intensität schneller oder langsamer den reizbaren Zustand, der die Zoosporenbildung ermöglicht, vernichtet. Die meist mit ihm verbundene höhere Temperatur wirkt dann in gleicher Richtung. Die Aufspeicherung der Stromastärke, die gelbliche Färbung der Zellen sind Anzeichen für das Verschwinden der Reizbarkeit. Bei kleiner Wassermenge ist der Aufenthalt im Dunkeln geradezu ein Mittel, den reizbaren Zustand zu erhalten, da dann eine Anhäufung organischer Stoffe nicht stattfinden kann. Daher ist es für die Untersuchung des Wassernetzes sehr nützlich, einen Teil des Materials im Dunkelschrank aufzubewahren. Wie ich früher (90 S. 360) betont habe, hält die Alge sehr lange im Dunkeln aus, so daß sie monatelang, ja bis zu einem halben Jahre im Wasser lebend bleibt.

Gehen wir jetzt von einer Alge in reizbarem Zustande aus und fragen wir, in welcher Weise das Licht bei der Veranlassung der Zoosporenbildung wirkt, so muß auch hierbei die Antwort je nach den begleitenden Umständen verschieden ausfallen. In der früheren Arbeit hob ich hervor, daß die Zoosporenbildung nur dann lebhaft erfolgt, wenn die Alge nach der Ueberführung aus Nährlösung in Wasser beleuchtet wird. Im Dunkeln tritt der 
Prozeß nicht ein. Allerdings beobachtete ich Ausnahmen, da auch manche Zellen in I-proz. Maltose bei einer Temperatur von $2 S^{\circ}$ im Dunkeln Zoosporen erzeugten und da bei einer unter besonderen Umständen aufgewachsenen Kultur der Prozeß selbst nach mehrtägigem Aufenthalt im Dunkeln erfolgte. Immerhin war die Abhängigkeit der Zoosporenbildung vom Licht die allgemeine Regel.

Um so überraschender war es daher, daß für diejenigen Zellen, die im Aquarium gelebt hatten, das Licht bei der Zoosporenbildung sich als gleichgiltig erwies. Der Uebergang aus dem Aquarium in eine kleine stehende Wassermenge reizt die Zellen zur Zoosporenbildung, und diese findet in gleichem Maße im Licht, wie im Dunkeln statt. Das Verluältnis der Zoosporenbildung zum Licht ist daher verschieden, je nach den Kulturbedingungen, unter denen die Alge vor dem Versuch gelebt hat. Die Frage nach der Bedeutung des Lichtes für die Nährsalzkulturen werde ich zusammen mit der Besprechung dieser behandeln. Die andere Frage, wie lange Hydrodictyon in dem Aquarium bei Lichtabschluß fähịg bliebe, bloß durch den Wechsel des Wassers ohne Zutritt des Lichtes Zoosporen zu bilden, konnte bisher nicht untersucht werden. Alser es ist kaum zweifelhaft, daß die Zoosporenbildung von Hydrodictyon ebenso wie die von Vaucheria in hohem Grade unabhängig von der Assimilation ist. Zufällig sah ich bei einer Kultur nach I4 Tagen des Aufenthaltes im Dunkeln, dabei im Thermostat (26-28"), die Bildung von Zoosporen. Gewöhnlich kann man bei Dunkelkulturen in kleinen Gefäßen die Zoosporenbildung nur dann hervorrufen, wenn sie beleuchtet werden. In dieser Beziehung verhalten sich die Dunkelkulturen ebenso wie die Algen, die aus Nährlösung in Wasser übergeführt worden sind. Sie unterscheiden sich nur darin, daß kein 
Wechsel des Mediums stattfindet, und sie zeigen, daß der Uebergang aus Dunkelheit in Licht für sich allein die Zoosporenbildung veranlassen kann.

\section{Der Einfluß des fließenden Wassers und des Samerstoffs.}

Das Wassernetz kommt nicht in lebhaft strömenden Bächen vor, sondern nur in langsam fließenden oder stehenden Gewässern. Die Kultur in meinem Aquarium zeigte aber deutlich den ungemein belebenden Einfluß des stets sich erneuernden Wassers. Während die Netze selbst in einem großen, sonnig stehenden Glasgefäß nach einigen Tagen anfingen sich gelblich zu färben, blieben solche im Aquarium stets frisch grün. Mehrfach wurde der Versuch mit Erfolg gemacht, solche gelben Netze, die schon den reizbaren Zustand verloren hatten, durch die Kultur im Aquarium wieder lebenskräftig und reizbar zu machen. Von den früher besprochenen Eigenschaften des Aquariumwassers (s. S. 82) kommen, zur Erklärung seiner Wirkung, die gleichmäßige niedere Temperatur und die Zuführung von Nährsalzen und Sauerstoff in Betracht. Die Temperatur betrug in den Sommermonaten Ende Mai bis Ende Juli I4-16,5 .

Nahm ich ein Netzstück aus dem Aquarium, brachte es in destilliertes oder auch Leitungswasser und stellte das Versuchsglas ins Laboratorium, so bildeten bereits nach 24 Stunden fast sämtliche Zellen Zoosporen. Da das Licht bedeutungslos ist, so konnte nur die Veränderung der Temperatur und der Beschaffenheit des Wassers wirksam sein. Um den Einfluß der Temperaturerhöhung auszuschließen, brachte ich ein Netzstück in ein wasserdicht verschlossenes Gefäß, das völlig untergetaucht ins 
Aquarium gestellt wurde. Die Zoosporenbildung trat niemals in so lebhaftem Grade nach 24 Stunden ein, wie im Laboratorium, wo ein gleiches, fest verschlossenes Glas bei $20-22^{0}$ sich befand. Meistens erfolgte die Zoosporenbildung im Aquariumglas langsam in den folgenden Tagen; sie konnte bisweilen gering sein und durch Gametenbildung ersetzt werden. Aus den Versuchen folgt, daß eine Temperaturerhöhung den Prozeß sehr befördert, der aber durch den Uebergang der Alge in eine kleine stehende Wassermenge allein veranlaßt werden kann. Hierfür wird ein Nlangel an Nährsalzen bei der Kürze der Versuchszeit weniger verantwortlich zu machen sein als diễ Verminderung des Sauerstoffgehaltes. Die Beobachtungen an Vaucheria (s. S. 87) könnten noch zur Stütze dieser Annahme dienen. Immerhin fehlt auch für Hydrodictyon der strenge Nachweis für die Richtiglieit der Ansicht.

In meiner früheren Arbeit glaubte ich noch der Auffassung von $\mathrm{W}$ alz zustimmen zu liönnen, nach der unter Umständen frisches, sauerstoffhaltiges Wasser anregend auf die Zoosporenbildung wirken könne. Ich erklärte mir dadurch die Erscheinung, daß hie und da ein W'echsel stehenden Wassers Zoosporenbildung bei einzelnen Zellen veranlaßte. Ein solcher WVechsel des W'assers könnte aber deshalb als Reiz wirken, weil durch ihn osmotische Veränderungen des Zellsaftes herbeigeführt werden, die ihrerseits den Anstoß zur Zonsporenbildung abgeben würden, in ähnlicher Weise, wie beim Uebergang aus Nährlösung in Wasser. Nie läßt sich aber durch Wechseln des stehenden Wassers eine lebhafte Zoosporenbildung veranlassen. Jedenfalls wirkt fließendes, sauerstoff haltiges Wasser, wie das meines Aquariums, nicht fördernd, sondern eher hindernd auf den Prozeß ein. Denn ich halse in den 8 Wochen, wo ich täglich Netzstücke aus 
dem Aquarium untersuchte, niemals Zoosporen an ihnen gesehen; sie können auch nicht in größerer Menge an ihnen gebildet worden sein, weil die Netze bis zum Schluß der Sommeruntersuchung ihren Zusammenhang bewahrten. Damit will ich nicht behaupten, daß die Zoosporenbildung unmöglich gewesen sei; im Herbst sah ich z. B. eine solche an den Netzen des Aquariums. Aber eine wirklich lebhafte Bildung erfolgt unter allen Umständen erst in stehender kleiner Wassermenge, die weniger Sauerstoff enthält als das Wasser des Aquariums. Der Erfolg des Versuches wird nicht beeinträchtigt, wenn man das Wasser lange stehender Kulturen nimmt; man kann noch den Partiärdruck des Sauerstoffes ganz bedeutend herabsetzen. Die Versuche wurden in derselben Weise wie bei Vaucheria angestellt. Kleine Netzstücke wurden aus dem Aquarium in kleine Gläschen mit destilliertem Wasser gebracht und darin unter die Luftpumpenglocke gestellt. Nachdem diese I-2 Stunden ausgepumpt worden war, wurde die Kultur einige Stunden lang dem niedrigsten erreichbaren Drucke ausgesetzt; dann wurde so viel Luft zugelassen, als wünschenswert erschien. Bei einer Reihe von Versuchen wurde der Apparat verdunkelt; nach 48 Stunden wurde die Kultur genau geprüft. Es zeigte sich die erste Netzbildung bei einem Luftdruck von $80 \mathrm{~mm}$ (Temperatur $20-22^{\circ}$ ); zum Teil waren die eben gebildeten Netze normal beschaffen, zum Teil waren sie nicht zu Stande gekommen, weil die Zoosporen nicht fertig geteilt waren. Bei noch niedrigerem Drucke fand überhaupt keine Netz- oder Zoosporenbildung mehr statt. Sowie dagegen die betreffende Kultur wieder dem gewöhnlichen Luftdrucke ausgesetzt wurde, trat lebhafteste Zoosporenbildung ein. Bedarf auch Hydrodictyon eines höheren Partiärdruckes des Sauerstoffes als V. repens (s. S. 79), so erkennt man doch, daß 
seine starke Verminderung die Zoosporenbildung nicht verhindert.

Wenn der gleiche Versuch gemacht wird nur mit dem Unterschiede, daß das Tageslicht zugelassen wird, so erhält man etwas andere Resultate. Dann findet bereits bei einem Luftdruck von $4 \mathrm{~mm}$ die lebhafteste Zoosporenund normale Netzbildung statt, und nur selten unterbleibt sie, wemn man ihn bis auf $3 \mathrm{~mm}$ verringert. Unzweifelhaft wird durch die Kohlensäure-Assimilation in den Zellen sellsst oder in ihrer nächsten Umgebung der Partiärdruck des Sauerstoffs erhöht; bei der langsamen Diffusion der Gase können die Zellen trotz des niedrigen Luftdruckes in der Glocke sich eine Zeit lang in sauerstoffreicherem Medium befinden, als dem Manometerstande entspricht und für ihre Zoosporenbildung daraus Vorteil ziehen.

Die Versuche beweisen nur, daß eine gewisse Menge Sauerstoff vorhanden sein muß, um normale Zoosporenbildung zu veranlassen; die Luftpumpenversuche im Dunkeln geben ungefähr die Grenze dafür an. Allerdings geht aber aus den Versuchen nicht hervor, daß eine Sauerstoffverminderung den Prozefs hervorruft oder wenigstens befördert.

\section{Der Einfuß der anorannischen Verbindungen.}

Das Hauptinteresse knüpft sich bei Hydrodictyon an die Untersuchung an, welche Rolle die Nährsalze spielen. Es gielst kaum ein anderes Beispiel unter den Algen, bei dem sich ihr Einfluß in so auffälliger Weise bemerkbar macht. In einer besonderen Arbeit (Klebs 9I) habe ich ausführlich dargelegt, wie die Algen in Nährlösungen von 0,2 Proz. an kaum mehr wachsen, dagegen tiefgreifende Veränderungen in der Beschaffenheit des Zell- 
inhaltes erfahren. Die Reservestoffe, namentlich die Stromastärke, werden aufgelöst, der schön grüne, anfangs sehr dünne Chromatophor erreicht allmählich eine mächtige Entwickelung, zahlreiche Zellkerne entsteben durch Teilung, während die sicher vorhandenen Veränderungen des Zellsaftes noch nicht erkannt worden sind. Zugleich verleiht die Nährlösung den Zellen eine bestimmte Neigung zur Zoosporenbildung, so daß es sehr große Mühe kostet, diese Neigung zu unterdrücken und die Gametenbildung zu veranlassen.

Der besprochene Einfluß der Nährlösung hängt innerhalb weiter Grenzen nicht von ihrer Konzentration ab. Schon verdünnte Lösungen von $0,05-0,1$ Proz. können bei genügender Flüssigkeitsmenge und nicht zu kränklichem, altem Algenmaterial einen solchen Einfluß ausüben. Andererseits können die Algen auch in einer Lösung von 4 Proz. aushalten und in der angegebenen Weise sich verändern, wenn man sie ganz allmählich daran gewöhnt. "Am geeignetsten ist eine Lösung von 0,5-I Proz.

Die Nährsalzlösung bewirkt aber zugleich, daß die von ihr erregte Neigung zur Zoosporenbildung nicht zum Ausbruch kommt. Nur bei verdünnten Lösungen von 0,05-0, I Proz. kann sie unmittelbar darin erfolgen. Wenn man daher Netze, die in kleiner Wassermenge bereits gelb gefärbt und mit Reservestoffen angefüllt sind, in einer solchen verdünnten Nährlösung heller Beleuchtung aussetzt, so gehen nach einiger Zeit alle Zellen in Zoosporenbildung über. Bei höherer Konzentration muß erst die Lösung durch Wasser ersetzt werden; dieser Wechsel des Mediums wirkt dann als auslösender Reiz.

Die wasseranziehende Eigenschaft der Salze kommt anscheinend bei ihrer hemmenden Wirkung weniger in Betracht als die chemische. Denn die Zoosporenbildung wird 
auch dann ausgelöst, wenn die Netze aus einer Nährlösung von 0,5 Proz. in eine Zuckerlösung von Io Proz. d. h. aus einer sehr schwach wasseranziehenden in eine stark wasseranziehende Flüssigkeit ühergeführt werden. Das Wesentliche bleibt, daß die Nährsalze aus den Zellen entfernt werden, daß eine chemische Aenderung des Zellsaftes eingeleitet wird. Noch auf anderem Wege läßt sich der chemische Einfluß der Nïhrsalze nachweisen.

Wenn Hydrodictyon aus 0,5-proz. Nährlösung I bis 2 Tage im Wasser kultiviert und dann wieder in die gleiche Nährlösung gelıracht wird, so greht in dieser die im Wasser begonnene Zoosporenbilkung einigre Tage weiter; selbst in I-proz., lisweilen in 2-proz. Lösung gelingt es noch, die Bildung zu beobachten. Das gleiche geschieht, wenn man Netze aus dem Aquarium direlit in 0,5- oder I-proz. Nährlösung bringt. In clen ersten Tagen, wo hauptsächlich die wasseranziehende Eigenschaft der Nährlösung wirksam ist, hinclert sie clen Prozeß nicht. Allmählich treten die Salze mehr und inehr in die Zelle, besonders in den Zellsaft ein und grestatten von nun an keine Zoosporenbildung mehr.

Man kann annehmen, lałs die lebhafte Neigung zur Zoosporenbildung in der Nährlösung durch die von ihr veranlaßte, starke Vermehrung der Zellkerne hedlingt wird. Hemmend wirken die Salze dagegen durch ihren Eintritt in den Zellsaft, wo sie selır wahrscheinlich chemische Verändlerungen seiner Bestandteile bewirken. Auch die allgemeine Vermehrung der plasmatischen Substanz, besonders des Chromatophors, kann bei der Hemmung beteiligt sein. Denn es müssen der Zousporenbildung lelhafte Unlagerungen des Zellinhaltes vorausgehen, die aber erst nach Entfernung der überschüssigen Nährsalze erfolgen können. Je länger die Alge in der Nährlösung verweilt, um so stärker macht sich 
die Hemmung geltend. Nach monatelangem Aufenthalte in $0,5^{-}$oder I-proz. Lösung geschieht die Zoosporenbildung nach dem Uebergang in Wasser sehr langsam und ungleichmäßig bei den verschiedenen Zellen. Sind nun gleich in der ersten Zeit nach dem Mediumwechsel die äußeren Bedingungen nicht günstig, so können die Zellen aus dem reizbaren in den indifferenten Zustand übergehen, wenn sie nicht vorher zur Gametenbildung veranlaßt worden sind.

Das Eigenartige des Verhaltens von Hydrodictyon gegenüber den Nährsalzen liegt darin, daß das Licht einen so wichtigen Einfluß darauf hat. Die erwähnten Veränderungen des Zellinhaltes durch die Salze geschehen nur bei Mitwirkung des Lichtes; ebenso ist daran die Entstehung der specifischen Neigung zur Zoosporenbildung gebunden. Allerdings kann der Prozeß bei Algen erfolgen, die im Dunkeln, in Nährlösungen gelebt haben, dann in Wasser übergeführt und beleuchtet werden. Aber man gewinnt dadurch kaum einen Vorteil gegenüber Wasserkulturen, die im Dunkeln gestanden haben.

In der Regel muß das Licht nach dem Uebergange aus Nährlösung in Wasser mitwirken, damit die Zoosporenbildung wirklich eintritt. Da der Prozeß an und für sich, wie die Aquariumnetze zeigen, auch unabhängig vom Licht erfolgen kann, so kann dessen Wirkung für die Nährsalzalgen nur eine mittelbare sein; es muß dazu dienen, gewisse Hemmungen zu beseitigen, die durch den Aufenthalt in Nährlösung geschaffen worden sind. Ich möchte annehmen, daß das Licht die im Zellsaft chemisch gebundenen, überschüssigen Nährsalze aus dem Zellsaft entfernen hilft.

Bei Vaucheria und anderen Algen genügt der einfache Uebergang aus Salzlösung in Wasser, um als Reiz $\mathrm{zu}$ wirken; das Licht ist nicht notwendig dafür. Auch bei 
Hydrodictyon wird die einzelne Zelle, beim Uebergange aus Nährlösung in Wasser bei Lichtabschluß, einige Veränderungen erfahren; so werden z. B. Salze aus dem Zellsaft heraustreten. Aber das wirkt nicht als Reiz, und das Verhalten der Alge beweist, laß für Hydrodictyon der einfache, osmotische Austausch zwischen Zellsaft und Wasser für sich allein von geringerer Bedeutung ist, und erst dann wirksam wird, wemn das Licht den Vorgang befördert. Bringt man Netze aus der beleuchteten Nährlösung in Wasser und stellt sie dunkel, so bleiben sie vegetativ; ans Licht gebracht, entwickeln sie lebhaft Zoosporen. Der Versuch gelingt mit großer Sicherheit, mit sehr viel größerer, als wenn man einfache Wasserkulturen aus der Dunkelheit ins Licht bringt.

Die Wirkung des Lichtes hängt wahrscheinlich mit seiner Rolle bei der Assimilation zusammen. Wir können uns vorstellen, daß die dabei entstehenden Kohlehydrate die in irgend einer Form im Zellsaft gebundenen Nährsalze an sich ziehen, sie verarbeiten und damit zu ihrer Entfernung beitragen, wenn der erste Anstoß dazu infolge des Ersatzes der Nährlösung durch Wasser gegeben ist. Wir wissen, daß überhaupt bei jeder Assimilation der Kohlensäure Salze, wie die des Kaliums, notwendig sind, wenn auch ein näherer Einblick in ihre Beziehungen zu dem Prozesse noch nicht möglich ist. Man könnte aber bei Richtigkeit meiner Ansicht verstehen, warum das Licht nicht absolut unersetzlich ist. Denn schon früher habe ich angegeben, dał es gelingt, Nährsalznetze bei Lichtabschluf ab und zu zur \%oosporenbildung zu veranlassen, wenn man sie in Maltose unter Anwendung einer höheren Temperatur überführt. Für diesen V'ersuch müssen am besten die Netze aus der Nährlösung einen Tag in reinem Wasser zubringen, um die anhängenden und von der Zellhaut imbilbierten Salze zu verlieren, bei deren Gegenwart leicht in der Maltose Fäulnis eintreten kann. 
Diese Versuche gelingen nicht immer, aber doch häufig, sie weisen mit großer Wahrscheinlichkeit darauf hin, daß das Licht deshalb die Zoosporenbildung mitbedingt, weil es bei der Erzeugung eines Kohlehydrates mitwirkt, das ähnliche Eigenschaften wie die Maltose besitzt. Andere Kohlehydrate, wie z. B. Rohrzucker, können nicht die Wirkung des Lichtes in dieser Weise ersetzen.

Auch durch das Verhalten der Alge in verdünnter Luft kann man diese Anschauung stützen, wobei zugleich der scharfe Unterschied von Nährsalznetzen und Aquariumnetzen klar hervortritt. Während bei den letzteren die Zoosporenbildung bei einem Luftdruck von $3 \mathrm{~mm}$, Beleuchtung vorausgesetzt, erfolgt, verlangen die aus Nährlösungen stammenden und in Wasser übergeführten Netze einen sehr viel höheren Luftdruck, so daß selbst noch bei $120 \mathrm{~mm}$ die Zoosporenbildung sehr spärlich ist. Da im Dunkeln bei Aquariumnetzen ein Luftdruck von ca. $80 \mathrm{~mm}$ ausreicht, um die erste Zoosporenbildung zu gestatten, so ist es sehr wahrscheinlich, daß das andere Verhalten der Nährsalznetze bei Gegenwart des Lichtes, weniger auf ihr größeres Bedürfnis nach einem höheren Partiärdruck des Sauerstoffs, als nach einem solchen der Kohlensäure zurückzuführen ist. Der niedrige Kohlensäuredruck vermindert den Assimilationsprozeß und damit die Bildung des Kohlehydrates, das für die Nährsalznetze nach dem Uebergang in Wasser meiner Ansicht gemäß notwendig bei der Zoosporenbildung mitwirken muß. In der That dient Maltose auch unter diesen Umständen dazu, die Lichtwirkung zum Teil zu ersetzen. Denn aus Nährlösung in Maltose übergeführt, vermögen die Netze bei Gegenwart des Lichtes und einem Luftdruck von $3 \mathrm{~mm}$ Zoosporen zu bilden; sie verhalten sich also wie die Aquariumnetze, nur daß 
bei diesen der Versuch sehr viel sicherer und allgemeiner zum Ziele führt.

Einzelne Salze, wie salpetersaures Kali, Kalknitrat, phosphorsaures Kali, schwefelsaures Kali, wirken in ähnlicher, nur nicht so kräftiger IVeise, wie die Nährsalzmischung. Vorausgesetzt wird dabei, daß die Alge sich nicht in zu schlechtem Zustande befindet, da die einzelnen Salze nicht so günstig wie die Mischung auf das ganze Leben der Zellen einwirken. Am besten sind die Nitrate geeignet, weil die Algen sie von allen Salzen in relativ größter Menge beanspruchen. Nach dem Uebergang aus der Salzlösung in Wasser tritt bei Gegrenwart des Lichtes Zoosporenlildung ein. Selbst bei Anwendung von Chlornatrium, dessen ermährende Rolle nach der herrschenden Annahme nur unbedeutend ist, kann noch der Prozeß herbeigeführt werden.

Man kann Hydrodictyon an eine höhere Konzentration, z. B. von Salpeter, wewöhnen, wenn man einen kleinen Zusatz von Nährlösung macht. Unter diesen Umständen ertragren die Algen eine Lösung von 2- und 2,5-proz. Salpeter, dessen Ersetzung durch WTasser ebenfalls Zoosporenbildung anregt.

Besonders hat mich bei Hydrodictyon auch die Frage interessiert, bei welcher Konzentration einer Salzlösung die Zoosporenbildung gehemmt wird. Hauptsächlich wurden die Versuche mit Salpeter angestellt; sie fielen sehr verschieden aus, je nach den sie begleitenden Umständen. Die Aqariumnetze bildeten in gleich lebhaftem Grade wie in Wasser die Zoosporen in einer Salpeterlösung von O,I Proz. Bei wenig höherer Konzentration machten sich bereits Störungen bemerkbar, weil las Salz während des Bildungsprozesses die Zellen schädigte. Bereits in einer Lösung von 0,2 Proz. finden sich nach 24 Stunden relativ nur wenige Zellen mit nor- 
malen Zoosporen, die aber nicht mehr im Stande sind, ein Netz zu bilden. Mit steigender Konzentration nimmt das Absterben der Zellen zu; in 0,5 Proz. halten nur wenige Zellen aus, die dann stets in vegetativem $\mathrm{Zu}$ stande verharren.

Andere Resultate erhält man, wenn man Netze aus gewöhnlichen Wasserkulturen in eine Salpeterlösung bringt, der man Maltose oder Dulcit zugesetzt hat. Dann bilden sich reichlich normale Zoosporen und normale Netze in einer Lösung von 0,5-proz. Salpeter; sogar in I Proz. bemerkte ich bewegliche Zoosporen, während eine Netzbildung unterblieb. Besonders deutlich war das Resultat, als ich von dem gleichen Netz ein Stück in Salpeterlösung von 0,6 Proz., ein anderes in eine Mischung dieser Lösung mit I-proz. Maltose brachte. In dem ersten Versuche zeigten vereinzelte Zellen Zoosporen ohne Netzbildung, in dem zweiten bildeten fast sämtliche Zellen junge, normale Netze. Man darf sich auch hier vorstellen, daß die Maltose gleich die Verarbeitung des in den Zellsaft eintretenden Salpeters veranlaßt, so daß der Zellsaft weniger von dem Salze enthält als in dem Versuche mit Salpeter ohne Maltose.

Je nach den Kulturbedingungen wirkt auf die Alge die gleiche Salpeterlösung verschieden; es kommt bei ihrer bald mehr, bald weniger schädlichen Wirkung auf die Größe des vorher in den Zellen herrschenden osmotischen Druckes an. Ich habe früher gezeigt (K lebs 9o, S. 365), daß, wenn man die Größe des Zellsaftdruckes durch eine ihm isotonische Nährsalzlösung bestimmt, diese zwischen I, 8 und 4 Proz. schwanken kann, er also sehr große Verschiedenheiten aufweist, die bei den Einwirkungen des Salpeters und anderer Verbindungen wohl in Betracht kommen. 
Von anorganischen Substanzen, die direkt keine nähere Beziehung zur Ernährung haben, wurde hauptsächlich Magnesiumoxycl untersucht. Ursprünglich lag der Anwendung dieses Körpers der Gedanke zu Grunde, daß durch ihn die Kohlensäure-Assimilation bei Zutritt des Lichtes behindert werde, da er die Kohlensäure lebhaft anzieht und sie in dem unlöslichen Magnesiumkarbonat bindet. Aber Magnesiumoxyd vermag dieses einigermaßen nur dann zu thun, wenn es im Ueberschuß vorhanden ist, wobei die Alge bald leidet. Außerdem entsteht in der Flüssigkeit lösliches, saures Karbonat, das die Algre zur Assimilation benutzen kann (vergl. Hassack 88). Dagegen konnte Magnesiumoxyd für die Frage benutzt werden, in wie weit ein alkalisch reagierendes Medium auf den Prozeß der Zoosporenbildung wirke. In einer gesättigten Lösung, die mit Phenolphtalein dunkelrot gefärbt wird und sich innerhalb eines luftdicht verschlossenen Gefäßes befindet, können die Zellen des Wassernetzes einige Tage leben, ohne zur Zoosporenl,ildung zu kommen. Diese tritt in einer halbgesättigten Lösung bei Gegenwart von Licht nach 48 Stunden ein, besonders wenn man noch Maltose zugesetzt hat. In dieser Zeit war die Lösung noch deutlich alkalisch geblieben, wenn auch die Phenolphtaleinfärbung schwächer geworden war.

Im Anschluß an die Besprechung des Einflusses alkalisch reagierender Flüssigkeiten will ich nur kurz erwähnen, daß auch der Einfluß von Säuren mehrfach geprüft wurde. Aus Nährlösung in 0,02-proz. Citronensäure übergeführt, zeigen die Netze in wenigen Tagen lebhafte Zoosporenbildung, ebenso in o,oI-proz. Aepfelsäure. In 0,05-proz. Citronensäure vermögen die Zellen sich zum Teil noch lebend zu erhalten, die Netzbildung tritt ganz vereinzelt ein oder unterbleibt völlig. Bei höherer Konzentration sterben die Zellen ab. 


\section{Der EinfluB organischer Stoffe, besonders der Kohle- hydrate.}

Wie bei den anorganischen Substanzen muß man auch bei den organischen die Prüfung nach zwei Richtungen vornehmen. Einmal handelt es sich darum, wie die einzelnen Stoffe die in ihren Lösungen erregte Zoosporenbildung beeinflussen. Ferner fragt es sich, in welchem Grade sie den Prozeß selbst anregen. Für die Untersuchung der ersten Frage kann der Rohrzucker als Beispiel dienen; für die der zweiten die Maltose.

Im allgemeinen kann Rohrzucker in nicht zu konzentrierten Lösungen (von I-4 Proz.) das Wasser vertreten. Ein Vorteil der Zuckerlösung ist nur bei den Nährsalznetzen zu bemerken, die in ihr gleich in den ersten Tagen lebhaft Zoosporen bilden und es auch bei schwächerer Lichtintensität thun als im Wasser. Im Dunkeln übt der Rohrzucker keine günstige Wirkung aus, und für die Aquariumnetze ist eine solche ebenfalls nicht zu bemerken. Nimmt man Netze ohne besondere Neigung zur Zoosporenbildung, so erfolgt diese ebensowenig in Zuckerlösung wie im Wasser. Ersetzt man in den ersten Tagen die Zuckerlösung durch Wasser, so kann durch den Wechsel eine schwache Zoosporenbildung veranlaßt werden. Sehr bald aber vernichtet der Aufenthalt in Zuckerlösung den reizbaren Zustand; wenn nicht Gametenbildung eintritt, werden die Zellen indifferent und müssen erst wieder durch Nährlösung reizbar gemacht werden.

Steigert man die Konzentration, so treten schädliche Nebenwirkungen auf; von 6 Proz. ab unterbleibt die normale Netzbildung. Die Zoosporenbildung selbst kann bei sehr viel höherer Konzentration erfolgen. So ging 
bei Aquariumnetzen der Bildungsprozeß noch in 20-proz. Zucker vor sich, wenn auch sehr viele Zellen dabei abstarben, und nur wenige noch schwach bewegliche \%oosporen zu erzeugen im Stande waren. Bei Nährsalznetzen wirken oft schon geringere Konzentrationen von I2-I5 Proz. schädlich ein und verhindern den Prozeß.

Aehnlich wie Rohrzucker verhalten sich Traubenzucker ( $\mathrm{I}-5$ Proz.), Mannit ( $\mathrm{I}-2$ Proz.), Glycerin ( I-2 Proz.), ohne daß sie merkbare Vorteile bieten; sie schädigen eher mehr, was ebenso von Milchzucker, Asparagin, Amygdalin gilt. Diese Stoffe führen zu jenen über, die die Zoosporenhildung der Nährsalznetze deutlich hemmen, wie Galaktose, Sorbin, Quercit, Harnstoff. Die Aquariumnetze sind in ihrem Verhalten gegen diese Sulsstanzen nicht geprüft worden.

Unter allen organischen Stoffen, mit denen Versuche angestellt wurden, nimmt die Maltose eine besondere Stellung ein, wie schon aus dem vorhergehenden Kapitel klar geworden ist. Die Maltose befördert und erregt die Zoosporenbildung in specifischer Weise. Nicht bloß bilden die Nährsalznetze in I-2-proz. Maltose sehr schnell und allgemein Zoosporen; diese treten in ihr auch bei Netzen aus gewöhnlichen Wasserkulturen auf. Wir haben gesehen, wie die Maltose die Rolle des Lichtes zum Teil ersetzen kann. Es läßt sich auch ihre unmittelbare Wirkung auf die Zellen des Wassernetzes leicht beoloachten, wenn nan diese in Maltose, bei Lichtabschluß kultiviert. Auffallenderweise wird durch dieses Kohlehyclrat eine schnelle Auflösung der Stromastärke wie der I'yrenoidstärke des Chromatophors veranlaßt (Klebs 9I). Wenn wir auch nicht die dabei thätigen, chemischen I'rozesse erkennen können, so folgt doch so viel aus diesen Thatsachen, daß die Maltose schnell in die Zellen eindringt und unmittelbar in ihre Lebensprozesse eingreift. 
Das gleiche geht aus ihrem Verhältnis zur Zoosporenbildung hervor. Vergleicht man die Wirkung der Maltose mit der der Nährsalze, so ergiebt sich in einer Richtung ein wesentlicher Unterschied. Zellen, die ihre Reizbarkeit für Zoosporenbildung verloren haben, gewinnen sie in Maltose nicht wieder, wie in der Nährsalzlösung. Die Zellen müssen eine ganz leise Neigung zur ungeschlechtlichen Fortpflanzung bereits besitzen. Sonst bilden sie in Maltose Gameten oder werden ganz indifferent. Diese Substanz hat ferner den Nachteil, daß sie leicht durch niedere Organismen chemisch verändert wird und dann eher schädlich wirkt. Der Uebergang aus Maltoselösung in Wasser reizt die Alge nicht zur Zoosporenbildung. Wenn die Zelle in den ersten Tagen in Maltose keine Zoosporen erzeugt, so thut sie es sicherlich nicht nach dem Uebergang in Wasser oder in eine andere Kohlehydrat-Lösung.

Einigermaßen ähnliche Wirkungen wie Maltose übt auch eine Dulcitlösung von $\mathrm{I}-2$ Proz. aus, die infolgedessen vielfach von mir benutzt worden ist. Sie verändert sich weniger rasch wie Maltose, giebt aber auch nicht so prägnante Resultate.

\section{Der Einfluß der Temperatur und der Feuchtigkeit.}

Von den beiden Temperaturgrenzen, innerhalb deren die Zoosporenbildung erfolgen kann, ist nur die obere genauer von mir bestimmt worden. Aus den früheren Beobachtungen ergab sich, daß bei Nährsalznetzen der Prozeß unter $8^{\circ}$ nicht mehr eintritt. Ob die Aquariumnetze sich anders verhalten, habe ich versäumt nachzusehen. Dagegen wurden gerade die Aquariumnetze benutzt, um die obere Grenze zu bestimmen. Sie bilden bei einer gewöhnlichen Zimmertemperatur im Sommer, 
bei Is $22^{\circ}$ innerbalh 24 Stunden Zoosporen nach Ueberführung in eine lileine Wassermenge. Für die genauere Untersuchung wurde der Thermostat benutzt; es zeigte sich, daß bei $26-28^{\circ}$ der Prozeß an schnellsten verläuft, dil er dann nur 12 Stunden braucht. Netze, um 8 Uhr abends aus dem Aquarium genommen und in den Thermostat gestellt, zeigten um 8 Uhr morgens des nächsten Tages bereits die Zoosporen. Steigert man die Temperatur über $29^{\circ}$, so beginnen krankhafte Erscheinungen bemerkhar zu werden. Bei konstanter Temperatur von $30^{0}$ kontrahieren sich die Zoosporen zu stark, verlieren zum Teil iluren Zusammenhang, so daß abnorm gestaltete Netze entstehen. Bei $32^{\circ}$ sah ich überhaupt keine jungen Netze mehr, die Zoosporen bewegen sich noch, kommen aber für sich zur Ruhe. Das gleiche Resultat hatte der Versuch, als bei der Temperatur von $32^{\circ}$ Licht zu den Kulturen treten konnte. Bei $33^{\circ}, 34^{\circ}$ finden sich Andeutungen, gleichsam Versuche, Zoosporen zu bilden; es ist dann schwer zu entscheiden, ob dies wirklich der Fall ist, oder ob es sich um Gameten handelt, die unter diesen Umständen sich bilden können.

In vegetativem Zustande halten die Zellen des Wassernetzes eine beträchtlich höhere Temperatur aus ; sie bleiben lebend innerhalb 24 Stunden bei $40^{\prime \prime}$; von $41^{\text {" an }}$ sterben sie ab.

Diese hohe Temperatur braucht die Reizbarlieit für Zoosporenbildung, so weit die Aquariumnetze eine solche besitzen, nicht zu zerstören, wenn auch nicht selten Gametenbildung nach dem Uebergange in gewöhnliche Zimmertemperatur erfolgt.

In den Fällen, wo die Zoosporenbildung durch eine 'Temperatur von $8^{0}$ verhindert worden ist, löst eine Erhöhung der Temperatur auf $16-20^{\circ}$ den Prozeß aus. Die niedere Temperatur erhält auch bei Lichtzutritt den reiz- 
baren Zustand der Alge im Wasser lange Zeit, so daß nach mehrwöchentlichem Aufenthalt bei $o-5^{\circ}$ eine Temperaturerhöhung den Prozeß noch erregt. Dagegen kann eine solche, auch wenn man das Optimum von $26-28^{\circ}$ anwendet, nicht Zoosporenbildung bei Netzen veranlassen, die bei $15-20^{\circ}$ im Wasser einige Zeit gelebt haben.

Für den Uebergang aus Nährlösung in Wasser braucht zur Erzeugung der Zoosporen nicht notwendig eine Temperaturerhöhung mitzuwirken. Bei den Aquariumnetzen jedoch befördert diese in sehr hervorragendem Maße den durch den Wechsel des Wassers angeregten Prozeß (S. I42). Die Frage, ob unter Bedingungen, wie sie das Leben im Aquarium gewährt, eine plötzliche Temperaturerhöhung für sich allein als auslösender Reiz der Zoosporenbildung wirken könne, ist nicht untersucht worden; ich möchte es nicht für unwahrscheinlich halten.

Ueber den Einfluß des Aufenthaltes in feuchter Luft habe ich den Angaben meiner früheren Arbeit (Kle b s 90) nichts hinzuzufügen. Nährsalznetze auf feuchtem Filtrierpapier oder auf feuchtem Lehm, Torf u. s. w. kultiviert, bilden keine Zoosporen, bewahren aber ihre lebhafte Neigung dafür wochen- ja monatelang. Wenn man ein Netzstück so befestigt, daß ein Teil feucht liegt, ein anderer in Wasser oder Maltoselösung taucht, so erzeugt nur der von Flüssigkeit umgebene Teil die Zoosporen.

\section{Die Bedingungen der Gametenbildung und ihr Verhältnis zur Zoosporenbildung.}

In meiner früheren Arbeit habe ich ausführlich die physiologischen Bedingungen der geschlechtlichen Fortpflanzung des Wassernetzes besprochen. Ich möchte an dieser Stelle nur die Hauptsachen wiederholen, besonders 
um das Verhältnis der ungeschlechtlichen zur geschlechtlichen Fortpflanzung klar hervortreten zu lassen. Bei keiner anderen von mir bisher untersuchten Alge ist der Zusammenhang der beiden Fortpflanzungsweisen so enge und so bestimmt ausgesprochen, la die einzelne \%elle an und für sich in gleichem Maß̉e fähig ist, Zoosporen oder Gameten zu bilden, aber nur eines von beiden leisten kann. Wie ich mich früher ansdrückte, verhalten sich die esblichen Anlagen ler beiden Fortpflanzungsweisen yleichsam wie zwei Gegner, von welchen jeder den anderen vollständig unterdrücken muß, um zu seinem Ziele, seiner Entwickelung, zu kommen. In dem beständigen Wechsel der äußeren Verhältnisse müssen hestimmte Kombinationen von äußeren Bedingungen zusammentreffen, um den Sieg des einen, die Unterdrïckung des anderen Gegners herbeizuführen, während andere Kombinationen diesem über jenen siegen helfen.

Die Gametenbildung kann, wie die Zoosporenbildung, erst von einer gewissen Größe der Zelle an zur lintfaltung geloracht werden. Die kleinsten \%ellen, bei denen sie bisher beobachtet wurde, hatten eine länge von 0,03 $\mathrm{mm}$; die größten eine solche von $10 \mathrm{~mm}$. Nach den früheren Angaben über die Znosporenbildung (siche S. I37) gelang diese erst bei Zellen von 0,2 mm Länge an.

Ueberhaupt erscheint es bei Zellen unter I mm stets etwas leichter, Gameten- als Zonsporenlildung zu erhalten. Gehen wir von Netzen aus, deren Zellen eine Lïnge von I mm haben, so können diese ununterbrochen wachsen bis zu Io mm Länge. Wälırend der ganzen Zeit kam in jedem Augenblick Zoosporen- oder Gametenbiliung das Wachstum unterl,rechen. Es wäre denlibar, daßs bei anhaltend günstigen Wachstumsbedingungen die Zellen noch ïber Io mu hinaus an Länge zunähmen, ebenso wie Vaucheria-Fïden anscheinend beliebig lange 
zu wachsen vermögen. Wahrscheinlich aber giebt es für Hydrodictyon eine Maximalgröße, die aus inneren Gründen nicht überschritten werden kann. Dafür spricht, daß der plasmatische Wandbeleg größerer Zellen im Verhältnis zur Zunahme der Zellwand und des Zellsaftes abnimmt, so daß sehr wahrscheinlich die langen Zellen bloß infolge ihres Wachstums eine etwas andere Beschaffenheit besitzen als die kleineren, was schließlich zu einer Hemmung des Wachstums führen kann. Erst durch die völlige Umlagerung und Veränderung der Zellbestandteile infolge der Fortpflanzung erhalten dann die Tochterzellen wieder die normale, ungeschwächte Wachstumsfähigkeit. Auf eine solche Verschiedenheit im Bau des Protoplasmas wird man die Thatsache zurückführen können, daß ganz junge Zellen mit relativ dichtem Plasma und einem sehr kleinen Zellsaft, überhaupt nur Wachstum und keine Fortpflanzung zeigen, daß bei allmählicher Zunahme der Zellgröße und der damit verbundenen Zunahme und andersartigen Beschaffenheit des Zellsaftes die Bildung der Gameten leichter zu veranlassen ist als die der Zoosporen. Bei weiterem Wachstum sind die Zellen in gleichem Grade fähig, geschlechtlich wie ungeschlechtlich sich fortzupflanzen, bis dann gegen die Wachstumsgrenze hin die ganz großen Zellen sich leichter zur Zoosporenals Gametenbildung reizen lassen. Diese Abhängigkeit der Fortpflanzung vom Wachstum läßt sich als eine innere, nur in der Organisation der Hydrodictyon-Zelle begründete Bedingung bezeichnen.

Aber diese Bedingung ist nur für die jüngsten Zellen maßgebend; es ist sehr wahrscheinlich, daß, sowie eine Zelle Gameten bilden kann, sie auch ebenso gut Zoosporen zu erzeugen fähig wäre, wenn man die äußeren Bedingungen für den letzteren Prozeß noch besser erkannt haben wird. Für die ganz großen Zellen in der Nähe 
der Wachstumsgrenze ist es zweifellos, daß bei ihnen die Gametenl)ildung hervorgerufen werden kann.

Meine früheren Versuche haben den Nachweis geführt, dafs die äußeren Bedingungen der Gametenbildung anclerer Art sind als die der Zoosporenbildung. Alser der Geschlechtsprozeß läßt sich nicht mit einer solchen Sicherheit veranlassen, wie die Zoosporenbildung bei den Aquarium- und den Nährsalznetzen. Wohl sind die Bedingungen soweit erkannt worden, dafs bei gesundem Material stets geschlechtliche Fortpflanzung hervorgerufen werden kann, so daß die Methoden für den praktischen Gebrauch durchaus genügen. Immerhin kommt es namentlich bei Algen verschiedenartiger Herkunft nicht selten vor, daß die Versuche nicht die gewünschten Resultate geben. Die Zellen fahren entweder fort, Zoosporen zu erzeugen oder sie werden noch häufiger völlig indifferent. Die äußeren Bedingungen, welche den reizbaren Zustand der Zelle für Zoosporenbildung in einen solchen für Gametenbildung umwandeln, können bisweilen zu schwach oder zu stark wirken; im letzteren Falle werden die Zellen eben indifferent. Dann kommen noch die nicht kontrollierbaren Nachwirkungen der vor dem Versuch vorhandenen Bedingungen in Betracht, durch die ebenfalls die anscheinende Launenhaftigkeit der Hydrodictyon-Zelle begründet ist.

Bei der Darlegung der physiologischen Bedingungen für die Gametenbildung müssen wir jedenfalls die frühere Kulturart der Netze berücksichtigen; wir wollen gesondert betrachten die Netze mit schwacher Neigung zur Zoosporenbildung, wie sie die im Sommer der freien Natur entnommenen oder in größeren Kulturgefüßen erzogenen Netze besitzen und zweitens solche, die durch Kultur in Nährsalzlösung oder im Aquarium eine entschiedene Neigung zur Zoosporenbildung erhalten haben. 
a) Netze mit schwacher Neigung zur Zoosporenbildung.

Gesunde, im Wachstum begriffene Netze werden zur Gametenbildung angereizt, wenn man sie in relativ wenig Wasser hell, sonnig stellt. Dabei kann es vorkommen, daß durch den Wechsel des Wassers in den ersten Tagen eine geringe Zoosporenbildung stattfindet, die aber bald aufhört. Die kleine Wassermenge bedingt sehr schnell einen Mangel an Nährsalzen, das Wachstum steht still, und die etwa vorhandene Neigung zur Zoosporenbildung wird unterdrückt. Das helle Licht, in Verbindung mit höherer Temperatur, führt eine reichliche Ansammlung organischer Stoffe herbei, die zunächst den Zellen eine Neigung zur Gametenbildung verleiht. Auch in größeren Kulturgefäßen, die hell im Garten stehen, kommt nach einiger Zeit der Moment, wo das Wachstum bei nicht gewechseltem Wasser sich verlangsamt, schließlich aufhört, wo die Netze, bei Mangel an Reizen, die die Zoosporenbildung auslösen, sich gelblich färben, Stärke aufspeichern und zur Gametenbildung geneigt werden.

Der Prozeß kann im Wasser direkt erfolgen und um so lebhafter, je schneller durch helle Beleuchtung und hohe Sommertemperatur die Neigung dazu erweckt wird, während in den trüben Wintermonaten die Ansammlung der organischen Stoffe zu langsam vor sich geht, vielleicht auch andere Substanzen entstehen, die der Gametenbildung nicht so günstig sind. Die Netze werden in dem trübem Licht bei relativ niederer Temperatur indifferent, bevor Gametenbildung eintreten kann. Sehr viel allgemeiner und lebhafter tritt die Gametenbildung bei Anwendung von Rohrzuckerlösungen ein. Nach 6-8 Tagen bilden dann fast sämtliche, nach Hunderten zählende Zellen eines Klebs, Fortptlanzungsphysiologie. 
Netzes Gameten, so daß dieses vollständig zerfällt. Es ist im Sommer nicht immer notwendig, die Netze vorher mit wenig Wasser sonnig zu stellen; die Rohrzuckerlösung regt unmittelbar den Prozeß an, auch bei solchen Netzen, die anfangs in ihr Zoosporen bilden, so daß an dem gleichen Netze zuerst einige Zellen sich ungeschlechtlich, die anderen sich nach kurzer Zeit geschlechtlich fortpflanzen.

Die Konzentration des Rohrzuckers übt einen greringen Einflufs aus. Schon Lösungen von I Proz., mitunter von 0,5 Proz. erregen den Prozeß; andererseits bilden sich Gameten in Lösungen bis zu I6 Proz., wenn die Zellen lebend bleiben. Andere Kohlehydrate, wie Traubenzucker, Milchzucker, ferner Stoffe wie Glycerin, Erythrit verhalten sich ähnlich wie Rohrzucker, wirken aber nicht in so sicherer Weise (K lebs go S. 378).

Bei andauernd ungünstiger Beleuchtung und niederer Temperatur kann auch die Zuckerlösung unwirksam sein und die Zellen indifferent machen. Sie ist nicht im Stande, Zellen mit lebhafter Neigung zur Zousporenbildung umzustimmen, wie die früher besprochenen Versuche mit den Aquarium- und Nährsalznetzen zeigen (s. S. I53).

Wenn auch für die sichere Erregung der Gametenlildlung in Zuckerlösung helle Beleuchtung sehr fürderlich ist, so erscheint sie doch nicht als durchaus notwendig. Sogar Wasserkulturen können im Dunkeln einige Tage hindurch Gameten erzeugen; noch häufiger geschieht dies in Zuckerlösungen. In solchen beobachtete ich die Gameten nach 3-4-wöchentlicher Verdunkelung (K lebs 1. c. Tabelle II S. 380); in einem Versuch mit 2-proz. Glycerin sah ich sogar nacl $3 / 4$-jährigem Aufenthalt im Dunkeln bewegliche Gameten. Aber noch viel weniger sichere Resultate als bei Beleuchtung geben in vielen Fällen die Versuche in Dunkehn. 
Die Dunkelheit kann unter anderen Umständen die Gametenbildung geradezu befördern. Besonders ist dies der Fall bei Anwendung von Maltose und Dulcit. Beide Substanzen erregen bei normalen Netzen sehr lebhaft die Zoosporenbildung, aber wie wir wissen, vorzugsweise im Licht. Im Dunkeln wird die Zoosporenbildung meist gehemmt, beide Substanzen können dann eine Ansammlung organischer Stoffe in der Zelle herbeiführen und dadurch die Gametenbildung hervorrufen. In der Tabelle III meiner früheren Arbeit (l. c. S. 385) ist eine Reihe von Versuchen angeführt, die mit demselben Netz angestellt wurden, dessen eine Hälfte in Maltose oder Dulcit $(0,5$, I oder 2 Proz.) im Dunkeln stand, während die andere Hälfte in den gleichen Lösungen im Licht kultiviert wurde. In allen Versuchen erzeugte die beleuchtete Hälfte Zoosporen, die verdunkelte Gameten. Dann nahm ich von der gametenbildenden Netzhälfte die noch vegetativen Zellen und stellte sie hell, ohne Aenderung des Mediums; es traten in einigen Versuchen wieder Zoosporen auf, während in anderen die Gametenbildung fortging.

Die früheren Angaben ergänzend, kann ich noch hinzufügen, daß bei Anwendung schwachen Lichtes die Resultate der Versuche verschieden ausfielen. Meistens fing die Zoosporenbildung an und wurde bald durch Gametenbildung ersetzt; diese konnte auch gleich eintreten oder, wenn die Zellen indifferent wurden, ganz ausbleiben. Haben die Netze durch die Kultur in wenig Wasser bei heller Beleuchtung bereits eine gewisse Neigung zur Gametenbildung gewonnen, so erfolgt diese in Maltose und Dulcit auch im Licht.

Fassen wir das sehr charakteristische Verhalten von Hydrodictyon gegenüber Maltose und Licht zusammen, so können wir sagen: 
Zellen mit entschiedener Neigung zur Zoosporenbildung erzeugen Zoosporen stets in Maltose bei heller Beleuchtung, oft auch bei schwachem Licht und im Dunkeln bei höherer Temperatur.

Zellen mit entschiedener Neigung zur Gametenbildung erzeugen Gameten in Maltose bei heller oder schwacher Beleuchtung, ebenso im Dunkeln.

Zellen mit schwacher Neigung zur Zoosporenbildung erzeugen in hellem Licht Zoosporen, im Dunkeln Gameten.

Der Aufenthalt im Dunkeln erregt bei gewöhnlichen Wasserkulturen ohne entschiedene Vorliebe zu einer der beiden Fortpflanzungsweisen lieine besondere Neigung zur Gametenbildung. Lange Zeit im Dunkeln kultivierte Netze können nach Versetzung in helles Licht leicht Zoosporen bilden; ist aber in den ersten Tagen das Licht weniger günstig, so daß der bald eintretende Mangel an Nährsalzen die Zoosporenlildung hemmt, so kann später die Gametenbildung erfolgen. Netze mit entschiedener Neigung zur Zoosporenbildung bewahren diese im Dunkeln lange Zeit und erzengen, hell gestellt, nur Zoosporen.

Die Grenzen der Temperatur für die Gametenbildung sind ungefähr die gleichen wie für die Zoosporenbildung. Unter $8^{\circ}$ tritt der Prozeß nicht ein; die obere Grenze läßt sich nicht so genau bestimmen, weil die Gametenbildung nicht in kurzer Zeit zu veranlassen ist, infolgedessen schädliche Nebenwirkungen der höheren Temperatur störend eingreifen können. Die Grenze scheint für die Gameten etwas höher zu liegen als für die Zoosporen, etwa bei $33-34^{\circ}$. Im allgemeinen dient eine gleichmäßig höhere Temperatur dazu, eine schwache Neigung zur Zoosporenbildung zu unterdrücken und Gametenbildung hervorzurufen.

Sehr wesentlich verschieden von der Zoosporenbildung verhält sich die Gametenbildung gegenüber den anor- 
ganischen Salzen. Wenn Netze eine lebhafte Neigung zur Gametenbildung besitzen oder mit dieser bereits begonnen haben, so kann der Prozeß noch in den ersten Tagen in einer Nährsalzlösung oder Salpeterlösung von 0,5 Proz. stattfinden. Aber bald hört er auf, um nie wieder zu erscheinen, da, wie wir wissen, die Netze besonders in Nährlösung eine entschiedene Neigung zur Zoosporenbildung erlangen. In einer Nährsalzlösung von I Proz. hört bei heller Beleuchtung die Gametenbildung sehr schnell auf. Selbst bei Netzen, die in Rohrzucker von 5 Proz. in lebhaftester Weise Gameten erzeugen, genügt ein Aufenthalt von 2 Tagen in Nährlösung von I Proz. bei hellem Licht, um die noch vegetativ gebliebenen Zellen völlig umzustimmen. Mitunter reicht selbst der Uebergang aus Rohrzucker in Wasser dazu aus, daß gametenbildende Netze sich in zoosporenbildende umwandeln. Jedenfalls ist es sicher, dąß jedes Netz mit noch so lebhafter Neigung zur Gametenbildung in ein zoosporenbildendes umgeändert werden kann.

Auch gegenüber feuchter Luft verhält sich die Gametenbildung anders als die Zoosporenbildung. Netze aus gewöhnlichen Wasserkulturen zeigen auf feuchtem Filtrierpapier, noch besser auf einem solchen, das mit Rohrzuckerlösung getränkt ist, lebhafte, geschlechtliche Fortpflanzung. Dagegen erhält sich bei Nährsalznetzen, wie ich früher betont habe, die lebhafte Neigung zur Zoosporenbildung in feuchter Luft sehr lange Zeit.

b) Netze mit lebhafter Neigung zur Zoos porenbildung.

Nachdem die Umwandlung gametenbildender Netze in zoosporenbildende so leicht und sicher gelungen war, überraschte es, daß der umgekehrte Versuch großen Schwierig- 
keiten begegnete, sobald die Netze eine entschiedene Neigung zur Zoosporenbildung in Nährlösung erlangt hatten. In meiner früheren Arbeit habe ich die verschiedenen Methoden besprochen, die zunächst vergellich versucht wurden, um die vorhandene Neigung zu unterdrücken. Der Weg, der schließlich zum Ziele führte, hestand darin, die Nährsalznetze in Wasser oder in Zuckerlösung von 5 Proz. zu bringen und sie bei mäßig hellem Licht, z. B. an einem Nordfenster im Winter, bei einer Temperatur von IO- $12^{\circ}$ eine Zeit lang zu kultivieren. Nach IO-I4 Tagen wurden dann die Algen einer konstanten Temperatur von ca. $28^{\circ}$ bei Lichtahschluß ausgesetzt. Schwaches Licht und niedere Temperatur wirkten vereinigt zunächst dahin, dafs die Zoosporenbildung so gut wie vollständig behindert, und allmählich die specifische Neigung zu diesem Prozeß geschwächt wurde. Die hohe Temperatur und die Dunkelheit vereinivten sich dann, um der Gametenbildung den Sieg zu verleihen. Sehr zahlreiche Versuche mit sicherem Erfolge sind von mir im Winter r88990 angestellt worden; die Tabelle $\mathrm{V}$ meiner Arbeit (9o, S. 389-39I) giebt über eine Anzahl dieser Versuche näheren Aufschluß. In neuerer Zeit gelang es mir auch, Nährsalznetze dadurch zur Gametenbildung zu bringen, dafs sie, in Wasser übergeführt, im Dunkeln bei $28^{\circ} \mathrm{ge}$ halten und dann bei Zimmertemperatur beleuchtet wurden.

Aber die besprochenen Nethoden reichen doch nicht für alle Fälle aus. Ich besaß im Winter I889/90 eine Hydrodictyonkultur (90 S. 393), die anfangs leide Arten (ler Fortptlanzung zeigte, die aber nach dem Aufenthalt in Nährlösung auf keine Weise mehr zur Gametenbildung sich zwingen ließ. Selbst die nächste, daraus erzogene Generation ließ sich im Frühjahr I 890 nur sehr schwer zur Gametenbildung bringen, während es bei der dritten Generation sicher und leicht grelang. Die physiologischen 
Gründe für diese Fixierung der ungeschlechtlichen Neigung ließen sich nicht erkennen; jedenfalls müssen besondere Kombinationen äußerer Verhältnisse dabei maßgebend gewesen sein.

Die von mir früher nicht benutzten Aquariumnetze stehen in der Mitte zwischen den Nährsalznetzen mit entschiedener Neigung und anderen Netzen mit schwacher Neigung zur Zoosporenbildung. Dementsprechend sind auch die Versuche ausgefallen, die die Aquariumnetze zur geschlechtlichen Neigung umstimmen sollten, wenn auch meine Untersuchung in dieser Beziehung nicht sehr eingehend war. Die Zuckerlösung veränderte die Neigung der Netze nicht; ihre gametenerregende Wirkung war zu schwach gegenüber dem energischen, zoosporenerregenden Reiz, der durch den Mediumwechsel auf die Aquariumnetze ausgeübt wurde. Dagegen wurde bei diesen die geschlechtliche Fortpflanzung durch den Aufenthalt in verdünnter Luft und bei höherer Temperatur erregt. In den Versuchen mit niedrigem Luftdruck (s. S. I42), bei Gegenwart des Lichtes bildete immer eine Anzahl Zellen der Aquariumnetze Gameten; häufiger war es der Fall, wenn das Licht ausgeschlossen wurde und deshalb niedriger Luftdruck die Zoosporenbildung noch eher hemmen konnte. Auch bei den Versuchen, wo die Aquariumnetze in ein fest zugepfropftes Gefäß gebracht und wieder ins Aquarium gestellt wurden, lieferte immer ein Teil der Zellen Gameten. Ihre Bildung wurde durch den Aufenthalt im Thermostat bei $30-32^{\circ}$ sehr gefördert, wo bereits die Zoosporenbildung etwas gehemmt wird. Nach 24 Stunden schon konnten einige Zellen Gameten erzeugen. Bei allen diesen Versuchen zeigte sich der früher berührte Unterschied zwischen den kleineren und größeren Zellen; die ersteren ließen sich leichter umstimmen als die 
letzteren, obwohl beide unter gewöhnlichen Umständen gleich lebhaft Zoosporen zu bilden vermögen.

Zum Schluß möchte ich noch kurz die Versuche erwähnen, künstliche Parthenogenesis bei Hydrodictyon zu veranlassen. Am luesten ist es für diesen Zweck, wenn man einzelne Zellen, die bereits in der Gametenbildung ziemlich weit vorgeschritten sind, in einen Tropfen einer 1-proz. Nährlösung l,ringt und in der feuchten Kammer beobachtet. Die Gameten werden normal ausgebildet, bewegen sich lebhaft, wenn sie auch meistens nicht austreten. Durch ununterlbrochene Beobachtung überzeugte ich mich, daß keine Kopulation stattfand und daß3 die Gameten schließlich kleine, runde Sporen bildeten. Unter normalen Verhältnissen in Wasser wie in konzentrierter Zuckerlösung kopulieren die Gameten der gleichen Mutterzelle sehr lebhaft. Die Parthenosporen konnte ich indessen nicht zur Weiterentwickelung bringen, während die Zygoten in Nährlösung gleich weiter zu wachsen vermögen. Ich muß mich daher mit der Thatsache begnügen, daß die Gameten ohne Kopulation membranumgebene Sporen bilden können. Unsicher ist es, unter welchen Umständen diese zur weiteren Entwickelung kommen. 


\section{Protosiphon Klebs und Botrydium Wallroth nebst Bemerkungen über die Bedeutung und die Methode der Reinkultur für niedere Algen.}

(Tafel I.)

Botrydium granulatum, die einfachste Form der Siphoneen, gilt nach der bekannten, vortrefflichen Arbeit von Rostafinski und Woronin (77) als eine der formenreichsten Algen, welche die mannigfachsten Anpassungen an die wechselnden, äußeren Bedingungen erkennen läßt. Für meine Untersuchung über den Einfluß äußerer Bedingungen auf die Fortpflanzung erschien Botrydium von besonderem Interesse; eine eingehende Erforschung von neuen Gesichtspunkten aus war notwendig. In der Umgebung Basels findet sich Botrydium an einer feuchten Stelle zwischen Basel und St. Ludwig. Bald nach der ersten Untersuchung konnte ich die durch Rostafinski und Woronin so schön dargestellten Zellformen und Entwickelungszustände beobachten. Doch fiel mir gleich auf, daß zwei, ihrer Zellstruktur nach verschiedene Zellarten hervortraten, die man auch leicht auf den Tafeln bei Rostafinski und Woronin unterscheiden kann, dagegen nicht in der Beschreibung, weil die Forscher, den Anschauungen ihrer Zeit gemäß, kein Gewicht auf den Zellinhalt gelegt haben. Bei der einen Zellart sieht man sehr deutlich einzelne, scheibenförmige 
Chlorophyllkörper, bei der anderen eine einzige, zusammenhängende Chlorophyllschicht. Die einen Zellen bilden unter keinen Umständen Stärke, dagegen viel fettes Oel, die anderen hesitzen Amylonkerne und Stromastärke, und haben ïberhaupt einen ähnlichen Bau wie eine Hydrodictyonzelle. Wenn wirklich diese beiden Zellarten in den Entwickelungsgang ein und derselben Species gehören würden, so wäre dies eine sehr merkwürdige und bedeutungsvolle Thatsache. In diesen Zellarten finden wir die beiden Haupttypen der Zellstruktur, besonders die des Chromatophors vertreten, die unter den niederen Algen verbreitet sind. Rostafinski und Woronin (77), Schmitz (82), Strasburger (84), Berthold (86), die über Botrydium geschrieben haben, behandeln diesen wichtigen Punkt nicht. Meine weitere Untersuchung führte mich zu der Ueberzeugung, daß die beiden Zellarten selbständigen, scharf unterschiedenen Algen angehören, daß die Darstellung bei Rostafinski und Woronin, so richtig sie in vielen Einzelheiten ist, ein ganz falsches Bild der wirklichen Entwickelung von Botrydium giebt. In früherer Zeit sind die beiden Organismen als besondere Pflanzen beschrieben worden; die eine ist das eigentliche Botrydium, eine Siphonee, die andere ist der Protococcus botryoides Kützing (45), dessen Entwickelung schon Cienkowski (55) sehr richtig beschrieben hat. Nachdem bereits Kützing (45 S. 2) den Zusammenhang beider Arten behauptet hatte, schien er durch Rostafinski und Woronin endgiltig bewiesen. Sieht man ihre Arbeit genauer durch, so kann man beide Organismen mit Hilfe der Figuren crut von einander sondern. Auf Taf. $\mathrm{V}$ sind die Figuren Nr. ${ }_{5}$ die einzigen, welche scheinbar den Uebergang der einen in die andere Art angeben. Diese Figuren sind bei schwacher Vergrößerung, ohne Angaben der 
Zellstruktur gezeichnet, sie können deshalb nichts beweisen. Gewisse Stadien der einen Alge erinnern auffallend an solche der anderen, so daß die Annahme ihrer Zusammengehörigkeit erklärlich ist, zumal auch beide an dem gleichen Standort leben. In der weiteren Darstellung werde ich die beiden Organismen trennen; das Hauptgewicht lege ich auf den Protococcus botryoides, den ich wegen der Unhaltbarkeit der Gattung Protococcus als Protosiphon botryoides bezeichnen werde.

Nachdem einmal der Gedanke wachgerufen war, daß das von Rostafinski und Woronin beschriebene Botrydium aus zwei Algenarten bestehe, mußte der Nachweis mit möglichst großer Sicherheit geführt werden. Die gleiche Frage nach der Selbständigkeit oder dem genetischen Zusammenhange niederer Algen tritt uns bei jeder Bearbeitung dieser immer wieder entgegen und beansprucht gerade im Augenblick lebhaftes Interesse. Ich möchte daher den Anlaß benutzen, diese Frage in allgemeinerem Sinne zu betrachten, bevor ich auf den speciellen Fall von Botrydium eingehe; ich möchte versuchen, die Wege zu bezeichnen, die zur Lösung der Frage führen können und die, wie ich hoffe, die große Verwirrung in der Algologie beseitigen werden.

Wenn auch schon in der ersten Hälfte des Jahrhunderts eine Anzahl niederer, grüner Algen beschrieben worden war, so wurde doch erst durch Kützing und Naegeli die Grundlage für unsere heutige Kenntnis dieser Formen geschaffen Namentlich hat Kützing eine Unmasse von Arten beschrieben, die er teils in neue Gattungen, teils in die von $\mathrm{Naegeli}$ mit besonderem Geschick aufgestellten Gattungen verteilte Neben der Neigung zu einer weitgehenden Artspalterei finden wir bei Kützing die Ueberzeugung, daß niedere Algen sich in höhere Formen, sogar in Moosprotonema umwan- 
deln (41). Indessen haben diese polymorphistischen Ideen $K$ ützin w's lieine Geltung erlangen können, weil sie auf zu Hüchtigen Untersuchungen beruhten. Man fuhr ruhig fort, neue Arten und Gattungen niederer Algen zu beschreiben, bis Cienkowski in dem Jahre 1876 seine Beobachtungen über den Palmellenzustand der Fadenalgen, Stigeoclonium, Ulothrix u. s. w. bekannt machte. Durch diese sehr vertrauenswürdigen Untersuchungen schien es bewiesen, daß niedere Algen nur Entwickelungszustände von Fadenalgen sind. Cienkowski sellsst, ebenso andere Forscher sprachen dann auch ihren Zweifel über die Selbständigkeit der meisten einzelligen, grünen Algen aus. Um die Frage zu entscheiden, habe ich I879-I881 viele Kulturen solcher Algen angestellt. Meine Beobachtungen, von denen ich nur einen ganz kurzen Auszug im Jahre I $88_{3}$ veröffentlichte, bewiesen, daß die niederen Algen, bei den damals mir zugänglichen Methoden, sich so selbständig und konstant verhielten, wie irgend eine andere höhere Pflanze.

Der gremeine, überall verbreitete Organismus Pleurococcus vulgaris zeigte $z$. B. nie etwas anderes als vegetative Teilung, und er ließ sich auf keine Wreise in eine andere Alge umwandeln. In der Untersuchung von Artari (92) wurde die gleiche Frage von neuem in Angriff genommen und in gleichem Sinne beantwortet. Ebenso hat Gay (9I) teils für die gleichen, teils für andere Formen ihre Selbständigkeit durch Kulturen nachgewiesen. Indessen taucht die alte Idee eines weitgehenden Polymorphismus bei den Algen immer wieder auf.

Nachdem Hansgirg (85) alle möglichen Algen als Formen einer einzigen Art angenommen hatte, und dabei ebenso kritiklos wie einst $\mathrm{K}$ ïtzing vorgegangen war (vergl. meine Kritik, 86 S. 64I), haben in neuester Zeit Chodat und ganz besonders Borzi den genetischen 
Zusammenhang vieler Algen, die bisher als selbständig galten, verteidigt. Beide Forscher haben Kulturversuche angestellt und dadurch ihren Meinungen größere Berechtigung zu geben versucht. Wie weit Borzi von der Idee des Polymorphismus beherrscht wird, zeigt in seinem neuesten Werke (95) die Behandlung des Formenkreises von Protoderma viride, zu welchem er Arten der folgenden Gattungen rechnet: Protococcus, Botryococcus, Chlorococcum, Limnodictyon, Physodictyon, Palmella, Tetraspora, Nephrocytium, Trochiscia, Oocystis, Scenedesmus, Raphidium. Den Zusammenhang aller dieser Formen will Borzi auf dem Wege der Kultur nachgewiesen haben. Nach der Ansicht dieses Forschers haben die verschiedenartigen Entwickelungszustände „stadii anamorfici", wie z. B. die Raphidium-, ScenedesmusFormen die Fähigkeit, sich unter Umständen jahrelang als solche zu erhalten und zu vermehren, um dann gelegentlich wieder in die höheren Formen umzuschlagen.

Chodat geht in seinen polymorphistischen Ideen sehr viel weniger weit als Borzi und drückt sich weniger klar und bestimmt aus. Er behauptet (93, 94, 95) nur, daß eine Alge, wie z. B. Raphidium, sehr variiere, so daß sie sich bald wie ein Scenedesmus, bald wie ein Protococcus oder ein Characium, Dactylococcus, Sciadium verhalte. Der Scenedesmus verhält sich unter Umständen wie ein Dactylococcus, dieser wie jener. Trotz aller Uebergänge zwischen den niederen Algen, trotz des Schwankens aller ihrer Charaktere und des Verschwimmens aller Grenzen nimmt $\mathrm{Chodat}$ doch eine gewisse Selbständigkeit der Formen an. Nur läßt sich aus seinen Angaben nicht ersehen, ob diese Variationen der niederen Algen auf bestimmten Einwirkungen äußerer Bedingungen beruhen oder vielmehr konstanten Varietäten oder Rassen angehören. Chodat hat auch nicht immer 
die richtigen Konsequenzen gezogen. Denn ist seine Beobachitung (94 S. 6I3) richtigr, daß der schon vorhin erwähnte Pleurococcus vulgaris in ein Stigeoclonium auswachsen kann, so muß er anch zu den verzweigten fiadenalgen gerechnet werlen. Num sagt aber Chodat: "Je ne pense pas que Pleurococcus soit un état d'algue supérieure. Je pense qu' il faut le considérer comme type dégénéré par l'habitat et qui peut dans l'eau et dans les conditions favorables, tendre vers son état primitif". Also es soll Pleurococcus eine Degenerationsform eines Stigrcocloniums sein, die sich aber wie eine sellständiore, einfache Alge verhält. Nimmt man die Beobachtungen von Cliodat und Borzi zusammen, so weit sie sich auf die gleiche Form beziehen, z. B. Raphidium polymorphum (resp. Braunii), so erhält man das Bild einer Species, die an Merkwürdigkeit nichts zu wünschen übrig läßt und einzigartig in der Welt der Organismen dasteht. Demn das Raphidium soll nach Borzi auch in den Formenkreis verschiedener lıöherer Fadenalgen (Prasiola, Ulothrix etc.) gehören; es soll (ladurch entstehen, daß 2 Zoosporen infolge anormaler Entleerung des Sporangiums mit ihren Hinterenden verwachsen und dieses Paar sich dann in Raphidium umwandelt. (Borzi 95 S. 231: „Le mie colture escludono ogni dubbio su tal fatto.") Wenn nicht ein so beliannter, vortretticher Algologe, wie Borzi, diese Behauptungen aufgestellt hätte, so wü̈rle man es srar nicht der Mühe wert finden, ein Wort clarüber zu verlieren; unter diesen Umständen muß man sich damit beschäftigen. Jedenfalls geht aus dieser yanzen Darstellung (leutlich hervor, daß eine grenzenlose Verwirung in (ler Systematik der niederen Algren herisclit, daß sellst über die einfachsten und gemeinsten ()ronismen, wie Pleurococcus, Raphidium etc, die widersprurhvollsten Anschauungen walten. 
Theoretisch läßt sich keine Entscheidung treffen, ob eine Form selbständig ist oder genetisch mit einer anderen zusammenhängt. Es ist thatsächlich vorgekommen, daß Formen, die früher für selbständig galten, als Entwickelungszustände anderer Arten sicher nachgewiesen worden sind. Es ist denkbar, daß unter der Masse der beschriebenen Algenarten viele das gleiche Schicksal treffen wird. Der einzig mögliche Weg, zur Klarheit und Gewißheit zu kommen, ist die Anwendung einer jeder Kritik standhaltenden, wissenschaftlichen Methode.

Es ist merkwürdig, daß aus der Geschichte der Wissenschaft so wenig gelernt wird. Schon zweimal hat in der Botanik der gleiche Streit über den Polymorphismus geherrscht, zuerst bei den Pilzen und dann bei den Bakterien. Beide Male ist dieser Streit aus unfruchtbaren Diskussionen in die richtigen, streng wissenschaftlichen Bahnen geleitet worden, als man die Reinkultur der Organismen als notwendigen Ausgangspunkt für jede Untersuchung in dieser Richtung verlangte. Chodat und Borzi hätten nun in der heutigen Zeit für die Lösung der sie beschäftigenden Fragen von der Reinkultur ausgehen müssen; sie haben es nicht gethan.

In der Algologie hat überhaupt die Reinkultur bisher keine Rolle gespielt; unsere Kenntnisse sind auf dem Wege der direkten Beobachtung gewonnen worden, die durch Forscher, wie Thuret, Cohn, Pringsheim, de Bary u. a. in vollendetster Weise benutzt worden ist. In der That sind die charakteristischen Eigenschaften vieler Algen völlig genügend, um diese unter anderen Organismen zu erkennen und ihre Entwickelung bei fortlaufender direkter Beobachtung zu verfolgen. Es kommt noch hinzu, daß die Kultur vieler dieser Algen auf große Schwierigkeiten stößt. Auch niedere Algen giebt es, bei denen unreine Kulturen zu keinen Verwechselungen An- 
laß gegeben haben. Formen, wie Hydrodictyon, lassen sich in ihrer ganzen Entwickelung beobachten, wenn auch andere kleinere oder größere Algen sich daneben vorfinden. Ganz anders liegt aber die Sache bei allen jenen Algen, deren äußere, merkbare Eigenschaften geringfügrig sind, bei denen zugleich eine solche Mannigfaltigkeit der Artbildung herrscht, daßs alle mögrlichen, sog. Uebergangsformen existieren. Das ist der Fall z. B. bei den in der Luft lebenden, ulothrixartigen Orgarismen, eljenso bei den niederen, grünen Algen, den zahlreichen Pleurococcus-, Protococcus-, Palmella- etc. Arten, die äuberst leicht mit einander verwechselt werden könn n. Nun kommt hinzu, daß thatsächlich die höheren Algen Entwickelungszustände besitzen, die in ihrer äußeren Erscheinung niederen Algen gleichen; der fehlerhafte Schluß, daß deshalb alle niederen Algen überhaupt Entwickelungsformen höherer Algen seien, ist oft genug gemacht worden. Schwärmende Gameten von Chlamydomonasarten kann man nicht von Gameten von Ulothrix unterscheiden; daraus folgt doch nicht, daß Chlanydomonas zu Ulothrix grehört. So können Fadenalgen protococcusartige Zustände bilden; daraus folgt ebensowenigg, daß alle Protococcusarten zu höheren Fadenalgen gehören. Die bloßse formale Aehnlichkeit oder scheinbare Gleichheit zweier Formen entscheidet nichts; wer sich darauf verläist, läuft Gefahr, in die gröbsten lrrtümer zu verfallen. Selbst zwei so ausgezeichnete Forscher wie Rostafinski und Woronin haben sich bei ihren Beobachtungen über Butrydium nur dadurch täuschen lassen, daß die Entwickelungszustände vom echten Botrydium und von Protosiphon äußerlich eine auffallende Aehnlichkeit besitzen.

Fis fragt sich nun, in welcher Weise man vorgehen muss, um das Problem über die Selbständigkeit oder 
den genetischen Zusammenhang zweier oder mehrerer Algen mit möglichster Sicherheit zu lösen. Nach meiner Ansicht müssen für die Untersuchung drei wesentliche Forderungen aufgestellt werden:

I) Die Reinkultur der in Frage kommenden Organismen.

Eine solche Reinkultur, wie sie für jede entwickelungsgeschichtliche Untersuchung eines Pilzes oder einer Bakterie selbstverständlich ist, muß auch für niedere Algen den notwendigen Ausgangspunkt bilden. Im allgemeinen wachsen die Algen viel langsamer als die Pilze und Bakterien; die Kulturen bedürfen daher einer längeren Zeitdauer, und die Gefahr der Verunreinigung einer ursprünglich reinen Kultur darf auch bei den Algen nicht außer Acht gelassen werden. Denn kleine Zellen, Sporen der Protococcoideen etc. befinden sich im Staube der Luft. Man braucht nur eine sterilisierte Nährsalzlösung, nicht sehr geschützt, im Licht stehen zu lassen, um sich zu überzeugen, daß Algen durch den Staub in sie hineinkommen. Aus den Arbeiten von Chodat und Borzi geht hervor, daß diese Forscher nur unreine Kulturen zur Verfügung gehabt haben, weil sie das der freien Natur direkt entnommene, stets artenreiche Algenmaterial meist in größerer Menge zu ihren weiteren Kulturen verwendet haben, weil sie auch, soweit sich dies nach ihren Arbeiten beurteilen läßt, keine Rücksicht auf die Fehlerquelle des Staubes genommen haben.

2) Die direkte Beobachtung.

Stets ist es notwendig bei den niederen Algen ihre Entwickelung oder den Uebergang der einen Zellform in die andere direkt unter dem Mikroskop zu beobachten. Diese Methode kann unter Umständen den Mangel einer Reinkultur ersetzen, sie muß in jedem Falle angewandt werden, auch wenn man eine Reinkultur allem Anschein 
nach besitzt. In Verbindung mit ihr wird sie sehr sichere Resultate geben. Chodat und Borzi haben viel zu wenig diese Methode angewandt. So hätte Borzi die Doppelzoosporen von Prasiola etc. isolieren und ihr weiteres Schicksal ununterbrochen beobachten sollen, um sich zu ïberzeugen, daß sie sich wirklich in Raphidium umwandeln. Ebenso notwendig wäre es gewesen, aus dem Raphidium wieder die Fadenalge, sei es Prasiola oder Protoderma, direkt hervorgehen zu sehen, was Borzi, wie es scheint, nicht beobachtet hat. Das gleiche gilt von der Behauptung Chodat's, daß Pleurococcus vulgaris in Stigeoclonium sich umwandle. Auch er hat nicht eine unzweifelhafte Pleurococcuszelle unmittelbar in Stigeoclonium übergehen sehen, ebensowenig hat er den Uebergang von diesem in Pleurococcus beobachtet.

3) Die genaue Kenntnis der Bedingungen, unter welchen die einzelnen Entwickelungsstadien eintreten, oder der Uebergang der einen Form in die andere stattfindet.

Diese Forderung hat bisher auch bei anderen Organismen, z. B. den Pilzen, noch kaum irgend welche Beachtung gefunden und ist auch noch nie als notwendig erkannt worden, weil man bisher nicht daran gedacht hat, laß die Bedingungen sich erkennen lassen. In den Arbeiten, die den Polymorphismus behandeln, seit Kützing bis auf Borzi, wird allerdings den äußeren Bedingungen große Bedeutung für die Formumwandlung zugeschrieben, aber nur in einer ganz allgemeinen, unbestimmten und unklaren Weise. Niemals ist irgend eine der Entwickelungsformen als notwendige Folge bestimmter äußerer Bedingungen klar erkannt und nachgewiesen. sondern jede ist meist zufällig und gelegentlich beobachtet worden. In seiner Arbeit über Eremosphaera beschreibt Chodat (95) neben den beliannten typischen Zellen 
kleine Zwergformen mit etwas veränderter Struktur, er beschreibt Palmella-Gloeocystiszustände, er bringt auch eine Chlamydomonasform in Zusammenhang mit diesen, alles Entwickelungsformen, vielleicht auch selbständige Arten, die zufällig in der gleichen Kultur von Eremosphaera sich vorgefunden haben. Nirgends finden wir eine Andeutung, wie man sich erklären soll, daß so verschiedene Zustände bei der gleichen Alge in der gleichen Kultur auftreten.

Nachdem meine Untersuchungen gezeigt haben, daß in der That die Außenwelt für das Auftreten von Fortpflanzungsformen vieler Algen entscheidend ist, muß jetzt bei allen ähnlichen Arbeiten wenigstens versucht werden, die für jede Entwickelungsform charakteristischen Bedingungen aufzufinden.

Das nächste erreichbare Ziel muß die Lösung der Aufgabe sein, die Bedingungen so genau kennen zu lernen, daß man die Entwickelungsform willkürlich jederzeit hervorrufen kann. Natürlich erfordern diese Untersuchungen sehr viel Mühe und viel Zeit; dabei können sie bei manchen Organismen nicht zu dem gewünschten Ziele führen. Denn trotz der festen Ueberzeugung, daß äußere Bedingungen bei gewissen Arten bedeutungsvoll sein müssen, können sie doch nicht klar genug erkannt werden, wie es mir z. B. bei Ulothrix zonata, Hormidium nitens etc. gegangen ist. So lange bleibt dann eine Lücke, die mit Hilfe besserer Methoden später ausgefüllt werden muß. Oder eine Entwickelungsform kann möglicherweise nur aus inneren, daher unerkennbaren Gründen auftreten; dann zeigt sie sich, nach allen Erfahrungen, auch ganz regelmäßig in geeignetem Lebensstadium und kann stets wenigstens in ihrer Beziehung zur Species beobachtet werden. Bei allen niederen Algen, die ich hauptsächlich hier im Auge habe, nötigen meine Erfahrungen zu der 
Ueberzeugung, dafs für das Auftreten jeder Entwickelungsform äufere Bedingungen maßgebend sind; daher gilt es jetzt, dieser Forschungsrichtung bei den Arbeiten über solche Algen die größte Beachtung zuzuwenden.

Wenn nun auf den von mir angegebenen Wegen die niederen Algen untersucht werden, so wird es möglich sein, aus cler jetzt herrschenden Verwirrung herauszukommen und die Algologie auf einen höheren Standpunkt zu bringen. Solche Untersuchungen werden nach meiner Ansicht für die Speciessystematik nicht bloß dadurch Bedeutung haben, daß der Formenkreis einer Art bestimmt wird, sondern auch, daß neue Charaktere für die Beschreibung der Species erkannt werden. Die Art, wie die niederen Organismen in ihren verschiedenen Lebensstadien auf äußere Einwirkungen reagieren, besonders die Art der Abhängigkeit ihrer Fortpflanzung von der Außenwelt giebt ebenso wichtige Speciesmerkmale, wie sie die Morphologie liefert. Diese physiologischen Charaktere werden um so wichtiger, je unbedeutender die äußeren Merkmale sind. Bei den Bakterien hat luereits die Not dazu geführt, ihre physiologischen Eigenschaften mit zu berücksichtigen. Die Zeit wird nicht mehr sehr fern sein, wo es sellsstverständlich sein wird, daß in der Diagnose einer neuen Alge, nelsen der genauen Kenntnis der Struktur und der Entwickelungsgeschichte, das Verhalten gegen die Außenwelt klar ausgedrückt wird. Hier bei solchen niederen Organismen wird man sich am ehesten dem eigentlichen Ziele der Systematik nähern, von einem Organismus ein Gesamtbild aller seiner Eigenschaften zu entwerfen, während heutzutage in diesem Gebiete der Botanik noch viel zu sehr der Zweck der Bestimmung, der Namengebung, im Vordergrunde steht.

Alle meine neueren Erfahrungen an den Algen bestätigen meine früheren, stimmen mit den Ergebnissen der 
Bakterien- und Pilzkunde darin überein, daß die Außenwelt innerhalb der Versuchszeit nicht wesentlich die erblichen Eigenschaften eines Organismus verändert. Die Variationen in der Größe, Gestalt, der Zellstruktur, in dem Abhängigkeitsverhältnis zur Außenwelt bewegen sich innerhalb bestimmter, bisher nicht überschreitbarer Grenzen. Die Konstanz der Species tritt wenigstens bei den Kulturen und Versuchen auffallend klar entgegen; es wird von weiteren Versuchen mit längerer Dauer, besseren Methoden abhängen, ob die Grenzen nicht doch durchbrochen werden können. Darauf weisen schon die wichtigen Beobachtungen an gewissen Bakterien hin, bei denen erbliche Eigenschaften, wie die der Virulenz, der Farbstofferzeugung, lange Zeit hindurch unterdrückt werden können. Aehnliches konnte bisher bei den Algen nicht erreicht werden, ist aber später zu erreichen möglich. Trotz der thatsächlichen Konstanz der Artcharaktere bei den Algen ist die Schwierigkeit, die Arten in Gattungen, Familien einzuordnen, außerordentlich groß, weil eine überraschende Mannigfaltigkeit der Artbildung vorhanden ist. Es finden sich, zwischen den für die Gattungen typischen Arten, zahlreiclıe andere Algenformen, Varietäten, die jede für sich eine konstante Form darstellen, aber die Grenzen zwischen den Gattungen und Familien verwischen. Bald wird für die niederen Algen das gleiche gelten, was ich bei der Bearbeitung des Flagellatensystems (92) ausgesprochen habe, daß, je mehr wir den Formenreichtum übersehen, unser System immer schwieriger und künstlicher wird. Der Widerspruch zwischen der Konstanz der einzelnen Form, nennen wir sie Art oder Varietät, und der Veränderlichkeiten aller Eigenschaften innerhalb eines größeren Formenkreises, sei es Gattung, sei es Familie u. s. w., ist bisher noch nicht beseitigt; der Darwinismus hat diesen Wider- 
spruch erst klar aufgedeckt, aber noch nicht zu lösen verstanden.

Aus der vorliegenden Darstellung wird die große Bedeutung der Reinkultur auch für die niederen Algen hervorgehen; jetzt handelt es sich um die praktische Methode. Die ersten Reinkulturen verdankt man Beyerinck (90), der die Methoden der Bakterienkultur bei niederen Algen anwandte, indem er diese auf Gelatine mit Zucker, Pepton etc. erzog. Seine Versuche zeigen, dał3 Algen, wie Scenedesmus, Chlorella, auf solchen organischen Substraten wachsen können. Beyerinck hat mehrere Jahre hindurch diese Kulturen fortgesetzt. Die Thatsache, daß Algen organische Stoffe, namentlich Kohlehydrate, zu ihrem Wachstum benutzen können, haben ich (Klebs 87), ferner Loew (87 S. 277) durch Versuche mit Spirogyra und Zygnema nachgewiesen. Es liegt nichts auffallendes darin, daß die Algen auch auf Gelatine wachsen, und für manche Fragen wird diese Methode stets von Bedeutung sein. Besonders zeigen dies die neueren Reinkulturen, welche Krüger (94) mit einigen niederen Algen angestellt hat, die ausgezeichnet auf und in organischen Substanzen zu leben vermögen. Aber es kommt dieser Methode für die Kultur der niederen Algen keine allgemeine Bedeutung zu; die Algen auf Gelatine mit Pepton wachsen zu lassen, ist sehr unpraktisch und rerdoppelt die Schwierigkeiten. Man kann nicht einfach die Bakterienmethoden auf die Algen übertragen, weil diese doch wesentlich andere Ernährungsbedingungen verlangen. In welchem Maße ïberhaupt die Algen in den Kulturen Beyerinck's organische Substanzen direkt verarbeitet haben, läßt sich nicht erkennen. Alle Kulturen Beyerinck's standen im Licht; nie ist es ihm gelungen, wirklich die Algen saprophytisch gleich Bakterien zu erziehen. Wodurch nun Gela- 
tine und Pepton doch günstig auf das Wachstum gewirkt haben, können wir bisher nicht einsehen. Wahrscheinlich haben die beigemischten Bakterien die stickstoffhaltigen Bestandteile des Substrates in die für Algen leichter assimilierbaren Stoffe umgewandelt.

Den Ausspruch Beyerinck's, daß Scenedesmus als Stickstoffquelle nur Peptone, nicht aber Ammoniaksalze und Nitrate benutzen könne, halte ich für entschieden falsch, da die betreffende Alge in üppigster Weise in rein anorganischen Lösungen mit Nitraten wächst. Für die Zwecke der Reinkultur von grünen Algen halte ich die Gelatinemethode sowohl in praktischer wie theoretischer Richtung für nicht geeignet; denn man muß unnütze Mühe darauf verwenden, die Bakterien fern zu halten, und man kann, da diese bei längeren Kulturen doch nie ganz ausgeschlossen sind, die direkte Wirkung der organischen Stoffe nicht scheiden von der durch die Bakterienvegetation erst vermittelten. Viel aussichtsreicher wird diese Methode für solche Algen sein, die eine entschiedene Vorliebe für organische Stoffe haben, wie die Oscillarien etc. oder wie die von Krüger (94) beschriebenen Formen Chlorothecium saccharophilum, Chlorella protothecoides, die überhaupt als Uebergangsformen $\mathrm{zu}$ den Pilzen erscheinen.

Mein Streben, Reinkulturen zu erhalten, ging davon aus, diejenigen Bedingungen zu schaffen, die für die Ernährung der grünen Pflanzen maßgebend sind, und das sind die anorganischen Salze in Verbindung mit dem Licht. Die Bedeutung der Salze für die Algenkultur hat zuerst Famintzin (7I) erkannt. Nachdem ich schon seit längerer Zeit für den gleichen $Z$ weck die Nährsalze angewandt hatte, habe ich in den beiden letzten Jahren mit ihrer Hilfe von einigen Algen Rein- 
kulturen gewonnen. Man kann, wie bei den Bakterien, Hüssige und feste Nährmedien anwenden; es ist das beste stets beide Methoden neben einander zu benutzen. An dem speciellen Beispiel von Protosiphon will ich die Art meines Vorgehens angeben.

Man nimmt von dem Standorte in der freien Natur, an dem die Alge mit Botrydium und zahlreichen anderen Formen vorkommt, einige wenige von den grünen oder roten Zellen und bringt sie in eine Nährlösung von 0,2 bis 0,4 Proz. ans Licht. Allmählich entwickelt sich teils auf, teils in der Flüssigkeit eine lebhafte Algenvegetation von Diatomeen, Oscillarien, Protococcoideen, Ulothricheen. Unter ihnen wird man leicht die schlauchförmigen Zellen von Protosiphon erkennen, die man bei schwacher Vergrößerung mit einer feinen Glaspipette herausnimmt und in einem reinen Wassertropfen verteilt Man sucht sich dann mit einer solchen Pipette wenige Zellen davon aus und versetzt sie in sterilisierte Nährlösung. Nach einiger Zeit bilden sich neue Zellen, kleine Gruppen, die man jetzt, schon freier von anderen Organismen, herausnehmen und in frische Lösungen bringen kann. Man setzt dies Verfahren so lange fort, bis man eine Reinkultur erhält.

Man könnte zur Isolierung das Koch'sche Plattenverfahren modifiziert anwenden; aber da es sich bei den mich interessierenden Algen um Zellen handelt, die bei schwächerer Vergrößerung noch sichtbar sind, so kann man ganz gut die Zellen mit einer sehr fein ausgezogenen Glaspipette fischen. Für die Kultur selbst benutze ich fast ausschließlich Glasdosen mit übergreifendem Deckel, der Luftcirkulation gestattet und doch vor dem Staube schützt, der, wie ich schon bemerkte, ein großer Feind der Reinkulturen auch von Algen ist. In jedem Falle 
ist es zweckmäßig, wenigstens eine solche Reinkultur möglichst unberührt stehen zu lassen, um sie nur zur Gewinnung neuer Reinkulturen zu benutzen, die dann zum näheren Studium verwendet werden. Für die Benutzung aller Gegenstände, Glassachen, Pipetten, Nährflüssigkeiten gelten dieselben Regeln der Sauberkeit, der Sterilisation, wie bei den Pilz- und Bakterienkulturen.

Für die Kultur auf festen Substraten kann man entweder undurchsichtige oder durchsichtige Stoffe anwenden. $\mathrm{Zu}$ den ersteren gehört sterilisierter Sand mit Nährlösung getränkt und feuchter Lehm, auf dem die meisten Luftalgen ausgezeichnet gedeihen, Rindenstücke u. dergl. Als durchsichtigen Nährboden habe ich meist Agar-Agar benutzt. Die von Beyerinck empfohlene Gelatine hat sich als weniger brauchbar erwiesen, weil sie sich viel leichter verändert und in ihr leichter Bakterien auftreten. Agar-Agar fault nicht, die Gallerte enthält wenig nährende Bestandteile, so daß die Algen nur dann auf ihr wachsen, wenn Nährsalze zugefügt werden. Ich bereite mir den Nährboden in der Weise, daß ich 0,5 g Agar-Agar in $100 \mathrm{ccm}$ Nährlösung von 0,2, 0,4 oder auch I Proz. einweiche, erhitze, filtriere und sterilisiere. Für solche Kulturen von Protosiphon habe ich, von einer Reinkultur ausgehend, Schwärmer entstehen lassen, die dann auf die Agargallerte gebracht wurden.

In der ersten Zeit habe ich Kieselsäuregallerte benutzt, die von $\mathrm{K} u ̈ h \mathrm{ne}$ zuerst empfohlen und auch von Kossowitsch (94) benutzt worden ist. In der That wachsen die Algen, z. B. auch Diatomeen, ausgezeichnet auf und in der Gallerte, die ich von einer Kieselsäurelösung einfach durch einen Zusatz starker Nährsalzlösung gewann. Leider ist die Herstellung und Haltbarkeit der Kieselsäurelösung mit großen Schwierig- 
keiten verknüpft, so daß ich mich schließlich auf den Agar-Agar beschränkt habe.

Wenn ich bisher von Reinkultur gesprochen habe, so soll damit nur gesagt sein, daß eine bestimmte Algenart durchaus frei von irgend welchen anderen Algen aufwächst; dagegen ist das Vorhandensein von Bakterien nicht absolut ausgeschlossen. In den Nährsalzlösungen sind sie auch bei lang andauernden Kulturen so vereinzelt, daß man nach ihnen suchen muß. In Agarkulturen können sie bei wochenlanger Kultur etwas häufiger auftreten; aber so lange die Kultur beleuchtet wird, kommen sie nicht $z u$ einer nennenswerten Entwickelung, und selbst in schattig stehenden Kulturen schaden sie nichts.

Die Kulturvorschriften, die ich gebe, gelten zunächst für die Algen, die ich genauer untersucht habe, Protosiphon, Hormidium, Chlamydomonas. Für andere Algen, namentlich Protococcoideen, werden sie in gleicher Weise anwendbar sein, wenn auch für jeden einzelnen Fall ausprobiert werden muß, unter welchen Umständen die Alge am besten wächst, so dafs danach die Vorschriften sich ändern. Das Protosiphon soll zugleich als Beispiel dienen, um zu zeigen, wie weit man die von mir aufgestellten Forderungen praktisch durchführen kann. Das höchste Ziel, die vollständige Beschreibung des Organismus, ist nicht im entferntesten erreicht. Das liegt zunächst an den Grenzen unseres Könnens, vor allem an der relativ niederen Stufe, auf der die Zellenlehre und die Physiologie stehen. Alle wesentlichen Fragen des Zellenlebens kommen bei dem Versuch einer solchen Beschreibung zum Vorschein und müssen bei dem jetzigen Stande der Wissenschaft meist unbeantwortet bleiben. Man erkennt an einem solchen einzelnen Beispiel, wie wir nirgends in die Tiefe dringen können, sondern nur an der Oberfläche bleiben müssen. Dagegen das nächste Ziel, das ich mir 


\section{- $187-$}

vorgesetzt hatte, die Lösung der Frage, ob Protosiphon eine selbständige Form sei oder zu Botrydium gehöre, hoffe ich erreicht $z u$ haben. Wir wollen jetzt den Organismus näher kennen lernen. Seine Untersuchung wurde im Sommer I 894 begonnen, im Sommer I895 fortgesetzt, im Herbst und Winter 1895 beendet.

\section{Der Bau der Zellen von Protosiphon.}

Die Gestalt der Zellen ist sehr mannigfaltig, wie bereits Cienkowski (55 Taf. XI), Rostafinski und Woronin (77 Taf. III, Fig. 29-36; Taf. IV, Fig. 37-4I) dargestellt haben; man vergleiche auch meine Tafel I. Die Form wechselt in hohem Grade, je nach den äußeren Bedingungen. Bei vollster Ausbildung auf feuchtem Lehm, in heller Beleuchtung, wobei die Alge einen dichten, grünen Ueberzug des Lehmes bildet, haben die Zellen in der That die Gestalt kleiner Botrydiumpflänzchen (Taf. I, Fig. I). Sie bestehen aus einem oberirdischen, grünen, ovalen bis kugeligen Köpfchen, dessen Länge bis zu $0,4 \mathrm{~mm}$ betragen kann, und einem langen, dünnen, farblosen, im Boden steckenden Wurzelfaden von einer Länge bis $\mathrm{zu} \quad 0,8 \mathrm{~mm}$ und einer Dicke von 0,016 bis $0,032 \mathrm{~mm}$. Doch selbst in den prächtigsten Kulturen erlangen die Köpfchen niemals die durchschnittliche Größe von $\mathrm{I}-2 \mathrm{~mm}$, die bei Botrydium sich findet, und der Wurzelteil zeigt niemals die lebhafte Verzweigung von Botrydium; er ist vielmehr meist unverzweigt.

Auf sehr feuchtem Lehm, in den trüben Wintermonaten November und Dezember, auch im Sommer bei dichter Aussaat sind die Zellen von Protosiphon lang schlauchförmig, weil der grüne, obere Teil in die Länge gestreckt, keulenförmig bis cylindrisch erscheint. Ebenso beobachtet man bei heller Beleuchtung innerhalb 
von Nährlösungen von $0,4^{-1}$ I Proz. lange schlauchförmige Zellen, die durch Aussprossungen und Verzweigungen sehr verschiedenartiges Aussehen gewinnen (Taf. I, Fig. I6). In nährsalzarmem Wasser bleiben die Zellen klein, kugelig bis kurz keulenförmig, und das gleiche ist der Fall in Nährlösungen bei schwacher Beleuchtung̣.

Bei allem Wechsel der äußeren Gestalt bleibt die innere Struktur der Zelle sich im wesentlichen gleich. Die Zellhaut ist dünn, ohne auffallende Merkmale, sie färbt sich nicht mit Chlorzinkjod, wohl aber mit Jod und Schwefelsäure. Der Protoplast besteht wie bei Hydrodictyon der Hauptmasse nach aus der großen Zellsaftblase, die von einem relativ dünnen Wandbeleg umgeben ist. Nur in den jungen, noch kugeligen Zellen füllt das Protoplasma das Innere fast ganz aus, während der Zellsaft auf lileinere Vakuolen beschränkt ist. Im plasmatischen Wandbeleg folgt auf eine dünne, farblose, äußere Schicht der Chromatophor, der in kugeligen Zellen die ganze Peripherie der Zelle einnimmt, bei den langen, botrydium-ähnlichen Zellen nur im oberen angeschwollenen Teile sich befindet. Der Chromatophor stellt eine dünne, netzförmig durchbrochene Platte dar, die bei stärkerer Vergrößerung sehr feinkörnig erscheint, ohne die Zusammensetzung aus kleineren Stücken wie bei Hydrodictyon zu zeigen (Taf. I, Fig. I5).

Je nach den Ernährungsbedingungen ist der Chromatophor stärker oder schwächer ausgebildet. Am mächtigsten wird er in einer Nährlösung von I Proz. bei heller Beleuchtung. Dicke Leisten springen von der Platte nach innen vor und vereinigen sich $z u$ einem den Zellsaft durchsetzenden Netzwerk. Ein nie fehlender Bestandteil sind die Amylonkerne, die in größeren Zellen in Mehrzahl vorhanden sind; sie liegen in der Chlorophyllschicht, nach innen vorspringend oder finden sich 
auch in den Netzleisten. Das Pyrenoid ist von einer Hülle kleiner Stärkekörnchen umgeben. Bei Wasser- oder Lehmkulturen, ebenso in verdünnten Nährlösungen sind in dem Chromatophor zahlreiche Stärkekörnchen (Stromastärke) eingelagert, die dagegen in einer Nährlösung von I Proz. wie bei Hydrodictyon nicht zur Ausbildung kommen. Fettes Oel findet sich bei gesunden Kulturen nur in kleinen Tröpfchen und sammelt sich erst unter ungünstigen Verhältnissen in größerer Menge an. In der Plasmaschicht an der Innenseite des Chromatophors liegen zerstreut kleine Zellkerne von gleichem Bau wie bei Hydrodictyon (Taf. I, Fig. $15 \mathrm{n}$ ). Sie finden sich ebenso in dem chlorophyllfreien Teile der Zelle. Ueber die Beschaffenheit des Zellsaftes ist nichts näheres bekannt.

Die Zellen von Protosiphon können sich, wie Cienkowski, ebenso Rostafinski und Woronin beschrieben haben, auf dreierlei Weise fortpflanzen:

a) durch Teilung,

b) durch unbewegliche Sporen,

c) durch Schwärmer (Gameten).

Alle diese Entwickelungsformen lassen sich in den feuchten Kammern beobachten, weshalb bei der ganzen folgenden Untersuchung von dieser Methode der ausgedehnteste Gebrauch gemacht worden ist. Den Ausgangspunkt bildeten in allen Fällen die Reinkulturen der Alge auf Lehm oder in Nährlösungen.

\section{Die Teilung von Protosiphon.}

Die Teilung der Zelle kann, wie die genannten Forscher beobachtet haben, in verschiedener Art verlaufen. Die kleinen, jungen Kugeln können durch wiederholte Zweiteilung mit Zellwandbildung Gruppen von 4 
oder 8 oder I6 Zellen erzeugen, von denen dann jede zu einer schlauchartigen Pflanze heranwachsen kann. Daher sieht man auch in den Nährsalzliulturen so viele kleine Gruppen von solchen, an der Basis noch zusammenhäng̣enden Schläuchen (Taf. I, Fig. 2).

Die schlauchartigen Zellen können sich weiter teilen, indem sie seitliche Ausstülpungen treiben, die dann durch eine Querwand abgetrennt werden und sich wieder zu Schläuchen heranbilden können (vergl. Rostafinski und Woronin 1. c. Fig. 29-4I). So entstehen sehr verschiedenartig geformte, wenigzellige Kolonien. Seltener findet die Teilung so statt, daß ein wenigzelliger, unverzweigter Faden entsteht.

Das Aussprossen kann unter Umständen noch einen eigentümlicheren Charakter annehmen. An dem angeschwollenen grünen Ende der Zellen werden nebeneinander kleine Auswüchse getrieben, die durch eine Querwand abgetrennt werden, sich seitlich berühren und dann eine besondere Zellschicht auf dem Scheitel der Hauptzelle bilden.

Die Bedingungen, von denen die beschriebenen Teilungsweisen abhängen, sind noch nicht näher aufgeklärt. Nur soviel läßt sich sagen, daß äußere Verhältnisse eine Rolle dabei spielen. Unter sehr günstigen Umständen, auf nährsalzreichem Lehmboden in feuchter Luft, können die kleinen, anfangs kugeligen Zellen direkt zu den typischen, botrydiumartigen Pflänzchen heranwachsen; vorhergehende Teilungen sind nicht absolut notwendig. Die Teilung selbst hängt sehr wesentlich von der Beleuchtung ab; sie wurde niemals im Dunkeln beobachtet, und sie ist bei schwachem Licht, z. B. im November und Dezember, sehr behindert. Sie tritt auch dann nicht ein, wénn die jungen Zellen in Rohrzuckerlösungen bei höherer Temperatur, z. B. $25^{\circ}$, kultiviert 
werden. Dagegen kann man stets lebhafte Teilungen erhalten, wenn junge Zellen in wenig Nährlösung hell gestellt werden. Die Auszweigungen der schlauchartigen Zellen treten besonders innerhalb der Nährlösungen auf, ebenso bei sehr feucht gehaltenen Lehmkulturen. Die Bildung kleiner Zellen an dem Scheitel beobachtete ich vor allem an solchen Zellen, die in Nährlösung von 0,4-I Proz. an der Oberfläche über die Flüssigkeit hinaus gewachsen waren.

\section{Die Sporenbildung von Protosiphon.}

Die Zellen von Protosiphon können, wie Cienkowski zuerst beschrieben hat, Rostafinski und Wor on in bestätigt haben, unbewegliche, runde Sporen bilden, die jahrelange Trockenheit ertragen. Bei ihrer Bildung zieht sich der Protoplast von der Zellhaut zurück, zerfällt je nach seiner Größe in eine Anzahl von rundlichen, kleineren Zellen, die, von einer Membran umgeben, die Sporen vorstellen (Taf. I, Fig. 4). Gegenüber den vegetativen Zellen zeichnen sich die Sporen durch die Reduktion des Zellsaftes aus. Das Plasma samt Chromatophor und Zellkernen füllt mehr oder weniger das Zellinnere aus; die Amylonkerne liegen gewöhnlich im Centrum der Zelle.

Die Gestalt der Sporen ist meistens kugelig, wenn nicht mechanische Hindernisse entgegenwirken, wie der gegenseitige Druck der Sporen oder in den schmalen Zellen der Gegendruck der Zellmembran. Die Größe der Sporen schwankt naturgemäß sehr; bei den größeren Zellen haben sie durchschnittlich einen Durchmesser von $23 \mu$. Die Zahl der Sporen hängt von der Größe, der Gestalt und dem Wassergehalt der Zellen ab. In dem kugeligen oder keuligen oberen Teile einer Zelle zerfällt 
der Zellinhalt in einen Haufen ron Sporen. Man kann je nach der Größe der Zelle 2, 4, 8 Kugeln und mehr zählen, so daßs es den Anschein hat, als ginge der Zerfall nach der Zweizahl vor sich. In dem langen schlauchartigen Teil der Zellen, oder überhaupt bei einer schmal cylindrischen Gestalt dieser, zerfällt der Protoplast in eine Reihe nebeneinander liegender Sporen. Wenn die Zellen klein sind und einen relativ kleinen Zellsaft besitzen, so kontrahiert sich der Protoplast nur wenig und wird ohne Teilung zu einer Spore. Die ganze Kontraktion kann sich darauf beschränken, daß eine neue Zellhautschicht an die alte angelegt wird. Die vegetativen, kleinen Zellen wandeln sich dann direkt in Sporen um.

Die Bedingungen der Sporenbildung lassen sich einigermaßen erkennen, da man jederzeit den Prozeß bei Protosiphon hervorrufen kann. Verschiedene Methoden führen zu dem gleichen Ziel. Zunächst liann, wie bereits Cienkowski beobachtete, durch Wasserentziehung, z. B. allmähliches Eintrocknen, die Sporenbildung veranlaßt werden. Das gleiche geschieht bei der Anwendung wasserentziehender Flüssigkeiten. Bringt man gesunde, wachsende Zellen aus einer Agarkultur oder einer Nährlösung von 0,2 Proz. in eine solche ron 2 Proz., die an und für sich noch keine Plasmolyse herbeiführt, so erfolgt sanz langsam im Laufe von 24 Stunden die Bildung membranumgebener Sporen und zwar ebenso im Dunkeln wie im Licht.

Ferner kann auch die Sporenbildung, innerhalb einer Flüssigkeit ohne besondere wasserentziehende Eigenschaften, erfolgen, dann, wenn ein Mangel an notwendigen, anorganischen Salzen eintritt. In reinem Wasser gehen schließlich alle Zellen zur Sporenbildung über, voraussresetzt, dals das Licht mitwirkt. Die Zellen hören auf zu wachsen, fahren fort $\mathrm{zu}$ assimiliren, und hiermit sind 
bei Protosiphon chemische Veränderungen des Zellsaftes verbunden, die zu einem Ausstoßen von Wasser, der Kontraktion des Protoplasten und seiner Umbildung in Sporen führen. Im Dunkeln dagegen findet, auch nach Wochen, die Sporenbildung unter solchen Umständen nicht statt, was uns zeigt, daß für den Prozeß eine gewisse Summe von Nahrungsstoffen in der Zelle vorhanden sein muß.

Die Sporenbildung tritt ebenso in Nährlösungen ein, wenn diese durch die Alge chemisch verändert und dadurch für ihr weiteres Wachstum ungeeignet geworden sind. Je nach der Menge der Nährflüssigkeit im Verhältnis zur Alge geschieht der Prozeß bald schneller bald langsamer; auch hier fördert ihn helle Beleuchtung, weil das Wachstum und die Vermehrung durch sie rasch gesteigert werden; besonders schnell wirkt direkte Bestrahlung durch die Sonne.

Rostafinski und Woronin geben bereits an, daß die Sporen bei der Insolation entstehen, was leicht $z u$ beobachten ist, wenn man eine Lehmkultur in die Sonne stellt. Zunächst wirkt die Sonne dadurch, daß die Luft schnell relativ trocken wird und daß dann die starke Wasserverdunstung die Sporenbildung veranlaßt. Aber auch die erhöhte Temperatur befördert direkt den Prozeß. Wenn man gut gewachsene Zellen einer Wasserkultur der Temperatur von $30^{\circ}$ aussetzt, so hat der größere Teil bereits nach 24 Stunden im Dunkeln Sporen gebildet. In einer von der Sonne längere Zeit bestrahlten Kultur steigt im Sommer die Temperatur leicht über $30^{\circ}$ hinaus, so daß also bei der Insolation die thermische Wirkung sehr wohl in Betracht kommt. Wenn die Zellen von Protosiphon bei ungünstiger Beleuchtung aufgewachsen sind, wie z. B. im November, so kann die Temperatur von $30^{\circ}$ 
die Sporenbildung nicht veranlassen. Es tritt zu schneli ein Nangel an Nahrungsstoffen ein.

Das Schicksal der Sporen hängt nun ganz von den äufieren Bedingungen ab. Sie können wieder direkt zu schlauchartigen Zellen heranwachsen, wie z. B. die Fig. 66 auf Taf. $V$ bei Rostafinski und WVoronin zeigt (meine Fig. 3 auf Taf. I). Ganz regelmäßig erfolgt dieses Auswachsen, wenn eben gebildete Sporen in frische Nährlösung, bei heller Beleuchtung gebracht werden. Die oben erwähnten, in 2-proz. Nährlösung gebildeten Sporen zeigten dasselbe T'erhalten, als sie ohne Aenderung des Mediums dem Licht ausqesetzt wurden.

Alle Sporen, seien sie im Wasser oder in Nährlösung, seien sie beim Austrocknen entstanden, färben sich bei Lichtzutritt rot, indem sie Hämatochrom erzeugen; sie werden zu Dauersporen, die, wie Cienkowski, ebenso Rostafinski und Woron in nachgewiesen haben, jahrelange Trockenheit ertragen können. Es entsteht der eigentliche Protococcus botryoides K ützing.

Wie die genannten Forscher bewiesen haben, können schliefilich die Sporen, seien sie grün, seien sie rot gefärbt, zur Schwärmerbildung übergehen, deren Bedingungen weiter unten besprochen werden sollen.

\section{t. Die Bildung der Schwairner (Gameten) bei Protosiphon.}

Die Schwärmerbildung läßt sich mit der größten Sicherheit jederzeit veranlassen. Nur bei den allerjüngsten Zellen gelang es bis jetzt nicht. Die lileinsten, bei denen ich die Schwärmer sah, hatten einen Durchmesser von $0,008 \mathrm{~mm}$; andererseits können die Zellen (Köpfchen mit Wurzelteil) zu einer Länge von $1,2 \mathrm{~mm}$, d. h. um das I50-fache heranwachsen und dann erst die Schwärmer erzeuren. Aus der Darstellung ron Rostafinski und 
Woronin (77 S. I2) scheint hervorzugehen, daß die Sporenbildung die notwendige Vorstufe der Schwärmer sein müsse. Das ist indessen nicht der Fall, da jede Zelle, gleichgiltig ob sie sich geteilt oder Sporen erzeugt hat, der Schwärmerbildung fähig ist (vergl. Cienkowski 55). Für die weitere Besprechung wollen wir die Bildungsweise der Schwärmer, die physiologischen Bedingungen des Prozesses und das Verhalten der Schwärmer gesondert betrachten.

a) Die Bildungsweise der Schwärmer.

Von Rostafinski und Woronin wird die bestimmte Angabe gemacht, daß die Schwärmer durch eine simultane Teilung des Zellinhaltes entstehen. Meine Beobachtungen ergeben das Resultat, daß bei Protosiphon ebenso wie ich es für Hydrodictyon nachgewiesen habe (Klebs 9I), die Vielzellbildung sich auf eine abgekürzte Zweiteilung zurückführen läßt. Es giebt kaum ein besseres Objekt, um in wenigen Stunden direkt den ganzen Zellbildungsprozeß unter dem Mikroskop zu verfolgen. Am klarsten erscheint er bei solchen Zellen, die aus einer Nährlösung von I Proz. in einen hängenden Wassertropfen einer feuchten Kammer gebracht und so an den Rand des Tropfens gelegt werden, daß man den Vorgang mit starken Vergrößerungen beobachten kann.

Die ersten Anfänge des Prozesses erkennt man an den Veränderungen des Zellinhaltes (Taf. I, Fig. $7 a$, rechte Zelle). Die Amylonkerne werden aufgelöst, die Stromastärke tritt reichlich in feinen Körnchen auf, auch dann, wenn der Prozeß direkt in einer Nährlösung von I Proz. vor sich geht, in der die Stromastärke im vegetativen Zustande der Zelle fehlt. Die Zellkerne vermehren sich durch Teilung. Dann beginnt eine langsame Kon- 
traktion des Protoplasten und eine allmähliche Abtrennung des die Schwärmer bildenden Plasmas von der Zellsaftblase, die, wie bei Hydrodictyon, an dem Prozeß unbeteiligt ist (Taf. I, Fig. $7 a$, linke Zelle). Bei den langen schlauchartigen Zellen sammelt sich das Plasma mit Chromatophor und Zellkernen gewöhnlich im oberen Teile der Zelle auf einem kleinen Raum an, während der Zellsaft, von eigener Plasmahaut umgeben, im farblosen Teile zurückbleibt, häufig in eine Anzahl kleinerer Bläschen zerfallend. Bei den kugeligen Zellen wird der Zellsaft während des Bildungsprozesses immer kleiner, er wird an die Seite gedrückt und bleibt als kleine Blase mit ölartigen Tröpfchen übrig (Taf. I, Fig. 7a-c, Zellsaft $z$ ). Bei den ganz kleinen Zellen (Durchmesser 8 -- I2 $\mu$ ) findet gar keine Kontraktion statt, und der unbedeutende Zellsaft entzieht sich bei der 'Teilung der Beobachtung.

In dem grünen, die Zellkerne enthaltenden Plasma tritt eine Sonderung in kleinere Stücke ein (Taf. I, Fig. $7 a$, linke Zelle, $7 b$ rechte Zelle). Bei den schlauchartigen Zellen beginnt die Sonderung meist an dem oberen Ende und schreitet langsam gegen das untere Ende vor. Wenn durch die sich kontrahierende Zellsaftblase das Plasma zufällig in mehrere größere Partieen geteilt ist, so erfolgt in jeder von diesen, unabhängig von den anderen, die Sonderung (Taf. I, Fig. 8, oberes Stück des Plasmas in Teilung, unteres $p$ zwischen den Zellsaftblasen noch ungeteilt). Oft kann in der obersten Partie die Schwärmerbildung schon fertig sein, während eine untere eben erst mit der Sonderung beginnt. Hin und wieder kann es auch vorkommen, daß ein wenig chlorophyllhaltiges Plasma bei dem Prozełs unverbraucht zurückbleibt. Ich bemerkte sogar, daß nach Entleerung der Schwärmer solche Plasmareste, mit dem Zellsaft in Verbindung bleibend, in der Nährlösung sich wieder zu einer neuen 
Zelle regenerierten. Wahrscheinlich war auch ein Zellkern zurückgeblieben.

Durch die Sonderung entstehen Plasmastücke, die in kleineren und größeren Zellen ungefähr die gleiche Größe haben. Innerhalb der gleichen Zelle können aber die einzelnen Stücke etwas verschiedene Größe und Gestalt besitzen. Sie haben eine Länge von ca. 9-I4 $\mu$, eine Breite von ca. 7-9 . Sie erzeugen durch einen sicher nachweisbaren, zweimaligen Teilungsprozeß die Schwärmer (Taf. I, die erste Teilung, Fig. $7 b$, die zweite Teilung, Fig. $7 c$, linke Zelle). Jedes Plasmastück verhält sich wie eine Amöbe, die sich etwas in die Länge streckt und sich dann in der Mitte allmählich durchschnürt. Während der Teilungen finden leise Verschiebungen und amöboide Veränderungen der Plasmastücke statt, die bis kurz vor der 2. Teilung noch durch Fäden, ähnlich wie bei Hydrodictyon, zusammenhängen. Dann erfolgt die Abrundung der kleinen Plasmastücke, deren Durchmesser etwa $3,6 \mu$ beträgt, schließlich ihre Umwandlung in die Schwärmer.

Die inneren Veränderungen, welche zu der Sonderung des Plasmas führen, sind unbekannt; es läßt sich daher nicht genau entscheiden, in welcher Beziehung der Spaltungsprozeß zu einer gewöhnlichen $Z$ weiteilung steht. Bei solchen kleinsten Zellen von Protosiphon, die schon Schwärmer zu bilden vermögen, werden diese wohl durch Zweiteilung entstehen; ich sah Zellen mit nur vier Schwärmern. In der Mehrzahl der genau untersuchten Fälle beobachtete ich in den kleinen Zellen 6, 9, I2 Schwärmer, so daß vielleicht die Teilung nach der Dreizahl verlief oder sich zuerst 3 Plasmastücke bildeten, die dann durch eine resp. zwei Zweiteilungen die Schwärmer erzeugten. In welcher Weise die Teilung wirklich erfolgte, konnte ich nicht sicher feststellen. 
Die Entleerung der Schwärmer geschieht in einfacher Weise. Bei den lang schlauchförmigen Zellen geraten die Schwärmer nach erlangter Reife in lelshafte Bewegung innerhalb des relativ großen Zellraumes. Dann sieht man, wie die Zellwand am oberen Ende an einer begrenzten Stelle gallertartig wird, wie die ersten Schwärmer sich langsam durch die Gallerte nach außen bohren, bis das Loch groß genug für den schnellen Austritt aller ist. Eine besondere Quellsubstanz konnte ich nicht nachweisen. Bei den kugeligen Zellen quillt ebenfalls die Zellwand an einer Stelle auf, an der langsam die Schwärmer austreten (Taf. I, Fig. I2b); oft dauert es mehrere Stunden bis die letzten frei werden. Nur bei Zellen mit dickerer Membran, namentlich bei den Sporen findet sich der Entleerungsprozeß, den Rostafinski und W o ron in beschreiben, wobei die Schwärmermasse, von einer Gallertblase umgeben, als Ganzes austritt (Fig. 9). Diese Art der Entleerung erklärt sich daraus, daß die Verquellung sich auf die ganze, innere Membranschicht erstreckt.

Die Schwärmer (Taf. I, Fig. Io) sind anfänglich dick eiförmig bis birnförmig; ihre Länge $=6-7 \mu$, ihre Breite meist $=3,5 \mu$ Allmählich werden sie schmal eiförmig, und in Nährsalzlösung werden sie lang gestreckt und flachen sich dabei ab; ihre Länge $=9 \mu$, Breite $=2,7 \mu$. Jedoch können auch etwas größere Schwärmer entstehen, wahrscheinlich dadurch, daß ab und zu die letzte Teilung unterbleibt. Ferner kommen besonders in Zuckerlösungen unvollständig geteilte Doppelindividuen zur Beobachtung. Am Vorderende sitzen bei den normalen Schwärmern zwei zarte Cilien (Rostafinski und Woronin, Taf. V, Fig. 53); ich beobachtete konstant einen kleinen, undeutlich yefärbten Augentleck, ferner ein paar kleine, kontraktile Bläschen. Der Körper ist zart grün oder bei Entstehung 
aus trockenen Sporen rot gefärbt. Die Schwärmer bewegen sich sehr lebhaft und besitzen, wie Strasburger (78 S. I6) bemerkt hat, eine große Lichtempfindlichkeit, so daß sie sich stets am Lichtrande der Kultur ansammeln. Ihr weiteres Verhalten werden wir weiter unten kennen lernen.

Sicher ist es, daß Protosiphon nur eine einzige Art von Schwärmern besitzt, daß bei ihm niemals die einwimperigen Zoosporen des echten Botrydiums vorkommen.

b) Die Bedingungen der Schwärmerbildung.

Cienkowski (55 S. 78I) beobachtete zuerst, daß vegetative Zellen von feuchter Erde oder trockene Sporen nach Ueberführung in Wasser Schwärmer entwickeln. Rostafinski und Woronin bestätigten die Beobachtungen hauptsächlich für die Sporen. Man kann indessen auch auf andere Weise den Prozeß mit der gleichen Sicherheit veranlassen. Es zeigt sich dabei die zuerst für Hydrodictyon festgestellte Thatsache, daß die Bedingungen der Schwärmerbildung etwas verschieden sind, je nach der früheren Kulturweise der Zellen. Man muß unterscheiden I) die vegetativen Zellen, die auf feuchtem Lehm gewachsen sind; 2) die Sporen, die durch Austrocknen oder in Nährsalzlösungen gewonnen worden sind; 3) die vegetativen Zellen, die in einer Nährlösung entstanden sind.

Die Zellen der Lehmkultur bilden, in Wasser gelegt, bei Zimmertemperatur in 6-7 Stunden die Schwärmer, gleichgiltig in welcher Stunde des Tages der Versuch unternommen wird. Schon Cienkowski stellte fest, daß der Prozeß in gleicher Weise im Licht wie im Dunkeln vor sich geht. Die Anwendung von verdünnten Nährlösungen oder von Rohrzucker-, Traubenzucker-, Maltose- etc. Lösungen verändert das Resultat nicht; die 
Nährlösungen von 0,4 Proz. an verzügern, die Zuckerlösungen von I-2 Proz. beschleunigen etwas den Verlauf des Prozesses. Bei einer Nährlösung von I Proz. können 24 Stunden vergehen, bis lebhafte Schwärmerbildung eintritt. Der Versuch gelingt mit um so größerer Sicherheit, je besser ernährt die Lehmkultur ist. Doch sind es überhaupt seltene Fälle, dass die Zellen nach dem Uebergang in Wasser, selbst bei ungünstiger Beleuchtung im Winter, keine Schwärmer bilden. In solchen Fällen muß man die betreffenden Zellen am besten in Nährlösung kultivieren, um sie wieder entwickelungsfähig zu machen. Protosiphon ist gerade deshalb ein ganz vorzügliches Objekt der Untersuchung, weil die Reizbarkeit für die Erregungr der Schwärmerbildung selten verloren geht und auch dann immer wieder herzustellen ist.

Die eben gebildeten Sporen einer Lehmkultur verhalten sich wie die vegetativen Zellen. Auch die durch Eintrocknen gewomnenen, roten Sporen liefern nach Uebergießen mit Wasser regelmäßig die Schwärmer (Rostafinski und Woronin, 1. c. S. II). Ein Unterschied zeigt sich nur darin, daß bei Zimmertemperatur der Bildungsprozeß in den roten Sporen langsamer erfolgt, so daß gewöhnlich erst nach 24 Stunden die Schwärmer entleert werden. Häufiger noch als bei den vegetativen Zellen beobachtet man, daß eine Anzahl Sporen erst in den darauf folgenden Tagen ihre Schwärmer erzeugt.

Die in den Nährsalzlösungen entstandenen Sporen (s. S. I93) entwickeln die Schwärmer bei Ueberführung in reines Wasser oder in frische Nährlösung. Im letzteren Falle ereignet es sich oft, daß eine größere Anzahl Sporen sich zu vegetativen Zellen direkt umbildet und um so häufiger, je konzentrierter die Nährlösung ist. Im allgemeinen geht bei den Nährsalzsporen der Prozeß nicht so regelmäßig vor sich, so daß Versuche in 
feuchten Kammern mit ihnen nicht immer gute Resultate geben. Besser ist es, eine größere Anzahl Sporen in kleine Gläschen mit Wasser oder Nährlösung zu bringen. Obwohl der Prozeß bei solchen Kulturen auch im Dunkeln erfolgt, so scheint er doch allgemeiner und schneller bei Gegenwart des Lichtes einzutreten, weil dieses wohl die Auflösung der aufgespeicherten Stoffe in den Sporen beschleunigt. Bei den Nährsalzsporen wirkt jedenfalls die Veränderung der chemischen Beschaffenheit des Mediums als auslösender Reiz. In alter Nährlösung von o,4 Proz. einmal gebildet, bleiben die Sporen darin beliebig lange unverändert; weder höhere Temperatur noch Dunkelheit üben einen wesentlichen Einfluß aus. Erst der Uebergang in frische Nährlösung von o,4 Proz. oder sogar in eine solche von I Proz. bewirkt die Schwärmerbildung bei sonst unveränderten, äußeren Bedingungen, seien es die des Lichtes oder der Temperatur.

Die in normaler, frischer Nährlösung wachsenden Zellen verhalten sich in einer Beziehung wesentlich verschieden von den Zellen der Lehmkultur oder den Sporen. Der am sichersten wirkende Reiz für die Erregung der Schwärmerbildung ist Lichtmangel. Dieses Verhalten offenbart sich am klarsten bei dem Versuch, die Zellen in der unveränderten Nährlösung von 0,4 Proz. ohne Aenderung der Temperatur einfach zu verdunkeln. Bei gut ernährten Zellen erfolgt die lebhafteste Schwärmerbildung in 5-8 Stunden, je nach der herrschenden Zimmertemperatur. Man kann auch die Konzentration der Nährlösung erhöhen, die Zellen aus 0,4-proz. in I-proz. Lösung überführen. Dadurch wird der Bildungsprozeß verlangsamt, aber nicht verhindert. Ich beobachtete sogar nach dem Uebergang in eine Lösung von 2 Proz. bei einzelnen Zellen normale, bewegliche Schwärmer. Ebenso bemerkt man ihre Bildung, nach dem die Zellen 
aus 0,4-proz. Nährlösung in IO-proz. Rohrzuckerlösung gebracht worden sind. In allen diesen Versuchen, die mit größter Sicherheit gelingen, spielt die chemische oder physikalische Aenderung des Mediums keine entscheidende Rolle, vielmehr einzig und allein der Uebergang aus licht in Dunkelheit.

Helle, sonnige Beleuchtung wirlit dem Bildungsprozeß der Schwärmer in so intensiver Weise entgegen, daß im Sommer die Nachtzeit im allgemeinen keine erregende Wirkung ausübt. Daraus erklärt sich ferner, (laß die Resultate am schnellsten dann eintreten, wenn die Versuche in den Vormittagsstunden eingerichtet werden. Bei Zellen, die am Tage bereits beleuchtet waren und am Nachmittag erst verdunkelt werden, erfolgt die Schwärmerbildung viel langsamer und um so mehr, je näher der Beginn des Versuches dem Eintritt der Nacht ist. Helle Beleuchtung bewirkt auch, daß die Zelien, aus Nährlösung von I Proz. in reines Wasser übergeführt, trotz Wechsels des Mediums keine Schwärmer bilden, während im Dunkeln unter diesen Umständen der höchste Grad der Schwärmerbildung erreicht wird. Völlige Verdunkelung ist zur Erlangung des Zieles nicht notwendig; eine Schwächung der Lichtintensität thut die gleichen Dienste, nur daß der Prozeß etwas längere Zeit braucht und bei vielen Zellen erst in den folgenden Tagen eintritt. Die Grenze der Lichtintensität ist nicht genauer bestimmt worden. Man beobachtet aber sehr leicht, daßs an einem trüben Sommertag das relativ schwächere Tageslicht in Verbindung mit der Nacht genügt, um bei einzelnen Ze!len einer ruhig am Fenster stehenden Nährsalzkultur Schwärmerbildung hervorzurufen. Noch auffallender ist die Erscheinung in den Monaten November und Dezember. $Z u$ dieser Zeit gelingt es überhaupt nicht, gut ausgewachsene Zellen von 
Protosiphon in Nährlösungen zu gewinnen, weil die jungen Zellen, kaum zu kleinen Kugeln herangewachsen, durch das trübe, schwache Tageslicht fort und fort zur Schwärmerbildung veranlaßt werden. Die gleiche Beobachtung macht man, wenn man in dieser Zeit in feuchten Kammern die Schwärmer in einer Nährlösung von 0,4 bis I Proz. kultiviert. Die kleinen Zellen von 0,009 bis o,O I mm Durchmesser bilden bereits wieder neue Schwärmer.

Bei längerer Kultur in der nicht gewechselten Nährlösung geraten mit deren chemischen Veränderung die Zellen in einen indifferenten Zustand, wo sie nicht mehr recht Schwärmer erzeugen. Dann hört aber auch bald das Wachstum auf, die Zellen gehen zur Sporenbildung über.

Nachdem wir jetzt die Methoden kennen gelernt haben, die Schwärmerbildung zu jeder Zeit hervorzurufen, müssen noch einige wichtige, äußere Bedingungen hinsichtlich ihres Einflusses auf den Prozeß berücksichtigt werden. Vor allem kommt die Temperatur in Betracht, deren Wirkung an den Kulturen in feuchten Kammern geprüft wurde. Im Thermostat wurden die feuchten Kammern noch besonders in kleine, mit Wasser versehene Glasschalen gebracht, um das Austrocknen bei höherer Temperatur zu verhindern. Der Bildungsprozeß findet im Eiskasten bei $\mathrm{O}-\mathrm{I}^{0}$ nicht statt; die Zellen bleiben unverändert. Die untere Grenze ist nicht ganz genau bestimmt worden; sie wird etwa bei I "liegen. Man kann aber zwischen $\mathrm{O}-\mathrm{I}^{*}$ die Schwärmerbildung hervorrufen, wenn der Versuch in der Weise angestellt wird, daß die Kultur einige Stunden, z. B. von Io Uhr vormittags bis 2 Uhr nachmittags, im Zimmer steht und dann erst in den Eiskasten gebracht wird. Der begonnene Prozeß geht ganz langsam weiter, und die Schwärmer erscheinen in etwa 24 Stunden. Genauer geprüft wurde 
das Verhalten gegen höhere Temperatur. Von $27^{\circ}$ an beginnt eine Verlangsamung des Prozesses, eine Anzahl Zellen reagiert nicht mehr; bei 28 und $28,5^{\circ}$ kann noch hin und wieder Schwärmerbildung eintreten; bei $29^{\circ}$ bleiben alle Zellen unverändert. Bei $30^{\prime \prime}$ kann unter Umständen Sporenbildung erfolgen (s. S. 193); bei steigender Temperatur bleiben alle Zellen indifferent, erhalten sich aber noch lebend, wenn man sie direkt aus Zimmertemperatur 24 Stunden lang bei $40^{\circ}$ hält. Bei $4 \mathrm{I}^{\circ}$ beginnt das Absterben, bei $42^{\circ}$ ist die Mehrzahl nach 24 Stunden tot.

Sehr auffallend ist die Wirkung der Temperatur auf die Zeitdauer, welche vom Beginn des Versuches bis zur Entleerung der Schwärmer verläuft. Die Versuche wurden zur Bestimmung der Zeit ausschließlich mit Zellen der Lehmkulturen angestellt, die in Wasser übergeführt und verdunkelt wurden. Die folgende, kleine Tabelle giebt Aufschluß, wie viel Zeit bei den genannten Temperaturen für den Bildungsprozeß notwendig ist:

$$
\begin{aligned}
& \text { bei } 4-6^{\circ} \text { in } 24-48 \text { Stunden } \\
& " 7-8^{0} " \mathrm{I} 2-\mathrm{I} 4 \quad " \\
& \text { " } 8-10^{\circ} " \text { 9-10, } \\
& \text { " } 12-14^{\circ} ", 8-9, \\
& \text { "14-16" }, 6-7 \text { " } \\
& \text { " } 16-18^{0} " \quad 5-6 \text { " } \\
& " 18-20 ", 4-5 \text { " } \\
& \text { "20-230" } 3-4 \text { ", } \\
& " 23-26^{\circ} " 2^{1 / 2}-3 \text { " }
\end{aligned}
$$

Die einzelnen Zellen der gleichen Kultur zeigen grofse, individuelle Unterschiede; die Zahlen gelten nur insofern als nach der angegebenen Zeit in den Kammerkulturen eine große Anzahl Schwärmer entleert worden waren. In jeder Kultur giebt es Zellen, die später, oft erst in den nächsten Tagen, ihre Schwärmer erzeugen. 
Dieses geschieht um so häufiger, je niedriger die Temperatur ist, so daß bei $4-5^{\circ}$ der Prozeß viele Tage lang fortgeht, während er bei $23-26^{\circ}$ sehr allgemein bei den Zellen einer Kultur eintritt. Das Optimum liegt bei $24-26^{0}$, wo die Schwärmer bereits nach $2^{1} / 2$ Stunden in sehr großer Anzahl entleert werden. Protosiphon ist bisher wohl das einzige bekannte Beispiel, bei dem ein Fortpflanzungsprozeß in so kurzer Zeit verläuft. Da es nun bei den Zellen einer Lehmkultur gleichgiltig ist, zu welcher Tagesstunde der Versuch begonnen wird, so kann man, besonders bei Anwendung einer Temperatur von $24-26^{\circ}$, aber ebenso auch bei Zimmertemperatur, zu jeder voraus zu bestimmenden Zeit Schwärmer in größter Menge erhalten, was für viele $Z$ wecke von unschätzbarem Werte ist, um so mehr, da Protosiphon so leicht und zu jeder Zeit des Jahres sich kultivieren läßt.

Als erregender Reiz für die Schwärmerbildung spielt die Temperatur eine weniger wichtige Rolle. Temperaturschwankungen können aber dann sicher auslösend wirken, wenn der durch andere Reize erregte Prozeß durch zu niedere oder zu hohe Temperatur gehemmt war. Im ersteren Falle, z. B. bei Kulturen, die im Eiskasten gestanden haben, veranlaßt eine schwache Temperaturerhöhung stets den Prozeß. Im letzteren Falle thut eine Temperaturerniedrigung dasselbe. Aber die hohe Temperatur zwischen 30 und $40^{\circ}$ bewirkt anscheinend innere Veränderungen der Zellen, so daß das Resultat der Versuche unsicher ist und viele Zellen indifferent werden, infolgedessen sie überhaupt nicht eher Schwärmer bilden, als bis sie in frischer Nährlösung, bei heller Beleuchtung wieder reaktionsfähig gemacht worden sind. Oh starke Temperaturschwankungen allein, bei Konstanz aller anderen Bedingungen, genügen, um Schwärmerbildung zu veranlassen, kann ich nicht sicher beantworten; nach meinen Erfahrungen halte ich es für unwahrscheinlich. 
Der Satuerstoffgehalt der Ungebung hat für die Fortptlanzung ron Protosiphon nur eine beschränkte Bedeutung. Bei lem Uebergange aus feuchter Luft in Wasser oder aus Licht in Dunkelheit wird der Sauerstoffgehalt für die Alge eher verringert. Sie braucht nur einen sehr geringen Partiärdruck des Sauerstoffes, wie die V'ersuche in verdünnter Luft beweisen. Zellen von Protosiphon aus Nährlösung oder einer Lehmkultur wurden in feuchte Kammern gebracht, doch so, daß das Deckgläschen dem feuchten Papprahmen nicht vollständig licht auflag; durch Aufstellungr eines besonderen VVassergrefäßes wurde für eine feucht gesättigte Luft gesorgt. Die Schwärmer wurden normal gebildet und traten auch bei einem Luftdruck bis zu $4 \mathrm{~mm}$ aus. Bei dem niedrigen Druck ron ca. $3 \mathrm{~mm}$ blieb immer eine Anzahl Zellen unverändert, und nur ein Teil bildete Schwärmer, die meist nicht entleert wurden; doch konnte ich sicher den Austritt von einigen konstatieren, da sie am 'Tropfenrande schnell zur Ruhe gekommen waren.

c) Das Verhalten der Schwärmer (Gameten).

Cienkowski (5j S. 78I) macht die Angabe, daß die Schwärmer von Protosiphon direkt zu neuen PHänzchen heranwachsen. Erst Rostafinski und Woronin stellten fest, daß die Schwärmer geschlechtlich sind und zu je zweien mit einander verschmelzen. Die dadurch gebildeten Zygoten sind entweder glatt und gleich keimfähig oder sie sind mit regelmäßigen Höckern versehen, so daß sie sternartig erscheinen; diese sind erst nach einer Ruheperiode entwickelungsfähig. Solche Sternsporen sollen lann entstehen, wenn die Mutterzellen unter einer tiefen schicht Wasser zur Bildung der Schwärmer gelangen. Diejenigen Schwärmer, welche nicht kopulieren, gehen 
nach den beiden Verfassern, wie auch nach Janczewski, zu Grunde. Dagegen sollen solche, die aus jahrelang trocken aufbewahrten Sporen hervorgehen, im Stande sein, ohne Kopulation keimfähige Zellen zu bilden. Strasbu rger ( 84 S. 381 ) hat ebenfalls die Kopulation beobachtet und giebt an, daß die nicht kopulierenden Schwärmer im Dunkeln zu Grunde gehen und im Licht zur Ruhe kommen.

Meine Untersuchung zeigte bald, daß in diesen Angaben Wahres mit Falschem gemischt ist; ich erkannte, daß die Schwärmer sowohl geschlechtlich wie ungeschlechtlich sich verhalten können, und ich habe versucht, hier an dem Beispiel von Protosiphon die physiologischen Bedingungen, welche diesem verschiedenen Verhalten zu Grunde liegen, genauer zu erkennen. Wenn man Sporen oder Zellen einer Lehmkultur in Wasser bringt und dem Tageslicht aussetzt, so beobachtet man den höchsten Grad der Kopulationsfähigkeit. Kaum aus den Zellen ausgetreten, ziehen sich die Schwärmer lebhaft an, stürzen auf einander zu, wobei oft Gruppen von 6 und mehr Schwärmern entstehen, die sich dann wieder auflösen, wenn je zwei Schwärmer sich verbunden haben. Hunderte von solchen Paaren sieht man dann in kurzer Zeit herumschwimmen; da aber immer neue Zellen Schwärmer entwickeln, so kann man während mehrerer Stunden neue Kopulationen beobachten, und bei Anwendung niederer Temperatur (7-8 ${ }^{\circ}$ ) während mehrerer Tage. Die Schwärmer berühren sich, wie in den meisten ähnlichen Fällen, mit ihren farblosen Spitzen, legen sich seitlich zusammen und vereinigen sich dann allmählich während der Bewegung (Rostafinski und Woronin, S. II, Taf. V, Fig. 6o; meine Taf. I, Fig. I I $a$ bis c). Wie die citierte Figur 60 zeigt, können auch drei Schwärmer sich vereinigen; auffallend viele solcher 
Vorgänge beobachtete ich dann, als ich die Schwärmer in organischen Lösungen, z. B. in Sorbit von I Proz., entstehen ließ. Entweder vereinigten sich gleichzeitig drei Schwärmer, oder, was noch häufiger war, es kopulierte mit einer schon gebildeten Zygospore ein dritter Schwärmer.

Die gegenseitige Anziehung, bei welcher vielleicht Chemotaxis (Pfeffer 84) eine Rolle spielt, geht augenscheinlich von den Spitzen aus. In manchen Kulturen, wo die Schwärmer bei niederer Temperatur $\left(5-6^{\circ}\right)$ entstanden waren, fiel es mir auf, daß die Anziehung auch von anderen Teilen des Körpers ausging. Die Schwärmer berührten sich in den verschiedensten Stellungen und bewegten sich darin weiter, so daß das Bild der schwärmenden Paare gegenüber der normalen Erscheinung ganz verändert erschien. Doch konnte ich nicht sicher feststellen, daß die Verschmelzung auch in diesen abnormen Stellungen ror sich ging.

Da die Größe der Gameten wechselt, so kommt es auch häufig, aber durchaus nicht regelmäßig, vor, daß die kopulierenden Schwärmer ungleich groß sind. Die Zygosporen mit ihren vier Wimpern bewegen sich noch lange Zeit, wenn auch im allgemeinen etwas kürzer als die nicht kopulierenden Schwärmer. Bei beiden hängt die Bewegungsdauer von der Beleuchtung und von der Temperatur ab. Für diese Untersuchung müssen die Schwärmer mit einer feinen Pipette isoliert und in feuchte Kammern gebracht werden. Beleuchtung verkürzt die Bewegungszeit gegenüber dem Aufenthalt im Dunkeln; ebenso vermindert sich die Bewegungsdauer mit steigender Temperatur. Gameten und Zygosporen, bei Zimmertemperatur entstanden und gemischt, bewegten sich bei $7-8^{\circ}$, in Dunkeln in der Mehrzahl 24 Stunden, die letzten noch nach 36 Stunden; bei $15-17^{0}$ in der Mehr. 
zahl I2-I6 Stunden, die letzten noch nach 24 Stunden; bei $24-26^{\circ}$ nur wenige Stunden. Sind die Schwärmer (Gameten allein) bei einer Temperatur von $24-26^{\circ}$ entstanden, so bewegen sie sich etwas länger, durchschnittlich 6-8 Stunden. Im Licht kommen ganz allgemein Gameten und Zygosporen schneller zur Ruhe, so daß die Bewegung, z. B. bei einer Temperatur von $7-8^{\circ}$, bereits nach 9-II Stunden aufhören kann.

Die Hauptfrage, die mich interessierte, bezog sich darauf, unter welchen Umständen die Kopulationsfähigkeit erlischt. Im Sommer I894 beobachtete ich zum ersten Male, daß Schwärmer, die ich in einen Tropfen Nährlösung brachte, aufhörten zu kopulieren. Indessen erkannte ich bald, daß, um sichere Resultate zu erhaiten, der Zusatz der Nährlösung am besten während des Bildungsprozesses oder kurz vorher zu machen ist; dann ist überhaupt ausnahmslos die sonst so überaus lebhafte Kopulationslust verschwunden, und sämtliche Schwärmer bilden Parthenosporen. Die ausführliche, im Sommer und Winter I895 fortgesetzte Untersuchung lehrte dann, daß auch bei der vorliegenden Frage die frühere Kulturweise der Mutterzellen für das Verhalten der Schwärmer sehr wesentlich in Betracht kommt.

Allerdings giebt es ein Mittel, den Schwärmern aus Zellen jeder Herkunft ihre geschlechtliche Fähigkeit zu rauben, und das ist konstante Temperatur von $26-27^{\circ}$. Bei einer solchen Temperatur, im Wasser und im Dunkeln entstehende Schwärmer kopulierten nie, so oft ich auch den Versuch wiederholt habe; nur bei Anwendung von Rohrzucker (I Proz.) sah ich hier und da Versuche der Paarung, aber ganz verschwindend gegen die Unmasse der Schwärmer, die in lebhaftester Bewegung durch einander wirbelten und doch teilnahmlos an einander vorübereilten. 
Die Kopulationsfähigkeit zeigt sich auch dann nicht mehr, wenn die Schwärmer aus dem Thermostat in eine niedrigere Temperatur z. B. von $16-17^{0}$ gebracht werden. Anders verhält sich die Sache, wenn man die Zellen einer Lehmliultur im Vasser, bei $25-27^{0}$ etwa $2-21 / 4$ Stunden läßst und dann ins Zimmer bringt. Die in der niedrigeren Temperatur austretenden Schwärmer zeigen bald deutliche Kopulation. Wenn man andererseits den Versuch so ausführt, daß die Zellen etwa 3-4 Stunden bei $17^{0}$ in Wasser oder Rohrzuckerlösung liegen und dann in den Thermostat bei $26^{\circ}$ kommen, so kann bei den zuerst entstehenden Schwärmern Kopulation eintreten, während die später frei werdenden dazu nicht mehr im Stande sind. Die Beobachtungen führen zu dem Schlusse, daß eine Temperatur von $25-27^{\circ}$ den Schwärmern in ihrem letzten Bildungsstadium die Kopulationsfähigkeit nimmt. Der bloße Aufenthalt der Zellen bei einer Temperatur von $29-40^{\circ}$ übt auf die später bei niederer Temperatur entstehenden Schwärmer keine Nachwirkung aus.

Die merkwürdige Wirkung der Temperatur beginnt deutlich zu werden bei $24^{\circ}$ und ist schon sehr auffallend bei $25^{\circ}$, wenn auch vereinzelte Paarungen noch möglich sind. Niedere Temperatur ist wirliungslos, da z. B. bei $4-5^{0}$ die Kopulationen ebenso zahlreich sind wie bei $15^{\circ}$, und sie selbst bei $\mathrm{O}-\mathrm{I}^{0}$ stattfinden, wenn in der früher besprochenen W'eise (siehe S. 203) bei dieser Temperatur Schwärmerbildung veranlaßt worden ist.

Die Kopulationsfähigkeit der Schwärmer wird ferner von der chemischen Beschaffenheit des Mediums, in dem sie entstehen, beeinflußt. Hierbei kommt aber die vorhergehende Kulturweise der Zellen in Betracht. Die in einer Nährlösung von 0,4-I Proz. entstandenen Zellen liefern bei Zimmertemperaturen Schwärmer, die unter keinen Umständen in so lebhaftem Grade kopulieren, 
wie es vorhin geschildert wurde. Immerhin ist die Kopulation noch deutlich bemerkbar, wenn man die Zellen aus der Nährlösung in Wasser bringt und verdunkelt. Wenn man jedoch die Zellen in 0,4-I-proz. Lösung läßt oder selbst dann, wenn man sie einige Stunden in Wasser hält, und das Wasser wieder durch eine Lösung von 0,4-I Proz. ersetzt, so erfolgt im Dunkeln nie eine Kopulation ${ }^{1}$ ). Der Versuch gelingt mit größter Sicherheit. Fügt man zu den im Wasser bereits kopulierenden Schwärmern Nährlösung, so kann anfangs die Kopulation noch fortgehen, sie nimmt aber bald an Intensität ab. Am sichersten wirkt jedenfalls die Nährlösung ebenso wie die höhere Temperatur im letzten Bildungsstadium der Schwärmer auf sie ein. In Nährlösung von I Proz. wird vielfach der Austritt der Schwärmer behindert, so daß sie innerhalb der alten Mutterzelle zur Ruhe kommen. Wie die Knop'sche Nährsalzmischung wirkt auch eine solche ohne Stickstoff, oder ohne Phosphor, ohne Kalium, oder ohne Calcium.

Anders verhalten sich die Schwärmer aus Zellen einer Lehmkultur oder aus Sporen. Diese werden durch eine Nährlösung von 0,4 Proz. lange nicht so stark beeinflußt; man beobachtet lebhafte Kopulation sowohl im Dunkeln wie bei Gegenwart des Lichtes. Immerhin wirkt der Aufenthalt im Dunkeln der Kopulation entgegen, so daß bei Schwärmern einer Lehmkultur, die in 0,4 -proz. Nährlösung nach I2 Stunden Dunkelheit entstehen, nur noch schwache Kopulation bemerkt wird. Ebenso wirkt die Nährlösung bei steigender Konzentration hemmend ein, so daß die Kopulation in einer Lösung von I Proz., auch bei Lichtzutritt sehr deutlich verringert ist. Läßt man nun

I) Diese Versuche, die ersten, die ich über diesen Punkt machte, waren die Veranlassung, daß ich in meiner Rede in der NaturforscherVersammlung zu Lübeck (95) darüber sprach. 
die Schwärmer aus Zellen der Lehmkultur in einer Nährlösung ron I Proz. im Dunkeln entstehen, so vereinigen sich die beiden hemmenden Eintlüsse dahin, daß die Kopulation völlig unterdrückt wird, und wir dann die gleiche Erscheinung haben wie bei den Schwärmern, die aus Zellen der Nährsalzkultur entstanden sind. Die Nährsalze wirken hemmend auf die Kopulation ein, so lange die Schwärmer direkt ihrem Einflusse unterworfen sind. Die ungeschlechtlich gestimmten Schwärmer können aber wieder geschlechtlich werden, wenn man die Nährsalze entfernt. Ich habe den Versuch öfters mit Erfolg ausgeführt. Zellen einer Lehmkultur wurden in einen Tropfen Nährlösung von I Proz. ins Dunkle gebracht; nach einigen Stunden war der Tropfen von Schwärmern erfüllt, die nicht kopulierten und sich am Lichtrande ansammelten. Jetzt wurde vorsichtig die Flüssigkeit entfernt und durch reines Wasser ersetzt. Die nächste Folge war, daß die Schwärmer aufhörten sich schnell zu bewegen; sie zitterten auf der Stelle hin und her und wandelten ihre lang gestreckte Gestalt in eine mehr birnförmige um. Schon nach IO- I5 Ninuten trat dann bei den allmählich wieder lebhafter werdenden Schwärmern Kopulation ein.

Rohrzuckerlösungen wiıken verschieden, je nach ihrer Konzentration; eine Lösung von I Proz. gestattet die lebhafteste Kopulation, während bei einer solchen von 5 Proz. an hemmende Wirkungen deutlicher werden, so daßz. B. in Ioproz. Zucker die Schwärmer kaum mehr kopulieren, voraussesetzt, daß sie im Dunkeln sich befinden. Bei Lichtzutritt kann die Kopulation in geringem Grade erfolgen. Viele Versuche wurden von mir angestellt, um zu entscheiden, ob irgend welche organischen Substanzen den Kopulationsprozeł in specifischer Weise beeinflussen. Lösungen von Traubenzucker (I Proz.), Laevulose (I Proz.), Raffinose (I Proz.), Maltose ( I Proz.), Dextrin (i Proz.), Mannit (I Proz.), 
Erythrit (I Proz.), Arabinose (I Proz.), Dulcit (I Proz.), Sorbit (I Proz.), Glykogen (I Proz.), Asparagin (I Proz.) wirken nicht wesentlich anders ein als Wasser oder I-proz. Rohrzucker. Hie und da schien es, wie z. B. bei den Zuckerarten, daß die Kopulation in den ersten Stunden bein Aufenthalt im Dunkeln außerordentlich lebhaft wäre wie sonst nur im Licht. Bei längerer Dauer der Dunkelheit nahm die Kopulation jedoch ab. Wenig günstig für die Entwickelung der Schwärmer sind Galactose (I Proz.), Sorbin (I Proz.), milchsaures Eisenoxydul (0,2 Proz.), die aber noch Kopulation gestatten. Noch ungünstiger wirkt Coffeïn von O,I Proz., worin nur relativ wenige, dick eiförmige Schwärmer entstehen, die aber doch sich zu kugeligen Zygosporen vereinigen. Die Schwärmerbildung wird verhindert durch Tannin ( 0,5 Proz.), kohlensaures Kali (0,5 Proz.), chromsaures Kali (O,I Proz.), Substanzen, die auch das Leben der Zelle schließlich schädigen.

Niederer Luftdruck wirkt nicht auf die Kopulationsfähigkeit der Schwärmer ein; bei einem solchen von Io $\mathrm{mm}$ finden normale Kopulationen statt, wie sich an den beweglichen Zygosporen nachweisen läßt. Nach Zutritt der Luft sieht man auch bei Schwärmern, die bei einem Druck von $3 \mathrm{~mm}$ entstanden sind, lebhafte Kopulation.

Nach den Angaben von Rostafinski und Woronin fehlt die Kopulationsfähigkeit bei Schwärmern, welche aus Sporen entstehen, die mehrere Jahre trocken gelegen haben. $\mathrm{Ob}$ sie nicht wieder durch bestimmte, äußere Bedingungen hervorzurufen wäre, müßte eine besondere Untersuchung zeigen; mir stand ein Sporenmaterial von der besprochenen Eigenschaft nicht zur Verfügung. Dagegen konnte ich noch feststellen, daß die Schwärmer der gleichen Mutterzelle nicht miteinander kopulieren. Wenn in einem Versuch die erste Zelle ihre Schwärmer entleert, so sieht man zunächst keine Kopulation; wenn 
die Schwärmer nicht aus dem Sporangium heraustreten, sich aber in ihm lebhaft bewegen, so habe ich niemals Kopulation beobachtet. Ich habe die Beobachtung ununterbrochen bis zum Ruhestadium der Schwärmer fortgesetzt. Auch aus den weiter zu besprechenden Erscheinungen ergiebt sich die Richtigkeit dieser Thatsache für die Mehrzahl der Fälle, wenn auch Ausnahmen vorkommen (siehe weiter unten).

Man darf, ohne die Kopulation direkt gesehen zu haben, ihr Stattfinden oder Fehlen behaupten, weil man noch ein anderes Mittel besitzt, geschlechtliche und ungeschlechtliche Schwärmer zu unterscheiden, indem man ihr weiteres Verhalten prüft. Meine Untersuchungen haben mir die Ueberzeugung gegeben, daß von den beiden durch Rostafinsli und Woronin erwähnten Sporenarten, den glatten und den sternartigen, die ersteren Parthenosporen, die letzteren Zygoten sind. Beide Sporenarten sind scharf unterschieden, und das Hauptgewicht lege ich auf die sichere Thatsache, daß die glatten Sporen stets sofort wachstumsfähig, die Sternsporen dagegen Ruhezustände sind, die selbst bei den günstigsten, äußeren Bedingungen erst nach einigen Wochen zur Keimung zu bringen sind. Die Parthenosporen (Taf. I, Fig. I $2 a-c$ ) haben gleich nach der Abrundung der Scliwärmer einen Durchmesser von $3,6 \mu$ und wachsen in Nährlösung bei heller Beleuchtung in wenigen Tagen zu größeren Zellen (Fig. 12 $b-e$ ) heran, die gleich wieder zur Schwärmerbildung veranlaßt werden können. Bei Mlangel an Nährsalzen, beim Austrocknen werden die Parthenosporen ebenfalls zu Dauerzellen, die aber jeden Augenblick wieder zum Wachstum gebracht werden können. Die Zygoten haben anfänglich einen Durchmesser von 6,5 ", sie wachsen bei heller Beleuchtung nur ein wenig, werden dabei zuerst polygonal und 


\section{$-\quad 215$}

bilden dann eine etwas abgeflachte, kuchenförmige Zelle, deren Membran am oberen, ebenso am unteren Rande fünf oder mehr regelmäßig verteilte, spitze oder auch rundliche Höcker bildet (Taf. I, Fig. I3 $a, b$ ). Auf einer der flachen Seiten liegend, bietet jede Zygote den Anblick eines fünfeckigen, bisweilen auch sechs- und siebeneckigen Sternes dar. Allmählich tritt in dem Zellinhalt gelblich-rötliches Oel auf, und der Ruhezustand ist fertig. Abgesehen davon, daß die Sternsporen nur im Licht sich mit ihrer besonderen Struktur ausbilden, ist noch zu erwähnen, daß sie in organischen Lösungen, z. B. in Dextrin (I Proz.), Erythrit (I Proz.), auch im Licht nur geringe oder keine Höckerbildung zeigen (Fig. I3 b). In solchem Falle ähneln die Zygoten den Parthenosporen, sind aber stets durch ihr physiologisches Verhalten zu unterscheiden. Um die Sternsporen zur Keimung zu bringen, ist es am geeignetsten, sie völlig auszutrocknen und dann nach einigen Wochen in Nährlösung von 0,4-I Proz. bei heller Beleuchtung zu kultivieren. Die Keimung (Taf. I, Fig. I4) selbst haben $\mathrm{R}$ os t a fin ski und Wor on in richtig beschrieben; die Zelle, ohne deutlich eine Cystenhaut abzustoßen, wächst allmählich heran, wobei die Höcker undeutlich werden und bildet eine vegetative Pflanze, die sich dann genau wie die Zellen aus den Parthenosporen verhält.

Die vorhin erwähnte Meinung von R ostafinski und Woronin, daß die glatten wie die sternförmigen Sporen Zygoten seien, und daß die letzteren entstünden, wenn die Muttersporen unter einer tiefen Schicht Wasser die Gameten bilden, entbehrt jeder thatsächlichen Begründung. In ganz kleiner Wassermenge wie in größerer können sowohl glatte wie sternförmige Sporen entstehen. Ausnahmslos erhalten wir die glatten Sporen in jenen Versuchen, wo durch die höhere Temperatur oder durch die Nährlösung 
im Dunkeln die Kopulation verhindert worden ist und nur Parthenosporen sich bilden könnten. Die Hauptbedingung für diesen Nachweis ist, daß in der feuchten Kammer lieine vegetativen Zellen mehr vorhanden sind, wenn man sie dem Licht aussetzt, damit nicht im Licht und bei Zimmertemperatur entstehende, neue Schwärmer Kopulationen ausführen, die dann das Resultat stören. Bei Gegenwart des Lichtes zeigt sich auch die wichtigste Eigenschaft der glatten Parthenosporen, sofort zu vegetativen Zellen heranzuwachsen.

In einer feuchten Kammer, in der aus Zellen einer Lehmkultur oder aus Sporen im Licht Schwärmer entstanden sind, die lebhaft kopuliert haben, wird die größte Anzahl der Sporen sternartig und wandelt sich auch im Licht und in der zugefügten Nährlösung in Ruhezellen um. Einkleiner Teil derSporen ist glatt und gleich entwickelungsfähig. Solche glatte Sporen treten häufiger auf in Kulturen, wo Nährsalzzellen im Wasser, im Dunkeln Schwärmer gebildet haben, ebenso in solchen, in denen Zellen der Lehmkultur in o,4-proz. Nährlösung, im Dunkeln sich fortgepflanzt liaben; liurz, das Auftreten der glatten Sporen resp. der Sternsporen hängt von dem Stattfinden der Parthenogenesis oder der Kopulation ab. Ich kann nun schließlich nicht behaupten, daß die Kopulationsprodukte immer zu Ruhezuständen werden; ich kann nur sagen, daß ich es nie anders habe feststellen können. Für die allgemeine Richtigkeit meines Satzes spricht theoretisch, daß dem wesentlichen, physiologischen Unterschiede der beiden Sporenarten doch eine wesentliche, innere Verschiedenheit zu Grunde liegen müsse, und wir können sie nirgends anders finden als darin, daß die einen durch Parthenogenesis, die anderen durch Kopulation entstanden sind.

Mit Hilfe dieses Satzes kann man im allgemeinen bestätigen. was die direkte Beobachtung in den einzelnen 
Fällen bereits sichergestellt hat, daß nämlich die in einer Zelle zur Ruhe kommenden Schwärmer, die z. B. aus Zellen einer Lehmkultur oder aus Sporen im Licht entstanden sind, in der Regel als Parthenosporen sich verhalten; nur in seltenen Fällen sah ich in lang-schlauchförmigen Zellen, die vorher in zahlreiche Sporen (S. I9I) zerfallen waren, vereinzelte Sternsporen. Wahrscheinlich hatten Gameten verschiedener Sporen der gleichen Mutterzelle kopuliert. Ferner ergiebt sich, daß in den größeren Reinkulturen der Alge in 0,4-I-proz. Nährlösung sehr wenig Kopulationen stattfinden, da die Mehrzahl der Schwärmer sich gleich weiter entwickelt. Man muß auf dem Grunde der Gefäße schon genauer nachsehen, um die vereinzelten Sternsporen zu finden.

Fassen wir die Beobachtungen über das Verhalten der Schwärmer kurz zusammen, so können wir sagen, daß bei Protosiphon unter bestimmten Bedingungen eine einzige Art von Schwärmern entwickelt wird, die man ebenso gut als Zoosporen wie als Gameten bezeichnen kann. Die Schwärmer kopulieren in lebhaftester Weise und bilden ruhende Sternsporen, wenn sie im Wasser bei heller Beleuchtung aus Zellen einer feuchten Lehmkultur oder aus Sporen entstehen. Die Schwärmer kommen zur Ruhe, bilden gleich keimfähige, glatte Sporen, wenn sie in nährsalzreichen Flüssigkeiten, besonders bei Lichtabschluß, aber auch im Licht selbst, ferner wenn sie bei einer Temperatur von $25-27^{\circ}$ entstehen. Man fragt sich natïrlich, warum die Nährsalze oder die höhere Temperatur, die an und für sich geschlechtlichen Schwärmer ungeschlechtlich machen. Von allen Versuchen kann vielleicht derjenige auf den rechten $\mathrm{Weg}$ weisen, bei welchem die bereits ungeschlechtlich gewordenen Schwärmer durch Uebergang aus Nährlösung in Wasser wieder geschlechtlich gemacht werden (s. S. 212). Wir müssen 
annehmen, dafs der Eintritt der Salze in den Plasmakirirper des Schwärmers ihm die Kopulationsfähiglieit raubt, der Austritt sie ihm wieder verleiht. Die Salze werden in erster Linie durch ihre chemische Eigenschaft, in zweiter durch ihre wasserentziehende Kraft hemmen, während z. B. Lösungen von Rohrzucker in verdünnter Form eher die Kopulation befördern, in konzentrierter dagegen wegen der starken Wasseranziehung einen hemmenden Einfluß ausüben. Daß andererseits die Schwärmer aus Sporen oder Zellen einer Lehmkultur in verdünnten Nährlösungen kopulieren, ist vielleicht darauf zurüclizuführen, daß durch den in ihnen angesammelten Reichtum organischer Stoffe die eintretenden Nährsalze gleich wieder verarbeitet und dadurch unschädlich gemacht werden. Das ist um so mehr der Fall, wenn Licht mitwirkt, in welchem organische Substanz neu gebildet wird; die Assimilationsthätigkeit kann sogar ausreichen, um selbst den Schwärmern in Nährsalzlösungen die Kopulation zu gestatten.

Sehr schwierig ist die Beantwortung der Frage, warum höhere Temperatur von $25-27^{\circ}$ die Kopulation verhindert. Die Temperatur von $30^{\circ}$ befördert, wie ich gezeigt habe, die Sporenbildung, d. h. sie wirkt wie eine stark wasserentziehende Salzlösung. Vielleicht wirkt eine Temperatur von $25-27^{\circ}$ auf die zarten Schwärmer kurz vor ihrer Reife auch wasserentziehend oder sie bewirkt innerhalb des Plasmas ein Freiwerden von Salzverbindungen, so daß die Wirkung die gleiche ist, als ob von außen Salze einträten. Ein Unterschied zeigrt sich aber darin, daß die durch höhere Temperatur ungeschlechtlich gemachten Schwärmer durch Temperaturerniedrigung nicht sofort wieder geschlechtlich werden können (s. vorhin). Der Eintluß der höheren Temperatur greift also tiefer in die Beschaffenheit der Schwärmer ein als die Nährlösung. 


\section{Allgemeiner Entwickelungsgang ron Protosiphon; Stellung im System.}

Bei der Besprechung des sog. Generationswechsels ihres Botrydium granulatum haben Rostafinski und W oronin den Versuch gemacht, in der Mannigfaltigkeit seiner Entwickelungsformen den notwendigen Generationswechsel von den sekundären Anpassungs-Erscheinungen zu sondern. Der Generationswechsel soll sich darin zeigen, daß das befruchtete Ei zur vegetativen Zelle wird, welche die Sporen -- die sporophore Generation - liefert. Die Sporen erzeugen in der Form der geschlechtlichen Schwärmer die zweite, die oophore Generation. In dieser Darstellung der Autoren fällt das echte Botrydium überhaupt ganz fort, was sehr bezeichnend ist; es wird nur zu den sekundären Anpassungs-Erscheinungen gerechnet. Indessen die ganze Idee des Generationswechsels ist für Protosiphon gänzlich überflüssig und geradezu falsch. Kein einziges Entwickelungsstadium muß notwendig auf ein anderes folgen; es ist nur notwendig, daß die aus den Schwärmern entstandene Spore ein klein wenig an Umfang zunimmt. Ist dies geschehen, so kann die Weiterentwickelung der kleinen Zelle in folgenden, verschiedenen Weisen vor sich gehen:

I) Die kleine Zelle $(0,008-0,0$ I $\mu)$ wächst ununterbrochen bis zu einer Maximalgröße von $I, 2-I, 4 \mathrm{~mm}$, die bisher nicht überschritten wurde.

2) Die kleine Zelle beginnt nach einigem Wachstum sich zu teilen, einen Haufen kugeliger Zellen bildend, oder die Teilung tritt in irgend einem späteren Stadium der Entwickelung ein.

3) Die kleine Zelle erzeugt Schwärmer sofort oder in irgend einem beliebigen, späteren Entwickelungsstadium bis zu ihrer Maximalgröße. 
4) Die kleine Zelle erzeugt sofort oder in irgend einem beliebigen, späteren Fntwickelungsstadium eine bis viele Sporen.

5) Die Sporen können zu einer vegetativen Zelle bis zur Maximalgröße direkt heranwachsen oder sich in irgend einem Stadium teilen oder sofort resp. in späterem Stadium Schwärmer erzeugen.

6) Die Schwärmer können zu je zweien kopulieren und Dauerzustände bilden, oder sie kommen parthenogenetisch zur Ruhe, wachsen sofort weiter oder können ebenfalls zu Dauerzellen (Sporen) werden.

Für die Fälle I und 2 sind die specifischen, äußeren Bedingungen noch nicht im Einzelnen genau erkannt worden, für die Fälle 3-6 dagegen soweit, daß sie jederzeit sich verwirklichen lassen.

Die systematische Stellung von Protosiphon läßt sich nicht sehr genau angeben, weil überhaupt die niederen Algen einer systematischen Einteilung die größten Schwierigkeiten in den Weg legen (siehe S. I8I). Abgesehen von der unvollständigen Kenntnis dieser Algen ist gerade die Formenmannigfaltigkeit, wie bei den Flagellaten, ein Hindernis klarer Anordnung und Einteilung. Eine einzelne, niedere Alge zeigt nach ganz verschiedenen Seiten Verwandtschaftsbeziehungen, und es bleibt subjektiver Schätzung überlassen, auf welches verwandtschaftliche Band man gerade den Hauptnachdruck legt. Mir scheint auch heutzutage die von mir vertretene und im Flagellatensystem durchgeführte Anschauung die zweckmäßigste $z u$ sein, daß man typische Vertreter einer Alteilung, sei es Familie oder Gattung, annimmt und daran die Formen anschließt, die den Uebergang zu verwandten Abteilungen bilden. In meinem ersten Versuch ( $\mathrm{K}$ lebs $8_{3} \mathrm{~S} .3 t^{2}$ u. w.) liabe ich durch klares Hervorheben typischer Formen eine Anzahl Abteilungen unter den 
niederen, grünen Algen gesondert und dabei eine Familie der Endosphaeraceen unterschieden (vergl. auch Wille 9I S. 65). Diẹ einzelne Zelle einer dazu gehörigen Form pflanzt sich durch eine Art von Schwärmern fort, die entweder geschlechtlich oder ungeschlechtlich sind, während die vegetative Teilung fehlt. Ein Vertreter der Familie, Phyllobium (Klebs 8I), zeichnet sich durch seine lang schlauchförmigen Zellen aus. Unstreitig nähert sich Protosiphon den Endosphaeraceen, besonders der Gattung Phyllobium, und ich halte es zunächst für das beste, die Alge zu dieser Familie zu rechnen. Aber man muß im Auge behalten, daß sie nicht mehr als eine typische Form zu bezeichnen ist; sie weist auch nach anderen Seiten deutliche Verwandtschaftsbeziehungen auf. Sie erinnert in ihrer Zellstruktur auffallend an Hydrodictyon, sie weicht von den anderen Endosphaeraceen durch die vegetative Teilung $a b$, in welcher Beziehung sie sich den Chlorosphaeraceen nähert.

Zum Schluß will ich noch die Diagnose der Alge geben, wobei ich alle wesentlichen Eigenschaften berücksichtige.

$$
\text { Protosiphon Klebs. }
$$

Zelle anfangs kugelig, später schlauchförmig und bei vollster Entwickelung botrydiumartig, aus einem grünen, kugeligen, oberirdischen Teil und einem langen, meist unverzweigten, farblosen Wurzelteil bestehend; Maximallänge $=\mathrm{I}, 2-\mathrm{I}, 4 \mathrm{~mm}$.

Ausgebildete Zellen mit wandständiger, netzförmig durchbrochener Chlorophyllschicht nebst Amylonkernen und Stromastärke; zahlreiche kleine Zellkerne im ganzen Plasma verteilt; eine große Zellsaftvakuole in der Mitte. Jede Zelle teilungsfähig; eine kugelige, kleine durch 
successive, gewöhnliche Zweiteilung; eine schlauchartige Zelle durch Aussprossen und Abtrennen von Seitenzweigen.

Unter stark wachstumhemmenden Bedingungen: Austrocknen, stark wasseranziehende Salzlösungen, direkte Sonnenwirkung tritt Zerfall des Protoplasten in eine bis viele ruhende Sporen ein, die im Licht sich rot färben und Trockenheit aushalten.

Jede vegetative Zelle wie Spore ist der Schwärmerbildung fähig beim Uebergang aus feuchter oder trockener Luft in Wasser, oder bei Lichtabschluß, wenn sie vorher in Nährsalzlösung kultiviert worden ist.

Die Schwärmer klein, lichtempfindlich, mit zwei Wimpern, Augenfleck, kontraktilen Vakuolen; im Wasser, im Licht bei Temperaturen von $\mathrm{I}-24^{\circ}$ kopulierend und ruhende, sternartige Sporen liefernd; in Nährlösungen im Dunkeln oder überhaupt bei 'Temperaturen von $25-27^{\circ}$ ohne Kopulation zur Ruhe kommend und glatte Zellen bildend, die sofort wachstumsfähig sind.

Die Alge lebt auf feuchtem Boden, häufig in Gesellschaft von Botrydium, gedeiht ebenso auch in nährsalzhaltigem Wasser.

Protosiphon botryoides ( $\mathrm{K}$ ü $\mathrm{z}$ ing) Klebs。 Einzige Species.

Protococcus botryoides K ützing. Tabulae phycol. I 845 , Vol. 1, S. 2, Tab. II; Cienkowski, Bot. Zeitung I 855, S. 780, Taf. XI B.

Protococcus coccoma $\mathrm{K}$ üt $\mathrm{z}$ ing. Phycologia generalis 1843 , S. 168 , Tal. VII, Fig. I.

Botrydium granulatum zum Teil, bei Rostafinski und Woronin. Bot. Zeitung I877, Nr. 4 I-42, Taf. VIII, Fig. I5-I7; Taf. IX, Fig. 29-35; Taf. X, Fig. 37-4I ; Taf. XI, Fig. 50-66 (exkl. 65). 


\section{Botrydium granulatum.}

Nachdem Protosiphon aus dem Formenkreis von Botrydium ausgeschieden ist, erscheint der Entwickelungsgang des letzteren verhältnismäßig einfach, soweit die bisherigen Untersuchungen ein Urteil erlauben. Ich habe mich nicht so ausführlich mit der Alge abgegeben und werde sie nur in einigen Punkten näher behandeln, um die Angaben von Rostafinski und Woronin zu ergänzen.

Botrydium bildet bald einzeln stehende, bald dicht gedrängte, grüne Blasen von $\mathrm{I}-2 \mathrm{~mm}$ Durchmesser auf feuchtem Boden. Jede Blase geht in einen reich verzweigten, farblosen Wurzelteil über, der im Boden steckt. Der grüne, oberirdische Teil der Zelle besitzt um den großen Zellsaft einen Wandbeleg mit zahlreichen einzelnen Chlorophyllkörpern (vergl. Schmitz 82) und mit zahlreichen kleinen Zellkernen. Das einfachste Mittel, die Zoosporenbildung hervorzurufen, haben Rostafinski und Woronin bereits angegeben; es besteht darin, die aus der Erde herauspräparierte Alge in Wasser zu legen. Der Uebergang aus feuchter Luft in Wasser spielt auch bei Botrydium den Hauptreiz für die Zoosporenbildung. Ob die Bildung der Zoosporen wirklich durch eine simultane Teilung erfolgt, wie bisher angenommen wird, weiß ich nicht; das Vorkommen von Doppelsporen mit zwei Wimpern könnte darauf hinweisen, daß auch bei Botrydium eine Art abgekürzter Zweiteilung, wenigstens im letzten Stadium des Prozesses, stattfindet. Die Zoosporen sind verhältnismäßig groß (Länge bis zu $20 \mu$ ) und zeichnen sich durch den Besitz einer Wimper aus; sie bewegen sich nur sehr kurze Zeit und bilden, zur Ruhe kommend, kugelige Sporen. Diese 
können austrocknen, wobei sie aber niemals rot werden und nicht mit den Sporen von Protosiphon verwechselt werden können. Im Wasser keimen sie nie (Rost afinski und Woronin 1. c.); sie brauchen dazu, wie meine Versuche zeigen, kleine Mengen von Nährsalzen. Man kann z. B. die Sporen auf 0,5-proz. Agar-Agar aussähen und wird kaum vereinzelt einen Anfang der Keimung beobachten. Fügt man nach 3-4 Wochen eine Nährlösung von 0,2 Proz. hinzu, so treiben alle Sporen in kurzer Zeit Keimschläuche aus. Diese wachsen in dem Agar-Agar oder auch direkt in einer Nährlösung von 0,4 Proz. zu langen Schläuchen aus, die aber äußerst leicht sich von den Schläuchen von Protosiphon unterscheiden lassen, da die Chlorophyllkörper immer deutlich herrortreten (Taf. I, Fig. I7-I8). Das Auffallende ist, daß die Chromatophoren der jungen Schläuche je ein nacktes, croßes Pyrenoid besitzen, was bisher weder von Rostafinski und Woronin, noch von Schmitz oder anderen gesehen worden ist (vergl. Taf. I, Fig. I9 $a$ ). Jeder Chlorophyllkörper wölbt sich in der Mitte kegelförmig hervor und umschließt ein Pyrenoid, das nach Jodfärbung als ein braun gefärbter, etwas eckiger Körper hervortritt. Nach Fixierung mit Alkohol und Behandlung mit Säurefuchsin und Anilinwasser (siehe Zim merma n n, Mikrotechnik, ()2 346$)$ färbt sich das Pyrenoid intensiv rot, nach dem Auswaschen mit Glycerin violett-rot. Die Chromatophoren älterer Botrydiumpflänzchen enthalten dagegen kein Pyrenoid; es ist nicht näher bestimmt worden, in welchem Zeitpunkt es verschwindet.

Sehr hervorzuheben ist die Thatsache, daß Botrydium unter keinen Umständen Stärke bildet, daß dagegen wie bei Vaucheria fettes Oel in wechselnder Menge erzeugt wird. Das farblose Plasma ist in den jungen Schläuchen von Botrydium in beständiger Bewegung 
und Formveränderung begriffen. Im Plasma finden sich zahlreiche, kleine Zellkerne (Fig. I9 $n$ ).

In der Nährlösung wachsen die Schläuche von Botrydium lebhaft fort und beginnen dann sich in sehr unregelmäßiger Weise zu verzweigen, ähnlich wie es die Figuren $42-44,48$ bei Rostafinski und Woronin zeigen. Doch bemerkte ich dabei nie eine Abtrennung der Zweige durch Querwände. In den Schläuchen sammeln sich die Chlorophyllkörper am oberen Ende an, während der längere, untere Teil nur farbloses Plasma mit einer Anzahl von Zellkernen enthält. Aehnliche, verzweigte Bildungen treten auch in Agar-AgarKulturen auf.

Die jungen, schlauchförmigen Zellen bilden nach dem Uebergange aus Nährlösung in Wasser ab und zu Zoosporen, die, ohne auszutreten, innerhalb der alten Zellhaut zur Ruhe kommen. Aber der Versuch gelingt aus unbekannten Gründen nicht häufig; mitunter tritt eine solche Sporenbildung auch in der Nährlösung direkt ein. Als ich einige Schläuche aus einer Nährlösung von 0,4 Proz. in eine solche von I Proz. brachte, erfolgte eine wirkliche Zellteilung, so daß aus dem Schlauch ein Zellfaden entstand, wobei allerdings vielfache Unregelmäßigkeiten bemerkbar wurden. Dicht über einer älteren Zellwand wurde eine neue gebildet, so daß sehr ungleichartige Zellen den Faden zusammensetzten.

Auf sterilisiertem, feuchtem Lehm erhielt ich aus den Zoosporen eine prächtig gedeihende Reinkultur, in der die Zellen ihre typische Ausbildung erlangten. Nur fiel mir auf, daß sehr häufig zwei grüne Bläschen an einem gemeinsamen Wurzelsystem saßen, was darauf schließen ließ, daß das grüne Ende der jungen Zellen sich einmal dichotomisch verzweigt hatte.

$\mathrm{Kl}$ e bs, Fortpflanzungsphysiologie. 
Rostafinski und Woronin haben noch einige andere Abweichungen im Entwickelungsgang von Botrydimm beschrieben. Bei langsamem Austrocknen oder bei clirrkter Sonnenwirkung zieht sich der ganze Protoplast in die Wurzel hinein und zerfällt in eine Anzahl größerer Sporen, die sog. Wurzelzellen. Diese künnen direkt wieder zu Botrydium-Pflänzchen heranwachsen oder sie künnen Zoosporen bilden oder sich bei gleichmäßiger Feuchtigkeit zu dunkelgrünen, mit dicker Membran versehenen "Hypnosporangien" umwandeln, die nach Begießung mit Wasser zu Zoosporangien werden.

Es gelang mir nicht, auf die von den beiden Verfassern angegebene Weise die Wurzelzellen zu erlangen, olne daß ich auf diese negativen Resultate großes Gewicht legen möchte. Sie deuten nur darauf hin, daß noch unbekannte, äußere Bedingungen für die Entstehung cler Wurzelzellen maßgebend sein müssen.

Nach den bisher bekannten Thatsachen ist Botrydium granulatum eine typische Siphonee mit schlauchförmigem Thallus, der eine Differenzierung in einen oberirdischen, grünen, assimilierenden und einen unterirdischen, farblosen, reich verzweigten, wurzelartigen Teil besitzt. Die Zelle hat neben zahlreichen Zellkernen viele scheibenförmige Chlorophyllkörper, erzeugt fettes Oel, aber niemals Stärke. Der Thallus pflanzt sich durch eine einzige Art von Schwärmern fort, einwimperigen, ungeschlechtlichen Zoosporen. Ol, noch eine geschlechtliche Fortpflanzung existiert, ist bis jetzt ungewißß. 


\section{Die Konjugaten.}

(Holzschnitt Fig. 5-7.)

Die Gruppe der Konjugaten zeichnet sich vor der Mehrzahl der Chlorophyceen durch den Mangel der Zoosporenbildung aus, sowie durch die Form der geschlechtlichen Fortpflanzung, die seit V a ucher's Entdeckung (03) oft und eingehend beschrieben worden ist (vergl. de Bary 58).

Bei der Konjugation vereinigen sich die Inhalte zweier Zellen, die sich anscheinend von gewöhnlichen, vegetativen Zellen nicht unterscheiden; das Produkt der Verschmelzung, die Zygote, stellt eine Dauerspore dar, die nach einiger Zeit der Ruhe keimt. Bei der Konjugation vereinigen sich außer dem Protoplasma auch die Kerne beider Zellen, wie Schmitz (79 S. 23), Overton (88 S. 7I) nachgewiesen haben, während nach Chmielevsky (90 S. 776) von den Chlorophyllbändern nur die der einen Zelle sich erhalten, die der anderen, und zwar die der männlichen, zu Grunde gehen.

Die beiden verschmelzenden Zellen erscheinen bei den Desmidiaceen völlig' gleichartig, während bei den Spirogyren die erste Andeutung einer Geschlechtssonderung bemerkbar ist. Bei allen Arten mit leiterförmiger Konjugation sind die Zellen des einen Fadens die aktiv wandernden, während die des anderen Fadens passiv sich verhalten und die ersteren ruhig erwarten. Die aktiven Zellen können wir als die männlichen, die passiven als die weiblichen bezeichnen. 
Eine besondere Art der ungeschlechtlichen Fortpflanzung findet sich nicht bei den Konjugaten. Die Zellen vermehren sich ausschliełlich durch gewöhnliche Teilung; bei den Desmidiaceen trennen sich meistens die Tochterzellen gleich nachher; bei den fadenbildenden Formen bleilen sie vereinigt. Auch bei diesen kann eine Loslösung einzelner Zellen erfolgen, und es kann dadurch eine Vermehrung der Fäden herbeigefülhrt werden. Die Ursache liegt darin, daß in einer Zelle, besonders häufig der Endzelle, durch verschiedenartige, ungünstige Unstände der Turgor sinkt. Die viel turgescentere Nachbarzelle sucht dann ihre Querwand in die andere hinein zu drücken, wobei der Zusammenhang beider, den die dünne, cuticulare Schicht vermittelt, gelockert und schließlich aufgehoben wirl. Die abgetrennte Zelle kann weiter leben und sich vermehren. Besonders bei Spirogyra orthospira kann man eine solche Abspaltung von einzelnen Zellen beobachten. Strasburger ( 76 S. 57) beschreibt, wie bei dieser Alge manchmal ein Zerfallen ganzer Fäden in einzelne Zellen eintritt.

Die genannte Spirogyra-Art läßt sich gut kultivieren; so lange sie in kräftigem WTachstum ist, erfolgt keine Abspaltung, auch kein Zerfall der Fäden. Erst unter ungïnstigen Umständen, z. B. bei der Kultur in wenicr Wasser und direkter Sonnenbeleuchtung, beobachtete ich den Zerfall, der durch den Untergang einzelner Zellen. im Fadenverbanıl unterstützt wird. Es gelang mir jedoch nicht, eine bestimmte Methode herauszufinden, um einen regelmäßigen Zerfall der Fäden in normale, lebende Zellen mit Sicherheit zu veranlassen, etwa in ähnlicher Weise, wie es bei Hormidium-Arten gelingt. Pfeffer (92 S. 239 Anm.) giebt an, daß er mit Hilfe von Chloroformwasser den Zerfall hat herbeiführen können. 
Die physiologischen Bedingungen, welche bei der geschlechtlichen Fortpflanzung der Konjugaten eine Rolle spielen, sind bisher nicht erforscht worden. Sie sollen im folgenden berücksichtigt werden, wobei ich als Vertreter der fadenbildenden Formen die Gattung Spirogyra untersucht habe, und als Vertreter der einzelligen Desmidiaceen die Gattungen Closterium und Cosmarium.

\section{Spirogyra.}

Die Arten dieser Gattung finden sich zu allen Jahreszeiten in Sümpfen und Teichen vor. Bei der Konjugation (vergl. de Bary 58) bilden sich gewöhnlich bei aneinander liegenden Fäden Verbindungskanäle zwischen zwei opponierten Zellen; der Protoplast des männlichen Fadens wandert dann durch den Kanal zum weiblichen hinüber und verschmilzt mit ihm. Neben dieser leiterförmigen Vereinigung der Fäden finden wir bei manchen Arten eine seitliche Konjugation zwischen zwei benachbarten Zellen desselben Fadens.

Bereits de Bary (58 S. 6), später Petit ( 80 S. 3) wiesen nach, daß bei der gleichen Species beide Formen der Konjugation beobachtet werden können. Sehr leicht kann man dies bei der verbreiteten Sp. Weberi sehen.

Die interessante Frage, welche Ursachen das Wachstum und das Zusammentreffen der Kopulationsfortsätze bedingen, ist noch nicht aufgeklärt. Nach der wichtigen Entdeckung der chemischen Reizwirkungen durch P feffe $\mathrm{r}$ (84) lag es nahe, auch für Spirogyra anzunehmen, daß Ausscheidungen chemisch reizender Stoffe bei der Anlage und der Wachstumsrichtung der Kopulationsschläuche 
mitwirken. Overton (88 S. 69) und Haberlandt (90 S. 2 u. w.) haben sich in dieser Weise ausgesprochen.

Haberlandt hebt besonders hervor, daß eine wechselseitige, chemische Beeinflussung der kopulierenden Fäden vorausgesetzt werden müsse. So unbestimmt und wenig bewiesen diese Annahme ist, so kann man sie vorläufig durch keine bessere ersetzen, und sie erklärt doch manche charakteristischen Erscheinungen der Kopulation, auf die Haberlandt aufmerksam gemacht hat. Er weist darauf hin, daß die Kopulationsfortsätze eines Fadens nur unter dem Einfluß des gegenüberliegenden hervorgerufen werden. Den sichersten Beweis liefert dafür ein einfacher Versuch, den ich mehrfach angestellt habe. Man bringt Fäden von Spirogyra varians, bei der alle Zellen zweier Fäden zu kopulieren pflegen, im richtigen vorbereiteten Stadium auf eine Agar-Agar-Gallerte, $(0,5$ Proz.), auf der die Fäden in mannigfachsten Windungen die einmal angenommene Lage nicht mehr verändern. Erfolgt dann nach einigen Tagen die Konjugation, so sieht man mit größter Bestimmtheit, daß ein einzelner Faden, mag er bei seinen Schlingungen noch so oft sich selbst nahe kommen, niemals Fortsätze treibt, daß ferner zwei Fäden nur dort liopulieren, wo sie einander ganz nahe liegen. Ein einzelner, männlicher Faden kann bei seinen Windungen an verschiedenen Stellen mit drei bis vier weiblichen Fäden für kurze Strecken in Kopulation treten. Alle diejenigen seiner Zellen, die keinen weiblichen Fäden nahe kommen, müssen steril bleiben, trotz lebhaftester Neigung zur geschlechtlichen Fortpllanzung. Nach einiger Zeit, namentlich bei Zusatz einer verdünnten Nährlösung, nehmen die zur Sterilität gezwungenen Fäden ihr vegetatives Wachstum wieder auf und teilen sich. Die Grenze für die gegenseitige Einwirkung der Fäden auf einander liegt in einer Entfernung des 
2-3-fachen Durchmessers der Alge (Haberlandt 90 S. 6).

Nahe der Grenze kann es sich ereignen, daß zwei gegenüberliegende Zellen noch kurze Fortsätze treiben, die sich aber nicht erreichen können, weil die Reizwirkung zu schwach ist.

Die Kopulationsfortsätze werden, wie $\mathrm{Haberlandt}$ betont, nicht gleichzeitig angelegt; vielmehr treibt die eine Zelle zuerst einen Fortsatz und veranlaßt durch weitere Reizwirkung an der gerade gegenüberliegenden Stelle der anderen Zelle den entsprechenden Fortsatz. So kommt es, daß die kopulierenden Fäden die bekannte leiterförmige Gestalt erhalten. Wenn die Fortsätze nicht genau gegenüber sich entwickeln, so krümmen sie sich gegen einander, bis sie sich treffen. Besonders deutlich sieht man dies, wenn drei Zellen miteinander kopulieren.

In einer Kultur von Spirogyra Weberi, die einige Ze itin 4-proz. Rohrzuckerlösung sich befand und dann, in Wasser übergeführt, kopulierte, waren die männlichen Zellen vieler Fäden doppelt so lang als die weiblichen. Je zwei weibliche Zellen kopulierten häufig leiterförmig mit einer männlichen, so daß diese zwei Fortsätze bilden mußte, obwohl ihr Inhalt nur mit einer weiblichen verschmolz. Waren die Vorbereitungen dafür schon weit vorgeschritten, so mußte die andere weibliche Zelle allein einen Fortsatz treiben, der vergeblich den entsprechenden der männlichen Zelle erwartete.

Bei einigen Arten, besonders der von mir viel untersuchten Sp. inflata, wird das Zusammentreffen der Kopulationsfortsätze noch auf andere Weise sehr erleichtert. Bevor noch irgend etwas von den Fortsätzen zu sehen ist, krümmen sich die Fäden wellig hin und her, weil die einzelnen Zellen bald nach dieser, bald nach jener Seite konvex oder geradezu knieförmig sich biegen. An 
diesen Stellen treiben dann die weiblichen Fäden in nächster Nähe der männlichen je einen Fortsatz, dem nur ein ganz kurzer der männlichen Zelle entspricht.

Auf die Vorgänge, welche bei der Vorbereitung für die Verschmelzung, sowie bei dieser selbst stattfinden, will ich bei der Besprechung der Parthenogenesis zurückkommen.

Für die mich beschäftigenden Fragen nach den Bedingungen der Konjugation war es vor allem erforderlich, die Spirogyren kultivieren zu können. Ich habe mit den verschiedenen, in Basels Umgebung vorkommenden Arten Versuche angestellt, bis ich einige fand, welche ich einigermaßen im Laboratorium ziehen konnte. Es ist sehr bekannt, daß die Spirogyren leicht in Zimmerkulturen zu Grunde gehen. Durch die interessanten Untersuchungen Nägeli's (93) haben wir kennen gelernt, wie kleine Spuren gewisser Substanzen, besonders von Metallen, äußerst giftig auf die Spirogyren einwirken. Ueberhaupt können kleine Aenderungen der Lebensbedingungen eine Anzahl empfindlicher Fäden töten, und der Fäulnisprozeß dieser greift dann überraschend schnell um sich. Besonders empfindlich sind nach $\mathrm{N}$ ägeli die großen Arten, während kleinere Arten, wie varians, longata, inflata, Weberi, die ich hauptsächlich untersuchte, mehr aushalten können. Ich habe bei diesen Arten folgende Kulturmethode eingeschlagen. Die Spirogryren, aus der freien Natur geholt, brachte ich in große Glasgefäße, die mit Regen- oder Leitungswasser gefüllt waren. Die Gefüße wurden in ein kühles Nordzimmer ans Fenster gestellt und ruhig sich selbst überlassen. Es konnte sich dabei ereignen, daß in der ersten Zeit Fäulnis eintrat, aber die Algen erholten sich und wuchsen lebhaft heran. Solche im Zimmer aufgewachsenen Spirogyren waren für die Versuche sogar besser geeignet, 
weil sie augenscheinlich viel weniger empfindlich waren, als die direkt der freien Natur entnommenen. Am ausführlichsten habe ich die Versuche mit Sp. inflata und varians gemacht.

\section{Spirogyra inflata Vaucher.}

Diese Art bildete im Frühjahr 1894 dichte, hellgrüne Watten im Weiher von Allschwyl. Die Fäden dieser Species haben einen Durchmesser von I5-I7 $\mu$; die Zellen sind IO-I2 mal so lang als breit und besitzen ein einziges, zartes Chlorophyllband. Die Querwände sind stets gefaltet. Ich machte eine Kultur Anfang Februar und verwandte ausschließlich diese zur Untersuchung. Am kühlen, zugleich etwas schattigen Standort des Zimmers bildete die Alge bis Mitte Mai keine Zygoten; zu der Zeit wurden die Versuche abgebrochen. Am natürlichen Standort beobachtete icch Anfang Mai die Anfänge der Konjugation. In der Zeit von Mitte Februar bis Anfang Mai konnte ich jederzeit die Konjugation hervorrufen. Wie ich vorhin bemerkte, zeigt sich die erste Vorbereitung dazu in dem Hin- und Herkrümmen der Fäden, deren Zellen durch lebhafte Teilung kürzer werden. Gleich nach oder kurz vor der Kopulation zweier Zellen schwillt die weibliche Zelle bauchig an, die männliche dagegen nicht. Die Vereinigung der Protoplasten erfordert bei inflata im allgemeinen lange Zeit; es vergehen oft 8 Tage, bis die ersten Sporen auftreten. Auch sah ich nicht eine allgemeine Konjugation aller Zellen, sondern es blieb immer eine Anzahl steril.

Die sterilen Fäden wurden zur Konjugation veranlaßt, als ich sie in 2-4-proz. Rohrzuckerlösung hell sonnig stellte. Das gleiche erreichte ich, als ich die Fäden mit wenig Wasser in die Sonne brachte, nur daß unter 
diesen Umständen ihre Hauptfeinde, die Vampyrellen, sich zu stark vermehrten, während diese in der Zuckerlösung sich nicht recht entwickeln konnten. Weitaus die Hauptbedeutung für die Konjugation lrommt dem Lichte zu; entsprechende Rohrzuckerkulturen, dunkel oder halbdunkel gestellt, zeigten keine Spur von ihr. So stand eine Kultur in 4-proz. Rohrzuckerlösung vom 9. März bis 12. April an einer schwach beleuchteten Stelle des Zimmers; sie erhielt sich lebend, blieb aber steril. Einen Teil der Kultur stellte ich am 2I. März sonnig und beobachtete am 28. März die Vereinigung der Fäden, später reife 7ygoten.

Wie bei Vaucheria, beeinflußt auch bei Spirogyra intlata das Licht in zweierlei Weise die Konjugation, erstens als Vermittler der Ernährung, da der Prozeß eine Ansammlung organischer Substanzen erfordert, zweitens in specifischer Weise. Der Zucker kann nur die erste Art der Wirkung ersetzen, nicht die zweite; er kann nur veranlassen, daß die Konjugation bei einer etwas geringeren Intensität des Lichtes erfolgt, als in reinem Wasser. Ich stellte neben die Hauptkultur im kühlen, nicht sehr beleuchteten Zimmer eine Kultur in 4-proz. Rohrzuckerlösung; während die erstere steril blieb, trat in der Zuckerkultur die Kopulation ein.

Die Versuche mit künstlicher Lichtquelle gelangen nur teilweise. In $25 \mathrm{~cm}$ Entfernung von der Auer'schen Lampe traten deutliche Krümmungen und Knickungen der Fäden, hier und da spärliche Kopulationen auf, ohne dak aber reife Zygoten sich entwickelten. In $50 \mathrm{~cm}$ Entfernung war bereits lieine Andeutung einer Kopulation mehr vorhanden, trotzdem die betreffende kiltur in 2-proz. \%uckerlösung vom I7. März bis 16. April sich an der Stelle lebend erhielt. Einen Versuch machte ich mit den doppelwandigen Glocken, der gelben (Pikrinsäure), der 
roten (saures chromsaures Kali), der blauen (Methylenblau 0,002 Proz.) und der weißen, blau fluorescierenden (Chinin). Am 9. März wurde unter jede Glocke ein Gläschen mit steriler Spirogyra in 4-proz. Rohrzuckerlösung gebracht. Am 15. März beobachtete ich Kopulationen unter der Chininglocke sowie der roten und gelben, während solche unter der blauen Glocke erst am 26. März bemerkbar wurden, zu einer Zeit, als in den anderen Kulturen bereits fertige Zygoten sich befanden.

Die Temperatur hat keine specifische Wirkung auf den Sexualprozeß. Ich hing ein Gefäß mit sterilen Fäden, die in 2-proz. Zuckerlösung sich befanden, am I5./III. in den Brunnen; am I./IV. fanden zahlreiche Kopulationen statt, am I2./IV. Zygoten. Während der Zeit schwankte die Temperatur des Brunnens zwischen 6-8 ${ }^{\circ}$. Das gleiche Resultat hatte ein Versuch im Aquarium bei einer Temperatur von 7-8". Auch eine Zuckerkultur, die im Freien im Monat März, vor direkter Sonne geschützt, stand, zeigte nach I4 Tagen die ersten Kopulationen. Die Temperatur sank des Nachts auf $+3-4^{0}$ und erhob sich am Tage bis höchstens $12^{\circ}$; es erklärt sich daraus die Verzögerung im Eintritt des Prozesses. Andererseits halten die Kulturen der Sp. inflata die starke Temperatursteigerung durch die Sonne aus. Ich stellte die Gefäße mit den Algen im März und April direkt in die Sonne, welche die Temperatur der Kulturflüssigkeit mehrere Stunden hindurch bis auf $28-30^{\circ}$ steigerte. Bei einer konstanten Temperatur von $26^{\circ}$ beobachtete ich in einer Wasserkultur in 5 Tagen eine Anzahl Zygoten; der Prozeß wird also jedenfalls durch eine solche Temperatur beschleunigt. Rohrzuckerkulturen haben bei ihr kein positives Resultat gehabt, weil chemische Veränderungen, Gärungen etc. zu bald störend wirkten. 
Finen auffallend hemmenden Einfluß üben die Nährsalze auf den Konjugationsprozeß aus. Schon in einer Lösungr von 0,1 Proz. habe ich hei heller Beleuchtung keine reifen Zygoten gesehen. Die Fäden krümmten sich, knickten ein, teilten sich lebhaft, vereinigten sich auch hier und dort; aber eine Verschmelzung trat nicht ein. Selbst in einer Lösung von I Proz., in der die Algen im März und April grut fortkamen, zeigten sich noch einzelne Anfänge der Kopulation, doch ohne jeden weiteren Fortschritt, so daß die Kulturen thatsächlich steril blieben. Der hemmende Einfluß wirkte sogar nach, so daß auch nach Ueberführung in Wasser keine rechte Konjugation mehr stattfand. Wir lernen hierbei einen selır wichtigen Punkt kennen, der für das Verständnis des Verhaltens mancher Spirogyra-Arten im Auge zu behalten ist. Wenn die Lebensbedingungen nach irgend einer Richtung hin nicht ganz normal und günstig sind, so kann die Alge in einen Zustand geraten, in welchem sie trotz aller für den Sexualprozeß notwendigen, äußeren Umstäncle steril bleibt. So rring es auch mit meiner Hauptliultur, die seit Anfang Felıruar in relativ geringer Wassermenge liühl und schattig grelel)t hatte. Anfang Mai konnte ich die Alge nicht mehr zur Kopulation bringen; sie ging allmählich zu Grunde, da ich specielle Versuche, sie wieder zur vollen Lebenskraft zu bringen, nicht angestellt habe.

\section{Spirogyra varians IIassall.}

Diese Art gehört zu den häufigeren Spirogyren in ler Umgebung Basels und ist für die vorliegende Untersuchung sehr geeignet, weil sie bei günstigen Bedingungen in wenigen Tagen äußerst reichlich konjugiert. Sie hat den Nachteil, daß sie in sehr schwachem Licht 
nicht lange aushält, in stärkerem aber zu leicht sich fortptlanzt. Um sterile und doch lebensfähige Fäden zu erhalten, kann man bei dieser Art verdünnte Nährlösungen anwenden, oder sie auch im Aquarium ziehen.

Die sterilen Fäden haben einen Durchmesser von 26-36 " und bestehen aus cylindrischen Zellen, die 3-5 mal so lang als breit sind und ein Chlorophyllband von 4-6 Umgängen besitzen. Die ersten Anfänge der Kopulation kann man mit bloßem Auge erkennen. Denn während die vegetativen Fäden, parallel zusammenliegend, lange, aufstrebende Bündel bilden, verflechten sie sich mit dem Beginn der Kopulation zu einem verworrenen Netz. Die kopulierenden Zellen sind infolge der vorausgegangenen, lebhaften Teilung kürzer als die vegetativen, etwa nur 2-3mal so lang als breit. Die weiblichen Zellen sind angeschwollen; besonders charakteristisch ist es, daß auch die steril bleibenden Zellen der kopulierenden Fäden stark bauchig anschwellen.

Stellt man sterile Fäden hell sonnig, so zeigen sich bereits nach 3-4 Tagen die Anfänge der Kopulation; nach 5-6 Tagen sind fast sämtliche Fäden in Mitleidenschaft gezogen, und zahllose Zygoten finden sich vor. Da die Versuche in den Sommermonaten gemacht wurden, so habe ich auf die Verwendung von Zuckerlösungen verzichtet. Zuerst brachte ich die Fäden mit wenig Wasser in die Sonne; später fand ich es am geeignetsten, eine relativ kleine Fadenmasse in ein Gefäß mit $100 \mathrm{ccm}$ Leitungswasser zu bringen und während des Vormittags direkt in die Sonne zu stellen. Die Algen halten die direkte Sonnenbeleuchtung und die damit verbundene starke Temperaturerhöhung sehr gut aus, wenn man sie vom frühen Morgen an der Sonne aussetzt, während sie bei Versuchen, bei denen ich sie plötzlich aus diffusem Zimmerlicht in die Mittagssonne brachte, oft zu Grunde gingen 
In schwachem Licht, in der Dunkelheit, erfolgt keine Kopulation. Wie ich schon bemerkte, kann man Spirogyra varians kaum I-2 Wochen unter solchen Umständen lebend erhalten. Auch die Versuche mit der künstlichen Lichtquelle weisen auf die große Bedeutung der Lichtintensität hin. In $25 \mathrm{~cm}$ Entfernung von der Lampe trat nach 5 Tagen leblafte Konjugation ein; in $50 \mathrm{~cm}$ Entfernung zeigten sich noch Anfänge dazu, ohne daß es zur Versclımelzung kam. Solche Fäden gingen zu Grunde, während die ganz vegetativ gebliebencn sich lelsend erlielten. Es ist höichst wahrscheinlich, daß auch für Sp. varians das Licht in den beiden Richtungen bedeutungsvoll ist, wie für inflata und Vaucheria. Die Ansammlung organischer Substanzen ist jedenfalls für den Sexualprozefs notwendig, da die Alge in kohlensäurefreier Luft bei vollem Lichtzutritt nicht einmal eine Andeutung davon zeigt. Die Alge blieb vom 26./IV.-9./V. im Apparat (s. S. 36); an dem letzten Termin wurde sie frei ans Fenster gestellt, und sie begann am I5./V. zu kopulieren.

So leicht und sicher bei Spirogyra varians die Konjugation erfolgt, so ist es doch möglich, trotz heller Beleuchtung und kräftiger Ernährung den Sexualprozeß vollständig zu verhindern, während Wachstum und Teilung sehr lebhaft vor sich gehen. Es gelingt dieses

I) durch tließendes Wasser;

2) durch Nährlïsung.

Ich fand Spirogyra varians in einem Brunnen von Arlesheim, wo sie ganz große, grüne, schwimmende Massen bildete, die völlig steril waren. Nach drei Tagen sah ich im Zimmer bereits die Kopulation. Einen Teil des Materials brachte ich in mein Aquarium, wo es sich mehrere Wochen gut hielt und steril blieb, so daß es vie]fach für die Versuche diente, die vorhin erwälnnt worden sind. Am klarsten ging der Finfluß des sich stets 
erneuernden Wassers aus dem Versuch vom I7./IV. I894 hervor, wo ich einen Teil der Alge in ein großes Glasgefäß brachte, und ins Aquarium stellte. Licht und Temperatur (IO-II ${ }^{0}$ ) blieben sich gleich; die frei schwimmende Alge erhielt sich steril, die in begrenzter Wassermenge befindliche hatte nach \& Tagen Zygoten. Die Verzögerung erklärt sich daraus, daß keine direkte Sonne mitwirkte, und die Temperatur relativ niedrig war. Der Einfluß des fließenden Wassers läßt sich auch an anderen Arten beobachten, die in Bächen vorkommen. Im allgemeinen kennt man nicht viele Spirogyren als Bewohner von lebhaft strömenden Gewässern. Doch beobachtete ich im Oktober I893 in dem Birsigflusse bei Basel eine mächtig entwickelte Spirogyra, die sich später als die seltene fluviatilis erwies. Borge (94 S. 9) hat die Rhizoidbildung dieser Alge untersucht und sie vom Oktober I893 bis Mai I894, wo sie verschwand, in der freien Natur stets steril gefunden, während sie in seinen Kulturen mehrfach Zygoten bildete. Die früheren Beobachter Hilse (Kirchner 78 S. I24), Petit (So S. 27) haben diese Alge stets nur steril beobachtet; der Fundort war immer fließendes Wasser.

Die Wirkung des fließenden Wassers wird höchstwahrscheinlich wie für Vaucheria auch für Spirogyra darin bestehen, daß durch die lebhafte Zuführung von frischer Luft und Nährsalzen, unterstützt durch die gleichmäßige, niedere Temperatur, Wachstum und Teilung beständig fortgehen, so daß es zu einer geschlechtlichen Fortpflanzung nicht kommen kann.

In specifischer Weise hemmend auf den Sexualprozeß von Sp. varians wirken die Nährsalze ein, sowie eine gewisse Grenze der Konzentration überschritten wird. In einer Nährlösung von 0,05 Proz. findet Konjugation statt, wenn auch die Zygoten sich nicht so reichlich ausbilden, 
als in reinem Wasser. Die steril gebliel,enen Fäden wachsen lebhaft zu einem liräftigen Bünclel heran. In einer o, I-proz. Lijsung kommt es bereits selten zu einer wirklichen Vereinigung, in einer solchen von 0,2 Proz. sah ich bisher keine Andeutung daron. Andererseits wachsen die Spirozyren darin vortrefflich, so daß ich die Alge im Laufe des ganzen Sommers erhalten konnte, während sie in den Wasserkulturen infolge lebhafter Zygotenbildung verschwand. Zum Unterschiede von Spirogyra inflata macht sich bei Spirogyra varians nach Ueberführung in IVasser keine hemmende Nachwirkung bemerkbar. 1ch machte am I4./IV. IS94 eine Kultur in 0,2-proz. KN-Lösung und stellte mit dem Material Versuche zu verschiedenen Zeiten an:

I) am $17 . / \mathrm{IV}$. in Wasser sonnig; am 21./IV. Vereinigung der Fäden; 24./IV. zahlreiche Zygoten.

2) am 7./V. in Wasser sonnig; am II./V. Vereinigung; I3./V. Zygoten.

3) am 22./VI. in IVasser sonnig; am 26./VI. Vereinigung; 28./VI. Zygoten.

So gelingt es, Spirogyra varians nach Belieben zur rein vegetativen Vermehrung oder zur sexuellen Fortpflanzung zu nötigen.

\section{Andere Arten; Allgemeines.}

Auf dieselbe Weise wie Spirogyra varians habe ich auch andere Arten, die ich steril in der freien Natur fand, zur Konjugation gebracht. Sehr gut gelingen die Versuche mit der häufigen Spirogyra longata, die ich auch mehrere Wochen in schwachem Licht steril gehalten habe; ebenso verhielt sich Spirogyra communis, catenaeformis. Etwas genauer müchte ich noch Spirogyra arcta und Weberi behandeln. 
Spirogyra arcta Kützing (vgl. Kirchner 78 S. I2I) fand ich in sterilem Zustande Juni 1893 im See von Neudorf. Die Hauptkultur stellte ich kühl und schattig, einen Teil am 6./VI. sonnig, mit wenig Wasser. Nach einigen Tagen zeigte sich bei diesem seitliche Kopulation; am I4./VI. sah ich die Zygoten. Bald darauf ging der größte Teil der Hauptkultur an Fäulnis zu Grunde. Doch einige Fäden blieben lebend und vermehrten sich lebhaft. Am 8./VII. brachte ich wieder einige davon in die Sonne und beobachtete am 2I./VII. die Zygoten. Das gleiche Resultat hatte ein am I7./VIII. angestellter Versuch, während die Hauptkultur völlig steril blieb. Während der großen Ferien wurde diese noch schattiger gestellt und ging dann zum Teil an Fäulnis zu Grunde. Die Kultur blieb ruhig stehen, die noch vorhandenen Fäden erholten sich und wuchsen seit dem Januar I894 wieder lebhaft. Ein Teil der Fäden, am 28./I. I894 mit wenig Wasser, sonnig gestellt, bildete am I4./II. eine Menge Zygoten.

Spirogyra Weberi, eine der häufigeren Arten mit gefalteten Querwänden, kommt seit mehreren Jahren regelmäßig im Teich des botanischen Gartens von Basel vor. Im Monat März zeigen sich die ersten Fäden, im Laufe des Aprils entivickeln sich dichte, grüne Watten. Ende April oder Anfang Mai, je nach der Witterung, erfolgt die Konjugation, die Alge verschwindet. Erst im Herbst, sei es aus überlebenden, einzelnen Fäden, sei es aus Zygoten, entwickelt sich die Alge noch einmal, kommt aber nicht mehr zur Konjugation. Spirogyra Weberi zeigt sowohl leiterförmige, wie seitliche Konjugation.

Im Frühjahr I893 machte ich mit sterilen Fäden Versuche, teils in wenig Wasser, teils in 4-proz. Rohrzuckerlösung, bei sonniger Beleuchtung. Im Wasser sah ich nach wenigen Tagen lebhafte Konjugation nach dem leiterförmigen Typus; in 4-proz. Rohrzuckerlösung vereinzelte, 
seitliche Konjugation; in anderen Versuchen mit Rohrzuckerlösungen sah ich leiterförmige, aber ohne Auslildung von Zygoten. Fin neuer, am i . Mai angestellter Versuch mit wenig Wasser lieferte Konjugation nach beiden Typen, während halbdunkel oder hell in o,2-proz. KNLiosung kultivierte Algen steril blieben. In der freien Natur verschwand die Alge Ende Mai vollständig. Am I. Juni I 893 brachte ich Spirogyra aus der 4-proz. Rohrzuckerlösung vom 4./V. in Wasser, in die Sonne und beobachtete am 6./VI. zahlreiche Kopulationen; denselben Versuch mit gleichem Erfolg machte ich noch am I3./VI. I 893.

Im Frïhjahr I894 versuchte ich wieder von Anfang April an die sterile Sp. Weberi zur geschlechtlichen Fortpflanzung zu bringen, aber vergeblich, während diese sich in der freien Natur bereits Mitte April zeigte. Wegen des auffallend warmen Aprils verschwand die Alge im Freien Ende des Monats, so daß Materialmangel eintrat. Die Ursache des Mißerfolges in den Zimmerkulturen konnte ich nicht erkennen; man sieht nur daraus, wie empfindlich manche Arten gegenüber kleinen Aenderungen äußerer Einflüsse sind, die sich nicht genauer abschätzen lassen.

Sehen wir von diesem Mißerfolg zunächst ab, so können wir auf Grund der Versuche mit verschiedenen Spirogyra-Arten sagen, daß bei lebenskräftigem Material die Konjugation eintritt, wenn bei Verzögerung oder Hemmung des Wachstums helles Licht einwirkt. Die Kultur in wenig Wasser oder auch in etwas größerer, aber nährstoffarmer Wassermenge behindert notwendig durch den bald eintretenden Mangel an Nährsalzen das Wachstum. Das helle Licht veranlaßt trotzdem Assimilation und damit eine Ansammlungr organischer Substanz. Zugieich muß das Licht noch andere unbekannte Prozesse auslösen, die 
auch hier beim Sexualprozeß mitwirken müssen. Dieser wird verzögert und schließlich ganz verhindert, wenn die für das Wachstum besonders günstigen Bedingungen, wie Sauerstoff, Nährsalze, fortdauernd wirken, wie z. B. in strömendem Wasser. Es wäre auch denkbar, daß minimale Ausscheidungsprodukte der Algen dahin wirkten, das Wachstum zu hindern, die Konjugation $\mathrm{zu}$ befördern. Um dieses zu prüfen, filtrierte ich eine Zuckerlösung von 4 Proz., in der seit 28./II. Sp. inflata gelebt und kopuliert hatte, und brachte am 27./III. neue, sterile Fäden in das Filtrat. Am 8./IV. beobachtete ich zahlreiche Kopulationen, so daß die alte Zuckerlösung nicht anders als frisch bereitete gewirkt hatte. Die Temperatur beeinflußt innerhalb der Grenzen, die nicht genau bestimmt wurden, nur den zeitlichen Verlauf des Prozesses. Direkte Sonnenbeleuchtung, durch die die Temperatur über $20^{\circ}$, bis $30^{\circ}$ gesteigert werden kann, beschleunigt, niedere Temperatur unter $10^{0}$ verzögert den Prozeß.

Aus der ganzen Darstellung geht hervor, daß der Eintritt der Konjugation wesentlich auf bestimmte, äußere Einflüsse zurückzuführen ist, und nicht als Folgeerscheinung innerer Ursachen betrachtet werden darf, die den Organismus nach einer bestimmten Entwickelungszeit notwendig zur geschlechtlichen Fortpflanzung zwingen. Man könnte sich ja vorstellen, daß von der Keimung der Zygoten ab nach so und so viel Teilungen allmählich in den Fadenzellen innere Zustandsänderungen sich vollzögen, die notwendig zur Konjugation führten. Die äußeren Bedingungen könnten dann den Prozeß verzögern oder beschleunigen, aber nicht veranlassen. Wären die äußeren Verhältnisse ungünstig für den Geschlechtsprozeß, so würde die Alge schließlich absterben müssen. Nach dieser Annahme würde Spirogyra eine auf inneren Ursachen beruhende, bestimmte Lebens- 
periocle von der Keimung der Zygote bis wieder zur Bildung der Zygote zeigen. Aber meine Versuche mit $\mathrm{S}_{1}$. varians weisen aufs allerdeutlichste nach, daß eine solche Lebensperiode nicht existiert. Die Fäden wachsen so lange fort als die dafür günstigen Bedingungen vorhanden sind, sie lionjugieren, wenn die dafür notwendigen Bedingungen eintreten. Selbst wenn las letztere der Fall ist, und eine Alge sich im richtigen Zustand für den Geschlechtsprozeß befindet, kann man durch verdünnte Nährlösung ihn verhindern und erneutes, lebhaftes Wachstum veranlassen (vergl. auch das Verhalten der Fäden auf Agar-Agar S. 230).

Zur weiteren Ergänzung will ich noch einen anderen Versuch erwähnen. Bringt man eine in lebhafter Kopulation begriffene Fadenmasse von Sp. varians in eine Nährlösung von I Proz., so hört jede Geschlechtsthätigkeit sofort auf, ebenso auch das Wachstum. Die Zellen, die nicht kopuliert haben, ernähren sich weiter und bleiben wochenlang schön grün. Führt man sie in Wasser über und setzt sie der Sonne aus, so kopulieren die alten Fäden von neuem.

Die Frage, von welchem Zeitpunkte ab die aus den Zygoten hervorgehenden Keimlinge kopulationsfähig werden, konnte ich bisher nicht entscheiden. Nach Analogie mit Vaucheria wäre es möglich, daß gleich nach der Keimung oder nach geringem Wachstum die äußeren Bedingungen den Geschlechtsprozeß veranlassen könnten.

In der freien Natur pflegen viele Spirogyren im Frühjahr und Frühsommer zu kopulieren, doch ohne irgend welche bestimmte Regel; man findet Zygotenbildung ebenso im Sommer, bisweilen sogar im Frühherbst bei sehr sonnigem Wetter. Die massenhafteste Konjugation beobachtet man in kleinen Wasseransamm- 
lungen, die ohne Erneuerung des Wassers der warmen Sonne ausgesetzt sind. Aus der früheren Darlegung läßt sich leicht eine· Erklärung dafür ableiten.

Nicht immer gelingt es, bei Spirogyra-Arten die Konjugation zu beobachten; meine Versuche, z. B. mit den dicken Arten, wahrscheinlich setiformis oder crassa, mißlangen mehrfach, ebenso auch mit einigen anderen, unbestimmbaren Formen. Das Verhalten der Sp. inflata (S. 236) und Weberi läßt vermuten, daß irgend welche hemmenden Einflüsse dabei mitspielten. Wir haben kennen gelernt, daß verdünnte Nährlösungen hemmen, daß bei Sp. inflata die Hemmung fortdauert, wenn man die Nährsalze entfernt; ebenso könnten noch andere zufällige Beimischungen ähnliche Wirkungen ausüben. Wie ungeheuer empfindlich sind doch die großen Arten gegenüber unwägbaren Spuren von Metallverbindungen (Nägeli 93), die in kurzer Zeit tödlich wirken. Noch geringere Mengen könnten Leben und Wachstum zwar gestatten, nicht aber die Konjugation. Dann müssen noch andere Umstände berücksichtigt werden, die wir schon bei Vaucheria kennen gelernt haben. Wenn irgend wie eine Behinderung des Wachstums eintritt als Vorstufe für den Sexualprozeß, so kann dieser nur erfolgen bei heller Beleuchtung. Ist diese gerade in der Zeit nicht sehr günstig, so kann die Alge allmählich in einen indifferenten Zustand übergehen und überhaupt unfähig werden zu konjugieren. Ich hebe alles dieses hervor, um zu zeigen, daß negativ ausfallende Versuche nichts gegen die von mir ausgesprochene Abhängigkeit der Konjugation von äußeren Bedingungen beweisen.

\section{Parthenogenesis bei Spirogyra.}

Schon öfters hat man beobachtet, daß die Protoplasten kopulierender Zellen von Zygnemaceen aus irgend 
welchen unbekannten, zufälligen Gründen nicht zur Verschmelzung gelangten, sondern für sich zur Ruhe kamen. Die sprorenähnlichen Gebilde bezeichnete man als Azygosporen oder Parthenosporen (Wittrock 78 S. 8 , ferner Gay $8_{3}$ S. 206). Am interessantesten in dieser Beziehung verhielt sich die von Kolderup-Rosenvinge (83) beschriebene Spirogyra croenlandica, bei der in den Färlen bald Zygoten, bald Parthenosporen sich fanden. Bei einer kleinen Anzahl von $Z$ ygnemaceen kommt überhaupt niemals Konjugation vor, sondern es bilden sich zygotenähnliche Sporen ohne Befruchtung. Für die folgende Betrachitung müssen wir die beiden Fälle auseinander halten.

a) Parthenosporen bei kopulierenden Spirogyra-Arten.

Beobachtungen an Desmidiaceen, auf die ich weiter unten zurückkomme, veranlaßten mich, auch bei Spirogyra zu versuchen, künstlich Parthenogenesis herbeizuführen. Die Versuche gelangen mit größter Sicherheit. Ich ging davon aus, die Protoplasten im richtigen Stadium an ihrer Vereinigung dadurch zu hindern, daß ich schwach wasserentziehende, dabei nicht schädliche Substanzen zur Anwendung brachte. Aus früheren Versuchen (Klebs 88 S. 534) wußte ich, daß die Protoplasten von Spirogyra in IO-20-proz. Rohrzuckerlösung noch leben, selbst wachsen können. Allerdings ließen die ersten Beobachtungen, die ich im Frühjahır ı 893 bei Sp. Weberi machte, keinen großen Erfolg erwarten.

An Fäden der Alge, dlie in 4-proz. Rohrzuckerlösung, bei heller Beleuchtung kultiviert wurden, bildeten sich eine Menge Kopulationsfortsätze und auch einige Zygoten. Die Protoplasten anderer Zellen kontrahierten sich aber so 
stark, daß die Vereinigung unterblieb. In den männlichen wie weiblichen Fäden gingen die Protoplasten nicht zu Grunde, sondern umgaben sich mit einer Membran. Sie wandelten sich aber nicht in zygotenähnliche Sporen um, sondern blieben vegetativ, verhielten sich wie die von mir früher beschriebenen, kontrahierten Zellinhalte gewöhnlicher, vegetativer Zellen (Klebs 87 S. 534). Hier handelt es sich also nicht um eine Parthenogenesis, sondern nur um ein Vegetativwerden der Geschlechtszellen.

Anders verhielten sich die Fäden von Sp. inflata bei Versuchen im Frühjahr 1894. In 4-proz. Rohrzuckerlösung fand normale Konjugation statt; gleich nachdem die Fortsätze gebildet worden waren, versetzte ich die Fäden in 6-proz. Zuckerlösung. Während die vegetativen Zellen dadurch nicht verändert wurden, kontrahierten sich die zur Vereinigung sich anschickenden Protoplasten so stark, daß die Verschmelzung unmöglich wurde, selbst dort, wo bereits der männliche Protoplast zum weiblichen hinübergewandert war. Die kontrahierten Protoplasten wandelten sich zum Teil in Sporen um, die vollkommen den Bau, die Struktur und Färbung der Zygoten besaßen, nur daß sie kleiner waren. Viele der Protoplasten, die an der Konjugation verhindert worden waren, gingen zu Grunde. Es ließ sich dabei feststellen, daß die weiblichen Zellen, leicht kenntlich an der Auftreibung der Zellwand, sich häufiger zu Parthenosporen umbildeten, als die männlichen, die leichter abstarben.

Besonders diente Sp. varians als Versuchsobjekt über die Parthenogenesis, welche in verschiedener Weise hervorzurufen war. Ich stellte folgende Versuche an:

I. Sterile Fäden wurden auf erstarrte Agar-AgarGallerte gebracht und sonnig gestellt. In wenigen Tagen begann die Kopulation, es bildeten sich eine Menge nor- 
maler Zyggoten aus. Aber in vielen Fällen kam es nicht zu einer Vereinigung, sondern die sich kontrahierenden Protoplasten wurden zu Parthenosporen, vollkommen aussehend wie die Zygoten. Männliche und weibliche Zellen verhielten sich dabei gleich.

I1. In Kopulation begriffene Fäden wurden in o,4-proz. KN-Lösung versetzt. Abgesehen von den schon grebildeten Zygoten gingen die zur Verschmelzung sich vorbereitenden Protoplasten vielfach zu Grunde. Andere erhielten sich lebend, wurden aber nicht zu Parthenosporen, sondern blieben vegetativ, indem sie sich mit einer neuen, dünnen Zellhaut bekleideten und die gewöhnliche Strulitur bewahrten. Sie wuchsen nicht, während die ganz steril gebliebenen Zellen lebhaft in der Nährlösung sich verlängerten.

III. In Kopulation begriffene Fäden wurden in 6-proz. Rohrzuckerlösung versetzt. Nach I4 Tagen wurde die Alge wieder in Wasser übergeführt, wobei man die Zellen in verschiedenen Zuständen antraf:

a) einzelne reife Zygoten;

b) zahlreiche Parthenosporen.

Viele von diesen waren nach der Bildung der Membran abgestorlsen, andere waren noch unfertig, wieder andere ebenso reif wie die Zygoten. Zwischen männlichen und weiblichen Zellen gab es keinen Unterschied; bald waren die einen, bald die anderen, bald beide zu reifen Parthenosporen geworden.

c) Zellen, die in den ersten Stadien der Kopulation aufgehalten und stark bauchig angeschwollen waren, die im übrigen sich wie vegretative verhielten, nur daß sie im Wasser nicht grewachsen waren.

d) sterile /ellen zwischen den kopulierenden. Sie waren etwas angeschwollen, hatten eine dicke Membran 
gebildet, sich mit Oel und Stärke angefüllt, so daß sie vegetativen Ruhezuständen glichen.

e) vegetative Zellen, normal wachsend und sich teilend.

IV. In Kopulation begriffene Fäden in I-proz. KNLösung (vergl. Fig. 5). Hierbei entstand eine sehr Fig. 5 .



Fig. 6.

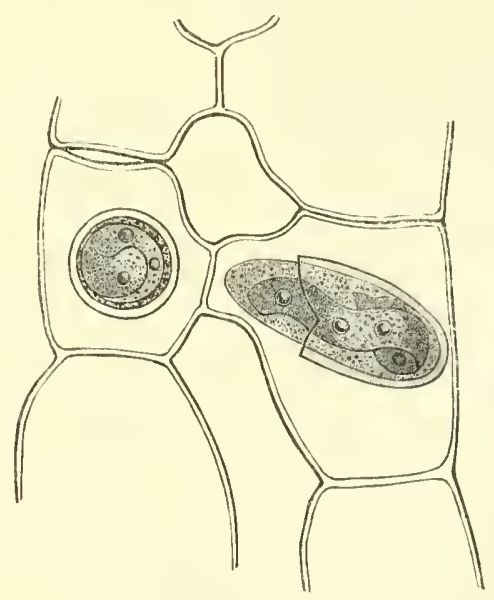

Fig. 5. Spirogyra varians, nach Beginn der Kopulation in Nährsalzlösung von I Proz. gebracht. $\approx$ Zygote; $p$ Parthenosporen. Vergr. 300.

Fig. 6. Spirogyra varians. Parthenosporen in der Keimung begriffen. Vergr. 300.

große Menge Parthenosporen, sowohl in männlichen wie weiblichen Fäden, ohne irgend welchen Unterschied.\&

Die Zygoten wie die Parthenosporen besaßen in der Lösung ein anderes Aussehen als im Wasser oder in Zucker- 
lösung. Vor allem trat die Bräunung der mittleren Zellhautschicht nur sehr wenig hervor. Außerdem fand eine relativ sehr geringe Ansammlung von fettem Oel statt, und die Aufspeicherung der Stromastärke unterblieb ebenso wie in den vegetativen Zellen. Als einige Fäden mit solchen Sporen in Wasser gel)racht wurden, nahmen die Zygoten wie die Parthenosporen normale Färbung und Struktur an.

Nach I 4-tägigem Aufenthalt in der Nährlösung wurde der größte Teil der Fäden mit den Sporen in Wasser übergeführt. Allmählich begann in den folgenden Tagen die Keimung, und zwar zuerst meistens bei den Zygoten, später bei den Parthenosporen (vergl. Fig. 6). Die letzteren verhielten sich dabei vollkommen wie die ersteren, wodurch der Beweis geliefert ist, daß die Parthenosporen in der That durchaus gesunde, der Fortpflanzung fähige Gebilde sind.

So folgt aus den Versuchen, daß die Protoplasten kopulierender Zellen von Spirogyra im Stande sind, auch ohne Verschmelzung sich zu Sporen umzuwandeln, die im Bau, in der Keimfähigkeit vollkommen den Zygoten entsprechen und nur durch geringere Größe sich unterscheiden. Dagegen kommt es vor, daß die Parthenosporen leichter zu Grunde gehen als die Zygoten und meist etwas später keimen.

In der Fähigkeit, Parthenosporen zu bilden, läßt sich bei Sp. varians, ebenso auch bei longata, bei welcher ähnliche Versuche angestellt wurden, nicht der geringste Unterschied zwischen männlichen und weiblichen Zellen entdecken. Bei Sp. inflata scheinen indessen die weiblichen Zellen besser dazu im Stande zu sein als die männlichen. Vielleicht findet sich bei anderen Arten noch ein deutlicherer Unterschied in dieser Beziehung. 
Da nicht jede beliebige, vegetative Zelle, sondern nur eine solche, die in der Vorbereitung für die Konjugation begriffen ist, zur Parthenogenesis genötigt werden kann, so muß noch genauer der Zeitpunkt bestimmt werden, von dem ab Parthenosporen entstehen können, während vor ihm die Zellen vegetativ bleiben. Die Konjugation zweier Zellen von Spirogyra, so einfach sie auf den ersten Blick erscheint, ist doch schon ein sehr komplizierter, physiologischer Vorgang. Man kann an ihm bei der jetzigen, geringen Kenntnis vielleicht folgende Stadien unterscheiden:

I. Die Bildung der Kopulationsfortsätze. Mit Haberlandt (vergl. S. 230) nehme ich eine Wechselwirkung beider Geschlechtszellen an, doch so, daß die eine Zelle zuerst einen Fortsatz bildet, der dann den entsprechenden der anderen Zelle zu sich hinlockt.

II. Die Herabsetzung des Turgordruckes, zuerst in der männlichen, dann in der weiblichen Zelle. Die Versuche mit wasserentziehenden Substanzen, Rohrzucker, Nährlösung, beweisen, daß der Turgordruck in den Zellen, die im Stadium I sich befinden, sehr viel niedriger ist als in den vegetativen Zellen; sie plasmolysieren bereits in 4-6-proz. Zuckerlösung, während die vegetativen dazu etwa Io Proz. verlangen. Was sonst für innere Veränderungen in den Zellen vor sich gehen, ist unbekannt.

III. Die Kontraktion des männlichen, später des weiblichen Protoplasten, jedenfalls bewirkt durch eine Ausstoßung von Wasser. Haberlandt (90 S. 8) macht darauf aufmerksam, daß die weibliche Zelle nur dann sich kontrahiert, wenn die männliche gesund ist. Er nimmt eine direkte Reizwirkung seitens der männlichen Zelle an. Das gleiche gilt aber von der männlichen Zelle, welche nur dann sich kontrahiert, 'wenn sie mit 
der weiblichen verbunden ist. Auch hier haben wir also eine gegenseitige Beeinflussung der beiden Geschlechtszellen, möge sie nun stattfinden durch Ausscheidung bestiminter Substanzen oder durch Elektrizität etc.

IV. Die Auflösung der Querwand in Leitungskanal, bis jetzt nur verständlich durch Ausscheidung eines Cellulose lösenden Fermentes.

V. Das Hinüluerwandern des männlichen Protoplasten zum weiblichen. Man hat den Vorgang physikalisch erklären wollen. So nimmt z. B. Overton die Ausscheidung einer Gallertsubstanz an, durch deren Quellung der Protoplast herübergedrückt wird. Die Gallerte ist nicht nachgewiesen. Es könnte sich aber um eine aktive Plasmabewegung handeln unter dem anziehenden Einfluß der weiblichen Zelle.

\section{Die Verschmelzung der beiden Protoplasten.}

Künstliche Parthenogenesis konnte ich nicht früher hervorrufen als bis die Zellen im Begriff waren, vom 2. ins 3. Stadium überzugehen. Nit dem Sinken des Turgordruckes ist noch nicht notwendig die Umbildungsfähigkeit des Protoplasten in eine Spore gegeben. Denn bei Sp. inflata konnte ich bereits durch 4-proz., noch besser durch 6-proz. Rohrzucker eine Plasmolyse der Geschlechtszellen herbeiführen; diese blieben aber vegetativ. Während des Ueberganges von Stadium II zu III müssen irgend welche innere Veränderungen Platz urreifen, so daß auf einmal der eigentliche Geschlechtszustand eintritt. In diesem Uebergangsstadium kann aber eine starke Wasserentziehung diesen Geschlechtszustand schneller herbeiführen. Denn hei Spirogyra varians blieben in einer o,4-proz. Nährlösung die Zellen vom Stadium II vegetativ; in einer Lösung von I Proz. gelang es bei der Mehrzahl Parthenosporen zu erhalten. Das Herüberwandern wird bereits durch sehr schwach wasserent- 
ziehende Mittel, wie 0,4-proz. KN-Lösung, 4-proz. Rohrzucker bei Sp. inflata, 6-proz. bei Sp. varians, verhindert, was eher dafür spricht, daß es sich um eine Plasmabewegung handelt und nicht um einen Quellungsvorgang. Selbst wenn der Protoplast schon in die weibliche Zelle hinübergewandert ist, so erfolgt wegen der plötzlichen Bewegungshemmung keine Verschmelzung.

Ist meine eben dargelegte Meinung richtig, so würde sich daraus die Folgerung ergeben, daß bei Spirogyra die Parthenogenesis nur dann möglich ist, wenn bereits eine gegenseitige Beeinflussung der beiden Geschlechtszellen stattgefunden hat. Ohne eine solche werden sie vegetativ - der einfachste Fall der sog. Apogamie.

Welche Umstände bei der Bestimmung des männlichen und weiblichen Geschlechts entscheiden, ist bisher rätselhaft. Ich nehme an, daß jede Zelle die Anlagen für beide Geschlechter besitzt, daß die während der Entwickelungszeit der Alge wechselnden, äußeren Bedingungen, die für die Fäden einer Algenmasse nie völlig gleich sind, in den einen Fäden der männlichen in den anderen der weiblichen Anlage zur Herrschaft verhelfen (vergl, auch Overton 88 S. 70). Experimentell könnte man dem Problem bei jenen Spirogyren nahe treten, die sowohl leiterförmige wie seitliche Kopulation zeigen, wie z. B. Spirogyra Weberi. Derselbe Faden kann an einer Stelle eine männliche Zelle haben, die mit der weiblichen eines anderen Fadens verschmilzt und an einer anderen Stelle eine weibliche Zelle, die sich seitlich mit einer männlichen des gleichen Fadens vereinigt. In den einen Kulturen waltet die leiterförmige, in anderen die seitliche Kopulation vor. Es müssen hierfür äußere Bedingungen entscheidend sein. Es gelang mir bisher nicht, Methoden zu finden, um mit Sicherheit die eine 
oder diefandere Kopulationsart willkürlich zu veranlassen. Doch wird es bei besser geeigneten Methoden wohl gelingen.

b) Geschlechtslose Spirogyren mit zygotenähnlichen Sporen.

Die bekannteste und mehrfach beschriebene Art, die hierher gehört, ist Spirogyra mirabilis (Hassall) Kg. Ihr Entdecker H a s s a 11 ( 45 S.156) gielst an, daß in den Zellen der Fäden ohne Verbindung mit anderen Zellen sich je eine braune Spore bildet, die in der Mitte der angeschwollenen Zelle liegt. A. Braun (5I S. 32I) nahm an, daß innerhalb einer Zelle eine Teilung und Wiedervereinigung des Protoplasten stattfindet, und Petit (So S. I4) glaulute diesen Prozeß beobachtet $z u$ haben. Doch hat schon de Bary (58 S. 7) nachgewiesen, daß einfach der Protoplast jeder Zelle sich kontrahiert und sich zu einer Spore umbildet. Später hat Lagerheim (83 S. 55) in einer kurzen Notiz erwähnt, daß die Keimung der Sporen wie die der Zygoten anderer Arten verläuft. Dagegen macht Solms-Laubach (88 S. 648) die Angabe, daß die Sporenbildung von Spirogyra mirabilis durch eine parasitische Chytridiacee hervorgerufen werde.

Spirogyra mirabilis trat in meinem Laboratorium in einer schattig stehenden Algenkultur auf und hielt sich I894 das Frühjahr wie den Sommer hindurch. Man kann die sterilen Fäden leicht zur Sporenbildung bringen, wenn man sie in einem Gefäß mit Brumnenwasser der Sonne aussetzt. Dann beginnen in wenigen Tagen die Zellen sämtlicher Fäden anzuschwellen; der Protoplast kontraliert sich und wandelt sich in eine braun gefärbte Spore um, die vollkommen den Zygoten der anderen Arten entspricht. Jedenfalls handelt es sich hier um einen völlig normalen Vorgang. Die Form der Sporen schwanlit sehr, 
je nach den Zellen; alle Uebergänge zwischen fast kugeligen bis cylindrischen finden sich vor. Den Versuch, durch helle Beleuchtung mit relativ wenig Wasser die Sporenbildung steriler Fäden hervorzurufen, habe ich im Laufe des Sommers wiederholt gemacht. Die Sporenbildung bei Spirogyra mirabilis hängt also von den gleichen Bedingungen ab, wie die Zygotenbildung durch Konjugation.

Da ich durch Erfahrungen bei Spirogyra varians wußte, daß der Aufenthalt in Nährlösungen die Keimung der Zygoten begünstigt, so machte ich den gleichen Versuch mit sporenbildenden Fäden von Spirogyra mirabilis. Ich kultivierte sie in o,4-proz. KN-Lösung. Nach I4 Tagen begann in der Lösung selbst die Keimung der Sporen (Fig. 7), ich überzeugte mich, daß sie in der That, wie Lagerheim angiebt, genau so verläuft wie die Keimung der Zygoten. Spirogyra mirabilis ist daher eine Art, bei der auf ungeschlechtlichem Wege unter den gleichen Bedingungen das gleiche Produkt, eine Ruhespore, entsteht, die bei der Mehrzahl der anderen Arten geschlechtlich erzeugt wird.

Für die Auffassung dieser Form bieten sich, wie immer in solchen

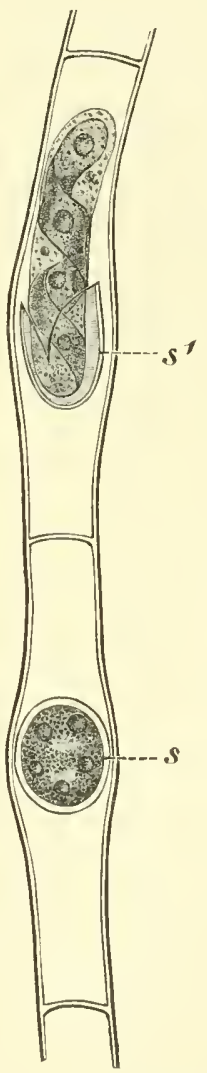

Fig. 7. Spirogyra mirabilis. $s$ Spore; $s^{t}$ Spore keimend. Vergr. 500.

Fällen, zwei Wege dar. Man kann diese Art als den einfachsten Typus einer noch nicht geschlechtlichen Art 


\section{$-\quad 256-$}

betrachten, von der erst die konjugierenden Arten herstammen; oder man kann sie als eine abgeleitete, ungeschlechtlich gewordene Form auffassen. Entscheiden läßt sich natürlich diese Frage nicht. Der Wunsch, sich eine Vorstellung von dem ersten Werden des Zeugungsvorganges machen zu können, ist vielleicht der innerste Grund, daß ich dazu neige, an die erstere Möglichkeit zu glauben. Man würde so gern aus dieser Spirogyra mirabilis sich die seitliche Kopulation zweier benachbarter Zellen, später die leiterförmige Kopulation von Zellen verschiedener Fäden herleiten. Bei der Ausstoßung der Flüssigkeit im Moment der Kontraktion von einer Spirogyra mirabilis-Zelle könnten Substanzen austreten, die auf die Nachbarzellen einen Wachstumsreiz ausübten; es bildete sich die Fusion der Zellen aus, es entwickelte sich die Fähigkeit der Protoplasten, miteinander zu verschmelzen.

Spirogyra mirabilis ist nicht das einzige Beispiel mit ungeschlechtlichen Sporen. Nach Nordstedt's Beschreibung (78 S. 17) pflanzt sich auch Zygnema spontaneum ausschließlich auf solchem Wege fort, nach Wittrock (78 S. 9) die Mesocarpee Gonatonema. In neuester Zeit hat Emma Hallas (95) ein Zygnema reticulatum beschrieben, das genau wie Spirogyra mirabilis nur durch Azygosporen sich fortpflanzt. Hallas hat auch die Keimung dieser zygotenähnlichen Sporen beobachtet.

\section{Desmidiaceen.}

Obwohl diese zierlichen Algen in größter Mannigfaltigkeit der Formen, oft in großer Individuenzahl vorkommen, obwohl sie wie wenige andere Algenfamilien 
das Lieblingsstudium zahlreicher Gelehrten ausmachen, so wird die geschlechtliche Fortpflanzung relativ sehr selten beobachtet und beschrieben. Die Zygoten finden sich nur bei wenigen Arten häufig, bei der Mehrzahl sehr zerstreut; bei vielen sind sie noch unbekannt. Die Konjugation (vgl. de Bary, 58 S. 48) erfolgt zwischen zwei Zellen, deren Protoplasten aus einem Riß der Zellhaut heraustreten und sich $\mathrm{zu}$ einer Zygote vereinigen. Klebahn (90 S. 420) hat die interessante Beobachtung gemacht, daß die beiden Kerne in der Zygote nicht sofort, sondern erst gegen Ende der Ruhezeit verschmelzen. Bei der Keimung tritt der Inhalt einer Zygote als Kugel heraus, deren Kern sich in 4 ungeich große Kerne teilt. Die Zelle zerfällt dann in zwei Tochterzellen, die jede einen größeren und einen kleineren Kern erhalten, von denen der letztere später verschwindet. Eine Sonderung in männliche und weibliche Zellen läßt sich bei den Desmidiaceen nicht beobachten.

Die Desmidiaceen-Flora Basels ist arm, da Torfgewässer fehlen. Von den sonst in Teichen vorkommenden Arten findet man relativ wenige, zerstreute Individuen, und ihre Kultur bereitet viele Schwierigkeiten. Ich beschränkte mich darauf, einige gemeine Formen wie Cosmarium Botrytis, Closterium lanceolatum, Lunula zu untersuchen. Diese Arten finden sich vereinzelt zwischen anderen Algen, häufig auch in fließendem Wasser, worin sie sich mit Hilfe ihrer Gallerteausscheidung gut festhalten können. Wenn man diese Arten mit anderen Algen in einem Gefäß an einem kühlen Ort kultiviert, so vermehren sie sich lebhaft. So gelang es mir z. B. Cosmarium Botrytis den Winter I889/90 über zu erhalten, und als ich die Alge in ein mit Lehmgrund versehenes, flaches Wassergefäß brachte und ins ungeheizte Zimmer stellte, gewann ich im Frühjahr I\$9o eine prachtvolle Kultur 
mit unzähligen Individuen, die durch Gallerte zusammengehalten waren. Die Kultur wurde vom Februar an etwas vom Fenster entfernt und erhielt sich bis Ende Juli, bis zu welcher Zeit keine Zygoten in ihr auftraten. Mit Zellen dieser Kultur stellte ich folgende Versuche an:

Nr. I. Am I9./II. wurde eine Anzahl Zellen in 5-proz. Rohrzuckerlïsung, sonnig gestellt. Es erfolgte eine sehr lebhafte Teilung. Anfang März begann die Konjugation; bis IO./III. waren Hunderte von Zygoten gebildet.

Nr. 2. Am 2I./II. in 2-proz. Maltose, sonnig. Am 4./III. zahlreiche Zygoten.

Nr. 3. Am I9./II. in Wasser, sonnig. Bis zum I2./III. sah ich keine Konjugation. Ein Teil am 4./III. in 5-proz. Rohrzuckerlösung, sonnig. Am 9./IIl. einzelne Zygoten, zahlreiche Parthenosporen.

Nr. 4. Am 9./III. in 2-proz. Invertzuckerlösung, sonnig; am I6./III. zahlireiche Zygoten.

Nr. 5. Am i2./III. in 4-proz. Rolırzuckerlösung, sonnig. Am I7./III. die ersten Zygoten, später mehr.

Nr. 6. Am I./VI. in 2-proz. Rohrzuckerlüsung, sonnig; am 9./VI. die ersten Zygoten.

Nr. 7. Am I9./II. in 0,4-proz. KN-Lösung, sonnig, lebhafte Vermehrung; bis I9./III. keine Konjugation. Ein Teil am 26./II. in Wasser; am I2./III. vereinzelte Zygoten.

Nr. 8. Am I4./III. in 0,5-proz. KN-Lösung, sonnig; Vermehrung durch Teilung, aber keine Konjugation bis I6./IV.

Nr. 9. Am 4./III. in 5-proz. Rohrzuckerlüsung, dunkel; bis zum I6./IV. keine Konjugation. 
Nr. Io. Von Mitte Juni ab gelangen mehrere Versuche, durch 5-proz. Rohrzuckerlösung und sonnige Beleuchtung, Konjugatiọn hervorzurufen, nicht mehr.

Aus diesen Versuchen geht hervor, daß eine Kultur von Cosmarium Botrytis von Mitte Februar bis Mitte Juni, also während 5 Monaten, in Wasser am kühlen, schattigen Ort sich nur durch Teilung vermehrte. Die Konjugation trat ein, als man die Algen sonniger Beleuchtung aussetzte, und sie wurde durch Zuckerlösung sehr befördert. Dagegen hemmten verdünnte Nährlösungen den Prozeß, während die Teilung fortging. Im wesentlichen verhält sich also Cosmarium wie z. B. Spirogyra inflata; die Versuche mit der ersteren Form gaben aber den Anstoß zur Untersuchung der Spirogyren, die dann erst mehrere Jahre später unternommen wurde. Wie bei Spirogyra inflata (S. 236) versagten die Versuche mit dem Material der 5 Monate alten Kultur. Die Alge vermehrte sich noch in der Zuckerlösung anscheinend ebenso lebhaft durch Teilung wie früher, aber sie kopulierte nicht. Durch irgend welche kleinen Veränderungen der Kulturbedingungen sind innere Veränderungen der Zellen veranlaßt worden, die den Kopulationsvorgang hemmen. Die Jahreszeit als solche kann nur indirekt dabei wirksam gewesen sein. De Bary beobachtete z. B. die Konjugation von Cosmarium Botrytis auch im Juli. Als ich nun neue Versuche im Frühjahr I894 anstellte, mißlangen sie ebenfalls, ohne daß ich genau angeben kann, weshalb. Jedenfalls muß die Alge in einem besonders kräftigen Lebenszustand sich befinden, damit die äußeren Bedingungen den Zeugungsprozeß veranlassen können. Wir vermögen diesen Lebenszustand nicht genau zu erkennen, daher auch nicht mit Sicherheit in allen Fällen hervorzurufen. Wir verstehen aber, warum die so empfindlichen Desmidiaceen auch in der freien Natur so unregelmäßig konjugieren. 
Ganz entsprechende Resultate erhielt iclı bei der Untersuchung von Closterium Lunula und lanceolatum. Die erste Art hatte sich im April I893 neben Vaucheria chavata sehr üppig entwickelt. Die Kultur wurde kühl und schattig gestellt; sie blieb steril. Ich stellte folgende Versuche an:

Nr. I. Am 3./V. mit wenig Wasser, in der Vormittagssonne; am 8./V. zahlreiche Zygoten.

Nr. 2. Am 8./V. ebenso; I2./V. zahlreiche Zygoten.

Nr. 3. Am 8./V. mit wenig Wasser, halbdunkel; keine Zygoten bis Ende Mai.

Nr. 4. Am 8./V. mit wenig Wasser, dunkel; keine Zygoten bis $\mathrm{I} 4 . / \mathrm{V}$.

Nr. 5. Kultur Nr. 4 am I4./V. sonnig; am I8./V. die ersten Zygoten.

Nr. 6. Am 16./V. in 0, I5-proz. KN-Lösung, sonnig; keine Zygoten.

Nr. 7. Am 4./V. in 4-proz. Rolırzuckerlösung, sonnig; am Io./V. zahlreiche Parthenosporen.

Einige Versuche habe ich auch mit Closterium lanceolatum angestellt. Zellen mit wenig Wasser, hell beleuchtet, bildeten im Juni und Juli I\$93 Zygoten. Als ich mit einer anderen Kultur der gleichen Alge im Juli I893 den gleichen Versuch machte, hatte er ein negatives Resultat; ebenso mißlangen die Versuche im Juli I 894 .

Ein besonderes Interesse beansprucht das Auftreten von Parthenosporen. Ich bemerkte sie zuerst bei Cosmarium Botrytis in 5-proz. Rohrzuckerlösung. Der Beginn der Kopulation verlief ganz normal, die beiden Zellen, durch Gallerte vereinigt, ïffneten ihre Zellwand, die Protoplasten traten heraus, kamen aber, ohne Verschmelzung zu zeigen, jecler für sich zur Ruhe und bildeten sich zu Sporen um, an denen auch die charakteristische Stachel- 
bekleidung hervortrat. Sie glichen in allem den Zygoten, nur daß sie kleiner waren. Als ich kopulationsfähiges Material von Closterium Lunula zur Verfügung hatte, wandte ich ebenfalls eine 4-proz. Rohrzuckerlösung an. Es bildeten sich überhaupt ausschließlich Parthenosporen aus. Diese blieben aber innerhalb der alten Zellmembran stecken, obwohl diese an der gewöhnlichen Stelle gesprengt und an der Oeffnung mit Gallertesubstanz versehen war, die mit Congorot sich lebhaft färbte. Ich bemerkte indessen auch Zellen, wo die Membran noch unzerrissen war und die Parthenospore noch ganz umschloß, die sich zu einer zygotenähnlichen, reifen Spore ausgebildet hatte. Wir haben demgemäß bei den Desmidiaceen die gleiche Erscheinung wie bei Spirogyra. Zwei Zellen, die sich zur Kopulation anschicken, erzeugen bei Anwendung schwach wasserentziehender Mittel je eine Parthenospore. In der Litteratur habe ich über diese Gebilde nur wenige Angaben gefunden. Lundell (7I) hat die Bildung von Doppelsporen bei Cylindrocystis diplospora und Penium didymocarpum beobachtet; möglicherweise handelt es sich um Parthenosporen. Bennet ( 92 ) hat solche bei Closterium lanceolatum beschrieben. Klebahn (90 S. 34I) hat die Keimung kleiner Sporen von Cosmarium mit nur einem Chromatophor, einem Zellkern beobachtet; seine Annahme, daß es sich um Parthenosporen handelt, hat große Wahrscheinlichkeit für sich. 


\section{Oedogonium.}

Diese artenreiche Gattung gehört seit clen ausgezeichneten Arbeiten Pringsheim's (56 und 58) zu den sehr gut bekannten Algengruppen, deren Bau und Entwickelungsgeschichte relativ klar sind. Durch die Forschungen von demselben Gelehrten, ferner von Wit trock (74) und Nordstedt u. A. erscheint die Gattung auch in systematischer Beziehung sehr wohlgeordnet. Die Mannigfaltigkeit im Bau und in der Verteilung der Geschlechtsorgane bei den einzelnen Arten gestattet es, diese durch gute Unterscheidungsmerkmale zu charakterisieren in einer Weise, wie es bei wenigen Algen sonst der Fall ist. Zwei Arten sind von mir als Vertreter der Gattun@ untersucht worden, da mir von ihnen genügendes Material zur Verfügung stand. Die Untersuchung zeigte, daß die Arten auch hinsichtlich der Physiologie der Fortpflanzung auffallende Verschiedenheiten darbieten.

\section{Oedogonimm diplandrum Juranyi.}

(Holzschnitt Fig. S.)

Diese Art findet sich in der Umgebung Basels nur an einer einzigen Stelle, am Beginn des sog. Leerlaufes der Faloriken bei Haagen im Wiesenthal, wo ich die 
Pflanze im Sommer I893 entdeckte und wo sie sich auch bis heute erhalten hat. Der Leerlauf ist eine Ableitung des eigentlichen Fabrikkanals, der von der Wiese herkommt, und dient dazu, während des Stillstandes der Fabriken einen großen Teil des Wassers abzuführen; er mündet unterhalb der Fabriken wieder in den Kanal. Die Alge bildet hellgrüne Ueberzüge auf den Steinen, mit denen der Leerlauf gepflastert ist. Sie stimmt genau mit der von Juranyi (73) beschriebenen Form überein; nach Wittrock (74 S. 19) ist sie vielleicht mit Oed. pluviale Nordsted t identisch.

Die Fäden haben einen Durchmesser von 20-27 $\mu$ und bestehen aus Zellen, die so lang als breit oder breiter als lang sind und sich durch eine sehr derbe Zellhaut auszeichnen. Der Chromatophor füllt anscheinend fast die ganze Zelle aus, er enthält in der Mitte einen dicken, großen Amylonkern. Gegen die Basis der Fäden werden die Zellen schmäler; die letzte befestigt den Faden an den Stein.

Die Kultur der Alge bereitet keine großen Schwierigkeiten. Einmal hält sich die Alge in den Kulturgläsern bei einer Temperatur unter $10^{0}$ sehr lange in einem brauchbaren Zustande, wenn auch manchmal Feinde, besonders eine Vampyrella, in schädlicher Menge auftreten können. Viel besser läßt sich die Alge kultivieren, wenn man die Steine mit ihr auf einem Teller direkt unter den Wasserstrahl eines Brunnens bringt. Auf diese Weise habe ich die Alge ein volles Jahr in durchaus normalem Zustande erhalten und stets frisches Material gehabt. Nie hat sich allerdings die Alge dabei irgendwie ausgebreitet; selbst am natürlichen Standorte fällt es auf, wie die Alge nur eine kurze Strecke des Leerlaufes bedeckt, weiter unten nicht auftritt. Die genannte Strecke befindet sich 


\section{$-264-$}

dicht an der Schleuse, wo die Bewegung des Wassers an lebhaftesten ist.

\section{Die Zoosporenbildung.}

Die Zoosporen, eiförmige Gebilde mit einem Kranz von feinen Wimpern um die farblose, kegelförmige Spitze, entstehen, wie bei allen Oedogonien, einzeln in jeder Zelle; vergl. Pringsheim (58), Juranyi (73), Strasburger $(80,92)$. Nur einen Punkt in der Bildungsgeschichte möchte ich hier berühren, die Entstehung der Hüllblase, von der umschlossen die Zoospore heraustritt. Diese Hülle ist unzweifelhaft eine Neubildung, ich halte sie ebenso wie Pringsheim für ein Ausscheidungsprodukt der Zoospore ${ }^{1}$ ). Die Hülle hat die Eigenschaft, mit wässeriger Jodlösung sich violett zu färben, während die Zellmembran ungefärbt bleibt. Infolgedessen erkennt man die Bildung der Zoospore auch dann, wenn diese nicht austritt. In dieser Färbung haben wir ein untrügliches Zeichen dafür, daß der Bildungsprozeß stattgefunden hat, was für die Untersuchung sehr bequem ist. Gewöhnlich verfuhr ich dabei in der Weise, daß ich die Fäden kurz in konzentrierte Salpeterlösung legrte und dann mit Jod tötete. Dann traten an den plasmolysierten Zellen, soweit sie in Zoosporen umgewandelt waren, die violetten Hüllen deutlich hervor.

Bei Oed, diplandrum macht sich eine Erscheinung bemerkbar, die in der Litteratur von Vaupell (59 S. 194) erwälnnt wird. Die Zoosporenbildung beginnt immer an den Spitzen der Fäden und schreitet nach der Basis hin

1) Strasburger (92 S. 64) luält die Hülle für ein Unbildungsprodulkt (ler Hautschicht der \%ouspore; das kann möglich sein, läßt sich aber nicht sicher nachweisen. 
fort. Das rührt nicht davon her, daß die Zellen an der Spitze anders beschaffen sind als die tiefer stehenden. Bei Oedogonium herrscht kein eigentliches Spitzenwachstum; vielmehr sind alle Zellen, mit Ausnahme der untersten Zellen, teilungsfähig. Schneidet man von einem Büschel Fäden mit einer scharfen Schere die obersten Zellen weg und ruft man die Bildung der Zoosporen hervor, so entstehen diese wieder an den neuen Enden. Ferner beobachtete ich an abgerissenen Fadenstücken in Rohrzuckerlösung, daß Zoosporen an beiden Enden gebildet wurden. Daraus folgt, daß die zu äußerst stehenden Zellen zuerst die Veränderungen der Außenwelt empfinden, die die Zoosporenbildung erregen; allmählich pflanzt sich die Reizwirkung weiter fort. Natürlich kann es vorkommen, daß einzelne Zellen scheinbar übersprungen werden, d. h. aus irgend welchen in ihnen selbst liegenden Gründen, auf den Reiz später oder gar nicht reagieren; die Geltung der Regel wird dadurch nicht beeinträchtigt.

Die Zoosporenbildung kann mit größter Sicherheit bei gesunden Kulturen hervorgerufen werden; am bedeutungsvollsten sind dafür die Temperatur und der Sauerstoffgehalt des Wassers.

\section{Temperatur; strömendes Wasser.}

Zoosporen können gebildet werden bei einer Temperatur von $\mathrm{0}-0,5^{\circ}$; für den Versuch benutzte ich Kulturen mit 2-proz. Rohrzuckerlösung, die zwischen Eis gestellt wurden. Der Austritt der Zoosporen erfolgt dabei nur selten, häufiger erst bei $\mathrm{I}-2^{\prime \prime}$. Die obere Grenze liegt etwa bei $35^{\circ}$; bei $28-29^{\circ}$ erfolgt noch eine lebhafte Entleerung der Zoosporen, die bei steigender Temperatur immer seltener austreten; ebenso nimmt auch die Bildung der Zoosporen ab, 'die nur durch" ihre mit Jod 
sich violett färbenden Hüllen gekennzeichnet sind. Bei $31-32^{\circ}$ zählte ich an den Fäden je 20-30 Zellen mit Zoosporen. Schließlich bei $33-34^{\circ}$ wird die Zählung sehr schwierig, da man sich auf einzelne Zoosporen nicht verlassen darf. Die Grenze für das Leben der Alge liegt etwa bei $39-40^{\circ}$, bei welcher Temperatur nach 24-stündiger Einwirkung die Mehrzahl der Zellen abstirbt. Bei Temperaturen unter $15^{\circ}$ erfolgt nach gegebenem Anlaß die Zoosporenbildung nach 2 Tagen, wenn auch am ersten Tage bereits einzelne Zoosporen sich zeigen. Je höher die Temperatur ist, um so rascher läuft der Prozeß ab, so daß er z. B. bei $26^{\circ}-$ dem Optimum - in Io Stunden vollendet sein kann.

Temperaturwechsel ist einer der wesentlichsten Anlässe für die Zoosporenbildung von Oed. diplandrum; doch wirkt nur der Uebergang aus niederer in höhere Temperatur, dagegen nicht der aus höherer in niedrigere. Hauptsächlich machte ich die Versuche im Winter 1893/94, ich benutzte dazu Fäden, die an Wassermoosen (Fontinalis) sich festgesetzt hatten und daher bequem in einzelnen Büscheln zur Verfügung standen. Die Hauptkultur wurde in ein kaltes Zimmer grestellt, wo nach 14 Tagen die Zoosporenbildung aufhörte. Allerdings entstanden auch in Laufe der nächsten Wochen immer noch einzelne Zoosporen, welche für die meisten zu besprechenden Versuche nicht in Betracht kamen, dagregen die Bestimmung der Grenzen für die Wirkungen einzelner, äußerer Bedingungen erschwerten.

Fäden aus dieser Kultur, in ein warmes Zimmer iilsergeführt, entwickelten in 2 Tagen sehr lebhaft Zoosporen, so daß an einem Faden 100-200 Zellen auf einmal solche bilcleten. Die Beleuchtung war dabei gleichsiltig, ebenso ob das alte Wasser, destiliiertes Wasser oder frisches Leitungswasser angewendet wurde. Die 
Temperatur des kalten Zimmers schwankte zur Zeit der Versuche, vom November bis Januar, zwischen 6-0 ${ }^{0}$, doch so, daß sie, wie ich früher angab, ganz allmählich abnahm. Im warmen Zimmer herrschte eine Temperatur von ca. $15^{\circ}$ mit täglichen Schwankungen von $12-16^{\circ}$. Für das Gelingen des Versuches kam es nicht darauf an, ob die plötzliche Temperaturerhöhung etwas stärker oder schwächer war, wenn auch eine untere Grenze existierte. So brachte ich z. B. die Fäden aus einer Temperatur von $6^{\circ}$ in ein Gefäß, das ins Aquarium mit einer Temperatur von $7,5^{\circ}$ gestellt wurde. Nach 2-3 Tagen sah ich keine Zoosporen; jetzt wurde das Gefäß ans Fenster gestellt (Temperatur IO-I ${ }^{\circ}$ ). Diese Erhöhung, der Temperatur bewirkte lebhafte Zoosporenbildung. Fäden, aus $\mathrm{O}-\mathrm{I}^{0}$ ins Aquarium von $5,5^{\circ}$ gebracht, zeigten das gleiche. Eine Temperaturerhöhung von ca. $5^{\circ}$ veranlaßt eine sehr lebhafte Zoosporenbildung, aber nur dann, wenn die Ausgangstemperatur unter $10^{0}$ beträgt. Denn alle Fäden, die einige Tage einer Temperatur über $10^{0}$ ausgesetzt worden waren und mit der Zoosporenbildung aufgehört hatten, ließen sich nicht von neuem durch weitere Erhöhung, selbst bis auf $26^{\circ}$, dazu bringen. Nur ab und zu gelang es, solche Zimmerkulturen nach einem Aufenthalt im kalten Zimmer $\left(4-6^{\circ}\right)$ oder im Eiskasten $\left(\mathrm{O}-\mathrm{I}^{0}\right)$ durch Versetzung ins warme Zimmer wieder zur Zoosporenbildung zu veranlassen. Die Algen geraten eben leicht durch Temperaturen über $10^{\circ}$ in einen indifferenten Zustand, in dem sie noch monatelang vegetieren, aber sich nicht ungeschlechtlich fortpflanzen können.

Auch die Fäden der Hauptkultur im kalten Zimmer konnten nicht als solche bezeichnet werden, die sich in vollster Lebenskraft befanden; auch sie waren durch den Aufenthalt in begrenzter Wassermenge etwas geschwächt und verändert worden. Um so schärfer tritt die große Be- 
deutung der Temperaturerhöhung als Anlaß für die Zoosporenbildung hervor. Jetzt erscheint es notwendig, das Verhalten der Alge in völlig normalem Zustand kennen zu lernen, in welchem sie sich befindet, so lange sie in fließendem Wasser lebt. An den Kulturen im Brunnen beobachtete ich eigentlich ununterbrochen eine schwache Zoosporenbildung, und da die Neubildung der Zellen nicht in stärkerem Grade stattfand, so blieb infolgedessen auch die Länge der Fäden ziemlich die gleiche. Andererseits war es nicht zweifellhaft, daß die Versetzung in stehendes Wasser bei Zimmertemperatur die Zoosporenbildung sehr lebhaft veranlaßte. Um den Einfuß der Temperatur zu untersuchen, brachte ich die Oedogonien in ein Gefäß mit Brunnenwasser und hing es zugekorkt in den Brunnen hinein. Außerdem wandte ich für den gleichen Versuch eine Rohrzuckerlösung an. Solche Versuche stellte ich im Januar I894 an, zu einer Zeit, da die Brunnentemperatur $3^{0}$ betrug, die Luftemperatur unter $\mathrm{O}^{0}$. In Wasser wie in Rohrzuckerlösung trat eine Anzahl Zoosporen hervor, ca. 4-IO an den einzelnen Fäden. Brachte ich nach einigen Tagen die Kulturen in höhere Temperatur, so erfolgte lebhafte Zoosporenbildung (50-roo Zellen), und hierfür genügte eine Temperaturerhöhung von $2^{0}$, wie ein solches Kulturgefäß, das aus dem Brunnen von $3^{\circ}$ in das Aquarium von $5^{\circ}$ gebracht wurde, deutlich zeigte. Nach einigen Tagen hörte der Prozeß auf; dann, in das Zimmer grestcllt, entwickelte die Kultur von neuem Zoosporen. Im November und Dezember I894 wurden die Versuche mit neuem Material gemacht, das Ende September aus Haagen greholt und in den Brunnen gebracht worlen war. Die Temperatur des Brunnens betrug Mitte November 9,5 ${ }^{\circ}$, die des Aquariums $10^{\circ}$. Algen aus dem ersteren in letzteres (d. h. auch hier in einem zugekorkten Gefäßj) gebracht, entwickelten lebhaft Zoo- 
sporen. Das gleiche fand statt, als die Alge aus dem Brunnen am I4./XI. (Temperatur 9,5 ${ }^{\circ}$ ) ins kalte Zimmer versetzt wurde mit einer Temperatur von $9,8^{\circ}$. Allmählich sank die Temperatur im Zimmer bis zum 22./XI. auf $7,5^{\circ}$; trotzdem ging die Zoosporenbildung fort. Weitere Versuche im Dezember bestätigten, daß nach Uebergang aus fließendem in stehendes Wasser Zoosporenbildung auch dann eintritt, wenn damit gleichzeitig eine Temperaturerniedrigung verbunden ist.

Fassen wir die Resultate der verschiedenen Versuche zusammen, so können wir sagen, daß der Uebergang aus fließendem in stehendes Wasser, ebenso der aus niedriger (unter $1 \mathrm{IO}^{\circ}$ ) in höhere Temperatur zoosporenerregend wirkt. Von nicht näher bekannten Eigenschaften der zum Versuch angewandten Algen hängt es ab, welcher Reiz gerade stärker wirkt als der andere. Beide vereinigt üben die denkbar stärkste Wirkung aus. Temperaturerhöhung kann bei Kulturen, die schon einige Zeit in stehendem Wasser sich befinden, für sich allein als auslösender Reiz genügen. Niedere Temperatur begünstigt die Fortdauer der einmal begonnenen Zoosporenbildung; höhere Temperatur über $1^{0}{ }^{0}$ wirkt langsam hemmend. Bei einer Temperatur von $26^{\circ}$ erfolgt in den ersten Tagen sehr lebhafte Zoosporenbildung, die dann bald völlig verschwindet. Erregt man durch Uebergang in höhere Temperatur in einer Oedogonium-Kultur den Prozeß und versetzt sie wieder in niedere Temperatur, so geht die Zoosporenbildung sehr viel länger fort, als wenn man die Kultur in der höheren Temperatur gelassen hätte. So verteilte ich z. B. Fäden, die aus dem Brunnen am 20./XII. ins Laboratorium gebracht worden waren, am 21./XII. in 2 Gläser mit 2-proz. Rohrzuckerlösung; die eine Kultur stand am Fenster des Laboratoriums (IO-I4 "), bildete gleich lebhaft Zoosporen und hörte allmählich damit 
1)is zum 30./XII. auf. Die andere Kultur wurde ins kalte Zimmer gestellt, wo anfangs die Temperatur $5^{n}$ betrug, dann sank, so daß am 4.-5./I. I894 die Kultur einfror. Bis zu dem Noment wurden fortclauernd Zoosporen gebildet, und das geschah von neuem, als die Kultur am 6.I. auftaute; der Prozeß ging langsam fort bis zum 30./1., also einen Monat länger als bei der gleichaltrigen Kultur des wärmeren Zimmers.

Für den zoosporenerregenden Uebergang aus fließendem in stehendes Wasser spielt wohl auch bei Oedogonium die Verminderung des Sauerstoffgehaltes die Hauptrolle. Dagegen gelingt es nicht mehr bei Algen, die bereits einige Zeit in begrenzter, nicht gewechselter Wassermenge gelebt haben, durch weitere Sauerstoffverminderung, mit Hilfe der Luftpumpe, von neuem /oosporenbildung hervorzurufen. Für einen solchen Reiz sind diese Zimmerliulturen unempfindlich; schließlich werden sie es auch für den viel wirksameren Reiz der Temperaturerhöhung. Sehr leicht kamn man diese indifferenten Algen wieder in den reizbaren Zustand versetzen, sowie man sie dem belebenden Einfluß des strïmenden Wassers aussetzt. Es können bereits 24 Stunden des Aufenthalts in diesem eine solche Wirkung ausüben; noch besser natürlich ein längerer Aufenthalt. Oedogonium diplandrum auf einem Stein befand sich vom I4./I.--IO./III. IS94 in einem Gefäß und war vïllig steril und unempfindlich geworden. Am IO./III. wurde der Stein unter den Wasserstrahl des Brumnens gebracht, am I3./III. wieder ins Laboratorium, wo die Alge eine Menge Zoosporen lieferte. Die Methode führt mit größter Sicherheit zum Ziel.

Wenn auch die Verminderung des Sauerstoffgehaltes, die die \%oosporenbildung erregt, nicht gemessen werden konnte, so war es doch von einigem Interesse, zu wissen, welches die untere Grenze des Partiärdruckes des Sauer- 
stoffs für den Prozeß ist. Ich stellte den Versuch an wie bei Vaucheria (S. 77). Die Oedogonien wurden dabei aus dem kalten Zimmer in das Laboratorium, wo der Apparat stand, gebracht. Da auf vereinzelte Zoosporen kein Gewicht gelegt werden darf, so läßt sich die untere Grenze nicht genau bestimmen.

Nr. I. Am 28./XII. I893 in 2-proz. Rohrzuckerlösung bei $3 \mathrm{~mm}$ Luftdruck bei IO $^{\circ}$. Bei der Untersuchung am 30./XII. zeigten sich keine Zoosporen; am gleichen Tage in den Thermostat bei $28^{\circ}$ gebracht, entwickelte die Kultur am 3I./XII. Zoosporen.

Nr. 2. Am 8./I. I894 in 2-proz. Rohrzuckerlösung; Luftdruck $3 \mathrm{~mm}$ bei $12^{\circ}$. Am Io./I. keine Zoosporen; vereinzelte nur angelegt; am IO./I. ins Laboratorium gestellt, bildete die Kultur am I2./I. sehr zahlreiche Zoosporen.

Nr. 3. Am IO./I. I894 in 2-proz. Rohrzucker]ösung; Luftdruck $3 \mathrm{~mm}$ bei $\mathrm{I}^{\circ}{ }^{\circ}$. Am I2./I. waren keine Zoosporen nachweisbar; ebensowenig ließen sich mit Jodfärbung Anlagen davon bemerken.

Nr. 4. Am I2./I. I894 in destilliertem Wasser; Luftdruck $40 \mathrm{~mm}$ bei $\mathrm{I}_{4}{ }^{\circ}$. Am I4./I. zeigten sich in den Fäden deutlich Zoosporen angelegt; ich zählte bis zu 40 Zellen pro Faden.

Nr. 5. Am 4./I. I894 in 2-proz. Rohrzuckerlösung; Luftdruck I $8 \mathrm{~mm}$ bei II ${ }^{0}$. Am 6./I. ließen sich in den Fäden je 30-40 Zoosporen nachweisen; ausgetreten schienen keine $z u$ sein. In normaler Luft entleerten sich nach einer halben Stunde viele Zoosporangien.

Nr. 6. Am 2./I. I894 in 2-proz. Rohrzuckerlösung; Luftdruck ${ }^{2} 8 \mathrm{~mm}$ bei II ${ }^{0}$. Am 4./I. beobachtete ich lebhafte Zoosporenbildung; ein Teil war ausgetreten und hatte bereits gekeimt. 
Nr. 7. Am 6./I. I894 in 2-proz. Rohrzuclerlösung; Luftdruck $128 \mathrm{~mm}$. Am 8./I. sah ich eine Anzahl frei sich bewegenter \%oosporen; viele andere noch in den Zellen.

A us diesen Versuchen folgt, daß bei sehr niederem Luftdruck von ca. $3 \mathrm{~mm}$, d. h. einem wahrscheinlichen Sauerstoffgehalt in der Glocke von ca. 0,08 Proz., keine Zoosporenbildung stattfindet, daß diese bei ca. $40 \mathrm{~mm}$ (Sauerstoffgehalt I, I Proz.) schon erfolgen kann, während die Entleerung selbst noch bei II $8 \mathrm{~mm}$ beschränkt ist und erst bei $128 \mathrm{~mm}$ lebhafter vor sich geht.

In der freien Natur oder in der Kultur im Brumnen tritt bald mehr, bald weniger eine Umwandlung der Spitzenzellen der Fäden in Sporangien hervor. Man fragt, worin der Anlaß für die Zoosporenbildung unter diesen Umständen liege. Aller Wahrscheinlichkeit nach werden kleine Temperaturschwankungen in Verbindung mit Schwankungen des Sauerstoffgehaltes maßgebend sein. Die Fäden sind unter den günstigen Lebensumständen sehr empfindlich, so daß kleine Veränderungen genügen, um als auslösende Reize zu wirken. Aber gegenüber den Laboratoriumsversuchen ist die Wirkung dieser kleinen Reize nur geringfügig, da immer nur einzelne Zoosporen erzeugt werden, statt der großen Vasse, die bei Anwendung stärkerer Reize entstehen kann. Bei dem Standort im Leerlauf von Haagen kommt noch ein anderer Umstand in Betracht. Im Sommer, wo die Wassermenge des Kanals eine begrenzte ist, ist der Leerlauf während des Tages nur sehr spärlich mit Wasser versehen, die Oedogonien befinden sich zum Teil in feuchter Luft; sie werden dann nach Schluß der Fabriken plïtzlich lebhaft von Wasser übergossen. Viclleicht wirkt auch diese Veründerung fördernd auf die Zoosporenbildung ein, die im Hochsommer das Wachs- 
tum übertrifft, so daß zu dieser Zeit die OedogonienFäden sehr kurz sind. Am kräftigsten entwickelt sich Oed. diplandrum im Frühjahr und Frühsommer.

\section{Die chemische Beschaffenheit des Mediums.}

Wie bei Vaucheria habe ich hauptsächlich den Einfluß des Rohrzuckers und der Nährlösung untersucht. Der erstere wirkt im allgemeinen dahin, daß die einmal erregte Zoosporenbildung, gleich bei welcher Temperatur (abgesehen von den höheren Graden), länger andauert als im Wasser, weshalb ich für viele der früher erwähnten Versuche Lösungen von 2-proz. Zucker angewendet habe. Hat in solchen bei niederer Temperatur die Zoosporenbildung aufgehört, so läßt sie sich nicht mehr durch Temperaturerhöhung von neuem hervorrufen. Die Fäden sind durch den längeren Aufenthalt in Zuckerlösung völlig indifferent geworden. Von Interesse ist es zu erfahren, welchen Einfluß die Konzentration der Zuckerlösung ausübt, namentlich im Vergleich zu anderen Algen. Ich stellte die Versuche so an, daß Oedogonien aus dem kalten Zimmer oder aus der Brunnenkultur in die Zuckerlösung gebracht und am Morgen in den Thermostat bei einer Temperatur von $26^{0}$ gestellt wurden.

Am 27./XII. I893 wurden folgende Versuche angestellt:

I) in 3-proz. Rohrzuckerlösung; 28./XII. sehr lebhafte Bildung von Zoosporen.

2) in 4-proz. Rohrzuckerlösung; 28./XII. ebenso;

3) in 5-proz. Rohrzuckerlösung; 28./XII. viel weniger bewegliche Zoosporen, andere innerhalb der Zellen geblieben, ebenso am 3I./XII.;

Klebs, Fortpflanzungsphysiologie. 
4) in 8-proz. Rohrzuckerlösung,

5) in Io-proz. Rohrzuckerlösung;

am 28. XII. in beiden noch vereinzelte, bewegliche Zoosporen; am 29./XII. lieine mehr; dagegen fanden sich zahlreiche ( $80-100)$ in den Fäden ausgebildet, ohne austreten zu können.

Eine zweite Reihe Versuche machte ich am 28. XII. I893:

6) in I2-proz. Rohrzuckerlösung; am 29./XII. zeigten sich die vegetativen Zellen noch nicht plasmolysiert; vereinzelte Zoosporen waren ausgetreten und bewegten sich schwerfällig. Die Mehrzahl (50-Ioo pro Faden) blieb in den Zellen;

7) in 15-proz. Rohrzuckerlösung; am 29. XII. alle Zellen plasmolysiert; keine beweglichen Zoosporen mehr. Nach Jodfärbung ließen sich in den Fäden je 20-30 Zellen mit Zoosporen erkennen; am 30.XII. zählte ich in ein zelnen Fäden 150 - 160 Zellen mit Zoosporen;

8) in 20-proz. Rohrzuckerlösung; am 20. XII. und 30./XII. konnte ich nur vereinzelte Zellen mit Zoosporen durch Jodfärbung nachweisen; es ist unsicher, ob sie neu gebildet oder vielleicht schon vorher entstanden waren.

Die Grenze für die Bildung der Zoosporen liegt etwa bei 20 Proz., diejenige für ihre Entleerung bei I2 Proz.

Maltose ( -2 Proz.), Invertzucker (2 Proz.) wirken in ähnlicher Weise wie Rohrzucker von entsprechender Konzentration, ohne daß sie ihm gegenüber irgend welche Vorteile böten.

Verdünnte Nährlösungen von $0,2-0,4$ Proz. wirken in der ersten Zeit wie IVasser oder Zuckerlösung, die angeregte Zoosporenbildung geht in ihnen normal vor sich, nur daß sie früher zum Stillstand kommt. Eine Lösung von I Proz. wirkt vor allem hemmend auf den Austritt der Zoosporen, so claß nur vereinzelte frei 
werden. Ebenso hört die Neubildung nach 3 Tagen vollständig auf. Ich habe, ähnlich wie beim Rohrzucker, Versuche mit verschiedenen Konzentrationen gemacht, wobei ich stets auch eine höhere, konstante Temperatur von $26^{\circ}$ anwandte. In I,2 Proz. sah ich keine freien Zoosporen mehr, dagegen viele neugebildet, ebenso in $I, 5$ Proz. In 2 Proz. konnte ich durch Jodlösung nach 48 Stunden pro Faden 60-70 Zellen mit Zoosporen nachweisen; sie waren meist gleich nach ihrer Entstehung zu Grunde gegangen. In 2,5 Proz. waren noch vereinzelte Zoosporen nachweisbar, aber es war nicht sicher, ob sie neugebildet worden waren. Die Grenze für die Zoosporenbildung liegt etwa bei 2,4 Proz., für die Entleerung bei I,2 Proz. Auch bei Oed. diplandrum zeigt sich also die schon für Vaucheria festgestellte Thatsache, daß die Nährsalze bei einer relativ viel geringeren Konzentration als die Zuckerlösungen durch ihre besonderen, chemischen Eigenschaften hemmend einwirken.

Der Uebergang aus der Nährlösung in Wasser wird, wie bei anderen Algen, zum Anlaß für die Zoosporenbildung, doch lange nicht so sicher und regelmäßig, wie etwa bei Vaucheria und Hydrodictyon. Die Algen der vorhin erwähnten Kulturen in $0,5^{-}$, I-, I,2-, I,5-, 2-proz. Nährlösung wurden in Wasser gebracht, bei unveränderter Temperatur. In sämtlichen Kulturen traten nach 24 Stunden frei bewegliche, aber doch nicht sehr zahlreiche Zoosporen auf. Oft wurden solche Versuche wiederholt, und immer zeigte es sich, daß die Anzahl der erzeugten Zoosporen eine viel geringere war als bei der Wirkung der Temperaturerhöhung. Die Zahl der Zoosporen ließ sich schwer abschätzen, da sie sich ganz allmählich im Laufe mehrerer Tage entwickelten. 


\section{Das Licht.}

Das Licht spielt bei der Zoosporenbildung von Oed. diplandrum gar keine Rolle. Fs ist für alle Versuche wesentlich gleichgiltig, ob sie im Licht oder im Dunkeln ausgeführt werden, wenn auch der Prozeß im letzteren Falle nicht so lange andauert. Der Mangel der Ernährung bei Lichtabschluß kommt dabei ziemlich spät zur Geltung, wie nachfolgender Versuch beweist.

Einige Fäden in Wasser, die seit 25./XI. I893 im Zimmer (Temperatur unter $6^{\circ}$ ) gestanden hatten, wurden am I5./XII. dort verdunkelt; bis zum I8./XII. gab es keine Zoosporen. An diesem Tage wurde die Kultur ins warme Zimmer gebracht und ebenfalls verdunkelt. Am 20.|XII. zeigten sich zahlreiche Zoosporen. Am 21./XII. wurde die Kultur von neuem kalt und dunkel gestellt, infolgedessen die Zoosporenbildung aufhörte. Am 25. XII. wieder warm und dunkel gestellt, lieferte die Alge eine Anzahl Zoosporen. Leblafter war die Entwickelung bei einem Teil der Kultur, der an 25./XII. hell und bei einer Temperatur von $26^{\circ}$ gestanden hatte.

Jedenfalls beweist der Versuch, daß bei Oed. diplandrum noch nach I4-tägiger Verdunkelung Zoosporenbildung möglich ist, und er bestätigt, daß unter Umständen bei ein und derselben Kultur durch Temperaturwechsel zweimal Zoosporenbildung hintereinander hervorgerufen werden kann.

\section{Die geschlechtliche Fortpflanzung.}

Oed. diplandrum ist eine diöcische Species; die männlichen und weiblichen Fäden lassen sich aber erst nach Auftreten der Geschlechtsorgane unterscheiden. 
Die Oogonien (vergl. die Darstellung Juranyi's 73 S. 8 etc.; meine beistehende Figur $8 \mathrm{~B}$ ) sind stark angeschwollen und öffnen sich mit einem Riß im oberen Teil. Die männlichen Fäden (Fig. $8 A$ ) setzen sich im
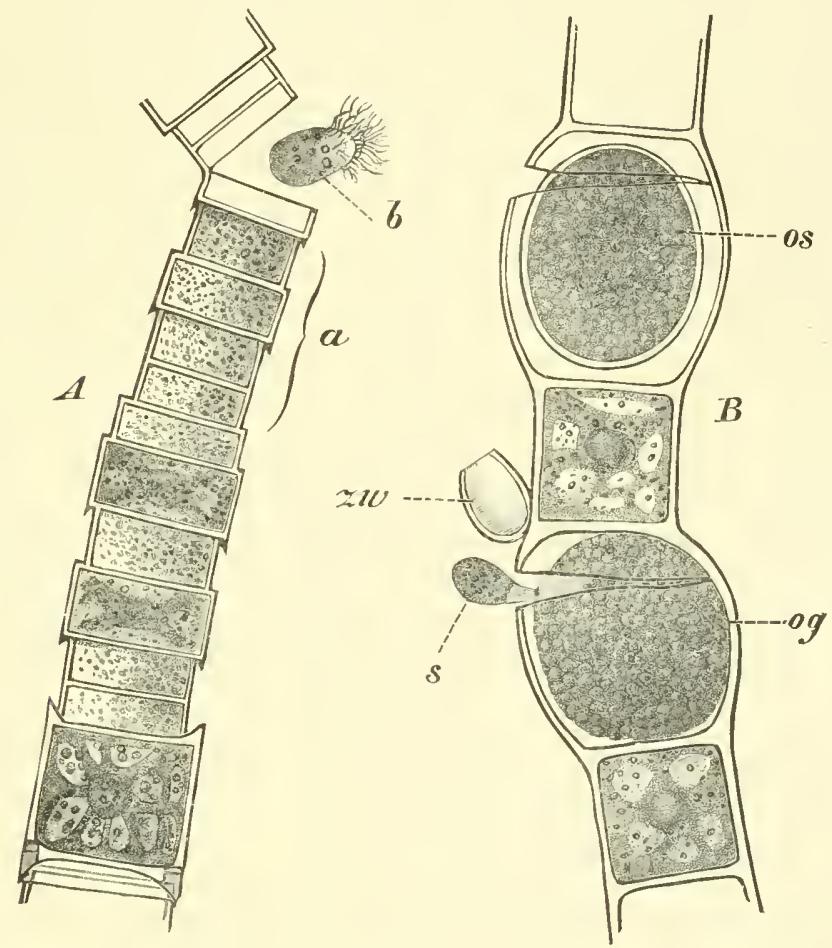

Fig. 8. Oedogonium diplandrum. A männlicher Faden; $a$ Antheridien; $b$ Androspore. $B$ weiblicher Faden; og Oogonium mit Eizelle eben durch das Spermatozoon $s$ befruchtet werdend; zw Zwergmännchen aus der Androspore entstanden, Mutterzelle der Spermatozoen. Verg. 500 .

geschlechtsreifen Zustande aus zahlreichen kleinen, kurz scheibenförmigen Zellen zusammen, die infolge der Veränderungen des Inhaltes gelbliche Färbung annehmen. 
lede der Zellen erzcugt einen Schwärmer, Androspore (Fig. $8 A$ b), der sich an dem weiblichen Faden in der Nähe des Oogoniums oder auf ihm direkt festsetzt und sich zu einem einzelligen Zwergmännchen ausbildet, dessen Inhalt in zwei amöboide Spermatozoen zerfällt. Die Befruchtung ist von Juranyi ausführlich beschrieben worden. Die befruchtete Eizelle umgiebt sich mit dicker Mlembran, füllt sich mit rotem Oel an und stellt eine Dauerzelle dar, die nach längerer oder kürzerer Zeit keimt, wobei der Inhalt heraustritt und in vier Zonsporen zerfällt.

Juranyi behauptet, daß bei Oed. diplandrun drei Arten von Individuen vorkämen, männliche, weibliche und neutrale, d h. solche, die nur Zoosporen entwickeln. Der einzige Charakter der neutralen Individuen besteht aber nur in dem Mangel an Geschlechtsorganen. Es liegt nicht der geringste Grund für die Annahme solcher rein ungeschlechtlichen Individuen vor. Denn alle Fäden irgend einer Kultur können geschlechtlich sein, oder alle können ungeschlechtlich sein; das hängt nur von den äußeren Bedingungen ab.

Drei Hauptluedingungen sind für die geschlechtliche Fortpflanzung małgebend:

I) ruhig stehendes Wasser;

2) Licht;

3) relativ geringe Zufuhr von Nährsalzen.

\section{Ruhig stehendes Wasser.}

Oed. diplandrum ist an dem natürlichen Standort im Leerlauf stets steril. Seit mehreren Jahren habe ich die Alge von dort zu verschiedenen Jahreszeiten auch im Hochsommer untersucht, und nicht die leiseste Andeutung von Geschlechtsorganen gesehen. 
Dasselbe Resultat ergaben die Untersuchungen an meiner Brunnenkultur. Ich habe einen bestimmten Stein mit Oedogonien ein volles Jahr, von Herbst I893 bis Herbst I894, im Brunnen gehalten, immer wieder geprüft und die Alge stets steril gefunden. Selbst ein relativ wenig bewegtes Wasser, wie das meines Aquariums, hemmt die Bildung der Geschlechtsorgane. Ich brachte z. B. am IO. Juni einen Stein mit Oedogonien in das Aquarium; sie blieben steril bis zum Ende des Versuchs am 20. Juli, obwohl die Temperatur während der Zeit $13-16^{0}$ betrug. So wie die Alge in einem kleinen Gefäß kultiviert wird, treten die Geschlechtsorgane auf. Wir haben hier also die gleiche Erscheinung wie bei den Vaucheria-Arten (s. S. I2I).

\section{Das Licht.}

Die Geschlechtsorgane verlangen zu ihrer Bildung unbedingt das Licht. Im Sommer genügen wenige Tage heller Beleuchtung, um an sterilen Fäden die Organe hervorzurufen. Von der vorhin erwähnten Aquariumkultur nahm ich einen Teil und stellte ihn mit wenig Wasser am 29./V. sonnig; am 3./VI. war bereits eine Menge befruchteter Oosporen vorhanden. Ein anderer Teil der Aquariumkultur wurde am I4./VI. sonnig gestellt; am 20./VI. war lebhafte Fruktifikation eingetreten. Von Fäden, die im Brunnen seit November I893 gewesen waren, wurde ein Teil mit wenig Wasser am 8./IV. I894 in die Sonne gebracht; am I4.IV. sah ich zahlreiche Geschlechtsorgane. Die ersten Anfänge dieser zeigen sich im Sommer nach vier Tagen.

Die Intensität des Lichtes spielt eine entscheidende Rolle. Die gleichen Versuche, im Winter angestellt, erfordern viel mehr Zeit. Infolgedessen können durch die Nachteile der kleinen Wassermenge, der schwachen Er- 
nährung die Färlen in einen schlechten, krankhaften Zustand geraten, in welchem sie üiberhaupt keine Geschlechtsorgane mehr bilden können. Für die Winterszeit hat es daher Vorteile, Rohrzuckerlösungen von 2 Proz. anzuwenden, durch welche der Teil der Lichtwirkung, welcher die Ansammlung organischer Substanz herbeiführt, ersetzt wird. Die specifische Wirkung des Lichtes auf den Geschlechtsprozeß läßt sich bisher durch kein Mittel ersetzen, und daher findet auch bei der schwachen Beleuchtung im Winter trotz Zuckerlösung die Bildung der Organe viel langsamer statt als im Sommer bei Wasserkulturen. In schwachem Licht, im Dunkeln erfolgt unter keinen Umständen die geschlechtliche Fortpflanzung. So stellte ich z. B. eine Kultur am 5./VI. IS94 halbdunkel, wo sie nach einem Monat noch steril war; am 5./VII. wurde sie sonniger Beleuchtung ausgesetzt; am Io./VII. fanden sich bereits befruchtete Eizellen vor.

Ain 2. Juli I 893 verteilte ich sterile Fäden auf drei Gläschen mit Wasser und stellte sie

a) dicht an ein großes Nordfenster; am 6./VII. eine Anzahl Geschlechtsorgane;

b) $2 \mathrm{~m}$ vom Fenster entfernt; am 6./VII. vereinzelte Oogonien an wenigen Fäden;

c) $3 \mathrm{~m}$ entfernt; die Kultur blieb steril.

\section{Die Nährlösung.}

Sehr auffallend ist die Hemmung der geschlechtlichen Vermehrung durch anorganische Salze. Unstreitig trägt, bei den Versuchen im Licht mit wenig Wasser, der rasch eintretende Mangel an Nährsalzen dazu bei, die Entstehung der Geschlechtsorgane zu begünstigen. Man kann Oed. diplandrum sehr lange Zeit völlig steril erhalten, auch bei sonniger Beleuchtung, in Nährlösungen 
von O,I-I Proz. Einige Versuche will ich genauer angeben.

Nr. I. Oed. diplandrum Io./III. I894 in o,I-proz. KN-Lösung hell; bis 22./VI. steril (Versuch unterbrochen). Von dieser Kultur:

a) ein Teil I./IV. in Wasser, hell; am IO./IV. Geschlechtsorgane.

b) ein Teil 18./V. in Wasser, hell; am 25./V. Geschlechtsorgane.

c) ein Teil 22./VI. in Wasser, hell; am 26./VI. Geschlechtsorgane.

Nr. 2. Oed. diplandrum am IO./V. 1893 in 0,2-proz. KN-Lösung hell; anfangs traten einige oogoniumartige Anschwellungen auf, die sich aber nicht weiter entwickelten und vegetativ blieben; die Kultur blieb steril bis Ende Juli, wo der Versuch unterbrochen wurde. Von dieser Kultur:

a) 29./V. ein Teil in Wasser, hell; 2./VI. Geschlechtsorgane.

b) 5./VI. ein Teil in Wasser, hell ; 9./VI. Geschlechtsorgane.

c) 6./VI. ein Teil in 4-proz. Rohrzuckerlösung; I3./VI. Geschlechtsorgane.

d) Io./VI. ein Teil in 0,05-proz. KN-Lösung; I./VII. noch steril.

e) I7./VI. ein Teil in I-proz. Rohrzuckerlösung; erst nach I4 Tagen reife Organe.

Nr. 3. Oed. diplandrum am 25./XI. I893 in I-proz. KN-Lösung. Die Kultur blieb bis 25./VI. I 894 schön grün und völlig steril; sie ging in den Sommerferien zu Grunde.

Die Versuche beweisen die ungemein hemmende Wirkung der Nährsalze, in denen andererseits die Fäden durchaus lebenskräftig und wachstumsfähig bleiben. Sie 
erscheinen sogar besonders gesund, weil die Ansammlung der Reservestärle unterbleibt und der Chromatophor daher lichtgrün hervortritt. Für die Erklärung der Sterilität von Oed. diplandrum in fließendem Wasser werden wir jedenfalls neben dem Einfluß des Sauerstoffs auch den der Nährsalze heranziehen können.

Den Einfluß der Temperatur habe ich nicht im einzelnen untersucht. Niedere Temperatur unter Io $^{0}$ wirkt mit, die Bildung der Organe zu verzögern, ohne sie irgendwie zu verhindern, wenn helle Beleuchtung zugegen ist. Das Temperaturminimum habe ich nicht bestimmt, ebensowenig das Maximum. Ich stellte nur fest, daß noch bei $25^{\circ}$ die Geschlechtsorgane gebildet werden können, wenn auch langsamer und weniger allgemein, als bei Temperaturen von $15-22^{\circ}$.

\section{Oedogonium capillare Kiitzing.}

(Holzschnitt Fig. 9.)

Diese Art zeichnet sich durch ihre Größe aus; die Zellen haben einen Durchmesser von 30-53 $\mu$, welche Zahl nur von wenigen anderen Arten erreicht wird. Auch im Bau der Antheridien stimmt die von mir beobachtete Alge mit den Beschreibungen von Kützing (43 S. 255). Wittrock (74 S. 30) überein, und auch Nordstedt, der so freundlich war, die Art für mich zu bestimmen, erkannte sie als capillare, obwohl die weiblichen Fäden nicht vorlagen. Die Alge findet sich in der Wiese in sehr wechselnder Menge, manchmal massenhaft, hisweilen sehr spärlich. Die Fäden sitzen nicht fest, sondern bilıen verworrene Fadenbüschel, die sehr häufig in 
Gesellschaft mit Conferva amoena um Wasserpflanzen geschlungen sind. Nach heftigen Regengüssen, bei starkem Anschwellen des Stromes werden auf einmal die Fadenmassen fortgerissen. Am mächtigsten entwickelt fand ich die Alge im Herbst 1894 in kleinen Kanälen im Wiesenthal. Dort bildete sie meterlange Fadenbüschel, die bisweilen zu großen, grünen Flächen ausgebreitet waren und die Kanäle fast verstopften. Eine eigentliche Kultur ist mir nicht gelungen wegen der Schwierigkeit, die Fäden im fließenden Wasser meines Brunnens festzuhalten.

Allerdings habe ich mich nicht viel damit abgegeben, weil die Alge auch in begrenzter Wassermenge sich lange Zeit lebenskräftig erhielt. Von ihren Fortpflanzungsorganen habe ich die Zoosporen und die Antheridien untersucht.

\section{Die Zoosporenbildung.}

Die Zoosporen entstehen in der gleichen Weise wie bei anderen Arten, z. B. diplandrum (Fig. 9 A). Die Bedingungen, welche für ihre Bildung maßgebend sind, unterscheiden sich wesentlich von denen, die wir bei diplandrum kennen gelernt haben. An erster Stelle ist der Einfluß des Lichtes und der Rohrzuckerlösung zu erwähnen.

Die Fäden von capillare, aus der freien Natur in das Zimmer gebracht, entwickeln wenige oder gar keine Zoosporen bei heller Beleuchtung. In dieser Beziehung weicht diese Art von zahlreichen anderen Algen ab, die bei so plötzlichen Aenderungen ihrer Lebensbedingungen regelmäßig lebhafte Zoosporenbildung zeigen. Ich hatte im Dezember 1893 vergeblich nach Zoosporen gesucht. Ende Dezember sandte ich eine Probe der Alge in 2-proz. Rohrzuckerlösung Herrn Nordstedt nach Lund zur Bestimmung. Er schrieb mir zurück, daß die Probe eine 
Unmasse Zoosporen gelsildet hätte, wovon ich mich auch selbst nach der Rücksendung überzeugte, da alle Fäden infolge der Zoosporenbildung aufgelöst worden waren. Nur die längere Lichtentziehung während der Reise konnte die nächste Ursache dafür gewesen sein. Die weitere Unter-
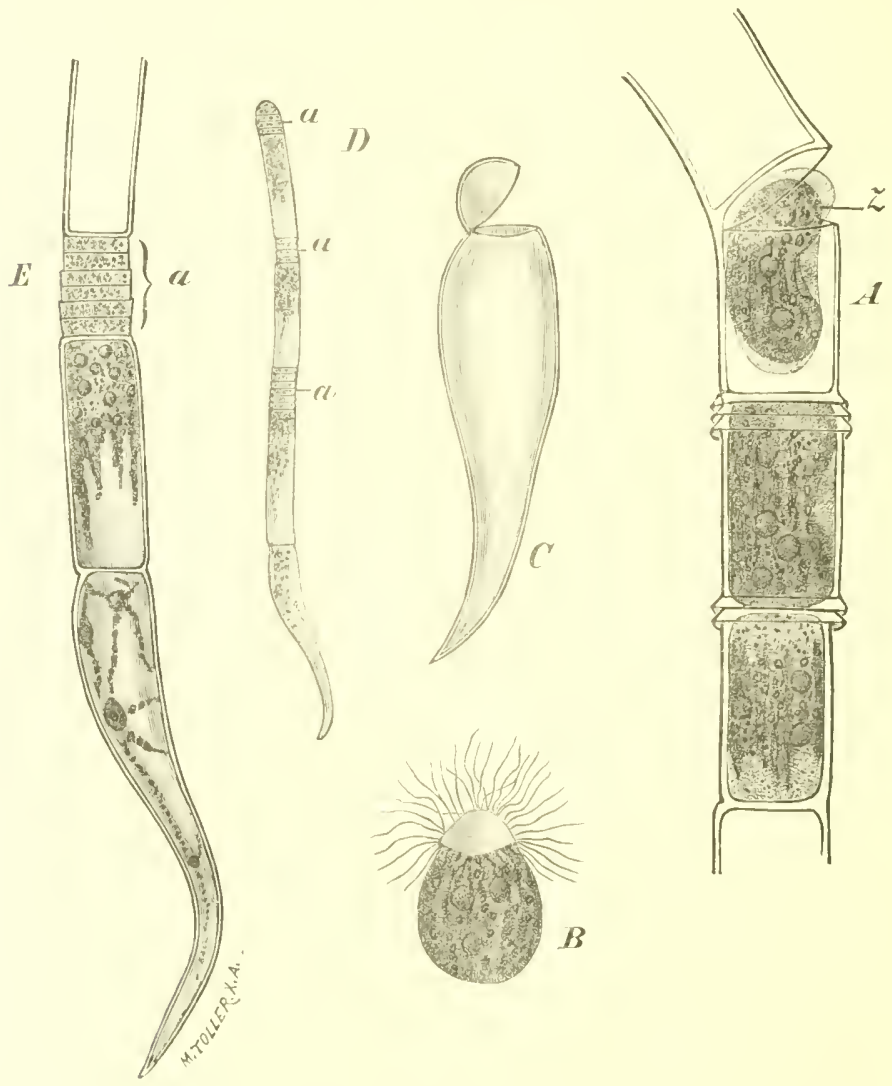

Fig. 9. Oedogonium capillare. A Faden zoosporenbildend; $\approx$ Zoospore von ejner Hülle umgeben, eben austretend. $B$ Zoospore. C Keimling durch erneute Zoosporenbildung entleert. I) Keim. pflänzchen mit Antheridien a. E Dasselbe stärker vergrössert. Vergrösserung $A, B, C, E 300, D 120$. 


\section{$-\quad 285-$}

suchung bestätigte vollkommen diese Annahme. Jede nicht zu schlechte Kultur von capillare in Wasser bildet regelmäßig nach Lichtabschluß Zoosporen; man kann fast sagen ausnahmslos, wenn man die Fäden in 4-proz. Rohrzuckerlösung bringt. Selbst krankhaft aussehende Fäden, die bereits durch lebhafte Antheridienbildung dem Absterben nahe sind, können noch in den einzelnen, vegetativ gebliebenen Zellen Zoosporen erzeugen. Nur die Intensität des Prozesses, gemessen an der Zahl der zoosporenbildenden Zellen eines Fadens, hängt von dem Gesundheitszustande des Versuchsmaterials ab.

Der Uebergang aus Licht in Dunkelheit spielt eigentlich nicht die Hauptrolle, sondern der Aufenthalt im Dunkeln. Bei Benutzung von Wasserkulturen findet nicht unmittelbar nach dem Lichtabschluß lebhafte Zoosporenbildung statt; sie beginnt nach zwei Tagen ganz langsam und geht dann je nach dem Zustande der Alge tagelang fort. Als Beispiel erwähne ich eine Kultur von Keimlingen in einem hängenden Tropfen vom 26./IX. I894; sie wurde am 28./IX. verdunkelt und täglich kontrolliert. In den ersten Tagen zeigten sich einige Zoosporen, dann nicht mehr, bis vom 6. X. bis I6./X. täglich wieder frische Zoosporen entleert wurden, wobei die neu gebildeten, jungen Keimlinge wieder Zoosporen erzeugten. Vom I6./X. wurde der Prozeß schwächer, hörte zeitweise ganz auf; doch selbst am I2./XI., d. h. nach 6 Wochen völliger Dunkelheit, sah ich aus den ganz verhungert aussehenden Zellen frische, bewegliche Zoosporen heraustreten. Dieser Versuch beweist zugleich, wie bei Oed. capillare die Zoosporenbildung in hohem Grade unabhängig von der Ernährung ist. Daher ist es verständlich, wie selbst krankhafte, durch Parasiten geschädigte Fäden nach Verdunkelung noch Zoosporen erzeugen können. 
W'ie hei Vaucheria wirkt Verminderung der Lichtintensität in gleicher Weise zoosporenerregend. Ich machte Versuche bei konstanter Beleuchtung mit der Auer-Lampe (S. 25). Die erste Versuchsreihe begann an I5.I. I894. Die Algenfäden wurden in 2-proz. Rohrzuckerlösung gebracht und $25,50,75 \mathrm{~cm}$ von der Lichtquelle entfernt gestellt; der Versuch dauerte bis 3I.I., während welcher Zeit die Temperatur bei $25 \mathrm{~cm}$ Distanz zwischen $\mathrm{I} 6-2 \mathrm{O}^{\circ}$, bei $75 \mathrm{~cm}$ zwischen $\mathrm{I} 5-\mathrm{I}^{\circ}$ schwankte. Zoosporen traten in $25 \mathrm{~cm}$ Entfernung nicht auf, wohl aber in 50 und $75 \mathrm{~cm}$, wenn auch nur vereinzelt.

Eine zweite Versuchsreihe begann ich am 3I./I. mit 5 Kulturen in 2-proz. Rohrzuckerlösungen, in 25, 50, 75, 100 und $150 \mathrm{~cm}$ Entfernung von der Lichtquelle. Erst bei $75 \mathrm{~cm}$ traten vereinzelte Zoosporen auf; bei Ioo, noch mehr bei $150 \mathrm{~cm}$ erfolgte lebhafte Zoosporenbildung, welche bis zum I9./II. fortging. Eine so vollständige Auflösung der Fäden durch Zoosporenbildung wie im Dunkeln trat aber selbst bei $150 \mathrm{~cm}$ Entfernung von der Lichtquelle nicht ein. Oed. capillare verlangt gegenüber Vaucheria eine viel stärkere Schwächung der Lichtintensität. Die Versuche, durch Behinderung der Assimilation im kohlensäurefreien Raum, bei Lichtzutritt den Prozeß hervorzurufen, gelangen bei Oed. capillare ebensowenig wie bei Vaucheria.

Bei den besprochenen Versuchen benutzte ich meist Kulturen in Rohrzuckerlösung, weil diese Substanz die Zoosporenbildung in besonderem Grade befördert. Sie wirkt im allgemeinen dahin, daß der Prozeß von vornherein rascher und lebhafter erfolgt und auch länger andauert als im Wasser. Der wesentliche Grund für diese Förderung liegt nicht etwa in der Zuführung organischer Nahrung, da diese, wie wir gesehen haben, eine 
relativ geringe Bedeutung hat. Vielmehr begünstigt die Zuckerlösung den Prozeß durch ihre langsame und unschädliche Wasserentziehung. Dieses Resultat ergiebt sich aus den Versuchen, die mit verschiedenen Konzentrationen der Zuckerlösung angestellt wurden. Schon eine Lösung von 4 Proz. veranlaßt, daß bei gesunden Fäden die Mehrzahl der Zellen naçh 2 Tagen im Dunkeln Zoosporen bildet. Diese treten dabei nur selten aus, sie keimen direkt in der Mutterzelle und lassen sich deshalb leicht von den vegetativen Zellen unterscheiden.

Noch auffallender ist die günstige Wirkung der Zuckerlösung bei 5, 6, 8 Proz.; das Optimum der Wirkung übt eine Lösung von Io Proz. aus. Im Januar I895 stellte ich Versuche mit noch höherer Konzentration an. In I2-proz. Rohrzuckerlösung, wo ein Teil der Zellen plasmolysiert wurde, war die Mehrzahl nach einigen Tagen in Zoosporen umgewandelt. In I5-proz. Lösung geschah das gleiche; man konnte von den kontrahierten, vegetativen Zellen die, welche Zoosporen gebildet hatten, gut unterscheiden, da man an ihnen leicht den farblosen Schnabel, die Wimpern, ferner die sich durch Jod violett färbende Hülle erkennen konnte. Auch in 20-proz. Lösung ließ sich auf solche Weise die Bildung von Zoosporen nachweisen. Bei höherer Konzentration, 24-27 Proz., ist jedenfalls die Zoosporenbildung völlig gehindert oder wenigstens zweifelhaft, da nur vereinzelte Zellen Andeutungen davon erkennen ließen.

Alle diese Versuche mit den Zuckerlösungen wurden im Dunkeln ausgeführt; es fragt sich, wie ihre verschiedenen Konzentrationen bei Gegenwart des Lichtes wirken. Bei heller Beleuchtung, in den Sommermonaten veranlassen Zuckerlösungen von 4-IO Proz. keine Zoosporenbildung. Wenn einzelne Zellen in Io-proz. Zuckerlösung schwach plasmolysiert werden, so umgeben sie sich mit einer neuen 
Zellhaut und beginnen sich zu teilen, während das Wachstum so gut wie vollständig behindert wird. Wie ich bereits in einer früheren Arbeit bei anderen Oedogonien beschrieben habe (Klebs 88 S. 553), erfolgt die Teilung in Zuckerlösungen sehr unregelmäßig, meist ohne vorhergehende Bildung eines Zellstoffringes. Ferner teilt die neue Querwand ganz ungleiche Teilstücke ab und verläuft oft schief zur ursprünglichen Längsachse des Fadens. Eine solche Kultur in IO-proz. Zuckerlösung, die vom 6. III. I 894 hell gestanden hatte, wurde am I8./III. verdunkelt. Auch dann traten in den pathologisch geformten Zellen Zoosporen auf. Die Hemmung der Zoosporenbildung durch helles Licht ist demnach größer als die fördernde Wirkung konzentrierter Zuckerlösungen. Wenn das Licht schwächer ist, wie z. B. im November, Dezember, kann der Einfluß der Zuckerlösung überwiegen und Zoosporenbildung veranlassen, auch in einem Licht, das für sich allein nicht schwach genug ist, um als auslösender Reiz zu wirken. In solchen Fällen ist aber die Menge der erzeugten Zoosporen gering gegenüber den Versuchen im Dunkeln. Dem schwächeren Lichte der Wintermonate ist es auch zuzuschreiben, daß die Zoosporenbildung, wenn sie in Zuckerlösung oder Wasser während des Aufenthaltes im Dunkeln begonnen hat, im Licht noch eine Zeit lang fortgeht; im Sommer hört sie unter solchen Umständen sofort auf.

Die fördernde Wirkung der Rohrzuckerlösung̣ liegt also allem Anschein nach zunächst in ihrer wasserentziehenden Eigenschaft. Bei dem Bildungsprozeß der Zouspore von Oedogonium muß eine gewisse Kontraktion des Plasmakörpers stattfinden (Berthold 86 S. 288). Die Rohrzuckerlösungr beschleunigt diese Kontraktion und hilft dazu, daß sie sehr allgemein bei den Zellen eines Fadens eintritt. Wenn nun bei Oedogonium, gemäß 
seiner besonderen Organisation, eine Wasserentziehung so stark die Zoosporenbildung begünstigt, so wäre es denkbar, daß die Wirkung des Lichtmangels darauf beruht, daß chemische Umsetzungen des Zellsaftes herbeigeführt würden, die seinen osmotischen Druck herabsetzten; um so leichter könnte dann selbst eine Zuckerlösung von 4 Proz. durch Wasserentziehung bei dem Prozeß mitwirken. Bei längerem Aufenthalt im Dunkeln werden gewiß Zuckerteilchen in die Zellen eintreten, aber man kann annehmen, daß sie gleich verarbeitet werden, so daß die osmotische Wirkung der Zuckerlösung nicht beeinträchtigt wird.

Ganz anders verhält es sich mit anderen schwach wasserentziehenden Mitteln wie Salzlösungen, die vermöge ihrer chemischen Einwirkungen die Zoosporenbildung in sehr viel höherem Grade hemmen, als sie diese durch ihre physikalische Eigenschaft fördern können. Ich stellte eine Reihe Versuche mit Salpeterlösungen bei Lichtabschluß an. In einer Lösung von o,or mol. (o, I Proz.) entsteht noch eine Anzahl Zoosporen, wenn auch die Bildung nach wenigen Tagen aufhört und in einigen Versuchen überhaupt nicht zu bemerken ist. In $0,02 \mathrm{~mol}$. beobachtet man vereinzelte, nicht austretende Zoosporen; in 0,03 mol. keine mehr. Die Grenze der Konzentration, die den Prozeß völlig hindert, liegt also für Salpeterlösungen bei o,o3 mol. (o,3 Proz.), für Rohrzuckerlösungen dagegen bei o, 6 mol. (20,5 Proz.), - ein gewaltiger Unterschied in der Wirkung der beiden Substanzen.

Dem Salpeter ähnlich verhält sich die gewöhnliche Nährsalzlösung. Einesolche von 0,2-0,3 Proz. hemmt bereits sehr stark die Zoosporenbildung, wenn man ganz gesunde Fäden bei Lichtabschluß in ihr kultiviert. In den ersten Tagen können darin vereinzelte Zoosporen sich zeigen, in 0,5-proz. Lösung dagegen nicht mehr. Die Nährlösungen 
von 0,5-I Proz. wirlien bei Lichtzutritt auch auf das Wachstum hemmend ein, so daß die Kultur darin für ()erl. capillare keine Vorteile bietet. Allmählich gehen die Algeen in solchen Lösungen zu Grunłle. Daher kommt es auch, daßß der Uebergang aus Nährlösung in Wasser diese sonst bei den Algen so sichere Methode, Zoosporenbildung hervorzurufen - für Oed. capillare wenig erfolgreich ist. Die Zoosporen treten nur vereinzelt, manchmal gar nicht auf, und es ist dabei auch gleichgriltig, ob der Versuch im Licht oder in Dunkeln angestellt wird, so daß selbst im letzteren Falle noch eine hemmende Nachwirkung der Nährsalze, trotz ihrer Entfernumg aus der Umgebung der Fäden, bemerkbar ist.

Um so überraschender sind die Resultate mehrfach wiederholter Versuche, die gerade das Gegenteil der eben besprochenen zu beweisen scheinen. Nimmt man alte Wasserkulturen, auch solche, die nach wochenlangrem Stehen in Licht Antheridien gebildet haben und nur relativ wenige, dem Absterben nahe, vegetative Zellen enthalten, und bringt sie in verdünnte Nährlösung von o, I Proz. ans Licht, so tritt nach wenigen Tagen eine auffallend lebhafte Zoosporenbildung ein. Die mit Stärke und Oel vollgepfropften, gelblich gefärbten Zellen lösen unter dem Einfluß von Licht und Nährsalzen ihre Reservematerialien auf, sie werden schön durchsichtig grün und lilden dann Zoosporen; der Prozeß kann eine Reihe von Tagen fortgehen. Auch die neu entstandenen Keimlingre wandeln sich wieder in Zoosporangien um. Da nun frische, gesunde Fäden unter keinen Umständen ein solches Verhalten in Nährlösungen bei Lichtzutritt zeigen, so muß der Zustand der alten Kulturen dafür maßgebend sein. Erforderlich ist nur noch, daß das Licht nicht zu intensiv ist, infolgedessen der Versuch am besten in den Wintermonaten gelingt. Halten wir uns an das, was zu 
sehen ist, so wird die Aufspeicherung organischer Nahrung als wichtigster Charakter der alten Zimmerkulturen bezeichnet werden können. Nährsalze bei Lichtzutritt beseitigen in kurzer Zeit diese Aufspeicherung; damit muß das Auftreten der Zoosporenbildung in einem Zusammenhange stehen, welcher allerdings unserer Erkenntnis sich entzieht. Immerhin ist die Annahme erlaubt, daß im wesentlichen der gleiche Anlaß zur Zoosporenbildung vorliege wie in den Versuchen mit Lichtabschluß, d. h. daß chemische Prozesse im Zellsaft Platz greifen, die auch seinen osmotischen Druck herabsetzen, was dann weiter auf das Protoplasma und die Zellkerne wirkt und schließlich zur Zoosporenbildung führt. Dem widerspricht nicht die Thatsache, daß die Nährlösung eine Auflösung der Reservestoffe, wie Stärke und Fett, veranlaßt; ich zeigte gerade für Hydrodictyon (Klebs 90 S. 365), daß unter solchen Umständen der osmotische Druck des Zellsaftes nachweisbar sinkt, und das gleiche kann auch für Oedogonium gelten.

Noch unter anderen Bedingungen beobachtete ich ein auffallendes Auftreten der Zoosporenbildung bei Oed. capillare. Im Herbst I894 legte ich von der mächtig entwickelten Alge aus dem Wiesenthal einen Teil in das Aquarium, dessen Temperatur vom 20./IX. I894, wo der Versuch begann, bis 20./X. von $\mathrm{I} 4,5^{\circ}$ allmählich bis auf I I ${ }^{0}$ sich erniedrigte. Die Fäden schwammen auf der Oberfläche, an einer Stelle durch Antrocknen an der Glaswand befestigt. Sehr bald bemerkte ich lebhafte Zoosporenbildung, welche bis zum 20 . $/ \mathrm{X}$. und noch länger fortging, bis allmählich infolge Antheridienbildung die Fäden vollständig zerfielen. An der hellsten Seite des Aquariums entwickelte sich ein grünes Band junger Keimlinge, welche aber nach wenigen Teilungen sofort wieder Zoosporen erzeugten - so ging es wochenlang fort. In einem 
kleinen Gefäß neben dem Aquarium befanden sich seit 20. IX. elenfalls Fäden von Oed. capillare, die nur in den ersten Tagen vereinzelte Zoosporen und dann keine mehr entwickelt hatten. Der Herlost war trübe, aber das relativ schwache Licht konnte unmöglich die Zoosporenbildung im A(puarium allein veranlaßt haben, sonst lätte es diese anch in dem daneben stehenden Kulturgefäß hervorrufen miissen. Ebensowenig hat die Temperatur, wie aus dem sonstigen Verhalten der Alge ihr gegenüber hervorgeht, einen Einfluß ansgeübt. Draußen in der freien Natur, in Hießendem Wasser war die Zoosporenbildung in jedem Falle beschränkt; denn einmal konnte man an dem frisch untersuchten Material nichts davon bemerken, ferner ging dies auch hervor aus der enormen Länge der Oedogoniumfädlen, welche auf weit überwiegendes Wachstum schließen ließ. Folglich mußte in der besonderen Beschaffenheit des Aquariumwassers irgend ein Grund für die auffallend lebhafte Zoosporenbildung, bei Gegenwart von Licht, gewesen sein. Die Alge kam ans einem Seitenkanälchen der Wiese, die aus kalkarmem Gebirge ihr Wasser erhält. Das Wasser des A puariums stammt aus dem Jura und ist sehr kalkreich. Dieser relativ große, stets sich erneuernde Kalkgehalt hat wahrscheinlich Wachstum und Teihung der an das Wiesewasser gewöhnten Alge behindert, während er nicht groß genug war, um die Zoosporenbildung zu hemmen. Die Assinilation ging ununterbrochen weiter, die Zellen füllten sich mit Nahrungsstoffen, die dann aber wieder infolge des reichlich Nährsalze enthaltenden Wassers rasch umgesetzt wurden, so daß schließlich ähnliche Verlä̈ltnisse vorlagen, wie liei ler kurz vorher besprochenen Einwirkung der Nährsalze auf schlecht gewachsene, ältere Kulturen.

Den Einflußs der Temperatur habe ich weniger genau untersucht, da die Versuche zeigten, daß sie innerhalb 
weiter Grenzen keine entscheidende Rolle spielt. Niedere Temperatur unter $10^{0}$ hält die Algen länger in lebenskräftigem Zustand; höhere über IO $^{*}$ führt sie bei Gegenwart von Licht in kleiner Wassermenge bald in einen krankhaften Zustand über. Die Zoosporenbildung findet bei $3^{\prime \prime}$ noch statt, nicht bei O-I ${ }^{0}$; die obere Grenze liegt bei $28^{\circ}$. Temperaturwechsel wirkt für sich allein nicht zoosporenerregend. Bei höherer Temperatur von ca. $25^{\circ}$ verläuft der durch Lichtabschluß veranlaßte Prozeß innerhalb 24 Stunden, während bei Temperaturen um $15^{\circ}$ herum mindestens 2 Tage, unter $10^{0} 3$ und noch mehr Tage notwendig sind.

Besonders bei Oedogonium-Arten sollte nach Walz (68 S. 497) der Wechsel des Wassers oder die Durchleitung von Luft eine Zoosporenbildung an älteren Kulturen hervorrufen. Die Arten, welche $\mathrm{W}$ alz untersucht hat, sind nicht angegeben. Oed. capillare gehört sicherlich nicht zu ihnen, da es überhaupt wenig empfindlich ist gegenüber dem Wechsel des Sauerstoffgehaltes. Aus fließendem in stehendes Wasser übergeführt, reagiert die Alge nicht wie Vaucheria clavata und Oed. diplandrum mit Zoosporenbildung, wenn der Versuch im Licht ausgeführt wird. Aeltere Kulturen werden durch den Wechsel des Wassers nicht verändert. Einige Versuche wurden angestellt, um die untere Grenze des Luftdruckes für den Prozeß zu bestimmen. In dem mehrfach erwähnten Apparat (siehe S. 77) wurde die Alge in Wasser oder in Rohrzuckerlösung gebracht; der Apparat wurde verdunkelt.

Nr. I. 24./X. I894 Luftdruck $38 \mathrm{~mm}$ bei $13^{\circ}$. a) in 4-proz. Rohrzuckerlösung; b) in Wasser. Am 26.|X. fanden sich weder in a noch in b Zoosporen.

Nr. 2. 26./X. Luftdruck $67 \mathrm{~mm}$ bei $13^{\circ}$. Kultur b von Nr. I; ferner eine frische Kultur in 4-proz. Rohrzuckerlösung; am 28./X. keine Zoosporen. 
Nr. 3. 28./X. Luftelruck $78 \mathrm{~mm}$ bei $13^{\circ}$. Kultur l, von Nr. 1 und 2; ferner eine frische Kultur in 4-proz. Rolurzuclierlösung; am 30. X. zeigrten sich in beiden Kulturen einzelne Zoosporen, 3-4 in jedem Faden.

$\mathrm{Nr}$. 4. 30./X. Luftelruck $85 \mathrm{~mm}$ bei $15^{\circ}$. Eine Kultur in 4-proz. Rohrzuckerlösung; am 2. X1. eine Anzahl /oxspuren innerhall, der Zellen.

Nr. 5. 19. X. Luftdruck $90 \mathrm{~mm}$ bei $12^{\circ}$. Eine Kultur in 4-proz. Rohrzuckerlösung; am 22.X. sehr zahlreiche Zoosporen, von denen die Mehrzahl imnerhalb der Zellen gelslieben war.

Die Versuche zeigen, daß die untere Grenze (les Luftdruckes (resp). des Partiärdruckes des Sauerstoffs) höher liegt als bei Oed. diplandrum; für dieses liegrt die Grenze etwa bei $40 \mathrm{~mm}$, für Oed. capillare bei 6o-70 $\mathrm{mm}$.

Fassen wir die wesentlichen Resultate für Oed. capillare zusammen, so können wir folgrende Bedingungen angreben, die als Anlaß für die Koosporenbildung dienen:

I) der Aufenthalt im Dunkeln - in allen Fällen die sicherste Methode;

2) der Aufenthalt in Rohrzuckerlösung von 4--10 Proz. bei mäßigem Licht; bei Lichtabschluß rlie Intensität des I'rozesses sehr fördernd, dagegen für sich allein unwirksam bei heller, sonniger Beleuchtung;

3) nach vorhergergangener, starker Aufspeicherung von lieservestoffen in lange stehenden Wasserkulturen der Aufenthalt in verdünnter Nährlösung $(0, I-0,2$ Proz.) bei Ciegenwart von Licht.

Sehr schwach oder gar nicht wirkt der Ueberging aus Nährlösung in Wasser, ebenso der Uehergang aus fliefiendem in stehendes Wisser und jecherler Temperaturwechsel; unwirksam ist auch ler Uelergang aus feuchter Luft in Wasser, weshalb ich auf diese Versuche nicht näher eingrehen werile. 
Interessant ist der Vergleich mit Oed. diplandrum. Seine Zoosporenbildung wird durch keine der für Oed. capillare maßgebenden Bedingungen veranlaßt. Vielmehr sind wirksam:

I) der Uebergang aus fließendem in stehendes Wasser;

2) der Uebergang aus niederer (unter $10^{\circ}$ ) in höhere Temperatur;

3) der Uebergang aus Nährlösung in Wasser.

Wir bemerken also eine sehr große Verschiedenheit der beiden Arten in ihren physiologischen Eigenschaften, obwohl sie fast an den gleichen Standorten vorkommen. Oed. capillare findet sich nicht selten direkt an dem Standorte von diplandrum vor.

\section{Die geschlechtliche Fortpflanzung.}

Oed. capillare gelıört, wie diplandrum, zu den rein diöcischen Arten. Einerseits sehr interessant, andererseits für meine Untersuchung bedauerlich ist die Thatsache, daß Oed. capillare in der Umgebung Basels nur in männlichen Fäden vorkommt - eine Erscheinung, die an ähnliche Vorgänge bei manchen Laubmoosen erinnert. Jedenfalls scheint die Diöcie eine vollkommen erblich gewordene Eigenschaft der Species zu sein. In der freien Natur, an den Standorten in der Wiese und deren Kanälen kommt Oed. capillare überhaupt nur in geschlechtlich sterilem Zustande vor. Ich sah bisher dort nie ein Antheridium und halte es für wahrscheinlich, daß diese Art sich wie diplandrum verhält und überhaupt nur in stehenden oder langsam fließenden Gewässern fruktifiziert. In meinem Aquarium habe ich übrigens im Herbst I 894 
leblafte Antheridienbildung bemerkt im Zusammenhang mit der schon leerührten Thatsache, duß das Wachstum und die Teilung dort sehr behindert waren. Jedenfalls ist schon wegen des Mangels an weiblichen Inclivicluen die Thatsache sicher, daß die Pflanze viele (wer weiß, wie viele?) Generationen in der Wiese rein ungeschlechtlich sich fortgepflanzt hat.

In ruhig stchendem Wasser tritt sehr lebhafte Antheridienbildung ein. Ueberhaupt jede gesunde, vegretative Zelle, vielleicht mit Ausnahme einer basalen Zelle, die an den fertigen Fäden nicht mehr zu finden war, ist im Stande, Antheridien zu bilden, indem sie an ihrem einen Ende nach und nach kleine, scheibenförmige Antheridienzellen alsscheidet. Die Zahl solcher von einer Mutterzelle sre. bildeten Antlueridien kann bis auf 12 gehen. Ein reifer, männlicher Faden besteht demnach abwechselnd aus den Mutterzellen, die vegetativen Charalkter tragen, und einer Reihe schmaler Antheridienzellen. Je mehr solche gebiklet worden sind, um so nahrungsärmer werden die Mutterzellen, die schließlich alssterben. Der männliche Faden ist daher vollständig dem Untergange geweiht. Auch ganz junge Keimlinge, aus wenigen Zellen bestehend, können Antheridienzellen bilden; die Basalzelle allein ist es nicht im Stande (Figr. 9 D, E, s. S. 284).

Die Bildung der Antheridien kann man jederzeit sicher veranlassen. Die Bedingungen sind: begrenzte Wassermenge, relativ geringer Gelialt an Nïhrsalzen und las Licht. In Dunkellkulturen sah ich nicmals Antheridien; aber ich möchte ihre Bilclung nicht für mmö̈glich halten unter hesonderen Bedingungen. Jedenfalls ist nur eine schr schwache lichtintensität für die Bildung notwendigr, vorausgesetzt dats Rohrzuckerlïsung angewendet wird. Am hesten geht dies ans den Versuchen mit der Auer'schen 1.impe hervor (niehe S. 25 die Einrichtung des Versuchs). 
Die Alge wurde am 20./XII. I893 aus der Wiese geholt und im kalten Zimmer kultiviert. Diese Hauptkultur bildete erst nach ca. 5 Monaten, d. h. im Mai I894, die Antheridien, da niedere Temperatur in Verbindung mit schwachem Licht ihre Bildung behindert hatte. Am I5.I. I894 wurden aus dieser Kultur Fäden in Gläschen mit 2-proz. Rohrzuckerlösung gebracht und in verschiedener Entfernung von der Auer'schen Lampe gestellt. Folgende Resultate ergaben sich:

a) in $25 \mathrm{~cm}$ Entfernung; am 22./I. fanden sich eine Anzahl Antheridien vor.

b) in $50 \mathrm{~cm}$ Entfernung; am 3I./I. die ersten Antheridien.

c) in $75 \mathrm{~cm}$ Entfernung; am 19./II. eine kleine Anzahl Antheridien (wahrscheinlich schon einige Tage früher gebildet).

Eine zweite Versuchsreihe stellte ich am 3I./I. I 894 an:

a) in $25 \mathrm{~cm}$ Entfernung; am 5./II. sah ich die ersten Antheridien;

b) in $50 \mathrm{~cm}$ Entfernung; am I6./II. bemerkte ich eine Anzahl Antheridien;

c) in $75 \mathrm{~cm}$ Entfernung; die Alge zu Grunde gegangen;

d) in $100 \mathrm{~cm}$ Entfernung; am I6./II. ganz vereinzelte Antheridien, am I9./II. etwas mehr;

e) in $150 \mathrm{~cm}$ Entfernung: zahlreiche Zoosporangien, keine Antheridien bis I9./II. (Versuch beendet).

Bei Gegenwart von Zuckerlösung genügt also ein sehr schwaches Licht, um Antheridienbildung herbeizuführen; vielleicht würde das Licht noch mehr vermindert werden können, wenn nicht unter diesen Umständen in der Zuckerlösung die lebhafte Zoosporenbildung wieder hindernd in den Weg treten würde, und wenn nicht schließlich bei den übrig bleibenden Zellen der 
lange Aufenthalt in der Zuckerlösung ungünstig wirkte. Denn selbst bei Lichtzutritt kann es vorkommen, daß die Fiiden aus irgend welchen zufälligen Gründen, vor alleın wegen rascher, chemischer Veränderung der Lösung durch Hefe und Bakterien, keine Antheridien bilden.

Wasserkulturen brauchen in allen Fällen eine längere \%eit der Beleuclitung und dahei intensiveres Licht als Zuckerkulturen, weil eine Ansammlung organischer Substanz durch die Assimilation erfolgen muß. Dabei richtet sich die Zeitdauer nach dem Lebenszustand der für den Versuch benutzten Algen. Frische aus der freien Natur genommene Fäden bilden rascher und allgemeiner die Antheridien, als lange Zeit in kleiner Wassermenge, kïhl und schattig erzogene Fäden. In destilliertem Wasser, namentlich wenn in der ersten Zeit schlechte Beleuchtung herrscht, geraten die Fäden leicht in einen krankhaften Zustand, in welchem sie steril bleiben.

Nährlösungen hemmen, wie bei Oed. diplandrum, die Geschlechtsthätigkeit. Im allgemeinen erhalten sich, wie ich angab, die Algen in den Nährlösungen nur wenige Wochen. Doch habe ich Fälen in 0,5-proz. Lösung vom 20./IX. I 894 bis I6./IV. 1895 bei Lichtzutritt in lebendem Zustande erhalten, ohne daß3 sie Antheridien gebildet hätten.

Bezüglich der Temperatur habe ich nur feststellen kïnnen, daß eine niedere Temperatur von $0-1$ " die Antheridienbildung hemmt, etwas höhere, bis gegen $10^{\circ}$, sie verzögert. Andererseits bemerkte ich Antheridienbildung in 5-proz. Rohrzuckerlösung bei $26-27^{\circ}$.

Aus der ganzen Darstellung gelit hervor, daß Oed. capillare ebensowenig wie diplandrum besondere, ungeschlechtliche Individuen besitzt. Alle Fädlen und alle Zellen in ihnen können sich ungeschlechtlich vermehren oder Geschlechtsorgane bilden; es hängt nur von äußeren Be- 
dingungen $a b$, welche Fortpflanzung eintritt. Denn auch die Antheridien bildenden Fäden können wieder durch Aufenthalt in der Dunkelheit zur Zoosporenbildung veranlaßt werden. Das gilt zunächst für diejenigen Zellen, die noch keine Antheridien abgeschieden haben. Sowie dies aber geschehen ist, verringert sich ungemein die Neigung der Zellen zur Zoosporenbildung, was leicht erklärlich ist, da sie zu große Substanzverluste erlitten haben. Doch kommt es zweifellos noch vor, daß nach Abscheidung weniger Antheridien die Mutterzelle im Stande ist, eine Zoospore zu erzeugen. Selbst in einem späteren Stadium, wo die Mutterzelle fast inhaltsleer erscheint, ihr Chromatophor verkümmert und gelblich gefärbt ist, kann man von neuem die Lebenskraft der absterbenden Zelle zur Entwickelung bringen, wenn man sie in eine verdünnte Nährlösung ( 0,2 Proz.) bringt. Allmählich ergrünt wieder die Mutterzelle, der Chromatophor wächst, die Amylonkerne werden wieder deutlich; es tritt hin und wieder Teilung ein, und die Zellen erzeugen Zoosporen.

Für solche Versuche benutzte ich auch mehrere Male Fäden, die gerade in lebhaftester Spermatozoenbildung begriffen waren. Ich machte eine Kultur im hängenden Tropfen (mit Nährsalzlösung), um sie direkt und fortdauernd zu beobachten. Die Spermatozoen traten heraus und gingen zu Grunde. Dagegen sah ich in einem unzweifelhaften Falle, daß ein beim Austreten stecken gebliebenes Spermatozoon wieder ergrünte und eine kleine, ovale, von Zellhaut umgebene, vegetative Zelle bildete. In dem Spermatozoon ist bei aller seiner speciellen Ausbildung als Befruchtungselement noch schwach die Möglichkeit für die Entwickelung der ganzen, vegetativen Pflanze vorhanden. 


\section{Ulothrix zonata Kützing.}

(Holzschnitt Fig. 10-II.)

Unter den vielen Arten der Gattung Ulothrix ist zonata die bekannteste, während die übrigen, in den Algrenwerken aufgezählten Arten nur sehr oberflächlich bisher beschrieben worden sind. Ul. zonata gehört zu den häufig vorkummenden Süßwasseralgen, deren Zoosporenbildung durch Kützing (43 S. 25I), Thuret (50 S. 222) u. a. heobachtet worden ist. Die geschlechtlichen Schwärmer und ihre Verschmelzung sind zuerst von Cramer (7I S. $7(1)$ gresehen worden. Die ganze Entwickelungsgreschichte der Alge findet sich in der Monographie von Dodel (76) dargestellt, auf der im wesentlichen unsere heutigen Kenntnisse dieser Species beruhen. Einzehe Punkte, wie besonders die Art der Zoosporenbildung sind somst sehr häufig bearlueitet worden, vor allem von Strasburger (So u. 92) und Berthold (86).

U1. zonata ist sehr formenreich, doch in einem anderen Sinne als Vaucheria sessilis. Wöhrend bei dieser mehrere Varietäten, die mit dem gleichen Recht als Arten aufgefaßt werden können, trotz mancher Uebergänge sich unterscheiden lassen, handelt es sich, wie Dodel richtig hervorhebt, bei zonata nur um eine Art, die je nach den Standorten in verschiedener Weise auftritt. 
Die Unterschiede beziehen sich auf die Dicke und Länge der Fäden, die Dicke der Zellhaut, während in allen wesentlichen Punkten der Organisation und Entwickelungsgeschichte Uebereinstimmung herrscht. Das eine Extrem bildet eine Form, die das ganze Jahr hindurch im Kaltbrunnenthal (Basler Jura) vorkommt. Die. Fäden, einen Durchmesser von 40-72 $\mu$ besitzend, lassen sich mit bloßem Auge von einander unterscheiden; sie bilden lange, flatternde Büschel in fließendem Wasser. Die Zellmembran ist relativ dick $(\mathrm{I}, 8-3,6 \mu)$. Die Zoosporen entstehen stets in größerer Anzahl: 8, I6, selbst 32. Diese Form maxima entspricht wahrscheinlich der Ulothrix valida Naegeli (Rabenhorst, 68 S. 362). Aus den Zoosporen entstehen in der Kultur junge Fäden, die vollständig übereinstimmen mit den schmäleren Formen. Am häufigsten ist bei Basel eine Form, die schlüpfrige, grüne Ueberzüge auf Steinen in den Bächen, Flüssen, Brunnen besonders zur Frühlingszeit bildet; der Durchmesser beträgt $33-46 \mu$, wenn auch stets Fäden beigemischt sind, deren Durchmesser nur I7-20 $\mu$ beträgt.

Die letzteren Fäden kommen auch an manchen Standorten, besonders in Brunnen, für sich allein vor; die Zellen sind kurz-scheibenförmig, die Zellmembran ist sehr dünn und zart; die gametenbildenden Fäden sind stark schraubig aufgerollt und nicht frisch grün, sondern bräunlich gefärbt. Hierher gehört die von Thuret (50 S. 223) beschriebene Ul. rorida, deren spindelförmige Zoosporen nach meiner Meinung bewegliche Zygosporen vorstellen. Alle diese Formen können unter Umständen an demselben Standort vorkommen und sind durch die leisesten Uebergänge miteinander verbunden.

Für die Untersuchung der physiologischen Bedingungen der Fortpflanzung war es auch hier die erste Aufgabe, die Alge zu kultivieren. Ul. zonata kommt aus- 
schlieflich in fließendem Wasser vor; sie ist so sehr (laran srebunden, daß ein wirlsliches, normales Wachstum unter andleren Bedingungen nicht möglich erscheint; wenigstens sind alle meine Versuche fellgeschlargen. 1)as einzige, was sich mit Hilfe niederer Temperatur in kleiner W'assermenge erreichen läßt, ist die Erhaltung des Lebens der Algre während einiger Wochen. I)ie Kultur gelang dagregren vollständig in dem Brunnen meines Gartens. Auf ein Postament von Steinen stellte ich einen Teller so auf, daß er der Oberfläche des Wassers nahe war, und der Strahl des Wassers aus dem Brunnenrohr gerade auf ihn herabfiel. Ich legte Herbst I893 auf den Teller einige Steine mit Ul. zonata, die sich seit der Zeit, allerdings mit sehr wechselnder Ueppigkeit je nach den Jahreszeiten, erhalten hat. In den Monaten Februar bis Mai wächst die Alge äußerst lebhaft und vermehrt sich sehr stark; gegen den Sommer hin nimmt sie ab, bleibt aber doch stets vorhanden, bis im Herbst eine zweite Periode kräftiger Lebensthätigkeit folgt; mit dem Beginn länger andauernden Frostes vermehrt sich die Alge langsamer, um dann im Februar (im Jahr 1895 erst im März) wieder die Höhe ihrer Entwickelung zu erreichen.

Um Ulothrix auch im Zimmer zu kultivieren, benutzte ich das Aquarium, in das ich Steine, die mit der Alge bedeckt waren, hineinlegte.

Trotz des stetig sich erneuernden Wassers ging doch dic Alge nach einigen Wochen langsam zu Grunde. Viel besser gelang der Versuch, als ich durch einen besonderen Heber an Stelle des eigentlichen Ablaufrolıres das Niveau des Wassers sehr niedrig erhielt, so daß die Steine mit Ulothrix dicht an der Oberfläche des Wassers sich befanden und direkt von dem Wasserstrahl des Zulaufrohres bespült wurden. Unter diesen Umständen erhielt sich die Alge sehr gut, sie bildete im Winter 6 
Wochen lang lebhaft Zoosporen. Allmählich aber sank auch hier die Lebensthätigkeit, höchst wahrscheinlich, weil bei der Stellung des Aquariums das Licht nicht stark genug war.

Die großen Schwierigkeiten, die die Kultur der Alge bereitete, vor allem ihre Unfähigkeit, in kleineren, stehenden Wasserbehältern normal sich zu entwickeln, ihre Empfindlichkeit gegenüber kleinen Veränderungen äußerer Bedingungen, alles dieses wirkte zusammen, die Lösung meiner Aufgabe, die Bedingungen der Fortpflanzung zu erkennen, sehr zu erschweren. Meine Versuche gestatten nur im allgemeinen den Einfluß der äußeren Bedingungen zu bezeichnen, dagegen nicht die für jede Fortpflanzung speciell notwendigen Faktoren genau experimentell festzustellen. Andererseits haben sich aber hinsichtlich mancher Punkte bedeutungsvolle Resultate ergeben, so daß eine ausführlichere Darlegung notwendig erscheint.

\section{Die Zoosporenbildung.}

Nach den im wesentlichen richtigen Angaben Dodel's entstehen die Zoosporen bei Ul. zonata durch successive Zweiteilung, nur daß, wie Berthold (86 S. 295), ich selbst (9I S. 856), Stra sburger (92 S. 86) hervorgehoben haben, die Zweiteilung allein im protoplasmatischen Wandbeleg sich abspielt, während die Zellsaftvakuole zurückbleibt. Neben den relativ seltenen Fällen, wo aus jeder Zelle nur eine Zoospore sich bildet, werden 2, 4, meistens 8 , in den Zellen der Forma maxima auch 16 und 32 Zoosporen erzeugt. Wahrscheinlich ist die Zahl in erster Linie bedingt durch die Größe der Zellen; je kleiner die Zellen sind, um so geringer ist die Anzahl von 
Zoosporen. Die Bildung von nur ein oder zwei Zoosporen bemerkte ich meist bei den schmalen Formen, und bei diesen liönnen noch andere Umstände dazu mitwirken. So veranlaßte ich durch Kultur in 8-proz. Rohrzuckerlösung an den schmalen Fäden meiner Brunnenkultur, daß fast simtliche Zellen eine oder zwei Zoosporen bildeten, wiblurend sie für grewöhnlich 4 oder 8 erzeugen. Hierbei wirlkte angenscheinlich die Wasserentziehung durch die Zuckerlösung mit, die weiteren Teilungen zu verhindern. Ich beobachtete vielfach Zoosporen, die unvollständig geteilt waren. In 4-proz. Rohrzuckerlösung sah ich bei schmalen Fäden eine Unmasse eigentümlich gestalteter Zoosporen, die besonders an ihrem Hinterende deutlich eine Zusammensetzung aus 2 oder 3, seltener 4 Stücken erkenmen ließen. Mitunter war ein Teil ganz frei mit Ausnahme eines dünnen Fadens, der ihn mit der Spitze des Zoosporenkörpers verband. In allen diesen Fällen war aber stets nur ein Augenfleck, waren nur 4 Wimpern vorhanden, wie gewöhnnlich. Ueberhaupt sind die Zoosporen durchans nicht immer regelmäßig eiförmig, wie sie in den Lehrbüchern nach Dodel bezeichnet werden. Stets sind die Zoosporen nach ihrem $\Lambda$ ustritt etwas platt gedrückt und bleiben es auch meist bis zu ihrer Keimung. Der Beschreibung ihres Banes von Dodel, Strasburger habe ich nichts hinzuzufügen (Fig. IO C). Die 4 gleich langen Wimpern gehen von der Spitze des Vorderendes aus; in ihm befinden sich die pulsierenden Vakuolen, unterhall, dieser liegt der Zellkern. An der Obertläche nahe der Hautschicht am vorderen Teil des Körpers liegt der länglichstal,fïrmige Augenfleck. Die Bewegung der Zoosporen dauert nach Braun (49 S. 239) I Stunde, nach Dodel etwa $1 / 2$ Stunde. Ich beobachtete, daß die Dauer der Bewegung in hohem Grade von dem Lebenszustand der zoosporenbildenden Fäden und von der Temperatur 
abhängt. Frische Zoosporen, gleich nach ihrem Austreten in einer feuchten Kammer isoliert, so daß eine Neubildung ausgeschlossen ist, bewegen sich der Mehrzahl nach bei I2-I $5^{\circ}$ von morgens ( $8-9$ Uhr) bis nachmittags ( $3-5$ Uhr); einige bewegen sich noch nach 24 Stunden, wenige nach 30 Stunden. Bei einer Temperatur von $3-4^{0}$ in 4 -proz. Rohrzuckerlösung isoliert, bewegt sich die Mehrzahl während 24 Stunden, eine Anzahl nach 48 Stunden, einige

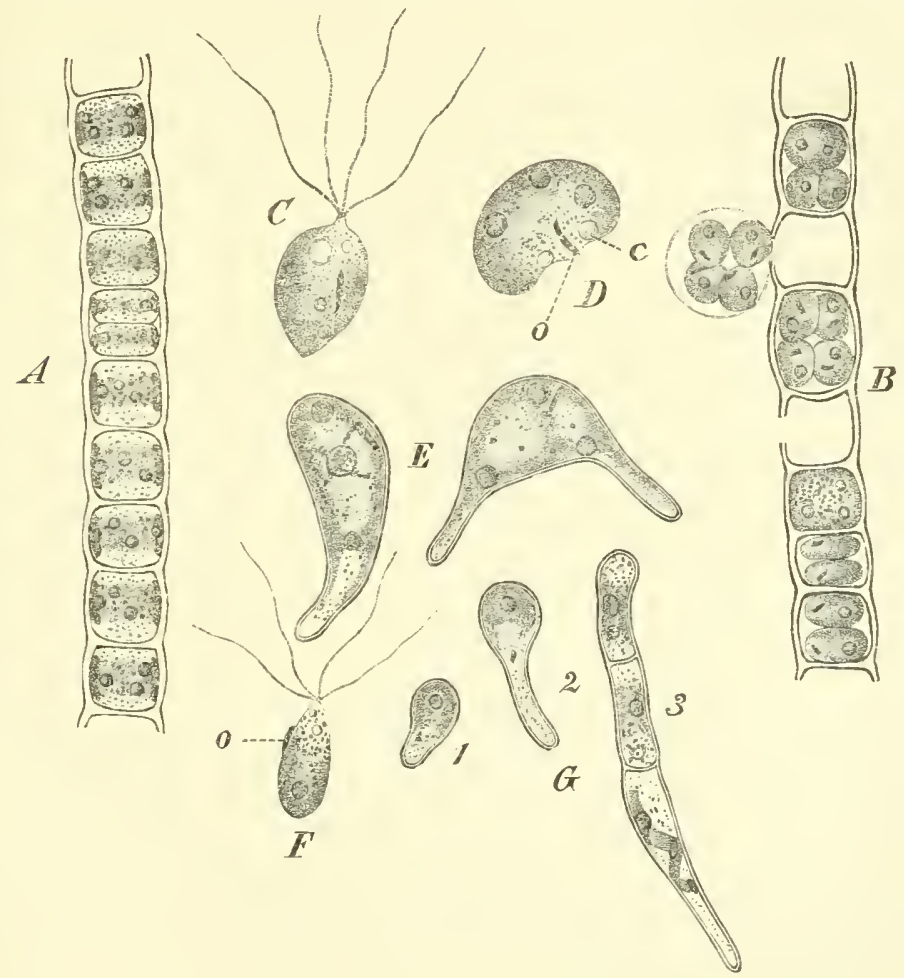

Fig. Io. Ulothrix zonata. A regetativer Faden; $B$ Faden mit Zoosporen; $C$ einzelne Zoospore; $D$ Zoospore zur Ruhe kommend; $o$ Augenfleck; $e$ pulsierende Vakuole; $E$ Zoosporen keimend; $F$ Mikrozoospore; $A$ 1-3 Mikrozoosporen keimend. Vergr. A, B 300; $C-G 1-2500 ; G 3250$.

Klebs, Fortpflanzungsphysiologie. 
nach 72 Stunden. Das schließt nicht aus, daß sehr viele Zoosporen unter ungünstigen Umständen, bei zu schneller Entleerung oder zu starkem WVechsel äußerer Bedingungen viel früher zur Ruhe gelangen können.

Solvald die Zoosporen zur Ruhe gekommen sind, keimen sie, welcher Vorgang von Dodel nicht richtig beschrieben worden ist. Er giebt an, daß die Zoosporen mit ihrem cilientragenden Ende sich festsetzen und ein Thizoid treiben, während das entgegengesetzte Ende zur Spitze des künftigen Fadens wird. Die direlite Beobachtung (vergl. Fig. IO $D$ ) im hängenden Tropfen zeigt dagegen, daß die Zoospore sich verbreitert und zwei seitliche Wülste hervorstülpt, so daß an dem vorderen, farblosen Ende eine Einbuchtung entsteht, in der noch eine Zeit lang die Cilien sitzen bleiben, bis sie völlig abgestoßen werden. Durch die Verbreiterung werden die beiden pulsierenden Vakuolen von einander entfernt; der Augenfleck, anfangs nahe der Einbuchtung liegend, wird an das Hinterende verschoben. Auf diese IVeise hat sich die noch nackte Zelle in der Richtung der ursprünglichen Querachse gestreckt, und diese wird nun zur Längsachse des küuftigen Fadens. Von Nembran umgeben, treibt dann die Zelle an der einen Seite ein Rhizoid, an der anderen wächst sie zum Faden aus. Bisweilen liommt es vor (Fig. IOE), daß an beiden Seiten Rhizoiden getrieben werden, wodurch abnorme Keimlinge entstehen. Die Verschiebung der Wachstumsachse um einen rechten Winkel, welche für Oedogonium bereits bei der Zoosporenbilclung selbst erfolgt, scheint für Ulothrix erst bei der Keimung zu geschehen.

Die Zoosporen lassen sich, wie lange bekannt ist, bei U1. zonata leicht dadurch gerrinnen, daß die Alge aus ler freien Natur in das Zimmer gebracht wird. Ich habe, soweit es möglich war, den Eintluß der ver- 
schiedenen, äußeren Bedingungen auf den Prozeß festzustellen versucht.

\section{Die Temperatur.}

U1. zonata wächst am üppigsten bei niederen Temperaturen unter $15^{\circ}$. Eine konstante Temperatur von $24^{\circ}$ tötet in 24 Stunden die Zellen, aber auch eine solche von I5-20 ${ }^{0}$ wirkt schädigend auf das ganze Leben und damit auch auf die Zoosporenbildung der Alge ein. Bei gewöhnlicher Zimmertemperatur erfolgt nach Ueberführung aus fließendem Wasser in eine kleine Wassermenge die Zoosporenbildung nur in den ersten Tagen lebhaft; mit jedem Tage nimmt sie ab, das Absterben der Fäden zu. Länger halten sich die Fäden bei niederer Temperatur von $3-10^{\circ}$. Dodel macht bereits aufmerksam, daß Ulothrix sehr gut das Einfrieren während der Nacht, das Auftauen am Tage aushält. Ich brachte Fäden in ein kleines Wassergefäß, das zwischen Eis gestellt wurde. Die Kultur gefror; nach 8 Tagen ließ ich sie auftauen, und ich bemerkte sofort lebhaftes Ausschwärmen der Zoosporen. Diese bewegen sich auch in schmelzendem Schnee, wie bereits G. Kraus (75 S. 774) es für Ulothrix tenuis beobachtet hat. Bringt man eine Ulothrix-Kultur in den Eiskasten bei O-I ${ }^{0}$, so kann die Zoosporenbildung I-2 Wochen hindurch fortdauern; allmählich wird auch hier die Alge kränklich.

Der große Einfluß der Temperatur auf Leben und Vermehrung der Alge zeigt sich am deutlichsten in ihrer Abhängigkeit von den Jahreszeiten, die ich vorhin berührt habe. Im Brunnen meines Gartens fällt der Höhepunkt der Entwickelung, je nach dem früheren oder späteren Eintritt wärmerer Temperatur, in die Monate Februar bis April, wo die Temperatur des Wassers von 3 oder 4" 
bis gegen $10^{0}$ steigt. Bei weiter steigender Temperatur nehmen Wachstum und Vermehrung ab, um im Hochsommer ihr Ninimum zu erreichen. Im Herbst I894 sah ich bei I $4{ }^{\circ}$ Wassertemperatur wieder deutliche Vermehrung der Fäden, die bei der allmählich sinkenden Temperatur immer zahlreicher erschienen, bis dann die lang andauernde Kälte in Januar und Februar I895 die Vegetation wieder zurückdrängte.

In diesem ganzen Verhalten drüclit sich zunächst die Abhängigkeit des Wachstums von der Temperatur aus; die Zoosporenbildung, welche stets kräftig wachsende, gesunde Fäden roraussetzt, hängt zunächst nur indirelit von der Temperatur ab. Es läßt sich sehr schwer erkennen, ob noch ein specieller Einfluß von ihr auf den Prozeßs wirksam ist. Zoosporen können entstehen und frei werden bei Temperaturen yon $0-24^{\circ}$. Wenn andere Reize ihre Bildung veranlassen, so fördert eine niedere Temperatur unter $10^{\circ}$ den Prozeß. Die Frage aber lautet, ob eine Temperaturerhöhung als besonderer, zoosporenerregender Reiz wirke. Meine Beobachtungen sprechen eher dagegen. Denn die aus dem Freien genommenen Fäden erzeugen in der ersten Zeit ebenso lebhaft Zoosporen, wenn sie in kleineren Gefäßen der Zimmertemperatur ron $15^{\circ}$ oder einer Temperatur von $2-3^{\circ}$ ausgesetzt werden, auch dann, wenn sie sich im Freien bei einer solchen von 6" entwickelt haben. Die plötzliche Temperaturerhöhung z. B. von 6 auf $15^{\circ}$ befördert, wie Dodel angiebt, die Entleerung, vielleicht in der allerersten Zeit auch ein wenig die Bildung, bald aber wirkt sie darauf hemmend ein. Eine Temperaturerniedrigung hält nicht im mindesten den Prozeß auf.

\section{Das Licht.}

Das Licht gehört zu den notwendigen Lebensbedingungen ron Ulothrix in einem viel höheren Grade, 
als bei Hydrodictyon oder Vaucheria. Nach wenigen Tagen der Verdunkelung wird die Alge kränklich. Die Zoosporenbildung leidet dabei zuerst, so daß bereits nach 24 Stunden der sonst so lebhafte Prozeß sehr verlangsamt wird, selbst wenn die Temperatur unter $10^{\circ}$ sich hält. Bei Anwendung von 2-4-proz. Rohrzuckerlösung gelingt es eher, mehrere Tage nach dem Lichtabschluß Zoosporenbildung zu beobachten, aber auch dann spärlicher und kürzere Zeit hindurch, als bei den gleichzeitigen Lichtkulturen. Um den Einfluß der Dunkelheit unter natürlicheren Verhältnissen zu untersuchen, benutzte ich die an Steinen festgewachsenen Fäden im Aquarium. Dicht neben dem Wasserstrahl wurde ein solcher Stein mit Stanniol locker umwickelt. Die Temperatur blieb sich gleich, der Zufluß des Wassers wurde etwas behindert, was indessen in der ersten Zeit nur die Zoosporenbildung hätte fördern müssen. Nach 48 Stunden zeigten die Fäden an einem solchen Steine nur sehr spärliche Zoosporen, später nicht mehr; nach 7 Tagen fingen die Fäden an abzusterben. Einen anderen Stein mit Ulothrix legte ich an die dem Zimmer zugewandte, schwächer beleuchtete Wand des Aquariums. Auch hier hörte die Zoosporenbildung in wenigen Tagen auf, die Alge fing an zu kränkeln. In der freien Natur findet sich die Alge fast immer an ganz sonnigen Stellen der Bäche und Flüsse.

Als Resultat meiner Beobachtungen läßt sich angeben, daß Ul. zonata sehr bald nach Lichtabschluß oder überhaupt bei schwachem Licht leidet, daß der Prozeß der Zoosporenbildung sofort davon betroffen wird, ohne daß sich seine specielle Abhängigkeit vom Licht etwa in der Weise wie bei Hydrodictyon nachweisen ließe. Immerhin läßt sich denken, daß eine geringe Schwächung der Lichtintensität die Zoosporenbildung gegenüber dem Wachstum fördere. Denn meine Kultur im Aquarium 
zeichnete sich dadurch aus, daß sie fortdauernd, 6 W'ochen hindurch, Zoosporen bildete, infolgedessen die Fäden immer liürzer wurden. Der Hauptunterschied der Kultur im Aquarium von der im Brunnen lag in der schwächeren Beleuchtung der ersteren. Das IVachstum scheint demnach empfindlicher gegenüber Lichtschwächung zu sein als die Zoosporenbildung.

\section{Die chemische Beschaffenheit des Mediums.}

In dieser Beziehung wurde hauptsächlich der Einfluß der Rohrzucker- und der Nährlösung geprüft. Eine Rohrzuckerlösung von 2-4 Proz. wirlt dahin, daß bei gleichen Temperatur- und Lichtverhältnissen die Zoosporenbildung etwas länger andauert, als im Wasser. Allerdings verhalten sich die verschiedenen Kulturen nicht gleich, weil die Intensität des Prozesses ron dem augenblicklichen Zustand der Alge abhängt. In Lösungen von 6-8 Proz. kann die Zoosporenbildung eine Anzahl Tage fortgehen, in Io-proz. können die rorher gebildeten Zoosporen entleert werden, während eine lebhafte Neubildung nicht mehr stattfindet, so daß nach 48 Stunden keine beweglichen Schwärmer zu sehen sind.

Eine Nährsalzlösung ron $0,2-0,5$ Proz. behindert bereits stark die Zoosporenbildung. In o,2-proz. Lösung können allerdings noch in den ersten Tagen Zoosporen austreten, in 0,5-proz. seltener; in I-proz. wird Entleerung wie Neubildung gehemmt.

In solchen Nährlösungen geht immer der größere Teil der Fäden zu Grunde, ein anderer paßt sich allmählich an, wobei aber das Aussehen der Fädlen verändert wird. Die einzelnen Zellen runden sich kugelig ab und schwellen stark an; sie werden ganz durchsichtig grün, weil die Stromastärke verschwindet. Schließlich zerfallen die 
Fäden mehr oder weniger in einzelne Zellen, die sich dann eine Anzahl Wochen lebend erhalten. Wenn solche Zellen in Wasser übergeführt werden, so kann gleich Zoosporenbildung eintreten. Eine Kultur der Form maxima wurde am 20./II. I894 in 0,2-proz. KN-Lösung versetzt. Ein Teil davon am 23./II. in Wasser gebracht und hell kultiviert, lieferte in den folgenden Tagen bis zum 6./III. fort und fort Zoosporen. Ein anderer Teil wurde am 8./III aus der Nährlösung in Wasser übergeführt und anfangs dunkel gestellt, wodurch keine Veränderung hervorgerufen wurde. Am Io./III. wurde die Kultur beleuchtet, und sie lieferte von I3.-I8./III. Zoosporen. Ganz ähnliche Versuche gelangen auch bei den gewöhnlichen UlothrixFormen.

Die Versuche mit der Nährlösung sind die einzigen, bei welchen Ulothrix-Fäden nach völligem Aufhören der Zoosporenbildung wieder dazu veranlaßt werden konnten. Der Uebergang aus Nährlösung in Wasser spielte hierbei die Rolle des auslösenden Reizes.

Besser als die alten Fäden passen sich die Keimlinge verdünnten Nährlösungen an. Solche wuchsen in 0,2-proz. zu vielzelligen, sehr schmalen und zarten Fäden heran, die nach der Ueberführung in Wasser Zoosporen bildeten.

\section{Das strömende Wasser.}

Schon aus den einleitenden Bemerkungen über die Kultur von Ulothrix geht hervor, daß die Alge in hohem Grade an beständig fließendes Wasser gewöhnt ist. Von seinen Eigenschaften, die früher (S. 82) erwähnt wurden, haben wir bereits die niedere Temperatur besprochen. Die mechanische Reibung spielt für Ulothrix ähnlich wie für Vaucheria keine entscheidende Rolle, da 
die Fäden in Brunnentrögen auch vom Wasserstrahl entfernt noch gut wachsen können. Weitaus den bedeutungsrollsten Einfluß übt die stete Zufuhr frischen, sauerstoffhaltigen Wassers aus; das schnelle Kränkeln in kleiner, stehender Wasssermenge erklärt sich aus dem relativ viel zu geringen Luftgehalt. Selbst als die Alge im stetig sich erneuernden Wasser meines Aquariums, aber $22 \mathrm{~cm}$ unter der Wasseroberfläche sich befand, hörte das Wachstum sehr bald auf, während bei niederem Wasserniveau die Alge sich dicht unter der Oberfläche lange forterhielt. Ueberhaupt kann man das stärkste Wachstum von Ulothrix überall dort beobachten, wo die Alge nur von einer dünnen Schicht lebhaft fortströmenden Wassers bespült wird. So sah ich z. B. 20-30 cm lange Fadenmassen an den Wehren der Ergolz bei Liestal, der Wiese, im Jura an Felsen, die von einer Quelle berieselt wurden. Als diese langen Fäden in das Zimmer gebracht wurden, trat lebhafteste Zoosporenbildung ein, die jedenfalls vorher in der freien Natur nur sehr spärlich stattgefunden hatte. Denn durch den Mangel der Zoosporenbildung bei lebhaftem Wachstum erklärt sich allein die relativ enorme Länge der Fäden. Ganz allgemein wird, selbst wenn in der freien Natur Zoosporenbildung irgendwie stattfindet, der Prozeß stets sehr befördert durch den Uebergang aus fließendem in stehendes Wasser. Die Verringerung des Luftgehaltes erscheint als die wesentlichste Ursache für den Eintritt und die Lebhaftigkeit der Zoosporenbildung. Weil aber der Mangel an Sauerstoff noch weitere und schädliche Einwirkungen auf das Leben der Alge ausübt, so muß dadurch indirelit der Prozeß der Zoosporenbildung betroffen werden; um so langsamer geschieht es, je niedriger die Temperatur bleibt.

In sehr vielen Fällen geht Zoosporenbildung in der freien Natur bei Ulothrix ununterbrochen fort neben dem 
Wachstum, so daß die Fäden sich eine mittlere Länge bewahren. Die Gründe dafür lassen sich nicht scharf erkennen, es könnten dabei kleinere Schwankungen des Wasserzuflusses und damit verbundene, kleine Veränderungen des Luftgehaltes in Betracht kommen; es könnten sich damit Einflüsse von Lichtschwankungen, vielleicht auch von Temperaturschwankungen verbinden, die zeitweilig in einer Anzahl Fadenzellen die Zoosporenbildung veranlassen. So viel steht fest, daß das ganze Verhalten der Alge der Annahme widerspricht, nach der irgend welche inneren Gründe notwendig die ungeschlechtliche Fortpflanzung herbeiführen müßten.

\section{Die Bildung der Mikrozoosporen und Gameten.}

Neben den Zoosporen beobachtete zuerst Cramer (7I S. 76) kleinere Schwärmer, die zu je zweien kopulierten. Nach der genauen Untersuchung Dodel's ( 76 S. 492 etc.) entstehen durch zahlreiche, auf einander folgende Zweiteilungen der Zellen zweiwimperige, kleine, eiförmige Schwärmer, die im übrigen sehr den Zoosporen gleichen. Sie gehen gewöhnlich zu Grunde, wenn sie nicht zur Verschmelzung kommen und Ruhesporen bilden können. Strasb u rge r (92 S. 88), der die Beobachtungen D o d e l's bestätigt, meint, daß es sich bei der Bildung der kleinen Gameten nur um einen weiteren Teilungsschritt handle, der sie der Möglichkeit beraubt, sich selbständig zu entwickeln. Dodel beobachtete in Ausnahmefällen, daß die Gameten ohne Kopulation zur Ruhe (1. c. S. 516) kamen und sich dann wie gewöhnliche Zoosporen verhielten, da sie sofort gleich diesen keimten. Allerdings geht nicht mit Sicherheit hervor, daß Dodel wirklich Gameten vor sich gehabt hat, da er sie als solche nur auf Grund ihrer Kleinheit bezeichnet, obwohl er selbst 
anciebt, dafs die Größe ron Zoosporen und Gameten sehr wechsle. Wie man sehen wird, handelt es sich in der That hierbei nicht um wirkliche Parthenogenesis (vergl. weiter unten).

Unter dem Einfluß der zu seiner Zeit herrschenden Lehre rom Generationswechsel nahm Dodel (76 S. 537) einen solchen auch für Ul. zonata an. Die Zygoten erzeugen seiner Ansicht gemäß nach längerer Ruhezeit ( $3 / 4$ - I Jahr) ungeschlechtliche Zoosporen, aus denen im Herlost und W'inter eine Reihe ungeschlechtlicher Generationen hervorgeht: im Frühjahr tritt eine geschlechtliche Generation auf, die die Gameten und die Zygoten bildet. Meine mehrjährigen Beobachtungen zeigen aufs deutlichste, daß ein derartiger Generationswechsel nicht existiert. Ulothrix kann sich während eines Jahres allein auf ungeschlechtlichem Wege fortpflanzen. Die gametenbildenden Fäden können zu allen Jahreszeiten auftreten, je nachdem die für sie günstigen Bedingungen vorhanden sind. Während Gameten an dem einen Standort in großer Masse sich bemerkbar machen, können sie zur gleichen Zeit an anderen Standorten völlig fehlen. So sind z. B. im Frühjahr die in den Brunnen wachsenden Fäden im allgemeinen sehr geneigt, Gameten zu bilden, während die in der Wiese, der Ergolz lebenden auf keine Weise dazu veranlaßt werden können. Dagegen konnte ich im Herbst ron der Wiese-Form die Gameten erhalten, von anderen Standorten im Sommer u. s. w. Wenn es nun sicher ist, daß äußere Verhältnisse das Auftreten der geschlechtlichen Schwärmer bedingen, so ist es dagegen sehr unsicher, welche Bedingungen maßggebend sind. Meine Versuche haben zu keinem entscheidenden Resultate geführt; es kam immer auf den Zufall an, ob die Fäden dabei Gameten bildeten oder nicht. Gegenüber Temperatur, Licht, Luftgehalt des Wassers, chemischer Beschaffenheit 
des Mediums zeigten die Gameten keinen charakteristischen Unterschied von den Zoosporen. Die sicherlich vorhandenen Unterschiede entzogen sich der Erkenntnis. Nur so viel möchte ich behaupten, daß die Gametenbildung resp. die Neigung dafür dadurch erregt wird, daß die Alge an ihren natürlichen Standorten infolge der Wasserabnahme über die Oberfläche kommt und nur zeitweilig bespritzt oder berieselt wird. Bei Brunnen sah ich besonders lebhaft gametenbildende Fäden an Holz- oder Eisenstäben, die fast oder völlig über dem Wasser sich befanden und nur von Tropfen der Wasserstrahlen getroffen wurden. An dem rasch fließenden Fabrikkanal des St. Alban-Teiches in Basel befanden sich im Frühjahr I 895 eine Anzahl Steine mit Ulothrix am Ufer, die nach Sinken des Wassers nur ein wenig bespritzt wurden, im übrigen frei lagen. Ins Zimmer gebracht, entwickelte die Alge in den nächsten Tagen Gameten, während sie auf solchen Steinen, die im Wasser selbst gelegen hatten, ausschließlich Zoosporen erzeugte. Möglich ist es auch, daß Temperaturerhöhung, sonnige Beleuchtung die Neigung für die Gametenbildung beförderten. Im Dunkeln können zwar auch Gameten entleert werden, aber eine Neubildung ist noch mehr als bei den Zoosporen ausgeschlossen. Wenn nun die physiologischen Bedingungen für die Gametenbildung leider nicht näher erkannt werden konnten, so ergaben sich aus meinen Untersuchungen nach einer anderen Richtung hin wichtige Resultate. Besonders die Untersuchung an der Ulothrix meiner Brunnenkultur zeigte die auffällige Thatsache, daß neben Zoosporen und Gameten noch eine dritte Form von Schwärmern existiert, welche gleichsam in der Mitte zwischen beiden steht; ich will sie als Mikrozoosporen bezeichnen (Fig. Io $F$ G, S. 305).

Im Herbst I894, als im Brunnen Ul. zonata lebhaft sich entwickelt hatte, bemerkte ich im Laufe des Oktobers 
nur Zoosporen. Anfang November zeigten sich zahllose lileine Schwärmer, die ich für Gameten hielt, die aber niemals kopulierten, sondern einfach zu Grunde gingen. Den ganzen November, Dezember hindurch bis zum Januar, wo scharfe Kälte eintrat, sah ich diese Mikrozoosporen; fast täglich habe ich sie im Laboratorium untersucht. Schon mit bloßem Auge konnte man bemerlien, wenn diese Schwärmer im Kulturglas auftraten. Die Zoosporen sammeln sich infolge ihrer Lichtempfindlichkeit in einem breiten, grünen Rand an der dem Fenster zugelegenen Seite des Glases. Die Mikrozoosporen häufen sich infolge ihrer größeren Lichtempfindlichkeit und längeren Beweglichlieit an einer kleinen Stelle in Form einer grünen Wolke an. Die Mikrozoosporen sind durchschnittlich lileiner als die Zoosporen; ihre Länge schwankt von 7-- I2 $\mu$; ihre Breite von 5,5-8 $\mu$. Sie sind nicht breitgedrüclit, sondern schmal-eiförmig mit längerem Schnabel, abgerundetem Hinterende; der Augenfleck liegt fast in der Mitte des Kürpers (Fig. IO F, S. 305). Was ihre Cilien angeht, so schwankt nach vielen Beobachtungen die Zahl. Unzweifelhaft hat ein großer Teil vier Cilien; bei anderen sah ich ebenso sicher nur zwei. Auffällig war mir, daß nach dem Töten mit Jodlösung oder Osmiumsäure häufig ein Cilienpaar abgestoßen wurde, so daß neben einer zweiwimperigen Schwärmspore das andere Paar Cilien lag. So läßt sich nicht absolut sicher behaupten, ob die zweivimperigen unter den Mikrozoosporen vorliommen, wenn auch die Häufigkeit der Beobachtung solcher in manchen Präparaten es sehr wahrscheinlich macht. Morphologisch stehen also die Mikrozoosporen in der Mitte zwischen Zoosporen und Gameten, gehen nach beiden Seiten ganz allmählich in sie über. Die Zahl der Wimpern steht vielleicht in einem engeren Zusammenhange mit der Größe des Körpers ; denn gerade bei den kleineren 
Mikrozoosporen, die überhaupt von den Gameten nicht zu unterscheiden sind, sah ich besonders häufig zwei Wimpern.

Sehr auffällig sind dagegen die physiologischen Unterschiede der Mikrozoosporen sowohl von den Zoosporen, wie von den Gameten. Bei einer Temperatur von $12-15^{\circ}$

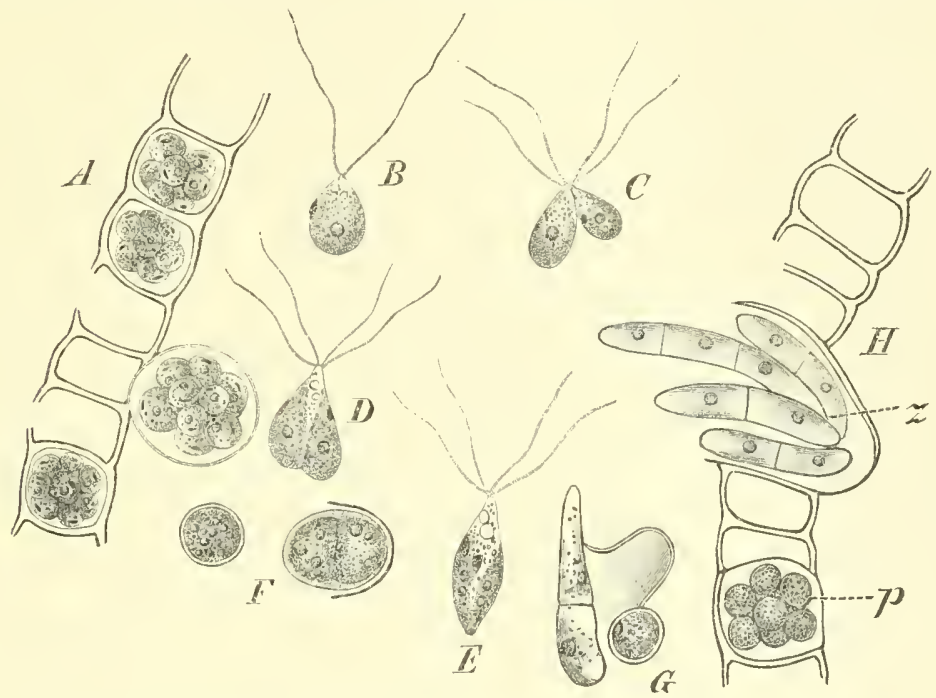

Fig. II. Ulothrix zonota. A Faden mit ausschlüpfenden Gameten; $B$ Gamete; $C, D$ Verschmelzung zweier Gameten; $E$ Zygospore; $F$ Zygote (oder Parthenospore); $G$ ihre Keimlinge; $H$ Faden mit keimenden Zoosporen $\approx$ und Parthenosporen $p$. Vergr. $A, H, F-G$ $300 ; B-E 500$.

keimen sie weder wie die Zoosporen, noch kopulieren sie wie die Gameten. Hat man gametenbildende Fäden, so läßt sich, wie Dodel angiebt, die Kopulation äußerst leicht und reichlich beobachten (Fig. I I $A-D$ ). Gleich nach dem Austritt der Gameten beginnen sich Pärchen zu bilden, und in kurzer Zeit beobachtet man eine Unmasse von Zygosporen (Fig. I I E). Diese haben, wie ich beobachtete, 
eine sehr charakteristische Gestalt, so daß man sie schon daran von den übrigen Schwärmerformen unterscheiden kann. Sie sind spindelförmig; besonders auffällig ist das spitze Hinterende. Während aus den Figuren Dodel's der richtige Sachverhalt nicht klar hervorgeht, halte ich dafür, daß die Zeichnungen 'Thuret's (50 S. 223, Taf. I8, Fig. I-7) von den Schwärmsporen seiner Ulothrix rorida den Zygosporen der Ul. zonata entsprechen. In früherer Zeit habe auch ich geglaubt, daß diese rorida eine besondere Species vorstelle, die durch solche spindelförmige Zoosporen charakterisiert sei. Aber eine genauere Untersuchung lehrte, daß es sich um die Zygrosporen handelt, die auch sehr leicht an dem doppelten Augenfleck zu erkennen sind. Die Augenflecke verschmelzen niemals, sondern liegen nur einander genähert im Körper der Zygosporen: sie sind eigentlich das beste Erkennungszeichen für die Kopulationsprodukte und dienen auch zur Unterscheidung ron den Mikrozoosporen, die mitunter durch ihre schlanke Form an die Zygosporen erinnern.

Da nun die eigentlichen Gameten mit solcher Sicherheit und Häufigkeit zur Kopulation kamen, war die Unfähigkeit der Mikrozoosporen, zu kopulieren, sehr auffällig. Irgend eine Bedeutung mußten sie doch haben, sie konnten unmöglich bloß gebildet werden, um zu Gruncle zu gehen. Den Schlüssel zur Lösung des Rätsels gab die Untersuchung des Temperatureinflusses. Zunächst wirkt die Temperatur in hohem Grade auf die Dauer der Bewegung ein. Bei $24^{\circ}$ sind die Mikrozoosporen innerhalb einer Stunde abgestorben; bei I2-I $8^{0}$ bervegt sich die große Mehrzahl IO-I2 Stunden, ein Teil 24 Stunden. Schon hieraus folgt, daß die Milirozoosporen durchschnittlich etwas länger sich bewegen als die Zoosporen. 
Auffälliger ist der Unterschied bei niederer Temperatur; bei einer solchen von $2-3^{0}$ war die Mehrzahl nach 72 Stunden noch beweglich, ein Teil nach Io8, vereinzelte nach 5 Tagen. Eine feuchte Kammer mit frischen, isolierten Mikrozoosporen brachte ich in eine Schale, die von schmelzendem Schnee umgeben war. Die Mehrzahl der Schwärmer bewegte sich lebhaft nach So Stunden, ein Teil nach I08 Stunden, vereinzelte sogar noch nach 6 Tagen - ein sehr merkwürdiges Verhalten im Vergleich zu den Schwärmerformen der meisten anderen Algen.

Bei niederer Temperatur - die obere Grenze liegt etwa bei $1^{0}$ - gehen die Mikrozoosporen nicht zu Grunde. Sie runden sich $a b$ und nach $2-3$ Tagen fangen sie an zu keimen (S. 305, Fig. Io $G I-3$ ). Die Kugel treibt ein farbloses Rhizoid; dann streckt sich der obere Teil und wächst langsain zu einem zarten, schmalen Faden heran, der durch weitere Teilungen vielzellig wird. Die Mikrozoosporen stellen daher eine besondere, ungeschlechtliche Schwärmsporenform vor, die durch geringere Größe, lebhaftere Lichtempfindlichkeit, längere Bewegungszeit, langsamere Keimung von den eigentlichen Zoosporen unterschieden ist. Die von Dodel angegebenen $(76$ S. jI6) schmalen Keimlinge, welche er als parthenogenetisch keimende Gameten aufgefaßt hat, stammen wahrscheinlich von solchen Mikrozoosporen.

Zur weiteren Ergänzung der Eigenschaften der Mikrozoosporen möchte ich noch hinzufügen, daß die Bewegungsdauer sehr vom Licht abhängt. Gleich nach ihrem Austritt, in einer feuchten Kammer, ins Dunkle gebracht, hören die Mikrozoosporen selbst bei Anwendung einer Temperatur von $2-3^{0}$ mit ihrer Bewegung nach I2-24 Stunden auf und gehen dabei ausnahmslos zu Grunde, während die Zoosporen im Dunkeln einen kurzen 
Keimschlauch treiben können. Bringt man die Milirozoosporen in einen Tropfen von 2-4-proz. Rohrzuckerlösung, so hewegen sie sich bei einer Temperatur von I2- I $8^{\circ}$ etwas länger als im Wasser bei gleicher Temperatur, so daß einige noch nach 48 Stunden beweglich sind. Wichtiger ist, daß ein Teil in Zuckerlïsung bei der genannten Temperatur zur Keimung gelangt. Größere Konzentration wirkt in dieser Richtung noch günstiger, so dafs z. B. in 8-proz. Rohrzuclierlösung fast sämtliche zur Keimung kommen. Bei niederer Temperatur unter $\mathrm{IO}^{0}$ hat die Anwendung der Zuckerlösung keinen Vorteil.

Eine Nährlösung von $0,2-0,5$ Proz. wirkt nicht besonders auf die Daner der Bewegung ein; sie begünstiğt lraum die Keimung bei Zimmertemperatur, wenn auch in den verschiedenen Versuchen einzelne Schwärmer keimten. Sehr auffallend verändert die Nährlösung die Lichtempfindlichkeit. Sowie man frische Mikrozoosporen in einen Tropfen Nährlösung bringt, so fangen alle an, sich rückwärts zu bewegen; allmählich nehmen sie ihre gewöhnliche Bewegungsart auf, haben aber fast vollständig die Fähigkeit verloren, sich nach dem Lichte hin zu beweren. Auch nach stundenlangem Aufenthalt in der Nährlösung gewinnen sie die Fähigkeit nicht wieder. Jie Rohrzuckerlösung wirkt im ersten Augenblicke ähnlich wie die Nährlösung ein; aber sehr bald passen sich ihr die Schwärmer an und erlangen wieder ibre volle Lichtempfindlichleit.

Schließlich spielt der Zustand der die Mikrozoosporen bildenden Fäden eine gewisse Rolle bei dem Verhalten (ler Schwärmer. Die erwähnten Resultate gelten nur für schwärmer, die am frühen Morgen, unmittelbar nach dem Uebergang der Fäden aus dem Brunnen in ein kleines Gefäfs, im Zimmer erzeugt worden sind. Solche Mikro- 
zoosporen, die in der Zimmerkultur nach einigen Tagen gebildet worden sind, hören viel früher mit ihrer Bewegung auf und gehen zu Grunde, auch bei Anwendung einer niederen Temperatur unter IO $^{\circ}$.

Die Gameten (Fig. I I B S. 3I7) ließen sich in ihrem physiologischen Verhalten nicht so genau untersuchen, weil sie sich nicht in größerer Menge ohne Kopulation erhalten ließen. Bei dem Austritt sind sie gewöhnlich rundlich, später etwas länglich; sie bewegen sich sehr unruhig hin und her und lassen sich bei einiger Aufmerksamkeit trotz ihrer großen Aehnlichkeit mit den Mikrozoosporen doch von diesen unterscheiden. In Nährlösungen von 0,5 Proz. wird die Kopulation verhindert; die Gameten gehen indessen leicht zu Grunde, wenn auch einzelne sich mehrere Stunden darin bewegen können. Das Hauptinteresse knüpfte sich für mich an die Frage, ob sie ohne Kopulation zur Ruhe kämen und was dann aus ihnen werde. Den ersten glücklichen Versuch stellte ich im April I894 an. Ulothrix zonata, aus einem Graben bei Lörrach, bildete nach 24 Stunden zahlreiche Gameten, die ich gleich mit einer Pipette auffing und in einen Tropfen von 0,5-proz. Nälırlösung in eine feuchte Kammer brachte. Nach einiger Zeit kamen alle Gameten zur Ruhe, die Mehrzahl ging zu Grunde, ein Teil erhielt sich und bildete kleinere und größere Zellkugeln. Man konnte scharf die Zygoten mit zwei Augenflecken und kleine Kugeln mit einem Augenfleck unterscheiden; es war mir ganz zweifellos, daß es sich bei den letzteren um echte Parthenosporen handelte. Die Kugeln wuchsen langsam heran, und nach einem Monat begann zu meinem Erstaunen die Keimung sämtlicher Ruhezellen, während nach Dodel's Beobachtungen die Zygoten 9-I2 Monate brauchen, bis sie keimfähig sind. Der von Dodel beschriebene Haftfortsatz der Zygoten wurde nicht beobachtet. 
Die Nährlösung ist es, welche bei meinem Versuch die schnelle Keimung veranlaßst hat. Die Keimung, die nicht direkt beobachtet wurde, verlief in etwas anderer Weise, als Dodlel sie beschrieben hat (Fig. I I $F, G$ ). Die alte Zellhaut wurde gesprengt und blieb noch lange als leere Kappe erhalten. Der Protoplast streckte sich etwas und teilte sich entweder in 2 oder 4 Zellen, die aber nicht zum Schwärmen kamen, sondern gleich weiterwuchsen, wobei sie mehrfach das Aussehen gewöhnlicher Keimlinge zeigten.

Nach Dodel zerfällt die Zygote durch simultane (?) Teilung in 2-I4 Zoosporen, deren Austritt von ihm nicht gresehen wurde; sie gingen vorher meist zu Grunde, und nur wenige zeigten einen Anfang der Keimung innerhalb der alten Zygotenhülle. Nicht unmöglich wäre es, daß bei den von mir beobachteten Keimungen eine schwache Bewegung der Keimlinge stattgefunden hätte. Sie blieben aber im allgemeinen, wie die alte Membran bewies, unverändert an der gleichen Stelle, und es ist zweifelhaft, ob sie überhaupt Wimpern entwickelt hatten.

Bei der Keimung lieken sich Parthenosporen und Zygroten nicht mehr unterscheiden; die Annahme ist erlaubt, daß die ersteren nur 2 Keimlinge geliefert haben, die letzteren 4. Im Frühjahr I 895 nahm ich die Untersuchung von neuem auf. Fäden, die in Gametenbildung begriffen waren, wurden gleich in einen Tropfen von o,2-proz. Nährlösung gebracht und in der feuchten Kammer beobachtet. Ein Teil der Gameten trat aus, bewegte sich, alser kopulierte nicht. Durch fortdauernde Beobachtung stellte ich fest, daß solche Gameten für sich zur Ruhe kamen und kleine, zygotenähnliche Sporen bildeten. Der größere Teil der Gameten blieb in den Zellen und ging entweder zu Grunde oder wandelte sich auch in Parthenosporen um, die noch einige Wochen als grüne Zellkugeln 
sich erhielten, während die in der gleichen Nährlösung zur Ruhe gekommenen Zoosporen direkt keimten (Fig. I I $H$ S. 317).

Die Gameten von U. zonata vermögen also ohne Kopulation sich lebend zu erhalten, wobei sie den $\mathrm{Zy}$ goten entsprechende Ruhezellen bilden.

Die spindelförmigen Zygosporen, die aus der Verschmelzung zweier Gameten hervorgegangen sind, bewegen sich eine Anzahl Stunden, bevor sie zur Ruhe kommen. Bei $7^{0}$ bleiben die meisten Zygosporen ca. Io Stunden beweglich, ein kleinerer Teil bis zu 15 Stunden.

Bei Ul. zonata kann man also folgende Formen von Schwärmern unterscheiden:

I) Zoosporen mit 4 Wimpern, einem Augenfleck im vorderen Teil des Körpers; etwas platt gedrückt, innerhalb 24 Stunden bei Temperaturen von $\mathrm{O}^{0}-24^{\circ} \mathrm{C}$ zur Ruhe kommend und gleich keimend.

$$
\begin{aligned}
& \text { Länge }=\text { IO-I5 } \mu \\
& \text { Breite }=9-12 \mu
\end{aligned}
$$

2) Mikrozoosporen mit 4 oder 2 Wimpern, einem Augenfleck im mittleren Teil des Körpers, schlank-eiförmig, bei Temperaturen über $10^{\circ}$ meist zu Grunde gehend, bei solchen unter IO $^{0}$ 2-6 Tage beweglich, dann zur Ruhe kommend und langsam keimend.

$$
\begin{aligned}
& \text { Länge }=7-12 \mu \\
& \text { Breite }=5,5^{-8} \mu
\end{aligned}
$$

3) Gameten mit 2 Wimpern, einem Augenfleck im mittleren Teil des Körpers, rundlich bis eiförmig, gleich nach dem Austreten zu je zweien kopulierend, doch fähig, ohne Kopulation zur Ruhe zu kommen, und Dauerzellen zu bilden (Parthenosporen).

$$
\begin{aligned}
& \text { Länge }=5-8 \mu \\
& \text { Breite }=4-5,5 \mu
\end{aligned}
$$


4) Zygosporen mit 4 Wimpern und 2 Augenflecken, spindelfirmig mit spitzem Hinterende, innerlall, r2 Stunden zur Ruhe kommend und Dauerzellen bildend (Zyłroten).

$$
\begin{aligned}
& \text { Länge }=1 \mathrm{I}-\mathrm{I} 3,5 \mu \\
& \text { Breite }=5,5-7 \quad \mu
\end{aligned}
$$

Die angegebenen Charaktere beziehen sich auf die Hanptmasse der Individuen einer Schwärmerform. Wie sich in morphologischer Beziehung alle Uehergänge zwischen den drei ersten Schwärmerformen finden, so ist sicherlich das gleiche auch für die physiologischen Eigenschaften der Fall. Am schärfsten getrennt, trotz der großen, morphologischen Aehnlichkeit, erscheinen auf den ersten Blick die Mikrozoosporen und die Gameten, weil die ersteren gleich keimen, die letzteren auch bei Mangel der Kopulation zu Dauerzellen werden können. Aber auch hier wird es Uebergangsformen geben, wenn sie bisher auch nicht beachtet worden sind. Alle drei Schwärmerformen entstehen auf die gleiche Weise durch successive \%weiteilung. Es ist nicht möglich, zu behaupten, daß tür jede (ler Formen eine bestimmte Zahl von Teilungen notwendig sei. Denn aus einer Zelle von Ulothrix können je nach der Größe I- 16 Zoosporen entstehen, S-32 Mikrozoosporen, 8-32 Gameten. Meine Beobachtungen weisen darauf hin, daß die Bildung von Zoosporen und Gameten durch bestimmte, äußere Bedingungen veranlaßt wird. Für die Entstehung der Mikrozoosporen muß ich das gleiche annehmen. In meiner Brunnenkultur traten sie vom Oktober bis Ende Dezember IS94 täglich auf; dann verschwanden sic beim Eintritt der lang andauernden Kälte, wodurch die Ulothrix-Kultur überhaupt etwas reduziert wurde, wenn sie auch beständig Zoosporen zu entwickeln im Stande war. Im März I895 zeigrten sich neben Zoosporen Gameten, wenn auch lange nicht so reichlich wie zur gleichen Zeit IS94. Bei Ul. zonata, die ich im März IS95 aus 
dem Albanteich (S. 315) holte, bemerkte ich einmal in den ersten 24 Stunden echte Mikrozoosporen, die bei niederer Temperatur keimten. Am 2. Tage wurden sie ersetzt durch kopulierende Gameten. Wahrscheinlich habe ich früher manchmal die Mikrozoosporen übersehen. Welche Bedingungen nun für das Auftreten der Mikrozoosporen maßgebend sind, ist ebenso unbekannt wie hinsichtlich der Bildung der Gameten. Es mußsich hier um die Wirkung sehr kleiner, äußerer Veränderungen handeln, die mit den bisher zugänglichen, groben Methoden nicht erkannt werden können.

Unter den Schwärmerformen sind die Mikrozoosporen von besonderem, theoretischem Interesse. Denn wenn bei einer so vielfach untersuchten, häufigen Alge wie Ulothrix zonata solche gametenähnlichen und doch ungeschlechtlichen Schwärmsporen vorkommen, so liegt es nahe anzunehmen, daß auch andere Algen solche unter Umständen erzeugen. Es würden sich daraus manche widerspruchsvollen Angaben über die geschlechtliche Bedeutung von Schwärmern vielleicht erklären lassen. 


\section{Hormidium.}

Zu der Cattung Ulothrix wird seit Kützing eine Anzahl Fadenalgen gerechnet, welche auf der Erde oder auf der Rinde von Bäumen lehen. Ursprünglich hatte K ü tzing (43 S. 244) diese Luftalgen in die Gattung Hormidium gebracht, später aber (49 S. 349) mit Ulothrix vereinigt. Diese Algen werden seit K ützing fortwährend zwischen verschiedenen Gattungen hin und her geworfen; man vergl. die Darstellung bei Gay ( 91 S. 53-55). Gay hat zunächst Ordnung geschafft, indem er diejenigen Hormidium-Arten (z. B. parietina, radicans) mit sternförmigem Chromatophor der Gattung Schizogonium zuwies; die in Wasser lebenden Formen mit wandständigem Chromatophor vereinigte er mit der Gattung Ulothrix, während er die terrestrisch lebenden Formen, die durch Zerfall der Fäden sich vermehren und keine Zoosporen bilden sollen, zu Stichococcus rechnete. Der bekannteste Vertreter cler letzteren Formen ist Ulothrix flaccida. Bor zi beobachtete bei dieser Art zweiwimperige Zoosporen (95 S. 358) und charakterisierte durch diese die Gattung Ulothrix, während er Ulothrix zonata als Hormiscia bezeichnete. Ich möchte nun die crste Gattung Hormidium wieder zu neuem Leten erwecken, den Namen Ulothrix der gut bekannten Species zonata überlassend.

Die Species-Systematik der ulothrixartigen, in der Luft lebenden Algen ist äuß̉erst unzulänglich. Es handelt 
sich hier um Algen, die in ihren morphologischen Eigenschaften wenig Bemerkenswertes zeigen und deshalb einander so nahe $\mathrm{zu}$ stehen scheinen, daß niemand weiß, was Art, Varietät, Standortsform sei. Die einzigen Charaktere, die zur Unterscheidung herangezogen werden, betreffen den Durchmesser, die Dicke der Zellwand etc. Da nun die Variationen in diesen wenigen Charakteren innerhalb einer Species nicht genau bekannt sind, anscheinend alle möglichen Uebergangs- und Zwischenformen existieren, so herrscht in den Bestimmungsbüchern große Willkür; man vergleiche z. B. genau die Diagnosen der zahlreichen Varietäten und Arten von Hormidium in der Algenflora, die Hansgirg (86 S. 6o) herausgegeben hat.

In der Einleitung des Abschnittes über Protosiphon habe ich näher angegeben, wie man aus der Verwirrung herauskommen kann. Man muß von Reinkulturen ausgehen und den Variationskreis einer bestimmten Form durch genaues Studium der Wirkung bekannter, äußerer Bedingungen feststellen. Bei den morphologisch sich so nahe stehenden Arten wird die Kenntnis ihrer physiologischen Eigenschaften oft von wesentlichem Vorteil sein. Hormidium nitens und flaccidum, die von Wildemann (88 S. 78), Gay (9I S. 58) in eine Species zusammengefaßt werden, kann man in der That nicht mit Sicherheit unterscheiden, wenn sie durcheinander gemischt vorkommen. Berücksichtigt man die Art ihres Wachstums in Reinkulturen, so kann kein Zweifel über die Selbständigkeit beider Arten bestehen. Die beiden genannten Arten sind es nun, welche ich einer genaueren Betrachtung unterziehen möchte. 


\section{Ilormidium nitens Menewhini.}

(Taf. Il, Fig. 25-29.)

Seit meinen Kulturen von Vaucheria repens war mir H. nitens l,ekamnt, da es an dem gleichen Standort auf den Koaksstücken im Gewächshaus vorkam. Die Alge war lange ein sehr unangenehmer Gast in den VaucheriaKulturen bei Anwendung von Nährsalzlösungen, besonders im Sommer bei hoher Temperatur. Schließlich wandte ich mich der Untersuchung dieser Algre zu und stellte von ihr eine Reinkultur her, indem ich von einem einzigen, kleinen Fadenfragment ausging, das in sterilisierte Nährlösung grebracht wurde. Die Alge wächst ausgezeichnet in Nährlösungen, auch in solchen von stärkerer Konzentration, so daß ich häufig Lösungen von I Proz. anwandte. Auf den Nährlösungen bildet die Alge einen sehr charakteristischen Ueberzug von eigenthümlichem Seidenglanze, so daß die Bezeichnung nitens von seiten des Entdeckers Meneghini sehr passend gewählt erscheint.

Die Fäden von Hormidium nitens sind stets unverzweigt und haben einen Durchmesser von 5,5-7!". Die einzelne Zelle (Taf. II, Fig. 25) besitzt eine zarte Zellhaut, im Inhalt einen wandständigen Chromatophor in Form einer gebogenen Platte, in seiner Mitte mit einem rundlichen bis länglichen Amylonkern versehen. Der Chromatophor läßst gewöhnlich die eine Länıssseite des Plasmas frei, so daß hier die Zelle farblos erscheint; in Plasma liegrt der einzige /elliern mit deutlichem Nucleolus. Die Zellen vermehren sich unter normalen Verhältnissen durch (Luerteilung. Bei Gegenwart von Licht und von Nährsalzen erreichen die Fäden durch Teilung eine beträchtliche Lảnge, die bis zu $20 \mathrm{~cm}$ und noch mehr beträgt. 
In den Nährsalzlösungen wachsen die Fäden wesentlich an der Oberfläche der Flüssigkeit und bilden hier eine zusammenhängende Haut, indem sich die Fäden bei ihrem beständigen Längenwachstum in regelmäßigen, parallelen, zierlichen Windungen dicht aneinander legen und schließlich die ganze Oberfläche bedecken. Die Haut besteht aus seidenartig glänzenden Feldern; der Seidenglanz kommt dadurch zu Stande, daß eine Reihe parallel aneinander liegender Fäden über die äußerste Oberflächenschicht der Flüssigkeit etwas hervortritt und das Licht anders reflektiert als es die Rinnen zwischen den Fäden thun. Durch die Windungen und Krümmungen der Fäden entstehen Felder von verschiedenem Seidenglanz; denn an der einen Stelle verlaufen die parallel gereihten Fäden in dieser Richtung, an einer daneben befindlichen Stelle in anderer Richtung. Uebrigens wächst ein kleiner Teil der Fäden auch am Boden der Kulturflüssigkeit.

Die Fortpflanzung von Hormidium nitens geschieht durch die Spaltung der Fäden, durch Zoosporen und Dauerzellen.

\section{Der Spaltungsproze[s.}

A. Braun (49 S. I40) hat zuerst angegeben, daß die in der Luft lebenden Hormidium-Arten sich durch Zerfallen der Fäden in einzelne Zellen vermehren. Das gleiche hat Gay (9I S. 60--63) bei Hormidium flaccidum und dissectum gesehen und näher beschrieben, Borzi bei Hormidium flaccidum und Gloeotila mucosa; letztere Alge ist höchst wahrscheinlich nichts anderes als ein Hormidium. Die Bedingungen des Spaltungsprozesses sind von den genannten Forschern kaum berücksichtigt worden. Nur bei Borzi (95 S. 36I-369) findet man die Angabe, daß nach Erreichung einer gewissen Länge die 
Spaltung eintrete, daß der völlige Zerfall in einzelne \%ellen bei hegrimencler Trockenheit, ferner bei Kultur auf Nihrgelatine sich einstelle.

1)er Spaltungrsprozeß bei Hormidium nitens hängt in keiner IVeise von der Zahl der T'eilungen und der Länge (les fädlen al). Wohl kann es vorkommen, daßs in lebenskräftigen, gut wachsenden Nährsalzkulturen hier und dort cin Faclen, namentlich an den Biegungsstellen, sich spaltet. Alver ein wirlicher Zerfall aller Fäden in ganz kurze, wenimzellige Stücke oder einzelne Zellen tritt niemals von selbst in solchen Kulturen ein, so lange die Emährungsbedingungen sehr günstig sind. Er erfolgt dayegen ausnahmslos, wenn man die äuberen Bedingungen in bestimmter Weise ändert.

Ueber die Morphologie der Spaltung läßt sich wenig angelen; es findet die Trennung an den Querwänden statt, indem die dünne, die Zellen eines Fadens verfsindende Cuticula reifst, die anscheinend gemeinsame Querwand sich in zwei Lamellen spaltet, und die Zellen durch allmälliches Hervorwölben sich voneinander lösen. Die Trennung geht an der einen Längsseite schneller vor sich, als an der anderen, so daß die Zellen einen Winkel miteinander bilden; indem dieser Winkel bald nach dieser, bald nach jener Seite sich öffnet, bildet ein zerfallender Faden häufig eine Zickzacklinie (Taf. II, Fig. 26) ${ }^{1}$ ).

1) Ich will hier nicht auf clie Frage eingehen, in welchem Verhältnis Stichococcus bacillaris Nï 2 eli zu den Hormidium-Arten stehe. Burzi (90 S. 406) betraclitet die erstere Form als einen Entwickelungszustand der letzteren. In der That sind die frei gewortenen Zellen von Hormidiun Stichococcus ähnlich, wenn ich mich auch zu urimern gliube, daß die Zellen von Stichococcus kein Pyrenoid besitzen. Ich habe dic Alge jetzt nicht weiter untersucht; es wird sich aber mit Hilfe eines emfachen Versuches die Frage lösen lassen. Man bringe Stichreoccus in eine frische Nïhrlösung und sehe nach, wie er sich dort verhält. Benimmit er sich dort atuch als einzellige Alge, so ist er zweifellos verschieden von den Zellen der HormidiunArten, dic unter diesen Linständen stets zu Fïden auswachsen. 
Der Spaltungsprozeß tritt stets ein I) bei Mangel an Nährsalzen, 2) bei Mangel an Feuchtigkeit. Bringt man Fäden aus einer Nährsalzkultur in reines Wasser, so kann in den ersten Tagen noch das Wachstum fortgehen; bald hört es auf, die Zellen füllen sich mit Reservestoffen, der Moment der Spaltung tritt ein, und der Prozeß schreitet fort, bis zum völligen Zerfall. Man kann in einer feuchten Kammer die Spaltung gut beobachten. Es fragt sich, worin eigentlich der nächste Grund für die Spaltung liege; die Frage kann man bisher nur durch eine Hypothese beantworten. Durch den Mangel an Nährsalzen wird zuerst die Teilung, dann das Wachstum der Zellen zum Stillstand gebracht; der Ernährungsprozeß geht jedoch fort, so daß die Zelle sich mit organischen Nährstoffen füllt, ihr Turgor steigt. Da nun infolge der mangelnden Teilung die dünne, die Zellen verbindende Cuticula nicht durch neue Zellhautschichten verstärkt wird, so wird sie zuerst durch das noch stattfindende Wachstum, dann weiter durch den steigenden Turgor der Zelle so stark gedehnt, daß sie zerreißt. Dadurch wird der Zusammenhang der Zellen bald hier, bald dort gelockert; die Querwand zwischen zwei Zellen, die gleich nach der Teilung mindestens aus zwei Schichten besteht, spaltet sich, indem jede Zelle infolge des in ihr herrschenden Druckes die ihr gehörige Querwandschicht hinauszuwölben sucht. Nach meiner Ansicht spielt also die Hauptrolle bei der Spaltung die Fortdauer der Ernährung nach dem Aufhören zuerst der Teilung und dann des Wachstums; die dadurch herbeigeführte Steigerung des Turgors wird zur Veranlassung, daß die Cuticula reißt, und dies hat zur weiteren Folge die Spaltung der Querwände, wofür der Turgor ebenfalls maßgebend ist. Wenn meine Ansicht richtig ist, so muß die Spaltung unterbleiben, wenn der Ernährungsprozeß verhindert wird. In 
der That findet die Spaltung nur bei Gegenwart des Lichtes statt. Im Dunkeln hören auch Teilung und Wachstum auf, die Färlen bleiben aber zusammenhängend. Der Turgor kann unter solchen Umständen nicht vermehrt werden, er wird vielmehr allmählich vermindert, da schließlich Substanzen des Zellsaftes veratmet werlen. Bringt man die ausgehungerten Fäden ans Licht, so tritt Spaltung ein, sofern Mangel an Nährsalzen herrscht. Ich l)rachte z. B. am 23./IX. I895 Fäden aus Nährlösung von 0,2 Proz. in Wasser in eine feuchte Kammer und verdunkelte die Kultur. Bis zum 23./X. trat keine Spaltungr ein; an diesem Tage wurde die feuchte Kammer hell gestellt, und nach einigen Tagen hegann der Spaltungsprozels. Bringt man dagegen die ausgehungerten Fäden in frische Nährlösung, so erfolgen nur Wachstum und Teilung. Das gleiche ist der Fall, wenn man die durch die Spaltung isolierten Zellen in frische Nährlösung bringt.

Der Zerfall kann auch innerhalb der Nährlösung eintreten, wenn diese durch das Leben der Alge ungünstig verändert wird. Man muß dabei verdünnte und konzentrierte Lösungen unterscheiden. In den ersteren z. B. von 0,2-0,5 Proz. muß schließlich durch das ununterbrochene Wachstum der Fäden ein Nangel an Nährsalzen eintreten; man beobachtet in der That nach einigen Wochen besonders im Sommer bei schnellerem Wachstum die Spaltung in normaler Weise. Macht man eine Kultur in 2-proz. Lösung, so geht an und für sich das Wachstum langsam vor sich. Vor allem aber treten schädliche Nebenwirkungen mit der Zeit ein; die Fäden sehen schließlich verändert aus. Die Zellen sind lang gestreckt un f bald nach dieser, hald nach jener Seite eingebogen. Nan sieht daher auch nicht mehr die seidenglänzende Haut, sondern nur mattgrïne, verworrene Fadenmassen. 
Allmählich sterben die Fäden ab, nachdem bald mehr, bald weniger Spaltung eingetreten ist, die aber niemals so vollständig ist wie im Wasser oder in verdünnten Nährlösungen.

In Nährlösungen von I Proz. wächst die Alge in den ersten Wochen ausgezeichnet, wenn man in $100 \mathrm{ccm}$ Flüssigkeit ein paar Fadenstücke hineinbringt. Steht die Kultur kühl und schattig, wie es meistens im Winter der Fall war, so hält sich die Alge auch nach Verlangsamung des Wachstums monatelang lebend und zerfällt normal. Im Hochsommer, bei hoher Temperatur, hellem Licht ist anfangs das Wachstum sehr intensiv; dann beginnen aber die Zellen sich in ähnlicher Weise wie bei der Lösung von 2 Proz. zu verändern, und allmählich sterben sie ab. Hier muß durch die Lebensthätigkeit der Alge selbst eine chemische Veränderung, möglicherweise eine Säurebildung, in der Nährflüssigkeit veranlaßt werden, die schädlich wirkt.

Da die Spaltung zunächst durch den Mangel an Nährsalzen herbeigeführt wird, so liegt die Frage nahe, welche von den Nährsalzen hauptsächlich wichtig dafür seien. Die Frage führte zu der Untersuchung, welche Elemente überhaupt für die Ernährung der Algen notwendig seien. Zur Zeit, als ich Hormidium nitens untersuchte, gab es in der Litteratur keine ausführlichen Angaben über dieses Thema; nur Loew und Bokorny hatten in ihren Arbeiten (87) einige Mitteilungen gemacht, die sich aber mehr auf die Wirkung einzelner Salze, Nitrate, Phosphate bezogen. Unterdessen ist eine Arbeit von $\mathrm{Molisch} \mathrm{(95)} \mathrm{erschienen,} \mathrm{der} \mathrm{das} \mathrm{Thema} \mathrm{im} \mathrm{allge-}$ meineren Sinne behandelt. Molisch weist darin nach, daß für Mikrothamnium die Elemente Stickstoff (in gebundener Form), Phosphor, Schwefel, Kalium, Magnesium notwendig sind, während Calcium fehlen kann. 
Antere Alugen, wie Vaucheria, Spirogyra, brauclıen auch Calcium zu ihrem Leben.

Fïr meine Untersuchung ging ich von der $\mathrm{K}$ nopschen Lösumg aus, in der Hormidium nitens ganz vortrefflich wächst. Ich machte mit folgenden Nährlüsungen vergleichende Untersuchungen:

I. Knop'sche Nähr]ösun@ von 0,5 und I Proz.; 4 Teile salpetersaurer Kalk, je I Teil phosphorsaures Kali, schwefelsaure Magnesia, salpetersaures Kali.

II. Nährlösung ohne Phosphor: Salze wie bei I. ohne phosphorsaures Kali.

III. Nährlösung ohne Stickstoff; je I Teil phosphorsaures Kali, schwefelsaure Magnesia, Chlorcalcium.

IV. Nährlösung ohne Kalium; 4 Teile salpetersalirer Kalk, je I Teil phosphorsaures Natron $\left(\mathrm{NaH}_{2} \mathrm{PO}_{4}\right)$. schwefelsaure Magnesia.

V. Nährlösung obne Magnesium; 4 Teile salpetersaurer Kalk, je I Teil phosphorsaures Kali, schwefelsaures Natron.

V1. Nährlösung ohne Schwefel; 4 Teile salpetersaurer Kalk, je I Teil phosphorsaures Kali, Chlormagnesium.

T'll. Nährlösung ohne Calcium; 2 Teile salpetersaures Natron, 2 Teile phosphorsaures Kali, I Teil schwefelsaure Maunesia.

In der einen Versuchsreihe benutzte ich eine Lösung (ler Salze von 0,5 Proz., in einer zweiten eine solche von I Proz. Stets wurden Ioo ccm Lösung genommen in mäßiog hohen Gläsern, so daß die Oberfläche der Flüssigkeit ca. 24 ( $\mathrm{cm}$ betru@r. Mit einer ausgeglühten Nadel wurden ron einer Reinkultur einige wenige Fäden von Hormidium in lie Lösungen geimpft. Ein besonderer Zusatz von Eisen wurde nicht gemacht; von der jedesmal neu ausgeglühten Stahlnadel lösten sich kleine Partikelchen los, die neben (len Spuren aus den Glasgefäßen genügten, wie meine früheren Erfahrungen zeigten. Die Kulturgläser, sorg- 
fältig bedeckt, standen am Südfenster, da die Versuche im Winter I894/95 angestellt wurden.

Nach 4 Wochen waren auffallende Unterschiede bei den einzelnen Kulturen bemerkbar. In denjenigen ohne Stickstoff, Phosphor, Magnesium hatte die Alge ein sehr geringes Wachstum gehabt. Hier und da waren auf der Oberfläche kleine, mattgrüne Fleckchen; ein anderer Teil der Alge befand sich auf dem Boden. Die Fäden waren in Spaltung begriffen, die Zellen waren zum Teil pathologisch verändert.

In den Kulturen ohne Kalium, Schwefel, Calcium fand, wie in der normalen Nährlösung, lebhaftes Wachstum statt; es entstand eine seidenglänzende, grüne Haut. In der schwefelfreien Lösung waren aber die Fäden kurz und bereits in Spaltung begriffen.

Die Versuche bewiesen zunächst nur, daß die Alge eine Zeit lang lebhaft und normal wuchs, wenn Schwefel, Kalium, Calcium nur in sehr geringen Mengen vorhanden waren, die aus dem Impfmaterial, den Verunreinigungen der Salze oder von der Glassubstanz herrühren konnten. Ich impfte jetzt von diesen Kulturen die Alge in neue schwefel-, calcium-, kaliumfreie Lösungen. In diesen fand nur äußerst geringes Wachstum statt, es trat Zerfall ein, und besonders auffallend war es, daß die Zellen in der calciumfreien Lösung schnell abstarben. Für ein längeres, gedeihliches Wachstum reichten die Spuren von Kalium, Schwefel, Calcium nicht aus.

Nach dem Erscheinen der Arbeit von Molisch habe ich mit den drei genannten Elementen eine neue Reihe von Versuchen angestellt. Ich bereitete mir dieses Mal Lösungen von 0,2 und 0,5 Proz. und impfte sie mit Fäden einer gesunden Reinkultur. In den kalium- oder schwefelfreien Lösungen war nach 4 Wochen eine glänzend grüne Decke gebildet, die aus normalen Fäden 
gelbildet war. In den calciumfreien Lïsungen war das VIachstum von vornherein schlechter, hesonders in der I.jsung von 0,2 Proz., wo die Zellen lereits verlogen und zum Teil abgestorben waren, während in der Liisung rom 0,5 l'roz. die Obertläche sich mit einer Alyenlatut leeleckt liatte, in der aber die Fäden in Spaltumg, und viele Zellen in Absterben begriffen waren. Von den lrej o,5-proz. Lisungen wurden die Algen in entsprechende, neue Lösungen geimpft. Die Algen zeigten alser in diesen kein rechtes Wachstum mehr; in der calciumfreien starben sie gleich ab, später auch in ler kalium- und schwefelfreien.

Nach diesen Untersuchungen verhält sich Hormiclium nitens wie eine höhere Pflanze; sie lraucht wie diese lie wleichen Elemente in Form von Salzen notwendig zn ihrem I)asein. Man kann diese in zwei Gruplen sondern; die eine umfaßt die Elemente Stickstoff, Phosphor, Magnesimm, welche stets in reichlicher Menge vorhanden sein müssen. Die zweite Gruppe enthält Kalium, Schwefel, Eiken, Calcium, die nur in selır geringen Mengen gelraucht werden. Der Mangel des Calciums macht sich, ähnlich wie nach den Beobachtungen Schimper's (0O S. 248) bei höheren Pflanzen, daran bemerklich, daß3 die \%ellen, wie infolge eines Giftes, wahrscheinlich der ()xalsäure resp. deren sauren Salze, absterben, während sie l,ei allmählich eintretendem Mangel an den übrigen lilementen sich länger lebend erhalten könmen. Die Beolsachtung von Molisch, daß Mikrothamnium ohne Kalk gerleihen kann, betrifft bis jetzt nur einen Einzelfall; (lie Melızahl der grünen Algen wird möglicherweise: wie $H$. nitens sich verhalten.

Für das Stattfinden des Spaltungrsprozesses wird der Mangel an den Elementen der ersten Gruppe hauptsächlich malbgebend sein, da in lem Wasser bei Anwendung 
von Glasgefäßen Spuren von den Elementen der zweiten Gruppe wohl stets vorhanden sind. Daher ist es auch verständlich, wie in den verdünnten Nährlösungen nach lebhaftem Wachstum und dem damit verbundenen Verbrauch der Nitrate und Phosphate Spaltung eintritt. Es könnte sein, daß in einer Nährsalzkultur an einer kleinen Stelle ein solcher Mangel zeitweilig sich bemerkbar machte, oder daß gewisse Zellen aus anderen Gründen an der Aufnahme der Salze momentan gehindert wären. Daraus könnte sich die Spaltung einzelner Zellen in einer an und für sich normalen Nährlösung erklären.

Die Spaltung kann auch bei Gegenwart von Nährsalzen erfolgen, wenn ein Mangel an Feuchtigkeit eintritt. Unter solchen Umständen haben Gay (9I S. 6I) und Borzi bei Hormidium-Arten den Prozeß beobachtet. Infolge der Trockenheit hört zuerst die Teilung auf, dann allmählich auch das Wachstum, während die Assimilation fortgeht; wir haben dann die gleichen Gründe, die die Spaltung bei Mangel an Nährsalzen herbeiführen. Hat man eine kräftig gewachsene Lehmkultur, und wird die Luft und der Boden allmählich trockener, so werden zuerst die Fäden an der äußersten Oberfläche der Algenschicht davon betroffen, wobei auch eine mangelhafte Zufuhr von Nährsalzen mitwirken kann. Die Fäden in den tieferen Schichten können noch ruhig; weiter wachsen. In solchen Kulturen beobachtet man daher lange Zeit alle Stadien der Fadenbildung bis zur Spaltung in einzelne Zellen. Schließlich zerfallen alle Fäden. Bei schnellem Trocknen der Kultur dagegen koinmt es nicht zu einem so vollständigen Zerfall; die Fäden und Fadenstücke erhalten sich in dem Zustande, in welchem sie von dem Wassermangel überrascht worden sind.

K\ e b s, Fortpflanzungsphysiologie. 
Borzi (95 S. 369) griebt weiter an, daß H. flaccidum auf Gelatine in den Stichococcus-Zustand übergehe, d. h. sich spalte. Sehr wahrscheinlich spielt die Gelatine als solche keine besondere Rolle, der Zerfall tritt ein wegen Mangels an Nährsalzen oder an Feuchtigkeit. Kultiviert man H. nitens auf reinem Agar-Agar, so erfolgt sehr bald die Spaltung; gebraucht man Agar-Agar mit einer Nährlösung von I Proz., so wachsen die Fäden monatelang und überziehen die Fläche. Organische Substanzen, die nach Borzi bei Gloeotila mucosa merkwürdige Formveränderungen herbeiführen sollen, üben auf $\mathrm{H}$. nitens keine besonderen Wirkungen aus. In Zuckerlösungen wachsen die Fäden anfangs, bis Mangel an Nährsalzen eintritt, der die Spaltung hervorruft. Ich habe mancherlei Substanzen geprüft und nur einmal ein abweichendes Verhalten der Alge beobachtet. Als ich Fäden in Congorot kultivierte, sah ich ein Anschwellen der Zellen, so daß rosenkranzartige Fäden entstanden (Taf. II, Fig. 27), deren Zellen durch Wände in verschiedenen Richtungen geteilt waren. Ich erkläre mir die Erscheinung durch den eigentümlichen Einfluß des Congorots. Dieser Farbstoff färbt die Zellwände lebender Zellen und übt, wie ich gezeigt habe (K lebs 88 S. 523), vielfach einen hemmenden Einfluß auf das Längenwachstum der Membranen aus. Die Zellen von H. nitens vermögen in ihrem Wachstumsstreben nur kugelig anzuschwellen, sich aber nicht in die Länge zu strecken. Die weitere Folge dieser Kugelform ist, daß bei der anfangs nicht gehemmten Teilungsfähigkeit die neuen Wände sich an die alte Zellhaut, gemäß dem Prinzip der kleinsten Fläche, ansetzen und den Kugelinhalt zerteilen, unabhängig von (ler Längsrichtung des Fadens ${ }^{1}$ ).

I) Möglicherweise sind es ähnliche Verhältnisse, die bei Uhothrix zonata gleiches hervorufen. Kïtzing hat an normalen Fäden 


\section{Die Zoosporenbildung.}

Hormidium nitens ist im Stande, zweiwimperige Zoosporen zu erzeugen, ich will aber hier nicht näher darauf eingehen, sondern diese Fortpflanzungsweise bei H. flaccidum besprechen, bei welcher Art die Zoosporenbildung ganz entsprechend vor sich geht. Auch auf die physiologischen Bedingungen kann ich nicht eintreten, weil sie mir nicht bekannt sind. Obwohl H. nitens seit mehreren Jahren ununterbrochen von mir in Kultur gehalten wird, ist es mir nicht gelungen, die Bedingungen der Zoosporenbildung zu erkennen; ich habe alle Methoden angewandt, die ich durch das Studium der anderen Algen kennen gelernt hatte. Aber die Resultate waren im höchsten Grade unsicher; ich war auf den reinen ZufalI angewiesen. In der überwiegenden Mehrzahl der Fälle trat keine Zoosporenbildung ein; hier und da beim Uebergang aus Nährlösung in Wasser, im Dunkeln zeigte sie sich, und ich sah manchmal, wie der größte Teil der Zellen zur Zoosporenbildung überging. So bemerkte ich sie z. B. an Fäden, die ich aus der schwefelfreien Nährlösung von 0,2 Proz. in Wasser und ins Dunkele brachte. Unstreitig hat die Zoosporenbildung für $\mathrm{H}$. nitens geringe Bedeutung; der Spaltungsprozeß hat sie bei ihm verdrängt, so daß sie nur unter besonderen Verhältnissen noch herbeigeführt werden kann. Wahrscheinlich hat Gay deshalb bei H. flaccidum die Zoosporen nicht beobachtet, weil er statt dieser Art nitens untersucht hat;

einzelne, kugelförmige Anschwellungen beobachtet, die durch Teilung in verschiedener Richtung zu kleinen Zellkörpern werden. Näheres über die Bedeutung und die Ursachen dieser Erscheinung ist mir nicht bekannt. 
er hält beide Arten für identisch, was sie nicht sincl. Bei dem echten $H$. flaccidum kann man die Zoosporenbildung niclıt übersehen.

\section{Die Bildung von Dauerzellen.}

Schon Gay (9I S. 6I) hat auf die Fähigkeit der Hormidium-Fäden, Trockenheit zu ertragen, aufmerksam gremacht. Sie unterscheiden sich in dieser Beziehung von der Mehrzahl der im Wasser lebenden Fadenalgen, die nur mit Hilfe besonderer Dauerzellen völlige Trockenheit aushalten können; nur manche im Wasser lebende Conferva-Arten verhalten sich wie Hormidium. Wenn man Fäden von H. nitens aus Nährlösung, wo sie lebhaft vegetiert haben, in Wasser bringt und gleich eintrocknen läßt, so bleiben die Fäden unverändert; nach neuer Wasserzufuhr leben sie weiter. Am besten ist es aber, wenn man die Fäden langsam eintrocknen läßt; dann erfolgt die Spaltung in einzelne Zellen. Diese selbst füllen sich mit Stärke und fettem Oel, erhalten eine etwas derbere Nembran und stellen nun Dauerzellen dar. Sie künnen nach völliger Trockenheit zu Staubteilchen werden, die durch die Luftbewegungen fortgeführt werden; sie spielen in dem Lebensgang von Hormidium eine wichtige Rolle, da sie die Art verbreiten. Solche kleine Dauerzellen befanden sich in ler Luft meines Laboratoriums; ließ ich eine sterilisierte Nährlösungr etwas offen stehen, so trat regrelmäßig neben Protococcoideen H. nitens auf. 


\title{
Hormidium flaceidum (Kg.) Braun.
}

\author{
(Taf. II, Fig. 21-24.)
}

H. flaccidum ist eine der gemeinsten Algen auf feuchtem Erdboden, an Baumrinden u. s. w. Sie ist auch heutzutage noch nicht scharf in ihren Charakteren erkannt, weil es eine ganze Reihe morphologisch ihr nahestehender Formen giebt, die in ihrem Verhältnis zu flaccidum nicht erforscht sind. Mir liegt es ferne, eine Monographie der Gattung Hormidium zu liefern, die dringend notwendig wäre, aber nur mit Hilfe von Reinkulturen und mit Berücksichtigung der physiologischen Charaktere sich machen ließe. Mir kommt es hier nur darauf an, einige Punkte in der Lebensgeschichte von flaccidum zu berühren und den Unterschied von nitens hervorzuheben.

Die Fäden und Zellen von $\mathrm{H}$. flaccidum sehen im allgemeinen wie diejenigen von nitens aus (Tafel II, Fig. 22); ich bemerkte bereits, daß ich nicht im Stande bin, sicher an einem einzelnen Faden die Species zu erkennen. Die Zellen von flaccidum sind durchschnittlich etwas länger gestreckt; ihr Durchmesser beträgt $6,5-8 \mu$. Der Zellinhalt scheint genau so beschaffen zu sein, wie bei nitens. Der am meisten charakteristische Unterschied zeigt sich, wenn man flaccidum in Nährsalzlösung kultiviert. Es erzeugt niemals die seidenartig glänzende Haut in der äußersten Oberflächenschicht der Flüssigkeit, sondern die Fäden bilden, in lockeren Windungen und Krümmungen durch einander geflochten, eine in der Flüssigkeit nahe der Oberfläche völlig untergetauchte, grüne Masse.

Die Alge pflanzt sich wie nitens durch Spaltung, durch Bildung von Zoosporen und Dauerzellen fort. In Bezug auf den Spaltungsprozeß und die Dauerzellen ver- 
weise ich auf die Bemerkungen bei nitens, da beide Arten sich im allgemeinen gleich verhalten; auf die feineren Unterschiede, die vielleicht auch hierbei existiren, habe ich nicht geachtet. Eingehender will ich die Zoosporenbildung behandeln. Der erste, welcher Zoosporen bei einer Hormidium-Art beobachtete, war Sorokine (74 S. Iyo-I92), der aber die falsche Angabe macht, daß die Zoosporen einen Wimpernkranz luesäßen. Später hat Borzi (95 S. 362) die Zoosporen bei H. flaccidum als zweiwimperig erkannt, wenn er auch ihre charakteristische Gestalt übersehen hat ${ }^{1}$ ).

Wenn die Fäden zur Zoosporenbildungschreiten, so erfolgt kurz vorher lebhafte Teilung. Während die vegetativen Zellen meistens $2-3 \mathrm{mal}$ so lang als breit sind, erscheinen die zoosporenbildenden so lang wie breit. Bei H. nitens konnte ich diese lebhafte Teilung nicht in dem gleichen Grade beobachten. Durch einen Verjüngrungsprozeß entsteht aus jeder Zelle eine einzige Zoospore. Sie tritt durch ein enges, seitliches Loch der Zellwand heraus (Taf. II, Fig. 2 I) ; zuerst stülpt sie die Zellwand papillenartig hervor und drängt sich dann ganz langsam heraus. Die Zoosporen (Fig. 23) sind nicht radiär wie bei vielen anderen Algen, sondern dorsiventral gebaut; sie lassen eine gewölbte Rückenseite und eine gerade Bauchtläche unterscheiden, die vielleicht in Wirklichkeit etwas kielartig zugeschärft ist. Das farblose Vorderende ist etwas schief abgestutzt und trägt 2 Wimpern, die lem Anschein nach

1) In seiner ersten Arbeit, in der Borzi über H. flaccidum schreibt ( $90 \mathrm{~S} .404$ ), berichtet er, daß die Zoosporen zu 4-I6 innerhalb einer Zelle entstehen. Jeilenfalls hat hier Borzi eine Uhothrix zonata oder dergl. untersucht und das echte H. Haccidum njeht schabt. In ler Arbeit von 1895 scheint er dagegen die richtige Species mit ciner einzjgen Zoospore in jeter Zelle beobachtet zu haben. 
nicht aus einem Punkte, sondern neben einander entspringen. Im vorderen Ende liegen 2 pulsierende Vacuolen; der Augenfleck fehlt. Der Chromatophor liegt an der Rückenseite, während die Bauchseite farblos erscheint. Sehr charakteristisch ist auch die Art der Bewegung, in der sich die Zoosporen sowohl von solchen der Ulothrix wie der Conferva unterscheiden. Die Bewegung erinnert an das Schwimmen gewisser Bodo-Arten (Klebs 92 S. 312). Die Zoospore wackelt abwechselnd nach rechts und links, ohne daß eine regelmäßige Rotation damit verbunden ist, wenn auch eine solche von Zeit zu Zeit stattfinden kann. Gewöhnlich liegt die Zoospore auf der Bauchseite und pendelt mit der Rückenfläche hin und her. Schon bei schwacher Vergrösserung kann man daran die Zoosporen von $\mathrm{H}$. flaccidum und nitens erkennen.

Nach einiger Zeit der Bewegung kommt die Zoospore zur Ruhe (Taf. II, Fig. 24) und bildet eine kleine, ovale Zelle, die bei Gegenwart von Nährsalzen sofort zu einem Faden heranwachsen kann; ein Rhizoid wird nicht ausgebildet. Es existiert bei Hormidium überhaupt nicht der Gegensatz von Spitze und Basis wie bei Ulothrix zonata.

Im Sommer I895, wo ich mich hauptsächlich mit der Alge beschäftigte, erhielt ich sehr leicht die Zoosporen, wenn ich Fäden aus der Nährlösung in Wasser brachte und verdunkelte. Ferner entstehen die Zoosporen beim Uebergang aus feuchter Luft in Wasser; ich benutzte hierbei die Kulturen auf feuchtem Lehm. In diesem Falle ist Verdunkelung nicht nötig, die Zoosporen entstehen ebenso im Licht wie im Dunkeln, wenn auch sehr helles Licht ähnlich wie bei Protosiphon bis zu einem gewissen Grade hemmend wirken kann. Bei frischen Nährsalzkulturen kann andererseits der Uebergang aus Licht in Dunkelheit genügen, um ohne Wechsel des Mediums den 
Prozeß hervorzurufen. Im ganzen benimmt sich H. flaccidum gegenüber dem Einfluß der äußeren Bedingungen wie Protosiphon und namentlich wie die später zu behandehnde Bumilleria. Die obere Temperaturgrenze für die Zoosporenbildung liegt bei $26^{\circ}$; die untere ist nicht näher liestimmt worden. Die obere Temperaturgrenze für das Leben der Alge liegt ungrefähr bei $4 \mathbf{I}-42^{\circ}$. Wenn die Alge, aus Nährlösung in Wasser gebracht, einer Temperatur über $26^{\circ}$ ausgesetzt wird, so verliert sie die Fähigkeit der Zoosporenbildung nicht. Wird sie nach $1-2$ Tagen wieder in Zimmertemperatur übergeführt, so erfolgt gewöhnlich der Prozeß in normaler Weise. Während die Zoosporenbildung in einer Nährlösung von i Proz., ebenso in einer Rohrzuckerlösung von 10 Proz. stattfinden kann, wirlit schon eine Salpeterlösung von 0,2 Proz. in hohem Grade hemmend ein, so daß sich kaum merkbare Anfänge des Prozesses zeigen. Wenn die Fäden aus einer Salpeterlösung von 0,2 oder 0,5 Proz. in Wasser gebracht werden, so tritt eine lebhafte Zoosporenbildung ein. In den eben genannten Lösungen von Nährsalzen ( fertig ausgebildet, liei der letzteren Substanz reichlicher als bei der ersteren; die Mehrzahl der gebildeten Zoosporen vermag aber nicht auszutreten.

Wie bei allen bisher besprochenen Algen können auch bei $\mathrm{H}$. flaccidum die Versuche nach den erwähnten Methoden, die sonst Zoosporenbildung veranlassen, ohne Erfolg sein. Ich will hier aber nicht auf die Umstände eingehen, welche bei solchen negativ ausfallenden Versuchen mitwirken. Bei den physiologisch sich ähnlich verhaltenden Bumilleria-Arten habe ich mich ausführlicher mit der Frage leschäftigt. Höchst wahrscheinlich kommen die clort nähıer erwähnten Verhältnisse auch für Hormidium 
flaccidum in Betracht; den genauen Nachweis mögen spätere Untersuchungen bringen.

Meine Beobachtungen an den Reinkulturen von H. nitens und flaccidum beweisen, daß diese Arten gar nicht so variabel sind, wie Hansgirg (88), Borzi $(90,95)$ u. a. angenommen haben; vergl. auch Gay (9I l. c.), der zu dem gleichen Resultat wie ich gekommen ist. Beide Arten erhalten sich in den Kulturen auch unter ganz verschiedenen Bedingungen sehr konstant. Es ist möglich, daß unter besonderen Bedingungen eine größere Veränderlichkeit der Arten existiert. Aber das wäre erst auf wissenschaftlichem, einwurfsfreiem Wege nachzuweisen. Dagegen giebt es neben den genannten Arten noch zahlreiche anclere, nah verwandte Formen, die bei flüchtiger Untersuchung oder bei unbrauchbarem Herbarmaterial teils identisch, teils wenig verschieden scheinen, die aber doch bei genauerer Prüfung sich als selbständige Arten oder Varietäten herausstellen werden. Ich habe selbst melırere solcher Hormidium-Arten in Kultur genommen und mich überzeugt, daß sie durch kleine, aber konstante morphologische und physiologische Unterschiede charakterisiert sind. Als gänzlich unbegründet und höchst zweifelhaft (S. I74, I78) muß ich die Ansicht Borzi's zurückweisen, nach der der einzellige Organismus Raphidium in irgend einem Zusammenhang mit Hormidium stehe. 


\section{Conferva.}

(Taf. II, Fig. $1-S$. .)

Die Arten der Gattung Conferva gehören zu den rerbreitesten Süßwasseralgen, mit denen man sich jedoch nicht gern beschäftigt, weil sie so wenig charakteristische und auffallende Lebenserscheinungen darbieten. Ursprünglich die Mehrzahl der Fadenalgen einschließend, umfaßte die Gattung seit Link (1820) die unverzweigten, gleichmäßig grünen Fadenformen, bis Thuret (50 S. 22I) bei gewissen Arten eine Zoosporenbildung entcleckte, bei welcher der Faden in H-förmige Stücke zerfiel. Thuret gründete auf diesen Charakter die Gattung Microspora, welche dann durch K. Rosenvinge (79) und Wille (\$1 u. \$7) eingezogen wurde, weil auch Angehörige der Gattung Conferva den gleichen Charaliter aufwiesen. Wille beobachtete zuerst eingehend die verschiedenartige Bildung von Dauerzellen bei mehreren Arten der erweiterten Gattung Conferva. Erst Lagerheim (89) schied Conferva und Microspora schärfer von einander; er beschränkte auf die erstere Gattung diejenigen unverzweigten Fadenalgen, deren Zellen einzelne, scheibenfürmige Chromatophoren besitzen, deren Zoosporen nur mit einer Wimper versehen sind und sich bei der Keimung mit einer kleinen Haftscheibe festsetzen. Die Gattung Microspora besitzt bandförmige Chromatophoren und zweiwimperige Zoosporen, die keinen Haftapparat bilden. 
Die Beobachtungen von Lagerheim wurden von Gay (9I S. 3I) bestätigt, der Conferva bombycina und tenuissima genauer untersuchte und die Ansicht Borzi's (83 S. 58) mit Recht zurückwies, daß Conferva in den Entwickelungskreis von Rhizoclonium und Cladophora gehöre.

Die Unterscheidung der Arten innerhalb der Gattung ist wegen des Mangels an brauchbaren, einigermaßen konstanten Charakteren äußerst schwierig und unzuverlässig. In den algologischen Werken wird das Hauptgewicht auf die Dicke der Zellen und das Verhältnis von Länge und Breite gelegt. Die von mir eingehend untersuchte Alge gehört zu den schmäleren Formen; nach der freundlichen Mitteilung von Wille, dem ich eine Probe der Alge sandte, entspricht sie seiner Conferva bombycina $\beta$ minor. Ich möchte sie aber doch als eine selbständige Art auffassen und werde sie als Conferva minor bezeichnen. Die Alge hatte sich seit mehreren Jahren in meinem Aquarium angesiedelt, aus welchem sie eine Zeit lang entfernt wurde, bis ich im Herbst I 894 ihre Untersuchung begann. Sie wächst, wenn sie ungestört ist, fast das ganze Jahr hindurch; im Dezember I894 ging sie in ihrem Wachstum zurück, so daß ich einen Teil in eine Nährsalzlösung brachte, wo sich die Alge während des Winters erhielt. Im Frühjahr I895 wurde die Alge aus dieser Kultur wieder in das Aquarium versetzt, wo sie sich in lebhaftester Weise entwickelte. Im Dezember I 895 nahm das Wachstum deutlich ab, die Alge erhielt sich aber den ganzen Winter hindurch. Im Aquarium sitzen die feinen, flockigen Fadenmassen an den Wänden und am Boden, um bei üppiger Entwickelung den ganzen Behälter zu durchziehen.

Die Zellen der Fäden (Taf. II, Fig. I) haben unter normalen Verhältnissen einen Durchmesser von 5-5,5 ", 
sie sind $I^{1} / 2-4$ mal so lang als breit. Sie sind an den Querwänden sehr schwach eingeschnürt, in der Mitte oft katum merklich angeschwollen. Sobald Wachstum und Teilung gehemmt sind und eine Ansammlung organischer Stoffe stattfindet, erhalten die Zellen eine tonnenförmige Gestalt; die Einschnürung an den Querwänden wird dann sehr deutlich. Die Zellmembran läßt an den lebenden Fäden nichts Besonderes erkennen; sie luesitzt aber den für Conferva charakteristischen Bau, den Rosenvinge (79 l. c.), Wille (1. c.) und Berthold (86 S. 275) beschrieben haben: Man kann ihn am einfachsten nachweisen, wenn man die Fäden mit konzentrierter Schwefelsäure einen Augenblick behandelt, dann auswäscht und mit Methylenblau färbt. Dann erkennt man, daß der Faden aus einer Anzahl abwechselnd größßerer und kleinerer $\mathrm{H}$-förmiger Stücke besteht, die durch die Quellung auseinander getreten sind, von denen aber stets ein kleineres von zwei größeren schachtelartig umfaßt wird. Der Bau kommt daher, daß bei jeder Teilung einer Zelle ein nenes $\mathrm{H}$-förmiges Stück eingeschoben wird, so daß jede neue Zelle ein älteres und ein jüngeres Zellwandstïck besitzt. Der Zellinhalt der Conferva minor entspricht ebenfalls dem der anderen Arten (Lagerheim 1. c., Gay 1. c.). In jeder Zelle (Taf. II, Fig. I) finden sich 2-4 einzelne Chlorophyllkörper, I-2 Zellkerne und eine Anzahl fettartiger Tröpfchen; Stärke wird unter keinen Umständen gebildet.

Die \%oosporenbildung ist zuerst von A. Braun (49 S. 196), eingehender von Lagerheim ( 89 S. 197 etc.) beschrieben worden. Die Zoosporen entstehen in der Zelle einzeln oder zu zweien und treten dadurch heraus, daf infolge der Ouellung einer bei der Bildung ausgeschiedenen Sulstanz die beiden Hälften der Zellwand auseinander getrieben werden, so daß bei lebhafter Zoo- 
sporenbildung der Faden völlig in einzelne H-förmige Stücke zerfälltt (Taf. II, Fig. 2 u. 6). Die Zoosporen (Lg. 9-II $\mu$, Br. 4,5-5,5 $\mu$ ) sind umgekehrt eiförmig, meist etwas abgeflacht und unsymmetrisch, da das Vorderende schief abgestutzt erscheint (Fig. $7 a-c$ ). Die von L a g er h e im entdeckte, einzige Wimper scheint mir nicht, wie er beschreibt, an der Spitze des Vorderendes zu sitzen, sondern von einer kleinen Einkerbung des schiefen Endes auszugehen. Dicht unter dem Cilienansatz finden sich zwei kontraktile Vakuolen. Im vorderen Teile liegen an den flachen Seiten zwei Chlorophyllkörper, während das hintere, kegelförmig zugespitzte Ende farblos ist und Fetttröpfchen enthält. Es verändert übrigens seine Form, und besonders am Tropfenrande einer Kultur verhält sich die ganze Zoospore zeitweilig wie eine Amöbe. In der Art der Bewegung unterscheiden sich die Zoosporen der Conferva von anderen Algenschwärmern, z. B. von Ulothrix; sie bewegen sich relativ gleichmäßig, zeitweilig auf einer der breiteren Seiten liegend, ohne zu rotieren und erinnern an die Bewegung von Monas-Arten. Ein Augenfleck fehlt, wie schon A. Braun (49 S. 223) erkannt hat; Lichtempfindlichkeit ist vorhanden, wenn auch nicht in sehr hohem Grade.

Bei der Keimung soll nach Lagerheim die cilientragende Spitze zur Basis des Keimlings werden, da sie sich in einen kleinen Haftfortsatz verlängern soll. Bei Conferva minor verhält sich jedenfalls die Sache anders, wenn es auch schwierig genug ist, Klarheit zu gewinnen, da die Zoospore kurz vor dem Uebergang zur Ruhe ihre Form verändert, so daß man dann Vorder- und Hinterende kaum mehr unterscheiden kann. Indessen gelanges mir doch, in einer ganzen Anzahl von Fällen den Uebergang genau zu verfolgen. In dem Augenblick, wo die auf der Stelle zitternde Bewegung aufhört, nimmt 
die Zoospore eine unregelmäßige Gestalt an (Taf. II, Fıg. $\&(a-d)$; dann streckt sie sich plötzlich in die Länge und sendet am Hinterende einen Plasmafortsatz aus, der zum Haftapparat wird, während eine der Chlorophyllplatten das Vorderende einnimmt. Die pulsierenden Takuolen verändern ihren Platz nicht wesentlich, und zeigen deutlich an, daß das cilientragende Fnde der Zonspore zu der Spitze des künftigen Fadens wird. In einigen Fällen sah ich sicher, wie die Cilie langsam eingezogen wurde.

Die Bedingungen der Zoosporenbildung sind bisher nicht erforscht worden. A Braun (49 S. I96) hebt als auffallend hervor, daß bei der so überaus gemeinen Conferva bombycina die Zoosporenbildung nur selten zu beobachten ist, und in der That habe ich selbst früher ähnliche Erfahrungen gemacht. Zunächst war es daher meine Aufgabe, eine Methode zu finden, mit Hilfe derer der Prozeß regelmäßig veranlafst werden kann. Das sonst so brauchbare Mittel, die Alge durch die Kultur in Nährlösung und den Uebergang in Wasser zur Fortpflanzung zu bringen, versagte. Die Conferva erhält sich sehr gut in Nährlösungen, wächst auch in diesen; aber die Fäden, in Wasser übergeführt, erzeugen wenige oder keine Zoosporen. Ebensowenig wirkt der Uebergang aus feuchter Luft in Wasser erregend.

Schließlich fand ich, daß Verdunkelung in Verbindung mit gewissen organischen Substanzen lebhafteste Zoosporenbildung hervorruft. Das Gelingen des Versuches hängt von dem Zustande der Alge und der chemischen Natur der organischen Substanzen ab. Die Alge kann leicht durch äußere Bedingungen ihre Reizbarkeit verlieren; die verschiedenen, organischen Substanzen erfordern für ilıre Wirkung bald in geringerem, bald in höherem Grade reizbare Zellen. Im allgemeinen 
befindet sich die Alge in einem relativ hohen Grade der Reizbarkeit, solange sie in dem Aquarium mit stets sich erneuerndem, frischem Wasser wächst. Ihre Reizbarkeit ist am höchsten während der Sommermonate, am geringsten während der trüben Zeit des Novembers und Dezembers, wenn es auch selbst dann bei Anwendung der geeigneten, organischen Substanz gelingt, lebhafte Zoosporenbildung zu veranlassen.

\section{Der Einfluß der organischen Substanzen.}

Bei der Untersuchung verschiedener Algen, wie Vaucheria und Hydrodictyon, haben organische Stoffe, besonders einige Kohlehydrate, wertvolle Dienste geleistet. Rohrzucker und Maltose sind im Stande, fördernd auf Fortpflanzungsprozesse einzuwirken. Aber ihre Wirkung hielt sich doch innerhalb enger Grenzen und konnte stets auch auf anderem Wege erreicht werden. Conferva dagegen ist ein ausgezeichnetes Beispiel für den Nachweis einer specifischen Wirkung organischer Substanzen auf die Fortpflanzung, so daß es geeignet erscheint, gerade die Beziehungen von Conferva zu ihnen eingehender zu untersuchen.

Die Versuche, von denen zunächst die Rede sein wird, sind ausschließlich im Dunkeln ausgeführt worden, so daß die Bildung organischer Substanzen durch die Kohlensäure-Assimilation nicht in Betracht kam. Wie wir später sehen werden, ist der Ausschluß des Lichtes für das Gelingen der Versuche unbedingt notwendig. Bringt man Conferva aus dem Aquarium in ein kleines Gefäß mit Wasser, ins Dunkle, so kann entweder in den nächsten Tagen infolge des Lichtmangels Zoosporenbildung erfolgen, was immer auf einen hohen Grad der Reizbarkeit hindeutet, oder die Alge bleibt unverändert. Auch 
im ersteren Falle hört nach wenigen Tagen die Zoosporenbildung auf; in beiden Fällen ist das Material für weitere Versuche im Dunkeln geeignet, wobei statt Wasser verschiedenartige, organische Substanzen in wässeriger Lösung angewendet werden können. Meine Untersuchungen erstrecken sich auf eine ziemliche Anzahl solcher Körper, die ich nach der Wirkung auf die Alge in vier Gruppen verteilen will.

Die Gruppe I umfaßt diejenigen Substanzen, welche Zoosporenbildung erregen bei Fäden, die im Wasser durch Verdunkelung nicht dazu veranlaßt werden können, und ebenso bei Fäden, die im Wasser im Dunkeln zuerst einzelne Zoosporen erzeugt, dann aber mit der Bildung aufgehört haben. Es sind dieselben Substanzen, welche die Zoosporenbildung in denkbar höchstem Grade erregen können, so daß nach $24-48$ Stunden die ganze Fadenmasse zerfällt und aufgelöst wird.

Die Gruppe II umschließt diejenigen organischen Substanzen, die ähnlich wie Wasser wirken, in denen beim Uebergang aus Licht in Dunkelheit die Zoosporenbildung bald mehr, bald weniger stark eintreten kann. Der höchste Grad des Prozesses wurde weder in Wasser, noch in den Substanzen der Gruppe II bisher beobachtet. Hat im Dunkeln der Prozeß einmal aufgehört, so vermögen die betreffenden Substanzen ihn nicht wieder zu erregen.

Die Gruppe III enthält diejenigen organischen Substanzen, in denen die Zoosporenbildung auch dann nicht stattfindet, wenn sie noch im Wasser erfolgt. Sie wirken hemmend auf den Prozeß ein, ohne zunächst oder für längere Zeit das Leben der Alge zu schädigen.

1)ie Gruppe IV umschließst diejenigen organischen sulsstanzen, die von vornherein der Alge schädlich sind; die Liste könnte natürlich beliebig erweitert werden. 


\section{Gruppe I.}

$\begin{array}{ll}\text { Inulin } & \mathrm{C}_{6} \mathrm{H}_{10} \mathrm{O}_{5} \\ \text { Amygdalin } & \mathrm{C}_{20} \mathrm{H}_{27} \mathrm{NO}_{11} \\ \text { Aesculin } & \mathrm{C}_{15} \mathrm{H}_{16} \mathrm{O}_{9} \\ \text { Salicin } & \mathrm{C}_{13} \mathrm{H}_{18} \mathrm{O}_{7} \\ \text { Maltose } & \mathrm{C}_{12} \mathrm{H}_{22} \mathrm{O}_{11} \\ \text { Raffinose } & \mathrm{C}_{15} \mathrm{H}_{32} \mathrm{O}_{16} \\ \text { Sorbit } & \mathrm{C}_{6} \mathrm{H}_{14} \mathrm{O}_{6}\end{array}$

Im Herbst 1894 habe ich ausschließlich Maltose zur Erregung der Zoosporenbildung benutzt; im Sommer I 895 fand ich, daß die Glykoside Aesculin und Salicin noch wirksamer sind. Im Herbst I895 wandte ich vorzugsweise Amygdalin an, und im Winter 1895 entdeckte ich, daß Inulin in überraschendster Weise als Reizmittel dienen kann. Der Reihenfolge, in der die Substanzen in der Tabelle aufgezählt sind, entspricht der Grad ihrer Wirksamkeit für die Veranlassung der Zoosporenbildung.

Inulin ist ein Kohlehydrat der Stärkegruppe, das in zahlreichen Compositen, Campanulaceen sich vorfindet. Es ist stets im Zellsaft gelöst und scheidet sich bei langsamer Einwirkung von Alkohol in Sphärokrystallen aus. An und für sich ist Inulin in kaltem Wasser nur in geringer Menge löslich, während es sich sehr leicht in heißem Wasser löst. Bereitete ich mir aus dem von Dr. Grübler-Leipzig bezogenen Präparat eine Lösung in kochendem Wasser, so schied sich nach dem Erkalten das Inulin gewöhnlich nicht aus; es entstand eine übersättigte Lösung, die sich oft viele Tage lang, selbst bei niederer Temperatur, erhielt. Für meine Versuche wandte ich stets solche übersättigten Lösungen an. Specielle Versuche zeigten, daß die Konzentration innerhalb weiter Grenzen von geringer Bedeutung ist. 
Selbst eine kalt gesättigte Lösung erregt Zoosporenbildung, wenn auch langsam und nicht so sicher, wie eine heiß bereitete Lösung ron I Proz.; andererseits wirkt sehr stark eine übersättigte Lösung von 5 Proz. Gewöhnlich nahm ich, ohne genau abzuwägen, eine Messerspitze voll Inulin in ca. $20 \mathrm{ccm}$ Wasser, was ungefähr einer Lösung von $1-2$ Proz. entspricht. Für jeden Versuch wurde die Lösung frisch bereitet.

Bei Temperaturen zwischen IO und $20^{\circ} \mathrm{C}$ traten in einer solchen Inulinlösung die ersten Zoosporen nach 24 Stunden auf; nach 48 Stunden war die Fadenmasse der Conferva völlig zerfallen infolge der lebhaftesten Bildung der Zoosporen. Eine Anzahl zeigte sich noch in den nächsten Tagen. Von Ende November bis Ende Dezember 1895 habe ich täglich die Versuche mit Inulin ausgeführt; sie hatten ausnahmslos das gleiche, positive Resultat. Da die Alge im Monat Dezember unter den ungünstigsten Lichtverhältnissen herangewachsen war und gegenüber anderen organischen Stoffen, wie Maltose, sich nicht sehr empfindlich verhielt, so darf man voraussetzen. daß auch zu allen anderen Zeiten des Jahres Inulin seine Wirksamkeit auf die im Açuarium lebende Alge ausülen würde. Dafür spricht auch, daß selbst lange Zeit in kleiner Wassermenge kultivierte, zum Teil in einen Ruhezustand übergegangene Conferven immerhin noch etwas durch Inulin zur Zoosporenbildung gebracht werden konnten. Es ist der einzige, mir bisher bekannte Fall, daßs eine bestimmte, chemische Substanz mit solcher Sicherheit einen bestimmten Fortptlanzungsprozeß veranlałst.

In sehr hohem Grade wirlssam sind auch die drei angeführten Glykoside, die deshall besonderes Interesse beanspruchen, weil zum ersten Male an ihnen gezeigt werden kann, dał diese im Pflanzenreich so verbreiteten 
Substanzen mit bisher unbekannter, physiologischer Bedeutung jedenfalls im Stande sind, bestimmte Wirkungen in der Zelle zu veranlassen. Das Glykosid der Roßkastanie, Aesculin, ist in kaltem Wasser wenig löslich; für den Versuch wirft man einfach eine Anzahl Krystalle in Wasser, wodurch eine schön blau fluorescierende Lösung von ca. O,I Proz. entsteht. Trotz der Verdünnung ist die Lösung äußerst wirksam, so daß bereits nach 24 Stunden bei $14-2 \mathrm{O}^{\circ}$ lebhafteste Zoosporenbildung der Conferva erfolgt. In der Aesculinlösung können die Conferva-Zellen mehrere Wochen hindurch in Dunkeln leben. Das Glykosid der Weide, Salicin, wurde in einer stets frisch bereiteten Lösung von 0,5 Proz. angewandt; fast ebenso wirksam ist noch eine Lösung von O,I Proz. Das bei Amygdalaceen, Pomaceen verbreitete Amygdalin wurde ebenfalls in einer Lösung von 0,5 Proz. benutzt; eine solche von 0,05 Proz. wirkt sehr schwach, deutlicher eine solche von O,I Proz. Im allgemeinen reagieren die überhaupt noch im Wachstum begriffenen Conferven leicht und sicher mit Zoosporenbildung bei Anwendung der genannten Glykoside. Aber es kann vorkommen, daß die Versuche negativ ausfallen, weil die Algen durch irgend welche äußeren Einflüsse, die sich im einzelnen schwer erkennen lassen, weniger reizbar geworden sind. So verloren z. B. die Fäden gegenüber Aesculin und Salicin ihre Reizbarkeit, als das Aquariumwasser während eines Tages durch Eisenoxyd verunreinigt worden war; erst nach 3-4 Tagen trat die Reizbarkeit wieder auf. Ebenso war diese geschwächt in den Monaten November, Dezember, und selbst mitten im Sommer konnte der Versuch für kurze Zeit nicht gelingen. Am meisten nähert sich das Amygdalin in seiner Wirksamkeit dem Inulin, so daß ersteres auch in den ungünstigen Monaten noch Zoosporenbildung veranlassen kann. 
Von den beiden Kohlehydraten der Rohrzuckergruppe, Maltose und Raffinose, wurde hauptsächlich Naltose zu zahlreichen Versuchen benutzt. Sie verlangt noch einen etwas höheren Grad der Reizbarkeit von Conferva, um bei ihr Zoosporenbildung hervorzurufen, als die Glykoside es thun. Besonders auffallend zeigte sich dies im Herbst I894, wo die Versuche im November ausnahmslos gelangen, während vom Dezember ab alle negativ ausfielen. Auch für Maltose suchte ich die Grenzen der Konzentration zu bestimmen, und ich kam zu dem gleichen Resultat wie beim Inulin. Gewöhnlich benutzte ich eine Lösung von I Proz.; wirksam ist aber noch eine solche von 25 Proz., in der dann die Bewegung der Zoosporen behindert ist; sie treten aus den aufplatzenden Zellen als unbewegliche Kugeln heraus. Raffinose (I Proz.), ebenso der sechswertige Alkohol Sorbit (I Proz.) wurden mehr beiläufig untersucht; ich stellte nur fest, daß sie in ähnlicher Weise wie Maltose wirken, daß sie noch im Stande sind, bei Fäden, die im Dunkeln, in Wasser keine Zoosporenbildung mehr zeigen, diese zu veranlassen.

Am besten wird der verschiedene Grad der Wirksamkeit der genannten Substanzen aus der folgenden Tabelle hervorgehen, in welcher ich einige Versuche specieller angeben will. Ich hatte 2 Conferva-Kulturen, die eine Zeit lang mit Wasser dunkel gestanden hatten; die Conferva $B$, seit 12 Tagen dunkel, hatte am Anfang vereinzelte Zoosporen gebildet und dann damit aufgehört; die Conferva A, seit 25 Tagen dunkel, war von vornherein indifferent geblieben. Von den Substanzen der Gruppe I, ebenso von einigen der Gruppe II wurden frische Lösungen bereitet; jede Lösung wurde in 2 Gläser verteilt, von denen das eine Conferva A, das andere Conferva B erhielt. Die Versuche wurden, wie immer, bei Lichtabschluß angestellt. In der Tabelle gebe ich die Resultate, 
wie sie nach 3 Tagen sich zeigten, da die darauf folgenden Tage an ihnen nichts änderten. Ich will drei Grade der Intensität unterscheiden. Entweder traten keine Zoosporen auf, oder viele, so daß auch an der Oberfläche eine ganze Anzahl von Keimlingen sich ansammelte, wobei aber doch viele Fäden ihren Zusammenhang bewahrten. Beim dritten und höchsten Grad wurden sehr viele Zoosporen gebildet, womit immer ein Zerfall der Fäden verbunden war.

Conferva minor.

Beginn des Versuches 9./XII. I895; Resultat am I2.|XII. I895

\begin{tabular}{|c|c|c|c|c|c|}
\hline & Organische Substanz & $\begin{array}{l}\text { Conf } \\
4 . / \mathrm{XI}\end{array}$ & $\begin{array}{l}\text { ferva } \text { A seit } \\
\text { I895 dunkel }\end{array}$ & \multicolumn{2}{|c|}{$\begin{array}{c}\text { Conferva B } \\
\text { seit } 27 \cdot / \text { XI I } 895 \text { dunkel }\end{array}$} \\
\hline I & Inulin,übersättigt,c. I Proz. & \multicolumn{2}{|c|}{ viele Zoosporen } & \multicolumn{2}{|c|}{ sehr viele Zoosporen } \\
\hline 2 & Amygdalin 0,5 Proz. & & " & " & " \\
\hline 3 & Aesculin, gesättigt & keine & " & " & ", \\
\hline 4 & Salicin 0,5 Proz. & $"$ & ", & " & $"$ \\
\hline 5 & Maltose I Proz. & " & $n$ & , & $"$ \\
\hline 6 & Raffinose I Proz. & $"$ & , & $"$ & . \\
\hline 7 & Sorbit I Proz. & $"$ & ", & 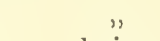 & $"$ \\
\hline 8 & Rohrzucker I Proz. & " & " & keine & " \\
\hline 9 & Milchzucker I Proz. & " & $"$ & $"$ & " \\
\hline 10 & Lichenin 0,5 Proz. & $"$ & ", & $"$ & ,. \\
\hline
\end{tabular}

Die Tabelle zeigt, daß die von vornherein indifferente, 25 Tage lang verdunkelte Conferva A nur durch Inulin und Amygdalin zur Zoosporenbildung veranlaßt werden konnte, wenn auch nicht der höchste Grad des Prozesses erreicht wurde. Dieser trat mit den beiden Substanzen be Conferva $\mathrm{B}$ ein, die sich ihnen gegenüber vollkommen wie frisch aus dem Aquarium genommene Fäden verhielt. Die Substanzen Aesculin, Salicin, Maltose, Raffinose, Sorbit vermochten nur bei Conferva B Zoosporenbildung hervorzurufen, aber nicht bis zum höchsten Grade, wie es durch diese Substanzen bei frischem Material möglich ist. Rohr-, Milchzucker und Lichenin waren wirkungslos. 
Wenn man nun untersucht, warum überhaupt die genannten sieben Sulsstanzen als Reizmittel wirken, so zeigen ihre chemischen Formeln, daß sie sehr verschiedenartig zusammengesetzt sind. Nur in einer Beziehung haben sie alle etwas Gemeinsames: sie lassen sich im Laboratorium leicht so umwandeln, daß Körper der GlykoseGruppe, die sog. Hexosen $\left(\mathrm{C}_{6} \mathrm{H}_{12} \mathrm{O}_{6}\right)$, entstehen. Bei der hydrolytischen Spaltung liefern Amygdalin, Aesculin, Salicin, Maltose den Traubenzucker, Inulin, Raffinose den Fruchtzucker. Sorbit liefert bei Oxydation ebenfalls Fruchtzucker. Es erscheint daher zunächst die Annahme berechtigt, daß die genannten Substanzen bei ihrem Eintritt in die Conferva-Zelle so umgewandelt würden, daß Hexosen entstünden, die dann in specifischer Weise den Prozeß der Zoosporenbildung erregten. Bieser Annahme widerspricht aber die Thatsache, daß die Hexosen, wenn sie den Zellen direkt von Außen geboten werden, in anderer Weise auf die Conferva-Zellen wirken, wie die nähere Betrachtung der Gruppe II darlegen wird.

$$
\text { Gruppe II. }
$$

$\begin{array}{llc}\text { Erythrit } & \mathrm{C}_{4} \mathrm{H}_{10} \mathrm{O}_{4} & \text { I Proz. } \\ \text { Arabinose } & \mathrm{C}_{5} \mathrm{H}_{10} \mathrm{O}_{5} & - \\ \text { Mannit } & \mathrm{C}_{6} \mathrm{H}_{14} \mathrm{O}_{6} & - \\ \text { Dulcit } & \mathrm{C}_{6} \mathrm{H}_{14} \mathrm{O}_{6} & - \\ \text { Traubenzucker } & \mathrm{C}_{6} \mathrm{H}_{12} \mathrm{O}_{6} & \mathrm{I}-2 \text { Proz. } \\ \text { Fruchtzucker } & \mathrm{C}_{6} \mathrm{H}_{12} \mathrm{O}_{6} & - \\ \text { Rohrzucker } & \mathrm{C}_{12} \mathrm{H}_{22} \mathrm{O}_{11} & \text { I-IO Proz. } \\ \text { Milchzucker } & \mathrm{C}_{12} \mathrm{H}_{22} \mathrm{O}_{11} & \text { I Proz. } \\ \text { Dextrin } & \mathrm{C}_{6} \mathrm{H}_{10} \mathrm{O}_{5} & - \\ \text { Lichenin } & \mathrm{C}_{6} \mathrm{H}_{10} \mathrm{O}_{5} & -\end{array}$

Die Substanzen sind nach ihrer Stellung im System der organischen Körper angeordnet, nicht nach ihrer 
Wirksamkeit bei der Zoosporenbildung von Conferva. Denn da eine genaue Zählung der Zoosporen schwer durchführbar war, die Menge dieser auch sehr von der stets etwas wechselnden Beschaffenheit der Versuchsfäden abhing, so ließ sich die Wirksamkeit der einzelnen Substanzen nicht genau abschätzen. Allen Substanzen dieser Gruppe ist gemeinsam, daß sie die Zoosporenbildung wesentlich nur erregen beim Uebergang aus Licht in Dunkelheit, daß sie meistens unwirksam sind, wenn die Conferva einige Zeit im Dunkeln gelebt hat. Die Substanzen verhalten sich im allgemeinen wie das Wasser. Unterschiede in dem Grade ihrer Wirkung treten allerdings auf; so bemerkte ich besonders bei Erythrit und Milchzucker, daß sie Zoosporenbildung veranlaßten bei Fäden, die im Wasser nach Verdunkelung nichts davon aufwiesen. Diese Körper bilden den Uebergang zu der Gruppe I, besonders zu ihren etwas schwächer wirkenden Gliedern Raffinose und Sorbit. Alle Substanzen der Gruppe II beanspruchen eine erhöhte Reizbarkeit der Algen, die nur bei sehr günstigen Wachstumsbedingungen erlangt wird, und oft durch sehr geringe, nicht erkennbare Veränderungen vernichtet werden kann. Daher kann man sich nicht auf diese Substanzen verlassen, wenn man sicher Zoosporenbildung veranlassen will. Bisher habe ich nie, selbst bei hoher Reizbarkeit der Alge, mit Hilfe dieser Substanzen den höchsten Grad der Zoosporenbildung hervorgerufen. Aber es wäre sehr wohl denkbar, daß es noch günstigere, äußere Bedingungen gäbe, als ich sie in der Kultur im Aquarium herstellen konnte, wobei so reizbare Fäden entstïnden, daß sie in Wasser und in den Substanzen der Gruppe II infolge Zoosporenbildung völlig aufgelöst würden.

Eine besondere Besprechung verdienen die Hexosen: Trauben- und Fruchtzucker. Die Erfahrungen lehren, 
daß Lösungen von I-2 Proz. die Zoosporenbildung mehr hemmen als fördern. Denn selbst bei hoher Reizbarkeit der Conferven treten in den Lösungen dieser Substanzen verhältnismäßig wenige Zoosporen auf; besonders bei Anwendung von Invertzucker ( $1-2$ Proz.) war ihre Zahl gering. Diese Zuckerarten rufen aber eine andere sehr auffallende Reaktion hervor; die Confervazelle füllt sich in den Lösungen schnell mit einer flüssigen, etwas lichtbrechenden Substanz an, die bereits nach 48 Stunden in solcher Menge aufgespeichert sein kann, daß die ganzen Fäden weiß erscheinen, wobei zugleich die Zellen tonnenförmig anschwellen. Die Substanz erfüllt entweder gleichmäßig den ganzen Zellsaft oder tritt in gesonderten Tropfen auf. Diese Reaktion ist deshalb besonders bemerkenswert, weil sie, ganz im Gegensatz zur Zoosporenbildung, überhaupt immer eintritt, so lange noch Leben in den Conferva-Zellen herrscht. Sie tritt ein bei $0^{0}$ wie bei $35^{\circ}$, ebenso bei einem Luftdruck von $10 \mathrm{~mm}$, sie zeigt sich im Licht wie im Dunkeln, in jedem Alter und Zustand der Zellen. Wir haben es hier mit einer unmittelbaren Wirkung bestimmter Substanzen, besonders von Kohlehydraten auf die Conferva-Zelle, zu thun. Von den anderen Körpern der Gruppe II wirkt eine Dextrinlösung (I Proz.) ebenso schnell und sicher (wahrscheinlich nur infolge des Gehaltes an Traubenzucker). Reiner Rohrzucker in frisch bereiteter Lösung veranlaßt zunächst keine Ansammlung der weißen Substanz; nach einigen Tagen erst beginnt diese in den Zellen zu erscheinen, während Rohrzuckerlösungen, die einige Zeit gestanden haben, sofort wirken. Jedenfalls muß der Rohrzucker invertiert werden, sei es indirekt durch Bakterien, Hefe oder vielleicht auch durch die lebende Zelle. Die anderen Körper, wie Milchzucker, Lichenin, die 4-6wertigen Alkohole bleiben stets unwirksam. Was den chemischen Charakter der weifen 
Substanz betrifft, so halte ich sie für Traubenzucker selbst oder eine nahe verwandte, reduzierende Zuckerart. Die Substanz tritt in flüssigen, konzentrierten Tropfen in den Zellen auf; nach Tötung der Zellen löst sie sich in Wasser auf. In Alkohol ist sie unlöslich; sie wird durch Jod nicht gefärbt. Erhitzt man Conferva-Zellen mit der weißen Substanz in Fehling'scher Lösung, sei es unter dem Deckglas, sei es im Reagenzröhrchen, so beobachtet man eine massenhafte Ansammlung von Kupferoxydul innerhalb der Zellen. Auch die gewöhnlichen ConfervaZellen zeigen diese Reaktion, aber lange nicht in solchem Grade.

Für die vorliegende Untersuchung ist besonders die Frage wichtig, wie sich die Körper der Gruppe I, die die Zoosporenbildung erregen, verhalten. Die Antwort lautet, daß keine der Substanzen unmittelbar die Bildung der weißen Substanz veranlaßt. Selbst nach wochenlangem Aufenthalt in Inulin, Amygdalin, Aesculin, Raffinose, Sorbit sah ich sie niemals in den Zellen erscheinen. Dagegen kann Maltose, wahrscheinlich infolge hydrolytischer Spaltung durch Bakterien, eine Ansammlung der weißen Substanz bewirken. Ferner konnte eine Salicinlösung, die mehrere Wochen im Dunkeln gestanden hatte und augenscheinlich in langsamer Zersetzung begriffen war, die Substanz in den Zellen hervorrufen. Diese alte Salicinlösung hatte aber die Fähigkeit, Zoosporenbildung zu erregen, verloren. Es macht den Eindruck, als schlössen sich die beiden physiologischen Reaktionen: Bildung von Zoosporen und der weißen reduzierenden Substanz, im großen und ganzen aus. Erst nach Abschluß der eigentlichen Untersuchung von Conferva entdeckte ich, daß konzentrierte Traubenzuckerlösungen anders wirken als verdünnte, während bei den Körpern der Gruppe I die Konzentration eine sehr geringe 
Rolle spielt. Als Conferven aus dem Aquarium in Traubenzuckerlösungen von 5 und Io Proz. ins Dunkle gebracht wurden, zeigten sie in der ersten Lösung keine, in der zweiten sehr zahlreiche Zoosporen. Doch mangelte diesen die Eigenbewegung; gleich nach dem Austritt waren sie unbewegliche Kugeln. Ebenso wirkte eine Traubenzuckerlösung von I5 und 20 Proz. In allen Zellen der Conferva trat auch hier die weiße Substanz auf, so daß also beide Reaktionen nebeneinander stattgefunden hatten. lch konnte nicht mehr näher untersuchen, ob die konzentrierten Traubenzuckerlösungen unter allen Umständen so zoosporenerregend wirken wie die Körper der Gruppe I. Ich muß mich hier mit der Annahme begnügen, daß die Aufspeicherung der reduzierenden Substanz leichter stattfindet als die Zoosporenbildung, daß die erstere bei Anwendung verdünnter Lösungen den Traubenzucker zu sehr in Beschlag nimmt. Erst bei konzentrierteren Lösungen ist Traubenzucker so reichlich vorhanden, um auch die Zoosporenbildung erregen zu können. In jedem Falle wirkt Traubenzucker anders als die Körper der Gruppe I, Inulin etc.; man wird daraus schließen müssen, daß diese in der Conferva-Zelle anders zersetzt werden als im Laboratorium, d. h. nicht durch ihre Umwandlung in Hexosen, die Zoosporenbildung erregen. Man müßte, um die Annahme zu retten, weitere Hypothesen machen, worauf ich wegen des Mangels an thatsächlichen Beweisen nicht weiter eingehen will.

Von sonstigen Wirkungen der Substanzen von Gruppe II ist noch zu erwähnen, daß in Arabinose die Zellen nach 48 Stunden tonnenförmig anschwellen, ohne daß die weiße Substanz bemerkbar wird. Arabinose tritt wohl direkt in den Zellsaft ein, seinen osmotischen Druck erhöhend, das Wachstum hemmend. Wenn die mit weißer Sulstanz erfüllten Conferva-Zellen in Lösungen ron 
Aesculin oder Inulin gebracht werden, so kann in den ersten Tagen noch geringe Zoosporenbildung erfolgen; auch die Zoosporen erscheinen dann mit der betreffenden Substanz erfüllt.

\section{Gruppe III.}

\begin{tabular}{|c|c|c|c|}
\hline Glycerin & $\mathrm{C}_{3} \mathrm{H}_{8} \mathrm{O}_{3}$ & 2 & Proz. \\
\hline Isodulcit & $\mathrm{C}_{6} \mathrm{H}_{12} \mathrm{O}_{5}$ & I & $"$ \\
\hline Galactose & $\mathrm{C}_{6} \mathrm{H}_{12} \mathrm{O}_{6}$ & I & \\
\hline Sorbin & $\mathrm{C}_{6} \mathrm{H}_{12} \mathrm{O}_{6}$ & I & \\
\hline lycogen & $\mathrm{C}_{6} \mathrm{H}_{10} \mathrm{O}_{5}$ & I & \\
\hline Quercit & $\mathrm{C}_{6} \mathrm{H}_{12} \mathrm{O}_{5}$ & I & \\
\hline Inosit & $\mathrm{C}_{6} \mathrm{H}_{12} \mathrm{O}_{6}$ & I & \\
\hline Harnstoff & $\mathrm{CH}_{4} \mathrm{~N}_{2} \mathrm{O}$ & I & \\
\hline Glycocoll & $\mathrm{C}_{2} \mathrm{H}_{5} \mathrm{NO}_{2}$ & I & \\
\hline Asparagin & $\mathrm{C}_{4} \mathrm{H}_{5} \mathrm{~N}_{2} \mathrm{O}_{3}$ & I & \\
\hline Weinsaures Kali & $\mathrm{C}_{4} \mathrm{H}_{4} \mathrm{~K}_{2} \mathrm{O}_{6}$ & 0,2 & \\
\hline Milchsaures Eisenoxydul & $\left(\mathrm{C}_{3} \mathrm{H}_{5} \mathrm{O}_{3}\right)_{2} \mathrm{Fe}$ & 0,2 & \\
\hline Arbutin & $\mathrm{C}_{12} \mathrm{H}_{16} \mathrm{O}_{7}$ & 0,5 & \\
\hline aponin & $\mathrm{C}_{32}{ }_{2} \mathrm{H}_{54} \mathrm{O}_{18}$ & 0,5 & \\
\hline oniferin & $\mathrm{C}_{16} \mathrm{H}_{22} \mathrm{O}_{8} \mathrm{ge}$ & sättig & \\
\hline offeïn & $\mathrm{C}_{8} \mathrm{H}_{10} \mathrm{~N}_{4} \mathrm{O}_{2}$ & $0, \mathrm{I}$ & \\
\hline
\end{tabular}

Alle diese Substanzen hemmen die Zoosporenbildung bei einer Alge, die an und für sich den Prozeß in Wasser, beim Uebergang aus Licht in Dunkelheit zeigen würde; sie bewirken aber wenigstens in den ersten Tagen nicht direkt ein Absterben der Zellen. Den Uebergang zu den Körpern der Gruppe II bildet das Glycerin, in dem vereinzelte Zoosporen auftreten können. Bei allen diesen Substanzen muß an die Möglichkeit gedacht werden, daß in ihnen bei sehr erhöhter Reizbarkeit der Alge eventuell der Prozeß stattfinden könnte. Für die Auswahl der geprüften Substanzen kamen solche in Betracht, die über- 
haupt physiologisch wichtig sind und besonders die, welche chemisch den Körpern der beiden früheren Gruppen nahe stehen. Wie verschieden chemisch verwandte Körper auf die Conferva-Zellen wirken, zeigt sich in dem Verhalten der Galactose und des Sorbins (oder Sorbinose); beide, obwohl isomer dem Frucht- und Traubenzucker, rufen niemals eine Aufspeicherung der weißen Substanz hervor. Sorbin bewirkt in 24 Stunden häufig ein tonnenförmiges Anschwellen der Zellen wie die Arabinose, schädigt aber schneller die Zellen. Von den 4 unschädlichen Glycosiden ist das Coniferin bemerkenswert, weil es, obwohl wenig in kaltem Wasser löslich, in 24 Stunden bereits eine Ansammlung der weißen, reduzierenden Substanz veranlaßt; es scheint also innerhalb der Zelle schnell eine Spaltung des Glycosids herbeigeführt zu werden. Coniferin bildet bei der Zersetzung durch das Ferment Emulsin neben Coniferylalkohol Traubenzucker; dieser ist es wohl, der die weiße Substanz in den Zellen bildet. Auch diese Thatsache würde dafür sprechen, daß Aesculin, Amygdalin, Salicin bei der Spaltung in der Zelle nicht direkt Traubenzucker lieferten.

Wenn nun auch die Körper von Gruppe III die Zoosporenbildung hemmen, so brauchen sie deshalb noch nicht den reizbaren Zustand der Alge zu vernichten, vorausgesetzt, daß diese vorher in einem solchen sich befand. In der Mehrzahl der Fälle trat bei den Fäden nach Ueberführung z. B. in Aesculin die Zoosporenbildung ein. Einige Versuche will ich anführen; sie wurden stets bei Lichtabschluß ausgeführt.

I) seit 2I./V. I895 in I-proz. Galactoselösung, II./VI. in Aesculinlösung; I2./VI. sehr viele Zoosporen.

2) seit 27./V. in I-proz. Quercitlösung, 31./V. in Aesculinlösung; I./VI. sehr viele Zoosporen. 
3) seit $27 . / V$. in I-proz. Isodulcitlösung, I./VI. in Aesculinlösung; 2./VI. sehr viele Zoosporen.

4) seit 23. V. in 2-proz. Glycerinlösung, 27./V. in I-proz. Maltoselösung; 28./V. sehr viele Zoosporen.

5) seit 23./V. in I-proz. Asparaginlösung, 27./V. in I-proz. Maltoselösung; 28./V. sehr viele Zoosporen.

6) I3./VI. in 0,5-proz. Saponinlösung, I6./VI. in o,I-proz. Salicinlösung; I7./VI. sehr viele Zoosporen.

\section{Gruppe IV.}

Convallamarin $\mathrm{C}_{2} \mathrm{H}_{44} \mathrm{O}_{12} \quad 0,5$ Proz.

Glycirrhizinum

ammoniacale

Quercitrin

$\mathrm{C}_{36} \mathrm{H}_{38} \mathrm{O}_{20}$

0,5 Proz.

Phloridzin

$\mathrm{C}_{21} \mathrm{H}_{24} \mathrm{O}_{10}$

gesättigt

Cumarin

$\mathrm{C}_{9} \mathrm{H}_{6} \mathrm{O}_{2}$

Vanillin

$\mathrm{C}_{5} \mathrm{H}_{8} \mathrm{O}_{3}$

Tannin

$\mathrm{C}_{14} \mathrm{H}_{10} \mathrm{O}_{9}$

Orcin

Pepton

$$
\mathrm{C}_{7} \mathrm{H}_{8} \mathrm{O}_{2}
$$

0,5 Proz.

gesättigt und $1 / 2$ gesättigt

In diesen Substanzen sterben die Conferven bald früher oder später $a b$, ohne Besonderes zu zeigen. Die vier zuerst genannten sind Glycoside, die sich demgemäß gegenüber der Alge verschieden von den Glycosiden der Gruppe I und III verhalten. Ein näheres Eingehen auf die rein schädlichen Substanzen ist an dieser Stelle unnötig.

\section{Der Einfluß des Lichtes.}

Das Licht ist notwendig für die normale Ernährung, das Wachstum, die Teilung der Conferven. Die lebhafte Bethätigung dieser Funktionen führt die Alge in den 
reizbaren Zustand, der die Vorbedingung der Zoosporenbildung ausmacht. In meinem Aquarium erhielt sich während des ganzen Jahres die Alge in reizbarem $\mathrm{Zu}$ stand; aber der Grad der Reizbarkeit wechselte, wie wir kennen gelernt haben. Diese nahm ab in den trübsten Monaten November und Dezember; sie konnte sich aber auch gelegentlich sonst vermindern, ohne daß die Gründe dafür in jedem Falle erkannt werden konnten. Ist die Alge einmal in reizbarem Zustand, so kann sich dieser lange Zeit in der Dunkelheit erhalten. Bereits die Versuche auf S. 357 beweisen es; ich will einige andere anführen mit Algen, die noch länger bei Lichtabschluß lisultiviert worden sind:

I) Seit I6./VI. I 895 in Wasser, dunkel, I9./VII. I 895 in Aesculin, dunkel; 20./VII. viele Zoosporen.

2) Seit 28./V. I895 in 0,2-proz. KN-Lösung, dunkel, I9./VII. in Aesculin, dunkel; 20./VII. viele Zoosporen.

3) Seit 28./V. I 895 in o,2-proz. KN-Lösung, dunkel, 24./VIII. in Aesculin, dunkel; 25./VIII. viele Zoosporen.

4) Seit 28./V. 1895 in 0,2-proz. KN-L.ösung, dunkel, 7. X. in Aesculin, dunkel; 8./X. wenige Zoosporen.

Conferven, die drei Monate lang im Dunkeln gestanden hatten, waren noch im Stande, nach Ueberführung in Aesculin Zoosporen zu bilden; erst nach mehr als vier Monaten war mit der völligen Erschöpfung der Alge der Prozefs sehr behindert. Doch fand er noch unzweifelhaft bei einigen Zellen statt; die Zoosporen zeigten aber keine Bewegung mehr, sondern blieben ruhig zwischen den auseinanderrückenden Zellhälften liegen.

1)er Aufenthalt im Dunkeln kann aber nicht deutlich die Reizbarkeit steigern oder hervorrufen. Ich brachte eine IIenge Algen, die durch Aesculin nicht reizbar waren, ins Dunkle und prüfte von Zeit zu Zeit ihre Realitions- 
fähigkeit mit Aesculin, ohne aber lebhafte Zoosporenbildung veranlassen zu können.

Das Licht ruft den reizbaren Zustand der Conferva nur dann hervor, wenn die anderen Bedingungen für das Leben der Alge günstig sind, wie vor allem frisches, stets sich erneuerndes Wasser, mäßige Temperatur. In nicht gewechselter Wassermenge wird das Licht zur Hauptursache für das Verschwinden oder wenigstens die Herabstimmung der Reizbarkeit.

Je nach der Intensität des Lichtes und der Temperatur wird die Alge bald schneller, bald langsamer unempfindlich; die Anhäufung von Reservestoffen, besonders von fettem Oel, ist das deutliche Anzeichen dafür. Den Körpern der Gruppe I gegenüber nimmt stufenweise die Reaktionsfähigkeit ab; am längsten bewahrt sich die Alge diese gegenüber dem Inulin, wenn auch die Intensität des Prozesses sehr sinkt, und schließlich dieser ganz ausbleibt. Bei Algen, wie Hydrodictyon, Oedogonium etc., läßt sich durch Kultur in Nährlösung der reizbare Zustand wieder hervorrufen. Bei Conferva wirkt der Aufenthalt in Nährlösung wenigstens so weit, daß der reizbare Zustand im Licht länger erhalten bleibt als im Wasser. So bildete eine Kultur, die seit I3./XI. I894 in Nährlösung von 0,2 Proz. hell gestanden hatte und am 30./V. I895 in Aesculin dunkel gestellt wurde, am 3I./V. eine Anzahl Zoosporen; eine Kultur vom 23./XI. I894 in 0,2-proz. Nährlösung, am 30./XI. I895 in Inulin übergeführt, zeigte ebenfalls noch einige Zoosporen. Doch die volle Reizbarkeit erhält die Conferva nicht durch die Nährlösung, sondern nur durch den Aufenthalt im Aquarium. Als ich während des Monats August I895 das Zuleitungsrohr des Aquariums abstellte, wuchs die Alge noch weiter, und erfüllte das stehende Wasser; sie war aber gegen Aesculin unempfindlich geworden 
und erlangte im September ihre Reizbarkeit erst, nachdem der Wasserzufluß wieder dauernd erfolgte.

Mit auffallender Schnelligkeit vernichtet das Licht die Reizbarkeit der Conferva, wenn die Substanzen der Gruppe I zugegen sind. Das Licht wirkt nicht bloß dahin, daß die Zoosporenbildung in diesen Lösungen ganz unterbleibt, sondern daß sie auch dann nicht mehr eintritt, wenn die beleuchteten Kulturen verdunkelt werden. Die Beleuchtung eines Sommertages genügt, um dieses auffallende Resultat hervorzurufen; im Winter ließ ich das Licht zwei Tage wirken. Man könnte auf den Gedanken kommen, daß das Licht die Lösungen zersetze, und in der That kann man beobachten, daß Aesculinlösung, während eines Tages beleuchtet, mißfarbig wird. Aber diese Zersetzung, die bei den übrigen Körpern der Gruppe I überhaupt nicht nachweisbar ist, kann nicht die Ursache sein für das Ausbleiben der Zoosporenbildung. Das beweist das folgende Experiment. Frisch bereitete Lösung, z. B. von Aesculin oder Inulin, wurde in zwei Gläser verteilt, von denen das eine a) Conferva, das andere b) nichts erhielt. Beide Gläser wurden einen oder zwei Tage beleuchtet. Dann wurden sie ins Dunkle gestellt, wobei das algenfreie Glas b jetzt frische Conferva bekam. Solche Versuche wurden mit Lösungen sämtlicher 7 Substanzen der Gruppe I ausgeführt und hatten ausnahmslos das gleiche Resultat. Im Glase a traten niemals Zoosporen auf, im Glase b, wo nur die Lösung beleuchtet, aber die Conferva erst im Dunkeln zufügt wurde, zeigte sich in normaler Intensität der Prozeß. Das Licht hemmt die Zoosporenbildung in den Lösungen, nicht weil es diese an und für sich verändert, sondern weil es bei dem Eintritt der Substanz in die ConfervaZelle Umwandlungen in ihr hervorruft, die andersartig als bei Lichtabschluß sind und die die Zoosporenbildung 
geradezu verhindern. Das geht auch daraus hervor, daß in der mit der Alge dem Licht ausgesetzten Lösung von Inulin frische Conferva bei Lichtabschluß normal Zoosporen erzeugt. In den Versuchen mit den in der Inulinlösung beleuchteten Conferven ist ihre Reizbarkeit nicht völlig vernichtet. Bringt man die betreffenden Conferven in frischer Inulinlösung, ins Dunkle, so tritt die Zoosporenbildung, wenn auch nicht sehr lebhaft, ein. Das im Licht entstandene, hemmend wirkende Umwandlungsprodukt des Inulins tritt unter diesen Umständen vielleicht heraus; die Alge spaltet das frisch eintretende Inulin bei Lichtabschluß in normaler Weise, so daß der Prozeß wie gewöhnlich erfolgen kann. Die Spaltung des Inulins in der Conferva-Zelle bei Gegenwart von Licht muß eine andere sein als im Laboratorium; Fruchtzucker entsteht jedenfalls nicht in der Zelle, da die weiße Substanz nicht bemerkbar ist.

Zuerst glaubte ich, daß das Licht in Verbindung mit der Kohlensäure-Zersetzung die hemmende Wirkung ausübe. Doch die Versuche im kohlensäurefreien Raum mit ausgekochter Inulinlösung, bei Gegenwart von Licht hatten dasselbe Resultat wie diejenigen, bei denen Assimilation stattfinden konnte. Weder im Licht noch nach dem Uebergange in Dunkelheit erfolgte Zoosporenbildung. So weit sich aus diesen Versuchen, bei denen vielleicht die Assimilation nicht absolut ausgeschlossen war, beurteilen läßt, ist die Wirkung des Lichtes eine direkte. Gegenüber dieser hemmenden Wirkung des Lichtes bei Gegenwart der sonst so lebhaft wirkenden Körper der Gruppe I zeichnet sich das Verhalten des Traubenzuckers um so auffallender aus. Konzentrierte Lösungen von I0-20 Proz. erregen bei Conferva Zoosporenbildung ebenso im Licht wie im Dunkeln, soweit die wenigen Versuche, die ich noch anstellen konnte, ein Urteil erlauben. 
Auch hier sehen wir demgemäß, wie anders die Substanzen der Gruppe I auf die Conferva-Zelle einwirken, als der Traubenzuclier.

Bei hoher Reizluarkeit erzeugt die Conferva im W'asser Zoosporen, wenn sie verdunkelt wird; der Lichtwechsel spielt hier die Rolle des auslösenden Reizes. Sehr möglich wäre es, daß der Uebergang aus dem fließenden in stehende: Wasser eigentlich als Reiz wirke, dafs aber die Realition nur bei Lichtabschluß eintrete. Sicher ist es, da1j die Dunkelheit nicht wie bei Vaucheria einen fortdauernden Reiz ausübt, da die Zoosporenbildung im Nasser nach wenigen Tagen erlischt, um nie wieder von selbst $z u$ erscheinen. Auch bei den erregenden Sulstanzen der Gruppe I, Inulin etc., kommt mehr der Mangel des specifisch hemmenden Einflusses des Lichtes in Betracht, als eine besonders fördernde Wirkung der Dunkelheit. Man darf aber kaum daran zweifeln, dafs Conferva bei Gegenwart von Licht unter besonderen Umständen Zoosporen zu bilden vermag, wenn es mir auch nicht gelungen ist, den Prozeß in hellem Licht zu beobachten. Schwaches Licht wirkt wie Dunkelheit; immerhin ist es auffallend, wie selbst das trübe Tageslicht im November noch die Zoosporenbildung zu hemmen vermag. Ich weiß nicht, in welchem Lmfange der Prozeß im Aquarium stattgefunden hat. Bei den hunderten ron Versuchen sah ich niemals Fäden mit Zoosporen; aber die Bildung der an den Glaswänden festsitzenden Fäden lief. doch auf das Vorkommen von Zoosporen schließen. Man könnte ihr Vorkommen auch erklären. Denn reizbare Fäden von Conferva um 6 Uhr Nachmittags in Aesculinlösung übergeführt, bildeten bereits am nächsten Morgen Zoosporen. So könnte bei sehr hoher Reizbarkeit Jer Alse die Nacht in Verbindung mit starker Lichtschwächung am 'Tage vorher den Prozeß veranlassen. 


\section{Der Einfiuß der Temperatur.}

Bei der Zoosporenbildung übt die Temperatur innerhalb gewisser Grenzen keinen besonderen Einfluß aus. Bringt man die Conferven aus dem Aquarium in ein wasserdicht verschlossenes Gefäß mit Inulin oder Aesculin etc., umwickelt es mit Stanniol und taucht es in dem Aquarium unter, so erfolgt trotz der Konstanz der Temperatur lebhafte Zoosporenbildung. Sie tritt ebenso ein, gleichgiltig, ob die Temperatur im Verhältnis zu der des Aquariums erhöht oder erniedrigt wird. Interesse beansprucht daher nur die Feststellung der Temperaturgrenzen.

Bei o- I ${ }^{0}$ findet keine Zoosporenbildung bei Anwendung von Inulin und bei Lichtabschluß statt; bereits bei $3^{0}$ kann der höchste Grad des Prozesses erreicht werden. Zwischen 10 und $20^{\circ}$ treten in Inulinlösung die ersten Zoosporen nach 24 Stunden auf, und nach 48 Stunden ist der völlige Zerfall der Fäden bemerkbar. Unter IO $^{\circ}$, besonders bei $3-7^{0}$, zeigen sich die ersten Zoosporen nach 48 Stunden, sehr viele nach 72 Stunden. Sehr zahlreiche Versuche habe ich gemacht, um die obere Grenze festzustellen, weil ich bemerkte, daß bei Temperaturen wenig über $20^{0}$ der Prozeß sehr unregelmäßig erfolgte, was mir sehr auffallend erschien, da die Alge ihre Lebensgrenze erst bei $35^{\circ}$ findet; nach 24 Stunden sind die Fäden bei dieser Temperatur im Begrift abzusterben. Bei Tem-. peraturen von $20-26^{\circ}$ im Thermostat zeigte sich eine wahre Launenhaftigkeit im Verhalten der Alge, deren Gründe ich durch sehr zahlreiche Versuche erkennen wollte. Eine der Versuchsreihen im Sommer I895 will ich genauer angeben. 


\begin{tabular}{|c|c|c|c|c|}
\hline 2 & $\stackrel{\Xi}{\Xi}$ & Nedium & $\begin{array}{l}\text { Temp. } \\
\text { in } 0\end{array}$ & Resultat und weiteres Verhalten \\
\hline 1 & 3./ SI. & Aesculin ges. & 20 & 4./VI. sehr viele Zoosporen. \\
\hline 2 & . TI. & , & 22 & $\begin{array}{l}\text { 5. VI. wenige Zoosporen; } 5 . / \text { VI. Labora- } \\
\text { torium } 16-20^{\circ} ; 6 . / \text { VI. sehr viele Zoo- } \\
\text { sporen. }\end{array}$ \\
\hline 3 & 9. VI. & " & $2 I$ & $\begin{array}{l}\text { IO./VI. keine Zoosporen; IO./ VI. Lab. ; } \\
\text { II./VI. keine Zoosporen. }\end{array}$ \\
\hline 4 & II. YI. & " & 23 & 12. VI. sehr riele Zoosporen. \\
\hline 5 & I 2. VI. & ", & 24 & 13. VI. sehr viele Zoosporen. \\
\hline 6 & I3.NI. & " & 24 & I4. VI. wenige Zoosporen. \\
\hline 7 & $\mathrm{I}+\mathrm{V}^{\top} \mathrm{I}$ & $\begin{array}{l}\text { a) Aesculin } \\
\text { b) Salicin } 0,5\end{array}$ & 24 & $\begin{array}{l}\text { 15./I. a) wenige Zoosporen. } \\
\text { b) sehr viele Zoosporen. }\end{array}$ \\
\hline 8 & $15.1 V^{\top} \mathrm{I}$ & $\begin{array}{l}\text { a) Aesculin } \\
\text { b) Salicin }\end{array}$ & 25 & $\begin{array}{l}\text { 16. VI. a), b) keine Zoosporen; } 16 . / \mathrm{VI} \text {. } \\
\text { Lab.; I7./VI. a), b) sehr viele Zoo- } \\
\text { sporen. }\end{array}$ \\
\hline 9 & I6. VI. & 0,5 Salicin & 25 & $\begin{array}{l}\text { I7./ VI. keine Zoosporen; I7. VI. Lab.; } \\
\text { 15. VI. sehr viele Zoosporen. }\end{array}$ \\
\hline I0 & $17 \cdot \mathrm{T}^{\top} \mathrm{I}$ & $\begin{array}{l}\text { a) Aesculin } \\
\text { b) Salicin }\end{array}$ & 26 & $\begin{array}{l}\text { IS./II. a), b) wenige Zoosporen; IS. VI. } \\
\text { Lab.; 19./VI.a), b) sehr viele Zoosporen. }\end{array}$ \\
\hline I I & I১. VI. & a) Aesculin & 26,5 & $\begin{array}{l}\text { 19. VI. a) keine Zoosporen; I9. VI. Lab.; } \\
\text { 20. VI. a) sehr viele Zoosporen. }\end{array}$ \\
\hline & & b) Salicin & & $\begin{array}{l}\text { 19. VI. b) wenige Zoosporen; I9. VI. } \\
\text { Lab.; 20. VI. b) viele Zoosporen. }\end{array}$ \\
\hline I 2 & 19./ VI. & $\begin{array}{l}\text { a) Aesculin } \\
\text { b) Salicin }\end{array}$ & 27 & $\begin{array}{l}\text { 20., VI. a), b) keine Zoosporen; 20. VI. } \\
\text { Lab.; 2I. VI. a), b) keine Zoosporen. }\end{array}$ \\
\hline 13 & 20.1 VI. & $\begin{array}{l}\text { a) Aesculin } \\
\text { b) Salicin }\end{array}$ & 27 & $\begin{array}{l}\text { 2I. (II. a), b) lieine Zoosporen; 2I. VI. } \\
\text { Lab.; 22.(VI. a), b) sehr viele Zoo- } \\
\text { sporen. }\end{array}$ \\
\hline 14 & 2I./ VI. & $\begin{array}{l}\text { a) Aesculin } \\
\text { b) Salicin }\end{array}$ & 27,5 & $\begin{array}{l}\text { 22. VI. a), b) keine Zoosporen; } 22 . / \mathrm{V}^{\top} \text {. } \\
\text { Lab.; } 23 . \text { (VI. a), b) viele Zoosporen. }\end{array}$ \\
\hline I5 & $23 . / \mathrm{TI}$ & Salicin 0,5 & 29 & $\begin{array}{l}\text { 24. VI. keine Zoosporen; 24. VI. Lab.; } \\
\text { 25. VI. a), b) sehr vicle Zoosporen. }\end{array}$ \\
\hline
\end{tabular}

Die in der Tabelle erwähnten Versuche, ebenso die übrigen von mir angestellten zeigen, daß bereits bei $2 \mathrm{I}-23^{\circ}$ die Zoosporenbildung behindert sein kann, dafs sie aber in anderen Versuchen lebhaft erfolgt. Ueber $23^{\circ}$ wird das Resultat noch schwankender, von $25^{\circ}$ an 
zeigen sich im besten Falle nur wenige Zoosporen; die letzten sah ich in Salicinlösung bei $26,5^{\circ}$. In der Mehrzahl der Fälle wurde der reizbare Zustand durch die höhere Temperatur (innerhalb 24 Stunden) nicht verändert, da ihre Erniedrigung den Prozeß normal auslöste. Für Maltose und Amygdalin beobachtete ich die Grenze ebenfalls zwischen 25 und $26^{\circ}$. Als ich die Bedeutung des Inulins für die Zoosporenbildung erkannte, habe ich mit ihm eine Anzahl Versuche bei höherer Temperatur angestellt. Ich beobachtete auch hierbei, daß der höchste Grad des Prozesses noch bei $20-2 \mathrm{I}^{0}$ stattfindet, daß bei geringer Steigerung bereits Hemmungen eintreten, so daß die Zoosporen mehr vereinzelt auftreten; bereits bei $24^{\circ}$ sah ich keine mehr. Etwas anders fielen die Versuche aus, als ich die Conferven in der Inulinlösung 24 Stunden lang bei niederer Temperatur $\left(4-7^{\circ}\right)$ stehen ließ und dann in den Thermostat brachte. Unter diesen Umständen trat ein völliger Zerfall der Fäden noch bei $24^{\circ}$ ein, während bei $25^{\circ}$ bereits der Prozeß stark, bei $26^{\circ}$ ganz gehemmt war.

Der Grund, warum eine Temperatur von $2 \mathrm{I}-24^{\circ}$ so wenig günstige Wirkungen durchschnittlich ausübt, kann nur darin liegen, daß die betreffende Temperatur während 24 Stunden konstant ist. Denn im Sommer stieg die Temperatur meines Versuchszimmers im Laufe des Tages manchmal auf $20-24^{\circ}$, ohne daß ich bei den Versuchen üble Folgen bemerkt hätte, wahrscheinlich weil in der Nacht, wo der eigentliche Bildungsprozeß 3 vor sich geht, die Temperatur unter $20^{\circ}$ sank. Immerhin ist das Verhalten von Conferva bemerkenswert gegenüber Oedogonium, Vaucheria, Hydrodictyon, Protosiphon, bei denen der Temperaturgrad, aber nicht seine Konstanz während 24 oder mehr Stunden bedeutungsvoll ist.

Ganz kurz will ich noch erwähnen, daß auch eine 
Anzahl V'ersuche in verdünnter Luft angestellt wurden, wobei ich immer Inulinlösung benutzte. Bei einem Lufttruck ron ca. $40 \mathrm{~mm}$ sah ich überhaupt keine Zoosporen; erst ron $50 \mathrm{~mm}$ an traten solche auf, aber immer vereinzelt. Selbst bei $120 \mathrm{~mm}$ ist die Zahl beschränkt crecrenüber der Quantität, wie sie bei normalem Luftdruck erscheint. Man merkte den Unterschied, sowie die Kulturgläser aus der verdünnten in die gewöhnliche Luft über@eführt wurden. Der Aufenthalt in verdünnter Luft, im Dunkeln rerändert die Reizbarkeit der Alge nicht.

\section{Das Verhalten ron Conferva gegeniiber ungiustigen, änBeren Bedingungen.}

Wille $(8 \mathrm{I}, 87)$ hat bei einer Anzahl Conferva-Arten die Bildung von Ruhezellen ausführlich beschrieben. Bei Conferva minor (87 S. 468, Taf. XVII, Fig. 66 u. 67) sah er an dem einen Ende angeschwollene Zellen mit etwas verdiclster Membran, die er als Ruhezellen auffaßt, wenn er auch ihre Keimung nicht gesehen hat. Lagerheim (89) beolsachtete anscheinend bei der gleichen Art die Bildung von Sporen, indem der Inhalt einer Zelle sich etwas kontrahierte und mit neuer Membran umgab. Die kugeligen Sporen wurden durch Auseinanderfallen der alten Jembranstücke frei. Auch Gay (9I S. 35 u. 36) sah bei Conferva minor die gleiche Bildung ron Ruhezellen, wobei er nur annimmt, daß die Sporenmembran die innerste Zellhautschicht der ursprünglichen Zellhaut sei.

Conferva minor ist im Stande, Trockenheit auszuhalten, ohne besondere Ruhezellen dafür zu erzeugen. Wenn man eine Anzahl Fäden in der feuchten Kammer allmählich eintrocknen läßt, so treten Erscheinungen auf, die an das Verhalten ron Hormidium-Arten erinnern. Die Fäden (Taf. II, Fig. 3) beginnen sich zu zerspalten, 
aber nicht so, daß die Zellhaut in H-förmige Stücke zerfällt, sondern durch Trennung an den Querwänden. Aber die Spaltung geht nie so weit, als bei Hormidium; die Fadenstücke sind meistens mehr- bis vielzellig. Sie können das Austrocknen gut ertragen und beginnen nach Uebergießen mit Nährsalzlösung sofort zu wachsen und sich $\mathrm{zu}$ teilen.

Läßt man die Alge längere Zeit in einem Gefäß mit Wasser, so treten die Veränderungen des Zellinhaltes ein, welche Wille und Gay beschrieben haben. Im Zellinhalt häuft sich fettes Oel an, die ganze Zelle schwillt tonnenförmig an, die Zellınembran verdickt sich. In einem solchen Gefäße beobachtete ich auch die von Wille beschriebenen Ruhezustände und zwar an den Fäden, die an der Glaswand über der Wasserfläche einer äußerst langsamen Austrocknung ausgesetzt waren. Hier entstanden die an einem Ende angeschwollenen, dickwandigen Ruhezellen (Taf. II, Fig. 4). Als ich solche Zellen in frische Nährsalzlösung versetzte, fingen sie nach wenigen Tagen an, frisch grün zu werden und sich zu strecken; die alte Zellhaut wurde zersprengt (Fig. 5), die durch Teilung neu entstandenen Tochterzellen hatten den normalen Bau.

Zum Schluß möchte ich noch hervorheben, daß ich nach meinen vielfältigen Erfahrungen mit Conferva minor, ebenso wie G ay (9I S. 32) die Ansicht B orzi's (83 S. 58) für unbegründet halten muß, nach der die Arten der Gattung Conferva, z. B. bombycina, utriculosa reduzierte Formen von Rhizoclonium seien; dafür liegt nicht der geringste Beweis bisher vor. 


\section{Bumilleria.}

Die Gattung Bumilleria, mit der einen Species sicula, ist von Borzi entdeckt und von ihm in seinem neuesten Werke (95 S. 185-200, Taf. XVI-XVII) eingehend beschrieben worden. Borzi, die Alge als einzellig betrachtend, stellt sie in die Familie der Botrydiaceen, während Wille ( $\left.\mathrm{W}^{\mathrm{S}} \mathrm{S} .85\right)$ mit richtigerem Blick sie zu den Ulotricheen neben Conferva und Mikrospora rersetzt. Wie wir sehen werden, steht Bumilleria der Gattung Conferva sehr nahe, so daß selbst eine Vereinigung sich verteidigen ließe. Indessen halte ich es doch für zweckmäßiger, die Gattungen zu trennen. Ich lege dabei das Hauptgervicht auf die Unterschiede in der Membranbildung, der Keimungsart der Zoosporen und auf das Vorkommen bez. den Mangel des Spaltungsprozesses. Ich habe noch eine andere Species von Bumilleria aufgefunden, so daß die Charaliteristik der Gattung sich bestimmter geben läßt.

\section{Bumilleria sieula Borzi.}

(Taf. II, Fig. 9-I4.)

Borzi fand diese Alge auf feuchtem Thonboden bei Milazzo in Sicilien; ich beobachtete sie in einer Nährlösung-Kultur, in die ich Lehm mit Botrydium-Sporen hineingelegt hatte. Ich isolierte nach der früher be- 
schriebenen Methode die Zellen und gewann eine Reinkultur, zuerst im Mai 1895, von welcher Zeit ab die Alge in fortlaufenden Kulturreihen im Laboratorium gehalten wurde. Ich kultivierte sie teils auf feuchtem Lehm, teils in Nährlösungen. Auf dem Lehm bildet sie, so lange er genügend feucht ist, einen dunkelgrünen Ueberzug, der beim allmählichen Austrocknen gelblich bis fast weißlichgrün wird. In Nährsalzlösungen von $0,1-0,5$ Proz. tritt die Alge in hellgrünen, wolkigen Massen auf, besonders am Grunde der Gefäße; will man sie mit einer Nadel fassen, so zerfließen und verteilen sich die grünen Flocken. Am günstigsten erwies sich eine Nährlösung von O,I Proz. In einem Gefäß mit $300 \mathrm{ccm}$ Flüssigkeit, in die einige wenige Zellen hinein gebracht worden waren, hat sich nach $3 / 4$ Jahr eine noch immer wachsende, lebenskräftige Kultur erhalten. In stärkeren Konzentrationen über 0,5 Proz. wächst die Alge anfangs ganz gut, kränkelt aber dann nach einigen Monaten.

Auf feuchtem Boden oder in älteren Nährlösungen erscheint die Alge, wie Borzi beschreibt, in 4-8-zelligen, kurzen Fadenstücken. Bei lebhaftem Wachstum dagegen kann sie vielzellige Fäden bilden (Taf. II, Fig. II), die immer leicht in kürzere Stücke zerbrechen. Der sehr lockere Zusammenhang der Zellen eines Fadens rührt von der Beschaffenheit der Membran her (Borzi l. c. S. I89). Gehen wir von einer einzelnen Zelle aus, so bemerken wir, daß diese sich in 2 oder 4 Zellen teilt, wobei die Mutterzellwand in 2 Stücke zerspalten wird, die durch das Wachstum der Tochterzellen von einander entfernt werden (Taf. II, Fig. $13 d$ ). Die Zellwandhälften werden dabei häufig an den Enden des kurzen Fadens etwas hinausgeschoben, so daß sie wie eine besondere Haube hervortreten (Borzi 1. c., siehe meine Taf. II, Fig. II, I3 d). Diese Membranteile können aber mit den 
neuen /ellwänden der Tochterzellen bis zu einem grewissen Grade verkleben; durch neue Teilungen, neue Spaltungen der älteren Memlianen und deren Verklebung mit den näclıt jüngeren kommt der Fadenzusammenhang zu Stande. Wüurde das Verkleben der verschiedenen Membrangrenerationen ein stärlieres sein, so würde ein normaler Conferva-Faden entstehen. Dieses ist der Fall bei ler nahe verwandten zweiten Species (siehe später). Jedenfalls ist Bumilleria sicula ein Beispiel, das uns die Anfänge der Fadenbildung klar vor Augen führt.

Die ringförmige Spaltung der Zellmembran erinnert etwas an die vorhin beschriebenen Verhältnisse bei Conferva. Aber es ist doch ein wichtiger Unterschied vorhanden. Die Zellwand einer einzelnen Zelle stellt einen volliommen geschlossenen, cylindrischen Schlauch vor und ist nicht von vornherein aus zwei Hälften zusammengesetzt. Behandelt man die Zellen mit konzentrierter Schwefelsäure, so erhält man ein ganz anderes Bild als bei Conferva. Der Zellinhalt quillt stark, dehnt die Zellhaut aus, bis sie an der dünnsten Stelle, gewöhnlich seitlich dem einen Ende genähert, platzt; niemals findet eine regelmäßige Spaltung in 2 Hälften statt.

Der lebende Zellinhalt entspricht, wie schon aus Borzi's Schilderung hervorgeht, demjenigen einer Conferva-Zelle. Die Chromatophoren sind scheibenartig bis kurz bandförmig; sie liegen zu 2, 4 oder $S$ in einer Zelle, entbehren des Pyrenoids wie der Stromastärke; es finden sich bisweilen zwei Zellierne vor. Im Plasma zerstreut liegen Tröpfchen fettartiger Natur.

I)ie Zellen teilen sich gewöhnlich der Quere nach; ab und zu erfolgen Längsteilungen. Borzi behauptet, claß diese nur bei der Fortpflanzung durch die Gonidien einträten. Jede gesunde, wachsende Nährsalzkultur zeigt aber bei den vegetativen Fäden solche Längsteilungen 
(vergl. Taf. II, Fig. II). Die äußeren Bedingungen, die diesen Wechsel von Quer- und Längsteilung veranlassen, sind bis jetzt unbekannt.

Die Alge pflanzt sich nach meinen Beobachtungen fort I) durch die Spaltung der Fäden und Fadenstücke, 2) durch Zoosporen, 3) durch Dauerzellen.

\section{Die Spaltung.}

Borzi spricht von einer Vermehrung durch unbewegliche Gonidien, die durch Teilung entstehen und frei werden. Diese Gonidien sind aber nichts anderes als gewöhnliche, vegetative Zellen; das Wesen der Erscheinung liegt nur in der Trennung der Zellen, einem Spaltungsprozeß, der vollkommen analog ist dem gleichen Vorgange bei den Hormidium-Arten. Allerdings zerknickt bei diesen ein fertiger Faden durch Spaltung an den Querwänden, unabhängig von der Teilung. Bei Bumilleria beobachtet man diese Art der Trennung nicht, weil die Zellen eines Fadens infolge des Verhaltens der alten Membranen überhaupt nur lose verklebt sind. Deshalb trennen sich schon infolge leichter, mechanischer Einwirkungen die Zellen eines Fadens - es ist das eine Vermehrung aus mehr zufälligen Gründen, die aber immerhin für die Species vorteilhaft erscheint. Die Spaltung macht sich als besondere Erscheinung nur kurz nach der Teilung bemerkbar. Eine Zelle teilt sich in vier Zellen; bevor noch deren Längsstreckung eintritt, trennen sich die Zellen durch Abrundung an den Querwänden und isolieren sich von einander (Taf. II, Fig. 9). Der Grund muß darin liegen, daß sofort bei der Teilung jede Zelle eine ringsum geschlossene Haut erhält und daß die ihnen gemeinsame, dünne Membranschicht verquillt. 
Borzi sagt, daß die Vermehrung durch die Gonidien nicht so häufig eintrete wie durch die Zoosporen. Das hängt aber nur von äußeren Bedingungen ab. Der Spaltungsprozeß kann jederzeit leicht veranlaßt werden. Am besten sieht man ihn, wenn Zellen von Bumilleria eine Zeit lang fast trocken gelegen haben und dann mit reinem Wasser (nicht mit Nährlösung) bedeckt werden. Lebhafte Teilung findet dann statt, während das Längenwachstum verzögert wird; die neuen, noch kurzen, oft fast kugeligen Zellen trennen sich leicht von einander. Stets tritt eine solche Spaltung ein, wenn eine Lehmkultur allmählich trockener wird. Das Endresultat ist, daß schließlich die ganze Algenmasse aus einzelnen, isolierten Zellen besteht. In den Nährsalzkulturen selbst bilder sich immer längere oder kürzere Fadenstücke aus; an den Glaswänden oberhalb der Flüssigkeit entsteht dagegen ein grüner Ueberzug, der in den oberen Regionen zuletzt nur aus einzelnen, durch Spaltung isolierten Zellen zusammengesetzt ist. Die Spaltung dient hauptsächlich zur Vermehrung bei langsam eintretendem Mangel an Feuchtigkeit, kann aber auch im Wasser bei Mangel an Nährsalzen erfolgen.

\section{Die Zoosporenbildung.}

Der Prozeß ist von Borzi in den Hauptzügen richtig beschrieben worden. Durch Teilung des Zellinhaltes entstehen 2 oder 4 Zoosporen, seltener eine einzige. Bei der Entleerung spielt wahrscheinlich eine quellbare, schleimige Substanz die Hauptrolle, insofern durch ihren Druck die Zellmembran zum Platzen gebracht wird. Sie spaltet sich nicht durch einen ringförmigen Riß wie bei der Teilung: vielmehr platzt sie zuerst an einer Seite dem einen 
Ende genähert auf und reißt dann ganz durch; langsam treten die Zoosporen an dieser Stelle heraus (Fig. Io).

Die Zoosporen haben den Bau derjenigen von Conferva, nur dał3 sie noch stärker amöboid sind (Borzi l. c.). Sie sind während des freien Schwimmens etwas plattgedrückt, ungefähr lang eiförmig bis schmal ellipsoidisch, an einer Seite häufig eingebuchtet (Taf. II, Fig. I2 $a, b$ ). Am vorderen, ein wenig schiefen Ende sitzt die einzige Cilie; unter der Ansatzstelle pulsieren 2 Vacuolen. Einen Augenfleck (nach Borzi soll er farblos sein) habe ich nicht beobachten können. Im vorderen Teile liegen die beiden Chromatophoren; das farblose, hintere Ende enthält Fetttröpfchen. In der Bewegung verhalten sich die Zoosporen wie die von Conferva; am Tropfenrande benehmen sie sich wie wahre Amöben. Die Entleerung findet hauptsächlich am Morgen statt (Borzi l. c.); die Dauer der Bewegung scheint nur kurz zu sein. Bei der Keimung runden sich die Schwärmer zu Kugeln ab, die sich mit einer Zellhaut umgeben. Dann strecken sie sich und teilen sich bei Gegenwart von Nährsalzen und von Licht. Unter Umständen, in schwächerem Licht oder im Dunkeln, in Wasser können die noch kugeligen Keimlinge sofort wieder Zoosporen bilden; es entsteht dann aus dem Inhalt gewöhnlich eine einzige Zoospore (Fig. I3 $a, b$ ).

Vor allem wollte ich bei meiner Untersuchung die Frage nach den Bedingungen der Zoosporenbildung erforschen, worüber Borzi nichts mitteilt.

Bumilleria sicula verhält sich im allgemeinen wie die Algen, die auf feuchtem Boden leben, z. B. Vaucheria repens, Protosiphon, Hormidium flaccidum. Die beiden Hauptmethoden, die zur Zoosporenbildung führen, bestehen darin, die Alge aus feuchter Luft in Wasser oder aus Nährlösung in Wasser überzuführen. Man kann auf diese Weise zu allen Zeiten des Jahres beliebige Mengen 
ron Zoosporen erhalten. Wenn man aber darauf aus«eht, daß die Versuche ausnahmslos gelingen sollen, so stößt man auf Schwierigkeiten, wie sie auch bei H. flaccirlum sich bemerkbar machen. Nebenumstände spielen eine wichtige Rolle; die Alge schien manchmal sehr launenhaft zu sein, so daß eine genauere Untersuchung erforderlich war, um wenigstens einen Teil der äußeren Verhältnisse kennen zu lernen, von denen die Unregelmäßigkeit im Erscheinen der Zoosporen bedingt wurde.

Für die Versuche dienten als Ausgangsmaterial die Reinkulturen auf Lehm oder in Nährlösungen. Die Versuche selbst wurden in feuchten Kammern angestellt, in denen die Alge normal weiter lebt und Zoosporen bildet.

Bei der Betrachtung wollen wir den Einfluß der Temperatur voranstellen, wobei zu bemerken ist, daß die Tersuche im Dunkeln ausgeführt wurden, wo der Mangel des Lichtes noch den durch den Mediumwechsel gegebenen Reiz verstärkt. Bei einer Temperatur von $\mathrm{O}-\mathrm{I}^{0}$ erfolgt keine Zoosporenbildung; sie beginnt bereits bei $1-2^{\circ}$. Bei $1,5^{\circ} \mathrm{sah}$ ich die Zoosporen austreten und frei umherschwimmen. Bei $3-4^{0}$ kann der denkbar höchste Grad der Zoosporenbildung erreicht werden. Sehr viel schwieriger läßt sich die obere Temperaturgrenze bestimmen, da Bumilleria bei höheren Temperaturgraden sich noch viel launenhafter zeigt, als z. B. Conferva minor. Unstreitig ist auf das unregelmäßige V'erhalten gegenüber der höheren Temperatur die frühere Kulturweise von Einfluß. Sommer- und Winterkulturen verhalten sich verschieden. Im Juni erzogene Algen liefern im Thermostat bei $25^{\circ}$ massenhaft Zoosporen, bei $26^{\circ}$ nicht mehr; der letztere Temperaturgrad ist wohl als obere Grenze anzunehmen.

Bei den Winterkulturen dagegen wirkt bereits eine 'Temperatur von 2 I" und darüber in hohem Grade hem- 
mend ein, so daß in den zahlreichen, immer wieder von neuem angestellten Versuchen bei $2 \mathrm{I}-25^{\circ}$ die Mehrzahl keine oder nur wenige Zoosporen lieferte. Aber noch auffallender ist es, daß im Winter bei einer Zimmertemperatur von $13-\mathrm{I}^{\circ}$ ebenfalls viele Versuche versagen. Man würde nun vielleicht zu der Annahme neigen, daß hier andere, zufällige Umstände mitgewirkt hätten, als gerade die Temperatur. Doch weisen folgende Versuche auf ihre Bedeutung hin. Nimmt man feuchte Kammerkulturen, die bei Zimmertemperatur keine Zoosporenbildung gezeigt oder diese sehr schnell beendet haben und bringt sie, ohne daran etwas zu ändern, in eine Temperatur von $5-6^{0}$, so tritt in sehr vielen Fällen die Zoosporenbildung ein. Es ist das einzige, mir bisher bekannte Beispiel, daß der Uebergang aus einer relativ niederen Temperatur von $13-17^{\circ}$ in eine solche von 5-6 $6^{0}$ zoosporenerregend wirkt. Der fördernde Einfluß der niederen Temperatur zeigt sich auch darin, daß die Versuche in ihr überhaupt sehr regelmäßig und sicher gelingen.

Denkt man nun daran, daß die Versuche im Sommer bei durchschnittlich $20^{\circ}$ ebenso gut gelingen, daf3 $\mathrm{Bu}$ milleria zuerst in Sicilien und wie es scheint, auch im Sommer von Borzi beobachtet worden ist, so erscheint das Benehmen der Alge sehr widerspruchsvoll. Vielleicht läßt es sich aus der Annahme erklären, daß die Temperatur, bei welcher die Alge aufgewachsen ist, ihr weiteres Verhalten beinflusse. Im Winter standen meine Kulturen dicht am Fenster, wo eine Temperatur von IO- I $2^{\circ}$, in der Nacht noch eine niedrigere, herrschte; diese niedere Temperatur stimmte die Alge dahin, auch ihre Zoosporen nur bei niederer Temperatur zu bilden, während im Sommer die Pflanze auf eine durchschnittlich höhere Temperatur gestimmt war. Es wäre möglich, daß die verschiedene 
Lichtintensität im Sommer und Winter mitwirkte, da, wie wir sehen werden, die Alge auch dem Licht gegenüber wechselndes Benehmen aufweist.

Die Zellen, die bei o-I ${ }^{0}$ keine Zoosporen gebildet haben, thun es sofort, wenn man sie in eine Temperatur von $3-4^{0}$ bringt. Man kann das Experiment mehrmals wiederholen; ich will einen speciellen Versuch genauer angeben. Die Zellen aus einer Lehmkultur wurden' in Wasser übergeführt und am 3./I. I896 im Dunkeln einer Temperatur von $5-6^{0}$ ausgesetzt. Nach einigen Tagen trat lebhafte Zoosporenbildung ein, welche trotz abnehmender Temperatur fortging bis zum IO./I., wo sie bei $I^{0}$ aufhörte. Am II./I. ins warme Zimmer versetzt, bildete die Kultur am I2./I. massenhaft Zoosporen; am I3./I. bei $0-\mathrm{I}^{0}$ keine, am I4./I. bei $\mathrm{I}_{3}-\mathrm{I} 7^{0}$ viele Zoosporen, am I5. I. bei $0-I^{0}$ keine. Am I6.I. trat im warmen Zimmer keine Zoosporenbildung mehr ein, die Zellen waren erschöpft, ausgehungert. Die bei sehr niederer Temperatur gehaltenen Kulturen bilden daher ganz allgemein nach dem Uebergang in eine Temperatur ron $13-17^{\circ}$ leicht und sicher Zoosporen.

Wenn die Zoosporenbildung durch höhere Temperatur im Sommer, z. B. durch 26-28 , gehemmt war, so erfolgt sie wieder bei einer niederen Temperatur, doch nicht ausnahmslos. Noch unregelmäßiger verhalten sich in Winter die bei $2 \mathrm{I}-26^{\circ}$ kultivierten Algen; der hemmende Einfluß macht sich auch darin bemerlilich, daß der Prozeß der Zoosporenbildung bei niederer Temperatur ungłeichmäßig erfolgt.

Einen wesentlichen Einfluß hat die Temperatur auf die \%eitcauer, bei welcher der Bildungsprozeß sich abspielt. Bei Zimmertemperatur von $13-17^{\circ}$ braucht der Prozefs vom Bewinn des Versuches bis zur Entleerung der Schwärmer $20-24$ Stunden, bei einer Temperatur von $24^{\circ}$ dagegen 
12-I4 Stunden. Der Versuch wurde im letzteren Falle so angestellt, daß die Zellen im Sommer, am späten Nachmittag in den Thermostat gebracht wurden; am nächsten Morgen waren dann reife Zoosporen gebildet. Bei Temperaturen unter $10^{0}$ beansprucht der Bildungsprozeß3 2 Tage, bei $3-4^{0}$ sogar meistens 3 Tage. Die Temperaturgrenze für das Leben der Alge liegt bei 35--36"; 24-stündiger Aufenthalt bei solcher Temperatur tötet die Zellen.

Neben der Temperatur ist bei Bumilleria auch das Licht von entscheidender Bedeutung. Die Zoosporenbildung kann an und für sich ebenso im Dunkeln wie im Licht stattfinden; das letztere übt aber je nach seiner Intensität eine bald mehr hemmende, bald mehr fördernde Wirkung aus. Von dem Ernährungsprozeß ist die Zoosporenbildung jedenfalls in hohem Grade unabhängig. Bei dem vorhin erwähnten Versuch bildeten sich die Zoosporen noch nach 12-tägiger, konstanter Dunkelheit, in einem anderen Versuch nach I4 Tagen. Bei Lichtabschluß findet keine Teilung, kein nennenswertes Wachstum statt; die zur Ruhe gekommenen Zoosporen bleiben kugelig und können, wie vorhin bemerkt wurde, gleich wieder Zoosporen bilden, unabhängig von Teilung und Wachstum. Aber natürlich giebt es auch hier eine Grenze; stark ausgehungerte Zellen sind nicht mehr im Stande, wieder Zoosporen zu erzeugen.

Wie bei Protosiphon und Vaucheria wirkt helles Licht bis zu einem gewissen Grade hemmend auf die Zoosporenbildung ein; dabei kommt aber die frühere Kulturart des Versuchsmateriales in Betracht. Zellen einer Lehmkultur erzeugen beim Uebergang in Wasser während der Wintermonate die Zoosporen im Licht wie im Dunkeln. Dagegen im Sommer macht sich der hemmende Einfluß des hellen Lichtes so weit bemerlibar, daß 
die Zoosporenbildung in solchem Licht verringert oder ganz verhindert ist. Deshalb ist es am sichersten, im Sommer die Versuche in Dunkeln auszuführen. Noch viel deutlicher zeigt sich der hemmende Einfluß des hellen Lichtes bei den Versuchen mit Nährsalzkulturen. Beim Uebergang in Wasser und bei Gegenwart eines solchen Lichtes findet keine Zoosporenl,ildung statt; man mufs stets verdunkeln. Der Reiz des Wechsels von Licht und Dunkelheit ist andererseits im Sommer so stark, daß es gar nicht nötig ist, die Alge zugleich einem Mediumwechsel zu unterwerfen. Zellen in ihrer unveränderten Nührlösung von $0,2-\cdots, 4$ Proz. bilden, ins Dunkle gebracht, lebhaft Zoosporen; sie thun es sogar, ähnlich wie Zellen ron Protosiphon, wenn man die Konzentration der Nährlösung steigert. So heobachtete ich Zoosporen beim Uebergange aus o,2-proz. in I-proz. Lösung. Der hemmende Einfluß des hellen Lichtes zeigt sich auch darin, daßs die Zellen, aus Nährlösung in Wasser übergeführt und hell kultiviert, nicht mehr recht die Fähigkeit haben, nach Versetzung ins Dunkle Zoosporen zu bilden; jedenfalls ist das Resultat sehr unsicher.

Im Winter, vom Olitober bis Närz in Nährlösung aufgewachsene Zellen verhalten sich etwas anders. Das Licht ist so schwach, daß es nicht hemmend, sondern erregend auf die Zoosporenbildung wirkt. Daher beobachtet man in cler Nährlösung von O, I Proz. beständig eine geringe Zoosporenbildung; erst in stärker konzentrierten Lösungen, z. B. von 0,4 Proz., verhindert der Salzgehalt den Prozeß. Bei allen solchen Nährsalzkulturen ist der Uebergang aus dem schwachen Tageslicht in clie Dunkelheit für sich allein so wenig wirkungswoll, dafi dabei ohne gleichzeitive Aenclerung des Mediums die Zoosporenbildung nur in schwachem Cirade, oder überhaupt nicht erregt wircl. Daher ist für die Winterszeit der Uebergang aus 
Nährlösung in Wasser bedeutungsvoller als im Sommer; er kann schon genügen, um in schwachem Licht allein den Prozeß zu erregen; am besten ist es aber, wenn man den Reiz durch Lichtmangel noch verstärkt.

Das schwache Tageslicht im Winter oder der völlige Lichtabschluß ist der Hauptgrund für die Erscheinung, daß die Zoosporen-Keimlinge im Wasser sofort wieder Zoosporen bilden; das kann mehrere Generationen hindurch vor sich gehen. Bei hellem Licht wachsen dagegen die Keimlinge und teilen sich auch, wenn genügende Nährsalze ihnen zur Verfügung stehen.

Aus diesen Darlegungen geht so viel hervor, daß die mancherlei Unregelmäßigkeiten in dem Stattfinden oder dem Fehlen der Zoosporenbildung sich erklären lassen durch die Wirkungen der unter gewöhnlichen Verhältnissen wechselnden Licht- und Temperatur-Einflüsse, wenn sich auch nicht für jeden einzelnen Fall der Zusammenhang genau nachweisen läßt. Es kommt noch hinzu, daß der Ernährungszustand des Versuchsmaterials ebenfalls wichtig ist. Lebhaft wachsende Kulturen auf Lehm oder in Nährlösungen müssen für die Versuche benutzt werden. Bei sehr langem Aufenthalt in wenig und nicht gewechselter Nährlösung oder bei Lehmkulturen, die allmählich trocken werden, geraten die Zellen von Bumilleria in einen Zustand, wo sie überhaupt wenig reaktionsfähig sind. Bemerkt man dies bei einer Kultur, so muß man die Alge wieder in günstige Ernährungsbedingungen bringen. Auf den Einfluß organischer Lösungen will ich nicht weiter eingehen, da ich bisher keine besonderen Wirkungen durch solche beobachtet habe; ebensowenig habe ich mich mit dem Einfluß des Sauerstoffs näher beschäftigt. 


\section{Die Bildung von Dauerzellen.}

Borzi hat zweierlei Ruhezustände bei B. sicula bewachtet. An dem natürlichen Standort der Alge fand er im Herbst protococcusartige, rundliche Zellen mit rötlichem Inhalt. Aus diesen Zellen entwickelten sich kleine Schwämer mit 2 Wimpern und einem einzigen Chromatophor; je zwei Schwärmer kopulierten und bildeten $\mathrm{Zy}$ goten, die mehrere Monate ruhend blieben; ganz kurz wird dann erwähnt, daß aus diesen Zygoten neue Fäden der Bumilleria hervorgingen. In dieser Darstellung ist zunächst sehr auffällig, daßß die Gameten aus Ruhezuständen entstehen und gleich wieder Ruhezustände bilden sollen. Borzi hat nicht nachgewiesen, daß die protococcusartigen Zellen wirklich von Bumilleria herstammen; das Vorkommen auf dem gleichen Standort beweist nichts. Da Borzi keine Reinkulturen zur Verfügung hatte, ist es auch unsicher, ob die Zellen, welche neue Fäden lieferten, wirklich Zygoten waren, oder nur ähnlich aussehende, vegetative Ruhezellen ron Bumilleria. So erscheint die sexuelle Generation dieser Alge noch sehr zweifelhaft. In einem anderen Falle hat Borzi zufällig Ruhezellen gesehen mit einer derben Membran, an der sich lileine Rauhigkeiten befanden. Diese Zellen, "Ipnospore“, lieferten bei der Keimung Schwärmer, die den vorhin erwähnten Gameten ähnlich waren; indessen lionnte Borzi nicht zur Gewißheit larüber liommen.

Ich habe meine besondere Aufmerksamkeit darauf crerichtet, die sexuelle Generation zu finden; bisher habe ich keine Andeutung, daß eine solche existiert, bemerken können; ich muß die Entscheidung der Frage späteren Untersuchungen überlassen. Jedenfalls braucht Bumilleria sicula nicht geschlechtlich erzeugte Ruhezustände, da die 
vegetativen Zellen im Stande sind, zu Dauerzellen zu werden. Allerdings haben sie nicht die Fähigkeit, unmittelbar wie die Zellen von Conferva minor, Hormidium nitens und flaccidum Trockenheit zu ertragen. Läßt man Fadenstücke schnell auf dem Deckglas eintrocknen, so gehen sie zu Grunde. Ganz anders verhält sich die Sache, wenn man eine Lehmkultur ganz langsam in hellem Lichte eintrocknen läßt. Wie wir gesehen haben, zerfallen alle Fadenstücke unter diesen Umständen schließlich in einzelne Zellen, die in Haufen zusammenliegen. Die einzelne Zelle füllt sich mit fettem Oel, erhält eine derbere Membran und wird zur Dauerzelle (Taf. II Fig. I4). Nach wochenlanger Trockenheit habe ich die Zellen in Wasser oder in Nährlösung gebracht; die Zellen strecken sich dann und beginnen sich schnell in der Nährlösung zu teilen. $\mathrm{Ab}$ und $\mathrm{zu}$ werden von ihnen im Wasser Zoosporen gebildet, die vollkommen den sonstigen Schwärmern entsprechen. Niemals tritt in solchen Dauerzellen ein rötliches Oel auf; der ganze Algenüberzug erscheint im trockenen Zustande vielmehr hell gelbgrün, weil das Chlorophyll zum Teil durch fettes Oel verdeckt ist.

\section{Bumilleria exilis Klebs.}

(Taf. II, Fig. 15-20.)

An dem gleichen Standort mit B. sicula fand ich im Frühjahr I895 eine Alge, die durch die Dünnheit ihrer Fäden ausgezeichnet war; der Durchmesser betrug 3,5-4 $\mu$, im Max. $4,5 \mu$. Eine Anzahl solcher schmalen Fadenalgen ist bereits beschrieben worden; von den genauer untersuchten sind zu erwähnen Ulothrix tenerrima, 
deren Zellen indessen nach Gay (9I S. 7I) einen Durchmesser ron $\delta$ " besitzen und überhaupt den Charakter ron Ulothrix zeigen; letzteres gilt auch für die Ul. subtilissina Gay, die in der Dünnheit an B. exilis erinnert. Ebensowenig stimmt mit dieser Alge die Conferva tenuissima überein, die nach Gay (1. c. S. 36) Keimlinge mit Haftscheibe wie eine typische Conferva bildet.

Abgesehen von dem großen Unterschied im Durchmesser, unterscheidet sich B. exilis von sicula dadurch, daß sie, wie die Mehrzahl der Ulothricheen lange Fäden bildet, deren Zellen häufig an den Querwänden etwas eingeschnürt sind (Taf. II, Fig. I7). Der stärkere Zusammenhang der Zellen bei exilis kommt jedenfalls zu Stande, indem nach der Teilung die alte Mutterzellhaut nicht plötzlich zerreisst, sondern ganz allmählich ausgedehnt und dabei mit den Tochterzellhäuten völlig verklebt wird, so daß Rißstellen nicht zur Beobachtung kommen. Den Zellen resp. Zellfäden fehlen daher auch die etwas abstehenden Zellwandhauben wie bei sicula. Die Zellhaut der einzelnen Zelle verhält sich wie bei sicula; bei der Quellung durch konzentrierte Schwefelsäure platzt die Haut seitlich. Der Zellinhalt umschließt gewöhnlich 2 Chromatophoren, einen Zellkern, Plasma und kleine Fetttröpfchen; Stärke wurde niemals beobachtet.

Die Kultur der Alge gelingt leicht in Nährlösungen von $0,2-0,4$ Proz., ebenso auf feuchtem Lehm. Im ersteren Falle bilden die langen Zellfäden ein zartes, auf der Oberfläche schwimmendes Häutchen; oder auch (z. B. in O,I-proz. Lösung) zusammenhängende, zarte, grüne, untergetauchte Fadenmassen. Die Fortpflanzung geschieht, wie bei sicula, durch Spaltung, Bildung von Zoosporen und Ruhezellen.

Bei der Spaltung verhält sich ein Faden von B. exilis wie ein solcher von Hormidium nitens. Sie tritt ein 


\section{$-391$}

hauptsächlich bei allmählichem Eintrocknen (Taf. II Fig. 15), aber ebenso auch bei langer Kultur in Nährlösungen, wenn die chemische Zusammensetzung ungünstig verändert ist; sie tritt auch bei Aufenthalt in reinem Wasser bei Gegenwart von Licht ein.

Die Zoosporen ( $\mathrm{Lg} .=4,5-5 \mu, \mathrm{Br} .=\mathrm{r}, 8-2 \mu)$ entstehen zu 2 in einer Zelle und werden durch ringförmiges Platzen der alten Zellhaut frei; der Faden zerfällt hierbei wie bei einer Conferva in $\mathrm{H}$-förmige Stücke (Taf. II Fig. I6). Die Zoosporen (Fig. I9 $a-c$ ) sind schmal eiförmig bis fast cylindrisch, meist leicht an der Seite eingebuchtet. Sie besitzen eine Wimper und an den Längsseiten 2 Chromatophoren. Das Hinterende tritt nicht als ein so besonderer Teil hervor wie bei sicula; aber die ganze Zoospore ist ebenfalls lebhafter, amöboider Bewegung fähig. Bei der Keimung wird die Zelle kugelig oder breit oval; ein Rhizoid wird nicht entwickelt. Die jungen Keimlinge vermögen unter günstigen Ernährungsbedingungen bei Gegenwart von Licht und Nährsalzen sich zu strecken und zu teilen; im Dunkeln können sie sofort wieder je eine Zoospore bilden (Fig. 20 $a-c$ ).

Die physiologischen Bedingungen der Zoosporenbildung bei $\mathrm{B}$. exilis sind im wesentlichen die gleichen wie bei sicula. Im Winter I895/96 habe ich, um die feineren Unterschiede zu beobachten, die Versuche immer gleichzeitig mit beiden Arten angestellt. B. exilis kann schon zwischen $\mathrm{O}-\mathrm{I}^{\circ}$ Zoosporen bilden; ich habe solche sogar bei $0^{0}$ beobachtet. Die obere Temperaturgrenze scheint die gleiche wie bei sicula zu sein; doch ist der Nachweis aus früher besprochenen Gründen (S. 382), die auch für exilis gelten, nicht ganz sicher. Der hemmende Einfluß des Lichtes auf die Zoosporenbildung prägt sich bei $B$. exilis noch deutlicher aus als bei sicula, so daß sogar im Winter die Zellen beim Uebergang aus Nähr- 
lïsung in Wasser, im Licht nicht so lebhaft Zoosporen. bilden als die von sicula; erst in sehr schwachem Licht, noch mehr in Dunkeln, tritt der Prozeß in lebhaftem Grade ein.

Jede /elle von B. exilis ist im Stande, zur Dauerzelle zu werden; in dieser Beziehung nähert sich die species selır den Hormidium-Arten. Ich habe nach langsamem Eintrocknen in feuchten Kammer-Kulturen das Wiederaufleben der Zellen beobachtet, während B. sicula unter gleichen Umständen zu Grunde ging. Bei allıählichem Eintrocknen der Lehmkulturen, wo zugleich ein Zerfall der Fäden in einzelne Zellen erfolgt, kann man die Dauerzellen in größter Menge erhalten; sie sind mit fettem Oel erfüllt und mit etwas derberer Membran als sonst versehen (Fig. I $8 a-b$ ).

Zum Schluß dieses Albschnittes erscheint es passend, eine kurze Charakteristik der Hauptgattungen der Ulothricheen zu geben, da sie sich durch meine Untersuchungen über Ulothrix, Hormidium, Conferva, Bumilleria vielleicht etwas verbessern läßt. Ich gehe aus von der vortrefflichen Bearbeitung dieser Familie durch Wille (90) in Engler und Prantl's ,Natürlichen Pflanzenfamilien“.

\section{Ulothrix Kiitzing.}

Fäden mit besonderer Basalzelle; Zellen mit einem ringswandständigen, plattenförmigen Chromatophor, einem oder mehreren A mylonkernen, außerdem mit Stromastärke. Zoosporen mit 4 Wimpern, einem Augenfleck, durch ein seitliches Loch austretend, zu ein bis vielen in einer Zelle entstehend, bei der Keimung ein Rhizoid bildend. Microzoosporen mit 4 oder 2 Wimpern, bei Temperaturen unter IO keimend. Gameten mit 2 Wimpern, zu je zweien kopu- 
lierend. Zygoten bei der Keimung 4 oder mehr Keimlinge erzeugend.

Die einzige, einigermaßen bekannte Species ist zonata mit zahlreichen Standortsformen. Die sonst im Wasser vorkommenden Arten sind noch sehr wenig bekannt; eine genaue Untersuchung mit Rücksicht auf die physiologischen Charaktere wäre sehr notwendig; wahrscheinlich wird man die Gattung später teilen müssen.

\section{Hormidium Kiitzing.}

Fäden ohne basale Zelle. Zellen mit einem plattenförmigen Chromatophor, einem Amylonkern und mit Stromastärke. Vermehrung durch Zerspaltung der Fäden in kleinere Stücke oder einzelne Zellen. Zoosporen nur von einerlei Art bekannt, mit 2 Wimpern, ohne Augenffeck, einzeln in einer Zelle entstehend, sich durch ein seitliches Loch durchpressend. Keimung ohne Rhizoidbildung. Jede Zelle im Stande, einen Dauerzustand zu bilden.

Die bisher näher bekannten Arten sind Hormidium nitens und flaccidum. Wahrscheinlich gehört hierher auch Gloeotila mucosa, die von Borzi (95 S. 357) neuerdings genauer beschrieben worden ist. Dagegen sind von der Gattung die Arten mit sternförmigem Chromatophor zu trennen (s. Schizogonium unten).

\section{Bumilleria Borzi.}

Fäden ohne basale Zelle. Zellen mit mehreren, kurz plattenförmigen Chromatophoren, ohne Amylonkern, ohne Stärke. Vermehrung durch Spaltung in kurze Fadenstücke oder einzelne Zellen. Zoosporen einzeln oder zu mehreren in einer Zelle entstehend, durch ringförmiges Zerreißen der Zellhaut frei werdend, mit einer Wimper, 


\section{- $394-$}

ohne Augenfleck, sehr amöboid. Keimung ohne Rhizoidbildung. Jede Zelle fähig, einen Dauerzustand zu bilden.

Die beiden bisher bekannten Arten sicula und exilis sind vorhin beschrieben worden, es ist leicht möglich, daß unter den Ulothrix - oder Conferva-Arten manche hierher gehören.

\section{Conferva Limné.}

Fäden mit basaler Zelle. Zellen mit 2 oder 4 plattenförmigen Chromatophoren, ohne Amylonkern, ohne Stärke. Membran aus $\mathrm{H}$-förmigen Stücken zusammengesetzt. Zoosporen einzeln oder zu zweien entstehend, durch Trennung der $\mathrm{H}$-förmigen Zellwandteile frei werdend, mit einer Wimper, ohne Augenfleck, amöboid. Keimung mit Bildung einer Haftscheibe. Jede Zelle fühig, einen Dauerzustand zu bilden.

Conferva ist heutzutage noch eine Sammelgattung; wahrscheinlich wird man später gut thun, eine Teilung vorzunehmen. Es giebt augenscheinlich Arten, z. B. amoena, die gar keine Zoosporen mehr zu bilden vermögen; ob nicht noch andere Unterschiede vorhanden sind, wird eine erneute Untersuchung nachweisen müssen.

\section{Microspora Thuret.}

Fäden ohne basale Zelle (?); Zellen mit einer Zellhaut wie bei Conferva, mit bandförmigen, einfachen oder verzweigten, wellig ausgebuchteten Chromatophoren, ohne Amylonkern, mit Stromastärle. Zoosporen mit 4 IVimpern. ohne Augenfleck. Nikrozoosporen mit 2 IVimpern; beide ohne Haftscheibe keimend. Verschiedenartig entstehende Dauerzellen. 


\section{- 395}

Diese Gattung, deren Kenntnis hauptsächlich Lag erheim (89) zu verdanken ist, läßt sich nach den bisherigen Angaben noch nicht recht umgrenzen; es fehlt die Reinkultur, es mangeln längere Beobachtungsreihen, so daß über eine Menge wichtiger Punkte, wie gerade über das Schicksal der Zoosporen und das Verhältnis der beiden Schwärmerarten Unklarheit herrscht.

\section{Schizogonium Kützing.}

Thallus fadenförmig oder bandförmig bis blattartig; Zellen mit centralem, sternförmigem Chromatophor. Zoosporen unbekannt. Vermehrung durch ein- oder mehrzellige, vom Thallus sich loslösende Teile.

In der Charakteristik dieser Gattung folge ich $\mathrm{G}$ a y (1. c. S. 85-86), da eigene Beobachtungen mir fehlen. Gay vereinigt wohl mit Recht Schizogonium und Prasiola. Die Gattung tritt aus dem Rahmen der Ulothricheen etwas heraus durch die Bildung des bandartigen oder flächenförmigen Thallus, und ferner durch den anscheinenden Mangel an Zoosporen.

Ueberblickt man die genannten Gattungen und sucht sich ihre gegenseitigen Verwandtschaftsbeziehungen klar zu machen, so findet man die gleiche Erscheinung wieder, auf die ich bereits in meinen Flagellaten-Studien (92) aufmerksam gemacht habe. Es erscheint unmöglich oder nur mit größter Willkür möglich, eine Stammform anzunehmen, von der aus alle anderen Formen ausgegangen sind. Die Verwandtschaftsbeziehungen gehen kreuz und quer, hin- und herüber und lassen sich nur durch ein Netz von Verbindungsfäden andeuten. Wenn wir zunächst fragen, in welcher Beziehung die Familie der Ulothricheen zu den niederen Algen, den Protococcoideen, stehe, so kann man von Hormidium ausgehen, da die Algen dieser 
Gattung unzweifelhaft mit Pleurococcaceen, z. B. Stichococcus, nahe verwandt sind; Gay vereinigt direkt beide Gattungen zu einer einzigen. Andererseits bietet sich aber auch von Ulothrix eine nahe Beziehung zu den Tetraspora-Arten (Wille 90 S. 83); die noch immer nicht klar erkannten Hormospora-Arten, gleichsam verschleimende Ulothrix-Arten, bilden anscheinend den Uebergang. Schließlich könnte man Bumilleria durch die Art sicula als ein Verbindungsglied zwischen einzelligen und fadenförmigen Algen auffassen. Innerhalb der Familie selbst kann man die einzelnen Gattungen in sehr verschiedener Weise gruppieren, je nachdem man Wert auf den Bau der Membran, des Chromatophors, der Zoosporen etc. legt. Wir haben bisher kein Mittel, die Verwandtschaftsbeziehungen, die wirklich auf gemeinsamer Abstammung von einer Urform beruhen, zu unterscheiden von solchen, die nur auf Analogieen im Entwickelungsgang, auf ähnliche Wirkungen bestimmter, äußerer Bedingungen zurückzuführen sind; so könnte z. B. der Spaltungsprozeß unabhängig von phylogenetischer Verwandtschaft bei verschiedenen Gattungen aufgetreten sein. Wenn man nun für den Augenblick die Frage offen läßt, so bleibt nichts anderes übrig, als alle Verwandtschaftsbeziehungen in irgend einer Weise anzudeuten. Ich will hier ebenso verfahren, wie bei der Besprechung der Flagellaten und die irgendwie verwandten Gattungen durch Fäden verbinden. Meine subjelstive Ueberzeugung will ich nur dadurch andeuten, daß ich die Beziehungen, die ich für wichtiger halte, durch Linien, die anscheinend weniger wichtigen durch Punktreihen bezeichne: 


\section{Protococcoideae}

Ulothrix-

Hormidium

Bumilleria

Microspora-

Conferva

Schizogonium

Jede neue Erforschung der zahlreichen, wenig oder gar nicht bekannten Arten von Ulothrix, Hormidium, Conferva wird das Bild wahrscheinlich völlig verändern. Es hat auch nur einen Augenblicks-Wert, es soll rasch eine Uebersicht der jetzigen Kenntnisse der Verwandtschaftsbeziehungen darlegen, und soll auffordern, durch neue Thatsachen, neue Auffassungen eine bessere Lösung der Frage herbeizuführen. 


\section{Stigeoclonium.}

(Taf. III, Fig. I-I3.)

Die Gattung, Stigeoclonium umschließt verzweigte, grüne Fadenalgen, ohne scharfe Sonderung von Hauptund Nebenachsen; man findet die $\lambda$ rten als schlüpfrige, meist festsitzende Polster oder Rasen in den Gewässern. Für die Systematik der Arten gilt das gleiche wie für die von Hormidium und Conferva, eine völlige Unsicherheit in der Bestimmung. Jeder, der sich mit Stigeoclonium beschäftigt. giebt die große Formveränderlichkeit zu. Aber von keiner Art sind die Grenzen ihrer Tariabilität auch nur im entferntesten bekannt; man unterscheidet die Arten in den Handbüchern nach der Dicke der Fäden, der Verzweigung, der Haarbildung, d. h. gerade nach den als variabel bezeichneten Eigenschaften. Torläufig kann man nichts anderes thun, als für irgend eine Stigeoclonium-Form nachweisen, daß sie ungefähr mit einer irgendwo beschriebenen Art übereinstimmt. Die große Unsicherheit in der Artbestimmung bringt auch nach einer anderen Richtung Uebelstände mit sich. Die von einem Forscher Leschriebenen Entwickelungszustände irgend einer Form kann man nicht sicher einer bestimmten Species zuweisen, la diese nicht genügend erkennlor ist. Das gilt gerade für jene Formen, bei denen Cienkowski $(76 a ; 76 c$ $\therefore$. Ic ff.) den Palmellen- und Protococcus-Zustand ent- 
deckt hat, der so viel Verwirrung herbeigeführt hat. Cienkowski, ebenso Famintzin, der die Beobachtungen des ersteren bestätigte (7I S. 264), haben die Arten, bei denen solche Zustände gesehen wurden, nicht genau bestimmt; man hat einfach das, was vielleicht einer oder wenigen Arten zukommt, gleich auf alle übertragen. In dieser Beziehung hat die Arbeit von Gay (9r) wertvolle Klarheit gebracht, da er bestimmte Formen längere Zeit untersucht und gezeigt hat, daß diese durchaus nicht in alle möglichen anderen Algen übergehen, sondern nur gewisse Zustände darbieten, die wohl an solche erinnern, aber doch den Stigeoclonium-Charakter niemals verleugnen. Auf die physiologischen Bedingungen der verschiedenen Entwickelungszustände hat $\mathrm{G}$ a y ebensowenig wie seine Vorgänger Rücksicht genommen. Ich habe den Hauptnachdruck gerade darauf gelegt und bin bestrebt gewesen, den Ursachen der Formveränderlichkeit von Stigeoclonium etwas nachzuspüren.

Für meine Aufgabe war es vor allem wesentlich, eine bestimmte Form stets zur Verfügung zu haben. Auf dem Teller unter dem Wasserstrahl des Brunnens siedelte sich neben Ulothrix ein Stigeoclonium an, das an diesem Standort am besten mit tenue ${ }^{1}$ ) $\mathrm{Kg}$. übereinstimmte (vergl. Kützing 49 S. 353, Kirchner 78 S. 68, Hansgirg 86 S. 66). Ich will die Alge auch weiter mit diesem

I) $\mathrm{Ob}$ das von Huber (93 S. 274) beschriebene Stigeoclonium tenue, das endophytisch in Lemna lebt, mit meiner Art identisch ist, kann ich nicht entscheiden; wahrscheinlich handelt es sich um eine andere Species. Huber zweifelt mit Recht an der Selbständigkeit der Gattung Endoclonium. Ich bin überzeugt, daß das Endoclonium polymorphum von Frank (83) nur ein Stigeoclonium ist, das er ohne genügenden Nachweis mit einer Protococcoidee in Zusammenhang gebracht hat. Fran k hat dafür nicht den entscheidenden Beweis geliefert. Die Protococcoidee ist wahrscheinlich identisch mit der von mir beschriebenen Chlorosphaera endophyta (Klebs 83 S. 334, Artari 92 S. 35). 
Namen benennen, obwohl man ihr mach ihrem Verhalten unter anderen Umständen auch andere Namen zuerteilen könnte. Die Alge hat sich seit mehr als drei Jahren ununterbrochen an dem Standort erhalten. Da ich sie zu den verschiedensten Zeiten des Jahres untersuchte und sie sich in den wesentlichen Eigenschaften, nach ihrem Benehmen bei den Versuchen im Laboratorium zu urteilen, gleich blieb, lag kein Grund zu der Annahme vor, daß vielleicht zwei verschiedene Arten vermischt waren.

Die Alge bildet während des größten Teiles des Jahres kleine, grüne Rasen auf dem Randle des Tellers; nur im Frühjahr erreicht sie eine mächtigere Entwickelung. die in den Monaten April und Mai I895 einen solchen Grad erreichte, daß die Alge den Brunnen fast auszufüllen vermochte. In derselben Zeit findet sich die gleiche Alge sehr allgemein in den meisten laufenden Brummen der Stadt Basel, aus denen sie während der übrigen Zeit des Jahres verschwunden zu sein scheint. Im allgemeinen Aufbau entspricht St. tenue der Schilderung, die Berthold (78 S. I99 ff.), neuerdings Gay (9I S. $4 \mathrm{I}$ ff.) von anderen Arten gegeben haben.

Die Alge ist durch rhizoidartige $Z$ weige, die von kriechenden Fäden auscehen, am Substrat befestigt. V'on den kriechenden Fäden erhelsen sich zahlreiche Hauptachsen, die aus lang gestreckten, an den Querwänden ein wenig eingeschnürten Zellen bestehen, und die in wechselnder Menge und Anordnung Seitenzweige entwickeln, welche aus kürzeren, gleichmäßig grünen Zellen zusammengesetzt sind. Die Mehrzahl der Seitenzweige enclet pfriemenförmig spitz, während hier und dort cinzelne in ein mehrzelliges, farbloses Haar auslaufen. Der Bau der \%elle ist von Berthol (l (l. c.), Gay (l.c.) beschrieben worden; der bandförmige Chromatophor nimmt in den älteren /sellen nur die Mitte ein, in den 
jungen fast die ganze Peripherie. Er enthält in wechselnder Anzahl Amylonkerne und kleine Körnchen von Stromastärke. In jeder Zelle pflegt ein Zellkern sich vorzufinden. Für die Besprechung des Einflusses der äußeren Bedingungen unterscheide ich:

I. die Gestaltung des Thallus;

II. die Zoosporenbildung;

III. die Mikrozoosporenbildung.

\section{Die Gestaltung des Thallus.}

Der auffälligste Charakter von Stigeoclonium zeigt sich zunächst in der Verzweigung. Berthold und Gay geben übereinstimmend an, daß der Grad der Verzweigung bei der gleichen Species sehr wechselnd sei. Diese Schwankungen können eigentlich gar keinen anderen Grund haben als den, daß äußere Bedingungen entscheidend eingreifen, und dafür läßt sich der Beweis liefern. Die Extreme, zwischen denen die Verzweigung sich bewegt, liegen beträchtlich auseinander.

Man beobachtet einerseits Fäden von St. tenue, die bei einer Länge von mehreren hundert Zellen unverzweigt sind, andererseits solche, bei denen jede einzige Zelle in einen Zweig ausgewachsen ist. Die langen, äußerst spärlich verzweigten Fäden beobachtete ich bei dem raschen Wachstum der Alge im Frühjahr I 895 in dem frischen, stets sich erneuernden Wasser des Brunnens, bei einer Temperatur von $10-12^{\circ}$, bei heller Beleuchtung. Ebenso beobachtete ich sehr lange, wenig verzweigte, dabei sehr schmale Fäden, als ich das Stigeoclonium auf Agar-Agar mit 0,2-proz. Nährlösung kultivierte.

Das andere Extrem kann man leicht erreichen, wenn man die Alge in einer feuchten Kammer, in einem Tropfen einer Nährlösung von I Proz. kultiviert. Hierbei wächst Klebs, Fortpflanzungsphysiologie. 
schließlich jede Zelle zu einem Zweige aus. Wenn man die Alge untergetaucht in einer größeren Menge derselben Nährlösung hält, so gewinnt man dicht knäuelfömige Zweigsysteme; aber die Zweige treten doch nicht so massenhaft hervor wie in der feuchten Kammer. weil das Wachstum im ersteren Falle schneller verlangsamt wird. Eine L_isung von 0,5 Proz. verhält sich wesentlich wie eine solche von I Proz.

Ein zweiter wichtiger Lmstand, der besonders die Anordnung der Zweige bestimmt, ist das Licht. Einseitig auffallend veranlaßt es einseitige Zweiglildung auf der stärker beleuchteten Seite.

Am besten macht man den V'ersuch, indem man ein kleines Stück der Alge in einer feuchten Kammer einige Tage sich an die Nährlösung gewöhnen läßt, ohne viel auf die Richtung des Lichteinfalles zu achten. Beginnt die Alge zu wachsen, so fixiert man die Kammer in einer ganz bestimmten, immer wieder leicht z.u erhaltenden Stellung zum einfallenden Licht. Dann sieht man, wie die bereits gebildeten Zweige positiv heliotropisch sich nach dem Lichte hinkrümmen; vor allem aber wachsen alle vorher unverzweisten Zellen ausnahmslos an der Lichtseite zu Zweigen aus (Taf III, Fig. 3 stellt ein Stïck eines solchen einseitig beleuchteten Thallus dar). Aucl in der freien Natur hat diese Empfindlichkeit der Alge für den Lichteinfall ihre Bedeutung. Denn an einem Polster, z. B. auf dem Teller im Brunnen, sind die peripherisch gelegenen Fäden stets einseitig beleuchtet, es erklärt sich daraus die vielfach hervortretende, einseitige Verzweigung, während hei den im Wasser schwimmenden, lockeren Fadenmassen mit dem sehr wechselnden Lichteinfalle eine sehr verschiedenartige Anordnung der Zweige sich beobachten lälst. 
Ein zweiter wichtiger Charakter, die Haarbildung, betrifft wahrscheinlicl! alle Stigeoclonium-Arten. Einerseits wird die Veränderlichkeit auch dieses Charakters betont (Berthold 1. c.); andererseits dient er wesentlich zur Art-Bestimmung (man vergl. die Diagnosen z. B. bei Hansgirg 86 S. 65-69). Für Stigeoclonium tenue wird im allgemeinen angegeben, daß die Haarbildung fehle. Das ist ungefähr richtig für die Exemplare, die in lebhaft strömendem Wasser wachsen. Die Thallusfäden meiner Brunnenkultur zeigen in der That nur relativ wenige Zweige mit deutlicher Haarbildung. Sowie aber ein Rasen oder ein paar Fäden in ruhig stehender Wassermenge, im Laboratorium kultiviert werden, wachsen überhaupt sämtliche Zweige in lange, dünne, mehrzellige Haare aus; man glaubt Stigeoclonium Longipilus oder eine andere haartragende Species vor sich $\mathrm{zu}$ sehen. Es ist nicht näher von mir bestimmt worden, welche Eigenschaften des strömenden Wassers dabei wesentlich mitwirken; vielleicht hemmt die mechanische Reibung die Haarbildung, vielleicht auch der beständige Einfluß frisch zuströmender Nährsalze.

Für die letztere Möglichkeit könnte die zweifellose Abhängigkeit der Haarbildung von dem Nährsalzgehalt des Wassers sprechen. In Nährlösungen von 0,5-I Proz. wächst die Alge die ersten Wochen noch ziemlich lebhaft; sie zeichnet sich vor den in reinem Wasser wachsenden Exemplaren höchst auffällig durch den Mangel jeder Haarbildung aus. Alle Zweige endigen in einer grünen, pfriemenförmigen Spitze. Dagegen bemerkte ich Haarbildung bei einigen Zoosporen-Keimlingen, die auf der Oberfläche der Flüssigkeit wuchsen.

Die Beziehung zwischen der Haarbildung und der chemischen Beschaffenheit des Mediums scheint nicht auf Stigeoclonium beschränkt zu sein. Zur Ergänzung möchte 
ich noch meine Versuche mit Aphanochaete repens A. Br. kurz anführen. Ich fand die Algre als Epiphyt auf Cladophora in einem Brunnen; sie zeigte sich in Form kurzer, haarloser, meist unverzweigter Zellfäden (Taf. III, Fig. I9), so daß ich sie zuerst als Herposteiron gracilis Hansgirg (88) bestimmte. Die Alge bildete lebhaft Zoosporen (Fig. 20), die mit 4 Wimpern versehen waren und die teils in Wasser, teils in Nährlösung von 0,5-I Proz. in feuchten Kammern kultiviert wurden. In Wasser wuchsen die Keimlinge zu kurzen Zellfäden heran (Fig. 2I), deren sämtliche Zellen Haare bilcleten, wie sie von $\mathrm{Huber}$ (92 S. 324; 93 Taf. IX, Fig. I-7), Klebahn (93 S. 286) für die betreffende Alge beschrieben worden sind. In Nährlösungen war das Wachstum viel lebhafter, die Alge verzweigte sich, bildete aber kein einziges Haar (Taf. III, Fig. 22). Als diese haarlosen Individuen in Wasser übergeführt wurden, beobachtete ich in wenigen Tagen das Auswachsen der Zellen in Haare. Der Versuch wurde mehrere Male mit dem wleichen Resultat gemacht.

Die beiden, den Thallus charakterisierenden Eigenschaften von Stigeoclonium, Verzweigung und Haarbildung, sind also in cler That sehr veränderlich, weil ihre Ausbildung in direkter Abhängigkeit von bestimmten, äußeren Bedingungen steht. Dieselbe Art kann in sehr spärlich verzweigten oder äußerst stark verzweigten, in einseitig oder allseitig verzweigten, in haarlosen oder reich mit Haaren versehenen Exemplaren auftreten. Die Dicke der einzelnen Zellen schwankt bei den gleichen Individuen in weiten Grenzen; man kann nur eine gewisse Maximaldicke der ïlteren Zellen angeben (IO-I5 " bei St. tenue). Das Verhältnis von Länge und Breite wechselt mit dem Alter, hängt von der Lebhaftigkeit der Teilung ab. Jüngere Zellen sind häufig isodiametrisch; ältere künnen bis 4 mal so lang als breit sein. Jüngere, 
wachsende Fäden sind meist glatt cylindrisch; ältere und besonders in Nährlösung kultivierte Fäden zeigen an den Querwänden eine mehr oder minder deutliche Einschnürung.

Prüft man, von diesen Thatsachen ausgehend, die Diagnosen der verschiedenen Arten und Varietäten von Stigeoclonium bei K ü tzing, Hansgirg u. a., so erkennt man die völlige Unzulänglichkeit der Art-Systematik, da gerade die zweifellos höchst variablen Eigenschaften allein zur Charakteristik benutzt worden sind. Wahrscheinlich muß ein Teil der mit Namen versehenen Formen gestrichen werden, weil sie bloße Standortsformen sind; es wird die Aufgabe einer besonderen Untersuchung sein, in dieser Beziehung Klarheit zu schaffen. Dagegen beweisen meine Beobachtungen nicht, daß Stigeoclonium tenue in verschiedene Arten sich umwandeln kann. Alle meine Bemühungen, den Palmellenzustand zu erhalten, wie ihn Cienkowski beschrieben hat, sind erfolglos geblieben. Man darf hierzu nicht die Erscheinung rechnen, daß in älteren Thallusfäden eine Längsteilung eintritt, daß kleine Zellkörper sich ausbilden; man beobachtet solche Teilungen unter ganz normalen Verhältnissen in fließendem Wasser. Das Charakteristische des Palmellenzustandes liegt in der Vergallertung der Membranen, den Teilungen nach allen Richtungen, dem Auseinanderfallen der einzelnen Zellen, so daß größere Palmellahaufen entstehen. Ich habe Stigeoclonium tenue monatelang in Wasser, Nährsalz- und Zuckerlösungen, auf feuchtem Agar-Agar, bei niederer und höherer Temperatur, unter verschiedener Beleuchtung kultiviert. Ueberall ist schließlich das Resultat gleich; nach Aufhören des Wachstums füllen sich die Zellen mit Reservestoffen, Stärke und Oel, und schwellen tonnenförmig bis kugelig an. In starken Nährlösungen kann auch eine Art Zerfall 
eintreten, indem die kugeligen Zellen sich von einander trennen. Aber das sind Erscheinungen, die bei der Nehrzalıl der Fadenalgen unter allmählich ungünstig cewordenen Lebensverhältnissen eintreten, ohne daß irgend ein besonderer Wert darauf zul legen wäre. Es ist mir also nicht gelungen, Stigeoclonium tenue zu dem typischen Palmellenzustand zu bringen; meine Beobachtungren bestätigen das, was G a y für andere Arten bereits behauptet hat.

Andererseits sind die Beobachtungen Cienkowski's jedenfalls richtig; ich habe sie selbst gelegentlich an Stigeoclonien einer Zimmerkultur liestätigen können, besafs aber zu wenig Material, un eine genauere Untersuchung anzustellen. Wahrscheinlich handelt es sich um cine hesondere Species; die physiologischen Bedingungen ihrer Entwickelungszustände sind bisher unbekannt. Würde man sie kennen, so wäre es vielleicht möglich, auch Stigeoclonium tenue zu ähnlicher Entwickelung zu veranlassen.

\section{Die Zoosporenbildung.}

Die Zoosporen von Stigeoclonium-Arten sind von Thuret (50 S. 222), Cienkowski (76a), Gay (9I S. 41) u. a. beschrieben worden. Sie entstehen meistens an (len Enden von Zweigen (Taf. III, Fig. I-2), unter Lmständen auch an älteren Zellen (Fig. 4) und treten aus einer seitlichen, verquellenden Stelle der Zellhaut heratus. Sie sincl bei St. tenue (Fig. $5(t-c)$ länglich eiförmig, an der Spitze mit 4 Wimpern versehen und erreichen durchschnittlich eine Länge von I2-I4 "I und eine Breite von 5,5-0,5 $\mu$. Im vorderen, farblusen lincle befindet sich ein Paar kontraktiler Vakuolen; der Augenfleck ist im Verhältnis zur Größe der Zoosporen 
nicht sehr deutlich. Er liegt etwa im mittleren Teil des Körpers, der Hautschicht nahe. Die Bedingungen der Zoosporenbildung scheinen im wesentlichen die gleichen zu sein, wie bei der am gleichen Standorte wachsenden Ulothrix zonata. Den Hauptreiz für die Veranlassung lebhafter Zoosporenbildung übt auch bei Stigeoclonium der Uebergang aus dem bewegten in ruhig stehendes Wasser aus. Mag man das Stigeoclonium vom Brunnen nehmen, zu welcher Jahreszeit es sei, stets erhält man auf die angegebene Weise Zoosporen, die um so reichlicher auftreten, je kräftiger vorher das Wachstum war. Daher gelingen die Versuche am besten in den Monaten Februar bis Mai. Dann kann die Zoosporenbildung eine Auflösung aller Zweige herbeiführen, so daß nur die älteren Thallusteile übrig bleiben.

Die Temperatur übt nur indirekt einen Einfluß auf den Prozeß aus. Von ihr hängt neben der Beleuchtung das ganze Wachstum des Thallus ab; die günstigste Temperatur ist nach meinen Erfahrungen eine solche von IO- $12^{\circ}$. Aber schon bei $4^{\circ}$ kann im Februar bei hellen Tagen die Alge sich kräftig entwickeln. Dagegen schädigt und hemmt höhere Temperatur das Wachstum; bei $15-17^{\circ}$ geht die Alge sehr zurück und erhält sich nur in unbedeutenden Polstern. Die Zoosporenbildung, durch den Wechsel des Mediums erregt, findet auch statt, wenn die Temperatur sich gleich bleibt oder verringert wird. Selbst bei O- $\mathrm{I}^{0}$ sah ich Jewegliche Zoosporen; lebhafter erfolgte die Bildung bei $3-4^{\circ}$. Andererseits hört der Prozeß bereits bei $24^{\circ}$ auf. Das Temperatur-Maximum liegt für das Leben der Alge bei ca. $27^{\circ}$. Nach 24-stündigem Aufenthalt im Dunkeln bei dieser Temperatur stirbt der größere Teil der Zellen ab.

Auch das Licht wirkt nicht in specifischer Weise auf die Zoosporenbildung ein. Helle Beleuchtung ist für 
eine kräftige Entwickelung der Alge notwendig. Daher kommt es, daß sie auch bei günstiger Wassertemperatur im November, Dezember nie so üppig gedeiht, als in den Monaten Februar, März etc., die durch klare Tage sich durchschnittlich auszeichnen. Die Zoosporenbildung geht, nach dem Uebergange der Alge aus dem Brunnen in ein kleines Gefäß, während der ersten Tage im Licht wie in der Dunkelheit vor sich; sie hört im letzteren Falle aber schneller auf, was besonders bei Anwendung einer Rohrzuckerlösung von 2 Proz. auffällt. Der Mangel des Lichtes schädigt die Alge und hemmt dadurch auch die Zoosporenbildung.

Zuckerlösungen wirken nur dahin, daß die Zoosporenbildung, namentlich bei Temperaturen von 4-10 ${ }^{\circ}$, längere Zeit fortgeht. In Nährsalzlösungen hört der Prozeß schneller auf als in Wasser. In einer Lösung von 0,5 Proz. tritt noch eine Anzahl Zoosporen auf; in I-proz. Lösung geht die Mehrzahl zu Grunde, eine kleine Menge keimt innerhalb der Mutterzellen.

Wenn St. tenue einige Tage sich im Zimmer hefindet, so hört (lie Zoosporenbildung auf und erscheint nicht wieder. Sie verschwindet um so schneller, je höher die Temperatur ist. Die Alge wächst, teilt und verzweigt sich in solchen Kulturen, namentlich wenn diese etwas Nährlösung enthalten, aber sie erzeugt keine Zoosporen heim Uebergang aus Licht in Dunkelheit oder aus niederer in höhere Temperatur. Selbst der Uebergang aus Nährlösung in Wasser wirkt nur sehr schwach, so daß ganz vereinzelte, oft aber gar keine Zoosporen auftreten. Dagegen wenn man die Alge wieder in den Brunnen unter den Strahl des Wassers bringt, so erhält sie ihre Reizbarkeit von neuem. Indessen wäre es doch wohl möglich, Kulturlsedingungen aufzufinden, die auch im Laboratorium wicklerholte Zoosporenbildung grestatteten'. Ich beobachtete 
in einem Glase mit 0,2-proz. Nährlösung, das während des Monats Oktober 1894 im Aquarium bei IO-I2 ${ }^{0}$ schwamm, die Entwickelung eines Stigeocloniums, das in dieser Lösung während längerer Zeit Zoosporen bildete. Doch war ich nicht sicher, ob es sich um St. tenue handelte. In der Brunnenkultur selbst findet beständig Zoosporenbildung statt; welche äußeren Bedingungen diese bewirken, habe ich nicht sicher feststellen können. Vielleicht spielen kleine Veränderungen des Sauerstoffgehaltes eine gewisse Rolle dabei.

\section{Die Mikrozoosporen.}

Cienk owski ( 76 c S. 24) hat zuerst kleine Schwärmer bei Stigeoclonium beobachtet, die er Mikrogonidien nannte; sie entstanden besonders aus dem Palmellenzustand durch successive Teilung der einzelnen Zellen. Die Schwärmer besaßen 2 Wimpern (ein Exemplar 76 S. 24 hatte 4) und keimten direkt ohne Kopulation. Reinhardt (76) behauptete, daß eine Kopulation stattfände, die er allerdings nicht beobachtet hat. Er hat kleine, grüne, oft X-förmige Zellen für Zygoten gehalten, welche bei der Keimung kriechende Fäden bildeten, die zu Stigeoclonium heranwuchsen. Das sind meines Wissens die einzigen Angaben, auf die sich Hansgirg (86) und Wille (90) in ihren Handbüchern stützen, wenn sie der Gattung Stigeoclonium geschlechtliche Schwärmer zuschreiben.

Unstreitig besitzt Stigeoclonium neben Zoosporen eine zweite Art von Schwärmern, die aber bisher nicht richtig beschrieben worden sind; ich weiß nicht, ob sie mit den Mikrogonidien von Cienkowski identisch sind. Zum ersten Male beobachtete ich sie im Juni I894, genauer und öfters im Mai I 895. In diesen Monaten erreichte die Alge im 
Brunnen ihre mächtigste Entwickelung; die steigende Temperatur, in Verl,indung mit der stärkeren Sonnenwirkung, war wohl der Grund, daß die früher ausschließlich herrschende Neigung zur Zoosporenbildung durch eine solche zur Mikrozoosporenbildung ersetzt wurde. Besonders waren die Farlenmassen ahseits vom Wasserstrahl, im ruhigeren Teile des Brunnembehälters zu den folyenden Versuchen sehr geeignet. Während die Fäden im Brunnen, so viel ich sehen konnte, nur Zoosporen erzeugten, entwickelten sie, ins Zimmer gebracht, große Mengen der Mikrozoosporen, besonders massenhaft, wenn man die Fäden in Rohrzuckerlösung von 2 Proz. brachte und hell stellte. Die Bildung war dann so stark, daß die ganzen Faclenmassen, Haupt- und Nebenachsen, völlig aufgelöst wurden mit Ausnahme der ältesten Thallusstücke.

I) Mikrozoosporen (Taf. III, Fig. I3) entstehen meist zu 4 durch successive Teilung des Zellinhaltes, wobei aber immer zarte Teilungswände gebildet werden. Sie sind heträchtlich kleiner als die Zoosporen; ihre Länge = 7 () ", Breite $=5-6,3$ \%. Sie besitzen stets 4 Wimpern. Charakteristisch ist gegenüber den Zoosporen die Lage des Augenfleckes, der sehr deutlich als rotes Stäbchen im unteren Teile (Fig. 6) des Körpers hervortritt. Die Mikrozoosjoren lassen sich auch an der Art ihrer Bewegung erkennen, da sie nicht gleichmäßig rotierend sich fortbewegen, sondern äußerst unregelmäßig im V'asser hin und her fahren oder sich zeitweilig auf der Stelle drehen. Sie bewegen sich auch viel länger als die Zoosporen, die nach wenigen Stunden zur Ruhe kommen. Isolierte Mikrozoosporen bewegten sich im W Wasser oder 2-proz. Rohrzuckerlösung bei einer Temperatur von $\mathrm{I}^{6}-2 \mathrm{O}^{\circ}$ der Nelurzahl nach 24 Stunden; eine kleine Anzahl noch nach 48 situnclen. Sie scheinen etwas lichtempfindlicher als die Zoosporen zu sein, analog den Mikrozoosporen von Ulothrix zonata (s. S. 3I6). 
Ueber den Einfluß des Lichtes bin ich nicht völlig ins klare gekommen. Es ist zweifellos, daß im Dunkeln im Wasser wie in Rohrzuckerlösung sehr zahlreiche Mikrozoosporen entwickelt werden, daß aber der höchste Grad ihrer Entwickelung bei Rohrzuckerlösungen, die beleuchtet wurden, bemerkbar war. Bei Wasserkulturen, die sonnig standen, war die Bildung bisweilen behindert, vielleicht weil die Algen zu schnell indifferent wurden. Im ganzen darf man sagen, daß der Prozeß nicht vom Licht direkt abhängig ist.

Die Mikrozoosporen haben niemals kopuliert; ich habe mich davon durch ununterbrochene Beobachtung feuchter Kammerkulturen überzeugt. Alle kamen ohne Ausnahme zur Ruhe und bildeten für sich kleine, grüne Sporen (Taf. III, Fig. 9). Diese vermögen nach einiger Zeit.zu keimen; so sah ich es am I4/V. 1895 z. B. bei einer Anzahl Sporen, die am 9./V. I895 im Wasser entstanden waren und dann in Nährlösung von o,4 Proz. gebracht wurden. Ebenso beobachtete ich die Keimung am 15./V. an Sporen, die am 2./V. in I-proz. Nährlösung übergeführt worden waren.

Die Zeit, welche die Sporen für ihre Keimung brauchen, wechselt sehr nach den einzelnen Zellen. Es kann vorkommen, daß die frisch gebildeten Sporen schon nach wenigen Tagen keimen, während andere nach mehreren Wochen noch unverändert sind. Auch die Art der Keimung ist nicht immer die gleiche. Die Spore kann, ohne sich viel zu vergrößern, direkt zu einem Keimfaden nach einer Seite auswachsen (Taf. III Fig. Io). In der Mehrzahl der Fälle wird die Spore etwas größer und teilt sich in 2, 4, bisweilen noch mehr Zellen (Fig. II - I2). Jede dieser Zellen ist im Stande, auszuwachsen, wenn auch häufig die eine Zelle damit voraneilt, während die anderen zurückbleiben und erst später lieimen, wobei 
dann eine Lockerung des gegenseitigen Verbandes eintritt. Bei den zweizelligen Keimkugeln sah ich auch, daß die beiden Zellen gleichzeitig nach entgegengesetzter Richtung auswuchsen. Die Sporen haben die Fähigkeit, Trockenheit auszuhalten. Ich ließ eine feuchte Kammer mit Sporen vom 2. V. I 895 an völlig austrocknen und fügte dann am I2. V. etwas Nährlösung hinzu. Eine Anzahl Sporen war lebend geblieben und keimte.

Die Mikrozoosporen und ihr Umwandlungsprodukt, die Sporen, stellen eine zweite Fortpflanzungsform vor, deren Bedeutung darin liegt, daß sie der Erhaltung der Species unter ungünstigen, äußeren Umständen dienen. Die von mir beolachteten Sporen entsprechen augenscheinlich den Ruhezellen, welche Pringsheim (60 S. 18) bei Stigeoclonium beschrieben hat. Auch Gay hat solche Dauerzellen bei St. variabile gesehen, bei welcher Species die Sporen zu einer oder mehreren in einer Mutterzelle entstehen, und von der alten Membran locker umkleidet bleiben. Bei einer anderen Species sah Gay (9I Fig. 53-55) die Keimung der braunrot gefärbten Sporen, die nach Zerreißung der äußersten Membranschicht, ohne vorhergehende Teilung, einen Keimfaden erzeugten. 


\section{Draparnaldia.}

(Taf. III, Fig. I4-I8.)

$\mathrm{Zu}$ den ihrem Aufbau nach hochstehenden Algen gehört die Gattung Draparnaldia, die mit Stigeoclonium, Chaetophora u. s. w. zur Familie der Chaetophoreen gerechnet wird. Der Thallus zeigt eine Sonderung von Hauptachsen, die, durch besondere Rhizoidfäden am Substrat befestigt, aus großen, wenig grünen Zellen bestehen, und von büschelförmig zusammensitzenden Zweigen, die in lange Haare auslaufen und die allein bei der Fortpflanzung thätig sind. Die Zellen dieser Seitenbüschel sind kleiner, lebhafter grün und sind daher auch die eigentlichen Assimilationsorgane [vergl. über den Aufbau Berthold (78), Gay (9I), Wille (90)]. Der ganze Thallus ist von einer mächtigen Gallerthülle umgeben. Die gewöhnliche Art ist glomerata, die mir allein zur Verfügung stand. Sie kommt bei Basel in strömenden Gewässern, z. B. in der Wiese, ebenso in kleineren Wassergräben vor. Meine Untersuchung beschränkt sich nur auf einige Punkte; ich habe eine längere Kultur der Alge nicht angestellt. Ich habe ihre Eigenschaft benutzt, in einem kalten Zimmer sich lange frisch zu erhalten, wenn auch ihr Wachstum dabei verringert ist. Ferner habe ich häufig frisches Material aus der freien Natur angewandt. 
Die Fortpflanzung von Draparnaldia geschieht durch lie Zoosporen, die seit lange bekannt sind, und durch Mikrozoosporen, welche bisher sehr wenig erforscht waren, deren Existenz aber aus dem Vorhandensein von Rubesporen vermutet wurde.

\section{Die Zoosporenbildung:}

Die Zoosporen sind oft beschrieben worden, so von Thuret (50 S. 222), Berthold (78 S. 209), Gay (9I S. 53), Johnson (93 S. 294). Sie entstehen aus den Zellen der Büschelzweige mit Ausnahme der fast farblosen Haarzellen. In einer Zelle entstehen I, 2 oder 4 Zoosporen, die eiförmig bis länglich-cylindrisch geformt sind (Taf. III Fig. I4). An dem farblosen Vorderende sitzen 4 lange Cilien; dicht unter dem Ansatz befinden sich mehrere kontraktile Vakuolen, und im oberen 1)rittel des Körpers liegt an der Peripherie ein schmales, rotes Plättchen, der Augenfleck. Die Länge beträgt bis $17 \mu$, clie Breite bis $8 \mu$.

Nach einiger Zeit der Bewegung kommen die Zoosporen zur Ruhe und keimen sofort, wobei sie zu mehrzelligen Fäden heranwachsen, an deren unterem Encle sich das erste Rhizoid (vergl. Gay 9I S. 50, Borge 94 $\therefore$ 49) bildet. Wenn die Zoosporenbildung sehr lebhaft eintritt, so werden sämtliche /weigbüschel dadurch aufgrelöst; es l,leiben nur dic Hauptachsen mit den tonnenfömingen Zellen übrig. In verdünnter Rohrzuckerlösung am Licht kultiviert, sind diese /ellen im Stande neue \%weigbüschel zu bilden.

Die sicherste Methode, Zoosjorenbildung zu veranlassen, bestcht in der Ueberführung der Alge aus thiebenlem in ruhig stehendes Wasser. Den denkbar höchsten Grad, die vïllige $\Lambda$ uflösung der Zweigbüschel, erreicht 
man, wenn der Versuch im Dunkeln bei Zimmertemperatur ausgeführt wird. Die Erhöhung der Temperatur, die mit einem solchen Uebergange aus dem kühlen Bachwasser in das Wasser von Zimmertemperatur verbunden ist, kann der Zoosporenbildung förderlich sein, ist aber nicht von entscheidender Bedeutung. Der Versuch gelingt auch, wenn die Temperatur nicht verändert oder sogar erniedrigt wird. Aus der freien Natur, in stehendes Wasser von $0-0,5^{\circ}$ gebracht, entwickelt die Alge in der Regel keine Zoosporen; doch schon bei $0,5_{-}^{-}{ }^{0}$ in Rohrzuckerlösung beobachtete ich bewegliche Zoosporen. Lebhafter ist ihre Bildung bei $3-4^{\circ}$. Niedere Temperatur unter Io $^{0}$ wirkt im allgemeinen dahin, daß die Zoosporenbildung langsamer, aber andauernder fortgeht. So sah ich z. B. in einer Kultur, die am I7./I. I895 in ein kaltes Zimmer gestellt wurde, die Zoosporenbildung fortgehen bis zum 30./I.; die Temperatur schwankte während dieser Zeit zwischen 4 und $6^{\circ}$. Bringt man die Alge aus einer Temperatur von $\mathbf{O}^{-} \mathbf{I}^{0}$ in das warme Zimmer, so bewirkt die Temperaturerhöhung, daß die Zoosporenbildung lebhaft eintritt. Dagegen gelingt es nicht, bei einer Zimmerkultur, die mit der Zoosporenbildung aufgehört hat, den Prozeß wieder hervorzurufen, sei es direkt durch Temperaturerhöhung, sei es durch den Aufenthalt im Eiskasten und darauf folgender Temperaturerhöhung. Die obere Grenze der Temperatur für die Zoosporenbildung liegt etwa bei $27^{\circ}$; bei $25^{-2} 6^{\circ}$ kann die Bildung der Zoosporen wohl noch erfolgen, aber diese treten nicht mehr aus den Zellen heraus. Das Temperaturmaximum für das Leben der Alge liegt beträchtlich höher; erst bei $36-37^{\circ}$ stirbt die Alge nach 24-stündigem Aufenthalt ab.

Der Ausschluß des Lichtes fördert unstreitig den Prozeß. Bei vergleichenden Versuchen mit frischem Material, (las in Wasser oder Zuckerlösung von 2 Proz. 
verteilt und teils hell, teils dunkel gestellt wurde, zeigte sich stets die Zoosporenbildung sehr viel lebhafter im Dunkeln als im Licht. Wenn dagegen eine Zimmerkultur im Licht mit der Zoosporenbildung aufgehört hat, so ruft einfache Verdunkelung den Prozeß nicht mehr hervor.

Die Kultur im warmen Zimmer, in relativ kleiner, nicht gewechselter Wassermenge unterdrückt die Fähigkeit der Zoosporenbildung; die Alge wird gegenüluer den äußeren Reizen indifferent. Der einfachste Weg, um sie wieder reizbar zu machen, ist, die Alge in strömendem Wasser zu kultivieren. Ich brachte im April I894 eine solche indifferente Zimmerkultur in eine Glasröhre, die an beiden Enden mit groblöcherigem Stoff verbunden war und hing sie dicht unter den Strahl des laufenden Brunnens. Nach drei Tagen wurde die Kultur wieder im Zimmer hell gestellt; hier erfolgte noch keine Zoosporenbildung, während sie sich nach Verdunkelung lebhaft einstellte. Die Alge war zuerst nur für den Reiz des Lichtmangels empfindlich geworden. In einem anderen V'ersuch, wo die Alge sich längere Zeit im Brunnen aufhielt, genügte der Uebergang in stehendes Wasser, auch bei Gegenwart des Lichtes, den Prozeß zu veranlassen.

Die Reizbarkeit für Zoosporenbildung erhält sich bei Zimmerkulturen wesentlich besser und länger, wenn man die Alge in Nährlösungen kultiviert. Frische Draparnaldia, in Lösungen von $0,2-0,5$ Proz. versetzt, erzeugt zahlreiche Zoosporen, die in 0,2 Proz. noch austreten, in 0,5 Proz. vielfach gleich nach dem Austritt oder dirckt in der Mutterzelle zur Ruhe kommen. In einer Lösung von I Proz. kann in den ersten Tagen noch eine schwache \%oosporenbildung erfolgen, wobei alle Zoosporen direlit in der Nutterzelle keimen. Später tritt sie 
nie mehr von selbst auf. Dagegen geht das Wachstum und die Verzweigung weiter; die Büschelzweige verlängern sich zu langen, peitschenförmigen Fäden, bei denen die Bildung der Haarzellen gegenüber Wasserkulturen stark unterdrückt, aber nicht völlig behindert ist. Die Haarbildung bei Draparnaldia scheint daher im Gegensatz zu der von Stigeoclonium zu einer etwas fester vererbten Eigenschaft, die nicht mehr so direkt von der Außenwelt abhängt, geworden zu sein.

Die Ueberführung der Alge aus Nährlösung in Wasser ruft Zoosporenbildung hervor. Dunkelheit begünstigt den Prozeß. So gelingt es mehrere Wochen hindurch, die Alge in reizbarem Zustande zu erhalten. Zoosporen, die ich in eine Nährlösung von I Proz. brachte, wuchsen in den ersten Wochen ganz vortrefflich. Solche Keimlinge, die aus einer Hauptachse bestanden, an der gleich gestaltete Nebenachsen sich entwickelt hatten, bildeten im Wasser ebenfalls Zoosporen. Ich sah diese in allen Zellen der Hauptachse gebildet, mit Ausnahme der haarähnlichen Endzelle. Im weiteren Verlaufe der Entwickelung verlieren die Zellen der Hauptachse die Fähigkeit der Zoosporenbildung.

Rohrzuckerlösungen wirken dahin, die einmal erregte Zoosporenbildung in kurzer Zeit allgemein eintreten $\mathrm{zu}$ lassen. Bereits eine Lösung von ${ }_{4}$ Proz. behindert aber das normale Austreten der Zoosporen, noch mehr eine Lösung von 6 Proz. Sie entstehen noch in Io-proz. Lösung, obwohl diese Lösung bereits die Zellen plasmolysiert.

Das ganze Verhalten von Draparnaldia glomerata zeigt, daß sie in dem Verhältnis ihrer Zoosporenbildung zur Außenwelt sich anderen Algen des fließenden Wassers nähert, bei denen der Uebergang aus diesem in ruhig stelendes Wasser als Hauptreiz wirkt. Entklebs, Fortpfldnzungsphysiologie. 
sclieidend lafür wird wohl auch hier die Veränderung des Sauerstoffgehaltes sein (vergl. S. 87), die das Wachstum momentan hemmt und die Zoosporenbildung veranlaßst, welche dann durch Lichtabschluß und Temperaturerhöhung gefördert wird. Zugleich ist Draparnaldia noch emplindlich für den Reiz des Ueberganges aus Nährlösung in WTasser, für den andere Vertreter der Bachflora, wie Stigeoclonium tenue, Oedogonium capillare, selbst Ulothrix zonata und Vaucheria clavata, wenig empfänglich sind.

\section{Die Mikrozoosporen und Ruhesporen.}

Pringsheim (6o S. I7, I9) beobachtete zuerst bei 1)raparnaldia die Bildung von Ruhesporen, einzeln oder zu 2-4 in jeder Zelle eines Büschelzweiges. Er sah auch einen Austritt von Schwärmern, die dann gleich in der Gallerte zur Ruhe kamen. Solche Ruhezellen mit verdickter Membran, rötlich-gelbem Inhalt, meistens liettenförmig aneinandergelagert, sind seit Pringsheim vielfach beobachtet worden, so von Anderson (88), Wille (90), Gay (9I) u. a. Niemand hat aber die Schwärmer deutlich gesehen, die nach Pringsheim doch unter Umständen auftreten sollen, obwohl auch er über ihren Bau nichts aussagen kann. Nur bei Wille (S. 88) findet man noch die Angabe, daß die Schwärmer einen Augentleck besitzen und später bei (ler Sporentildung eine unregelmäßige Form annehmen können.

In Wirklichkeit sind die Dauerschwärmer, wie Pringsheim sie nannte, nicht selten; ich habe sie zu allen Jalureszeiten bei Versuchen im Laboratorium gesehen, mit Ausnahme des Herbstes, wo mir bisher, wahrscheinlich aus rein zufälligen Gründen, liein frisches 
Algenmaterial zur Verfügung stand. Zuerst beobachtete ich die Schwärmer im Januar 1894, als ich aus einer kalt stehenden Kultur einen Teil in 2-proz. Rohrzuckerlösung, ins geheizte Laboratorium stellte. Nach 24 Stunden zeigten sich zunächst die Zoosporen, nach 48 Stunden eine sehr große Menge der Mikrozoosporen. Diese zeichnen sich vor den Zoosporen durch ihre geringere Größe aus; sie sind fast um die Hälfte kleiner (Länge $=$ 8 - I2 $\mu$, Breite $=3,6-7 \mu)$. Ihre Gestalt ist eiförmig bis fast rundlich (Taf. III, Fig. I5 $a-c$ ); am Vorderende sitzen 4 Cilien, die viel länger als der Körper sind. Ein konstanter Unterschied zwischen beiden Arten der Schwärmer besteht in der Lage des Augenflecks. Bei den Zoosporen liegt er im oberen Drittel des Körpers; bei den Mikrozoosporen springt er in der unteren Hälfte des Körpers auffallend als ein schwach gebogenes Stäbchen an der Peripherie hervor. Wir bemerken ferner einen ähnlichen, physiologischen Unterschied wie bei Ulothrix zonata in ihrem Verhalten zum Licht. Die Zoosporen sammeln sich in einem breiten, grünen Rande an der Lichtseite des Gefäßes an; die Mikrozoosporen, viel lichtempfindlicher, häufen sich an einem Punkte in Form einer kleinen, grünen Wolke an. Man kann daran schon mit bloßem Auge das Auftreten der Mikrozoosporen erkennen. Auch die Bewegungsfähigkeit der Mikrozoosporen ist eine länger andauernde als die der Zoosporen. Diese kommen im Laufe weniger Stunden meist zur Ruhe, die Mikrozoosporen können sich 24 Stunden lang bewegen. Genauere Bestimmungen mit Berücksichtigung der Temperatur habe ich versäumt zu machen.

Der wichtigste Unterschied der beiden Schwärmerarten zeigt sich in ihrem weiteren Verhalten. Die Zoosporen keimen sofort, die Mikrozoosporen bilden Ruhezellen. Die interessanteste Thatsache ist, daß die Mikro- 
zoosporen die Ruhezellen sowohl mit, wie ohne Kopulation erzeugen können; Draparnaldia ist ein Organismus, bei dem die Sexualität nur gelegentlich eintritt, wenn auch die Bedingungen, die über ihr Vorkommen oder Ausbleiben entscheiden, nicht näher bekannt sind. Das Material reichte für eine eingehendere Untersuchung nicht aus.

Die Mikrozoosporen, die sich in einer grünen Wolke am Lichtrand ansammelten und sich leicht in feuchten Kammern direkt beobachten ließen, zeigten niemals bisher Kopulation, so oft ich auch die V'ersuche wiederholte. Die Schwärmer gehen im Wasser bei Zimmertemperatur schließlich zu Grunde; vielleicht daß sie sich wie die Mikrozoosporen von Ulothrix bei niederer Temperatur lebend erhalten würden. Indessen thun sie es auch im warmen Zimmer, wenn man etwas Nährlösung oder Zuckerlösung zufügt. Ein großer Teil kommt dann zur Ruhe und bildet einfache Dauerzellen (Fig. I5 $d$ ), jede nur mit einem einzigen Augenfleck, der lange sichtbar bleibt.

Andererseits ist es zweifellos, daß eine Kopulation von je zwei Mikrozoosporen stattfinden kann. Innerhalb der (iallerte der Alge sieht man eine ganze Menge Kopulationsprodukte, die an dem doppelten Augenfleck und an zwei Chromatophoren leicht kenntlich sind. Nach vieler Mühı gelang es mir, den Kopulationsprozeß direkt zu verfolgen, der sich in cilienlosen, nicht frei beweglichen Zustand vollzog (Taf. IlI, Fig. I6 $a-e$ ). Die Mikrozoosporen zeichnen sich nach dem Abwerfen der Cilien überhaupt durch eine langsame, amöboide Beweglichkeit aus, sie nehmen eine oft sehr unregelmäßige Gestalt an, kleine Fortsätze aussendend. In diesem Zustande verschmelzen zwei einander sich nähtrnde Zellen sehr langsam, so daß der Prozeß von Anfang bis zu Ende mehrere Stunden in Anspruch nimmt. Außerdem muß aber auch eine Kopulation noch schwärmender Zellen möglich sein, da ich, wenn auch 
selten, in der weichen Gallerte einzelne, mit ihrem vorderen Ende verbundene Schwärmer sah, die unter meinen Augen völlig verschmolzen.

Die Ruhezellen (Taf. III, Fig. I7 $a$ ), deren Durchmesser 8-I4 $\mu$ betrug, wenn sie aus einzelnen Schwärmern in Nährlösung entstanden waren, kultivierte ich am Licht weiter. Nach drei Wochen beobachtete ich ihre Keimung (Fig. I7 $b-d$ ). Die Sporen schwollen ein wenig an, die äußere Membran platzte, und der Inhalt, von neuer Zellhaut umgeben, trat heraus, und wuchs zu einem kleinen Zellfaden heran, dessen weitere Entwickelung nicht verfolgt wurde. Die gleiche Keimung trat auch bei Sporenmaterial ein, das einer größeren Kultur entnommen war und neben Parthenosporen sicherlich $\mathrm{Zy}$ goten enthielt. Doch war ich nicht im Stande, die beiden Sorten scharf genug zu unterscheiden, um sicher sagen zu können, daß kein Unterschied in ihrem Verhalten existiere. Jedenfalls war ein solcher Unterschied in dem Gemenge der Sporen nicht zu erkennen.

Die von mir beobachteten Ruhezellen kamen in der Nährlösung nicht dazu, den Charakter der eigentlichen Dauerzellen anzunehmen, die ihre Membran noch stärker verdicken und sich mit gelbrotem Oel füllen. Solche Dauerzellen, wie sie auch von Gay (9I S. 5I) für Draparnaldia beschrieben worden sind, fand ich bei einem Material, das mir von Herrn Hirn aus dem Schluchsee im Schwarzwald gebracht worden war. Hier sah man, wie Pringsheim und Gay erwähnen, die ganzen Büschelzweige in Ketten von Sporen umgewandelt (Taf. III, Fig. I8). Jede Zelle hatte eine gelbrote Spore gebildet. An jenen Zweigen, wo die Dauerzellen noch jung und grün waren, sah man, daß jede nur einen Augenfleck besaß. Alles sprach dafür, daß in diesem Falle ebensowohl, wie bei der von Gay untersuchten Alge alle Sporen ohne Ko- 
pulation gebilclet worden waren. Ich konnte keine einzige Zygote entdecken. Unzweifelhaft hängt es also von äußeren Bedingungen ab, ob die Mikrozoosporen kopulieren oder für sich zur Ruhe kommen. Allem Anschein nach verwirklichen sich die Bedingungen für die Parthenogenesis häufiger, als diejenigen für die Kopulation.

Die Bedingungen für die Bildung der Mikrozoosporen habe ich nicht sehr genau erforschen können; doch kann ich aus meinen Beobachtungen im Zimmer, wie in der freien Natur einige Andeutungen darüber geben.

Die Algen, die ich zu den verschiedenen Jahreszeiten, ron verschiedenen Standorten in der Umgebung Basels untersuchte, bildeten mit einer einzigen, später zu erwähnenden Ausnahme in den ersten Tagen nur Zoosporen; die Mikrozoosporen traten immer erst bei der Kultur auf. Die Algen stammten stets aus fließendem Wasser. Ich darf wohl aus den Beobachtungen und aus der Analogie mit anderen Algen schließen, daß Draparnaldia in strömendem Wasser sich meist nur durch Zoosporen vermehre. Ein sicheres Nittel, die Alge im Laboratorium zur Bildung von Mikrozoosporen zu veranlassen, habe ich bisher nicht herausgefunden. Ich erhielt sie einmal, als die Alge nach kurzem Aufenthalt im Eiskasten, im Laboratorium warm und hell gestellt wurde. Ein anderes Nal ließ ich zuerst die Alge schattig stehen und brachte sie dann in helles Licht. Die meisten V'ersuche machte ich mit einer Alge, dit aus einem Bächlein bei Allschwyl stammte und die bereits eine gewisse Neigung zur Bildung der Mikrozoosporen besals. Brachte ich einen Teil in 2-proz. Rohrzuckerlösung an das Licht, so entwickelten sich nach I bis 2 'Tagen enorme Mengen der Schwärmer. Der gleiche V'ersuch, im I) unkeln ausgeführt, lieferte dagegen nur vereinzelte Mikrozoosporen, die, ohne Sporen zu bilden, zu Grunde gingen. Ueberhaupt habe ich die Weiterentwiclielung von Mikrozoosporen nur an beleuchteten Kulturen gesehen. 
Die nähere Untersuchung des Standortes bei Allschwyl erklärte die Neigung zur Bildung der Microzoosporen. Von dem Bächlein ging an einer Stelle ein kleiner Kanal aus, der das Wasser in den benachbarten Teich führte. Bei dem niedrigen Wasserstande im Mai I 894 war das Bächlein unterhalb der Ableitung fast stagnierend geworden und wurde durch die Sonne stark erwärmt. An dieser Stelle fand sich die etwas gelblich gefärbte Alge, die lebhaft Mikrozoosporen im Laboratorium entwickelte, während die Exemplare, welche oberhalb der Ableitung im fließenden Wasser sich befanden, lebhaft grün waren und im Laboratorium zuerst Zoosporen und erst später Mikrozoosporen lieferten oder auch indifferent wurden und sich gar nicht weiter fortpflanzten. Diese oft eintretende Indifferenz bei Zimmerkulturen, namentlich bei heller Beleuchtung ist der Grund, warum der Versuch, Mikrozoosporen hervorzurufen, nicht bei jedem Naterial gelingt. Man kann aber als sehr wahrscheinlich annehmen, daß Draparnaldia durch den Aufenthalt in wenig fließendem oder stehendem Wasser, bei hellem Licht und warmem Wetter zur Bildung der Mikrozoosporen veranlaßt wird, während sie sich in lebhaft strömendem, gleichmäßig kühlem Wasser allein durch Zoosporen fortpflanzt.

Die Neigung zur Microzoosporenbildung kann man ebenso, wie die zur Gametenbildung bei Hydrodictyon, unterdrücken und durch die Neigung zur Zoosporenbildung ersetzen. Man braucht nur die Alge in eine Nährlösung von o,j oder I Proz. zu bringen. In den ersten Tagen können die Mikrozoosporen noch auftreten, wenn sie auch meist innerhalb der Gallerte ohne Kopulation zur Ruhe kommen. Allmählich wird die Alge in der Nährlösung frisch grün und beginnt zu wachsen. Wenn man nach 8 Tagen die Alge in reines Wasser überführt, so entwickelt sie nur Zoosporen. 


\section{Chlamydomonas.}

(Holzschnitt Fig. I2.)

Die Gattung Chlamydomonas gehört zu den am besten beliannten Formen niederer Organismen. Seit den Werken von A. Braun (49) und Cohn (5o u. 54) sind zahlreiche andere Arbeiten erschienen, die den Bau, den Entwickelungsgang der Gattung klar gelegt haben. Auch in systematischer Beziehung ist sie gut durchgearbeitet worden, dank den Arbeiten von Goroschankin (9o u. 9I) und neuerdings von Dill (95). Wegen der Bedeutung, welche Chlamydomonas, als wichtiger Vertreter der einfachen Volvocineen, auf dem Gebiete der niederen Organismen besitzt, lag mir viel daran, wenigstens bei einer Art die physiologischen Bedingungen ihrer Fortpflanzung kennen zu lernen. Ich machte meine Studien an einer Art, die ich für neu halten muß. Sie steht nahe der Chl. parietaria Dill (l. c. S. I2), unterscheidet sich aber wesentlich durch die Kopulation der von Membran umgebenen Gameten und schliefst sich in dieser Hinsicht mehr an Chī. Ebrenbergii Goroschankin (9I S. 39) an. Ich nenne die Art Chl. media.

Ich fand den Organismus in einer Kultur von Hormidium flaccidum und versuchte ihn gleich in Nährlösung zu züchten. Als ich bemerlite, daß er darin ausgezeichnet wuchs, isolierte ich einzelne Zellen und brachte sie in sterilisierte Nährsalzlösung von 0,2 Proz. So erhielt ich 
im Herbst I895 eine Reinkultur, von der mein Versuchsmaterial abstammt. In der Nährlösung vermehren sich die Zellen sehr lebhaft, so daß die Flüssigkeit nach einiger Zeit vollständig grün erscheint. Es ist praktisch, von Zeit zu Zeit neue Kulturen anzulegen, etwa einmal in jedem Monat, um immer recht lebenskräftiges Material zur Verfügung zu haben. Bei der Untersuchung der physiologischen Bedingungen habe ich mich bei Chl. media auf einige Hauptpunkte beschränkt.
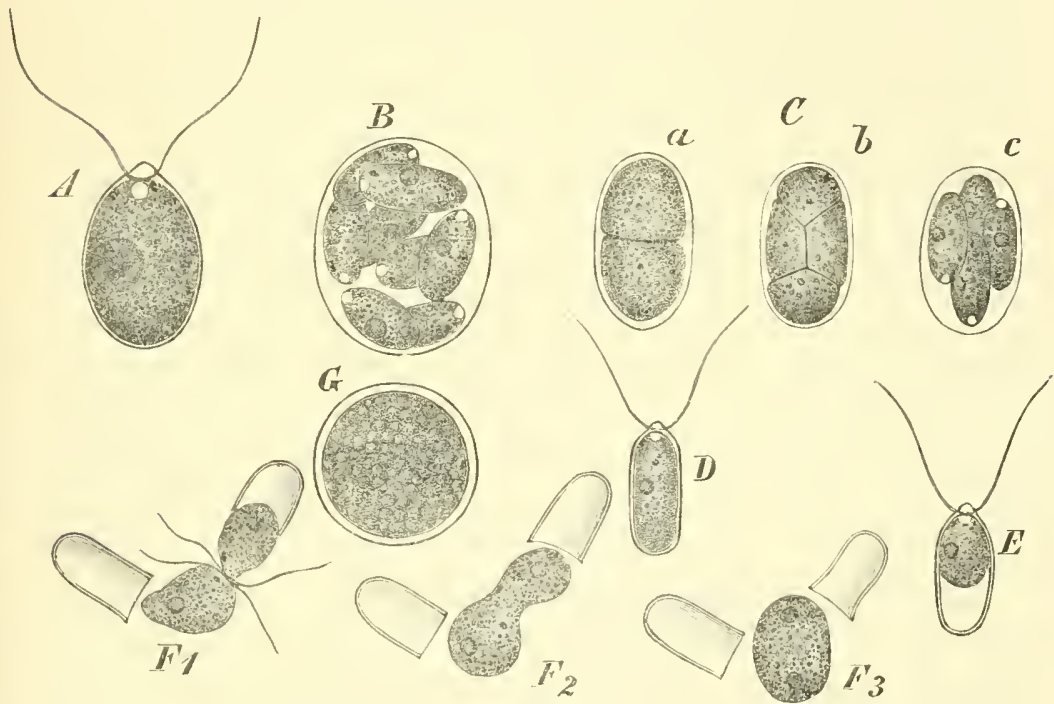

Fig. I2. Chlamydomonas media. A Ungeschlechtliche Zelle; $B$ Teilung in 8 Zellen; $C$ Teilung in + Zellen, $a-c$ mehrere aufeinanderfolgende Stadien; $D$ Gamete; $E$ Gamete mit kontrahiertem Plasmakörper; $F_{1}-F_{3}$ Stadien der Kopulation; $G$ Zygote. Vergrößerung IIOO.

Die schwärmenden, ungeschlechtlichen Zellen von Chl. media sind regelmäßig ellipsoidisch bis eiförmig, bisweilen fast cylindrisch; die größeren Individuen haben eine Länge von I8-20 $\mu$, eine Breite von II-I3 $\mu$; die 
bei lebhafter Vegetation am häufigsten vorhandenen Zellen eine Länge von 14-I6 $\mu$, eine Breite von 9-1 I $\mu$. Die Zellhaut, welche bei schwacher Vergrößerung an Vorderencle fast abgestumpft erscheint, läßt bei stärkeren Objektiven ein kleines Hautwärzchen erkennen, zu dessen Seiten je eine der krättigen Cilien oder Geißeln aus dem Körper hervortritt, genau wie bei Chl. parietaria (Dill 1. c. Taf. V, Fig. 10). In der Ruhe werden die beiden Geißeln in schiön greschwungener Krümmung gehalten (Fig. I2 A). Unterhalb des Hautwärzchens pulsieren die Vakuolen; ganz an der Peripherie liegt ein Augenfleck, der sehr wenig hervortritt, so daß er im Gegensatz zu den meisten anderen Arten bei Chl. media sehr gesucht werden muß. Der Chromatophor verhält sich wie bei Chl. parietaria, ist muldenförmig und trägt seitlich einen großen Amylonkern. In der Mitte der Zelle liegt der Zellkern. Die Fortpflanzung geschieht auf ungeschlechtlichem Wege durch Teilung, auf geschlechtlichem durch Kopulation von Gameten.

\section{Die Teilung.}

D ill hat zuerst (larauf aufmerksam gemacht, claß die Art und Weise der Teilung bei den einzelnen Species von Chlamydomonas verschieden verläuft. Die einen Arten, z. B. reticulata, teilen sich der Länge nach, andere, z. B. Reinhardti, der Quere nach. Bei einer dritten Gruppe wird die Längsteilung nur angelegt und geht (lann in Querteilung über. Ch. media gehört der zweiten Gruppe an, zeigt aber doch einige Besonderheiten.

Die Teilung geschieht, wie bei den meisten anderen Arten, in der Ruhe. Das erste deutliche Zeichen für den Beginn des Prozesses ist das Verschwinden des Amylonkernes; er wird wenigstens völlig unsichtbar und 
läßt keine 'Teilung erkennen. $\mathrm{Ob}$ irgend ein Rest von ihm übrig bleibe, lasse ich dahingestellt. Im Plasmakörper tritt feinkörnige Stromastärke auf. Man sieht dann an der einen Längsseite eine farblose Stelle auftreten, an welcher merkwürdigerweise die beiden pulsierenden Vakuolen sich befinden. Hätten diese einen festen Platz, so würde man schließen müssen, daß der Protoplast sich innerhalb der Zellhaut gedreht habe; die Teilung würde dann doch eine Längsteilung sein. Quer zur ursprünglichen Längsachse erfolgt nach Spaltung des Chromatophors eine Durchschnürung des Protoplasten (Fig. I2 $C a$ ). Gleich darauf beginnen die beiden Tochterzellen sich gegeneinander zu verschieben, so daß jetzt die Teilungsebene schief erscheint. Während der weiteren Verschiebung erfolgt die zweite Teilung (Fig. I2 $C$ b), die 4 neu entstandenen Zellen schieben sich jetzt nebeneinander, bis sie schließlich alle in der ursprünglichen Längsachse liegen (Fig. I2 $C$ c), so daß sie durch Längsteilung entstanden scheinen. In vielen Fällen kann noch eine dritte Teilung erfolgen, so daß \& Sprößlinge entstehen (Fig. I2 $B$ ).

Die Teilung findet am lebhaftesten in Nährlösungen von 0,2-0,4 Proz., bei hellem Licht und einer mittleren Temperatur von $\mathrm{I}_{5}{ }^{\circ}$ statt. Im allgemeinen erfolgt die Teilung gegen Abend bis in die Nacht hinein; so weit die Kulturen in der feuchten Kammer ein Urteil erlauben, teilt sich eine Zelle einmal während 24 Stunden, sei es in 4 oder 8 Tochterzellen.

Die Zahl der Teilungsprodulte einer Zelle richtet sich nach den vorhandenen Nahrungstoffen. Es sind besonders die großen Individuen, welche 8 Tochterzellen erzeugen; die kleineren bilden vier. Bringt man die Zellen ins Dunkele, so erfolgen in den nächsten Tagen noch Teilungen. Die Mehrzahl der Zellen erzeugt aber dann 
nur zwei Tochterzellen. Führt man dagegen den Versucl statt in Wasser in einer Zuckerlösung von 2 Proz., im Dunkeln aus, so beobachtet man häufig wieder Vierteilung. Sehr bald hört auch in Zuckerlösung die Teilung im Dunkeln auf. Der Teilungsprozeß vollzieht sich bei Chl. media noch bei sehr niedriger Temperatur. Bei $I^{0}$ sah ich Teilungen eintreten; die Zellen bewegen sich noch in Wasser von $\mathrm{O}^{0}$. Bringt man die Zellen aus der Nährlösung in Wasser, und setzt sie einer Temperatur unter $5^{0}$ aus, so hört zunächst jede Bewegung auf, es dauert einige Tage, bis sich die Zellen der niederen Temperatur angepaßt haben. Dann beginnen sie sich zu bewegen und sich zu teilen. Der Teilungsprozeß verläuft dann viel langsamer, weshalb man auch am Tage seine verschiedenen Stadien beobachten kann. Eine Folge der verlangsamten Teilung ist, daß die einzelnen Zellen viel größer werden als bei $15^{\circ}$; die Maßangaben bei den oben erwähnten, großen Exemplaren rühren von solchen Zellen aus niederer Temperatur her. Diese großen Zellen liefern regelmäßig auch bei $2-3^{\circ}$ acht Tochterzellen.

Empfindlicher sind die Zellen von Chl. media gegenüber höherer Temperatur. Allerdings liegt das Maximum relativ hoch, etwa bei $32^{\circ}$, bei welcher Temperatur die Zellen nach 24 Stunden absterben. Bei etwas niedrigerer Temperatur steht ihre Bewegung still. Bringt man Zellen aus Nährlösung in Wasser und setzt sie einer Temperatur von $2 I^{\circ}$ aus, so hört die Bewegung sehr bald auf, und es sind nur vereinzelte Exemplare, die noch eine solche zeigen. Bei 26" habe ich überhaupt keine Bewegung mehr gesehen; ebenso ist auch die Teilung selbst bei Gegenwart von Licht gehemmt. Im Dunkeln gehen die Zellen bereits bei 2 I" nach wenigen Tagen zu Grunde. 


\section{Die geschlechtliche Fortpflanzung.}

Die geschlechtlichen Schwärmer, die Gameten, von Chl. media verhalten sich im allgemeinen wie die von Chl. Ehrenbergii, reticulata Goroschankin, longistigma Dill, insofern sie vor der Kopulation mit einer Zellhaut umgeben sind. Sie entstehen durch Vierteilung oder Achtteilung. Die erstere scheint aber viel häufiger zu sein, weil die Gameten meistens aus kleineren, ungeschlechtlichen Zellen entstehen. Es ist also für die Gameten durchaus nicht notwendig, daß sie durch eine stärkere Teilung der Mutterzelle entstehen als die ungeschlechtlichen Zellen. Die Gameten (Fig. I2 $D$ S. 425) haben eine Länge von II-I3 $\mu$, eine Breite von 4,5-5,5 $\mu$, schließen sich demnach in ihrer Länge an die kleineren, ungeschlechtlichen Zellen an, sind aber meist schmäler. Indessen ist es kaum möglich, die Gameten von den kleineren Zellen zu unterscheiden, weil sie auch in ihrem Bau diesen ganz entsprechen. Anfangs sind die Gameten sehr lebhaft beweglich; bald zeigen sie eine Eigentümlichkeit, die sofort ihren sexuellen Charakter erkennen läßt und bei anderen Arten bisher nicht beobachtet worden ist. Ihr Protoplasmakörper kontrahiert sich und zieht sich gegen das vordere Ende hin, sich am Hinterende von der Zellhaut trennend (Fig. I2 E). Zuerst glaubte ich, daß der Protoplasmakörper überhaupt aus der gesprengten Zellhaut herausgetreten sei; aber ich habe mich überzeugt, daß es nicht der Fall ist. In dieser Gestalt bewegen sich die Gameten noch eine Weile lebhaft; allmählich werden sie ruhiger und zittern nur noch auf der Stelle hin und her. Dann legen sich zwei Zellen nebeneinander, die Zellhaut jeder Gamete platzt und die 
Protoplasten treten langsam heraus, wobei sie sich stärker abrunden und dicht an einander legen (Fig. I2, F. I-3). Die Wimpern gehen zu Grunde, die beiden Plasmamassen Hießen ineinander über und bilden eine Zygote, die sich bald darauf mit einer Zellhaut umgiebt. Nancherlei V'erschiedenheiten lassen sich in einzelnen Fällen beobachten. Die vorhin erwähnte Kontraktion des Plasmakörpers in noch beweglichen Zellen kann unterbleiben; sie erfolgt dann erst kurz vor oder bei der Kopulation. Vielfach sah ich, daß die eine Gamete der aktivere Teil war, der sich förmlich in die andere hinein bohrte. Die Zygote wächst zu einer dunkelgrünen Kugel heran, deren Durchmesser I6-20 " nicht verschmolzenen Amylonkerne noch sichtbar sind, während die beiden Augenflecke undeutlich werden.

Die Bildung der Gameten und Zygoten läßt sich jederzeit mit grösster Sicherheit hervorrufen. Schon Dill bemerkte bei seiner Chl. longistigma, daß die Gameten häufig auftraten, wenn er die Zellen aus Nährlösung in Nrasser brachte. Dieser Weg führt, gesundes Material vorausgesetzt, bei Chl. media immer zum Ziel. Bringt man mit ausgeglühter Nadel einige Zellen aus einer Nährlösung von 0,4 Proz. in ein kleines Gefäß mit reinem, destilliertem Wasser und stellt es hell bei einer mittleren Temperatur von ca. $15^{\circ}$, so bleiben die Zellen in lebhafter Bewegung und teilen sich normal. Man bemerkt nur am 2. und 3. Tage, daß die Zellen kleiner werden und noch rascher sich bewegen; bisweilen kann man auch schon Gameten mit kontrahiertem Plasmakörper beobachten. Im vierten Tage finden sich die ersten Zysoten; allmählich sammeln sich große Mlassen von diesen an. Die Versuche gelingen ausnabmslos, wenn man die Zellen aus frischen Nährsalzkulturen nimmt.

Von entscheidender Bedeutung für die Bildung der 
Gameten sind auch hier, analog anderen Fällen bei Algen, ein Mangel an Nährsalzen und das Licht.

Im Dunkeln erfolgt nach meinen bisherigen Versuchen niemals der Kopulationsprozeß; in den Kulturen mit Wasser kann anfangs noch Teilung eintreten, aber häufig, wie ich bemerkt habe, nur eine Zweiteilung. Allmählich hört die Teilung und die Bewegung auf. Bringt man nach einiger Zeit die Kultur ans Licht, so kann später Gametenbildung erfolgen. Zuckerlösung von 2 Proz., die die Teilung im Dunkeln etwas befördert, vermag das Licht aber nicht zu ersetzen. Die Notwendigkeit des Lichtes geht aus anderen Versuchen noch schlagender hervor. Ich stellte viele Versuche in feuchten Kammern an, in denen die Alge ganz normal gedieh, nur daß die Zellen, aus Nährlösung in den Wassertropfen übergeführt, etwas längere Zeit brauchten, bis sie Gameten bildeten. Wahrscheinlich liegt der Grund nur darin, daß die mit den Zellen eingeführte Nährlösung in dem kleinen Wassertropfen anfangs nur ungeschlechtliche Fortpflanzung gestattet. Nach 7-8 Tagen beobachtete ich die ersten Gameten. Brachte ich in diesem Zeitpunkt die Kultur ins Dunkle, so ließ sich keine Kopulation mehr beobachten, trotzdem sicher zahlreiche Gameten, darunter solche mit kontrahiertem Plasmakörper, vorhanden waren. Sie gingen nicht zu Grunde, sie wurden wieder rein vegetativ. Wenn man dann die gleiche Kultur nach ca. 8 Tagen wieder ans Licht stellte, so erfolgte nicht sofort Kopulation, sondern es dauerte fast ebenso lange, bis diese eintrat, als wenn die Zellen direkt aus Nährlösung in Wasser bei Lichtzutritt gehalten worden wären. Das Licht wirkt also einmal dahin, daß es leb hafte Teilung anregt, durch die die Gameten überhaupt erst gebildet werden; es ist ferner nötig, den Gameten 
die geschlechtliche Stimmung zu verleihen, welcher sie für die Kopulation bedürfen.

Ebenso notwendig wie das Licht ist für den Geschlechtsprozeß ein Mangel an Nährsalzen, vorausgesetzt, daß die Zellen vor dem Versuch bei Gegenwart von Nährsalzen kräftig haben gedeihen können. Stehen aber beständig den Zellen reichlich Nährsalze zur Verfügung, so tritt nach meinen bisherigen Erfahrungen niemals die Kopulation ein. Die erste Reinkultur wurde am I3./XII. I 895 angelegt und dazu Zellen benutzt, die während des Sommers in einer Nährlösung aufgewachsen waren. Seit der Zeit befinden sich die Abkömmlinge dieser Kultur in beständiger, lebhafter Vegetation in Nährlösung von o,4 Proz., ohne je Gameten gebildet zu haben. Es ist mir nicht im geringsten zweifelhaft, claß man die ungeschlechtlichen Generationen jahrelang wird auf diese Weise fortführen können, elsenso wie bei Vaucheria. Chl. media ist aber sehr viel geeigneter dazu als Vaucheria, weil man die Kulturen bei hellem Licht durchaus normal und in iippigster Vegetation halten kann.

Schon verdünnte Nährsalzlösungen wirken hemmend auf den Geschlechtsprozeß ein. Selbst in einer solchen von 0,05 Proz. konnte ich keine Gameten beobachten; als ich ein Paar Zellen am 8. II. I 896 in 50 ccm Flüssigkeit brachte, bildeten sich aus ihnen bald zahllose, nur ungeschlechtliche Schwärmer. Am 7.III. brachte ich einigre Zellen aus dieser Lösung in Wasser und bemerkte am I2.:III. die ersten Zygoten. Das gleiche Resultat hatten natürlich Lösungen von $0,1,0,2$ Proz. Bei stärker konzentrierten Lösungen, z. B. von I Proz., findet noch Wachstum und Teilung statt; in der ersten Zeit sind die Zellen unbeweglich und sammeln sich am Boden des Gefäßes oder an der Obertläche der Flüssigkeit an. Nach 3-4 Wochen aber werden die Zellen beweglicher; 
man beobachtet sehr große Exemplare mit verdickter Zellbaut am Hinterende. In Nährlösung von 2 Proz. habe ich keine Bewegung gesehen; die Teilung geht langsam vor sich. Nach zwei Monaten war ein Teil der Zellen zu großen, dunkelgrünen, sehr dickwandigen Kugeln (Dicke bis zu $50 \mu$ ) umgewandelt.

Als Beispiel für die Wirkung einzelner Salze habe ich Salpeter angewendet. In 0,05-proz. Salpeterlösung traten nach drei Wochen Gameten und Zygoten auf; in einer solchen von 0,1 Proz. habe ich keine mehr beobachten können, obwohl noch in 0,5-proz. Lösung lebhafte Teilung und Bewegung in den ersten Wochen stattfanden.

Lösungen organischer Substanzen habe ich für Chl. media wenig benutzt, nachdem die Versuche mit Zuckerlösung geringen Erfolg gehabt hatten. In einer solchen von 2 Proz. wurden Zygoten gebildet, aber später als im Wasser. Die rasche Aufspeicherung von Stärke und anderen Substanzen führt die Zellen leicht in einen krankhaften Zustand über, besonders bei höheren Konzentrationen von 5-Io Proz. Die Ueberführung aus solchen Zuckerlösungen in reines Wasser hat keinen Erfolg; die Zellen müssen erst wieder in Nährlösung zu normalem Wachstum gebracht werden.

Aber ein längerer Aufenthalt in den Nährlösungen macht die Zellen von Chl. media allmählich auch unfähig, Gameten zu bilden. Nach 4-5 Wochen im Winter und Frühjahr nehmen in den Lösungen von 0,2 bis o,4 Proz. das Wachstum, die Teilung und die Bewegung ab. Die Zellen sammeln sich am Boden oder auf der Oberfläche der Flüssigkeit an; langsam gehen noch Teilungen vor sich, die Sprößlinge bleiben unbeweglich. Macht man mit Zellen solcher Kulturen Versuche, wie sie vorhin beschrieben wurden, so erhält man keine Gameten mehr. Unzweifelhaft ist durch die LebensK lebs, Fortpflanzungsphysiologie. 
thätigkeit der Zellen die Nährlösung so verändert worden, clak sie ungünstig wirkt; wir haben die gleiche Erscheinung hei Protosiphon und Hormidium kennen gelernt. Deshalb ist es notwendig, daß man die Zellen von Zeit zu Zeit in frische Nährlösungen überimpft. Aber auch die bereits indifferent gewordenen Zellen kann man durch Versetzung in eine Nährlösung wieder frisch und reizbar für die geschlechtliche Fortpflanzung machen.

Auf den ersten Blick erscheint es auffallend, daß eine so verdünnte Lösung von 0,05 Proz. solche hemmenden Wirkungen ausübt, wie sie es thatsächlich vermag. Doch veschieht dies nicht unter allen Umständen. Bringt man eine Anzahl Zellen in einen kleinen Tropfen einer solchen Lösung in eine feuchte Kammer, so können wohl Gameten auftreten, wenn auch nach etwas längerer Zeit als im Wasser. Wie erklärt sich dieser Unterschied des Verhaltens? Hierfür kommt es sehr wahrscheinlich auf (lie absolute Menge der in der Flüssigkeit befindlichen Salzteilchen an. In dem kleinen Tropfen ist ihre Zahl überhaupt eine geringe; nach einiger Vegetation sind die meisten verarbeitet, der Tropfen ist reines Wasser gewvorden. In einer größeren Kultur, z. B. von $50 \mathrm{ccm}$ Flüssigkeit, ist trotz der Verdünnung doch die Zahl der Salzteilchen eine sehr beträchtliche. Daher sehen wir eine Zeit lang lebhafteste Vegetation bis zu dem Moment, wo gewisse Salzteilchen zu fehlen beginnen, sagen wir z. B. die Phosphate oder Nitrate, während von anderen Verbindungen noch Teilchen genug vorhanden sind. Während einerseits durch Nangel an Nitraten Wachstumshemmungen, die event. zur geschlechtlichen Fortpflanzung führen könnten, sich bemerkbar machen, verhindern andererseits die noch anwesenden Salze, daß es wirklich zur Bildung von Gameten kommt. Ganz langsam gehen die Zellen in einen indifferenten Zustand über, der nicht 


\section{- $435-$}

mehr verändert wird, selbst wenn schließlich alle Salzteilchen verbraucht würden. Bei den höher konzentrierten Nährlösungen wirkt der große Salzgehalt noch besonders hemmend auf die Gametenbildung ein.

Die äußeren Bedingungen, welche bei Chl. media zur geschlechtlichen Fortpflanzung notwendig sind, liegen, wie aus der vorhergehenden Darstellung ersichtlich ist, relativ klar. In welcher Weise aber das Licht und der Mangel an Nährsalzen wirken, um den Prozeß herbeizuführen, ist auch hier rätselhaft. Wir wollen nur versuchen, die Frage noch etwas bestimmter zu stellen.

Wenn Zellen aus Nährlösung bei Gegenwart des Lichtes in Wasser versetzt werden, so wird, wie es die Beobachtungen an feuchten Kammern wahrscheinlich machen, die Geschwindigkeit der Teilung nicht verändert. Man beobachtet nur, daß die Produkte der Teilung kleiner und beweglicher werden. Die größere Beweglichkeit ist vielleicht nur die Folge der Größenabnahme des Körpers bei sich gleichbleibender, mechanischer Kraft der Geißeln ; möglicherweise wirkt auch eine Abnahme des specifischen Gewichtes des Körpers mit. Die Größenabnahme können wir darauf zurückführen, daß der Mangel an Nährsalzen, z. B. an Nitraten, zuerst die Funktion des Wachstums betrifft und sie verringert, während die der Teilung davon direkt unabhängiger scheint. Aber es müssen mit jeder Teilung noch innere Veränderungen der Zellen verbunden sein, so daß jede Generation sich von der vorhergehenden ein wenig unterscheidet. Die Gründe dafür werden darin liegen, daß der Stoffwechsel bei allmählich merkbarem Mangel an Nährsalzen verändert wird. Die Erzeugung organischer Stoffe im Licht geht ununterbrochen fort; ihre weitere Verarbeitung wird durch Mangel an Kalium, Stickstoff, Phosphor etc. ohne Zweifel in andere Bahnen gelenkt. Das erkennt man sofort an der reichlichen Stärkeab- 
lagerung. Diese inneren Veränderungen müssen die nächste Ursache für die Erzeugung der Gameten sein; leider können wir sie nicht bestimmter angeben. Nur eine Veränderung kann man beobachten, die Verminderung les osmotischen Zellsaftdruckes, die bei Chl. media ihren leutlichsten Ausdruck in der Kontraktion des Plasmakörpers der Gameten findet. Die jedenfalls noch viel wichtigeren Veränderungen von Plasma und Zellkern lassen sich nicht einmal vermuten.

$\mathrm{Ob}$ für das Aneinanderlegen der Gameten von Chl. media besondere, gegenseitige Anziehungen anzunehmen seien, ist ebenso unsicher wie für das Sichtreffen beweglicher, nackter Gameten bei anderen Chlamydomonas Arten; vergl. Pfeffer (84 S. 44I). Die Menge der erzeugten Gameten erleichtert in hohem Grade das zufällige Nebeneinanderliegen. Dagegen für das Zusammenfließen der beiden aus ihren Zellhäuten austretenden Plasmamassen werden besondere, gegenseitige Reizwirkungen unbekannter Art eine Rolle spielen.

Von sonstigen Einflüssen der Außenwelt auf den Geschlechtsprozeß habe ich, wenn auch nicht eingehend, den ler Temperatur untersucht. Am schnellsten verläuft der Prozeß bei einer Temperatur von $12-16^{\circ}$. Er tritt aber auch bei niedrigerer Temperatur ein; so konnte ich feststellen, daß er bei einer Temperatur von $3-4^{\circ}$ nach 2--3 Wochen stattfindet; ich sah die Verschmelzung sogar bei $2^{\circ}$ normal vor sich gehen. In den ersten 8 Tagen nach Anstellung des Versuches geht die Teilung der Zellen sehr langsam vor sich; die Bewegung ist sehr leschränkt. Erst allmählich treten dann kleinere und beweglichere Zellen auf, die schließlich in Gameten übergehen. Nimmt man eine Kultur nach den ersten 8 Tagen des Aufenthaltes bei niedriger Temperatur und bringt sie in das wärmere Zimmer, so erfolgt die Teilung sehr leb- 
haft, es treten sehr bald Gameten auf. Anders verhalten sich die Kulturen, die einer höheren Temperatur ausgesetzt werden. Bei einer solchen über $20^{\circ}$ konnte ich bisher keine Gameten erhalten; die Zellen litten eher darunter, so daß sie dann bei Temperaturen von I2-16" viel langsamer zu dem Prozeß gelangten als solche, die gleichzeitig mit ihnen in das Zimmer als Kontrollversuch eingestellt wurden. Genauer habe ich die obere Grenze der Temperatur für den Geschlechtsprozeß nicht festgestellt.

Eine wichtige Frage bezieht sich auf das Schicksal der Gameten, welche nicht kopulieren. Ich hatte schon früher gelegentlich bei Chl. pulvisculus (wahrscheinlich dem Chl. Reinhardti Dangeard entsprechend) beobachtet, daß die Gameten für sich zur Ruhe kommen können (Kle bs 83 S. 334, Anm. 3). Ich wandte bei Chl. media gleich meine Aufmerksamkeit auf diesen Punkt. Schon die Beobachtungen über das Verhalten der Gameten im Dunkeln (S. 43I) wiesen darauf hin, daß sie im Falle gehemmter Kopulation vegetativ werden können. Noch sicherer ließ sich dies in folgender Weise feststellen. In den feuchten Kammer-Kulturen ließ ich die Zellen sich bis zum Auftreten der Gameten vermehren, die zum Teil an ihrem kontrahierten Plasmakörper erkennbar waren. Dann fügte ich einen Tropfen einer Nährlösung von I Proz. zu und stellte die Kultur wieder hell. Alle Zellen kamen zur Ruhe, die Kopulation war unmöglich geworden. Jetzt sah ich, wie der kontrahierte Plasmakörper einer Gamete innerhalb der alten Zellhaut sich mit einer neuen umgab und nach einiger Zeit sich zu teilen begann. Die nicht kopulierenden Gameten werden also wieder rein ungeschlechtlich. Allerdings ist der Unterschied in der Keimung gegenüber den Zygoten gering. Denn auch diese verhalten sich bei ihrer Keimung nicht anders, als daß sie sich teilen und ungeschlechtliche Zellen bilden. 
Der Hauptcharakter (ler Zygoten bei der Gattung ( 'hlamydomonas liegt in ihrer Fähigkeit, Trockenheit auszuhalten, während die gewöhnlichen Zellen dabei zu Grunde gehen. Bisher gelang es mir nicht, bei Chl. media $\mathrm{Zy}$ goten mit der betreffenclen Fähigkeit zu finden. Schon darin weicht diese Art von den meisten anderen, bekannten Arten al, daß die Zygoten sich nicht so lebhaft rot bis rotbraun fürben, sondern wochenlang grün bleiben und schließlich nur schmutzig gellgrün werden. Ich habe mehrfach den Versuch mit Hunderten von Zygoten gemacht, indem ich sie langsam austrocknen ließ. Stets gingen sie zu Grunde. Dagegen konnte ich bei einigen die Keimung sehen, als ich sie in frische Nährlösung brachte. Ebenso beobachtete ich die Keimung bei Zygoten, die in der ursprünglichen Flüssigkeit mehrere Monate gelegen hatten. Bei der Keimung in Nährlösungr verquillt die Zygotenmemlıran langsam, bei der Keimung in Wasser sah ich eine Sprengung der allerdings viel derberen Zellhaut. 


\section{Hydrurus.}

Die Gattung Hydrurus, mit der bekanntesten Species foetidus (Vau cher) Kirchner, nimmt unter den niederen Organismen eine besondere Stellung ein, weil sie in der allgemeinen Gestaltung und Wachstumsweise des Thallus als eine typische Alge erscheint, während der Bau der einzelnen Zelle auffallend an die gelben Flagellaten erinnert. Da ich vor einiger Zeit eine ausführliche Darstellung der Lebensgeschichte von Hydrurus gegeben habe (Klebs 92 S. 420), so will ich hier nur das Wesentliche kurz mitteilen, so weit es für das Folgende notwendig ist.

Die Alge bildet gallertartige, braungefärbte Ueberzüge auf Steinen in schnell fließenden Gewässern. Der Thallus erscheint in Form eines Gallertfadens, der sich an seinem oberen Ende in mannigfachster Weise in Zweige auflöst und bis zu Io selbst $30 \mathrm{~cm}$ lang werden kann. In der konsistenten Gallerte finden sich zahlreiche Zellen vereinigt, die in den jüngeren Teilen des Thallus dichter, in den älteren lockerer zusammenliegen. Die Zellen vermehren sich durch Längsteilung, der Thallus mit seinen Zweigen wächst an der Spitze durch Zellteilung und entsprechende Gallerteausscheidung. Jede Zelle ist nackt, $d$. h. ohne bestimmt differenzierte Zell- 
haut; sie enthält am vorderen Ende eine gelbgefärbte, muldenförmige Farbstoffplatte, in der Mitte einen Zellkern, im linteren Teile farbloses Plasma mit einer Anzahl kontraktiler Vakuolen, ferner Tropfen einer weißen, lichtbrechenden Substanz, die an das Leukosin der Chrysomonaden erimnert. In meiner früheren Arbeit habe ich angegeben, daß in dem Chromatophor ein Pyrenoid sich befinde, das von Lager h e im (87) zuerst erwähnt worden ist. Ich habe damals um so mehr der Angabe Lagerheim's getraut, als ich an den lebenden Zellen stets ein lireisförmiges Plättchen zu beobachten glaubte. Aufmerksam geworden durch ein vorzüglich gefärlotes Präparat von Hydrurus, das ich der Liehenswürdigkeit des Herrn Pfeifer von Wellheim verdanke, habe ich hei der erneuten Untersuchung das Pyrenoid ebensowenigr wie Pfeifer fixieren und färben können. Der Anschein eines solchen wird nur durch die Einfaltung eines Zipfels les Chromatophors hervorgerufen. Die Hydrurus-Zelle lesitzt daher kein echtes Pyrenoid und gleicht auch in dieser Beziehung den Chrysomonaden.

Die Fortpllanzung von Hydrurus geschieht durch zoosporen und durch Ruhezustände. Ich halse nur die Budingungen der Schwärmerbildung näher untersuchen kïmnen.

1)ie Zoosporen (vergl. R ostafinski 82, Lagerlı eim 87 , Klebs 92) entstehen an den jüngreren Teilen des Thallus durch Teilung der vegetativen Zellen und werden durch Verquellung der Ciallerte frei. Sie sind nit einer kurzen Cilie versehen und bewegren sich langsim zitternd und rotierend im Wasser. Anfangs oval vestaltet, nelmen die kleinen, amöboiden Schwärmer sehr verschiedene Formen an, unter denen die tetra(drische, an den Enden lang ausgezogene Form besonders auffallend ist. Nach einiger Zeit der Bewegung 


\section{- $44 \mathrm{I}-$}

kommen sie zur Ruhe, runden sich ab, umgeben sich mit Gallerte und können unter günstigen Bedingungen zu einem jungen Thallus heranwachsen (Rostafinski 82, Klebs 92).

Die Bedingungen der Zoosporenbildung von $\mathrm{Hy}-$ drurus zu untersuchen, machte anfangs sehr große Schwierigkeiten, weil die Alge äußerst leicht abstirbt, so wie man sie von ihrem natürlichen Standort nimmt und in das Zimmer bringt; eine Kultur dieser Alge ist daher früher niemals versucht worden. Nach dem Gelingen der Kultur von Ulothrix zonata, die an ähnlichen Standorten wie Hydrurus vorkommt, versuchte ich auch bei dieser Alge, sie in dem Brunnen meines Gartens zu züchten. Ich brachte im Februar I895 einige Steine mit Hydrurus auf einen Teller, der direkt von dem Wasserstrahl des Brunnens bespült wurde (S. 302). Die Alge ging zu Grunde, aber sie hatte doch vorher Zoosporen gebildet, welche am Rande des Tellers zu neuen, normalen Pflänzchen heranwuchsen. Im Februar I896 machte ich wieder den Versuch, er verlief in gleicher Weise, nur daß dieses Mal eine sehr lebhafte Vegetation des Hydrurus am Tellerrande sich entwickelte, dort, wo dicht unter der Wasseroberfläche beständig frisches Wasser sie lebhaft überströmte. Dieses Material war nun für meine Versuche vorzüglich geeignet.

Für das Wachstum von Hydrurus kommen zwei Eigenschaften des strömenden Wassers vor allem in Betracht, die niedrige Temperatur und die stete Zufuhr frischer Luft. Für den schnellen Untergang der Alge, der eintritt, wenn sie vom natürlichen Standort ins Zimmer gebracht wird, ist die Höhe der Temperatur in diesem entscheidend. Hydrurus zeichnet sich vor der Mehrzahl der Süßwasseralgen dadurch aus, daß das Temperaturmaximum für ihn auffallend niedrig liegt. Er stirbt bei 
I) - $20^{\circ}$ nach 24 Stunden ab, kränkelt und fault in wenigen Tagen bei I6-18". Dagegen kann man die Alge in kleiner, nicht gewechselter $\mathrm{W}^{\top}$ assermenge wochenlang bei Temperaturen unter $10^{0}$ lebend erhalten. Bei der Kultur im Brunnen ging sowohl I895 wie I896 die Alge Ende Mai alhmählich zu Grunde, als das Wasser eine Temperatur über $13^{\circ}$ annahm. Diese Abhängigkeit von der Temperatur bedingt, daß Hydrurus in der Ebene nur im Frühjahr gredeihen kann, daß er sich dagegen in den kalten Bächen der Alpen auch den ganzen Sommer hindurch findet. Trotz der niechrigen Temperatur vermag Hydrurus in kleiner, stehender Wassermenge nicht normal zu wachsen, weil er sehr sauerstoffbedürftig ist. Er kommt deshalb nur in rasch strömendem Wasser vor, und auch hier vor allem in der Nähe der Oberfläche; besonders kräftig entwickelt er sich an solchen Stellen, wo eine dünne Wasserschicht lebhaft über ihn fortströmt.

$W^{\top}$ enn man eine gesunde Kultur des Hydrurus, wie (lie meines Brunnens zur Verfügung hat, so läßt sich jederzeit die Zoosporenbildung hervorrufen. Man braucht nur einen Thallus in ein kleines Gefäß mit Wasser in einen liühlen Raum von 9- $0^{0} \mathrm{zu}$ stellen. Am folgenden Tage beobachtet man die lebhafteste Zoosporenlildung, die mitunter so stark um sich greifen kann, daß die Nehrzahl der jüngeren Zweige aufgelöst wird. Auch in (len folgenden Tagen werden noch neue Zoosporen gelildet, aber in abnehmender Zahl; doch sah ich selbst nach Io Tagen bei einem solchen Versuch bewegliche. tetraedrische Zoosporen. Es ist bemerkenswert, daß die Zeit. in welcher der Versuch während des Tages begonnen wird, für das schließliche Resultat sehr wenis Bedeutung hat. Der Versuch gelingt in gleicher Weise, wenn die Nige im Laufe des V'ormittags oder am Nachmittag in das kleine WVassergefäß übertragen wird. Nur die Stunden 
von Abends bis Morgens sind für die Zoosporenbildung wesentlich. Damit stimmt überein, daß das Licht keine Einwirkung ausübt, so daß man die Alge während des vorhergehenden Tages beleuchten oder verdunkeln kann, ohne dadurch das Resultat am folgenden Morgen zu beeinflussen.

Von den beiden wichtigsten, das Leben der Alge beherrschenden, äußeren Bedingungen hat die Temperatur keinen entscheidenden Einfluß bei der Erregung der Zoosporenbildung. Die Schwärmer werden erzeugt, gleich, ob die Temperatur während des eigentlichen Versuchs etwas höher oder niedriger als diejenige ist, in der die Alge vorher gelebt hat. Der Prozeß erfolgt noch bei einer Temperatur von $15-16^{\circ}$, nur daß die Alge dabei nach wenigen Tagen kränkelt. Die Zoosporen werden ebenso erzeugt, wenn die Temperatur nicht geändert wird. Ich brachte Hydrurus in ein Gläschen, das mit Kork verschlossen und in den Teller neben die normal wachsenden Algen gelegt wurde. Das Wasser in dem Gefäß hatte jedenfalls die gleiche Temperatur wie das Wasser seiner Umgebung; nichtsdestoweniger trat die Zoosporenbildung ein. Das geschieht auch, wenn die Temperatur vermindert wird. Im Mai 1895 betrug sie während einiger Tage in meinem Arbeitsraum 8-10 ${ }^{\circ}$, während das Wasser, in dem Hydrurus wuchs, eine Temperatur von $12^{\circ}$ hatte. Im Mai 1896 brachte ich mehrfach Hydrurus aus dem Wasser von $\mathrm{II}^{0}$ in ein Gefäß, das im Eiskasten bei $\mathrm{O}-\mathrm{I}^{0}$ stand. Am folgenden Tage bemerkte ich in mehreren Versuchen eine Anzahl Zoosporen, allerdings lange nicht in dem Maße als bei $8-10^{0}$.

Den eigentlichen Reiz, der die Zoosporenbildung veranlaßt, übt der Uebergang aus dem fließenden in stehendes Wasser aus. Hydrurus verhält sich in dieser Beziehung wie Ulothrix zonata, Stigeoclonium tenue, und andere 
Alıren der lebhaft strömenden Bäche. Bei keiner anderen Alge drängt sich aber so stark der Gedanke auf, daß die Verminkterung des Sauerstoffgehaltes die nächste Veranlassung zur Zoosporenbildung sei. Während das Wachstum von Hydrurus in ruhig stehendem Wasser selır balı aufhört, kann die Zoosporenbildung sogar bei schr verminderter Luftzufuhr eintreten. Ich füllte in ein Glischen mit eingeschliffenem Stopfen gut ausgekochtes, rasch abgeliühltes WTasser und brachte frischen Hydrurus hinein. Trotz des geringen Luftgehaltes in diesem Wasser beobachtete ich am nächsten Tage eine Menge von \%oosporen. Ein anderes Gefäß乃, das halb mit Wasser gefuillt war und in dem sich frischer Hydrurus befand, wurde luftdicht verschlossen und ganz in das Aquarium untergetaucht. Nach mehreren Tagen zeigten sich bei der Untersuchung bewegliche Zoosporen. Die chemische IBeschaffenheit des Wassers scheint von geringer Bedeutung zu sein. Denn der Versuch gelingt sowohl bei Anwendung des destillierten Wassers, wie des Brunnenwassers, das gewiß während des einen Tages kaum verinnlert wird. Der etwaige Verlust an Kohlensäure kann bei (lem Versuch in geschlossenen Gefäß nicht in Betracht kommen, ebensowenig die geringe Ausscheidung des liohlensauren Kalkes. Nan kann auch eine sehr verdünnte Nährlösung von 0,05 Proz. statt des Wassers anwenden; man beobachtet dann nur eine schwache Zoosprorenbildung, während das Leben der Zellen sich eine \%eit lang darin erhält. Stärkere l_ösungen, schon solche von 0,1 Proz., wirken tödlich auf die Alge ein, was sich wohl zum Teil aus der Nacktheit der Zellen erklärt. libenso führen verdünnte Zuckerlösungen schnell den Tod laerlei.

Wem die Alge in kleiner Wassermenge nach einigen Tagen aufgehört hat, Zoosporen zu bilden, so läßt sie 
sich nicht mehr von neuem dazu veranlassen. Sie gerät auch bei anhaltend niedriger Temperatur allmählich in einen pathologischen Zustand, der schließlich zum Absterben führt. Nach der Analogie mit Stigeoclonium, Draparnaldia u. a. darf man als sicher annehmen, daß erst die Kultur in strömendem Wasser die Alge wieder wachstumsfähig und zugleich reizbar machen würde. 


\section{ZWEITER ABSCHNITT. Pilze.}

\section{Eurotium repens de Bary.}

De Bary hat 1854 , eingehender I 870 den Zusammenhang des bekannten Schimmelpilzes Aspergillus glaucus mit dem Ascomyceten Eurotium herbariorum nachgewiesen. In der zweiten Arbeit (7o S. 2 u. I9) unterschied de Bary eine zweite Species E. repens, welche durch bedeutend geringere Größe aller Fortpflanzungsorgane vor E. herbariorum sich auszeichnete. Von beiden Arten entwarf de Bary ein sehr sorgfältig ausgeführtes Bild des Baues und der Entwickelung. Beide Pilze sind noch vielfach erwähnt worden, ohne daß wesentlich Neues hinzugekommen wäre bis auf die Arbeiten von Siebenmann ( 83 u. 88) und Elfving (90). Der erstere hat die Lebensledingungen der Eurotium-Arten näher studiert, der letztere hat speciell bei $\mathrm{E}$. herbariorum infolge von Lichtwirliungen eigentümliche Hefeformen erhalten, die sehr schnell zu erblichen Rassen geworden sind.

Von den beiden Arten habe ich ausschließlich E. repens zu meinen Versuchen benutzt. Augenscheinlich giebt es noch mehrere, einander nahe stehende Eurotium-Arten. Die von mir beoluachtete form stimmt vollständig mit der leschreibung von de Bary und Siebenmann ülserein. Der Pilz tritt regelmäßig auf Brod auf, das 
mäßig feucht gehalten wird. Das lockere, weiße Mycelium kriecht schnell über die Brodoberfläche, sie allmählich ganz überziehend. Später dringt es in das Brod hinein, um es schließlich ganz zu durchsetzen und aufzuzehren. Auf dem Mycelium zeigen sich sehr bald die bekannten Konidienträger als einzellige Schläuche mit angeschwollenem Ende (Figur I3 D). An dem Köpfchen entstehen dicht gedrängt zahlreiche, kleine Zweiglein, die Sterigmen, welche zahlreiche Konidien successive abschnüren, die eine Zeit lang in rosenkranzartigen Fäden sich erhalten. Die Konidien von E. repens sind meistens oval und besitzen eine fein warzige Haut; ihre Länge $=7,5-9,5 \mu$, ihre Breite $=5,5-7,5 \mu$. Sowie die Konidien in größerer Menge gebildet werden, erscheint der Pilz lebhaft grün gefärbt. Später treten dann unter Umständen die gelbgefärbten Früchte, die Perithecien auf (Fig. 13 C), das Mycelium selbst färbt sich dann rotgelb bis rotbraun.

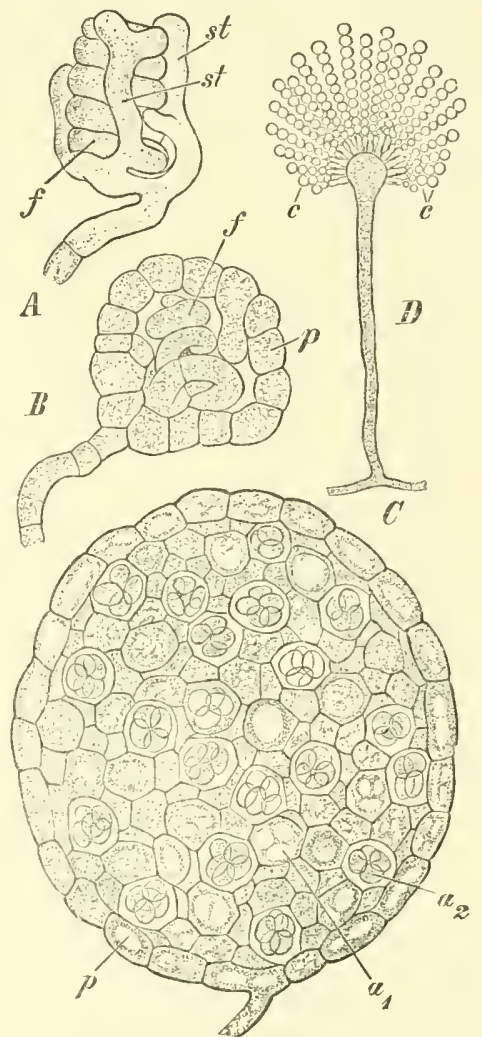

Fig. I3. Eurotium herbariorum. A Anlage der Schlauchfrucht; $f$ gewundene, fertile Hyphe; st sterile Hyphen. $B$ Junge Frucht ; $p$ die aus sterilen Hyphen gebildete Peritheciumwand. $C$ Halbreife Frucht mit 8-sporigen, reifen Asci $a_{2}$ und einer Anzahl unreifer Asci $a_{1} . D$ Konidienträger aus dem Mycel entspringend; $c$ Konidien (Nach Kny aus Strasburger, Noll, Schenk, Schimper, Lehrbuch 1895). 
Auf die Morphologie des Pilzes werde ich nicht näher eingehen; die beigegebene figur, die sich auf die sehr nahe stehende Species E. herlariorum bezieht, soll nur zur limnerung der schon sehr bekannten Thatsachen dienen. Ueber die Kulturmethoden brauche ich ebenfalls keine ausführlichen Bemerkungen zu machen. Selbstverstiindlich gilt für alle Versuche, daß sie mit Reinkulturen ausgeführt wurden, deren Herstellungsweise allgemein bekannt und bei sauberer, sorgfältiger Arbeit nicht schwierig ist. Ich benutzte für die Mehrzahl meiner Versuche Glasdosen verschiedener Größe, teils mit übergreifendem, lose aufliegendem Deckel, teils mit eingeschliffenem Deckel. Die Furcht, daß der Pilz in solchen Gefäßen wegen beschränkter Luftzufuhr schlecht wachse, ist gänzlich unbegründet. Ueber die Substrate, deren chemische und physikalische Eigenschaften für die Kultur des Pilzes von großer Bedeutung sind, wird weiterhin ausführlich gesprochen werden. Ich werde zuerst die Berlingungen der Konidienbildung, dann die der Perithecienbildung behandeln.

\section{Die Bedingungen der Konidienbildung.}

Eurotium repens erzeugt Konidienträger mit normalen Konidien nur innerhalt, gewisser Temperaturgrenzen und bei Vorhandensein gewisser Nahrungsstoffe. Ueber die Karlinalpunkte der Temperatur liegen Angaben von Siebenmann vor $\left(8_{3}\right.$ S. 24$)$, nach welchen $\mathrm{k}$. repens lei ro - $5^{\prime \prime}$ gut gedeihe, bei $25^{\circ}$ verschwinde. In seiner zweiten Arbeit (S8 S. 28 Anm.) teilt derselbe Forscher mit, (lat3 der Pilz noch bei $30^{\circ}$ wachse, wenn auch in veränderter Form. Für E. herbariorum liegt nach Elfving das () ftimum lei $20-25^{\circ}$; bei IO" ist das Wachstum langsam, l,ci 30 " keimen die Konidien nicht mehr. Ebenso 
giebt Johan-Olsen (86), der E. repens nur für eine Varietät von herbariorum hält, an, daß dieser Pilz über $30^{\circ}$ keine Entwickelung zeige.

Das von mir untersuchte E. repens verhält sich hinsichtlich der Temperaturgrenzen anders als der von Siebe $n$ man $n$ beobachtete Pilz; ich lasse unentschieden, ob es sich um eine andere physiologische Rasse handelt. Das Temperaturminimum liegt etwa bei $7^{\circ}$, das Maximum bei $37-38^{\circ}$, das Optimum bei ca. $27-29^{\circ}$. Die beifolgende Tabelle giebt Aufschluß über das Erscheinen der Konidienträger bei verschiedenen Temperaturen. Bei den in der Tabelle angeführten Versuchen wurde teils Brod benutzt, teils konzentrierter Traubensaft von ca. 20 Proz. Traubenzucker, worauf der Pilz ausgezeichnet wächst.

Temperatur

$$
\begin{aligned}
& 7-8^{\circ} \\
& 8-9^{\circ} \\
& 10-12^{\circ} \\
& 13-15^{\circ} \\
& 15-18^{\circ} \\
& 20-22^{\circ} \\
& 22-25^{\circ} \\
& 26-30^{\circ} \\
& 35-36^{\circ} \\
& 37-38^{\circ}
\end{aligned}
$$
Konidienträger; erstes Auftreten bis zu ihrer deutlichen Entwickelung: (nur schwaches Mycelium nach I4 Tagen) nach IO-I2 Tagen

$\begin{array}{ccc}" & 8-\mathrm{IO} & , \\ " & 4-5 & " \\ " & 3-4 & " \\ " & 2-3 & " \\ " & \mathrm{I}-2 & " \\ " & 20-24 & \text { Stunden } \\ " & 2-3 & \text { Tagen }\end{array}$

nur kümmerliches Mycelium.

Ob es möglich wäre, den Pilz an eine höhere Temperatur über $37^{\circ}$ allmählich zu gewöhnen, ist von mir nicht geprüft worden; die obigen Zahlen gelten für Konidien, die bei Zimmertemperatur oder bei $2 \delta-29^{\circ}$ entstanden sind. Während die Konidienträger bei $36-37^{\circ}$ keine anormalen Formen zeigten, verlief die Keimung der Konidien bei $37-38^{\circ}$ in abweichender Weise. Die Keimfäden, die sich zu kurz verzweigten, kleinen Mycelien entwickelten, 
wiesen stirk angescliwollene, abnorm gestaltete Zellen anf; ich sab ähnliche Bilder, wie sie Elfving (9O S. IO6) bei Eurotium-Kulturen beschreibt, die direktem Sonnenlicht auscesetzt worden waren, so daß es nicht unwahrshemlich ist, daßs labei die erhöhte Temperatur die Hauptrolle gespielt hat.

1)ie Bildung der Konidienträger hängt ferner von dem Vorhandensein gewisser Nährstoffe al, wobei die Quantität und Qualität dieser wichtig sind. Für meine Untersuchungen kam die Frage nicht in Betracht, welche Nïhrstoffe in cegebener Zeit bei sonst gleichen Bedingungen den höchsten Betrag von Pilzsubstanz liefern. Solche Bestimmungen sind für Aspergillus-Arten sowie fïr antere Pilze von R a ulin (69), Na egeli (79), Pfeffer (95) u. a. ausgeführt worden. Vielmehr kam es mir darauf an zu untersuchen, bei welcher Nahrungsbeschaffenheit und bei welcher Nahrungsmenge überhaupt Konidienträger gehildet wurlen. Nehmen wir ein gutes Nälırsubstrat wie Brod, so ist es selbstverständlich, daß die Mrnge der erzeugten Konidienträger von der Menge des dem Pilz, dargebotenen Brodes abhängt; sie nimmt noch zul, wenn man das Brod mit Traubensaft tränlit. Die Fragre lautet aber, ob die Quantität der Nahrungssubstanz einen Einlluß auf die Zeit und die Art des Auftretens der Konidienträger ausübe. In den Arbeiten von Brefold wirl gerade der Nalırungsmenge öfters eine gewisse Berleutung in dieser Richtung beigelegt. Für F. repens lälit sich leicht der Nachweis führen, daß thie Nahrungsmenge keine wesentliche Rolle spielt. Zerteilt man ein Brodstückchen in lauter kleine Krumen, lerrt man diese in Abständen in eine flache Schale und lusiat sie mit Konidien, so entwickelt sich der Pilz auf den kifinsten, wägbaren Teilchen von $0,2-0,5 \mathrm{mg}$ durchatse normal und in der gewohnten Zeit. Bei der Steri- 
lisation des Gefäßes vor dem Versuch breitet sich zwischen den Brodkrumen eine dünne Wasserschicht aus, die Spuren von Nährstoffen enthält. Die Konidien, die in diese Schicht fallen, keimen ebenfalls aus, sie bilden ein ganz zartes, wenig verzweigtes Mycelium, das aber doch einen Konidienträger zu erzeugen vermag. Er ist oft sehr verkümmert, hat eine Länge von 50-60 ", sein Köpfchen ist kaum angeschwollen und trägt nur 3 Sterigmen mit wenigen Konidien, die aber durchaus normal sind. Die Fortpflanzung durch Konidien erfolgt also bei den geringsten Spuren von Nährstoffen, wenn diese eine für den Pilz günstige Zusammensetzung haben.

Ebenso gleichgiltig für die Ausbildung der Konidien ist es, ob man viele oder wenige Konidien aussät; schon Bachmann (95 S. I28) hat für Thamnidium gegenüber Brefeld nachgewiesen, daß dieser Umstand sehr wenig Bedeutung hat. Ich nahm zwei würfelförmige Brodstücke von $4 \mathrm{~cm}$ Durchmesser und säte auf dem einen so zahlreiche Konidien aus, daß die Oberfläche grün gefärbt erschien. Auf das andere Brodstück brachte ich ein kleines Mycelium, das aus einer einzigen Konidie vorher auf Pflaumensaft entstanden war. In beiden Fällen entwickelte sich normales Mycelium mit Konidienträgern und Perithecien. Das konidienreiche Brod verhielt sich bei $28-29^{\circ}$ genau wie alle meine anderen Versuche bezüglich der Zeitdauer der Entwickelung. Das aus einer Konidie entstandene Mycelium brauchte etwas längere Zeit, da es sich erst an das feste Substrat gewöhnen mußte.

Etwas wichtiger als die Quantität ist die Qualität der Nahrungsstoffe. Si ebenmann (83 S. I7) hebt mit Recht hervor, daß E. repens vor allem auf Substraten wächst, die reich an Kohlehydraten sind, während die stickstoffreichen Substrate ihm nicht zusagen. Der Pilz gedeiht zwar auf Mist, Gelatine, Eiweiß, aber in jedem Falle 
antherolentlich viel kümmerlicher als auf Brod, Früchten u. (lersl. Diejenigen Nahrungssubstanzen, die der Pilz untwendig braucht, erkennt man am besten, wenn man untersucht, welche Stoffe für die Keimung der Konidicn ansreivhen. Diese keimen weder in reinem Wasser, noch in anorganischen Nährlösungen, sie keimen auch nicht in reiner Peptonlösung ( $\mathrm{I}-4$ Proz.), dagegen in solcher mit etwas anorganischer Nährlösung. Für die Keimung der Koniclien in Peptonlïsung genügt Kalisalpeter, der am besten in konzentrierter Lösung aus später zu erwähnenden Grünlen zuzusetzen ist. Ferner keimen die Konidien in einer Traubenzuckerlösung von 0,5 Proz. Wenn ich bei den folvenden Pilzuntersuchungen von anorganischer Nährlïsun spreche, so meine ich dabei stets eine solche, die sich aus salpetersaurem Natron (2 Teile), schwefelsaurer Magnesia (I Teil), phosphorsaurem Kali (2 Teile) zusammensetzt. Auf einen Zusatz von Calciumverbindungen habe ich nach den Arbeiten von Molis ch (94) und Benecke (95), (lie beide die Entluehrlichleit des Calciums nachgewiesen haben, verzichtet. Andererseits habe ich aber auf das Vorlıandensein von Calcium-Terbindungen keine Rücksicht uranommen.

Temperatur und Nahrungsstoffe gehören zu den allsemeinen Bedingungen für das Leben des Pilzes, und lamit auch für seine Fortpflanzung. Sie können aber in weiten Grenzen variieren, ohne daß die Bildung und lic Roife ler Konidienträger ladurch wesentlich bestimmt wirrlen Nur an der unteren wie oberen Grenze der Temperatur, chenso lei einer zu greringen Menge von Nahrung oder bei selnr unbrauchloarer Nahrungr leiden die Konidientrïgrer oder lï̈nnen unterdrückt werlen, während ein yanz. kümmerliches Mycelwachstum noch möglich ist.

Disergen ist es eine specifische Figenschaft der Kimilicntriger, dafis sie sich nur von Luft umgeben, nicht 
innerhalb von Flüssigkeiten ausbilden können. Diese Abhängigkeit der Konidienbildung von der Luft kommt bekanntlich bei sehr zahlreichen Pilzen vor. Allgemein angenommen ist wohl die Ansicht, daß die Konidienträger besonders sauerstoffbedürftig sind, und nur infolge Sauerstoffmangels nicht innerhalb von Flüssigkeiten entstehen liönnen (vergl. z. B. H offma n n 69 S. 307). Man hat diese Ansicht für so selbstverständlich richtig gehalten, daß sie nie einer näheren Prüfung unterzogen wurde.

Einfache Ueberlegungen weisen zunächst darauf hin, daß die Ansicht nicht so selbstverständlich sein kann; die Versuche legen dar, daß sie für Eurotium sehr unwahrscheinlich ist. Wenn man auf sterilisiertem, konzentriertem Traubensaft Konidien von E. repens aussät, so bildet sich auf der Oberfläche ein Mycelium, dessen Hyphen sich zum Teil in der obersten Flüssigkeitsschicht befinden, zum Teil ihr aufliegen. Nie entsteht aus einer Hyphe, die mit der Flüssigkeit in Berührung ist, ein Konidienträger. Fällt ein zuerst aufrechter, eben angelegter Konidienträger auf die Flüssigkeit, so wird er wieder zur vegetativen Hyphe; er ist nicht im Stande, in Berührung mit der Flüssigkeit reife Konidien zu erzeugen. Wie kann ein Mangel an Sauerstoff bei diesem Verhalten der Konidienträger mitwirken? Die Luft kann ungehindert und unverändert zum Mycelium treten, das nur oberflächlich auf der Flüssigkeit lelst; die augenblicklichen Veränderungen im Sauerstoff- und Kohlensäuregehalt, die durch das Wachstum des Pilzes bedingt sind, gleichen sich sehr schnell aus, sind überhaupt zu umbedeutend, so lange noch die Luft Zutritt hat. Die Umwandlung der angelegten Konidienträger in vegetative Hyphen kann allem Anschein nach unter den genannten Umständen nicht auf einen Sauerstoffmangel zurüickgeführt werden. 
Jedenfalls nïtigen diese Ueberlegungen zu der Untersuchung der Frage, welches die untere Grenze des Partiärdruckes des Saucrstoffs für die Bildung der Konidien sei. lch stellte die Versuche in der IVeise an, daß ich sterilisiertes 13rod nach der Impfung mit Konidien 10-I2 Stunden tei $28-29^{\prime \prime}$ hielt, so daß die erste Keimung und die Bil(lung des Myceliums stattgefunden hatte. Dann wurde die Kultur unter die L.uftpumpenglocke gebracht, entsprechend wie bei den Versuchen mit Vaucheria (S. 77). Ich pumpte I 2 Stunden aus, erhielt den niedrigsten Luftdruck von (a. 3 $11 n$ während mehrerer Stunden und ließ dann so viel Luft hinzutreten, als mir nötig erschien. Die Temperatur schwankte zwischen 12 und $16^{\circ}$ während 24 Stun(len. Die Versuche mit relativ noch hohem Luftdruck unterbrach ich, wenn ich die grüne Färbung des Brodes infolge der Konidienbildung bemerkte. Dazu waren nötì:

$$
\begin{aligned}
& \text { hei } 95 \mathrm{~mm} 3 \text { Tage } \\
& \text { " } 50 \text { " } 4 \text { " } \\
& \text { " } 35 " 6 " \\
& \text { " I5" } 7 \text { " }
\end{aligned}
$$

Bei einem Luftdruck unter $15 \mathrm{~mm}$, wo das Wachstum des Pilzes schon sehr gehemmt resp. verlangsamt war, unterl)rach ich den Versuch, wenn ich eine deutliche Ausloreitung des llyceliums erkennen konnte. Nach dem \%utritt der Luft untersuchte ich das Mycelium mit dem Miliroskop, wo ich dann die noch weißen Konidienträger nachweisen konnte. Ich beobachtete solche:

$$
\begin{aligned}
& \text { lei } 12 \mathrm{~mm} \text { in } 5 \text { Tagen } \\
& \text { " } 7,5 ", 6 \text { " } \\
& \text { "6 " " " } 6 \\
& \text { "3-4, nicht mehr }
\end{aligned}
$$

bei einem LuftIruck von 3-4 $\mathrm{mm}$ wurde eine ranze Reihe V'ersuche angestellt auch in der Weise, daß 
frisch geimpftes Brod unter die Glocke gebracht wurde. Nach 8-io Tagen bemerkte man dann keine Keimung, oder nur Spuren eines zarten Myceliums, niemals Konidienträger, die dann im Thermostat bei $28-29^{\circ}$ nach 24 Stunden auftraten.

Nehmen wir $5 \mathrm{~mm}$ als untere Grenze des Luftdruckes für die Bildung der Konidienträger an, so entspricht das einem Partiärdruck des Sauerstoffs von $\mathrm{I}, 05 \mathrm{~mm}$ und einem wahrscheinlichen Sauerstoffgehalt von o, I4 Proz. Die alssolute Menge des Sauerstoffs betrug bei der angenommenen Grenze, dem Volumen des Apparates (380o ccm) ungefähr $5 \mathrm{ccm}$. In Wirklichkeit war der Sauerstoffgehalt noch geringer, da er durch die Atmung des Pilzes während der Keimung der Konidien und des Mycelwachstums allmählich abnahm, wenn auch diese Verminderung bei den wenigen, ausgesäten Konidien und ihrem langsamen Wachstum nicht sehr beträchtlich war. Jedenfalls beweisen die Versuche mit Sicherheit so viel, daß der Pilz noch bei einer relativ geringen Sauerstoffmenge normale Konidienträger ausbilden kann. Wenn er dazu nicht im Stande ist, bei bloßer Berührung einer Flüssigkeit, so kann nicht ein damit verbundener Sauerstoffmangel die Ursache der Hemmung sein. Es müssen andere Umstände entscheidend wirken. Der Sauerstoff ist ebenso wie Temperatur und Nahrungssubstanz eine allgemeine, keine specifische Bedingung der Konidienbildung. Erst an der untersten Grenze des Sauerstoffgehaltes zeigt sich, daß die Konidienträger ihm gegenüber etwas empfindlicher sind als das Mycelium. Für die vorliegende Frage ist noch besonders wesentlich, daß in der Nähe der untersten Grenze die Konidienträger zwar wenig zahlreich, klein und konidienarm sind, aber niemals die charakteristische Umbildung in vegetative Hyphen erleiden, wie bei Berührung mit Flüssigkeit. 


\section{- $456-$}

Von vornherein war es nicht sehr wahrscheinlich, (lin Lnterschięle des Kolılensäuregehaltes von Flüssigkeit und Luft cine Bedentung für die Konidienträger haben. Vrexen der langramen I)iffusion der Kohlensäure wird ihre Mrenge in (ler Flüissigleit durchschnittlich etwas größer scin als in der dariber befindlichen luft. Man lionnte den Kolslensiuregelıalt auf einfache Weise steigern, wenn man dem Pil\% nur ein kleines, begrenztes Luftvolumen zur V'erfügung stellte. Ein kleines Gefäß wurde zu \%/s mit Traubensaft gefüllt und mit Konidien verselıen. Dann wurile es luftdicht mit Hilfe von Paraffin verschlossen. Während iter Keimung, des Mycelwachstums, besonders (ler Lulhyphen, mulite das kileine Luftvolumen sehr reich an Kohlensäure werlen, dagegen arm an Sauerstoff. ludesien entstanden trotzdem rejclilich normale Konidientrïger mit vielen Konidien. Einen ebenso wenig hemmen(t+n Finfluß auf sie hatte die Kultur des Pilzes auf Traulsensift unter einer kleinen Gilocke mit Kali, welches die Luft son ker Kolılensäure befreite; der Pilz entwickelte sich nicht anders als in normaler Luft.

Dem Hauptbestandteil der Luft, dem Stickstoff, liamn erst recht keine Bedeutung zukommen. Er scheint für len l'ilz überhaupt gleichgiltig zu sein, da dieser nicht fillig ist, ihn direlit zu verarbeiten, sondern nur vermag nuit Ilile von Stickstoffverbindungen wirklich zu gedeilsen. Auhertem gelten diegleichen L'eluerlegrmgen und V'ersuclse für den Stickstoff wie für den Sauerstoff. WTenn nun für lie specifische Abhängierlieit der Koniclienträger von der l.uft ihr chemischer Charakter nicht in Betracht kommt, (1) mut. ihre plyysikali-che Beschaffenheit den Ausschlas walen. I)ie Konidienträger bilden sich möglicherweise lahalls nur in der I uft aus, weil diese nur damplförmiges, unr hein flüssiges IVasser enthält. Das Mycelium hat li. Fihiglieit, in llüssigen Medien zu wachsen; der 
Konidienträger vermag in direkter Berührung mit solchen seine normale Funktion nicht $z u$ erfüllen und wird wieder zur vegetativen Hyphe. Nach dieser Ansicht würde der Mangel an flüssigem Wasser in der Luft die wesentliche Ursache dafür sein, daß die Konidienbildung allein in ihr stattfinden kann. Ich bin überzeugt, daß diese Ansicht, an die man meines Wissens überhaupt nie gedacht hat, richtig ist.

E. repens ist gerade ein gutes Beispiel für den Nachweis des Einflusses, den das flüssige Wasser auf die Konidienbildung ausübt. Der Pilz wächst überhaupt am schnellsten auf Substraten, die nicht zu feucht sind. Man nehme zum Vergleich zwei würfelförmige, gleich große Brodstücke von $5 \mathrm{~cm}$ Durchmesser, das eine ein wenig an der Luft abgetrocknet, das andere mit Wasser getränkt. Nach der Impfung werden beide Brodstücke in geschlossenen Dosen einer Temperatur von $28-29^{\circ}$ ausgesetzt. In wenigen Tagen ist das relativ trockene Brodstück völlig vom Pilz bedeckt; auf dem nassen Brod ist das Wachstum außerordentlich verlangsamt, so daß in einem Falle nach 8 Wochen der Mycelffeck nur einen Durchmesser von $3 \mathrm{~cm}$ hatte. Vor allem aber ist es wichtig hervorzuheben, daß die Lufthyphen dieses Myceliums keine normalen Konidienträger mit reifen Konidien bilden. Sehr viele von solchen Trägern werden angelegt, werden aber mehr oder minder mycelial. Da noch mehrfach auf cliese Umbildungen cler Konidienträger Rücksicht grenommen werden muß, so will ich hier die verschiedenen Stadien kurz angeben. Man kann folgende Formen unterscheiden, die durch allmähliche Uebergänge verbunden sind:

I) Die Konidienträger sind deutlich als derbe, lange, einzellige Schläuche angelegt; aber sie wachsen an der Spitze direlst in einen septierten Mycelfaden aus; 
II) Die Konidienträger zeigen ein etwas angeschwollenes Köpfchen, von dem an Stelle der Sterigmen zahlreiche, feine, septierte Mycelzweige ausitrahlen;

111) Die Sterimmen an dem Köpfchen erscheinen nur stark verlängert und schnüren sich an der Spitze etwas ein, ohne reife Koniclien zu bilden;

IV) Die Sterigmen sind verlängert und zugleich verzweint; an den Zweigen zweiten Grades können vereinzelte Konidien erzeugt werden. Diese pathologische Form erinnert bis zu einem gewissen Grade an die echten A-percrillus-Arten mit verzweigten Sterigmen.

Ein wasserreiches Substrat, wie das durchtränkte Brod, wirkt auf die an und für sich von Luft umgebenen Hyphen so cin, als wären diese vom Wasser direkt umgeben. Nun kann es infolge Wasserausscheidung sehr wohl vorkommen, daß die Enden der Luft-Hyphen von IVassertrïpfchen herïhrt werden. Aber das sind in allen Fällen nur cinzehe Hyphen, während die Mehrzahl frei in die feuchte Luft hinaufragt und doch keine normalen Konidienträgrer ausbiliten kann. Die gleichen Erfahrungen kann man mit anderen Substraten machen. Nimmt man eine frisch geschnittene Kartoffelscheibe, sterilisiert sie und impft sie mit Konidien, so zeigren sich bei $28-29^{\circ}$ das gleiche, langsame Wachstum des Iyceliums und die vegetativen Umbildungsformen der Komidlenträger. Läßt man dagegen eine solche Kartoffelicheibe an der Luft etwas abtrocknen und impft dann erst, so entwickelt sich schnell normales Eurotium. Die Versuche mit nassem Brod, feuchter Kartoffel müssen mit crößster Sorgfalt bei der Sterilisation und Impfung ansigefülırt werlen, weil solche Substrate sehr leicht fitulen und dann das Wachstum des Pilzes unmöglich machen. L'm die Bakterien leichter fern zu halten, habe ich mehrfach das Brod." die Kartoffelscheiben mit Citronen- 
säure von 2 Proz. durchtränkt; bei dem Brod bildet sich dann eine milchig weiße, beim Erkalten gerinnende Gallerte.

Wenn die Wirkung eines wasserreichen Substrates auf die Konidienträger gleich derjenigen einer Flüssigkeit * ist, trotzdem sie im ersteren Fall von Luft umgeben sind, im letzteren nicht, so folgt daraus ebenso wie aus den vorher angegebenen Versuchen, daß der Sauerstoff der Luft keine specifische Bedeutung für die normale Ausbildung der Konidien haben kann. Gemeinsam ist aber beiden Versuchsreihen auf Flüssigkeiten und wasserreichen Substraten, daß das Wasser den Hyphen zu reichlich zur Verfügung steht; es ist gleichgiltig, ob mehr oder weniger Luft zugegen ist. Weiter wird man schließen können, daß eine Erschwerung der Wasseraufnahme durch das Mycelium die Bildung der Konidienträger fördern, eine Erleichterung sie hemmen müsse. Die Richtigkeit dieser Folgerung läßt sich durch die Versuche über den Einfluß der Konzentration nachweisen.

Es ist bekannt, daß viele Pilze im Vergleich zu grünen Pflanzen viel höhere Konzentrationen der Nährflüssigkeit ertragen. Den genaueren Nachweis der großen, direkten Anpassungsfähigkeit mancher Pilze an hohe Konzentrationen liefert die Arbeit von Eschenhagen (89) der hauptsächlich Penicillium glaucum, Aspergillus niger geprüft hat. Die Grenze der Konzentration für das Wachstum von A. niger liegt bei 53 Proz. Traubenzucker, 2 I Proz. Natronsalpeter. Die plasmolytischen Versuche Es chenhagen's beweisen, daß die Pilze mit der Erhöhung der Konzentration bis nahe zur oberen Grenze ihrerseits den osmotischen Druck steigern, so daß in den Zellen stets ein gewisser Ueberdruck herrscht. Eine untere Grenze der Konzentration für das Gedeihen der Pilze wurde bisher nicht festgestellt. E. repens zeichnet sich vor den genannten Pilzen durch eine noch größere An- 
passungsfähigkeit konzentrierten Lösungen gegenüber aus; zugleich existiert für ihn unter gewissen Bedingungen cine untere Grenze der Konzentration. In meinen ersten Versuchen henutzte ich Brod als festes Substrat, das mit len Lösungen gretrïnkt wurde, weil ich die Angabe Siebenmann's anfangs hestätigt fand, dafs der Pilz auf Flïssigkeiton schlecht gredeiht. Die Brodstïcke wurden mehrere stunden bei 120 " erhitzt, um sie ganz trocken zu machen; noch in heißem Zustande wurden sie in die vorher sterilisierte Flüssigkeit gelegt, damit durchtrïnkt uncl diann greimpft. Nachdem ich erliannt hatte, daß der I'ilz hohe Konzentrationen vertragen kann, wandte ich Flïsigkeiten in stïrkerer Konzentration an und überzenute mich, dals der Pilz auf solchen ausgezeichnet wuchs. Ich wählte für die Versuche Rohrzucker, Traubenzucker und Gilycerin. Wenn ich sie flüssig anwandte, si) fügte ich meist etwas l'flaumensaft oder Traubensaft z11, indem ich an Stelle des Wassers den betreffenden, sanz verdünnten Saft gelırauchte. Sämtliche Versuche wurden im Thermostat leei $28-29^{\circ}$ ausgefülurt. Diese höhere Temperatur ist schon deshall, nötig, weil man rmst gar nicht lie höher konzentrierten Lösungen von Rohr-und Traubenzucker erhalten kann.

Die Tabelle zeigt, dafs die Konzentrationsorrenze für die Bildung der Konidlienträger ziemlich zusammenliallt mit der Grenze für das Wachstum überhaupt. Sie liegt bein 'Traubenzucker bei ca. (15 Proz, beim Glycerin hei ca. 57 Proz. Beim Vergleich der Versuche mit den Fhiissigkeiten uncl den Brodkulturen ergielst sich, datis auf den Jetzteren bei gleicher Konzentration die Konidientritger ziemlich spötes auftreten, was sich wohl daraus erkilirt, dith die trockene Stärlse des Brodes ihrerseits das IVatser (ter \%uckerliasung lebhaft anzieht, so daß dem Mycrium die Wasseraufnahme noch mehr erschwert ist. 
Eurotium repens.

\begin{tabular}{|c|c|c|c|}
\hline Substanz & 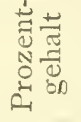 & $\begin{array}{c}\text { Substrat oder } \\
\text { Zusatz }\end{array}$ & Auftreten der Konidienträger \\
\hline Rohrzucker & IO & Brod & I Tage \\
\hline$"$ & 50 & " & 3 Tagen \\
\hline$"$ & 75 & $"$ & $1 \quad$ \\
\hline$"$ & 100 & $"$ & 9 \\
\hline " & 40 & Traubensaft & 2 \\
\hline$"$ & So & $"$ & 3 \\
\hline$"$ & 90 & $"$ & 4 \\
\hline$"$ & 100 & $"$ & $"$ \\
\hline Traubenzucker & 40 & $"$ & 3 \\
\hline$"$ & 50 & Brod & 7 \\
\hline$"$ & 65 & Traubensaft & $" 2 \quad 2 "$ \\
\hline$"$ & 80 & $\begin{array}{l}\text { rein } \\
\text { Brod }\end{array}$ & $4 \quad "$ \\
\hline$"$ & 00 & Pflaumensaft & $\Rightarrow \quad \begin{array}{r}9 \\
0-10\end{array}$ \\
\hline " & IOO & , & keine Keimung \\
\hline Glycerin & IO & , & in I Tage \\
\hline$"$ & 20 & " & $"$ I-2 Tagen \\
\hline$"$ & 30 & " & " \\
\hline$"$ & 35 & $"$ & $5 \quad$ \\
\hline$"$ & 40 & $"$ & $" \quad 6 \quad " \quad$ \\
\hline$"$ & 45 & $"$ & $"$ \\
\hline$"$ & 50 & $"$ & $" \quad 8$ \\
\hline$"$ & 55 & $"$ & "S-9 " \\
\hline$"$ & $\begin{array}{l}57,5 \\
60\end{array}$ & $"$ & keine Keimung \\
\hline$"$ & 00 & $"$ & $"$ \\
\hline
\end{tabular}

Im allgemeinen wird das Auftreten der Konidienträger mit steigender Konzentration verzögert.

Die Fähigkeit des Pilzes, auf hoch konzentrierten Substanzen zu wachsen, tritt auch noch in anderen Versuchen hervor. So wächst er ausgezeichnet auf ganz eingedicktem Malzextrakt (mit c. 65 Proz. Maltose neben anderen Bestandteilen). Er vermag auch auf gedörrten Pflaumen, die nur mit wenig Wasser angefeuchtet und 
sterilisiert wurden, zu gedeihen. Auf solchem Substrat wïchst z. B. nicht Thamnidium elegans ( $\mathrm{Bach}$ ma n $\mathrm{n}$ 95), anch nicht Mucor racemosus u. a. Pilze. Vielmehr müssen für dicse Organismen die Phammen eine Weile ausgeliocht werlen. Höclist wahrscheinlich hemmt die Konzentration der Nahrungsstoffe in den Früchten die Entwickelung dieser Pilze.

Verdümnt man die orranischen Substanzen, besonders die Zuclierlösungen, so zeigrt sich die überraschende Erscheinung, daß der l'ilz viel langsamer wächst, kümmerlich und vor allem anormal fruktifiziert. Die Konidicntriiger werden wohl in großer Zahl noch angelegt, aber sic erleiden die gleichen Umbillungen, als wären sie innerhalh einer Flüsigkeit oller auf wasserreichem Brod gewachsen. Vergleicht man z. B. eine Kultur auf So Proz. Rohrzucker mit einer solchen auf 20 Proz., einer immerhin noch substanzreichen Lösung, so ist der Unterschied in (ler Entwickelung des Pilzes sehr auffallend. Auf der 20-prozentigen Lösung bleibt das Mycelium klein, weil das Längrenwachstum der Hyphen beschränkt ist, während dic Verzweigung lebhaft fortgeht. Es entwickeln sich relativ weni@ Lufthyphen, weil das Mycelium allmählich ctwas untertaucht; neben einzelnen, normalen Konidienträgern zeigen sich die verschiedenen Stadien der vegetativen Umbildung. Auf der Lösung von So Proz. überzicht in wenigen Tagen das lebhaft wachsende Mycelium die ranze (Oberfläche, mit einem Teil der Zellen untertauchend, mit einem anderen darüber hervorragend. Es bilclet sich ein hoch strebendes, lockeres, reiches Luftmycelium, an dem normale Konidientrạ̈er in großer Anzahl entstehen. Die Köjpfchen fallen durch die Menge und besonters durch die Länge der Konidienreihen auf. Die llyphen des Myceliums sind sehr zart und erscheinen sregeniiber der stark lichtbrechenden Zuckerlösung ganz wässerior durchsichtig. 
Den Einfluß verdünnter Lösungen untersuchte ich hauptsächlich für Traubenzucker, weil in solchen auch ohne Zusatz anderer Substanzen der Pilz gedeihen kann. Ich versuchte Lösungen von $0,2,0,5, \mathrm{I}, 2,3,4,5,6,8$, IO, 15, 20 Proz. Schon bei 15 Proz. ist das Wachstum des Pilzes gegenüber 20 Proz. verlangsamt. Die Hemmung steigert sich mit Abnahme der Konzentration; ebenso nimmt damit die vegetative Umbildung der am Luftmycelium angelegten Konidienträger zu. Bei 6 - 8 Proz. können die verlängerten Sterigmen noch einzelne Konidien abschnüren; das Mycelium zeigt in diesen Lösungen zahlreiche, blasig aufgetriebene Zellen. Bei 2-3 Proz. taucht das Mycelium bald nach seiner schwachen Entwickelung größtenteils unter, bei I-0,5" kommen von vornherein nur ganz vereinzelte, anormale Konidienträger vor; bei o, 2 Proz. entsteht nur ein rudimentär bleibendes Mycelium.

Sehen wir von den Lösungen unter I Proz. ab, so kann der Grund der kümmerlichen Ausbildung des Pilzes zunächst nicht im Nahrungsmangel liegen. Ich nahm für diese Versuche $50 \mathrm{ccm}$ Flüssigkeit, so daß schon in einer 2-proz. Lösung I gr Traubenzucker den wenigen, ausgesäten Konidien zur Verfügung stand. Die dem Traubenzucker beigemischten Aschenbestandteile müßten ihnen auch genügt haben; ein Zusatz verdünnter Nährlösung ändert in der That an dem Resultat nichts. Wir können aus den Versuchen folgern, daß nicht die absolute Menge der vorhandenen Zuckerteilchen, sondern ihr osmotischer Druck, gemessen durch die Konzentration der Lösung, für das Gedeihen des Pilzes wesentlich ist. Wir können den Einfluß verstehen, wenn wir annehmen, daß gemäß der specifischen Organisation von Eurotium repens die Zellen einen Zellsaft von relativ hohem, osmotischem Druck besitzen, den sie noch steigern können, wenn der Außendruck der Nährflüssigkeit mit der Konzentration wächst. 


\section{$-464-$}

Verringert sich aber lieser Außendruck, so mußs das Mrcelium den Innendruck der Zellen entsprechend herabsetzen, und das vermag es nur lis zu einem gewissen (irade. Bereits bei 6 Proz. Traubenzucker geschieht diese Anpassung des Zellsaftes nur unvollständig; sein (s)motischer I)ruck bleibt in V'erhältnis zu dem der Zuckerlösung so stark, (łaß er eine zu lcbhafte Wasseraufnahne in die Zellen veranlaß̧ und bewirlit, daß die Zellen anormale Auftreibungen erhalten, genau wie solche bei Pilzen auftreten, die zuerst bei hoher Konzentration erzogen und dann plötzlich in eine Umgebung von viel niedrigerer Konzentration versetzt worden sind (vergl. Eschenhagen 89 $\therefore$. 35,47). 1)as Mycelium nimmt also unter diesen Lmständen zu viel Wasser auf; am meisten werden dadurch die kionidienträger betroffen, von denen wir bereits wissen, daß sie auf wasserreichen Sulstraten nicht normal ausgebildet werden lï̈nnen. Ihr Zellsaft wird verdünnt ; damit müssen andere, innere Veränderungen in der Zelle verbunden scin, die den Konidienträger zur vegetativen Hyphe umwantleln.

Wenn der ganze Gedankengang richtig ist, so müssen anorganische Salze in ähnlicher Weise wirken, wie die früher benutzten, organischen Substanzen, wenn nur für die nötige Nahrungssubstanz gesorgt wird. Die Versuche wurlen zuerst mit Kalisalpeter gemacht, mit dessen Lösuncen trockenes Brodl durchtränkt wurde. Bei Anwenclung von 10, 10, 20 Proz. Salpeter traten die Konidienträgrer im Thermostat nach 3 Tagen auf; bei einer Lösurng von 25 Proz., die bei $29^{\circ}$ sich erhält, ohne auszuliryctallisieren, in 4 Tagen. Eine obere Girenze der Konzentration liefs sich für diese Substanz nicht feststellen; uch pine gesättigte Salpeterlösung mit etwas Trauben,$- 1 \mathrm{ft}$ erestattet noch die Bildung von Konidienträgern. Ausfulurlicher wurde der Einflußs des Natronsalpeters unter- 
sucht. Ich setzte den verschiedenen Lösungen stets etwas Pflaumensaft zu, der für sich allein nur kümmerliches Wachstum gestattet und bei diesen Versuchen nur als sehr verdünnte Zuckerlösung mit geringen Nährsalzmengen wirksam war. Die Versuche wurden wieder im Thermostat bei $28-29^{\circ}$ ausgeführt.

Natronsalpeter Io Proz. normale Konidienträger in 2 Tagen



Aus den Versuchen ergiebt sich, daß anorganische Salze, wie Kali-, Natronsalpeter, ferner wie Chlornatrium dessen Nährwert unbedeutend ist, durch ihre wasseranziehende Kraft dahin wirken, daß der Pilz normale Konidienträger dann erzeugt, wenn er es bei der vorhandenen, geringen Konzentration organischer Substanzen, besonders des Zuckers, nicht thun würde. Das zeigen auch andere Versuche, z. B. mit einer Mischung von gesättigtem Kalisalpeter und 2 Proz. Traubenzucker, ebenso von I5 Proz. Kalisalpeter und o,8 Proz. Pepton. Die Versuche mit Kl e bs, Fortpflanzungsphysiologie. 


\section{$-466-$}

Mischungen von Natronsalpeter und Pepton haben kein Wachstum des Pilzes ergeben.

Gegenüber den organischen Substanzen treten in der I'irkung ler anorganischen einige Unterschiede hervor. 1)ie Grenze ihrer Konzentration für die Konidienträger liegt deutlich tiefer als diejenige für das Wachstum; man kann auf dicse W eise ein Luftmycelium ohne Fortpflanzung durch Konidien lange Zeit erhalten. Besonders auffallend benlachtete ich dieses Verhalten bei Natronsalpeter. Die Grenze seiner Konzentration für die Konidienträger liegt 1,ei 25 Proz.; nimmt man als Substrat trockenes Brod, so kiann man bei dieser Konzentration noch schwache Konidienliklung beobachten. Die letzten Spuren von Keimung sieht man noch bei 35 Proz. Die Versuche mit den anorganischen Salzen bestätigen die vorhin gewonnene Ansicht, daß das Mycelium nur dann normale Konidienträger auszubilden vermag, wenn durch die wasseranziehende Kraft der Umgebung die Wasseraufnahme durch den Pilz bis zu einem gewissen Grade erschwert wird. Das Wachstum des Pilzes auf den Salzlösungen mit beiyefüintem Pflaumensafte ist viel geringer als auf den organischen Substanzen, da der Nährwert von diesen ein betrïchtlich höherer ist. Bei den Versuchen mit Kalisalpeter, die von mir zuerst angestellt wurden, hinderte noch (in zweiter Umstand die kräftige Entwickelung des Pilzes. Das Nycelium tauchte langsam in der Salzlösung unter, so daß nur wenige Lufthyphen über sie hervorragten, während auf den stark konzentrierten Zuckerlösungen das Mycelium stets in der obersten Flüssigkeitsschicht blieb. In Natronsalpeter-1) und Chlornatrium-Lösungen erhielt sich

1) In den konzentrierten Lösungen von Kali-, Natronsalpeter, (hlornatrium färben sich die Mycelien schließlich rothraun, indem ristliche Firbstoffinteln an den Mycelfäden in großer Menge ausguchicden worden. Es ist augenscheinlich die gleiche Substanz, wie 
das Mycelium mehr an der Oberfläche. Ich führe das Verhalten des Pilzes im Kalisalpeter nur an, weil es mich auf den Gedanken brachte, daß die konzentrierten Zuckerlösungen auch deshalb so günstig für das Wachstum und die Fortpflanzung von E. repens wirken könnten, weil sie infolge der starken, inneren Reibung so zähe Flüssigkeiten vorstellen, daß sie dem Untertauchen der Mycelfäden einen gewissen Widerstand entgegensetzen könnten. Um der Frage näher zu treten, habe ich verschiedene Versuche angestellt. Ich wandte zuerst als zähe Flüssigkeiten mit relativ geringem, osmotischem Wert Dextrinlösungen von I5, 20, 40, 6o, 80 Proz. an. Auf I5 Proz. keimten die Konidien nicht recht, auf 20 Proz. entstand ein schwächliches Mycelium, das trotz der großen Zähigkeit der Lösung langsam untertauchte. Noch auf 40 Proz. konnte man einzelne, mycelial gewordene Konidienträger an den Lufthyphen beobachten; das Mycelium erreichte in 8 Tagen nur einen Durchmesser von IO $\mathrm{mm}$, während von 50 Proz. an das Wachstum sehr gefördert war, so daß der Pilz bei 60 Proz. Dextrin in 3 Tagen eine Kreisfläche von $20 \mathrm{~mm}$ Durchmesser bedeckte. Die warme Lösung von 80 Proz. erstarrte bei $29^{\circ} \mathrm{zu}$ einer ziemlich festen Masse, auf welcher der Pilz ausgezeichnet wuchs.

Um zähe Substanzen von noch geringerem, osmotischem Wert anzuwenden, vermischte ich 2 Proz. Traubenzucker mit einem Extrakt von Cetraria islandica, mit arabischem Gummi oder Traganthgummi. Bei diesen dickflüssigen Substanzen konnte das Mycelium nicht untertauchen; das Wachstum des Pilzes war aber ein äußerst beschränktes, die Konidienträger waren fast ausnahmslos

sie bei der Perithecienbildung an der Wandung der Friichte und den älteren Mycelteilen auftritt (de B ary 70 S. I3). Dieser Farbstoff löst sich zum Teil in den Salzlösungen, so daß die ganze Kulturflüssigkeit rot gefärbt erscheint. 
mycelal umgehildet. In einem Versuch mit dem braunen lixtralit von Cetraria waren aus den Konidien nach $4 W^{\prime}$ ochen bei $28-29^{\circ} \mathrm{im}$ Thermostat kleine, 3-4 $\mathrm{mm}$ Inreite und ebenso hohe Polster entstanden, die in den crsten drei Wochen schwach well,lich srefärl,t blieben und lieine normalen Konidienträger zu bilden in Stande waren. Erst in der vierten Woche, als allmählich der Fixtralit, infolge der langsamen Verdunstung, zu einer relativ festen Mlasse geworden war, bemerkte ich Konidienträger mit reifen, normalen Konidienreihen.

I'esentlich die gleichen Resultate erhielt ich lsei Anwendung von Gelatine, die bei $28^{\circ}$ flüssig, dabei aber so zähe ist, daß das Mycelium nicht untertauchen kann. Fin Gelatinezusatz von 5, I0, selbst 25 Proz. erhöht nicht An Einfluß einer Traubenzuckerlösung von 2 Proz.; sellsst hei einer solchen von Io Proz. Zucker wird noch ein großer Teil der angelegten Konidienträger vegetativ ausgebildet. Das Mycelium wächst auf der Gelatine sehr langsam und in Form eines dicken Polsters. Wenn man dagegen Cielatineblätter nimmt und sie mit etwas konzentriertem Traubensaft (ca. 20 Proz. Traubenzucker) tränkt, so wächst und fruktifiziert der Pilz in üppigster Weise. Ebenso verhalten sich Agar-igar-Kulturen; es erfolgt auf I-proz. Gallerte, die leei $28^{\circ}$ fest bleibt, mit wenigem Traubenzucker schlechtes Wachstum, auf konzentriertem Agar mit kunzentrierter Zuckerlösung vortreffliches Gedeihen.

Die Beohachtung, daß auf den mit der Zeit durch Verlumstung immer fester werdenden Sulsstraten, z. B. Cetrariaextralit, schließßlich normale Konidienträger entstanden, erwerkte die. Frage, ob nicht die Berührung mit einem fusten Substrat die Entwickelung der Konidientrïger befürdere. Ich liefs den Pilz in den Traubenzuckerlösungen von 2-6 Proz. eine \%eit lang wachsen und nahm dann die Fliissigkeit fort, so dafs das Mycelium den Boden des 
Gefäßes berührte. Unter diesen Umständen entstanden in der That gleich normale Konidienträger, zugleich ein Beweis dafür, daß nicht Nahrungsmangel daran Schuld ist, wenn sie auf der Flüssigkeit nicht reif ausgebildet werden. In gleicher Weise gelangen die Versuche, bei denen in einer großen Schale eine dünne Flüssigkeitsschicht von verdünntem Traubenzucker sich ausbreitete. Die ausgesäten Konidien berührten mit ihrem Mycelium sehr bald den Boden und entwickelten an den Lufthyphen eine Anzahl normaler Konidienträger. Diese Resultate zwingen nicht zu der Annahme einer besonderen Reizwirkung, die der Kontakt des Pilzes mit festen Körpern auf die Konidienbildung ausübt, wenn eine solche auch möglich wäre. Vielleicht erklärt sich der günstige Einfluß der Berührung daraus, daß die Lufthyphen sehr schnell in die Höhe wachsen können, daß infolge dessen die Wasserzufuhr für sie etwas erschwert wird. Wahrscheinlich wird bei den in feuchter Luft befindlichen Mycelien, ebenso auch bei einer dünnen Flüssigkeitschicht rasch eine Zunahme der Konzentration durch die Verdunstung günstig mitwirken. Die Agar- und Gelatinesubstrate, die, wie wir gesehen haben, lange Zeit die Fruktifikation hemmen, gestatten nur eine sehr langsame Verdunstung der Zuckerlösung, ohne dem Mycelium die Wasseraufnahme irgendwie zu erschweren.

Wenn nach meiner Ansicht die leichtere oder schwierigere Wasseraufnahme durch das Mycelium für die Ausbildung der Konidienträger entscheidend ist, so muß die Temperatur in dieser Beziehung Einfluß ausüben. Für höhere Pflanzen ist es bekannt (Pfeffer 8I $\$ 23$ ), daß niedere Temperatur die Wasseraufnahme durch die Wurzeln hemmt, höhere sie befördert. Gilt dieser Satz auch für die Pilze, so müßte niedere Temperatur die Konidienbildung befördern, höhere sie hemmen. Die Versuche zeigen in der 
That, daßs dieser auf den ersten Blick überraschende Schluß richtig ist. Dic optimale Temperatur von $28-29^{\circ}$ beschleunigt den Prozeßs der Konidienbildung; aber das silt nur für Sulstrate, die relativ trocken sind. Bei allen walsereichen Sulstraten, naswem Brod, feuchten Kartoffeln, Gelatine, Agarkulturen, verdünnten Zucker-Lijsungen ete, wirkt die optimale Temperatur wesentlich mit, die Bildung der Konidienträgrer zu hemmen oder anormal zu gestalten. Alle die früher beschriebenen $V$ ersuche sind bei $28-29^{\circ}$ angestellt worden. Setzt man (lie wleichen sulstrate einer Temperatur von I3 $15^{\circ}$ ans, so ist allerdings das Wachstum sehr verlangsant, lie Bildung der Konidienträger sehr verzögert, aber diese treten in normaler Form auf. Nimmt man z. 13. eine Kultur auf nassem Brod, auf der der Pilz bei 28 " einen likinen, gell,ichen Fleck mit lauter vegetativ gewordenen Kinnidienträgern getbildet hat und loringt das Ciefäfs in (lie Temperatur von 13 I5", so ist nach I-2 Wuchen ein grüngefärbter Rand ann alten Mycelfleck entstantlen, mit normalen Konidienträgern. Man kanı die Kultur wiecler eine Zeit ling der Temperatur von $28-29^{\prime \prime}$ aussetren, und man heoluachtet dann die Neul,ildung eines gedlen Ranles mit anormalen Konirlienträggern. Die Versuche mit den verschiedenartigen substraten hestitigen durchaus den angegebenen Sat\% von dem Einfluts der T(min)eratur.

Bei den stark konzentrierten Lïsmnen wirkt der EinHuts der konzentration auf die Wasseraufnahme des Pilze: demjenigen der loblen Temperatur entegegen; lie Konidienträger werden normal gebilelet. Wie wir später selsen werden, üht die Temperatur von 28" aber auch bei diesen Substraten einen gewissen lemmenden Einfluls auf die Nenge der lioniclienträger aus, namentlich im Verhailtnis y der Menge der Perithecien. 
Fassen wir die Resultate der verschiedenartigen Versuchsreihen zusammen, so können wir sagen, daß E. repens nur dann reife, normale Konidienträger in der Luft erzeugt, wenn das Mycelium seiner Umgebung das Wasser mit einer gewissen Kraft entziehen muß, so daß überhaupt die Wasseraufnahme nur in beschränktem Grade stattfinden kann. Einen Maßstab für die Größe der Kraft, die das Mycelium in Bewegung setzen muß, giebt der osmotische Wert einer Traubenzuckerlösung von ca. I5 Proz. bei einer Temperatur von $28^{\circ}$. Denn bei dieser Konzentration vermag das Mycelium neben anormalen noch normale Konidienträger zu bilden. Es bleibt sich nun gleich, ob das Mycelium das Wasser einer konzentrierten Zucker- oder Salpeterlösung oder trockenem Brod entziehen muß, da in letzterem Falle die lebhafte Anziehung der Stärke zum Wasser den osmotischen Wert der Lösungen ersetzt. Man kann den Sachverhalt auch mit den Worten ausdrücken, daß das Verhältnis zwischen der wasseranziehenden Kraft der Mycelzellen und der wasseranziehenden Kraft der Umgebung innerhalb gewisser Grenzen konstant bleiben muß, damit die normale Fruktifikation erfolgen kann. Der Pilz hat die Fähigkeit, bei steigendem Außendruck seinen Innendruck zu erhöhen; beim Sinken des ersteren dagegen vermag der Pilz seinen Druck nicht entsprechend zu verringern. Seine wasseranziehende Kraft bleibt zu stark, der Pilz nimmt sehr viel Wasser auf und preßt es in die Lufthyphen und in die etwa schon angelegten Konidienträger, die dadurch zur Bildung der Konidien unfähig werden. Wenn nun für diesen Prozeß eine Beschränkung der Wasserzufuhr notwendig ist, so liegt wohl der Grund für seine Abhängigkeit von der Luft überhaupt darin, daß nur in ihr die Hyphen jene wesentliche Beschränkung des Wassergehaltes erfahren. Man könnte wohl erwarten, 
daß es mö̈glich wäre, die Bildung (ler Konidienträger innerhallb (ler Flüssigkeit zn erreichen, sobald die Wasseranziehende Kraft dieser groß genug wäre. Das ist bisher nicht gelungen. Denn selbst wenn das Mycelium, las auf einer Rohrzuckerlösung von 80 Proz. gewachsen ist, untergetaucht wirl, so ist es nicht im Stande, in dieser Fiüssigkeit normale Konidienträger zu erzeugen; die vorher angelegten werden auch in ihr vegetativ. Elsenso wenig gelingt es, innerhalb von Gelatine den Prozeß zu veranlassen. Ich kultivierte den Pilz auf Gelatine mit 40 Proz. Rohrzucker und Pflaumensaft und goß auf das eben entstanclene Mycelium neue Gelatinelösung von gleicher Beschaffenheit. Das Mycelium wuchs in dieser Gelatine ungestört weiter, erzeugte aber nicht eher Konidienträger, als bis es wieder die Oberfläche erreicht hatte.

Diese Versuche heweisen, daß für die Bildung der Konidienträger es nicht allein notwendig ist, daß das Mycelinm in beschränktem Mał̉e Wasser aufnehmen muß, sondern claß cler Aufenthalt in der Luft auf die in ihr befindlichen Hyphen noch einen besonderen Reiz ausübt, (ler erst zur Auslüsung des genannten Prozesses führt. Dieser besondere Reiz muß3 auch deshalb angenommen werlen, weil viele andere Pilze, wie Penicillium glaucum etc., nur in (ler Luft ihre Konidienträger ausbilden, wenn ihr Wycelium in ganz verdünnten Nälırflüssigleeiten, sogar in Wasser wächst. Ich nehme nun an, claß die Transspiration der Lufthyphen zur nüchsten Veranlassung dazu wircl, daßs diese die Konidienträger und reife Koniclien atrsbilden. Allerdings erfolgt im allgemeinen der Bildunussprozeß in einer luft, clie mit Wrasserdampf gesättigt ist. 1)at aber die I'ilzhiclen lelhaft atmen und deshall, eine hiiluere temperatur als die ungebende Luft besitzen, so ist stets die Mö̈nlichlieit vorhandlen, daßs clie wärmeren Pilz- 
fäden Wasserdampt abgeben. Die Meinung, als müßten die Konidienträger sich in sehr feuchter Luft befinden, um normal gebildet $\mathrm{zu}$ werden, ist jedenfalls unrichtig. Ihre Bildung geschieht in relativ sehr trockener Luft, wenn nur das Mycelium genügend mit Wasser versorgt ist. Am besten zeigen dies Versuche, bei denen Brodstücke mit Kollodiumhaut überzogen wurden, so daß die Wasserverdunstung des Substrates selbst sehr gehemmt war. Ich übergoß frische Brodwürfel so lange mit dicker Kollodiumlösung bis ihre gesamte Oberfläche nach Verdunstung des Aethers mit einer weißen Kruste überzogen war. Dann impfte ich, ohne weiter zu sterilisieren, mit einer feinen Nadel das Brod an einer kleinen Stelle. Der Pilz wuchs lebhaft und überzog seinerseits die Kollodiumschicht, da er, wie Miyoshi (94) nachwies, diese zu durchbohren im Stande ist. Nachdem das Mycelium an solchen Brodstïcken sichtbar war, ließ ich diese frei und offen liegen, teils im Laboratorium, teils im Thermostat bei $28^{\circ}$. Das Mycelium entwickelte in der relativ sehr trockenen Luft des Thermostats eine große Menge von Konidienträgern sogar in viel höherem Grade als ein gleiches Kollodium-Brodstück, das in einer bedeckten Schale lag, wo, wie wir später sehen werden, die Perithecienbildung vorherrschte. In einer anderen Versuchsreihe bedeckte ich eine Zuckerlösung mit einer Kollodiumhaut und säte auf ihr die Konidien aus. Das Mycelium, mit üppiger Konidienbildung, entstand auch hier im Laboratorium wie im Thermostat bei freiem Zutritt trockener Luft. Ich brachte ein solches Gefäß mit 40 Proz. Rohrzucker und Kollodiumhaut unter eine kleine Glocke mit Chlorcalcium. Da die Kollodiumhaut die Flüssigkeit nicht völlig abschloß und wohl auch für Wasserdampf langsam permeabel war, so konzentrierte sich die Lösung allmählich. Die Konidienträger wurden aber in der sehr trockenen Luft normal und in Menge ausgebildet. 
I)er Nachweis, daß Transpiration stattfinden muß, Jamit die Konidienliddung normal erfolgt, ließ sich bisher nicht direkt füluren. Als indirekten Beweis meiner Annilhme fasse ich das Verhalten von li. repens gregenüber den wasserreichen Sulsstraten auf. Denn dieses erkliart sich an einfachsten daraus, daßs das Mycelium zu viel Wakser den Lufthyphen zuführt, so daß die Wirkung der Transpiration für die \%ellen aufgehohen wird. Die weitere Frage, in welchem \%ưammenhang die Wasserverdunstung mit dler Bilclung der Konidienträgrer stehe, läßt sich bisher nicht durch eine branchbare Hypothese beantworten. Es liönnte sein, dath die Erhöhung der Konzentration des Zellsaftes das erste Glied in der Kette von Vorgängen wäre, die schlieflich zur Erzeugung reifer Konidien führte; (s kömnten aber auch ganz andere Wirkungen auf Plasma und \%ellkerne in Betracht kommen. Wir stehen hier leitler vor verschlossenen Thüren, genau wie bei anderen L.chenserscheinungen der l'ilze. Ich erinnere nur an die merkwürligen Beolachtungen Elfving's (100) bei I'hycomyces. Die Konidienträger dieses Pilzes werden (Jurch Metallplatten angezogen, so daß Elfving hier ron ciner besonderen, plyysiologischen Fernwirkung der Mctalle sprach. Errera (()2) wies dann nach, daß einige dieser Körper, z. B. das Eisen, durch ihre hygroskopischen livenschaften auf den Pilz wirlien und erlilärte daher dic Fernwirkung als einen Fall von Hydrotropismus. Bei der crneuten Untersuchung Elfving's (93) stellte sich heraus, dirfs auch erhitzte Platinplatten die gleiche anzielende Wirkung ausül,ten, so daf hierbei Hydrotropismus lisine enticheidende Rolle spielen lionnte. Wie dem auch ri, so geht aus den Versuchen Errera's deutlich genug twerve, dals hydrotropische Krümmungen des Pilzes in an- Wheinend dampfgesiittigter Luft eintreten liönnen. Errera -pricht die Anicht ans: ,hyllotropisme (negative or po- 
sitive) is the bending of a plantorgan towards the point, not where it will find a minimum or maximum of moisture but where it will within certain limits transpire most or least." Errera hat seine Ansicht bisher nicht weiter begründet; es wäre in hohem Grade interessant, wenn es sich als richtig erweisen würde, daß die auf verschiedenen Seiten der Pilzhyphe ungleiche Transspiration zu Krünmmungen Veranlassung gäbe. Die bisher ganz vernachlässigte Bedeutung der Transpiration für das Leben der Pilze würde dadurch in eine neue Beleuchtung gebracht werden.

Als letzter äußerer Faktor, der von Einfluß auf die Konidienträger von E. repens sein könnte, ist das Licht zu behandeln. Bei Anwendung diffusen Lichtes läßt sich eine Einwirkung auf den Pilz nicht nachweisen. Ich würde mich kaum mit der Frage beschäftigt haben, wenn nicht Elfving (yo S. 105 ff.) bei Eurotium herbariorum die auffallende Beobachtung gemacht hätte, daß die Konidien bei einer gewissen, mittleren Intensität der Sonnenbeleuchtung Hefeformen lieferten, die sogleich derartig erblich fixierte Rassen vorstellten, daß sie sich nicht mehr in das Eurotium zurückführen liessen. Der Versuch grelang aber nur bei einer gewissen Eurotium-Form, dagegen nicht bei anderen, morphologisch ganz gleichen Pilzen. Ich habe die Versuche mit Eurotium repens teils auf Brod, teils auf Flüssigkeiten wiederholt. Die Kulturgefäße waren 4 Stunden am Vormittag direkter Aprilsonne ausgesetzt und waren auch die übrige Zeit am Tage hell beleuchtet. Bei anderen Kulturen schloß ich das Gefäß mit Paraffin luftdicht ab und stellte es in eine große Schale mit Wasser, das ich von Zeit zu Zeit erneuerte, so daß die Temperatur nie über $25^{\circ}$ stieg. Daneben standen Kulturen der direkten Sonne ausgesetzt, aber mit Stanniol dicht umwickelt, so daß nur die Tem- 
pratur-Erlïihung in Betracht kam. In keiner der Kulturen habe ich eine Hefeform erhalten, der Pilz entwiclielte normales Mycelium und Konidienträgrer. Der hell belenchtete l'ilz entwickelte allerdings diese sehr langsam und, wie mir schien, auch in kümmerlicher Ausbildung, so dafi eine gewisise hemmende Wirkung des hellen Lichtes zu bemertien war. Die Versuche Elfrings sind im Hochsonmer angestellt worden; es ist sehr wohl möglich, dats die Somnenwirkung in meinen Versuchen zu schwach war. Alver irgend eine Andeutung der Hefeformen hätte sich dloch zeigren müssen, wenn überhaupt der Pilz der bildung von solehen fähig crewesen wäre. Ehenso möglich wäre es alser auch, daß Elf ving durch zufällige Verunreinigungen der Kulturen irre geführt worden wäre. Ich habe darauf hingewiesen, daß die Keimung der Konidien thei sehr hoher Temperatur von $36-37^{\circ}$ ähnliche Formen zeigte, wie sie Elfvin r bei direkter Sonnenbeleuchtung leobachtete, ohne daß alser echte Hefeformen entstanden wären.

W'enn man zum Schluß dieses Alsschnittes einen Rückhlick auf die gewomenen, allgemeinen Resultate wirft, so werden diese luesser hervortreten, wenn man die Ergelınisse der Forsclung bei den Algren zum Vergleich heranzieht. Nelmen wir z. B. Vaucheria, so entspricht deren Zoosporenbildung der Konidienbildung des Pilzes. Meine Untersuchungen an Vaucheria halsen selehrt, laf die Zoosporenlildung, wie jeder andere Lebensprozeß, von gewissen, all„encinen Beclingungen abhängt, so von der Temperatur, tem. Saucrstoff etc.; ferner erfordert der Prozeß besondere Bulingungen, die z. B. für clas Wachstum nicht notwendig sint. Hierlier sehö̈rt die Abhängigkeit der Zoosporenbildung von dem Vorhandensein flüssigen Wassers. Sind whe diese Bedingungen gegreben, so erfolgt die Zoosporenbilkung lann, wenn specifische, äußere Reize den Prozeßs 
auslösen, wie z. B. Lichtmangel, Uebergang aus feuchter Luft in Wasser etc. Vergleicht man damit nun die Bedingungen für die Konidienbildung des Pilzes, so haben wir bei ihr ebenfalls allgemeine Bedingungen, wie Temperatur, Sauerstoff; wir haben ferner die besondere Bedingung des Mangels an flüssigem Wasser, da der Prozeß nur in feuchter Luft, im Gegensatz zum Mycelwachstum, vor sich geht. Wo sind nun aber die specifischen Reize zu suchen, die das vegetative Wachstum der Mycelfäden auf einmal in andere Bahnen lenken und die zum Anlaß für die Bildung der Fruchtträger werden? Solche Reize müssen an irgend einer Stelle eingreifen; leider läßt sich nicht sagen, wie und wo es geschieht. Wir können annehmen, daß durch das Leben in der Luft gewisse chemische und physikalische Veränderungen angeregt werden, die die Umwandlung der vegetativen Mycelfäden in fruktifizierende herbeiführen, ohne daß es möglich wäre, diese Veränderungen näher zu bezeichnen, da die Unkenntnis der Stoffwechselvorgänge innerhalb der Pilzzellen vorläufig jede Einsicht verhindert.

\section{Die Bedingungen der Perithecienbildung und ihr Verhältnis zur Konidienbildung.}

Die Entwickelung der Ascusfrüchte von Eurotium repens wurde von de Bary (70) genau erforscht; unsere Kenntnisse darüber sind seither nicht vermehrt worden. Die ersten Anfänge der Perithecien zeigen sich in Form schraubig gewundener Fäden (Holzschn. Fig. I3 $A-C$ S. 447), an denen zwei kleine Zweiglein entstehen, die der Schraube sich dicht anlegen. Eines der Zweiglein erreicht zuerst die Spitze der Schraube und verschmilzt mit ihr. De Bary faßte diese Verschmelzung als einen 
Sexualaht auf, van Tiegh em (77) bestritt die lichtigkeit dieser Auffassung; eine Entscheidung nach der einen oder anderen seite ist bisher nicht möglich gewesen. Aus der Schraube wachsen zahlreiche Zweige aus, die sic umhüllen. So entstehen kleine, bald sich gelb firbende Körper, deren Wandung nach Innen zu einem Füllgewelse anıwächst, das die Schraube umgielst. Später bilden sich an dieser neue $Z$ weige aus, deren letzte Auszweigungen zu den rundlichen Asci werden, in denen $\&$ siporen entstehen. Die Gelbfärbung der Perithecien herulht nach de Bary auf der Ausscheidung einer gelben, harzigen Substanz an den Zellen der Wandung. Allmählich setzt sich diese Ausscheidung anch auf clie Mycelfäden fort, die schließlich rotgelb bis rotbraun gefärbt werden (vergl. Anm. S. 467).

Nach de Bary treten bei Brodkulturen zuerst die Koniclientrïger, später die Perithecien auf. Die Bildung der letzteren kann infolge ungünstiger Ernährung unterbleiben. Nach Brefeld (8r S. I 32) soll die Perithecienhildung bei E. herbariorum hauptsächlich im Herbst stattfinden, wenn der Pilz zahlreiche Generationen hindurch grezüchtet worden ist. Siebenmann $\left(8_{3}\right.$ S. 23$)$ giebt an, laß3 die Früchte bei E. repens bei alınorm hoher Temperatur, z. B. bei $30^{\prime \prime}$, entständen und sich dann zahlreicher auslikleten als die Konidienträger. Ebenso hebt Elfving $(90)$ hervor, daß für E. herbariorum eine höhere Temperatur von 25 " wïnstig auf die Entwickelung der Ascusfrüchte wirke.

Für meine Untersuchungen war es zuerst notwendig, rine Ircthode zu finden, die unter allen Umständen zur l'erithecienbildung führte. Ich überzeugte mich bald, dats cine konstante, höhere Temperatur in (ler That das leste Nittel zur Erreichung des Zweckes war. Jede Brodkultur von E. repens zeigrt bei $28-29^{\prime \prime}$ ausnahmslos Perithecienbildung. Das erste Auftreten der Scliraubenfäden 
geschieht 48 Stunden nach der Impfung; am 3. Tage kann man bereits mit bloßem Auge die jungen, gelb gefärbten Perithecien beobachten. Nach 5 Tagen findet man schon Früchte mit reifen Ascosporen. Die Bildung und Ausreifung der Perithecien kann je nach der vorhandenen Nahrungsmenge lange Zeit fortgehen.

Wenn man den Einfluß der äußeren Bedingungen auf die Perithecienbildung erforschen will, so muß man stets Rücksicht auf die Fortpflanzung durch Konidien nehmen. Zwischen den beiden Fortpflanzungsweisen herrscht ein. ähnliches antagonistisches Verhältnis wie zwischen Zoosporen- und Gametenbildung bei Hydrodictyon, wenn auch der Gegensatz bei E. repens lange nicht so scharf ausgesprochen ist, weil die beiden Arten der Fortpflanzung nebeneinander am gleichen Mycelium erfolgen können. Dieselben äußeren Bedingungen wirken verschieden auf die beiden Fortpflanzungsweisen ein, es wird gerade eine interessante Aufgabe sein, diesen Unterschieden nachzuspüren.

Keine besondere Rolle spielt in dem Verhältnis von Konidien- und Perithecienbildung die Quantität und Qualität der Nahrungsstoffe. Auf allen Substraten, die überhaupt normales Wachstum der Pilze gestatten, können Perithecien entstehen. Ein Unterschied zeigt sich nur an der untersten Grenze der Nahrungsmenge, insofern die Ausbildung reifer Perithecien an eine größere Menge von Nahrung gebunden ist, als die der Konidien. Aber die ersten Anfänge der Schraubenfäden können auch bei minimalen Spuren von Nahrung entstehen wie z. B. in dem auf S. 450 erwähnten Versuch mit den Brodkrumen. Selbst ganz winzige Mycelien konnten die Schraubenfäden bis zur ersten Umhüllung ausbilden. Ebenso giebt es auch eine Grenze der Nahrungsqualität. Auf reiner Gelatine von 5o Proz., auf reinem Albumin, Hühnereiweiß 
relingt es, Konidienträger kümmerlicher Art zu erhalten, (l)enso auch Schraubenfäden, es kommt aber nicht z.u einer Ausbildung reifer Früchte. Sieht man von st)dchen Fällen ab, nimont man ein dem Pilz auch nur cinigermaßen zusagendes Substrat, so entscheidet die Menge der Nahrungssulbstanz zunäichst nichts über das Auftrcten der beiden Fortiflanzungsorgane.

Wichtiger ist hierfür das Verhalten gegenüber wasserreichen Substraten. Allerdings haben die Perithecien mit den Konidienträgern gemeinsam, daß sie, weder innerhall, einer Flüssigkeit angelegt, noch reif ausgebildet werden liönnen. Sie entstehen immer an Lufthyphen. Indessen sind sie etwas weniger empfindlich bei sehr wasserreichen Sulstraten. Bringt man ein stark durchfeuchtetes Brodstück mit Konidien in den Thermostat, so beobachtet man bei $28^{\circ}$ neben den verkümmerten, um(rel)ildeten Konidienträgern eine Unmasse von Sclraubenfïrlen. Man sieht nicht selten die interessante Erscheinung, daß die Konidienträger Sterigmen treiben, die clirekt in Schraubenfäden umgewandelt werden. Man erkennt daraus ohne weiteres, daß die beiden Fortpflanzungsarten nicht aus inneren Gründen auf einander folgen müssen, sondern laß es nur von den jeweiligen, äußeren liserlingungen abhängt, ob irgend ein Mycelteil, sei es auch ein 'Teil eines Konidienträgers, Konidien oder Perithecienanlagen erzeugt. Auf dem sehr wasserreichen Brod kommen aber die zalıllosen Schraubenfäden kaum writer als bis zur ersten Umhïllung und gehen dann zu (irunde. Allmählich wenn das Substrat weniger feucht wirl oder eine dicke Mycelschicht aufgelagert ist, reifen dic jungen Perithecien aus, wälırend die Konidienträger nocl annmal werden. So geschieht es, daß auf solchen fouchten sulsstraten die Perithecienbildung weit überwiegt, lie Konilienträger kaum merklich hervortreten. 
Das gleiche beobachtet man auf verdünnten Nährflüssigkeiten, Pflaumen- oder Traubensaft, auf Lösungen von 2-IO-proz. Traubenzucker etc. Auch hier werden gegenüber den relativ wenigen und dabei anormalen Konidienträgern zahllose Schraubenfäden angelegt, die indessen zu keinen reifen Perithecien werden. Bei io-proz. Traubenzucker sah ich gut ausgebildete Früchte, während die Konidienträger erst bei I5 Proz. reichlicher normal werden. Auf zähen Flüssigkeiten resp. festen Gallerten mit Traubenzuckerzusatz von 2-Io Proz. beobachten wir die gleichen Erscheinungen. Bleibt nun ein solches gallertartiges Substrat lange Zeit sehr feucht, so kann man den Pilz wochenlang bei $28-29^{\circ}$ ohne normale Fruktifikation kultivieren. So besaß ich eine Kultur nur auf dem braunen, gallertartigen Extrakt von Cetraria islandica, worauf das Mycelium bei $28-29^{\circ}$ viele Wochen hindurch langsam fortwuchs, ohne Träger mit reifen Konidien zu bilden; anfangs entstanden noch Schraubenfäden, die aber zu Grunde gingen. Dagegen auf dem Cetraria-Extrakt mit 2-proz. Traubenzucker beobachtete ich nach 3 Wochen die ersten normal wachsenden, jungen Perithecien. Mit zunehmender Konzentration wächst die Zahl der normalen Früchte. Bereits ein Traubensaft mit 20 Proz. Traubenzuckergehalt ist die denkbar beste Nährflüssigkeit, auf der nach 3 Tagen Hunderte von Perithecienanlagen in den verschiedensten Stadien bemerkbar sind. Ohne Schwierigkeit kann man auf diese Weise jederzeit beliebige Mengen von Perithecien gewinnen. Aehnlich verhält sich der Pilz auf anderen konzentrierten Flüssigkeiten. In der nachfolgenden Tabelle will ich die Resultate einer Anzahl meiner Versuche angeben, hauptsächlich um das Verhältnis von Perithecien- und Konidienbildung schärfer hervorzuheben, wofür die angewandten Konzentrationen von gewisser Bedeutung sind. Bei den Quantitätsangaben 
verstehe ich unter sehr viel den Fall, daß3 nach $2-3$ Wochen die ganze Oberfläche des Substrates von Perithecien beleckt und infolge dessen gleich gelb, später rotgelb uefärbt erscheint. In diesem Falle ist die Zahl der Konidienträger äußerst gering, und diese sind überhaupt nur mikroskopisch nachzuweisen. Viele Perithecien zähle ich dann, wenn sie zwar über die ganze Oberfläche zerstreut, aber doch mit den grünen Konidienträgern durchsetzt sind; bei wenigen Perithecien muß man sie mit der Lupe zwischen den Konidienträgern suchen, das Nycelium erscheint rein grün. Die Versuche wurden süntlich bei $28-29^{\circ}$ angestellt, als Tag des Auftretens rer Perithecien bestimme ich denjenigen, an welchem ich zuerst die gelb gefärbten, jungen, umhüllten Früchte sehen lionnte.

Die Tabelle weist die wichtige Thatsache nach, daß auf organischen Substraten bei einer Temperatur von $28-29^{\circ}$ bald die Perithecien-, bald die Konidienbildung überwiegt. Die Entscheidung darüber hängt vor allem von der Konzentration des Substrates ab. Bei steigender Konzentration, z. B. der Zuckerarten, nimmt die Perithecienbildung ab. Die Konidienbildung, weit weniger em1) findlich, kann infolge dessen beträchtlich zunehmen, bis sie schließlich allein herrscht. Die obere Grenze der Konzentration liegt für die Perithecienbildung tiefer als für die Koniclienbildung, entsprechend der vorhin erwïhnten Erscheinung, daß die untere Grenze der Konzentration für die erstere niedriger liegt als für die letztere. Die Versuche mit völlig getrocknetem Brod, das mit Zuckerlïsungen getränkt wurde, führten zu gleichen Resultaten; nur beobachtete ich bei Anwendung einer Rohrzuckerlösung von Ioo Proz. auf dem Brod überhaupt kcine Perithecienlildung mehr, weil die Wasseranziehung durch die Stärke das Sulsstrat für den Pilz noch kon- 
Eurotium repens.

\begin{tabular}{|c|c|c|c|c|c|c|}
\hline Substanz & 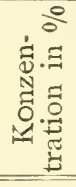 & Zusatz & & 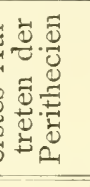 & 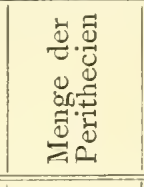 & 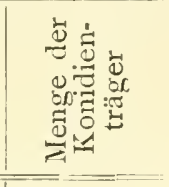 \\
\hline Traubenzucker & 20 & Traubensaft & 3 & Tage & sehr viele & sehr wenige \\
\hline$"$ & 40 & $"$ & & $"$ & $"$. & $"$ \\
\hline$"$ & 65 & $"$ & 5 & $"$ & wenige & viele \\
\hline$"$ & 80 & $"$ & 5 & $"$ & $"$ & $\eta$ \\
\hline$"$ & 90 & $"$ & & & keine & $"$ \\
\hline Rohrzucker & 40 & Pflaumensaft & 3 & $"$ & sehr viele & wenige \\
\hline$"$ & 70 & $"$ & 4 & $"$ & $"$ ". & $"$ \\
\hline$"$ & 90 & $"$ & 7 & $"$ & wenige & viele \\
\hline$"$ & 100 & & 7 & $"$ & $"$ & $"$ \\
\hline Invertzucker & 90 & Traubensaft & & & keine & $"$ \\
\hline Dextrin & 60 & allein & 3 & $"$ & sehr viele & wenige \\
\hline $\begin{array}{l}\text { "Malzextrakt, } \\
\text { konzentriert }\end{array}$ & 80 & $"$ & $\begin{array}{l}3 \\
9\end{array}$ & $"$ & $\begin{array}{c}\text { ", } \\
\text { wenige }\end{array}$ & $\begin{array}{l}\text { Spuren } \\
\text { viele }\end{array}$ \\
\hline Glycerin & 20 & Pflaumensaft & 3 & $"$ & viele & wenige \\
\hline$"$ & 30 & $"$ & 4 & $"$ & $"$ & $"$ \\
\hline$"$ & 35 & $"$ & 8 & $"$ & wenige & viele \\
\hline$"$ & 40 & $"$ & I 2 & ” & $"$ & $"$ \\
\hline$"$ & 45 & $"$ & & & keine & wenige \\
\hline Natronsalpeter & IO & $"$ & 3 & $"$ & viele & viele \\
\hline$"$ & I5 & $"$ & 5 & $"$ & wenige & wenige \\
\hline Chlornatrium & $\begin{array}{r}20 \\
5\end{array}$ & Pflaumensaft & 3 & $"$ & $\begin{array}{l}\text { keine } \\
\text { viele }\end{array}$ & $\begin{array}{c}\text { sehr wenige } \\
\text { viele }\end{array}$ \\
\hline$"$ & IO & $"$ & 3 & $"$ & $"$ & ." \\
\hline Kalisalpeter & $\begin{array}{l}\text { I5 } \\
\text { IO }\end{array}$ & $\begin{array}{c}\text { Io Proz. } \\
\text { Rohrzucker }\end{array}$ & 6 & $"$ & $\begin{array}{l}\text { keine } \\
\text { wenige }\end{array}$ & $\begin{array}{c}\text { vereinzelte } \\
\text { wenige }\end{array}$ \\
\hline$"$ & I5 & $\begin{array}{l}\text { o,8 Proz. } \\
\text { Pepton }\end{array}$ & 7 & $"$ & $"$ & $"$ \\
\hline Natronsalpeter & IO & $\begin{array}{l}\text { I6 Proz. } \\
\text { Traubenzucker }\end{array}$ & 6 & $"$ & viele & $"$ \\
\hline
\end{tabular}




\section{$-484-$}

zentrierter machte. Auf rlen Substraten mit anorganischen Substanzen tritt das verschiedene Mengenverhältnis der beiden Fruktifikationen nicht auffallend hervor, weil wegen der relativ geringen Masse organischer Sulstanz die Zahl der Fortpflanzungsorgane überhaupt eine beschränkte ist. Tränkt man trockenes Brod mit den Salzlösungen, so erhält man eine sehr viel lebhaftere Fruktifikation. Bei I6, 20, 25 Proz. Kalisalpeter ist die Zahl der Konidienträger gegenüber den wenigen Perithecien sehr groß; bei Io Proz. überwiegen die letzteren.

Nach den früheren Darlegungen wissen wir, daß die feuchten Substrate, besonders die Gallerten Agar-Agar, Gelatine bei der Temperatur von $28^{\circ}$ der Konidienbillung nicht förderlich sind. Vermeidet man zu feuchte Gallerte, nimmt man ganz konzentrierte Gelatine und Agar, mischt sie mit einem Traubensaft von 20 Proz. Zuckergehalt, so tritt die Perithecienbildung im höchsten Grade ein und verdrängt die Konidienbildung. Noch mehr unterdrückt erscheint dieser Prozeß bei Anwendung von Dextrinlösungen von 60 ... 8o Proz., wo von vornherein die Konidienbildung so gehemmt ist, daß man sie überhaupt nur nach sorgfältiger Prüfung nachweisen kann. Wie nun die Perithecienbildung gegenüber höheren Konzentrationen empfindlicher ist als die Konidienbildung, so ist das gleiche der Fall gegenüber trockener Luft. Auf jenen Brodstücken, die mit Kollodium überzogen worden waren (S. 473), war dieser Unterschied der beiden Fortpflanzungsarten sehr deutlich. Auf dem Brodstück mit Collodium, das in geschlossener Schale bei $28^{\circ}$ stand, trat die Perithecienbildung gegenüber der normalen Brodkultur etwas zurück, obwohl sie die Konidienbildung übserwog. Auf jenen Brodstücken, die offen im Thermostat lagen, war die Perithecienbildung trotz günstigen Sul,- 
strates und optimaler Temperatur ganz unterdrückt; die Konidienbildung herrschte allein auf dem Brod.

In der ganzen bisherigen Darstellung sind nur die Versuche berücksichtigt worden, die bei $28-29^{\circ}$ angestellt worden sind. Das Verhältnis von Perithecien- und Konidienbildung wird wesentlich verändert, wenn davon abweichende Temperaturen zur Anwendung kommen. Die Perithecienbildung wird durch niedere wie auch durch eine das Optimum übersteigende Temperatur in viel höherem Grade gehemmt als die Konidienbildung. Auf frischem Brod kann man die erstere zwischen 25 und $32^{\circ}$ absolut sicher erhalten. Unter $25^{\prime \prime}$ wird das Resultat unsicher; bei gewöhnlichen Zimmertemperaturen zwischen 12 und $22^{\circ}$ beobachtet man im allgemeinen keine Früchte, gleichgiltig welche Substrate man anwendet. Besonders überraschend ist ein Vergleich zweier Kulturen auf 80-proz. Dextrin; diejenige bei durchschnittlich $16^{\circ}$ ist nach Wochen rein grün, zeigt nur Konidienträger, die andere bei $28^{\circ}$ ist in wenigen Tagen gelb und weist wesentlich nur Perithecien auf.

Von vornherein erschien es nicht wahrscheinlich, daß die Perithecienbildung bei $16-22^{0}$ wirklich unmöglich ist. Vielmehr mußte man daran denken, daß die Konidienbildung gegenüber einer solchen Temperatur weniger empfindlich ist und nun die vorhandene Nahrungsmenge des Substrates so schnell erschöpft, daß für die Perithecienbildung nichts übrig bleibt. Man konnte zwei Wege einschlagen, um bei der relativ niederen Temperatur doch zur Perithecienbildung zu gelangen. Man mußte einmal ein möglichst nahrungsreiches Substrat wählen, so daß es trotz lebhaftester Konidienbildung für die Entwickelung der Früchte immer noch ausreichte. Ich benutzte z. B. Brod, das mit 40-proz. Traubenzuckerlösung getränkt worden war; in der That beobachtete ich bei einer Temperatur, 
die sich zwischen I2 und $16^{0}$ bewegte, eine Anzahl Perithecien, wenn sie auch zurücktrat gegrenüber der Masse v'u1 Konidienträgern.

Der zweite Weg mußte darin bestehen, die Konidienliklung zu hemmen, um der Entwickelung der Perithecien freie Bahn zu schaffen. Zuerst wandte ich die wasserreichen Substrate, nasses Brod, feuchte Kartoffeln, Kleister, Gelatine von Io-50 Proz. an, aber ohne Erfolg. Bei $12-16^{0}$ bildeten sich nur Konidienträger, normal oder anormal, je nach dem Wasserreichtum; bei $28-29^{\circ}$ traten Schraubenfäden in Unmasse auf. Dagegen gelangen die Versuche besser, als ich sie in ähnlicher Weise anstellte wie Brefeld (74 S. 4I) es bei Penicillium glaucum gethan hat. Ich preßte in eine Glasschale ein genau passendes Brodstück, nachdem ich es vorher halbiert und Konidien zwischen die Brodhälften gebracht hatte. In den schmalen Räumen zwischen Brod und Glaswand traten bei $12-16^{0}$ sehr zahlreiche Perithecien auf. Verschiedene Umstände konnten hierbei förderlich wirken. Durch die dichte Berührung der Brodfläche mit der Glaswand wird ein so enger Luftraum geschaffen, daß die Entwickelung der aufstrebenden Konidienträger mechanisch stark gehemmt wird, infolgedessen die Perithecien, die viel geringeren Raum beanspruchen, sich auf Kosten des vom Mycelium aufgenommenen Nahrungsmaterials ausbilden kïnnen. Man beobachtet leicht, daß überall dort, wo der 乙wischenraum größer ist oder wo im Brode eine relativ weitere Lufthöhle vorhanden ist, die Konidienbildung allein vorherrscht. Bei den gewöhnlichen Brodkulturen, namentlich solchen, die noch mit Nährstoffen reich getränkt sind, wird man aus gleichem Grunde die Perithecien an der Unterseite des Brodes finden, dort wo es glatt der Glaswand anliegt. 1ch habe bei $12-16^{\circ}$ auch auf der ()herseite Perithecien erhalten, als ich einfach eine dicke 
Glasplatte auf die recht glatt gemachte Oberfläche des Brodes legte.

Ein zweiter Grund für das Auftreten der Perithecien könnte darin liegen, daß bei der Wirkung des kleinen, engen Luftraumes ein Sauerstoffmangel von Bedeutung wäre. De Bary (66 S. 3I) hat zuerst auf die Möglichkeit aufmerksam gemacht, daß die Zygosporenbildung bei Mucor stolonifer durch Sauerstoffmangel begünstigt werde. V an Tieghem (75 S. 89) hat die gleiche Ansicht für Mucorineen angenommen, wenn auch nicht mit entscheidenden Versuchen begründet. Auch Brefeld (74 S. 40) hat bei den Versuchen, die zur Erlangung der Sclerotien von Penicillium führten, zuerst die Meinung de Bary's verteidigt, während er (8I S. 74) sie später aufgegeben hat, von der Anschauung ausgehend, daß das Auftreten der verschiedenen Fruchtformen weniger von äußeren Umständen, als von inneren Momenten abhängig sei. So viel geht aus den früher beschriebenen Versuchen mit Sicherheit hervor, daß Luftmangel nicht notwendigerweise eine Bedingung der Perithecienbildung ist. Sie bilden sich ja überhaupt nur in der Luft aus. Immerhin könnte der Prozeß gegenüber einem Mangel an Sauerstoff weniger empfindlich sein als die Konidienbildung. Dann würde ihre Hemmung die Perithecienbildung fördern und diese auch bei einer Temperatur von $12-16^{\circ}$ gestatten. Das Resultat eines Versuches könnte dafür sprechen. Ich füllte ein Cylindergrlas von IO $\mathrm{cm}$ Höhe, $5 \mathrm{~cm}$ Durchmesser zu $\%$ mit fest auf einander gepreßten Brodstücken an, impfte nach der Sterilisation und verschloß das Gefäß mit sorgfältig paraffiniertem Deckel luftdicht. Die Kultur stand bei einer Temperatur, die $16^{0}$ nie überstieg. Das Mycelium entwickelte sich zuerst lebhaft und wurde grün infolge der zahlreichen Konidienträger. Nach einigen Wochen 
hïrte anscheinend das $W^{\top}$ achstum des Pilzes auf. Ich iffnete las ciefäls nach 2 Monaten und bemerkte, daß in ler Nälue der broduberfläche zahlreiche selbe, allerdings nicht ausurereifte Perithecien sich vorfanden. Den eigentlichen Beweis, daf die Perithecienbildung gegenäber der Konidienbildung durch einen relativen Mangel an Sauerstolf beförlert wird, habe ich bisher nicht liefern können.

Bei meinen Versuchen mit verdünnter Luft gelang es mir nicht, die Perithecienbildung zu beobachten, sie sincl aber lisher nur bei sehr nierlerem Luftdruck angestellt worken, hei dem ïłerhauj)t das Wachstum kes Pilzes beschränkt war. Es wäre möglich, daß bei etwas höherem Luftdrucli die Perithecienbildung in stärkerem Grade eintreten kïnnte als die Konidienbildung. Versuche mit niederem Luftdruck und einer höheren Temperatur von 2.9-29" habe ich bisher nicht angestellt. Nit Hilfe der vorhin erwähnten Versuche habe ich feststellen können, dals die Perithecienbildung noch bei $12-15^{0}$ stattfinden kann. Unter $12^{\circ}$ hale ich sie nicht beobachten können. Ith weis nicht, ob dieser Temperaturgrad wirklich das Minimum vorstellt.

Alle V'ersuche über die Bedingungen der Perithecienhilklung sind im Dunkeln ausgeführt worden. Für E. herhariorum giebt Elfving (90 S. I05) an, daß das Jicht dic P'erithecienbildung unterdrücke. Seine V'ersuche berechtigen noch nicht zu dieser Folgerung, weil aus ihnen nicht hervorgeht, ob die während 24 Stunden herrschende, nittlere Temperatur genügend war, um die Perithecienbildung gegenüber der Konidienbildung wesentlich zu befördern. 1)ie relativ kurze Temperaturerhöhung wälnend lor Beleuchtung liann die niedere Temperatur während der ïhrigen Tageszeit nicht ersetzen. Bei meinen Versuchen ïber den linfluti des Lichtes (s. S. 475) habe auch ich 
keine Perithecienbildung beobachtet. Als ich aber nach 4-stündiger, direkter Sonnenbeleuchtung eines Apriltages sowohl Brod- als Zuckerkulturen in den Thermostat brachte, entstanden nach einigen Tagen normale Perithecien. Ihr Auftreten verzögerte sich um ein weniges im Vergleich zu den Kulturen, die von vornherein im Thermostat bei $28^{\circ}$ gestanden hatten. Auch hier lasse ich dahingestellt, ob die Versuche im Hochsommer anders ausfallen würden.

Ueberblicken wir die Versuche über den Einfluß der Außenwelt auf die Fortpflanzung des Pilzes, so ergiebt sich als allgemeines, sicheres Resultat, daß dieser Lebensprozeß in notwendiger Abhängigkeit von bestimnten, äußeren Bedingungen steht. Die beiden Formen der Fortpflanzung, Konidien- und Perithecienbildung verhalten sich aber verschieden den gleichen, äußeren Bedingungen gegenüber. Dadurch wird es möglich, genau wie bei den von mir untersuchten Algen jederzeit diejenige Fortpflanzungsweise zu veranlassen, die gerade gewünscht wird. Die Konidienbildung entspricht der ungeschlechtlichen Fortpflanzung der Algen, die Perithecienbildung der geschlechtlichen, wie zuerst de Bary klar erkannt hat. Es ist von sekundärer Bedeutung für diese Auffassung, ob bei Eurotium eine wirkliche Befruchtung stattfindet oder nicht. Die Perithecien von Eurotium sind physiologisch wie morphologisch die gleichen Organe wie die Ascusfrüchte von Eremascus, bei dem Eidam (83) die Befruchtung beobachtet hat, ebenso von Sphaerotheca Castagnei, bei der Harper (95) in neuester Zeit, die Aufffassung de Bary's voll bestätigend, auch die Verschmelzung der Zellkerne der männlichen und weiblichen Zellen nachgewiesen hat.

Bei allen genau untersuchten Algen liegt immer die Veranlassung für das Auftreten der geschlechtlichen Fort- 
pllanzung darin, daßs nach kräftigem, gesundem Wachstum eine Hemmung von diesem durch eine bestimmte, :̈ußere Einwirkung herbeigeführt wird. Dieser Anlaß liist als Reiz jene Vorgïnge im Organismus aus, die zur Aushliliung der Geschlechtszellen dann führen, wenn gleichzeitig noch andere äußere Bedingungen gegeben sind, unter denen bei der Mehrzahl der Algen das Licht von besonderer Bedeutung ist. Bei manchen Algen, z. B. Hydrodictyon, muß nur indirekt das Wachstum, direkt dagegen die ungeschlechtliche Fortpflanzung gehemmt werden. Vergleichen wir damit das Verhalten von Eurotium repens, so läßt sich keine volle Uebereinstimmung mit den Algen erkennen. Man kann allerdings sagen, daß höhere Temperatur für die Perithecienbildung die Rolle des specifischen Reizes ühernimmt, da sie das vegetative Wachstum und vor allem die Konidienbildung bis zu einem gewissen Grade hemmt und zugleich die ersten Prozesse in den Zellen veranlaßt, welche zur Bildung der Schraulsenfäden hinführen. Aber ein Unterschied zwischen den Algen und Eurotium zeigt sich darin, laß nicht ein besonders auffallender Wechsel der Temperatur zum Reiz wird und daß diese überhaupt nicht hoch zu sein braucht. Denn die Perithecienbildung findet auch hei $15^{\prime \prime}$ statt, wenn die Konidienbildung auf anderem Wege beschränlit wird. Der erste entscheidende Anlaß für die Bildung der Früchte ist ebenso wie der für die Bildung der Konidienträger unbekannt, weil er wahrscheinlich in bestimmten, durch die Außenwelt anreregten Stoffwechselprozessen besteht, von denen wir elen vorläufigr nichts wissen. Wir können nur annehmen, daß in den Pilzhyphen eine Hemmung der Konidienlililung notwendig ist, damit eine Ansammlung von oryanischer Sulstanz in ihnen stattfinden kann, daß dann bestimmte Umsetzungen dieser, durch eine Temperatur 
von $25-30^{\circ}$ begünstigt, Platz greifen, die die Zelle zur Bildung der Schraubenfäden, später der Perithecien, veranlassen.

Sehr wahrscheinlich werden die Bedingungen der geschlechtlichen Fortpflanzung bei den eigentlichen Phycomyceten viel auffallendere Analogien mit den Algen darbieten. 


\section{Mucor racemosus Fresenius.}

Mucor racemosus gehört zu den verbreitetsten Schimmelpilzen auf Brod, süßen Früchten, Mist und ähnlichen Sulstraten und ist deshalb selir oft untersucht worden, so von Fresenius (50), Bail (57), Hoffmann (63), Brefeld $(73,76,89)$, Paste ur $(76)$, Bainier $(83$ a und b), Léger (95), Morini (96). Besonders eingehend hat Brefeld die ungeschlechtliche Fortpflanzung des Pilzes untersucht, der in den morpholugischen Spekulationen des genannten Forschers eine hervorragende Stellung eimnimmt. Brefeld ( 89 S. 223) hat den Pilz zu dem V'ertreter einer eigenen Gattung Chlamydomucur erhoben, clie aber mit Recht nicht anerkannt worden ist (vergl. A. Fischer $92 \mathrm{~S}$. I82), weil die von Brefeld angeführten Gründe zu geringe Bedeutung halsen. Die geschlechtliche Fortpflanzung durch Zygoten ist von Bainier und nenerdings von Morin i beobachtet worden. Brefo:ld ist es nicht gelungen, sie zu erhalten, und ebenso wenigr lionnte ich trotz großer Variation in den Kulturmetluslen die Zygoten grewinnen. Die äußeren Bedingungen, die notwendig ihre Bildung herbeiführen, sind hisher unbeliant; weder $\mathrm{B}$ a in ier noch Morini laben Methoden, die unbedingt sicher die geschlechtliche Fortpllanzung erzielen, kennen gelehrt. Mich intoresiserte der Pilz lauptsächlich wegen der auffallenden Verinderlichlseit seiner Sporangrien- und Mycelformen; 
ich habe versucht, die äußeren Bedingungen, die für das Auftreten der einzelnen Formen bestimmend sind, genauer zu erkennen, da unser Wissen darüber bisher sehr lückenhaft und unsicher ist. Ich werde in meiner Darstellung folgende vier Punkte nach einander behandeln:

I. Die Sporangienträger;

II. Das schlauchförmige Mycelium;

III. Das septierte Mycelium;

IV. Die Gemmen oder Chlamydosporen.

Meine sämtlichen Kulturen im Winter und Frühjahr I896 sind von einem Sporangium ausgegangen, das ich einem zufällig auf Pflaumen entstandenen Rasen des Pilzes entnommen habe; ich habe nur mit Nachkommen dieses Sporangiums meine Versuche angestellt.

\section{Die Sporangienträger.}

Auf gedörrten, stark gekochten Pflaumen entwickelt das Mycelium des Pilzes zahỉreiche, aufrechte, verzweigte Sporangienträger, die einen dichten, gelblich-bräunlichen Rasen bilden (vgl. die Diagnose bei Fischer 92 S. I93). Die Träger können bei reichlicher Ernährung eine Höhe von $2-4 \mathrm{~cm}$ erreichen; sie endigen in ein größeres Sporangium mit einem Durchmesser bis zu $70 \mu$, während zahlreiche, kleinere Sporangien an kurzen Seitenzweigen sitzen. Die Sporangien zeichnen sich durch eine nicht zerfließende, sondern zerbrechliche Wandung aus, die mit kleinen Kalkkryställchen besetzt ist. Nach dem Oeffnen des Sporangiums bleibt von der Wandung ein kurzer Basalkragen neben der verkehrt-eiförmigen bis fast kugeligen Kolumella bestehen. Die Sporen, die im reifen Sporangium durch die Wandung sichtbar sind, erscheinen ellipsoidisch bis fast kugelig; nach den Angaben Fis cher's schwankt ihre Länge von $6-$ IO $\mu$, ihre Breite von $5-8 \mu$. Unter be- 


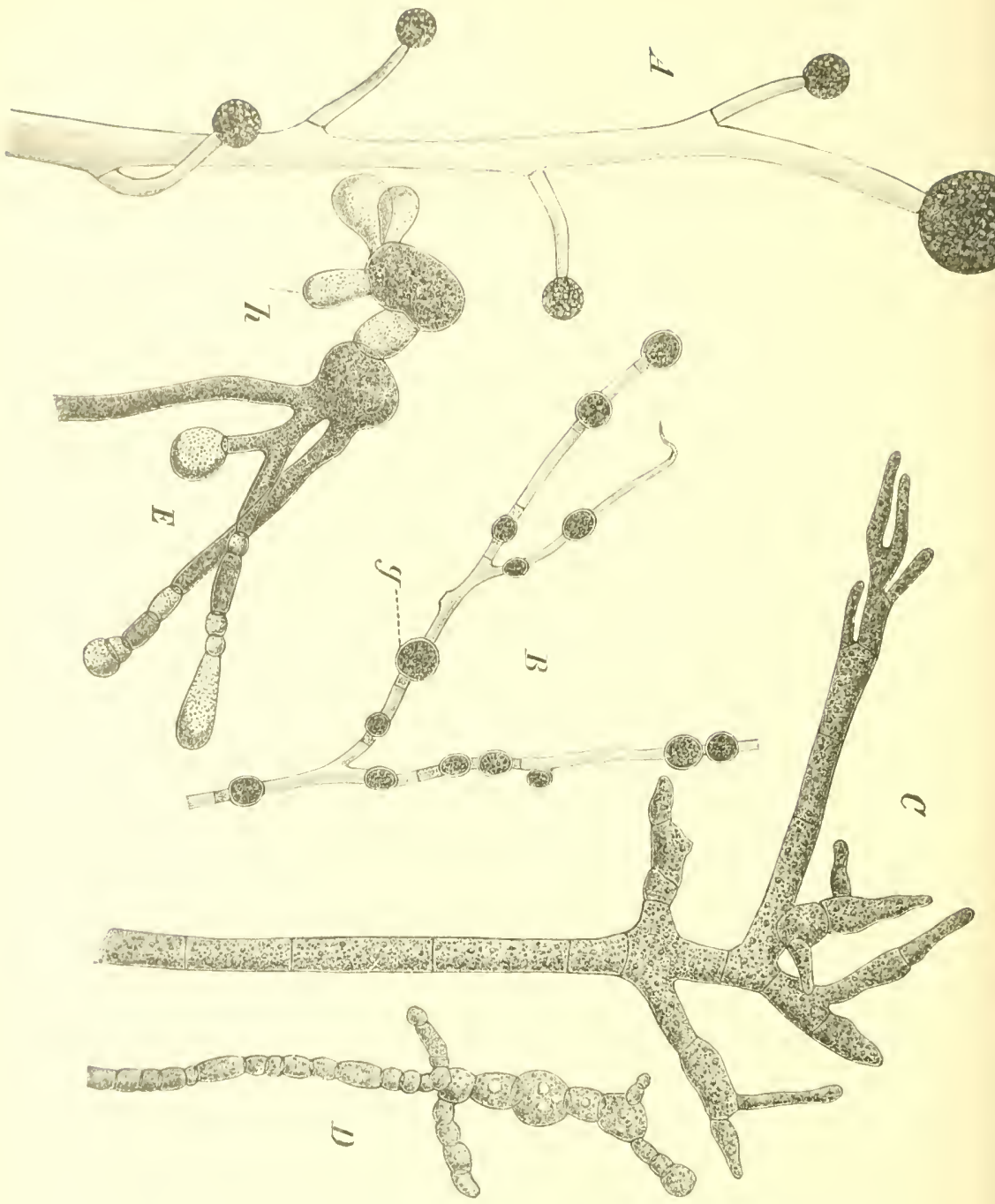

Fig. I. Mucor racemosus. A Sporangienträger mit lgroßem Endsporangium und kleineren Sporangien an kürzeren Seitenzweigen. /3 cin Stiick eines Myceliums mit Bildung von Gemmen $(g)$; $C$ ein Stiick cines septiertcu Myceliums in 50-proz. Traubenzucierlösung inturewachsen; I) cin Stück eines septierten Myceliums aus gärenden Trablucnsaft; $F$ cin Stïck eincs septierten und zum Teil (h) hefeartig sprossenden Myceliums, ebenfalls aus gärendem Traubensaft; die Lallcn /, mit glänzend weißem Inhalt. Vergr. A $120, B-E 300$. 
sonderen Umständen können die Sporen größer werden und abnorme Gestalten annehmen.

Obwohl alle Forscher, die sich mit dem Pilz näher beschäftigt haben, darin übereinstimmen, daß er äußerst vielgestaltig ist, so finden sich doch wenige, klar bestimmte Angaben über den Umfang und die Ursachen der Variabilität. Die Frage steht noch offen, ob die Vielgestaltigkeit auf dem Vorhandensein zahlreicher, erblicher Rassen oder auf einer direkten Abhängigkeit von den wechselnden, äußeren Bedingungen beruhe. Nach Abschluß meiner eigenen Untersuchung über diese Frage ist noch eine Arbeit von Morini (96) erschienen, die die gleiche Frage bei Mucor racemosus behandelt. Morini kommt zu dem auch von mir gewonnenen Resultat, daß die Außenwelt wesentlich den Formenreichtum des Pilzes bedingt; aber auch bei ihm fehlt der Nachweis, in welcher Weise und in welchem Grade die verschiedenen, äußeren Bedingungen die Bildung der Sporangienträger beeinflussen.

Zunächst muß festgestellt werden, innerhalb welcher Grenzen der Temperatur und bei welchen Ernährungsbedingungen ïberhaupt die Bildung reifer Sporangien stattfinden kann. Das Temperatur-Minimum liegt etwa bei $4^{0}$; zwischen 4 und $5^{\circ}$ kann eine schwache Keimung der Sporen stattfinden aber innerhalb 8 Tagen keine Sporangienbildung. Bei $7-9^{0}$ treten die Sporangien 3-4 Tage nach der Aussaat auf, bei IO- I2 ${ }^{\circ}$ in 2-3 Tagen, bei $12-30^{\prime \prime}$ in einem Tage. Das Optimum liegt bei 20-25 ${ }^{\circ}$, wo die ersten reifen Sporen 16-i8 Stunden nach der Aussaat sich zeigen. Von $30^{\circ}$ an wird das Wachstum des Pilzes verlangsamt, die Bildung der Sporangien beeinträchtigt; zwischen 32 und $33^{\circ}$ kann noch eine schwache Keimung stattfinden; bei $34^{\circ}$ keimen die Sporen nicht mehr. $\mathrm{Zu}$ diesen Versuchen benutzte ich 
1gur-Traubensaft als Substrat, da hierbei eine mikroskoj,ische Kontrolle leicht möglich war.

Die Bildung der Sporangien ist in sehr hohem Grade von der Quantität und Qualität der äußeren Ernährungshedingungen unabhängig, wenn man nur darauf Rücksicht nimmt, daß überhaupt keimfähige Sporen erzeugt werden. Ganz kleine Mycelabschnitte mit lebendem I'lasma können, wie bereits Brefeld (89 Taf. VII, Fig. 5) nachgewiesen hat, zwar sehr kümmerliche, aber doch normale Sporangien treiben. Die Sporen keimen in destilliertem Wasser, sie bilden ein schwächliches Mycelium, an dem noch ein kleiner Sporangienträger entstehen kann. Bei Versuchen mit verdünnter Luft beobachtete ich, daß eine einzelne Spore direkt im Sporangium zu einem kleinen, aber normalen Sporangienträger ausgewachsen war. Die geringe Menge Substanz in kleinen Mycelstücken oder einer einzelnen Spore genügt für den Notfall zur Neubildung von Sporen, wenn von außen keine andere Nahrung als Wasser zu Gebote steht.

Dagegen gilt auch für M. racemosus die gleiche Regrel wie für Eurotium und andere Pilze, daß normale Konidienbildung nur in der Luft und nicht innerhalb einer Flüssigkeit stattfinden kann. Die Frage, warum die Luft eine solche specifische, notwendige Bedingung für den Prozeß ist, läßt sich für Mucor noch schwieriger beantworten als für Eurotium. Für diesen Pilz ließ sich als sehr wahrscheinlich annehmen, dafs nicht der Sauerstoffgehalt der Luft von Bedeutung, sondern daß (lie in ihr erfolgende Wasserverdunstung für die Konidienbildung wesentlich ist. Die Gründe, die dafür sprachen, wie z. B. das Verhalten des Pilzes gegenüber wasserreichen, festen Substraten und sehr verdünnten Nährflüssigrkeiten, lassen sich für M. racemosus nicht anfülıren, da dieser Pilz in den verdünntesten Lösungen, 
auf den feuchtesten Substraten wächst. Um so mehr hoffte ich, daß das Verhalten des Pilzes in verdünnter Luft nach irgend einer Seite entscheidend sein würde. Die Versuche wurden in der gleichen Weise wie bei Eurotium angestellt (S. 454); als Nährböden benutzte ich AgarAgar mit Trauben- oder Pflaumensaft, ferner kleine Brodstücke. Da ich meistens gleichzeitig mehrere kleine Kulturgläschen für einen Versuch verwandte, so wurde infolge der Atmung der Pilze der Sauerstoffgehalt innerhalb der Luftpumpenglocke verringert. Das Manometer konnte diese Sauerstoffverminderung nicht anzeigen, weil die bei der Atmung und event. auch durch die Gärung entstehende Kohlensäure eher den Luftdruck etwas erhöhte. Um den Nachteil zu beseitigen, habe ich immer nach 2 Tagen einen Augenblick frische Luft in den Apparat eintreten lassen und dann von neuem bis zu dem bestimmten Stande des Manometers ausgepumpt. Die Resultate der Versuche sind die folgenden: Bei einem Luftdruck von 3-5 $\mathrm{mm}$ findet noch auf den Agar-Kulturen die Auskeimung der Sporen statt; aber nach 8-Io Tagen bildet sich nur ein kleines, korallenartig verzweigtes Mycelium ohne Sporangienträger höchstens mit vereinzelten, vegetativen Lufthyphen. In normaler Luft bilden solche Mycelien nach 24 Stunden reife Sporangienträger. Von ca. $6 \mathrm{~mm}$ Druck an beginnt die Anlage von Sporangienträgern; bei Io $\mathrm{mm}$ entstehen nach 8- Io Tagen auch reife Sporen. An den betreffenden Kulturen treten aber eine Reihe bemerkenswerter Eigentümlichkeiten auf; ich will diese näher beschreiben bei einer Kultur, die 8 Tage bei Io $\mathrm{mm}$ Druck und einer Temperatur von I6- $20^{0}$ gestanden hatte und dann untersucht wurde. Ich beobachtete dabei:

I) eine cymöse Verzweigung der Sporangienträger. Klebs, Fortptlanzungsphysiologit. 
Fine solche zeigte sich vielfach in ganz typischer Weise. Der aus dem Mycelium hervortretende, kurze Träger 'ndigte in ein Sporangium; dicht unter diesem entstand ein Zweig, der die Fortsetzung des Trägers übernahm, aber sehr bald wieder mit einem Sporangium sein Wachstum beschloß und dann seinerseits einen Zweig aussendete, der dasselbe Spiel wiederholte. Daneben fanden sich auch Uebergänge zur racemösen Verzweigung vor.

2) ein Aussprossen der Sporangienanlagen.

Die betreffenden, kugeligen Sporangienanlagen besałsen keine normale Columella, sondern waren durch eine einfache Querwand vom Träger getrennt. Diese (Zuerwand saß meistens etwas unterhalb der Anschwellung. Die Sporangienanlage wuchs entweder an der Spitze zu einer dicken Hyphe aus oder, was viel häufiger der Fall war, sie erzeugte eine ganze Anzahl dünnerer Hyphen, die von ihr nach allen Richtungen sternartig ausstrahlten. solche Hyphen konnten an ihrem Ende eine neue Sporangienanlage bilden.

3) Sporangien mit Columella und Sporen.

Die Sporen waren in geringer Anzahl vorhanden und meist abnorm gestaltet. Man sah lang-wurstförmige Sporen, die durch ihre Größe auffielen; Länge bis zu I5 "., Breite 8-II $\mu$. Einzelne dieser Sporen hatten innerhall, des Sporangiums ausgekeimt und eine Keimhyphe erzeugt, die durch eine Lücke der Sporangienhaut hervortrat und nach kurzem Wachstum ein neues Sporangium bildete. Besonders bei Kulturen, die I4 Tage in der verdünnten Luft gelelst hatten, bemerkte ich, daß in dem Sporangium eines solchen Keimfadens wieder Sporen erzeugt worden waren.

Bei den Kulturen, die einem Luftdruck von 6-10 mm aucgesetzt worden waren, war die Mehrzahl der in den crsten Tagren angrelegten Sporangien vegetativ ausge- 
wachsen; es kam kaum zu einer Bildung reifer Sporen. Noch bei einem Luftdruck von $15 \mathrm{~mm}$ sah ich die gleiche Erscheinung, wenn auch normale Sporangien überwogen.

Unter anderen Bedingungen habe ich dieses Aussprossen der Sporangienanlage von M. racemosus nur selten beobachten können; regelmäßig sah ich es in verdünnter Luft sowohl auf Agar-Agar, wie auf Brod-Kulturen. Es wäre möglich, daß die Verminderung des Sauerstoffgehaltes die nächste Veranlassung für dieses Verhalten der Sporangien sei, während die cymöse Verzweigung der Sporangienträger auch durch andere Umstände hervorzurufen ist. Man könnte nun das Verhalten des Pilzes in sehr verdünnter Luft als Beweis für die Ansicht betrachten, nach der die Luft durch ihren Sauerstoffgehalt die Sporangienbildung bedingt. Das könnte für M. racemosus richtig sein, ohne für andere Pilze allgemein gelten zu müssen. Eigentlich folgt aber aus den Versuchen nur, daß die Sporangien bei einem etwas geringeren Luftdruck angelegt werden als die Sporen in ihnen. An und für sich genügt für die Bildung dieser der sehr geringe Luftdruck von $10 \mathrm{~mm}$, was in der Glocke einem Prozentgehalt von 0,28 Sauerstoff entspricht. Es ist sehr unwahrscheinlich, daß in den obersten Schichten einer offen stehenden Flüssigkeit, wie z. B. von Pflaumensaft, ein so geringer Partiärdruck des Sauerstoffs herrscht. Trotzdem werden nicht einmal die Sporangien angelegt an den Mycelfäden, die sich nahe der Oberfläche befinden. Auch bei M. racemosus erhält man den Eindruck, daß die Mycelfäden, solange sie von Flüssigkeit, und sei es selbst von einer sehr dünnen Schicht, umgeben sind, vegetativ bleiben müssen. Erst das Fehlen der flüssigen Umgebung, der Aufenthalt in der Luft, die die Transpiration gestattet, ermöglicht die Ausbildung der Spor- 
angrienträger. Der eigentliche, den Bildungsprozeß ausliisende Reiz ist für Mucor ebensowenig bekannt wie für Eurotium.

Nachdem wir die Bedingungen kennen gelernt haben, welche für die Sporangienbildung notwendig sind, kommt es jetzt darauf an, zu untersuchen, in welcher Weise die Ausbildung der Sporangienträger, die Dimensionen dieser Organe von den äußeren Verhältnissen abhängen. V'on Bedeutung sind vor allem I) die Quantität und Qualität (ler Nahrungssubstanzen, 2) die Konzentration von diesen, 3) die Temperatur.

Ich hob schon hervor, daß ein kleines Mycelstück oder eine einzelne Spore olne Nahrungszufuhr von außen cinen ganz winzigen, unverzweigten Sporangienträger von 0,05 mm Länge erzengen kann; der Durchmesser des Sporangiums beträgt in solchem Falle 0,or2 mm. An(lererseits erreichen die Träger auf Brod, das mit Pflaumensaft getränkt ist, eine Länge bis $\mathrm{zu} 40 \mathrm{~mm}$; das Endsporangium kamn einen Durchmesser bis zu 0,105 mm halıen. Auberdem finden sich an den Trägern zahlreiche, kürzere Seitenäste mit kleineren Sporangien vor. Zwischen diesen Extremen giebt es alle denkbaren Uebergangsformen je nach der Menge der vorhandenen Nahrung (vergl. auch Morini 96 S. 84). Aber auch die Qualität (ler Nahrungssubstanzen hat für die Ausbildungsweise der ()rgane eine gewisse Bedeutung, wenn auch M. racemosus ähnlich wie Penicillium die Fähigkeit luat, neben geringen Mencren von Nährsalzen die verschiedenartigsten, organischen Substanzen für seine Ernährung zu benutzen. Der Pilz ernährt sich von den verschiedenen Kohlehydraten, sowohl den Zuckerarten wie von Stärke, lnulin, Lichenin, eljenso von stickstoff haltigen Stoffen wie Asparacin, weinsaurem Ammoniak, Pepton, Eiweiß, ferner auch Anygdalin, Salicin, Aesculin etc. Daher gedeiht der 
Pilz ebenso gut auf Früchten und Fruchtsäften, auf Brod und Kartoffeln, wie auf verschiedenartigem Mist. Nach den Untersuchungen B a ch mann's (95) wirken auf Thamnidium elegans die vorherrschend stickstoffhaltigen Substrate in anderer Weise ein als solche, die reich an Kohlehydraten oder Fetten sind. Die ersteren veranlassen neben dem Endsporangium dieser Mucorinee die dichotom verzweigten Seitenäste mit kleinen Sporangiolen, während die an Kohlehydraten reichen Substrate dahin wirken, laß die Sporangiolen größer werden und an weniger verzweigten Seitenästen sitzen. Ein so auffallender Unterschied läßt sich für M. racemosus je nach den Substraten nicht beobachten. Die traubig verzweigten, typischen Sporangienträger finden sich auf den verschiedensten Substraten, z. B. auf Agar-Agar sowohl mit Pepton als auch mit Traubenzucker, auf Mist wie auf Pflaumen. Dagegen beobachtete ich regelmäßig eine etwas abweichende Form bei den Brodkulturen des Pilzes, namentlich wenn das Brod noch mit Pflaumensaft durchtränkt war. Statt der kleinen, etwas gekrümmten, racemös angeordneten Seitenäste fanden sich weniger zahlreiche, aber sehr viel längere Zweige vor, die über das Endsporangium der Hauptachse hinausragten. Außerdem zeichneten sich die bräunlich aussehenden Sporangien durch ihre Wandung aus, die nur mit äußerst winzigen Kalkkörnchen bedeckt war und bei dem Aufplatzen fast ganz zerfloß und verschwand. Besonders auffallend war der Unterschied gegenüber den Sporangien, die sich auf konzentrierteren Peptonlösungen ( $15-20$ Proz.) gebildet hatten. Die Sporangiummembran war mit einer dichten Lage deutlicher Kalkkryställchen bedeckt und sehr spröde und zerbrechlich; die gleichen Kryställchen fanden sich auch am oberen Teile des Trägers vor. Der ganze Rasen erschien grau gefärbt. Ob bei Anwendung absolut calcium- 
freier Nährsubstanzen nicht die Krystallschicht auf der Sporangiummembran ganz zu unterdrücken wäre, habe ich nicht weiter untersucht. Die Nahrungssubstanzen beeinflussen die Ausbildung der Sporangienträger auch durch ihre physikalischen Eigenschaften, vor allem ihre wasserentziehende Kraft. Mit steigender Konzentration nimmt in allgemeinen die Länge der Sporangienträger sowie ihre Verzweigung ab. Zur Veranschaulichung will ich eine V'ersuchsreihe ausführlicher beschreiben, bei der ich Agar-Agar mit Traubenzuckerlösungen verschiedener Konzentration anwandte. Die Kulturen standen im Dunkeln bei Zimmertemperatur $\left(\mathrm{I} 3-17^{\circ}\right)$. Die beifolgende Tabelle giebt Aufschluß über die Resultate der Versuche.

Mucor racemosus auf Agar-Traubenzucker.

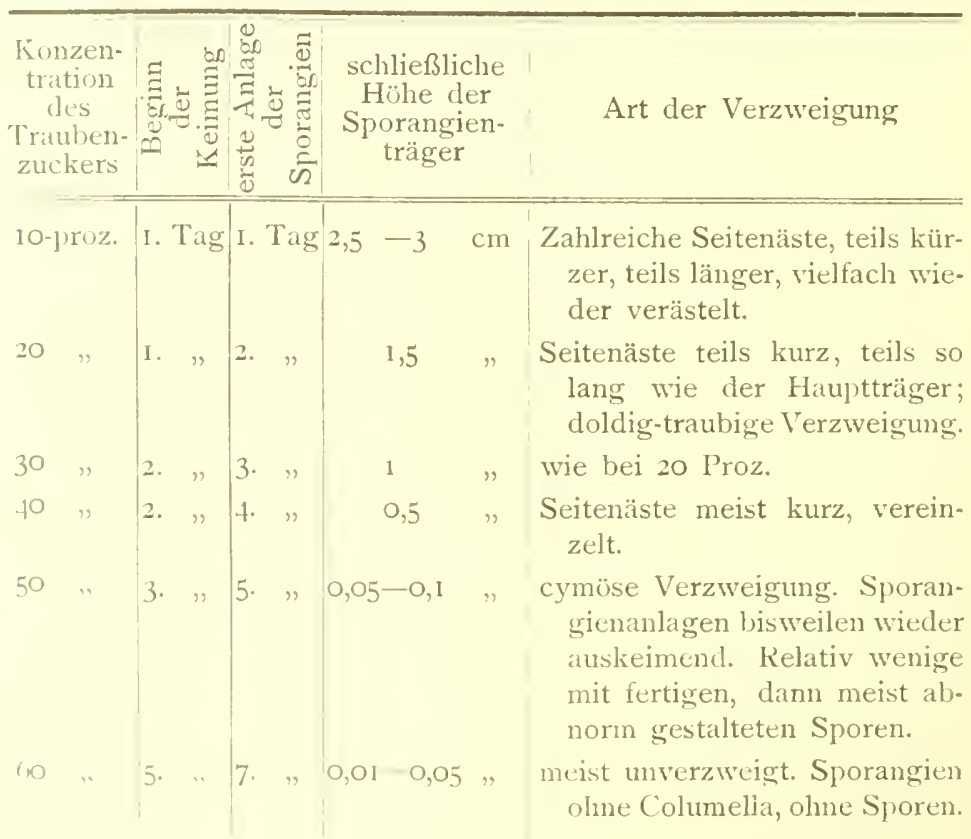


Die Tabelle zeigt den deutlichen Einfluß zunehmender Konzentration des Traubenzuckers auf die Gestaltung der Sporangienträger. Die anfangs fast rispenartige Verzweigung wird mit der Verkürzung der Hauptachsen doldig-traubig, dann einfach traubig, schließlich cymös. Bei 50 Proz. liegt etwa die Grenze für die normale Ausbildung der Sporangien, die bisweilen in ähnlicher Weise auskeimen wie in verdünnter Luft. Noch bei 60 Proz. können die Sporangien angelegt werden, ohne aber ausreifen zu können; bei 65 Proz. unterblieb bei den Versuchen die Keimung der Sporen.

In ähnlicher Weise wie konzentrierte Lösungen von Traubenzucker wirken solche von Invertzucker und Rohrzucker. Sehr gut kann man die verschiedenartige Ausbildung der Sporangienträger auf Pflaumen beobachten, je nachdem man diese kürzere oder längere Zeit auskocht. Nur wenig ausgekochte Pflaumen wirken wie hoch konzentrierte Lösungen; die Sporen keimen überhaupt nicht (s. S. 462). Auf etwas länger (5-10 Minuten) gekochten Pflaumen entwickelt sich ein schwacher, bräunlicher Anflug mit ganz kurzen Sporangienträgern; bei längerem Auskochen wird der Rasen des Pilzes höher, es bilden sich traubig verzweigte Träger $u$. s. w. Nimmt man dagegen Substanzen von relativ geringer, wasserentziehender Kraft, so werden die Sporangienträger auch durch höhere Konzentration nicht so stark beeinflußt. Zahlreiche Versuche habe ich mit Peptonlösungen angestellt von I-20 Proz.; auf den Lösungen von IO, I5, 20 Proz. entwickelten sich normal verzweigte Sporangienträger, wie auf den verdünnteren Lösungen.

Dagegen üben höhere Temperaturen einen ähnlichen Einfluß aus wie konzentrierte Nährsubstanzen, insofern die Träger sehr verkürzt werden. Bereits bei $27^{\circ}$ läßt sich dieser Einfluß bemerken, auffallender bei $28-29^{\circ}$, 
wo z. B. auf Brod der Pilz eine gleichmäßig sraue, nur etwis körnic erscheinende Schicht bilcket mit ganz kurzen sporangienträyern. Es liommt hinzu, daß durch eine solche Temperatur die Gemmenbildung in höchstem Maße gesteigert wird, so daß überhaupt die Sporangientrïger ganz zurückgedrängt werden. Sie zeigen dabei viclfach eine cymöse Verzweigung wie bei hoher Konzentration. Bei $3 \mathrm{I}^{0}$ werden Sporangien noch angelegt, sie bilken aber keine reifen Sporen aus.

$V^{\top}$ on anderen Bedingungen, die die Ausbildung der Sporangienträger beeinflussen, sind noch Feuchtigkeit und Licht zu erwähnen. Auf feuchten Substraten, in relativ trockener Luft werden die Sporangienträger im allgremeinen kürzer; der Rasen erreicht nie die Höhe wie in feuchter Luft. Noch beschränkter ist das Längenwachstum, wenn das Substrat relativ wasserarm ist; man heobachtet dann ähnliche Erscheinungen wie bei höherer Konzentration. Das Licht übt geringen Einfluß aus (Norin i 96 S. 84); bei (liffuser Beleuchtung entwickelt sich der Pilz nicht anders als im Dunkeln. Erst wenn man eine Pilzkultur an ein sonniges Fenster stellt, wobei die direkte Sonnenbeleuchtung aber verhindert wird, erscheint der Rasen einer solchen Brodlsultur gegenüber (:iner im Dunkeln wachsenden fast um die Hälfte kürzer. Wahrscheinlich ist es nicht das Licht, sondern die höhere T'emperatur, die dabei wirksam ist, indem sie eine lelhafte Wasserverdunstung des Substrates veranlaßt und es dalurch relativ trocken macht. Ob die Einwirkung dircliter Sonnenbeleuchtung einen besonderen Einflufs ausübe, habe ich nicht untersucht. Alle die verschiedenen, aiuferen Bedingungen, denen die ungreschlechtliche Fortfllanzung von M. racemosus unterworfen ist, wie Quantitit, @ualitït, Konzentration der Nalırungssubstanzen, l'artianlruck tes Sauerstoffs, Temperatur, Feuchtigkeit, 
wirken auf die Gestaltung der Sporangienträger ein. Daraus erklärt sich die Vielgestaltigkeit dieser Organe, ihre wechselnde Größe und Verzweigungsweise. Im allgemeinen üben die einzelnen Bedingungen ihren Einfluß in ähnlicher Weise aus, wenn sich auch kleine Unterschiede zeigen; doch ist es möglich, daß eine eingehendere Untersuchung noch weitere Unterschiede aufzudecken vermag.

\section{Das schlauchförmige Mycelium.}

Das Mycelium von M. racemosus besitzt bei normaler Ausbildung jene Eigenschaften, die im allgemeinen allen Mucor-Arten zukommen. Aus der keimenden Spore entsteht ein reich verästeltes, sich strahlig nach allen Seiten ausbreitendes Mycelium ohne Querwände, so daß es eine einzige Zelle darstellt. Im feinkörnigen Plasma, das der Wandung anliegt und bald mehr, bald weniger den Zellsaft durchsetzt, finden sich zahlreiche, kleine Zellkerne, die zuerst von Schmitz (79) nachgewiesen worden sind (vergl. auch Léger 95). Das Mycelium von M. racemosus wächst, wie seit $\mathrm{Brefeld}$ (73) bekannt ist, sehr gut innerhalb von Flüssigkeiten und läßt sich in sołchen beliebig langre ohne Sporangienträger kultivieren. Wenn man solche Kulturen in verschiedenartigen Nährflüssigkeiten anstellt, so beobachtet man, daß das Mycelium ungleichartig ausgebildet wird. Die bisherigen Beobachter von M. racemosus haben darauf nicht geachtet; dagegen hat Bachmann (95 S. I25) ähnliches für Thamnidium elegans nachgewiesen. Ich unterscheide zwei Haupttypen des Myceliums:

I) Mycelium mit relativ dicken Haupthyphen und stumpf endigenden Seitenästen. Das Plasma erscheint gleichmäßig feinkörnig, bräunlich gefärbt (Fig. I5 $A$ ). 
2) Mycelium mit dünnen Haupthyphen und sehr spitz endigenden Seitenästen. Das Plasma erscheint weiß, etwas lichtbrechend und sehr vakuolig (Fig. I5 $B$ ).

Den ersten Typus will ich kurz als das Zucker-Mycelium bezeichnen, weil es vor allem charakteristisch in zuckerhaltigen Nährflüssigkeiten auftritt, ebenso in Lösungen von

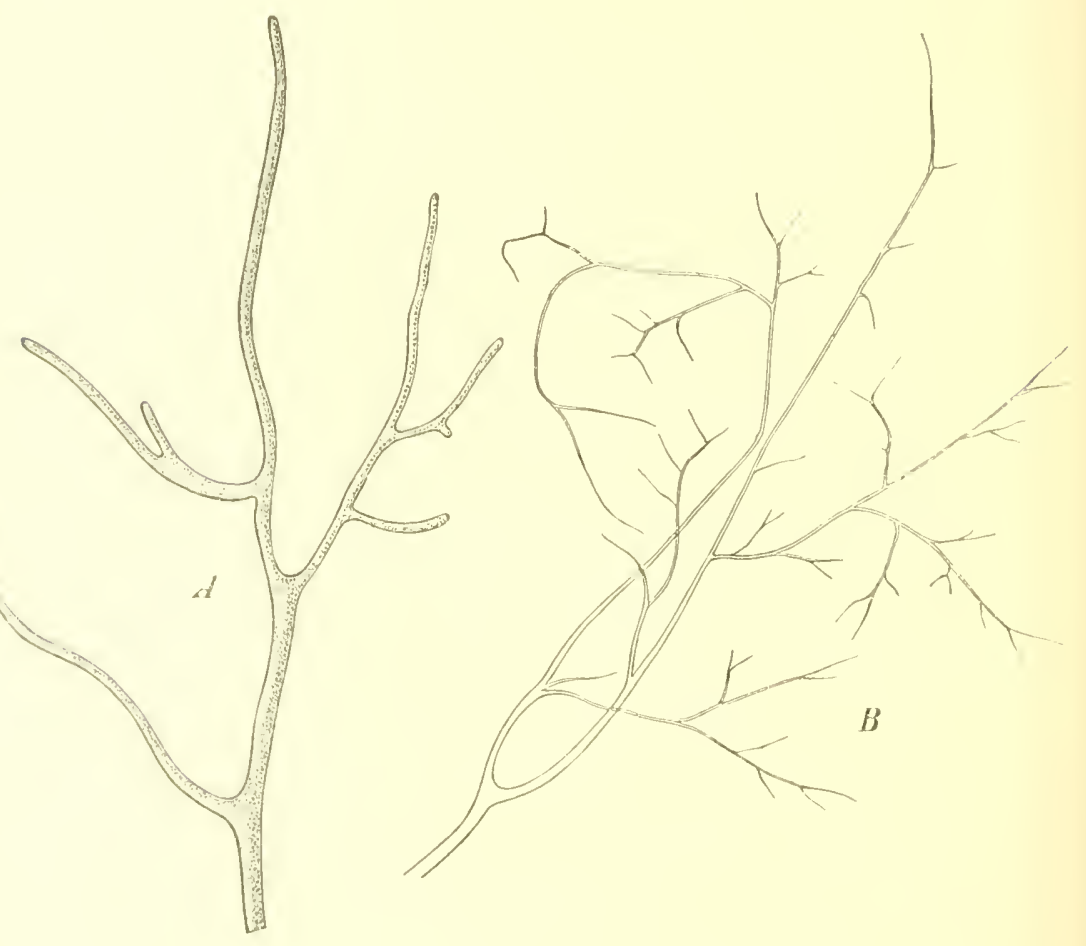

lïg. 15. Mucor racemosus. A Mycelium aus Zucherlösmngen; I) Mycreliun aus l'eptonlösung (2 Proz.). Vergr. 300.

anderen Kohlehydraten, die bei der Umsetzung Zuclier liefern, wie Stärke, Inulin, Dextrin etc. Die Dicke der Haupthyphen beträgt durchschnittlich 8- I I $\mu$. Indessen 
hängt der Durchmesser der Fäden noch von anderen Umständen ab. Nimmt man eine Lösung von reinem Kandiszucker, so ist der Durchmesser der darin wachsenden Mycelfäden auffallend klein; in einer Lösung von 20 Proz. hatten die stärksten Hyphen nur eine Dicke von I, $8-3,5 \mu$, so daß das ganze Mycelium eine äußerst zarte, leicht zerfallende Flocke vorstellte. So wie man anorganische Nährsalze (S. 452) zufügt, z. B. in Form einer Lösung von O, I Proz., so wird das Mycelium sehr kräftig, die Haupthyphen erreichen ihre normale Dicke. Noch auf einem anderen Wege kann man den Durchmesser der Hyphen erhöhen, nämlich durch höhere Konzentration des Zuckers. In 70-proz. Kandiszuckerlösung, in der das Wachstum verlangsamt ist, hatten die Hyphen vielfach eine Dicke von I3 $\mu$, abgesehen von einzelnen, noch viel breiteren Auftreibungen. Nicht so auffallend, aber doch bemerkbar ist der Einfluß der Konzentration beim Traubenzucker. Wegen des relativ großen Aschengehaltes auch des sog. chemisch reinen Traubenzuckers ist der Durchmesser der Hyphen selbst in verdünnter Lösung normal. Immerhin nimmt er bei höherer Konzentration zu, so daß er z. B. in einer Lösung von 50 Proz. II-I $8 \mu$ beträgt und bei den Auftreibungen des Myceliums $30 \mu$ erreichen kann. Auf die anderen Einwirkungen solcher höheren Konzentrationen werde ich weiter unten zurückkommen.

Den zweiten Typus des Myceliums will ich als PeptonMycelium bezeichnen. Er tritt am auffälligsten in reinen Peptonlösungen von I-4 Proz. auf. Die stärksten Hyphen haben einen Durchmesser von 4,5-5,5 $\mu$. Zwei verschiedene Eigenschaften des Peptons kommen bei seiner Wirkung auf das Mycelium in Betracht, einmal sein chemischer Charakter als stickstoffhaltige Substanz, zweitens sein geringer Gehalt an Aschenbestandteilen. Der chemische Charakter bedingt die feine, spitz-endigende 


\section{- $508-$}

Verzweigung und clas weiße, lichtbrechende Aussehen des Inhaltes; der Nangel an Nährsalzen führt die Dünnheit ler Hyphen herbei. Setzt man dem Pepton Nährsalze hinzu, so beobachtet man, daß die Haupthyphen stärker werden und den Durchmesser des Zuckermyceliums erreichen. Ebenso wirken auch einzelne Salze, wie Kali, Nitronsalpeter, Kochsalz, ferner Citronensäure (von 0,5 Proz.). Man gewinnt den Eindruck, als würden diese Substanzen durch ihren Eintritt in die keimenden Sporen den osmotischen Zellsaftdruck erhöhen und dadurch von vornherein eine stärkere, radiale Ausdehnung der Hyphen veranlassen, die indessen nur die Hauptliyphen betrifft. Die vorhin erwähnten Beobachtungen, die sich auf die Zunahme des Durchmessers beim Zuckermycelium leziehen, lassen sich wohl in gleicher Weise erlklären.

Der Typus des Peptonmyceliums tritt auch in Lösungen anclerer organischer Sulsstanzen auf, nur daß der Durchmesser der Haupthyphen je nach der Beimischung osmotisch wirksamer Stoffe höhere Werte erreichen kann. So ist es der Fall in Fleischextraktlösung von I Proz., in Mistelekokt, in weinsaurem Ammoniak von I Proz. Dals uleiche l'eptonmycelium mit stärkeren Hyphen beobachtet man in Löstungen von Asparagin (2 P'ruz.) uncl Harnstoff (1 P'roz.), denen man, um genügendes Wachstum zu erlailten, ctwas Nährlïsung zusetzen muß. In einer Knopscluen Nährlüsung von I Proz. ohne organische Beimengung lilkct sich aus der Spore ein äußjerst zartes Mycelium des l'eptontypus. Im allgemeinen sind es also die stickstoffreichen, organischen Sulstanzen, die die feine, spitze Veraweigung und das weibe Ansselien des Myceliums veranlatsen.

Mischt man Kohlehydrate und stickstoffreiche Körper, 13. Trambenzudier und Pepton, so steht das Mycelium 
in der Mitte zwischen dem Zucker- und Peptontypus. Bei einer Mischung z. B. von 2-proz. Pepton- und 4-proz. Traubenzuckerlösung kann man neben stumpfen noch reichliche, feine, spitze Zweige beobachten.

\section{Die Formen des septierten Myceliums.}

Bail (57) hat zuerst die Beobachtung gemacht, daß eine Mucor-Species (später als racemosus erkannt) in Bierwürze Gärung erregt und dabei in einer hefeähnlichen Form auftritt. Die Sporen des Pilzes, ebenso seine Gemmen (von Bail als Konidien bezeichnet), treiben in der Würze kürzere oder längere Sprosse, die durch Querwände in kurze Zellen geteilt werden; diese Zellen schwellen kugelig an, lösen sich los und können von neuem hefeartige Sprossungen erzeugen. B a il behauptete, daß diese Mucornefe sich direkt in die echte Hefe (Saccharomyces) umwandeln könne (6r S. 23). Dagegen wies Rees (70 S. 55 ff.) nach, daß die Mucorhefe niemals in die echte Hefe übergeht, sondern nur eine Entwickelungsform des M. racemosus ist, die sich in gärungsfähigen Flüssigkeiten bei gehindertem Luftzutritt ausbildet. Brefeld (73) bestätigte die Richtigkeit der Angaben von Reess, zog aber aus seinen Beobachtungen den Schluß, daß die anfangs in der Flüssigkeit normal wachsenden Hyphen dann hefeartige Sprossung zeigen, wenn das Medium sich allmählich mit Kohlensäure sättigt. In dem gleichen Jahre (I876), als Brefeld seine ausführlichen Angaben über die Hefesprossung mitteilte, sprach sich auch Pasteur (76 Chap. IV) über diese Erscheinung aus. Er kam zu dem Resultat, daß die Mucorhefe nur dann sich zu entwickeln vermag, wenn der Pilz anfangs bei Gegenwart von Sauerstoff wächst und darauf bei allmählichem Mangel an Sauerstoff 
den Traubenzucker vergärt. Die Nucorhefe ist von späteren Forschern vielfach erwähnt worden. V an Tieghem (75 S. 94), Bainier (83 S. 353,84 S. 20I) haben sie auch bei anderen Mucor-Arten beobachtet. Nach der Meinung von Bainier $\left(8_{4}\right.$ S. 202) könnte die Mucorhefe bei Mangel an Sanerstoff entstehen oder, was noch wahrscheinlicher wäre, bei Mangel an Transspiration, durch die sonst eine Flüssigkeitsströmung in der Zelle herbeigeführt würde. Eirgentliche Versuche werden von Bainier zur Unterstützung seiner Ansicht nicht angegeben.

In seiner neuesten Bearbeitung von M. racemosus bezeichnet Brefeld ( 89 S. 222 Anm.) den Namen Mucorhefe ,als thïriclat und unglaublich unrichtig“ (!); er bezeichnct die betreffende Mycelbildung als Oidienform. Brefeld nimmt sogar an, daß diese Mucoroidien nichts anderes als unentwickelte Fruchttrïgeranlagen seien, die physiologisch den Wert von Sporen angenommen hätten. Man kïnnte nun die Brefeld'sche Bezeichnung mit den gleichen Ausdrücken zurückweisen, die er gegenüber dem Namen Mucorhefe gebraucht hat, wenn nicht ïberhaupt solche Urteile in rein wissenschaftlichen Streitfragen ebenso überflüssigg wie unpassend wären. Die Bezeichnung Brefeld's ist um nichts besser als der gebräuchliche Ansdruck Mucorhefe oder Kugelhefe, sie ist mindestens chenso einseitig. Brefeld, die unzweifelhafte Aehnlichkeit mit der Hefesprossung übersehend, legt hauptsächlich Cicwicht auf die Septierung der Hyphen und die Loslïsung einzelner Zellen. Aber gerade in der letzteren beziehung zeigt sich zwischen Mucorhefe und typischer ()idienlildung ein wesentlicher Unterschied, da die Spaltung eines Zellfadens in seine einzelnen Zellen, wie sie geracle für die Oidienform charalsteristisch ist, bei Mucor häufigr ganz fehlt oder mehr zufällig eintritt. Der Ausdruck 
Oidienbildung kann daher ganz falsche Vorstellungen erwecken, und die Herleitung der echten Oidienfruktifikation höherer Pilze von den betreffenden Mycelformen des Mucor erscheint ganz willkürlich und sehr wenig ïberzeugend.

Man kann nur sagen, daß gewisse Mycelformen des Mucor an Hefe, andere an Oidium erinnern; keiner dieser Ausdrücke kann die Mannigfaltigkeit der Erscheinungsformen umfassen. Ich verzichte auf die Anwendung dieser Bezeichnungen, ich werde nur ganz allgemein von Formen des septierten Myceliums sprechen. Denn nach meiner Ansicht handelt es sich hier nicht um eine besondere Form von Fortpflanzungszellen, die morphologisch und physiologisch vom vegetativen Mycelium unterschieden sind. Vielmehr handelt es sich um einen besonderen Zustand des ganzen Myceliums unter bestimmten, äußeren Bedingungen. Wohl kann mit diesem Zustand eine Vermehrung verbunden sein; aber diese erscheint nicht als eine notwendige Folge dieses Zustandes, sie kann vollständig fehlen und darf nicht als Zweck, sondern höchstens als gelegentlicher Erfolg der ganzen Reaktion betrachtet werden.

Will man die hier in Frage kommenden Erscheinungen alle auf einmal beobachten, so fülle man mit einem Traubensaft von ca. 20-proz. Traubenzuckergehalt ein Glasfläschchen bis nahe zum Halse, pfropfe es nach der Impfung lose zu und stelle das Gefäß in den Thermostat bei $28^{\circ}$. Nach wenigen Tagen tritt langsame Gärung ein, und man bemerkt, daß die anfangs normal wachsenden Hyphen durch zahlreiche Querwände in kleine Zellen zerfallen (Fig. I4 $D$, S. 494) - die Oidienform Brefeld's. Ein Teil dieser Zellen, besonders an den Enden der Zweige, schwillt kugelförmig an und zeichnet sich häufig durch glänzend weißen Inhalt aus (Fig. I4 E). Wird die Kultur älter, so 
keimen solche Kugelzellen teils direkt, teils nach Lostrennung rom Faden, dann meist mit kürzeren, ebenfalls septicrten Hyphen und angeschwollenen Zellen. Vielfach werden an den Kugehn ganz kurze, angeschwollene Zellen reblildet (Fig. $14 E /$ ), so daß das Bild einer hefeartigen Siprossung entsteht.

Gegrenüber dem normalen, schlauchförmigen Mycelium fallen die beschriebenen Mycelformen zunächst durch zwei Eigentümlichkeiten auf:

a) durch die Septierung der Hyphen;

b) durch die Anschwellung der einzelnen Zellen.

Wir wollen in erster Linie untersuchen, welche aufieren Bedingungen diese Besonderheiten des Myceliunıs in möglichst reiner Form veranlassen.

a) Die Septierung.

M. racemosus lilklet normalerweise Querwände bei ler Bildlung der Sporangienträger, die an ilırer Basis durch eine Wand rom Mycelium getrennt werden. V an Tieghem (75 S. 19-22) wies nach, daß das Mycelium an verletzten oder durchschnittenen Stellen die Wunde durch Wandbildung verschließt, daß ferner junge, plasmareiche Teile des Myceliums sich auf die gleiche Weise von älteren, plasmaleeren Teilen absondern. In allen diesen Fällen beruht nach van Tieghem die Querwandbildung auf der ,faculté que possède le protoplasma vivant de se maintenir constamment fermé vis-à-vis du milieu extérieur et vis-à-vis des parties de son propre (c) rjes qui sont mortes déjà ou doivent mourir bientôt". Diese Worte geben aber nur eine Umschreibung der Thatsachen, sie weisen nicht darauf hin, welches die rigentlichen, die Wandbildung veranlassenden Reize sincl. Vielleicht kanı man der Frage etwas näher treten, wenn 
man die gleiche Erscheinung durch möglichst einfache, äußere Bedingungen zu erreichen sucht. Vor allem hat in dieser Hinsicht die wasserentziehende Kraft der angewandten Nährsubstanzen große Bedeutung.

Wenn man Sporen von M. racemosus in einem Erlenmeyer-Fläschchen in 50-proz. Traubenzuckerlösung bei Zimmertemperatur aussät, so geht die Keimung und das Wachstum des Pilzes sehr langsam vor sich. Nach I4 Tagen bemerkt man ein flockiges Mycelium, das aus relativ derben (s. S. 507), verzweigten Hyphen besteht, die sämtlich septiert sind, so daß man das Mycelium eines höheren Pilzes zu sehen glaubt (Fig. I4 C, S. 494). $\mathrm{B}$ refeld würde vielleicht hier von Oidienbildung reden; aber diese Bezeichnung hätte gar keinen Sinn, weil eine Abspaltung einzelner Zellen auch nach Wochen nicht stattfindet. Vielfach treten an den Hyphen Unregelmäßigkeiten hervor; die einzelnen Zellen sind verschieden lang, hier und dort blasig aufgetrieben. Der Inhalt aller Zellen ist gleichmäßig bräunlich, feinkörnig. In verdünnteren Lösungen des Traubenzuckers von 5, IO, 20, 30 Proz. ist das Mycelium schlauchförmig; es treten erst an gewissen Stellen Querwäncle auf, wenn aus anderen Gründen Gemmenbildung erfolgt.

In ähnlicher Weise wie beim Traubenzucker wirken konzentrierte Lösungen von Rohrzucker und Glycerin, denen man aber etwas Pflaumensaft zusetzen muß, um ein besseres Wachstum des Pilzes herbeizuführen. In 7o-proz. Rohrzuckerlösung beobachtet man relativ dicke Hyphen, die aus zahlreichen, bald kürzeren, bald längeren Zellen zusammengesetzt sind; es entstehen oft ganz engzellige Hyphen, wie in Figur I4 D. In einer Zuckerlösung von 80 Proz. findet keine Keimung mehr statt. Nimmt man reine Glycerinlösung, so ist das Wachstum bereits bei I5 Proz. behindert. In einer Lösung von 20 Proz. bei Zusatz von 
l'flaumensaft treten die Querwände an den wachsenden l'ilzhyphen meist an clen Enden auf, bei 30 Proz. in allen Trilen der Hyphen; bei 35 Proz. Glycerin erfolgt keine Keimung.

Die anorganischen Salze zeigen keine so klaren Wirliungen, la man ihnen stets organische Substanzen beifügen muß, um ülserhaupt ein Wachstum zu erhalten. Nimmt man Lösungen von Kali- oder Natron-Salpeter mit etwas Pflaumensaft, so beobachtet man bei Io Proz. eine starke Septierung der in ihrem Längenwachstum sehr behinderten Hyphen. Manche von den Zellen zeigen Anschwellungen uncl fallen durch ihren glänzend öligen Inhalt auf, so daß sich Zweifel erheben, ob es sich nicht vielleicht um Gemmen handle. Die Grenze der Konzentration für das Wachstum des Pilzes liegt etwa bei 15-proz. Kali- oder Natronsalpeter. Bei I5 Proz. werden bei Gegenwart von etwas Ptlaumensaft noch kleine, bald absterbende Keimschläuche getrieben, bei höherer Konzentration nicht mehr. Noch ungünstiger wirlst Natronsalpeter bei Zusatz von Pepton; sellsst in Io-proz. Lösung sah ich dabei keine Keimung, während in einer solchen von ${ }_{5} 5$ Proz. Kalisalpeter und 0,8 I'roz. Pepton noch kleine, eng septierte Hyphen entstanden.

Aus den angeführten Thatsachen folgt, daß Substanzen, wie die Zuckerarten, Glycerin, ferner auch Kalioder Natronsalpeter bei höherer Konzentration bei den in ihnen wachsenden Hyphen von M. racemosus lebhafte Querwandbildung hervorrufen. Es fragt sich, ob irgend ein Zusammenhang dieser Erscheinung mit der Querwandlildung existiere, die van Tieghem bei der Wundheilung oder der Absonderung älterer Hyphenteile beobachtet hat. Mlan kann die Frage bejahen, wenn man die Hypothese aufstellt, daß eine Querwand dort entsteht, wo ein Konzentrationsunterschied im Zellsaft resp. Zellplasma zwischen zwei benachbarten Stellen in der Hyphe vor- 
handen ist. Wenn man einen Mucorfaden im Wasser zerschneidet, so bildet das lebende Plasma an der Wundstelle eine neue Hautschicht. Auf ihrer einen Seite befindet sich das Wasser, auf der anderen die konzentriertere Zellflüssigkeit. In diesem Konzentrationsunterschied liegt nach meiner Meinung der besondere Reiz, der die Bildung der neuen Wand veranlaßt. Die gleichen Verhältnisse haben wir innerhalb jener Pilzhyphen, wo ein plasmareicher Teil mit substanzreicher Zellsaftvakuole einen durch starkes Wachstum oder durch andere Lebensprozesse substanzarm gewordenen Teil berührt. Auch hier muß meiner Ansicht zufolge eine Querwand entstehen. Wenn eine Pilzhyphe in hoch konzentrierten Zuckerlösungen wächst, so sind fortwährende Anlässe zu kleinen Konzentrationsunterschieden innerhalb der Hyphen gegeben. Die starke, osmotische Wirkung des Außenmediums reizt die Zelle zu chemischen Umsetzungen, die einen Ueberdruck der Zellflüssigkeit erstreben (vergl. Eschenhagen 89 Kap. III).

Ferner können bald hier, bald dort Zuckerteilchen direkt von außen nach innen treten. Durch das Wachstum, die Atmung werden andererseits Substanzteilchen immer wieder verarbeitet, so daß selbst in einem relativ kurzen, wachsenden Hyphenteil Unterschiede der Konzentration in der Zellflüssigkeit vorhanden sein werden; es wäre erklärlich, daß die Querwandbildung so reichlich erfolgt. Man darf nicht einwerfen, daß bei einer schlauchförmigen Zelle eine schnelle Ausgleichung der Konzentrations-Unterschiede stattfinde. Eine solche Ausgleichung kann leicht eintreten bei einer Zelle mit großen, zusammenhängendem Zellsaft, wie bei Vaucheria. Bei einem Mucorfaden, der im Wachstum begriffen ist, durchsetzt das Plasma bald hier, bald dort den Zellsaft, der daher mehr aus einzelnen, gesonderten Vakuolen besteht. 
lch grelse natürlich diese Hypothese mit allem Vorbehalt; es kïnnten noch andere Verhältnisse bei der Querwandhildung mitwirken. Vielleicht hat auch die in den komzentrierten Lösungen stattfindende Verlangsamung des Wachstums indirekt eine Bedeutung für die Wandbildung selbst.

Die Querwandbildung in clen Hyphen von M. racemosus liann jedenfalls noch durch andere Umstände befördert werden. Vor allem wirlt in dieser Hinsicht ein Mangel an Sauerstoff. In den Versuchen mit lionzentrierten Traubenzuckerlösungen kann durch ihre Absorptionsfähigkeit für Sauerstoff, in Verbindung mit der Atmung des Pilzes, zeitweise ein Mangel an Sauerstoff eintreten. l*ür die Bedeutung dieses Umstandes bei der Querwandbiklung kann die Thatsache sprechen, daß in den Versuchen mit Agar-Agar und konzentrierten Traubenzuckerlïsungen die Septierung der Hyphen an der Oberfläche der Gallerte bei 50 Proz. geringer war, als bei den Versuchen innerhalb einer gleich konzentrierten Flüssigkeit. Selbst bei (1) Proz. waren auf dem Agar-Agar die Querwände in den Hyphen nicht so massenhaft und gleichmäßig verteilt, wenn sie auch überall vorhanden waren. Bei den Versuchen mit verdünnter Luft, wobei Agarkulturen mit verdünntem P'flaumensaft angewandt wurden, zeigte sich bei 6 - Io $\mathrm{mm}$ Lufteluck an den Hyphen des Myceliums elsenfalls eine $\bigwedge n z a l y]$ (Querwände. So gleichmäßig septiert wie in den Trauhenzuckerlösungen war aber das Mycelium nicht.

b) Das Anschwellen der Zellen.

Bei der Besprechung der Wirkung konzentrierter Lissungen auf das Mycelium erwälnnte ich bereits, daß an den Hyphen viclfach Anschwellungen auftraten, die sich hesonilers deutlich bei der Anwendung konzentrierter Salz- 
lösungen bemerkbar machten. Solche Anschwellungen erklären sich wahrscheinlich aus den unregelmäßigen Turgorsteigerungen und der etwas wechselnden Beschaffenheit der Zellhaut; man vergl. die Erklärung ähnlicher Erscheinungen bei Wurzelhaaren in Zuckerlösungen durch Wortmann ( 89 S. 279ff.). Solche Anschwellungen können auch sonst in den verschiedenartigsten Nährflüssigkeiten auftreten. Da Anschwellungen der Zellen für die Bildung der sog. Mucorhefe sehr charakteristisch sind, so kam es darauf an, die fragliche Erscheinung sicherer und regelmäßiger ausgebildet $z u$ erhalten. Dies gelang in überraschender Weise, als ich Sporen von M. racemosus in eine 3-proz. Citronensäurelösung, der etwas Pflaumensaft zugesetzt war, aussäte. Für die Versuche benutzte ich größere Glasdosen, in denen die Nährflüssigkeit nur $1 / 2 \mathrm{~cm}$ hoch war, so daß ein störender Einfluß durch Luftmangel ganz ausgeschlossen war. Schon Brefeld (73 S. 39I) hatte bemerkt, daß Sporen von Mucor-Arten auf Citronensaft besonders bei Zusatz von etwas Citronensäure stark anschwollen; aber so auffallende Gebilde, wie ich sie in der eben erwähnten Kulturflüssigkeit grewann, hat er augenscheinlich nicht beobachtet. In seiner neuesten Arbeit über Mucor bespricht Brefeld überhaupt nicht die Anschwellungen.

In der Citronensäurelösung von 3 Proz. schwellen die Sporen des Pilzes zu Blasen an, die im Verhältnis zu der Anfangsgröße der Spore (O,O I mm) als enorm groß zu bezeichnen sind, da sie bisweilen einen Durchmesser von 0,5 mm erreichen können. Diese Riesenzellen sind aber nicht immer kugelig, sondern auch birnförmig, schlauchförmig, überhaupt verschiedenartig gestaltet. Nanche Sporen hatten zuerst bei der Keimung an mehreren Punkten kurze Keimschläuche getrieben, die dann ebenso, wie die Sporen selbst, anschwollen, so 
(als ganze Cirujpen solcher zusammenlä̈ngender Blasen ('ntstanden. Eine solche Riesenzelle hat eine dünne Zellhant, einen dünnen, bräunlich gefärbten, plasmatischen IV andbeley und einen sehr grolien Zellsaft. Solche Zellen lï̈nnen sellsst wieder Aussackungen treiben, die mitunter auch durch eine (Zuerwand getrennt werden; nach einiger Zeit gehen die Zellen zu Grunde.

Sehr schwierig ist die Beantwortung der Frage, wodurch Citronensäure die Bildung der Riesenzellen veranlasse. IVohl ist es wahrscheinlich, daß die Citronensiure die zrotse Turgorsteigerung herbeiführt, die bei dem Wathstum der betreffenden Zellen wirksam ist. Lenn man weiłs, daß die Citronensäure schnell in die zellen eintritt (I'feffer 86 S. 2yo) und als organische Säure einen lebhaften Anteil an der Tururorlisaft vieler Pflanzenzellen nimmt (de Vries 84 $\therefore 58 \mathrm{I}$. Die Citronensäure kann die Turgorsteigerung direlit durch ihren Eintritt in die Zelle, oder durch Erzengung osmotisth noch wirksamerer Substanzen des Zelliaftes herbeiführen. Für die Bildung der Riesenzellen kommt aber weiter in Betracht, dafs die normale Wachstumsrichtung verïndert wird. Jeder Mycelteil des Mucor wäichst vorzugsweise in die Länge; bei den Riesenzellen finclet ein mehr oder minder gleichmäßiges Wachstum in allen Richtungen des Raumes statt. In welcher Weise laluei die Citronensïure wirkt, ob sie die Dehnbarkeit rejo. Wachstumffühigkeit der Membran oder direliter das \%ellplasma beeinflufit, läßt sich nicht erkennen; wir lusitzen auch lieine srenügend begründete Wachstumstheoric, die in diesen liragen auf den richtigen Weg leiten liminte; vergl. l'feffer 92, Vil S. $240 ; 93$ S. 429.

Die besprochenen Wirkungen der Citronensäure von 3 l'roz. lassen sich, wie ich schon hervorhob, am besten dann heolachten, wenn die Säure einen Zusatz von ein wenig 
Pflaumensaft erhält. Dieser dient nicht bloß zur besseren Ernährung des Pilzes, sondern hilft auch bei der specifischen Wirkung der Citronensäure mit. Wenn der 3-proz. Citronensäure 0,8 Proz. Pepton zugefügt wird, so entsteht aus den Sporen bei sehr langsamem Wachstum ein stark verzweigtes Mycelium mit kleinen Anschwellungen, die später zu Gemmen werden; eine Bildung von Riesenzellen findet nicht statt. Nimmt man eine noch höhere Konzentration der Citronensäure (immer mit Zusatz von Pflaumensaft), z. B. 3,5 Proz., so bleiben viele Sporen unverändert; nur einzelne wandeln sich in Riesenzellen um. Ganz vereinzelt beobachtet man solche noch bei 4 Proz. Citronensäure. Wenn man dagegen verdünntere Lösungen dieser Säure, z. B. solche von 2 Proz., anwendet, so entwickeln sich aus den Sporen überhaupt ganz anders gestaltete Mycelien. Die Sporen treiben dann eine ganze Anzahl verzweigter Keimhyphen, die durch zahlreiche Querwände in kurze Zellen geteilt werden, welche dann sämtlich kugelförmig anschwellen, so daß jedes aus einer Spore entstandene Mycelium das Bild eines verzweigten Rosenkranzes darbietet. Die Teilung der Hyphen in kleinere Zellen, das Anschwellen dieser vereinigt sich, um eine eigentümliche Mycelform hervorzurufen, die weder an Hefe noch an Oidium irgendwie erinnert. Wenn nach einigen Tagen durch die Lebenstlıätigkeit des=Pilzes der Gehalt an Citronensäure verringert wird, so gehen die Enden der Hyphen zur Bildung normaler, schlauchförmiger Hyphen über. Noch schneller geschieht es in J-proz. Citronensäure mit Pflaumensaft; in 0,5-proz. Säure findet sich bei den kräftig wachsenden Hyphen in der ersten Zeit eine Reihe von Querwänden an den Enden; die abgetrennten Zellen sind ein wenig angeschwollen und erscheinen glänzend weiß.

Ueberblickt man die Resultate der bis jetzt angeführten 
Versuche, su wird man erkennen, daß das Mycelium von 11. racemosus unter bestimmten, äußeren Bedingungen mannigfache formen annehmen kam, bei denen die verschieclenartige ()uerwandhiklungr und die Anschwellungen (ler neugelıikleten \%ellen hauptsächlich hervortreten. Im allgemeinen ist mit dem Entstehen dieser Mycelformen eine I lemmung des normalen, lebhaften Längenwachstums verhunden. Die erwähnten Mycelformen erinnern nun in Irolnem Grate an diejenigen, welche der Pilz in gärenlem Traubensaft bei gehindertem Luftzutritt zeigt. Lis handelt sich jetzt um die Entscheidung der Frage, welche Eigenschaften eines solchen Traubensaftes die charakteristischen Mycelformen bedingen.

In dem vom mir (S. 5II) erwähnten Versuche benutzte ich einen Traubensaft mit 20 Proz. Traubenzucker. Diese Konzentration träst dazu bei, daß die Septierung der Hyphen schneller eintritt als in verdünnteren Lösungen. Septitrung der Hyphen in hö̈hstem Maße und viele Anschwellumgen ler \%ellen besbachtet man in noeh höher konzentrierten Liinung Traubenzuckergehalt, dem noch 25 Proz. dieser substanz zugesetzt wurden. Aber die hohe Konzentration des \%ucliers i.s nicht nötig, la ein 'Traubensaft mit ca. 5-proz. 'Traubenunler die gleiche Wirkung, wenn auch langsamer, herfriführt. In einem Trüubensaft mit 2 Proz. Kucker int dageren lei sonst gleichen Bedingungen die Bildung itheteilter mol angeschwollener Zellen sehr gering.

l) er Traulensaft, elenso der vielfach von mir an-

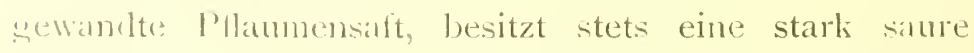
kealition, infolgr seinos (rehaltes an organischen Säuren und llaren saturen Salzen (ITeinstein etc.). Diese Säuren himmon, wis aus den vorhergehenden V'ersuchen folut, dic Septicrung ler llyphen, das Anschwellen der Zellen s-lur lefindern. Einmal ist aber die saure Reaktion nicht 
notwendig, weil auch neutralisierter (mit Soda) Traubenoder Pflaumensaft bei der Gärung die Bildung der betreffenden Mycelformen veranlaßt. Zweitens brauchen überhaupt organische Säuren nicht in irgend welcher Verbindung zugegen zu sein. Man erhält die gleichen Mycelformen, wenn man den Pilz in reiner Traubenzuckerlösung, z. B. von Io Proz., nach Zusatz von etwas Nährlösung (0,2 Proz.) bei gehindertem Luftzutritt kultiviert. Da die Nährsalze in der angewandten Verdünnung keine Wirkung auf die Gestaltung des Myceliums ausüben, sondern nur dazu dienen, lebhafteres Wachstum zu ermöglichen, so bleiben als wesentliche Bedingungen nur Traubenzucker und Luftmangel übrig. Seit Reess (70 S. 52) ist auch die Bedeutung dieser beiden Faktoren für die septierten Mycelformen von M. racemosus allgemein anerkannt worden. Der Traubenzucker ist notwendig, weil der Pilz ihn vergären kann und dadurch im Stande ist, bei Mangel an Sauerstoff zu leben. Diese Substanz kann nur durch solche Stoffe, die der Pilz in gleicher Weise vergären kann, ersetzt werden, vor allem durch den Zucker der Bierwürze, die Naltose, ferner auch durch Rohrzucker, da der Pilz diesen invertieren kann (vergl. Hansen 88 S. I62). Immerhin ist Rohrzucker für die Versuche nicht so greeignet, als die beiden anderen Zuckerarten. Kultiviert man dagegen den Pilz in nicht gärungsfähigen Substanzen, z. B. in Pepton, Asparagin etc. bei gehindertem Luftzutritt, in geschlossenen Cefäßen oder in sehr verdünnter Luft (6-10 $\mathrm{mm}$ Luftlruck), so hört das Wachstum sehr bald auf; es erfolgt Absterben oder Gemmenbildung.

Die Hemmung des Luftzutrittes ist ebenso wesentlich für die besprochenen Mycelformen wie die gärungsfälige Substanz; beides muß mit einander verbunden sein. Denn in Traubenzuckerlösungen, die gut durchlüftet sind, 
wachsen die Sporen zu normalem, schlauchfürmigem Mycelium aus. Aher zum Unterschiede von der echten Hefe ist 11. racemosus nicht im Stande, im sauerstofffreien Raum sofort Gärung zu erregen; auch bildet er darin keine septierten Mycelformen. Schon P'asteur ( $76 \mathrm{Ch}$. IV) wies die bemerlienswerte Thatsache nach, daß die Gärung nur dann erfolgt, wenn der l'ilz zuerst einige Zeit bei Sauerstoffzutritt rewachsen ist. Man kann sich davon leicht überzeugren, wenn man eine Kultur des Pilzes in Pflaumensaft einem Luftdruck von $3 \mathrm{~mm}$ aussetzt. Die Sporen sclivellen unter solchen Unstinden etwas an, keimen aber nicht weiter und verwiiren auch den \%ucker nicht. Bei $10 \mathrm{~mm}$ Luftdruck werden bereits kurze Keimschläuche gretrieben, die sich lann septieren und die kugelförmig anschwellen künnen, wobei zugleich langsame Gärung eintritt. Für das Gelingen der Gärungsversuche ist es daher am besten, wenn man in dem lose verschlossenen Kulturgefäß mit Traubenoler l'flaumensaft einen kleinen Luftraum über der Flüssick keit läßst. Der Sauerstoff genügt dann, um die Sporen zur Bildung von Hyphen zu veranlassen; allmählich tritt ein Mangel an Sauerstoff ein, die Hyphen beginnen den Zucker zu vergären und nehmen dann die charaliteristischen Formen an. In welchem Zusammenhange nun der Gärungsprozeß mit der Bildung dieser Mycelformen steht, läßt sich nicht klar erkennen. Der allmählich eintretende Sauerstoffmangel wirkt wahrscheinlich direkt auf (las Längenwachstum ein, das mehr und mehr verlangsamt wird. Schon dadurch kann vielleicht die Bildung von (2uerwänden herbeigeführt werden, die dann erheblich gesteigert wird durch den in den Hyphen sich abspielenden Spaltungsprozel. des Traubenzucliers, der dann weiter die Anschwellungen der einzelnen Zellen bewirlit, Vorsainge, die wahrscheinlich auf denselben Ursachen lerulen, wie die entsprechenden Erscheinungen in kon- 
zentrierten Zucker- oder Citronensäure-Lösungen. Ungewiß bleibt es, ob die Produkte der Spaltung entscheidend einwirken. Die Anhäufung von Kohlensäure, auf die Brefeld in seiner ersten Arbeit (73) Gewicht legte, scheint jedenfalls nicht sehr wesentlich zu sein. Denn in den Versuchen mit nicht gärungsfähigen Nährflüssigkeiten bei gehindertem Luftzutritt fand durch die Atmung des Pilzes ebenfalls eine Anhäufung der Kohlensäure statt, ohne daß dadurch besondere Mycelformen hervorgerufen worden wären. Ob der gebildete Alkohol auf das Mycelium specifisch einwirke, habe ich nicht untersucht. Immerhin wäre es möglich, daß durch die Anhäufung der Spaltungsprodukte das Wachstum der Hyphen und Zellen allmählich mehr und mehr gehemmt würde; es wäre aber auch denkbar, daß der Pilz überhaupt nur eine begrenzte Zeit sich im schließlich ganz sauerstofffreien Medium durch Vergärung des Zuckers erhalten könnte. Jedenfalls liegt in der immer stärker werdenden Ilemmung des Wachstums der Grund dafür, daß die später keimenden Sporen oder abgelöste Zellen des Myceliums bei ihrer Keimung immer kürzere Zweige treiben, so daß dann die hefeartig sprossenden Zellen entstehen. Die Ablösung einzelner, angeschwollener Zellen, worauf Brefeld einen so übertriebenen Wert legt, kommt wahrscheinlich dadurch zu Stande, daß zwischen den Endzellen der septierten Hyphen und den ihnen benachbarten Zellen plötzlich starke Turgordifferenzen entstehen, die zu einer Ablösung der ersteren führen. Man bemerkt besonders bei Anwendung verdünnter Fruchtsäfte, daß zuerst die Endzellen stark anschwellen; andererseits kann auch mitten im Faden eine Trennung erfolgen. Ich habe aber schon betont, daß die Ablösung einzelner Zellen oder Fadenstücke nicht regelmäßig stattfindet. Als letzte Eigentümlichkeit der Gärungsform des Myceliums ist der glänzend weiße, fett- 
reiche Inhalt mancher Zellen zu bezeichnen. Besonders zeichnen sich dadurch die Endzellen aus, welche gleich natch ihrer Bildung und Anschwellung selır inhaltsreich erscheinen; sowie sie weiter wachsen und das Fett verarbeiten, nehmen sic wioler ein bräunliches, feinkörniges Ausselıen an. Fs landelt sich bei den gränzend weißen Zellen um eine zeitweilige Aufspeicherung fein verteilter Fettsulstanz; solche \%ellen beobachtet man in srleicher Weise in den Kulturen mit Citronensäure ( $1-2$ Proz.) und mit konzentrierten Kalisalpeterlösungren.

Am Schluß dieses Alschnittes will ich seine Hauptrexultate liurz zusammenstellen. Jas normale, schlauchfirmige Mycelium von M. racemosus kann unter bestimmten, äußeren Bedingungen folgende, alweichende fiomen annehmen:

1) Verzweigte Pilzhyphen, die durch lehlafte Querwandbildung hald lang-, bald kurzzellis werden und hie und dal unrescelmäßige Anschwellungen zeigen. Diese Form tritt in lionzentrierten lïsungen von 'Traubenzuclier (50 - to l'roz.) auf, ferner auch in Rohrzucker-(6o-70 Proz.), (ilycerin-(25-30 Proz.), Kali-und Natronwalpeter-( o Proz.) Lösungen bei /usatz ron etwas I'flammensaft.

2) dinzehe, riesig angeschwollene Zellen oder Gruppen von solchen Rirsenzellen. Besonders aufallend zeigt sich diese Mycelform in einer 3-proz. Citronensäurelisung bei lusatz von etwats Pflaumensaft.

3) Verzweinte und stark septierte Pilzhyphen, deren \%ellon neist kugelformig angeschwollen sind. Diese Mycelform lecolnachtet man in r-2-proz. Citronensäurelösungen mit etwals J'flatumensaft.

4) Verzweigte Pilzhyphen in verschierlenem Grade soptiert und angeschwollen, hie und da einzelne \%ellen ofter hume Fulemstüclse alspaltend. Diese Mycelform rrscheint in gärungrfähigun Finchtsäften oder Zucker- 


\section{- $525-$}

lösungen bei allmählich eintretendem Mangel an Sauerstoff.

5) Hefeartig sprossende, einzelne Zellen oder mehrzellige Fadenstücke bei längerer Dauer der Gärung, infolge stärkerer Hemmung des Längenwachstums.

\section{Die Gemmenbildung.}

Als Gemmen oder Chlamydosporen (van Tieghem 73 S. 279) bezeichnet man meist etwas angeschwollene, sehr verschiedenartig geformte Zellen mit derber Membran, dichtem, fettreichem Inhalt, die in dem Mycelium wie in den Sporangienträgern von M. racemosus abgegliedert werden können. Wie bereits Reess (70 S. 53) hervorhob, entstehen die Gemmen an den Mycelien nach Bildung der Sporangien oder auch vorher bei schlechter Ernährung. Brefeld (73 S. 389) wies dann nach, daß die Gemmen Trockenheit aushalten und daß sie in feuchter Luft zu kleinen Sporangienträgern auswachsen können. Auch in seiner späteren Bearbeitung des M. racemosus ( 89 S. 2 I 8 ff.) legt Brefeld auf diese Keimungsart der Gemmen das größte Gewicht. Er bezeichnet sie als Fruchtträgeranlagen, die in der Flüssigkeit nicht zur Ausbildung gekommen sind und den Wert von Sporen angenommen haben. An und für sich ist die Vorstellung erlaubt, daß die Entstehung der Gemmen sich phylogenetisch aus verkümmerten Sporangienanlagen herleite. Aber bei der jetzt bestehenden Organisation des Mucor stellt die Gemmenbildung jedenfalls eine selbständige Fortpflanzungsweise dar, die unter anderen Bedingungen auftritt als die Sporangienbildung.

Die Fähigkeit, Sporangienträger zu bilden, ist keine specielle Eigenschaft der Gemmen; es folgt aus dieser 
Eigenschaft nicht der mindeste Beweis für die Vorstellungen Brefeld's. Wir wir gesehen haben, kann jede Spore, jedes kleine, abgesonderte, lebende Stück des Myceliums in der Luft Sporangienträger bilden; wollte man lionsequent sein, so müßte man das ganze Mycelium als verlï̈mmerten Sporangienträger auffassen.

Auf die Morphologie der Gemmenbildung brauche ich nicht näher einzugehen, da sie von Brefeld, van Tieghem, Bainier u. a. behandelt worden ist; die sichtharen Erscheinungen sind auch sehr einfach. An dem Mycelfaden wird durch zwei Querwände eine Zelle abgetrennt. Diese wird direkt oder nach vorhergehender Abtrennung einer kleineren Zelle zur Gemme, indem sie meist etwas anschwillt, sich mit fettreichem Inhalt füllt und ihre Membran verdickt, die oft mehrere Schichten erkennen läßt. Besonders auffallend erscheint die Anschwellung der Gemmen an solchem Mycelium, das sich durch die Schmalheit der Hyphen auszeichnet, z. B. in reinen Rohrzuckerlösungen von 20 Proz. (Fig. I4 $B$, S. 494). Auf der anderen Seite können die Gemmen ebenso dick oder sogar dünner als der sie bildende Mycelteil sein, so z. B. in den dickwandigen Trägern der Sporangien.

Im allgemeinen ist die von Reess u. a. ausgesprochene Ansicht richtig, daß die Gemmen bei ungünstiger Ernährung entstehen. Indessen erscheint dieser Ausdruck noch zu unbestimmt; es wird sich darum handeln, die physiologischen Bedingungen der Gemmenbildung etwas genaner zu bezeichnen.

Für die Bilclung der Gemmen kommen vor allem in Betracht die Quantität und Qualität der Nahrungsstoffe und die Temperatur. Die Gemmen treten in sehr verschiedenartig zusammengesetzten Nährflüssigkeiten auf, am schnellsten in solchen, wo aus irgend einem Grunde bald eine Beschränkung des Wachstums eintritt. In 


\section{- $527-$}

Flüssigkeiten, die nur sehr wenig brauchbare, organische Substanzen enthalten, ebenso in solchen, die bei genügendem Gehalt an organischer Nahrung der anorganischen Salze entbehren, erfolgt oft in wenigen Tagen nach der Aussaat der Sporen die Gemmenbildung. So entstanden bei Zimmertemperatur (I2-I $8^{\circ}$ ) Gemmen in:

Traubenzucker 4 Proz. in $2-3$ Tagen

\begin{tabular}{|c|c|c|c|c|c|}
\hline$"$ & IO & $"$ & $"$ & $2-3$ & $"$ \\
\hline$"$ & 25 & $"$ & $"$ & $3-4$ & $"$ \\
\hline 3 & 40 & $"$ & $"$ & $3-4$ & $"$ \\
\hline Rohrzucker & 2 & $"$ & $"$ & 2 & $"$ \\
\hline & 20 & $"$ & $"$ & $2-3$ & $"$ \\
\hline Milchzucker & 2 & $"$ & $"$ & $3-4$ & $"$ \\
\hline Maltose & 2 & $"$ & $"$ & $3-4$ & $"$ \\
\hline Inulin & übu & ersätti & tigt & 2 & 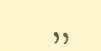 \\
\hline Dextrin & I5 & Proz. & in 1 & 12 & Tage \\
\hline Lösliche Stärke & 5 & $"$ & $"$ & $8-9$ & $"$ \\
\hline Glycerin & IO & $"$ & $"$ & $2-3$ & $"$ \\
\hline Asparagin & 2 & $"$ & $"$ & $3-4$ &, \\
\hline Harnstoff & 2 & $"$ & , & $3-4$ & $"$ \\
\hline Salicin & 2 & $"$ & $"$ & $4-5$ & 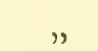 \\
\hline Aesculin & ge: & esättigt & & .0 & \\
\hline
\end{tabular}

Substanzen wie Dextrin, lösliche Stärke, die relativ viel Aschenbestandteile besitzen, verzögern das Auftreten der Gemmen. Ein Zusatz von anorganischer Nährlösung wirkt deshalb in gleicher Richtung. So entstanden bei Zusatz von o,2-proz. Nährsalzlösung die Gemmen in:

Glycerin 5 Proz. in 6-7 Tagen Asparagin 2 " " 7-8 " Mannit 14 " " 8-9 "

Alle diese Versuche wurden in Erlenme yer-Gläschen angestellt, die mit Wattepfropfen versehen waren.

Aber die Nährsalze verhindern die Bildung der Gemmen nicht, da diese doch an den älteren, nicht mehr recht 
wachsenden Teilen des Myceliums erscheinen, während die jüngeren, lebhaft wachsenden Hyphen frei davon sind. Besondlers günstig für die Bildung der Cemmen sind die Zucker-, namentlich Trauben- und Rohrzuckerlösungen, wo sie, auch bei Gegenwart von Salzen, nicht nur schnell auftreten, sondern zugleich in riesigen Mengen erscheinen. 1)ie Konzentration ülot bis zu einer gewissen Grenze keinen besonderen Eintluß auf die Gemmenbildung aus; sie zeigt sich auch in stark konzentrierten Lösungen, z. 13. in 40, 50-proz. Rohrzucker. Ich sah sie ebenso bei der Agar-Agar-Kultur mit 50 Proz. Traubenzucker und in 40 Proz. Dextrin.

Bei solchen resp. noch höheren Konzentrationen der grenannten Substanzen greifen aber die früher erwähnten Vorgainge der Querwandbildung und lokalen Anschwellungen störend ein; es wird nicht mehr möglich, die (iemmen von anderen Mycelzellen zu unterscheiden. So ist es der Fall in 50-proz. Traubenzuckerlösung, in 7o-proz. Rohrzuckerlösung, 30 Proz. Glycerin, auf AgarAgar mit 60 Proz. Traubenzucker. Den Uebergang von einfachen, kugeliu angeschwollenen Mycelzellen zu typischen Gemmen beobachtet man besonders zahlreich in den Kulturen mit I-2 Proz. Citronensäure (s. S. 519). In den ersten Tagen finden wir die kugeligen Mycelzellen in ganzen Ketten zum Teil mit glänzendem, fettreichem Inhalt; nach einigen Tagen, wenn bei Verminlerung der Säure lelhhafteres Längenwachstum erfolgt, nehmen die neu entstehenden Anschwellungen mebr und mehr den Charakter typischer Gemmen an. Sehr schwierig ist die Entscheidlung, mit was für Gebilden man es zu thun lat, in Lïsungen von IO-proz. Kalisalpeter mit Pepton (0,5, I Proz.). Das Aycelium besteht dann aus sehr zarten, inhaitsteer erscheinenden Füden, an denen einzelne oder dicht aneinandergereihte, stark angeschwollene Zellen mit 
äußerst glänzendem Inhalt sitzen. Wir haben hier wohl Zellformen, die zwischen Mycelzellen, deren Bildung durch die hohe Konzentration der Lösung veranlaßt worden ist, und typischen Gemmenzellen in der Mitte stehen.

Einen Einfluß auf die Gemmenbildung übt auch die Temperatur aus. Allerdings in niederen und mittleren Temperaturen, bis gegen $25^{\circ}$ bemerkt man kein besonderes Verhalten des Myceliums. Erst bei Temperaturen über $25^{\circ}$, besonders bei $28-30^{\circ}$, beobachtet man eine auffallende Förderung der Gemmenbildung, namentlich im Verhältnis zur Sporangienbildung. Die beiden Fortpflanzungsarten stehen im allgemeinen in einem Gegensatz zu einander, sie schließen sich mehr oder weniger aus, nur daß die Bedingungen für die Gemmenbildung weniger beschränkt sind als die für die Sporangienbildung. Die Sporangienträger erscheinen nur in der Luft; die Gemmen sowohl innerhalb der Flüssigkeit resp. des festen Substrates, als auch nach Aufhören der Sporangienbildung in den Trägern. Immerhin hemmt in der ersten Zeit die Sporangienbildung das Entstehen der Gemmen. Um sich davon zu überzeugen, braucht man nur die gleiche Menge $(50 \mathrm{ccm})$ 20-proz. Rohrzuckerlösung mit einigen Nährsalzen einmal in ein Erlen meyer-Fläschchen, zweitens in eine große, flache, lose bedeckte Schale zu gießen und mit Konidien des Pilzes zu versehen. Im ersteren Falle entwickelt sich in der Flüssigkeit ein Mycelium, das bereits nach 2-3 Tagen Gemmenbildung zeigt; in dem anderen Falle entsteht zuerst ein Rasen von Sporangienträgern, und erst nach Erschöpfung des Nährmaterials durch die Sporangienbildung treten Gemmen auf. Bei einer Temperatur von $28-30^{\circ}$ wird nun auf allen Substraten, in Flüssigkeiten wie auf festen Nährböden, z. B. Brod, Pflaumen, die Sporangienbildung durch die Gemmenbildung zurückgedrängt. Der erste Anlaß dazu liegt wohl in der Hemmung der Sporan- 
rrienbildung durch die hohe Temperatur; aber diese befördert auch direkt die Gemmenbildung. In wenigen Tagen überzieht sich z. B. das Brod mit einer grauen Pilzschicht, die sich, neben anormalen Sporangienträgern (s. S. 504), aus einer ungeheuren Menge von Gemmen zusammensetzt. Die an der Peripherie des Myceliums fortwachsenden Hyphen bilden sofort wieder Gemmen. Hierbei beobachtet man vielfach die von Brefeld (89 S. 220) erwähnte Thatsache, daß sich eine Sporangienanlage direkt in eine Gemme umwandelt. Bei Temperaturen über $30^{\circ}$ nimmt die Gemmenbildung ab; bei $3 \mathrm{I}-32^{\circ}$ kann man nur noch gemmenartige Anschwellungen beobachten, bei $32-33^{\circ}$ salı ich solche an dem kurz verzweigten Mycelium nicht mehr.

Die Ciemmenbildung erfordert nur einen sehr geringen Sauerstoffgehalt der Umgebung; das zeigt schon ihr Auftreten innerhalb der Zuckerlösungen, ebenso wie ihr Erscheinen an den Mycelien auf Agar und Pflaumensaft bei 6-IO $\mathrm{mm}$ Luftdruck. Dagegen kommen sie nicht in den gärenden Flüssigkeiten vor, in denen die früher besprochenen, septierten Mycelformen zu bemerken sind.

In der bisherigen Darstellung über die Bedingungen der Gemmenbildung ist einer organischen Substanz, des Peptons, noch nicht gedacht worden, welches sich vor allen anderen angewandten Substanzen durch einen specifisch hemmenden Einfluß auszeichnet. In reinen Peptonlösungen von $\mathrm{I}-4$ Proz. (ich benutzte ein Peptonpräparat von König in Leipzig) entsteht aus den Konidien das früher beschriebene, zarte, weiße, spitz und fein verzweigte Mycelium. Bei Zimmertemperatur beobachtet man nach wochenlangem Aufenthalt des Myceliums in der Peptonlösung keine Gemmen; die Hyphen gehen schlielslich zu Grunde. Dagegen können an der Oberfläche der Peptonlösungen normale Sporangienträger 
gebildet werden. Man muß sich die Frage stellen, weshalb die Peptonlösungen in dieser Weise wirken. Ein Zusatz von Nährsalzlösung ( 0,2 Proz.), ebenso auch ein solcher von Kochsalz ( 0,2 Proz), Citronensäure (0,5 Proz.), Kalisalpeter (I Proz.) oder Zuckerarten genügt, um die Gemmenbildung wieder hervorzurufen. Indessen ist ein solcher Zusatz zur Erreichung des $Z$ weckes nicht notwendig; eine Temperatur von $28^{\circ}$ bewirkt ebenfalls das Auftreten von Gemmen in den Peptonlösungen, und zwar in sehr großer Menge, während sie in den Mischungen von Pepton und Salzen relativ vereinzelt gebildet werden. Wie kommt nun die Hemmung und wie ihre Beseitigung zu Stande? Man kann die Frage im Augenblick nicht klar beantworten, man kann nur andeuten, in welcher Richtung nach der Antwort gesucht werden muß. Peptonlösungen haben eine relativ sehr geringe, osmotische Kraft. Wenn das Pilzmycelium nur mit Hilfe von Pepton sich ernähren muß, so wird seine Turgorkraft ebenfalls nur gering sein. Ich erklärte bereits daraus die auffallende Dünnheit des Peptonmyceliums (s. S. 508). Die Gemmenbildung erfordert andererseits einen viel höheren Turgordruck nicht bloß für die Bildung der Querwände, sondern auch für die Anschwellungen der Gemmenanlagen. Sowie irgend welche osmotisch wirksamen Substanzen, seien es organische Säuren, seien es beliebige, nicht schädliche, anorganische Salze, seien es Zuckerarten, dem Pepton zugefügt werden, so kann dann das Mycelium seinen Turgordruck erhöhen, und nicht bloß seinen Durchmesser vergrößern, sondern auch Anschwellungen bilden, die zu Gemmen werden. Ist die Annahme richtig, so wird man weiter folgern können, daß die höhere Temperatur in gleicher Richtung wie die angegebenen Substanzen wirkt, d. h. daß unter ihrem Einfluß aus dem Pepton osmotisch wirksamere Substanzen 


\section{- $532-$}

in den P'ilzhyphen entstehen, als dies bei niedrigerer Temperatur weschehen kann. Andere stickstoffreiche Substanzen, wie z. B. Mistdekokt, Fleischextraktlösung von I Proz., weinsaures Ammoniak von I Proz., gestatten die Gemmenbildung, wenn diese auch, namentlich in den beiden ersteren Flüssiglieiten, später auftritt als in Zuckerlösung. In den genannten Nährflüssigkeiten sind von vornherein osmotisch wirksame Verbindungen vorhanden. 


\section{Schlussbemerkungen.}

Wie aus dem Größenverhältnis der beiden Abschnitte über Algen und Pilze hervorgeht, sind die ersteren sehr viel ausführlicher behandelt worden als die letzteren. Von den Algen habe ich Vertreter einiger wichtigen Abteilungen der Süßwasserformen untersucht, während ich auf eine Erforschung der ganz anderen Lebensbedingungen angepaßten Meeresalgen habe verzichten müssen, da nur ein längerer Aufenthalt am Meere ein erfolgreiches Arbeiten möglich machen würde. Rein äußere Gründe haben mich verhindert, solche Untersuchungen vorzunehmen. Es ist mir aber nicht im geringsten zweifelhaft, daß die Fortpflanzung der Meeresalgen ebenso wie die der Süßwasseralgen in bestimmter Abhängigkeit von äußeren Bedingungen steht, daß die wechselnden Temperatur- und Lichtverhältnisse, die chemische Beschaffenheit des Wassers u. s. w. von entscheidendem Einfluß auf die verschiedenartigen Fortpflanzungsprozesse sind. Schon finden sich Andeutungen von solchen Einwirkungen in der interessanten Arbeit Oltmann's über die Kultur der Meeresalgen (92).

Von den Pilzen habe ich bisher nur je einen Vertreter der niederen und der höheren Formen untersucht; 
ich mußte, um mein Werk zum Abschluß zu bringen, meine Arbeiten unterbrechen. Doch hoffe ich, daß die Untersuchungen an den Pilzen wenigstens genügen wer(len, im den Anstoß zu ähnlichen, nur viel eingehenderen lorschungen zu geben. Ich bin überzeugt, daß in der Lehre von den Pilzen ganz neues, frisches Leben erwachen wird, wenn man einmal methodisch in der von mir angegebenen Richtung vorgehen und die physiologischen Bedingungen der so überaus mannigfaltigen Fortpllanzungrsweisen der Pilze der experimentellen Forschung unterwerfen wird.

Für die Lehre von der Fortpflanzung haben die beiden Reiche der Algen und Pilze jedes seine besondere Bedeutung. Unter den Pilzen giebt es eine große Anzahl, die sich verhältnismäßig leicht kultivieren läßt, und jede nähere Beschäftigung mit den Kulturmethoden wird lehren, noch viele andere Formen, die bisher der Kultur widerstanden hałen, zu bezwingen. Die Pilze haben den großen Vorzug, dal. nach Erkennung der Kulturbedingungen auch jederzeit, unabhängig von Tages- und Jahreszeit, gutwachsende kräftige Kulturen zu erhalten sind, da für diese meistens nur die Art des Nahrungssubstrates und die Temperatur entscheidend sind, die beide, einmal erkannt, sich immer wieder in der richtigen WTeise herstellen lassen. Auf der anderen Seite bieten die Pilze große Schwierigkeiten dar, weil vielfach die Bedingungen ihrer Fortpflanzung, wie z. B. die der geschlechtlichen bei Mucorineen, so besonderer Art sind, daß sie sich schwer auffinden lassen. Auch das physiologrische Verständnis für die Wirkungen (ler äußeren Einflüsse scheint sehr dadurch erschwert zu sein, daß die die Fortpllanzung direkt veranlassenden Reize auf besonderen, nicht recht erliennbaren Stoffwechselvorgängen im Innern der Zellen beruhen. Bei clen Algen, namentlich den höheren Fadenalgen, hat 
man dagegen trotz Kenntnis der Bedingungen fort und fort mit den Schwierigkeiten der Kultur zu kämpfen, da das Wachstum relativ langsam erfolgt und die für viele Algen erforderliche, richtige Verbindung von niederer Temperatur, hellem Licht und anderen Umständen praktisch für lange Zeit schwer durchzuführen ist. Dafür haben die Algen den großen Vorteil, daß3 die die Fortpflanzungsprozesse veranlassenden, äußeren Reize viel klarer und offener liegen, als bei den Pilzen, und daß namentlich die geschlechtliche Fortpflanzung der physiologischen Untersuchung viel zugänglicher ist. Die Forschungen an Algen und Pilzen ergänzen sich daher in vielen Punkten; die unerschöpfliche Mannigfaltigkeit ihrer Fortpflanzungsarten wird auch für die Zukunft diesen Organismen eine hervorragende Stellung in der Lehre von der Fortpflanzung bewahren; diese Bedeutung wird noch klarer aus dem allgemeinen Teil dieses Werkes hervorgehen. 


\section{Litteratur-Verzeichnis.}

5S. Anderson, On Palmella uvaeformis. Botanisk Notiser iss8. 92. Artari, A., Untersuchungen über Entwickelung und Systematik einiger Protococcoideen. Inaug.-Diss., Moskau IS92.

95. Baclinann, J., Einfluß der äußeren Bedingungen auf die Sporenbildung etc. Bot. Zeitg. I 895 .

57. Bail, L'eber Hefe. Flora I 857 .

61. - - Die wichtigsten Sätze der neueren Mykologie. Nova Acta Leop., Bd. XXVII, 1861.

Sza. Bainier, G., Observations sur les Mucorinées. Ann. de Sc. nat., Sir. VI, T. 15, IS83.

\$31. - - , Sur les zygospores des Mucorinées. Ebenda I8S3.

s. - Nouvelles observations sur les zygospores des Mucorinées. Ebenda, Sér. VT, T. 19, 1884.

54. Bary, A. de, Leber die Entwickelung und den Zusammenhang von Aspergillus glaucus und Eurotium. Bot. Zeitg. I 854.

58. - - Untersuchungen über die Familie der Konjugaten. Leipzig 1858 .

66. - - Zur Kenntnis der Mucorineen, in de Bary und Woronin's Beitr. z. Norph. u. Phy. der Pilze, 2. Reihe, I\$66.

70. - - Eurotium, Erysiphe etc. Ebenda, 3. Reihe, i\&7o.

92. Bennett, A. W., Non-sexual Formation of Spores in the Desmidiaceae. Rep. 61 Nect. Brit. Assoc. London IS92.

78. Burthold, G., Lntersuchungen iiber die Verzweigung einiger Süßswasseralgen. Noví Acta Leop., Bd. 40, 1878 .

sc. - - Studien über Protoplasmanechanik. Leipzig I886.

y. Beyerinck, Ml. W., Kulturversuche mit Zoochlorellen, Lichenengonidien und anderen niederen Algen. Bot. Zeitg. 1890.

4. Burge, O.. Luber die Khizoidenbildung bei einigen fadenfümigen Chlorophyceen. Upsila I89.1. 
78. Borodin, Ueber die Wirkung des Lichtes auf die Entwickelung von Vaucheria sessilis. Bot. Zeitg. I878.

83. Borzi, A., Studi algologici, fasc. I. Messina I883.

90. - - Stadii anamorfici di alcune alghe verdi. Nuovo Giorn. bot. ital., Vol. XXII, I89o.

95. - - Studi algologici, fasc. II. Palermo IS95.

49. (5I) Braun, A., Betrachtungen über die Erscheinungen der Verjüngung. Programm. Freiburg 1849; Leipzig I851.

73. Brefeld, O., Mucor racemosus und Hefe. Flora I873.

74. - -, Botanische Untersuchungen über Schimmelpilze, Heft II. Leipzig 1874.

76. - - Ueber Gärung, III. Landw. Jahrb., V, I876.

8I. - - Botanische Untersuchungen etc., Heft IV, I88I.

89. - - Untersuchungen aus dem Gesamtgebiet der Mykologie, Heft VIII. Leipzig I889.

90. Chmielevsky, V., Eine Notiz über das Verhalten der Chlorophyllbänder in den Zygoten der Spirogyra-Arten. Bot. Zeitg. I89o.

93. Chodat, R., und Malinesco, Polymorphisme du Scenedesmus acutus et du Raphidium Braunii. Bull. de l'Herbier Boissier, I893.

94-95. Chodat, R., Matériaux pour servir à l'histoire des Protococcoidées. Ebenda, I894 und I895.

95. - - Ueber die Entwickelung der Eremosphaera viridis. Bot. Zeitg. I895.

55. Cienkowsky, L., Algologische Studien. Bot. Zeitg. 1855.

76a. - - Zur Morphologie der Ulothricheen. Mélanges biol. St. Pétersbourg, T. IX, IS76; vergl. Just, Jahresbericht, IS76, S. 44

76b. - - Weitere Beobachtungen über den Palmellenzustand. Ber. V. Vers. russischer Naturf., I876; vergl. Just, Jahresbericht, I 876 , S. 47 .

76 c. - - Ueber Palmellenzustand bei Stigeoclonium. Bot. Zeitg. 1876.

50. Cohn, F., Zur Naturgeschichte des Protococcus pluvialis. Nova Acta Leop., Bd. 22, I850.

54. - - Untersuchungen über die Entwickelungsgeschichte der mikroskopischen Algen und Pilze. Nova Acta, Bd. 24, I854.

77. Cornu, M., Causes qui déterminent la mise en liberté des corps agiles etc. Comptes rendus, I877, T. 85, 2.

7x. Cramer, C., Ueber Entstehung und Paarung der Schwärmsporen von Ulothrix. Bot. Zeitg. I87I.

95. D il1, O., Die Gattung Chlamydomonas. Pringsh. Jahrb. f. wiss. Bot., Bd. XXVIII, I895.

76. Dodel, A., Ulothrix zonata. Pringsh. Jahrb. wiss. f. Botanik, Bd. X, I876. 
33. Eidim, E., Zur Kenntnis cler Entwickelung bei den Ascomyceten. Cilln's Beitr. z. Biologie, III, I 883 .

(o. Elfring, Fr., Studien über die Einwirkung des Lichtes auf die Pilze. Helsingfors I 890 .

so. - - Ueber physiologische Fernwirkungen einiger Körper. Helsingfors I\$go.

33. - - Zur Kenutuis der pflanzlichen Irritabilität. Ofver. Finska Vet. Soc. Förh., I 896.

92. Errera, Léo, On the cause of physiological action at a distance. Ann. of Botany, VI, IS92.

So. Eschenhagen, Fr., Ueber den Einfluß von Lösungen verschiedener Konzentrationen auf Schimmelpilze. Inaug.-Diss., Stolp issig.

7I. F a mintzin, A., Die anorganischen Salze als Hilfsmittel zum Studium der Entwickelung niederer chlorophyllhaltiger Organismen. Mélanges biol. St. Pétersbourg, T. VIII, 1871.

92. F ischer, Al., Phykomycetes, in Rabenhorst's Kryptogamenflora. 2. Aufl., Bd. I, Abt. IV, ISg2.

S3. Frank, II., Endoclonium polymorphum. Cohn's Beitr. z. Biologie, III, I883.

50. Frusenits, J., Beiträge zur Mykologie, Heft I-3. Frankfurt a. M. $1850-I 863$.

()1. Gay, Fr., Recherches sur le développement et la classification de quelpues Algues vertes. Paris ISgI.

90-91. Goros chan li in, Beiträge zur Systematik und Morphologie ron Chlamydomonaden. Bull. de la Soc. Imp. de Moscou, Teil I, Isgo, Teil II. ISgI.

yo. Ha berlandt, G., Zur Kenntnis der Konjugation bei Spirogyra. Sitzber. d. Wiener Akad., Bd. 99, ISgo.

95. Hallas, Emma, Om en ny Zygnema-Art med Azygosporer. But. Tidslirift, I 895 .

5). Hansen, E. Ch., Action des ferments alcooliques sur les divers espices de sucre. Compt. rend. des trav. du Labor. de Carls. berer, Vol. 11, Itiss.

55. Hansyirg, A., Leber den Polymorphismus der Algen. Botan. Centralilatt, Xill, 1885 .

S6. - - Prodromus der Alyentlora Böhmens, Teil I. Prag I886.

ss. - - E'eber dic ärophytischen Arten der Gattung Hormidium etc. Flora ISSS.

\$๖. - - Beitrag zur Kenntnis der Algrengattungen Entocladia etc. Floria Is8s.

15. H a r l) er. R. A., Die Entwickelung des Peritheciums bei Sphaerotheca Castagnei. Ber. d. deutsch. bot. Gesell., XIII, I895. 
87. Hartog, M., On the formation and liberation of the Zoospores of Saprolegnia. Quart. Journ. Micr. Sc., Vol. XXVII, I887.

88. Hassack, C., Ueber das Verhältnis von Pflanzen zu den Bicarbonaten. Tübinger Unters., II, I 888.

45. Hassa11, A., A history of the British Freshwater Algae. London 1845 .

90. Hick, P., On a case of Apogamy in Vaucheria hamata; citiert nach Just, Jahresbericht, I890, S. 266.

65. H of $\mathrm{m}$ a $\mathrm{n} n, \mathrm{H}$., Icones analyticae fungorum, Heft I-IV. Gießen $1861-65$.

69. - - - Ueber Bakterien. Bot. Zeitg. I869.

92. Huber, J., Observations sur la valeur morphologique et histologique des poils et des soies dans les Chaetophorées. Journ. de Bot., I 892.

93. - - Contributions à la connaissance des Chaetophorées. Ann. des Sc. nat., Sér. VII, I893.

93. Johns o n, L. N., Observation on the zoospores of Draparnaldia. Bot. Gazette, Vol. I8, I893.

86. J o han-O ls e n, O., Norske aspergillus-arter udviklingshistorisk studere. Christiania Vid. Sels. Forh. I886.

73. Juranyi, L., Beitrag zur Morphologie der Oedogonien. Pringsh. Jahrb., Bd. IX, I873-74.

9o. K leb a hn, H., Studien über Zygoten. Pringsh. Jahrb., Bd. XXII, I89o.

93. - - Zur Kritik einiger Algengattungen. Ebenda, Bd. XXV, I 893.

8I. Klebs, G., Beiträge zur Kenntnis niederer Algenformen. Bot. Zeitg. I88I.

83. - - Ueber die Organisation einiger Flagellatengruppen und ihre Beziehungen zu Algen und Infusorien. Tübinger Unters., I, I883.

86. - - Ueber die Organisation der Gallerte etc. Ebenda, III, I886.

86. - - Kritische Bemerkungen zu der Abhandlung von Hansgirg, Ueber den Polymorphismus. Biol. Centralblatt, V, I885 bis I886.

87. - - , Beiträge zur Physiologie der Pflanzenzelle. Tübinger Unters., II, I887.

90. - - , Ueber die Vermehrung von Hydrodictyon utriculatum. Flora 1890 .

91. - - Ueber die Bildung der Fortpflanzungszellen bei Hydrodictyon. Bot. Zeitg. I89I.

92. - - Zur Physiologie der Fortpflanzung von Vaucheria sessilis. Verh. d. Naturf. Gesell. Basel, X, I892. 
72. Klebs, (i., Flagellatenstudien. Zeitsclur. f. wiss. Zoologie, Bd. 55, Isi() 2 .

94. - - Veloer das Verhältnis des männlichen und weiblichen Geschlechtes in iler Natur. Jena I894.

95. - - Ueber einige Probleme der Physiologie der Fortpflanzung. Jenia ib95.

78. Kirchner, O., Algen in Kryptogamenflora von Schlesien. Brestiul 1 1878.

94. Kossowitsch, P., Lntersuchung über die Frage, ob die Algen freicn Stickstoff assimilieren. Bot. Zeitg. I89\%.

75. Krals, (r., Notiz üher Ulothrix tenuis. Bot. Zeitg. 1875, S. 774.

94. Krïger, W., Ueber zwei aus Saftflüssen rein gezüchtete Algen, in: Zoups Beitr. z. Morph. u. Phys. niederer Organismen, Heft IV, ISy.4.

4I. Kitzing. F. T., Die Umwandlung niederer Algenformen in höhere ctc. Natur. Verh. Holland. Naat. d. Wet. Haarlem, II, Istis.

43. - -, Phycologia generalis. Leipzig I843.

.45. - - Talbulae phycologicae. Vol. I, I845.

49. - - Species Algarum. Leipzig IS49.

83. Lagerleim, G., Bidrag till Sveriges algflora. Öfv, af Kgl. Vet. Akad. Förh. Stockholm, I883.

s7. - - Zur Entwickelungsgeschichte von Hydrurus. Ber. deutsch. bot. Ges. I88-.

So. - - Studien über die Gattungen Conferva und Microspora. Marburg 1889 .

95. Léger, 11., Recherches sur la structure des Mucorinées. Poitiers 1895 .

87. Loew, O., und Bokorny, Chemisch-physiologische Studien über Algen. Journ. f. prakt. Chemie, Bd. 36, 1887.

93. Loew: O., Worauf beruht die alkalische Reaktion, welche bei Assimilationsthätigkeit von Wasserpflanzen beobachtet wird? Flora 1893 .

71. Lundell, De Desmidiaceis quae in Suecia inventae sunt. Nov. Act. Upsaliens. I $87 \mathrm{I}$.

S8. Migula, W., Ueber den Einfluß stark verdünnter Säuren. Inaur.-Diss. I888.

9.1. Miyoshi Manabu, Ueber Chemotropismus der Pilze. Bot. \%citg. Isq.].

94. 11 ol isch, H., Die mincralische Nahrung der Pilze. Wien I894.

95. - - Die Emährung der Algen. Sitzungsber. Wiener Akadem., Bd. IO.1. I 895 .

g,6. Ilorini, P., Note micologiche. Malpighia, X, I896. 
79. N a egeIi, K., Emährung der niederen Pilze. Botan. Mitt., III, I879.

93. - - Ueber oligodynamische Erscheinungen in lebenden Zellen. Zürich 1893 .

78. Nordstedt, O., De Algis Sandvicensis. Symb. soc. phys., Lundae $\mathrm{I} 887$.

92. Oltmanns, F., Ueber die Kultur und Lebensbedingungen der Meeresalgen. Pringsh. Jahrb., XXIII, I892.

95. - - Ueber die Entwickelung der Sexualorgane bei Vaucheria. Flora 1895 .

88. Overton, C., Ueber den Konjugationsvorgang bei Spirogyra. Ber. d. deutsch. bot. Gesell., VI, I888.

76. Pasteur, L., Études sur la bière. Paris IS76.

8o. Petit, P., Spirogyra des environs de Paris. Paris I88o.

8I. Pfeffer, W., Pflanzenphysiologie, Bd. I. Leipzig I8SI.

84. - - Lokomotorische Richtungsbewegungen durch chemische Reize. Tübinger Unters., I, I884.

86. - - , Ueber Aufnahme von Anilinfarben in lebende Zellen. Ebenda, Bd. II, I 886.

92. - -, Studien zur Energetik. Leipzig I\$92.

93. - - Druck und Arbeitsleistung durch wachsende Pflanzen. Leipzig 1893.

95. - - Ueber Elektion organischer Nährstoffe. Pringsh. Jahrb., Bd. XXVIII, I895.

55. Pringsheim, N., Ueber die Befruchtung und Keimung der Algen. Monatsb. d. Berliner Akad., I855.

56. - - Ueber die Befruchtung und den Generationswechsel der Algen. Ebenda, I856.

58. - - Beiträge zur Morphologie und Syst. der Algen. I. Oedogonieen. Pringsh. Jahrb., I, I858.

6o. - - , Ueber die Dauerschwärmer des IVassernetzes. Monatsb. d. Berliner Akad., I860.

64. Rabenhorst, L., Flora europaea, Algarum aquae dulcis et submarinae. Lipsiae I-III, IS64-68.

69. Raulin, J., Études chimiques sur la végétation. Ann. d. Sc. nat., Sér. V, T. XI, I\$69.

7o. Reess, M., Botanische Untersuchungen über die Alkoholgärungspilze. Leipzig 1870.

76. Reinhard, L., Die Kopulation der Zoosporen von Chlamydomonas und Stigeoclonium. Arb. der Naturf. Ges., Charkow I876; Referat, Just, Jahresber. IV, I $\$ 76$, S. 48.

87. Reinsch, P., Eine nene Vaucheria der Corniculatae. Ber. d. deutsch. bot. Gesell., I887. 
79. Rosenvinure Kolderup, Bidrag till Kundskaben om Sl. [']uthrix og Conferva. Bot. Tidskrift I879.

83. - - Om Spirogyra groenlandica etc. Öfr. Vet. Akad. Förh., Stockholm I\$83.

77. Rostafinski und Woronin, Ueber Botrydium granulatum. Leipzig IS77; Bot. Zeiter. I877.

82. Rostafinski, J., Hydrurus i jego pokrewienstwo (mit deutschem kesumé). Krakauer Akad. IS82.

S7. Sachs, J., Uteber die Wirkung der ultravioletten Strahlen auf dic I3lütenbildung. Arb. des Würzburger Institutes, III, I887.

85. Schimper, A. F. W., Untersuchungen über die Chlorophyllkïrper. Pringsh. Jahrb., XVI, I885.

9o. _-, Zur Frage der Assimilation der Nährsalze durch die grünen I’łlanzen. Flora isgo.

79. Schmitz, F., Ueber die Zellkerne der Thallophyten. Sitzungsber. 1. niederrhein. Gesell., Bonn I879.

82. - - Die Chromatophoren der Algen. Bonn 1882.

83. Siebenm ann, Fr., Die Fadenpilze Aspergillus flavus, niger und fumigatus, Eurotium repens und ihre Beziehungen zur Otomycosis aspergillina. Wiesbaden 1883 .

s8. - - Neue botanische und klinische Beiträge zur Otomycose. Wiesbarlen isss.

67. Solms-Laubach, Graf zu, Ueber Vaucheria dichotoma. Bot. Zeity. I 867 .

85. - - Kurze Notiz zu de Bary's Species der Saprolegnieen. Bot. Zeitgr. I888, S. 648 Anm.

74. Sorokine, N., Note sur le développement de l'Hormidium varium. Nuov. Gior, bot. ital., VI, I87\%.

76. Strasburger, E., Ueber Zellbildung und Zellteilung. 2. Aufl. Jena 1876.

78. - - Wirkung des Lichtes und der Wärme auf Schwärmsporen. Jena 1878 .

so. - - Zellbildung und Zellteilung. 3. Auflage. Jena I8so.

84. - - Das botanische Praktikum. Jena 1884.

92. - - Histologische Beiträge, Heft IV. Jena 1892.

73. Tieghem, Th. van, et G. le Monnier, Recherches sur les Mucorinées. Ann. d. Sc. nat., Sér. V, T. I7, I873.

75. Tieghem, Th, van, Nouvelles recherches sur les Mucorinées. Ebenda, Sér. VI.

77. - - Sur le développement de quelques ascomycétes. Bull. de la Soc. bot. de France, T. 24, I877.

43. Thuret, G., Recherches sur les organes locomoteurs des spores des Algrues. Ann. d. Sc. nat. Bot., Sér. II, T. I9, IS43. 


\section{- $543-$}

50. Thuret, G., Recherches sur les Zoospores des Algues. Ebenda, Sér. III, T. I4, I\$50.

07. Trentepohl, in: Roth's Botanischen Bemerkungen und Berichtigungen. Leipzig $1807, \mathrm{~S}$. I80.

43. Unger, Fr., Die Pflanze im Momente der Tierwerdung. Wien I843.

03. Va u cher, Histoire des Algues d'eau douce. Genève I803.

59. Vaupell, Ch., Sur la reproduction et la fécondation d'une espèce du genre Oedogonium. Ann. d. Sc. nat., Sér. IV, T. II, I859.

84. Vries, H. de, Eine Methode zur Analyse der Turgorkraft. Pringsh. Jahrb. f. wiss. Bot., I 884 .

66. Walz, J., Beitrag zur Morphologie und Systematik der Gattung Vaucheria. Pringsh. Jahrb., V, I866-67.

68. - - Beitrag zur Kenntnis der Zoosporenbildung bei den Algen. Bot. Zeitg. 1868

83. Wieler, A., Die Beeinflussung des Wachsens durch verminderte Partiärpressung des Sauerstoffs. Tübinger Unters., I, I883.

78. Wiesner, J., Die heliotropischen Erscheinungen im Pflanzenreich, I. Teil. Wien 1878 .

88. Wildeman, M. de, Sur l'Ulothrix flaccida et le Stichococcus bacillaris. Bull. de la Soc. Belge de Microsc. I888.

8ı. Will e, N., Om Hvilceller hos Conferva. Ofv. Kgl. Vet. Akad. Förh., Stockholm I88I.

87. - - Algologische Mitteilungen. Pringsh. Jahrb., f. wiss. Bot., Bd. I8, 1887.

90-9I. - - Chlorophyceae in Engler und Prantl Natürliche Pflanzenfamilien. Leipzig I890-9I.

67. Wittrock, V., Algologiska Studier. Upsala I867.

74. - - Prodromus monographiae Oedogoniarum. Acta soc. sc. Upsala Ser. III, V. 9, I874.

78. - - - On the spore-formation of the Mesocarpeae. Bihg. t. Vet. Acad. Förh., Stockholm V, I878.

89. Wortmann, J., Beiträge zur Physiologie des Wachstums. Bot. Zeitung I889. 


\section{Berichtigungen.}

S. 22 al. 5 von unten: chromsaurem Kali statt chromsauren Kali ;

ऽ. 23 at. 18 von oben ebenso;

S. 32 al. 14 ron unten: Auer'schen Lampe statt Auer'sche Lampe :

S. 63 al. I4 von unten: anäisthetisch statt anästhetisierend.

s. 85 al. 5 von oben: ron 1892 und 1894 statt von 1893 und 1894 .

S. 404 al. 5 ron oben: Entocladia statt Herposteiron.

$\therefore 409$ al. I5 ron unten: Reinhard statt Reinhardt.

$\therefore 437$ al. 13 ron oben: Reinhardi statt Reinhardti. 
Tafel I. 


\section{Tafel I.}

Fig. 1-J6. l'rotosiplon botryoides (kig.) Klebs.

lïg. I. Eine ausgewachsene Zelle einer Lehmkultur. Vergr. 100.

"2. Eine (iruppe junger Zellen aus Nährlösung (O,4 Proz.). Vergri. 500.

" 3. Sporen in Nährsalzlösung von 1 Proz., kemend. Vergr. 300.

"4. Zellen zum Teil mit Sporen (s) aus Nährsalzlösung von I Proz. Vergr. 500.

"5. Junge Zellen, sich teilend, in Nährlïsung von 0,4 Proz. Vergr. 500.

6. Zellen aus Nährlïsung von I Proz. Vergr. 300.

" 7 a-c. Zwei Zellen in Schwärmerbildung begriffen; a 3 Uhr 35 Min., b 4 Uhr I5 Min., c 5 Uhr; z Zellsaft. Vergr. 500.

8. I) as obere Ende einer schwärmerbildenden Zelle; das chloroplyyllhaltige Plasma in 2 Stücke durch eine Zellsaftvakuole (z) getrennt; das obere Stiick in Teilung begriffen, das untere (j) noch ungeteilt. Vergr. 500 .

" 9. Junge Zelle, die Schwärmer entleerend. Vergr. 500.

" Io a-f. Schwärmer $a-c$ in IVasser, $d-f$ in Nährlösung von I Proz. Vergr. Iooo.

", 11 a-b. Schwärmer copulierend; II c. Zygospore. Vergr. 1000. "12 a-c. Zellen aus Parthenosporen entstanden; a Parthenospore eben gebildet; b nach kurzem Wachstum wieder Schwïmer liefernd; $\mathrm{c}-\mathrm{e}$ junge, vegetative Zellen. Vergr. 500 .

"I 3 a-c. Zygoten; a, b von der breiten Seite gesehen; c ron der schmalen. Vergr. Iooo.

" I.4. Keimung einer 7ygote. Vergr. 1000.

" I5. Ein Stïck einer vegetativen Zelle; $a$ Amylonkern, $\boldsymbol{n}$ Zellkern. Vergr. 1300.

" I6. Eine verzweigte, schlauchförmige Zelle aus Nährlösmug von 0,1 Proz. Vergr. I20.

Fig. 17-I9. IBotrydium granulatum Greville.

" 17. Junge, kugelige Zelle aus einer Zoospore entstanden in Nährlïsung von 0,4 Proz.; die dunklen Punkte in den scheibenfïminen Chromatophoren sind Pyrenoide. Vergr. 500.

" IS. Schlauchförmige Zelle, ehenfalls aus einer Zoospore in glcicher Näbrlösung entstauden. Vergr. 300.

" I1). Ein Stück eincr schlanchförmigen Zelle; $a$ Pyrenoid (durch (lunkle Fiarlung hervortretend); $n$ Zellkern. Vergr. 1300. 


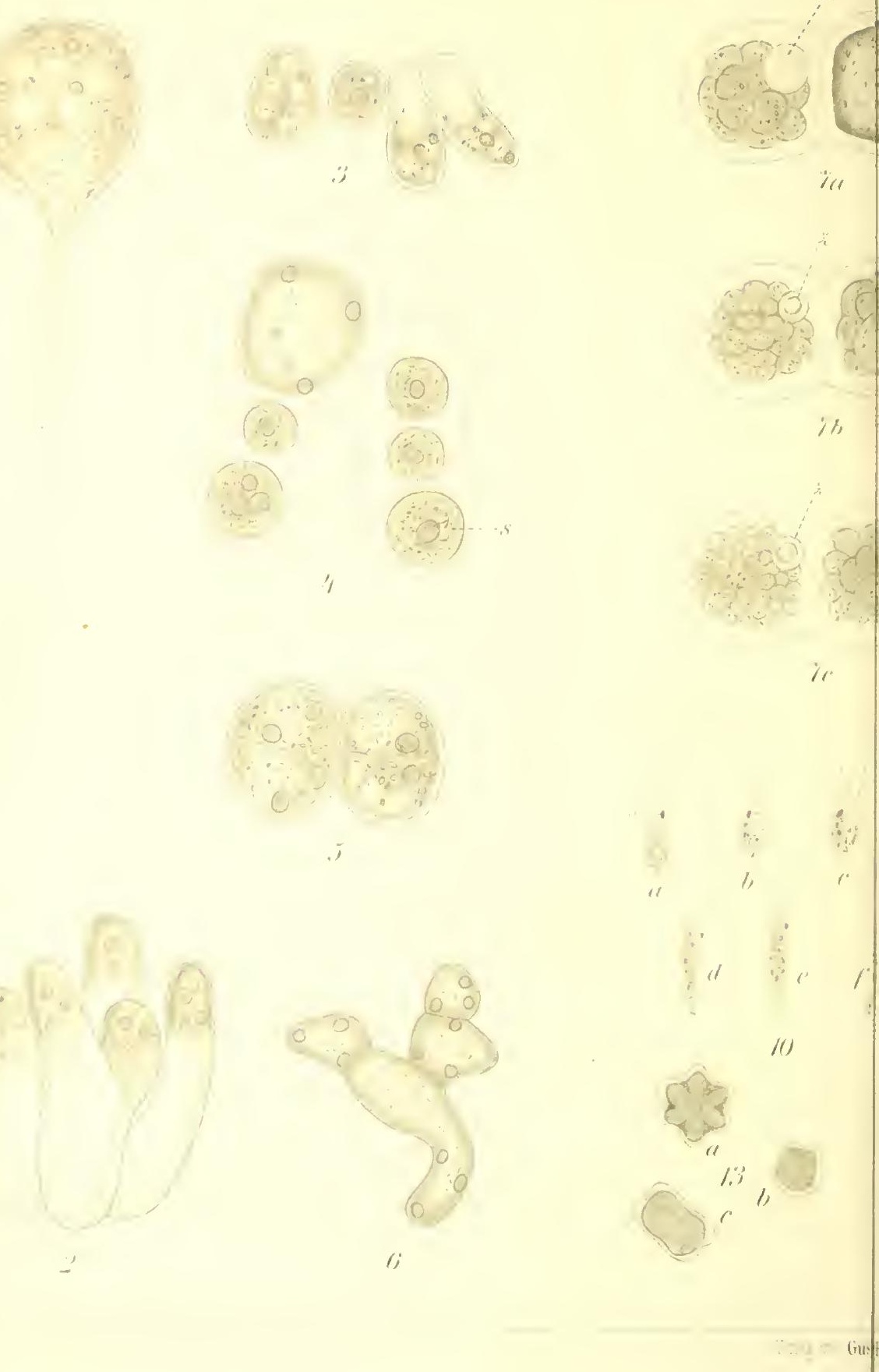

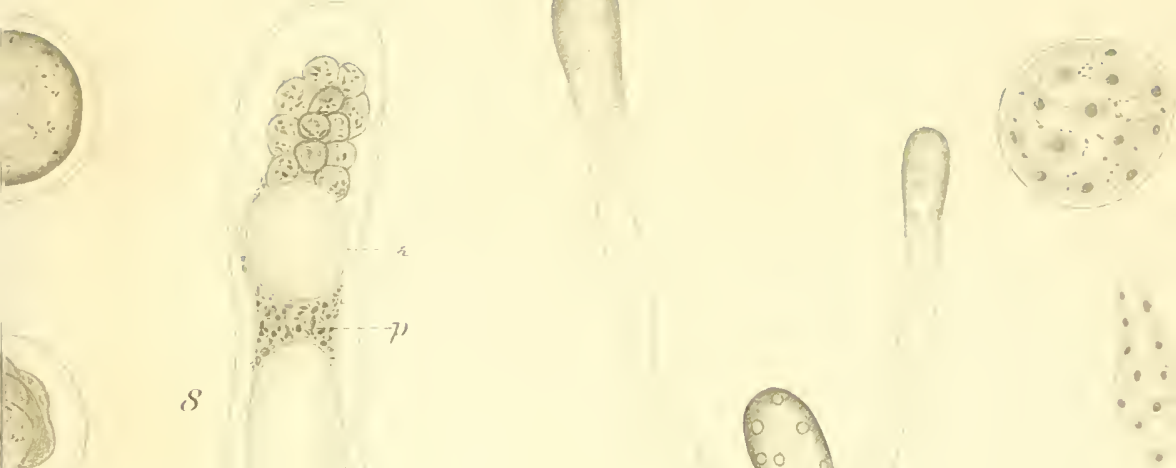
$S$

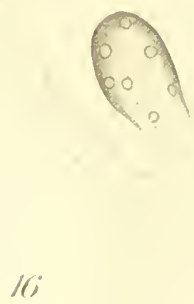

16

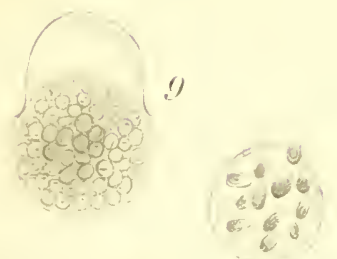

18

2

(4) 1 ,

iso a
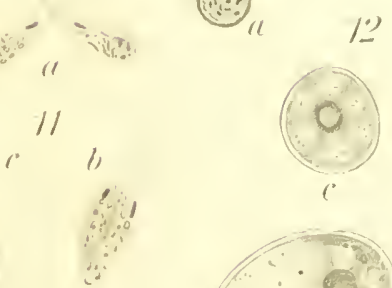

0
5
6

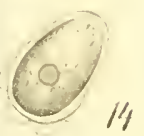

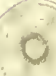

(')
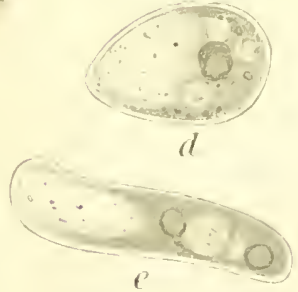

i.'

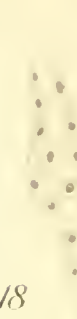

(1)

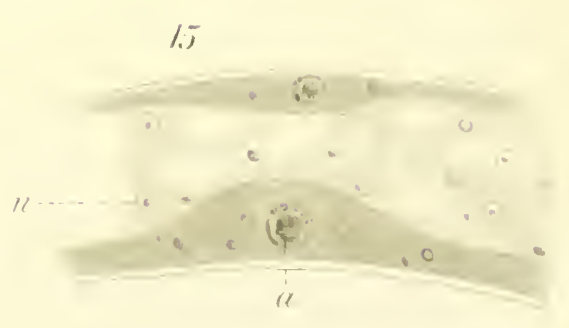

ischer in ela. 

Tafel II. 


\section{Tafel II.}

\section{Fig. I-8. Couferva minor Klebs.}

Fig. 1. Das Stück eines Conferva-Fadens. Vergr. IOoO.

2. Eis Fadenstücli in Zoosporenbildung begriffen. Vergr. IooO.

3. Ein Fadenstick in einer feuchten Kammer allmählich in verlïmnter Nälnrlösung eingetrocknet, im Beginn, sich nach Befcuchtung etwas zu zerspalten. Vergr. I000.

1. . Ein Fadenstücli am Rande einer lange stehenden Wasserkultur; Zellen in den Ruhezustand übergegangen. Vergr. I000.

5. Solche Dauerzellen in Nährlösung keimend. Vergr. Iooo.

6. Hinzelne Zelle mit eben gebildeter Zoospore. Vergr. Iooo. 7 a-c. Zoosporen von Conferva. Vergr. Iooo.

$\mathrm{S} \mathrm{a}-\mathrm{b}$. Zoosporen eben keimend; $\mathrm{c}-\mathrm{d}$ junge Keimlinge. Vergr. I000.

Fig. 9-I4. Bumilleria sieula Borzi.

Fig. 9. Ein Fadenstück, sich teilend und in einzelne Zellen zerfallend. Vergr. 500.

, Io. Ein Fadenstück, Zoosporen bildend. Vergr. 500.

"II. Ein Fadenstück in Nährlösung von 0,4 Proz., am oberen Ende verzweigt durch die Längsteilung der Endzelle. Vergr. 500.

, 12 a-1). Zoosporen. Vergr. I000.

"13a-l. Zoosporenkeimlinge; b sofort wieder eine Zoospore crzeugend; d durch mehrfache Teilung einen jungen Faden bildend. Vergr. I000.

"14. Eine Dauerzelle einer trocken gewordenen Lehmkultur. Vergr. 1000.

\section{Fig. 15-20. Bumilleria exilis Klebs.}

Figr. 15. Ein Fadenstück, im Begriff, in einzelne Zellen sich zu zerspalten. Vergr. IOOO.

1) I6. Ein Fadenstück in Zoosporenbildung begriffen. Vergr. I000.

" 17. Ein Fadenstiick aus einer Nährlösung von 0,4 Proz. Vergr. 1000 .

"1Sa-b. Dauerzellen aus einer trocken gewordenen Lehmkultur. Verur. Io00.

"19 a-c. Zoosporen. Vergr. I000.

". 20 a c. a Zoosporenkeimling; b sofort wieder eine Zoospore erzengend; c nach Austritt der Zoospore. Vergr. IOOO.

\section{Fig. 2I-24. IIolmidium flaceidum (Kğ.) Braum.}

Figr. 21. Jin liadenstiick in Zoosporenbildung begriffen. Vergr. I000. 22. Fin Fadenstïck aus einer Nährlösung von 0,4 Proz. Vergr. I 000.

23 a b. \%uosporen. Vergr. I000.

24 it b. Zousporcnkeimlinge. Vergr. I000.

\section{Fig. 25-29. IIormidium niteus Meneghini.}

lier. 25. Ein Farlenstïck aus Nährlösung von 0,4 Proz. Vergr. Iooo.

26. Ein Farlenstiick in Spaltung begriffen. Vergr. 500.

27. Ein Fatenstück in Kongorotlösung. Vergr. Iooo.

2S. Fin Fadenstiicli aus Nährlösung von I Proz. Vergr. 500.

2). Keimlinge von Zoosporen. Vergr. 500. 



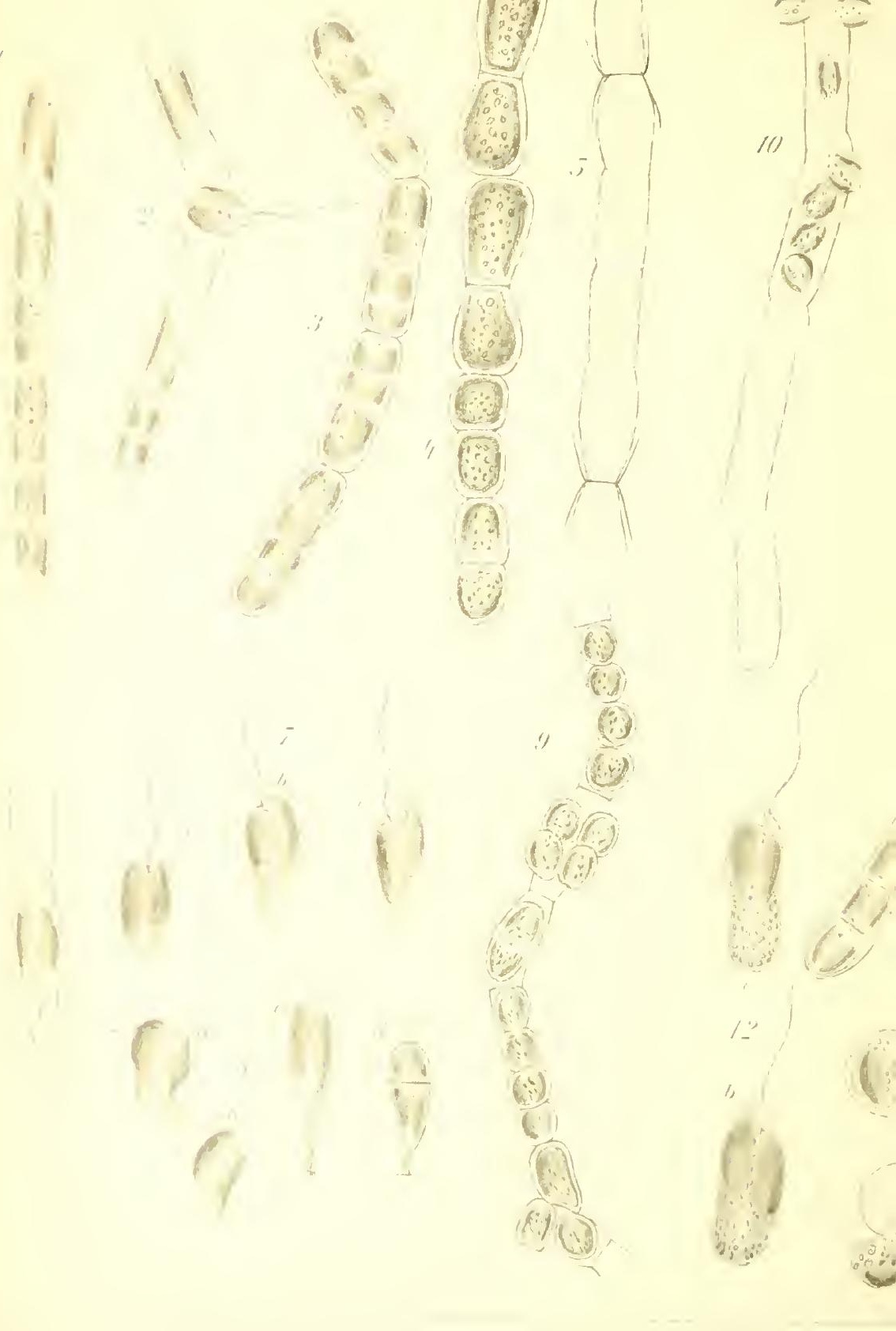


L t 1
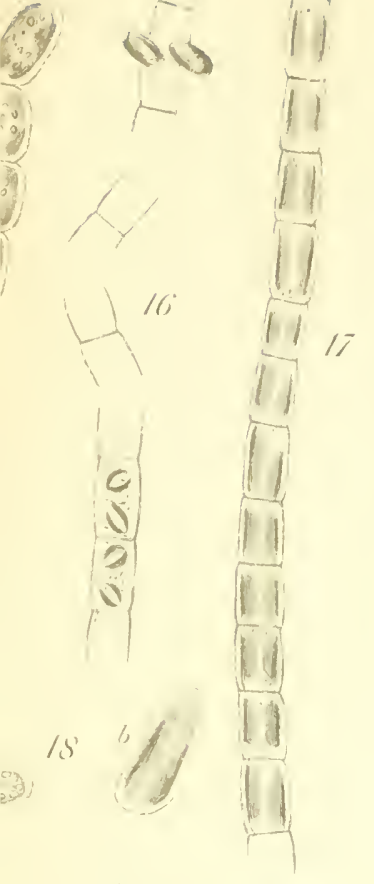

5)
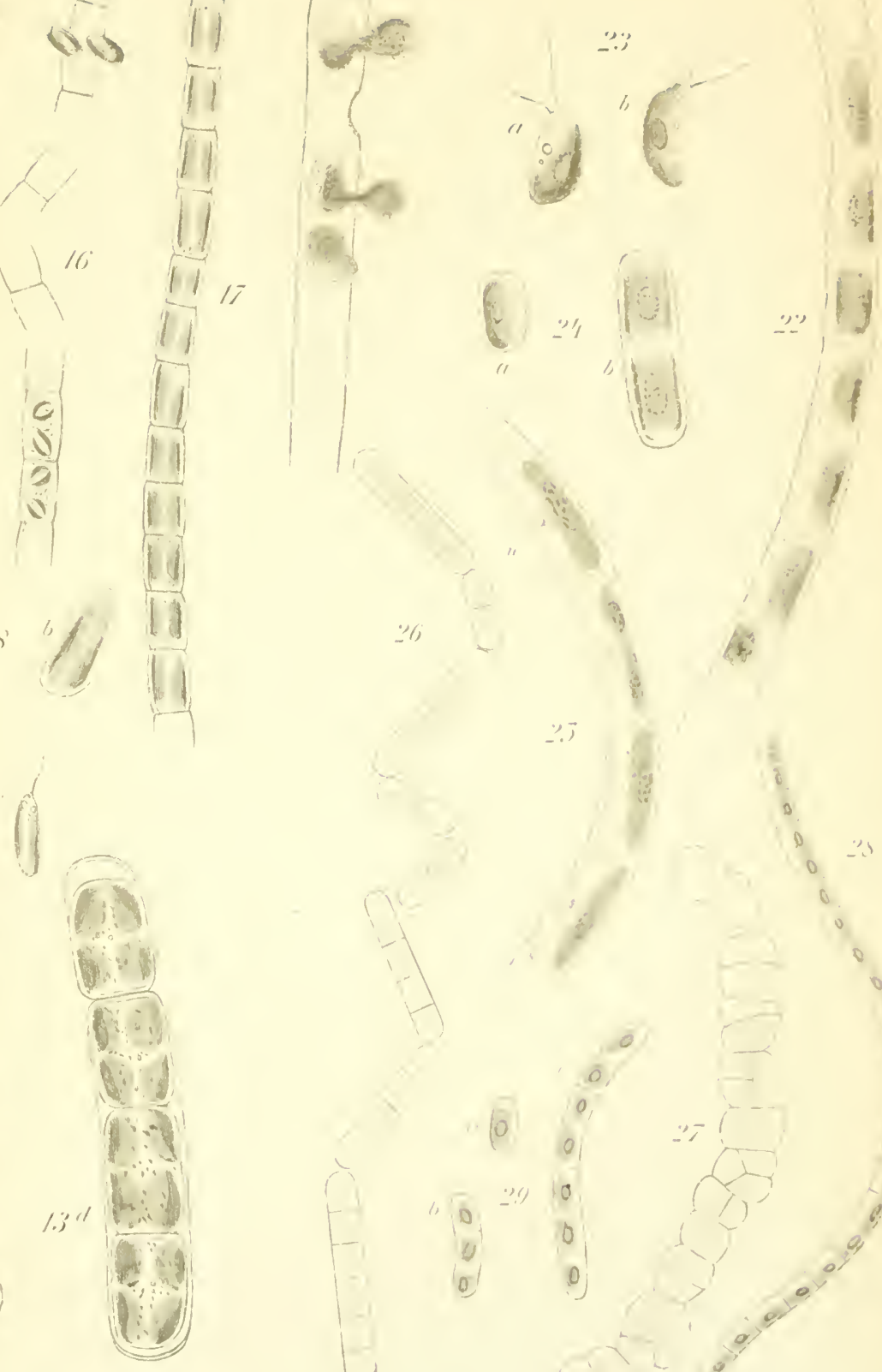

is

(4)

$\therefore \overline{1}$
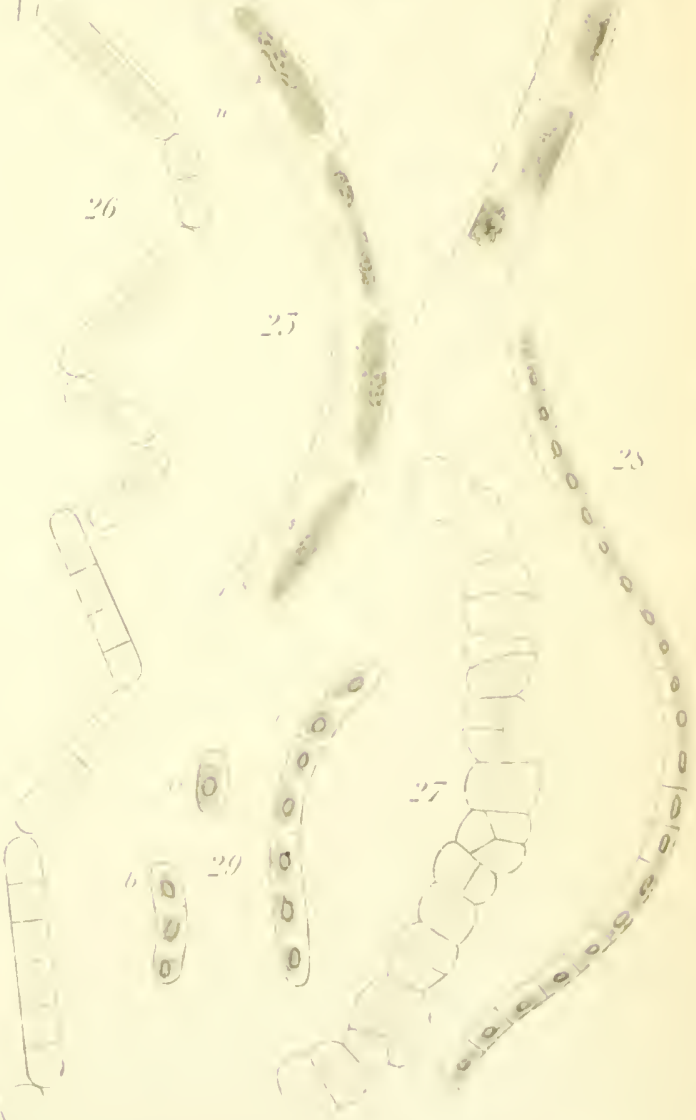

Tafel III. 


\section{Tafel III.}

Fig. I-I3. Stigeodoniun tente Kiitzing.

Fig. I. Ein Zweig in 'Zoosporenbildung begriffen. Vergr. 300.

2. " " " " " " $"$ "

". 3. Ein Thallusstück aus "Nährlösung von I Proz. in Wasser einseitig beleuchtet; der Pfeil grieht die Richtung des bei dem Versuch wirksamen Lichteinfalles an. Vergr. 300.

"4. Zoosporen eben austretend. Vergr. Iooo.

" 5 a-c. Zoosporen. Vergr. I000.

"6. Mikrozoosporen. Vergr. IO00.

"7. Zoosporenkeimling im Wasser. Vergr. 300.

"S. Zoosporenkeimling aus Nährlösung. Vergr. 1000.

" 9. Eine Dauerzelle aus einer Mikrozoospore entstanden. Vergr. IOOO.

" Iо. Keimung einer Dauerzelle. Vergr. Iooo.

" 1I. Zellkörper an der einen Seite zu einem Stigeocloniumfaden ausgewachsen, aus einer keimenden Dauerzelle entstanden. Vergr. 500.

, I2. Keimende Dauerzelle wie bei Fig. II. Vergr. Iooo.

"13. Ein Fadenstick mit Mikrozoosporen. Vergr. Iooo.

\section{Fig. I4-I8. Draparmaldia glomerata $\boldsymbol{\Lambda} \mathrm{g}$.}

Fig. I4. Zoospore. Vergr. I000.

"I5 a-b. Mikrozoosporen; I5 c eine solche olne Wimpern; $15 \mathrm{~d}$ zur Ruhe gekommene Mikrozoospore.

" I6 a-e. Mikrozoosporen kopulierend; a Io Uhr 45 Min., b I I Uhr I5 Min., c Zygote 3 Uhr, d eine andere 7 ygote, e ein anderes Kopulationspaar. Vergr. Iooo.

, I7 a-d. Dauerzellen (Parthenosporen) keimend. Vergr. 500.

"IS. Ein Fadenstück mit Dauerzellen aus dem Schluchsce. Vergr. 500 .

\section{Fig. 19-22. Aphanochate repens $\Lambda$. Branu.}

Fig. I9. Zwei Algen auf Cladophora aus einem fließenden Brunnen. Vergr. 500.

"20. Eine Zoospore. Vergr. Iooo.

"2I. Junger Faden, aus einer Zoospore entstanden, im IVasser liultiviert. Vergr. 500.

"22. Junger Fatlen, aus einer Zoosjore entstanden, in Nährlïsung von 0,4 Proz. kultiviert. Vergr. 500. 


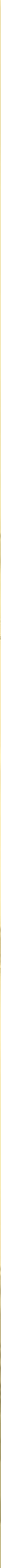

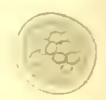

III

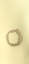

o

O









